\title{
Assessing the Socio-economic Impacts of the Framework Programme
}

\author{
PREST \\ AUEB \\ BETA \\ ISI \\ Joanneum Research \\ IE HAS \\ Wise Guys
}

June 2002 


\section{Assessing the Socio-economic Impacts of the Framework Programme (ASIF)}

$\underline{\text { Editors }}$

Policy Research in Engineering Science and Technology PREST, University of Manchester, England

Luke Georghiou, John Rigby, Hugh Cameron

Contributors

Policy Research in Engineering Science and Technology PREST, University of Manchester, England

Luke Georghiou, John Rigby, Hugh Cameron

Innovation and Knowledge Management Center, Management Sciences Laboratory, Athens University of Economics and Business, Greece

Nick Vonortas (also George Washington University, USA), Gregory

Prastacos, Yiannis Spanos

Fraunhofer Institute for Systems Innovation and Research, Germany

Stefan Kuhlmann, Thomas Henize

Bureau d'Economie Théorique et Appliquée (BETA), Université Louis Pasteur, France

Laurent Bach, Patrick Cohendet, Marc J Ledoux, Mireille Matt

Joanneum Research Institute, Austria

Wolfgang Polt, Andreas Schibany, Oliver Fritz

Institute of Economics, Hungarian Academy of Sciences, Hungary

Lajos Nyiri (Zinnia Group), Attila Havas

Wise Guys, England

Ken Guy

The ASIF Team would like to acknowledge with gratitude the support of the Research Directorate General for this work and the constructive comments and suggestions received at all stages. However, the views expressed in the report remain the sole responsibility of the authors. 


\section{Contents}

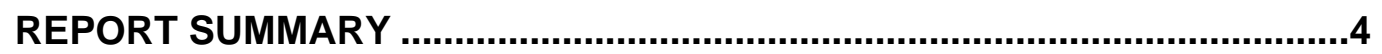

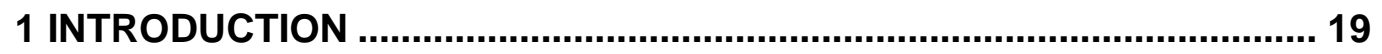

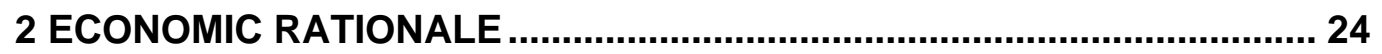

2.1 Macro-Economic Perspectives on Technical Change.........................................24

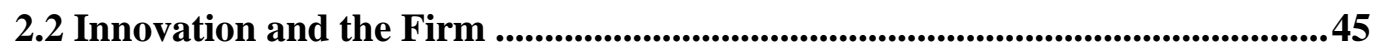

2.3 Industry-Science Linkages .............................................................................69

2.4 Rationale for Science \& Technology Policy ........................................................93

2.5 Review of the key developments of the knowledge-based economy ................121

2.6 Linkages to Other Policy Areas .......................................................................................... 138

3 SOCIO-ECONOMIC ASSESSMENT SECTION .................................... 146

3.1 Socio-Economic Assessment of European RTD Policies ..................................146

3.2 EU RTD Framework Programmes - a "Mini-Meta-Evaluation" ..................151

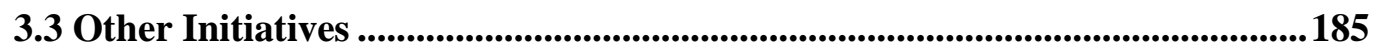

3.4 Inventory of Effects \& Evaluation Methods...................................................... 198

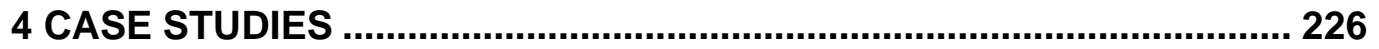

4.1 Market-Oriented Case Study .......................................................................................226

4.2 Service Sector Case Study ...............................................................................282

4.3 Programme-Level Case Study ................................................................................294

4.4 Social Science Research Case Study ......................................................................314

4.5 Accession Countries Case Study ..............................................................................325

5 EVALUATION OF SOCIO-ECONOMIC EFFECTS IN THE EUROPEAN

RESEARCH AREA ........................................................................... 355

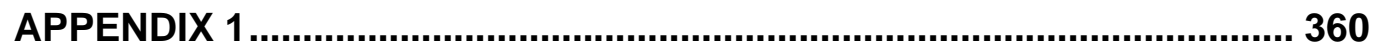

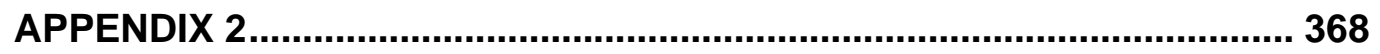




\section{Report Summary}

1) This study was undertaken in order to examine the socio-economic assessment of the impacts of the Community Framework Programmes and to improve understanding of how such impacts might be designated, defined and measured. The rationale for the work lies in the mounting appreciation of the importance of research and technological development (RTD) for economic growth and the emergence of the knowledge-based economy.

2) The study follows earlier actions to promote the assessment of socio-economic impact of the Framework Programmes and in particular the reflections of the ETAN group in 1999. The study was conceived both as a means of delivering a rigorous and defensible academic statement on the justifications for RTD support and best available means of its evaluation, and as a functional document which could give help to policy makers who were directly concerned with the delivery and evaluation of policy in the field of RTD.

3) The study has four major parts:

- Justification of the role of RTD and its benefits through an examination of the academic and policy literature;

- An examination of the evaluation practice of the Framework Programmes and other relevant RTD activities with the aim of delivering lessons and suitable practical principles to which to apply to evaluation;

- Case studies chosen to exemplify approaches to evaluation;

- Observations about future evaluation strategy in the light of recent developments at the level of the European research system.
PART I ECONOMIC PERSPECTIVES ON RTD

4) The economics literature on technical change provides significant tools to appraise the causes and effects of resources devoted to the production and dissemination of new knowledge. However, the complexity of this matter requires multi-dimensional analytical approaches with different insights offered and different aspects highlighted by conventional neo-classical, new growth theory and evolutionary frameworks.

- Mainstream economics highlights resources and incentives for firms while taking technological possibilities and capabilities of firms as a given;

- New growth theory contributes to a better understanding of the conditions for economic convergence between countries;

- Evolutionary theory highlights the importance of institutions and of path-dependence in the selection of technologies.

5) Empirical studies have established that R\&D expenditures contribute to the growth of industrial output and productivity. Social rates of return are higher than private rates, indicating high levels of inter-firm and inter-industry spillovers, though rates of return vary considerably by industry and by sponsor.

6) Academic research has become a major underpinning of industrial innovation in many science-based industries. Estimates of the rate of return to publicly funded research range from $20 \%$ to $60 \%$ with the social return, the overall return to society, sometimes reaching far higher levels. 
Innovation and the Firm

- The adoption of decentralized and informal organizational structures

- The formation of intra and interorganizational networks

- "Open" communication culture

- Human capital as an important innovation input

- $\quad$ The use of Information and Communication Technologies

- The existence or the ability to access financial resources

- Knowledge accumulation and exploitation

- Enhancement of employees entrepreneurship

\section{Innovation at the Level of the Firm}

7) Management research has been concerned with identifying the factors that promote or inhibit firms' capacities to innovate. It also shows that the impact of innovation on competitive advantage is generally positive.

8) Empirical findings support a positive impact for innovation on profitability of large firms but are equivocal in relation to small firms, particularly in the absence of financial incentives, access to venture capital and support for development of complementary assets. The literature also identifies numerous firm qualities conducive to innovation.
Policy Rationale for Public RTD Support

\section{Returns to Research and Development}

Publicly Funded

\begin{tabular}{|c|c|c|}
\hline \multirow[t]{2}{*}{ Author (year) } & \multicolumn{2}{|c|}{$\begin{array}{c}\text { Estimated } \\
\text { rates of return } \\
\%\end{array}$} \\
\hline & Private & Social \\
\hline Nadiri (1993) & $20-30$ & 50 \\
\hline $\begin{array}{l}\text { Mansfield } \\
\text { (1977) }\end{array}$ & 25 & 56 \\
\hline $\begin{array}{l}\text { Terleckyj } \\
(1974)\end{array}$ & 29 & $48-78$ \\
\hline $\begin{array}{l}\text { Sveikauskas } \\
(1981)\end{array}$ & $10-25$ & 50 \\
\hline $\begin{array}{l}\text { Goto-Suzuki } \\
\text { (1989) }\end{array}$ & 26 & 80 \\
\hline $\begin{array}{l}\text { Bernstein- } \\
\text { Nadiri (1988) }\end{array}$ & $9-27$ & $\begin{array}{l}10- \\
160\end{array}$ \\
\hline Scherer (1984) & $29-43$ & $\begin{array}{l}64- \\
147\end{array}$ \\
\hline $\begin{array}{l}\text { Bernstein- } \\
\text { Nadiri (1991) }\end{array}$ & $14-28$ & $\begin{array}{l}20- \\
110\end{array}$ \\
\hline
\end{tabular}

9) Econometric studies have indicated a high rate of return on basic research but there have been measurement and conceptual difficulties. New approaches have identified a wider range of benefits from basic research and moved away from the traditional justification for basic research solely as a source of new, codified, knowledge. These highlight the importance of mobility of trained researchers, cooperative R\&D and creation of new enterprises. Industry-science relations are shown to be moderated by policy-related framework conditions. There is evidence of a growing impact from participation in the Framework 
Programmes upon industry-science interaction.

10) The economic rationale for science and technology policy provides the main justifications for State and Community intervention. Again, the main distinction is between rationales deriving from the neoclassical framework and those deriving from the evolutionary-structuralist framework. The report concludes that S\&T actions derived from both analytical frameworks are neither necessarily different nor antagonistic. However, the choice of rationale has implications for the subsequent design of policy evaluations.

11) For the neo-classical framework the basic principles of S\&T policy are to achieve the following:

- reduce uncertainty;

- to provide investment where science is a public or non-rival good;

- and to allow for the internalisation of externalities.

The policy rationale is grounded in rectifying market failures including imperfect information, non-rivalry and non-excludability, indivisibilities, and problems of appropriability through knowledge, market and network externalities.

12) Within the evolutionary-structuralist framework, the basic principles of S\&T policy are to develop and orient the cognitive capacity of actors and provide the conditions for use of this capacity. Policy rationale is grounded in learning failures, including exploration /exploitation failures, selection failures, innovation system failures, and knowledge-processing failures.

13) Rationales for the Framework Programmes reflect the diversity of the objectives it serves and the instruments it encompasses but in broad terms can be seen to have evolved from neo-classical arguments in the 1980s to an evolutionary foundation today.

14) Additionality is at the heart of justification of intervention. It is therefore a critical factor for evaluation. It is posed in terms of the questions of what difference is made by intervention and whether the difference justifies the intervention. Four types of additionality are considered, the first two deriving from a neo-classical perspective and the latter two from a structuralist-evolutionary perspective.

- Output additionality: the counterfactual of whether the same outputs would have been obtained without policy action;

- Input additionality: whether the public action adds to, or substitutes for the agents inputs (usually financial);

- Behavioural additionality: the differences to the agent's behaviour following the policy action, or its persistence beyond the action; and

- Cognitive capacity additionality: whether the policy action changes the different dimensions of the cognitive capacity of the agent.

\section{European Added Value}

15) European Added Value (EAV) is a primary plank in the rationale for the Framework Programmes and has its main dimensions embodied at Treaty level. It combines in a complex way additionality, subsidiarity and proportionality. However, it is used at all levels, from high level goal down to that of a mechanical filter at project selection level. A shift during FP5 from a compliance model to an attainment model 
means that ex post evaluation is pressed to investigate the amount or extent of EAV generated. However, EAV is still best addressed at the ex ante stage of programme formulation.

\section{Implications of the Knowledge-Based Economy}

16) The knowledge-based economy (KBE) is directly based upon the production, distribution and use of knowledge and information. Among the indicators of its existence are GDP and multi-factor productivity growth and the achievement of high ICT-intensiveness. In a KBE the relationship between science and technology has evolved towards a more cooperative type, boosting the economic performance of scienceintensive sectors. Considerable controversy surrounds the identification and measurement of the variables considered important for the KBE. One example is the so-called "productivity paradox" in realising the benefits from ICTs.

17) A key aspect of the $\mathrm{KBE}$ is the learning capacity of agents (firms and citizens), which places a major premium on effective education to prevent the emergence of social inequality. The case for increased research support and better education is strongly reinforced within the $\mathrm{KBE}$ perspective. Other vital issues for policy are privacy and security issues and intellectual property rights.

\section{Policy Linkages}

18) RTD cannot be isolated from other policy areas. All laws, regulations and policies targeted at the economy will affect performance in invention, innovation and diffusion of new technology. A wide range of social policies also affect and are affected by RTD. From a policy perspective this implies increasing linkage between technology policy and broader policies in the socio-economic domain. A more synthetic approach to science, technology and innovation policy is needed to build bridges and blend with broader economic and social policies.

\section{PART II SOCIO-ECONOMIC ASSESSMENT}

19) Scarcity of public funds and the demand for transparency in the inner workings of the science system combine to make RTD projects, institutions and programmes increasingly the subject of evaluation. RTD policy assessment aims to enlighten the relation between a public intervention and the achieved direct or indirect effect in the spheres of science, the economy or society. However it is necessary to be clear about the pre-supposed assumptions of policymakers and evaluators. These include embedding RTD in innovation systems, the heterogeneous interests and expectations of actors, the variety of policy rationales and purposes, the multiple levels at which policies are pursued and the difficulty of attributing effects to interventions.

This section on Socio-economic assessment is in three parts and reviews evaluation practice within the Framework Programmes, other key RTD programmes to draw out lessons for evaluation of RTD. The final section examines socioeconomic benefits and attempts to relate methods to possible areas of use.

- Framework Programme Mini-Meta Evaluation

- Review of EUREKA and Advanced Technology Programme evaluation methodologies;

- Research Methods Mapping to Types of Socio-economic Benefit 


\section{How well have the Framework Programmes Been Evaluated?}

20) The mini-meta-evaluation review of the Framework Programme reviews 28 studies which focused on socio-economic impact in various parts of the FPs. Historically, such evaluations have encompassed the Panel Five Year Assessments, annual monitoring, evaluations of specific programmes, horizontal evaluations of cross-programme issues and national impact studies. An analytical framework compares them in terms of focus, design, effects studied and data and methodology-related issues. Two main types emerge: 'exploratory' and 'solid' studies:

- Exploratory studies consider what a future state of the world might look like given certain conditions (for example considering what legal or economic impacts could arise in the context of use of genetic fingerprinting). They are discursive in character. Other exploratory studies examine potential effects ex ante but have a more economic and quantitative focus. They are best used in providing guidance for decisionmaking on future RTD policy initiatives.

- Solid studies employ more characteristic evaluation approaches, take place ex post and are concerned with a full range of effects. The relation between effects studied and methodologies used is reviewed here in terms of suitability, validity and reliability, and exhaustiveness.

21) RTD evaluation audiences for which reports and analysis are required are a heterogeneous group. They comprise the following groups, each of which have different requirements in terms of scope, timing and depth.

- Programme Managers

- Programme Committees

- FP Management

- CREST

- European Parliament

- Council

- Economic and Social Committee

- Committee of the Regions

Outputs are better covered than are impacts regardless of type of effect. Generally, more attention is given to short term impacts rather than longterm impacts, despite the greater importance of the latter. Socio-economic effects are given slightly more attention than pure scientific and technological issues.

22) Problems of methodology include:

- Data are often uni-dimensional (surveys or interviews are not validated against company information or official statistics);

- Data are not analysed exhaustively (frequency tables are not analysed statistically);

- Quantitative information is overstated and non-participants' attitudes neglected;

- Efforts to trace societal effects are underdeveloped;

- A coherent and comprehensive impact evaluation methodology is lacking.

23) The section identifies and examines three examples of good practice, the first of which (CleanEffEn) combines quantitative and qualitative information fruitfully and has two time horizons, the end of the projects and three years after; the second (Tap-Assess) analyses different 
stakeholders systematically; and the third (FinImpact) combines a tick-list approach with factor analysis.

24) A basic requirement for the monitoring, evaluation and assessment of future Framework Programmes is the systematic collection of data at the level of individual projects, specific Programmes and Framework Programme itself. The structure and the quality of the data will determine whether it can be aggregated for the purpose of evaluation at the levels of the Specific Programmes and of the Framework Programme itself. The reporting frequency for monitoring and assessment could be reconsidered.

25) Evaluation can be made more efficient and less burdensome. External monitoring reports should probably be issued every two years, instead of every year as at present. "Evaluation fatigue" can be a problem with project participants who have to respond to many different questionnaires, especially when these ask repeatedly for the same data. The systematic collection of data should engage the following principles:

- Participants should not be required to deliver the same information to more than one study;

- Evaluators should have unrestricted access to all relevant documents held by the Commission;

- Surveys should be scientific in their execution;

- Expert interviews should be used to compensate for the limitations of surveys;

- A post-completion tracking system should be installed for longer-term effects.

26) The panel system used by the Commission to conduct its assessments successfully addresses the need for demonstrated independence. The purely panel-based overall "Five-Year Assessments" of the EU FPs were predominantly concerned with recommendations for future high-level policy, and did not include a comparative portfolio analysis, and made only weak reference to the actual results of all the evaluative efforts made by the Specific Panels and others.

27) Many of the recommendations drew not so much on an evaluation of past Framework activities, but on the collective opinions and assessments of the Panel members concerning the general structure and organisation of science, technology and innovation in the EU. However, since panels do not have a monopoly of wisdom, supporting studies should be conducted and their results made generally available. Any "intelligent" assessment of RTD impacts by panels needs supporting information which to a great extent can be achieved from independent studies.

28) There is still plenty of room for exploring new methodological approaches to the evaluation of socioeconomic impacts of RTD funding. For example the identification of the contribution of public RTD to the development of vivid socio-economic clusters and networks of public (centres of excellence in research and education) and private (producing companies, knowledgeintensive business services) actors and institutions is methodologically still in an infant stage.

29) Intelligent assessment of RTD impacts needs supporting information from independent studies including those based upon foresight and socio-economic studies of needs of sectors or societal groups.

30) A demanding assessment approach as discussed in this report needs a dedicated budget. Programme managers can only 
organise monitoring, evaluation and assessment procedures appropriately once certain amounts have been explicitly earmarked for assessment efforts. In other contexts a budget of $0.5 \%$ of the RTD funds allocated has shown itself to be sufficient, so there is clearly still plenty of scope for extending the monitoring, evaluation and assessment budget of the Framework Programme.

\section{Benefits of Systematic Evaluation}

31) As part of the extended review of evaluation methodologies, two major research programmes from around the world are reviewed. The first, the Eureka Initiative, which is an inter-governmental European research activity, and the second, the United States Advanced Technology Programme are both major programmes of RTD support. Both have adopted systematic evaluation strategies. The ATP in particular has devoted substantial financial resources to evaluations which have a strong economic focus. Both look at broader and longerterm impacts of the programmes.

\section{Mapping the Socio-Economic Impacts of Programmes}

32) An inventory of effects and evaluation methods is presented, to provide a resource for the development of specific evaluation methodologies to match the needs of Commission staff and those working in collaboration with them. This inventory is in three parts and examines the following:

- Defining socio-economic impacts: reviews typologies of social and economic impacts at the level of individuals, firms, industries and the whole economy.

- Building an approach to impact evaluation: deconstructing the research process; and

- Mapping of methods and impacts: mapping methods to the classified impacts.

33) The methods included are those for data generation (interviews, questionnaires, expert judgement, review and case study) and those which cover analytical approaches (systemic approaches, sociometric, longitudinal/ historical studies, statistical, scoring methods, econometrics and financial/ accounting). These are mapped against micro, meso and macro economic levels, and employment and quality of life.

\section{4) Two major and six sub-categories of socio-economic impact are presented:}

\section{Economic}

- Micro - Firm-based capacities and efficiencies (product and process improvements)

- Meso - Within networks of innovation

- Macro - Market and Economy Level increases in capacity and efficiencies, improvements to stock of knowledge

\section{Social}

- Employment - Human Capital Development, Rate of Employment

- Quality of Life - Service / Product Based Benefits in terms of Health and Environment (Environmental Protection) and also

- Social Cohesion, Inclusion and Security, and Freedom of Action

35) A vast array of techniques is available for socio-economic impact assessment. Many techniques are specialist methods, often derived within 
social science research; others are developed to be uniquely suitable for specific areas of RTD impact assessment; others are flexible and can be used in a variety of contexts. But the choice of methods follows from the issue of the research dimension, the key scoping activity that should precede any enquiry into the social effects of programmes.

36) Evaluation research activity contains six major stages dealing with the following questions:

1. What is being assessed?

2. How will the evaluation research be done?

3. How shall the data be obtained?

4. How shall the data be analysed?

5. How shall the findings be reported and disseminated?

6. What use can be made of the evaluation findings?

37) Focusing on the third, evaluation research stage, the key functions it serves are:

- Assessing the link between cause and effect of policies (attribution); and

- Measuring the effects.

38) Issues to be addressed include:

- the level of engagement the evaluator has with the subject matter, which involves a trade-off between deeper understanding and objectivity;

- timing of evaluation in relation to the research it assesses, where the trade-off is between early delivery for policy relevance and allowing the effects time to emerge;
- focus of evaluation research, with the main decision being between meta-analysis of existing data and new data collection;

- research methods, quantitative, qualitative or mixed; and

- scope of evaluation in terms of the relative emphasis on efficiency, effectiveness and appropriateness.

\section{Mapping Techniques to Impacts}

39) The classes of methods described in the report can be mapped against the impact types listed above. The methods which are preferred for particular types of impact areas are indicated by a coding shown below the table. The table and coding and shown below in Table A1.

\section{PART III CASE STUDIES}

40) Following the mapping exercise, the report introduces five case studies which illustrate the diversity of approaches to socio-economic evaluation and the need to deploy a wide range of techniques. The case studies cover the following areas, which also are meant to be representative of FP activity and of the forthcoming major challenges to evaluation:

- Market-Oriented case study (comparing the Beta method, costbenefit analysis and option-pricing and providing a fully-worked example);

- Service Sector case study (reviewing literature on innovation in services and providing a project example);

- Programme Level case study (Reanalysing the participant questionnaire for the 1995-99 Five Year Assessment and describing two programme evaluation approaches); 
- Social Science Research case study (reviewing literature on evaluation of social science and providing a project example);

- Accession Country case study (analysing the effects of the Framework Programme Framework Programme for Hungarian participants).

41) The case studies illustrate the use of existing best available methods in a sample of representative cases of Framework Programme activity. These examples help to demonstrate the relevance and importance of a range of evaluation techniques for the evaluation of socio-economic impoacts that occur within differing contexts.

- at varying lengths of time after programme action;

- in different social and economic contexts;

- in simple narrowly defined cost (financial) terms;

- in terms increasing innovation performance at organisational, institutional, regional and systemic levels. 
Table A1 Major Methodological Uses for Socio-Economic Evaluation by Impact Type

\begin{tabular}{|c|c|c|c|c|c|}
\hline $\begin{array}{c}\text { Methodology } \\
\text { Area }\end{array}$ & $\begin{array}{l}\text { Economic } \\
\text { Micro }\end{array}$ & $\begin{array}{c}\text { Economic } \\
\text { Meso }\end{array}$ & $\begin{array}{l}\text { Economic } \\
\text { Macro }\end{array}$ & $\begin{array}{c}\text { Social } \\
\text { Employment }\end{array}$ & $\begin{array}{c}\text { Social } \\
\text { Quality } \\
\text { of Life }\end{array}$ \\
\hline Interview & $\bullet \bullet$ & $\bullet \bullet$ & & $\bullet$ & $\bullet$ \\
\hline $\begin{array}{l}\text { Questionnaire } \\
\text { Survey }\end{array}$ & $\bullet \bullet$ & $\bullet \bullet$ & & • & • \\
\hline $\begin{array}{c}\text { Expert } \\
\text { Judgement } \\
\text { Based }\end{array}$ & & $\bullet \bullet$ & & & \\
\hline $\begin{array}{l}\text { Review } \\
\text { Methods }\end{array}$ & & $\bullet$ & & & - \\
\hline Case Study & $\bullet \bullet$ & $\bullet$ & & $\bullet$ & $\bullet$ \\
\hline $\begin{array}{c}\text { Systemic } \\
\text { Approach - } \\
\text { Sociological - } \\
\text { Socio-economic }\end{array}$ & & $\bullet \bullet$ & & • & • \\
\hline $\begin{array}{l}\text { Longitudinal / } \\
\text { Historical } \\
\text { Studies }\end{array}$ & $\bullet$ & $\bullet$ & & $\mathrm{O}$ & o \\
\hline $\begin{array}{c}\text { Sociometric } \\
\text { Studies - } \\
\text { Scientometrics / } \\
\text { Technometrics }\end{array}$ & $\bullet$ & $\bullet \bullet$ & $\bullet \bullet$ & $\mathrm{o}$ & $\bullet \bullet$ \\
\hline $\begin{array}{l}\text { Mathematics \& } \\
\text { Statistics Based }\end{array}$ & $\bullet$ & $\bullet$ & & & \\
\hline $\begin{array}{l}\text { Scoring } \\
\text { Methods }\end{array}$ & & - & & $\bullet$ & $\bullet$ \\
\hline $\begin{array}{l}\text { Economics / } \\
\text { Econometrics }\end{array}$ & • & $\bullet$ & $\bullet \bullet$ & • & • \\
\hline $\begin{array}{l}\text { Financial / } \\
\text { Accounting }\end{array}$ & $\bullet$ & $\bullet$ & $\bullet$ & • & • \\
\hline
\end{tabular}

\section{Coding Note}

- Indicates general applicability. $\bullet$ Indicates the technique is especially suitable

o Indicates applicability but has been little used 


\section{Case 1: Market-Driven Programme}

42) This employs a "fictitious" case, set up largely on the basis of past real case studies performed by the BETA team, to demonstrate how different evaluation techniques can be applied at the level of the firm (or programme participant level). The different methods chosen within the case study include:

- The Beta Method for assessing direct and indirect effects on a participant;

- The Option Method for ex ante assessment;

- The Classical Cost Benefit Analysis Method;

It is concluded that all three approaches have a strong focus on outputs produced by participants and their subsequent effects on these and other actors.

\section{3) Main limitations are:}

- Beta Method: wide scope of effects measured but scope of actors covered is limited to the participant being studied;

- Cost-benefit and Option pricing: confined to market effects but wide range of actors can be covered.

Areas where further methodological work is needed are:

- Better understanding of additionality at levels of aggregation above that of participant;

- Better tools are needed to assess the effects of RTD on capacity/capability of participants;
- The problem of project fallacy needs to be addressed;

- The specific quantitative/semiquantitative data collection approaches of these three methods need to be complemented by collection of broader qualitative data.

The issues listed will become more important in the context of the broader goals of the European Research Area.

\section{Case 2: Service Sector}

44) This draws upon the recent study of the impacts of the Telematics Applications Programme in the Fourth Framework Programme. The project which has been carried out demonstrates the complex nature of the innovation processes involved in services innovation, and demonstrates the delayed nature of benefits where services innovation is concerned and in the health sector in particular. The case study also confirms the importance of the role of users and innovation champions within the context of innovation and RTD support activities.

45) The service sector case study concludes with a discussion of the range of impacts observed and the balance between impacts upon the process of innovation itself and those evident upon direct beneficiaries of the technology whose development was facilitated by the project. Any RTD supporting activity which seeks to address a service based context will therefore have lead to a range of socioeconomic impacts within the process of innovation in the first instance and thereafter upon the users of such technologies and those affected by them in the longer term. As well as standard socio-economic effects, some 
specific issues to be addressed in the service sector include:

- Improved levels of service/ and higher consumer satisfaction;

- Improved access to service higher numbers of people using the service;

- Improved safety;

- Better informed consumers number of people with access to information is increased and there is a reduction in the number of errors caused by misinformation;

- More active citizen participation occurs;

- Greater trust in the security and reliability of electronic interactions occurs;

- Reduced social exclusion more groups defined as socially excluded are able to make use of services;

- Greater equality between European regions in terms of access.

\section{Case 3: Programme Level}

46) This shows how the impacts associated with projects conducted within the context of RTD programmes can be explored and assessed in many ways. Some approaches specifically attempt to provide quantitative estimates of particular outputs, outcomes and impacts. These include publication, patent and product counts on the one hand and attempts to measure the commercial returns associated with participation in individual projects on the other.
47) This programme level case study examines the following major evaluation methods issues:

- the use of ex post questionnaires to assess the range and relative importance of impacts associated with participation in RTD programmes;

- the use of external project evaluators conducting telephone interviews and desktop analyses to perform comprehensive ex post reviews of all projects within a programme;

- the combined use of questionnaires and mini-case studies to identify and analyse projects with high commercial returns.

48) The analysis of the programme responses gives results which are typical of collaborative RTD programmes, with knowledge-oriented goals such as the development of new tools and techniques and the enhancement of existing knowledge bases cited much more frequently as important goals than those more overtly concerned with eventual exploitation, e.g. the development of new products or improved competitiveness in the market place. In terms of expected and realised outputs exploitation incentives were very important. However, the survey results simply reflect the fact that the primary goals of RTD projects are couched in terms of knowledge-related ambitions, whereas the longer-term expectations of the organisations involved in these projects are that improvements to the knowledge base will ultimately be translated - either directly or indirectly - into improvements in overall performance in the market place. 
49) The case study also showed that 'soft', that is, behavioural and organisational 'effects' of FP participation are likely to be crucial besides the 'usual' outputs and impacts.

\section{Case 4: Social Sciences Research}

50) This examines and characterizes the range of effects of the research and technological development activities supported by the Framework Programme in the area of social sciences research, an area of increasing importance to the European Union. The case study focuses on a Framework Programme funded network of social scientists whose work on social policy had impacts upon policy making within the European Union in the area of social inclusion/exclusion.

51) This study provides an opportunity to examine an area of increasing policy relevance in which attempts at evaluation of benefits have been slow. A conceptual discussion introduces a typology of potential socio-economic benefits of social research and a range of methods is put forward which may be appropriate in the assessment of funded programmes of research in this area. Social research is considered both as supporting other_forms of RTD and in its own right as the leading or sole domain knowledge for areas such as social, immigration and health and quality of life policies.

52) The outcomes of FP funded social science research are examined with the aim of categorizing research and suggesting appropriate evaluation approaches. Research outcomes and impacts in this area are broad and comprise the following:
- Direct Policy Contribution (eg on social inclusion)

- Research Infrastructure improvement, discovery of previously unknown and unrecognised problems in research infrastructure;

- Interactivity and involvement with users to elicit further research requirements and needs from groups which might be normally located close to the social periphery;

- Conceptual Tools, Models;

53) Evaluation approaches are likely to involve close attention to and monitoring of the link with users in the context of socially involved research. It is also important to consider involvement of users with groups considered as peripheral or marginal. Evaluation should also focus on the role of researchers in building infrastructures for a range of RTD activities.

\section{Case 5: Accession Country}

54) This examined Hungarian experiences as an example of an accession country's experience of participation in Framework Programme projects. Wide-ranging and deep social and economic changes in Central and Eastern Europe (CEE) have created new opportunities for the European research community which Eastern European research organisations and firms are now seeking to engage with. The Fifth Framework Programme is the first FP in which it has been possible for all the associated countries to participate at the programme level.

55) The case study examines the experience of firms and research 
organisations in their participation within European research activities and gives insight into the nature of impacts occurring within these contexts and the most appropriate methods for the assessment of benefits.

56) Wider benefits arising from FP5 participation include the realisation by academic institutions in Hungary and elsewhere in CEE that the commercialisation of its $R \& D$ results is not a 'strange', but a natural and customary activity. Learning the tools, management methods and good practices how to run this business in an effective way should be considered as one of the most important benefits of FPs for countries in transition.

57) The view is put forward that it would well worth the effort to apply this methodology - based on the techniques applied in current EUmembers, and tailored to the systemic characteristics of a country in transition - to a larger, statistically representative sample. Thus a reliable description could be obtained, on which basis sound policy conclusions could also be drawn.

58) A further main finding has been the importance of the overall institutional context, namely two underlying characteristics of the Hungarian national system of innovation upon the way in which impacts have occurred:

- The research system has been fragmented during the planned economy period;

- The process of socio-economic transition, following liberalisation of the economy has restricted RTD opportunities to a limited range of areas;
59) Nevertheless, engagement by Hungarian firms and academic institutions with the Framework Programme has resulted in the reappearance of new institutions and the presence of stronger incentives that have led to new partnerships, and strengthened collaborations.

\section{PART IV EVALUATING THE EUROPEAN RESEARCH AREA}

60) This section considers socioeconomic assessment in and of the European Research Area concept and its principal new modes of support, Networks of Excellence and Integrated Projects. The implications of the ERA in terms of the conceptualisation of benefits from research carried out at the EU level and the implications in terms of assessing and maintaining quality and appropriateness are considered here. While the European Evaluation Area concept presents significant new opportunities for the delivery of further growth with the European Union, the operation, management and evaluation of its new instruments will present a significant new challenge for individual governments and for the European Union. There are many dimensions of evaluation relevant but here only socio-economic assessment is considered.

61) So far as Networks of Excellence are concerned, the emphasis in evaluation will be placed on the added value generated by the networks. The scope of evaluation will extend well beyond the scope of the funded part of the activity into the core activity of the participants. Additionality will be generated both in the immediate EAV and in the persistence of the integration beyond 
the funding period. Evaluation will need to take a long-term perspective.

62) For Integrated Projects in terms of evaluation, the socio-economic dimension clearly has priority for this instrument. However, the approach is somewhat different to that for evaluation of smaller isolated projects. In the case of the IPs the project should achieve a critical scale whereby the strategic direction of a sub-sector of the economy is affected. This implies that the evaluation needs to engage with the socio-economic status of that subsector to understand the potential and actual impact of the IP. Effects could include such broader aspects as market structure. This can be described as a meso-level evaluation.

63) For both of these project types the much larger scale of projects in relation to previous Framework Programmes implies that choices will have to be made on strategic grounds as well as criteria of excellence. Excellence in any case is very problematic to compare across fields. This implies the need for ex ante appraisal both at programmatic level, and at the project selection stage. For some NoEs and all Integrated Projects this will involve socio-economic criteria of the type discussed in this report and linkage to a policy rationale.

64) Integration of research policies has the natural consequence for evaluation at a European level that it will need to extend beyond the evaluation of the Framework Programme. Closer integration of research policies requires mutual understanding of what has been achieved and of the balance of benefits. An evaluation of a programme which links national activities needs to comprehend the widely varying institutional settings for the same work (for example an aspect of cancer research could be carried out in a university in one country, a branch of a national research organization in another, a central laboratory in a third and by a nongovernmental charitable foundation in a fourth). Comparing inputs to research will require an understanding of the dynamics of all of these settings.

65) It may also be necessary to establish a clearer common understanding of what constitutes quality and excellence in each country. However, progress will require a shift of focus for evaluation towards a broader systems perspective.

66) A central problem which must also be faced is one of standards. The solution is likely to be that a European Research Area has a corresponding development - "a European Evaluation Area" in which there is a common methodological and procedural understanding that allows members to accept and validate each other's findings. Without this, member states may greet with some suspicion proposals that a particular institution or centre meets a particular level of excellence in some dimension of its performance. 


\section{Introduction}

With a foundation in previous programmes in support of industrial competitiveness, the Fifth Framework Programme now encompasses wider socio-economic criteria in its rationale. The European Research Area initiative extends further the reach of European co-operation and in so doing brings new challenges for the process of socioeconomic assessment. Despite the considerable achievements of the European Commission in developing a system for the evaluation of its RTD programmes, assessment of their socio-economic impact remains an area of difficulty. A succession of studies have emphasised the need for methodological development and support.

This study seeks to build upon the foundations of this and other evaluation work in the area of socio-economic impact assessment to achieve the following specified aims:

- To develop a rigorous examination of the different elements of socioeconomic impact; and

- To develop effective methodologies for the socio-economic evaluation of the Framework Programme

The report addresses the first of these aims through consideration of the following issues:

- The general contribution of RTD to economic growth and social welfare, covering both the traditional rationales for RTD support, and newer modes of understanding which have emerged in the context of the knowledge driven economy;

- The more specific rationale for support of publicly funded RTD;

- For the Framework Programme itself, the specific rationales for support which have been adopted at a EU level, which have been developed from the Reisenhuber criteria through to the present concept of European Added Value.

In addressing the second of these aims through the development of working methodologies, the report will show that:

- There is no single methodology, which can address all aspects of socioeconomic impact. Rather, a portfolios of approaches should be applied, with a clear understanding of the limitations of each one;

- Different approaches are needed at different levels of aggregation. The most important levels are those of project, individual programme, the Framework Programme as a whole and the more general contribution which the Framework Programme is a component (and into the future the European Research Area); 
- Evaluation approaches should not impose undue burdens upon researchers however, systems should be present which will generate sufficient data that can be collected to evidence of socio-economic impacts and that such data is available throughout the European Union;

- Recommended methodologies should be capable of producing results which are clearly understood by policy makers and which can be easily acted upon.

This report on the Assessment of the Socio-economic impacts of the Framework Programme takes the following form:

- A first major section considers the economic rationales for technology policy.

- This is followed by the second major section, which considers the theory and practice of socio-economic assessment of RTD, particularly of Framework Programme activities.

- A third major section uses a series of case studies to demonstrate the range of effects arising from project and programmes and the usefulness of different methods and techniques in elucidating and measuring such effects.

- A number of comments are then made in section 5 about the challenges posed by the introduction of the European Research Area and the instruments of policy through which its aims shall be met.

The section on economic rationales includes a review of the literature on technical change including the role of scientific research in engendering technical change. This issue is considered at the macro economic level, where there is a discussion of how the role of technology is understood within the neoclassical tradition and within neoSchumpeterian and evolutionary perspectives. The contribution of micro-economics in the areas of industrial economics and management literatures is also considered.

Also within this section, the role of science and technology policy is examined with reference to areas of much contemporary interest and importance - industry science linkages. Universities and to a lesser extent public laboratories are increasingly seen as the providers of knowledge which can be subsequently commercialized, given the appropriate structures and practices and policy support mechanisms. This section reviews the latest work in this area including reference to data collected by the CIS and considers the importance of the flow of knowledge and people in the innovation process. The section on economic rationales then moves to a discussion of the rationales for intervention in the area of technology policy, including concepts from public administration theory such as additionality, substitution and deadweight.

This is then followed by a section on the key developments in the knowledge-based economy. The final element of the section on economic rationales is a discussion of the important issue of linkages between RTD policy with other areas of policy. This section examines the increasing level of commitment in other policy areas, and 
reviews the other mechanisms such as monetary and fiscal policy by which the goal of economic growth and societal benefits can be enhanced.

The section on economic rationales is followed by an examination of socio-economic assessment theory and practice. The main tasks which are undertaken within this section are a review of the effects which are produced by Framework Programme interventions and a review of the methodologies which have been used in the delineation and measurement of these activities. Reference is made to two other exemplar programmes operating in the area of socio-economic impact - the Eureka project and the Advanced Technology Programme - from which lessons for evaluation methodology are taken.

The section finally examines the key evaluation and research steps and methods, which should underlie evaluation activities aimed at the assessment of socioeconomic impacts. This final section puts forward a number of recommendations about appropriate evaluation methods for particular areas of socio-economic benefit in the form of a mapping between types of impact and suggested methods. The section on socio-economic assessment ends by reference to the wider policy contexts in which RTD activities operate, outlining the dependencies of different types of socioeconomic impact upon policies other than RTD activities.

The section on socio-economic assessment is followed by five case studies which examine the range of impacts arising from projects and programmes and which demonstrates the utility of selected methods and techniques for identifying and elucidating those impacts. The case studies which are used are intended to be representative of the scope and role of Framework Programme initiatives, and to be responsive to the Commission's increasing interest in the contribution which social science research makes to socio-economic well-being.

A First case study examined support in the area of Market-Driven RTD. Again, the study compared different methods that can be used at firm level (or more generally at individual participant level) through applying them to the same case. This approach is intended to be informative on the issues of the applicability of data between different research methodologies, the feasibility of the approaches, their complementarity, their respective scope of relevance, with a particular emphasis on the range of socioeconomic effects and impact they take into account, their relevance for the evaluation when firms are involved in different RTD projects (some funded by EU and others not), the way they are dealing with classical evaluation problems such as additionality and the one related to the determination of the scope of actors affected by EU RTD Framework Programme, and their relevance for evaluating to which extent the EU RTD Framework Programme help firms to adapt to the permanently changing constraints related to competition, innovation, and demand change.

A Second case study is from the services sector and draws upon the recent study of the impacts of the Telematics Applications Programme in the Fourth Framework Programme. This had a strong services focus. The study which has been carried out examines the complex nature of the innovation processes involved in services innovation, and demonstrates the delayed nature of benefits where services innovation is concerned and where the sector is the health sector in particular. The case study 
also confirms the importance of the role users and innovation champions within the context of innovation and RTD support activities.

The Third case study is a detailed analysis of past surveys of Framework Programmes. The questionnaire analysis will demonstrate that the range of impacts associated with participation in the Framework Programmes is very broad, ranging from immediate 'first circle' effects, e.g. project outputs (publications, new or improved methods and tests, demonstrators, prototypes or pilots) and impacts affecting the researchers themselves (improved knowledge bases, enhanced scientific and technological capability); through downstream 'second circle' impacts affecting whole participating organisations (e.g. new or improved products and services, improved competitiveness, commercial returns etc.); to longer-term or 'third circle' socio-economic impacts in a variety of external spheres (e.g. improved economic development, improved policy formulation etc.). A number of observations about future questionnaire design are also made here.

The Fourth case study focuses on a Framework Programme funded network of social scientists whose work on social policy had impacts upon policy making within the European Union in the area of social inclusion/exclusion. This study provides an opportunity to examine an area of increasing policy relevance in which attempts at evaluation of benefits have been slow. Initially, a conceptual discussion takes place in which the potential socio-economic benefits of social research are considered as are the range of methods which may be appropriate in the assessment of funded programmes of research in this area. In the first main section, a conceptual discussion takes place which introduces the research which has been carried out on the use of social science / social research and the assessment of its value and effectiveness. In the second section, the case studies are used to examine the outcomes of FP funded social science research with the aim of categorizing research and suggesting appropriate evaluation approaches.

After discussion with the Commission, it was felt that a fifth case study that focused upon an accession country's experience of participation in Framework Programme projects would be timely. Wide-ranging and deep social and economic changes in Central and Eastern Europe (CEE) have created new opportunities for the European research community which Eastern European research organisations and firms are now seeking to engage with. The presently running Fifth Research, Technological Development and Demonstration Framework Programme (FP5) is the first FP in which it is possible for all the associated countries to participate at the programme level. It took a decade achieving this close co-operation from individual project participation to opening some of the specific programmes for project participation, then a broad participation on a project by project base to the full programme level participation. The case study examines the experience of firms and research organisations in their participation within European research activities and gives valuable insight into the nature of impacts occurring within these contexts and the most appropriate methods for the assessment of benefits. In terms of wider benefits, the realisation by academic institutions in Hungary and elsewhere in CEE that the commercialisation of its R\&D results is not a 'strange', but a normal activity. Learning the tools, management methods and good practices how to run this business in an effective way should be considered as one of the most important benefits of FPs for countries in transition. 
The case studies are followed by a section dealing with the European Research Area and its principal new modes of support, Networks of Excellence and Integrated Projects. The implications of the ERA in terms of the conceptualisation of benefits from research carried out at the EU level and the implications in terms of assessing and maintaining quality and appropriateness are considered here. While the European Evaluation Area concept presents significant new opportunities for the delivery of further growth with the European Union, the operation, management and evaluation of its new instruments will present a significant new challenge for individual governments and for the European Union. 


\section{Economic Rationale}

\subsection{Macro-Economic Perspectives on Technical Change}

"It hardly seems necessary these days to point out the importance of technical advance. We look to it to rescue us from the consequences of exhausting essential natural resources; abate inflation through productivity increases; improve our balance of payments deficit; eliminate famine; and cure cancer, heart disease, and a variety of other ailments. Our faith in technical advance is bolstered by achievements such as the atomic bomb, electronic computers, the landing of a man on the moon, heart transplants, and test-tube babies. We no longer ask if something is possible, but how soon it can be done and at what price." (Kamien and Schwartz, 1982, p.1)

Thus two important mainstream economists opened their landmark book almost two decades ago. It was one of a set of seminal publications in the late 1970s and early 1980s that changed the image of economists as laggards in the study of technological advance. This set would certainly include Caves (1982), Chandler (1977), Freeman (1982), Mansfield et al. (1977), Nelson and Winter (1982), Rosenberg (1976, 1982), and Stoneman (1983), among others. While only a subset of these economists would classify their work into the "mainstream", they have all stepped more or less on the shoulders of the same giants, including Adam Smith (1976), Alfred Marshall (1911), and Joseph Schumpeter (1942).

Nonetheless, much more recently Chris Freeman wrote that a continuing paradox in economics "... has been the contrast between the general consensus that technical change is the most important source of dynamism in capitalist economies and its relative neglect in most mainstream literature." (Freeman, 1994, p. 463). Such views can better be explained by Nelson and Winter's (1982) dichotomy between "appreciative" economic theorizing and "formal" economic theorizing. Appreciative theorizing stays very close to empirical analysis and case study work. Its strength lies in moving fast to interpret what is going on and explain relationships among important variables. The principal weakness of this kind of theorizing is its basis on what the analyst thinks is happening and may contain logical inconsistencies. Formal theorizing, on the other hand, often stays at some distance from applied work. Empirical work is used to provide stylized facts rather than wholesome stories. The strength of formal theorizing is the elimination of logical inconsistencies; its weakness is its slower pace that often leaves it at some distance from actual events. Formal economic theorizing is basically what one has in mind when one talks about "economic theory": an abstract edifice to explore logical arguments.

Critics have tended to attack formal economic theorizing for its slow response to newer concepts and empirical findings regarding the causes of technological advance and its impact on the economy. But that should be expected if the argumentation above is correct. Moreover, formal economic theory is not a good descriptor of what amounts to a very significant contribution of economists in this area of study.

This short summary will present basic economic arguments on the causes and effects of technological advance while disregarding the aforementioned dichotomy. The first section takes a short historical recount of the general direction and main puzzles of the 
economic analysis of technological advance. Several following sections deal with a specific analytical objectives.

\section{Economic Directions and Puzzles Regarding Technological Advance}

Economists became concerned with the effects of technological change early on in view of the industrial revolution unfolding around them. Unfortunately, classical economists did not perceive technological change as part and parcel of the economic process. For example, they failed to conceive the true nature of natural resources as "man-made" rather than "natural", missing the fact that changes in the relative scarcity of resources creates conditions for substituting one resource for another (including technological advance). And they did not adequately appreciate the fact that rapid technological advance is not simply the outcome of capitalist forces but also shapes and moulds the forces and institutions of the capitalist system. Classical economists had to overcome significant limitations. Their understanding of the forces underlying technological progress varied widely. They lacked reliable empirical information. And, the novelty of their field of inquiry made it difficult to agree on methodological issues.

The introduction of consistent analytical structure in economic theory was the pursuit of the marginal utility school, starting in the second half of the $19^{\text {th }}$ century. In addition to the factors influencing consumer behaviour, proponents of this school emphasized the objective aspects of production. But in the effort to produce a workable theoretical construction of the production function, the study of technological change was ostracized. "(A)s the importance of the production function increased, so the question of technical change receded into the background. Those who produced the most mathematical treatment of the production function, i.e., Walras, Wicksteed and Barone, tended to ignore the changes caused by technology." (Heertje, 1977, p. 94). The neoclassical microfoundations were now in place.

With few exceptions - one may cite the early work of zealots like Kuznets and Schumpeter - economists were minimally interested in the process of technological advance as a core topic of economic analysis in the first half of the $20^{\text {th }}$ century. The time of systematic consideration of technological change, including theoretical, empirical and policy oriented work would come well into the century when organized R\&D activities in industry became widespread and technology was recognized to be a central part of the engine of economic growth. Several reasons have accounted for the renewed interest of economists in technological advance in the latter half of the century (see also Rosegger, 1996):

1. Massive commitment of government resources in $R \& D$ during the war demonstrated that purposeful searches for technological solutions to specific problems can be organized.

2. Once they had engaged in the purposeful search for innovations, firms learned that this is an economic activity like others, albeit with some peculiar characteristics and fuzzy relationship between inputs and outputs (Lundvall, 1992).

3. It was quickly recognized that the impact of this activity transcended the conventional economic measures of performance (positive and negative external effects). 
4. Questions of international competitiveness, relating first to the dominance of the United States and then to the emergence of Japan and Europe as formidable powers, started to increasingly focus on scientific and technological capabilities.

5. A large group of newly established developing countries after the war were looking for ways to close the gap with the industrialized countries. Technological and, more generally, innovation capabilities seemed to be key.

6. A rapid process of globalisation has had at its epicentre large multinational corporations the existence of which has been explained since the mid-1960s on the basis of intangible assets and related market failures (Caves 1996). The foremost intangible asset is frequently argued to be technological capability and, more generally, ability to innovate.

It was the appreciative theoretical work of Schumpeter (1942) which probably contributed more than any other in providing the necessary impetus for contemporary economic research in the causes and consequences of technological change. His stylised representation of the process of technological advance as "gales of creative destruction" captured the imagination and proved a turning point in economists' conceptualisation of technological progress. Schumpeter's contribution triggered a prolonged discourse over the relationship between market structure and evolution, economic institutions, and the incentives for and the intensity of technological invention and innovation. Sorting out the implications of the so-called neoSchumpeterian hypotheses concerning market concentration, firm size, and the pace of technological advance attracted a lot of attention. It did not matter much that Schumpeter's path breaking ideas were neither complete not always right (Nelson, 1990). What really mattered was that economists now had a new handle on a issue too important to disregard. They started paying attention not only to the effects of new technology but also to the factors inducing technological change.

However, the task of finding an appropriate procedure to incorporate technological progress into existing formal theory proved daunting. A number of unsettling observations were made quickly:

1. Endogenising technology complicated theoretical modelling significantly, especially if dynamics were to be introduced.

2. This area required genuine thinking given that market failure in producing technological knowledge was suspected to be widespread, rendering traditional models less satisfactory.

3. The preoccupation of standard economic theory with utility maximizing rational choice subject to known constraints created a genuine problem in explaining technological creativity since the latter often implies an attack by an individual on a constraint that everyone else takes as given (Mokyr, 1990).

4. There was a problem with the actual process leading to technological innovation: only fairly simplified hypotheses of this process could be handled by standard economic theory, given the theory's unsatisfactory record with investigating economic institutions.

In recent decades, formal economic theorists:

(a) have moved swiftly to tackle the first two problems at both the macro-level (e.g., endogenous growth theory (Grossman and Helpman, 1991; Romer, 1990) 
and micro-level (industrial organization, game theory (Tirole, 1988; Stoneman, 1995);

(b) have been creative in going around the third;

(c) have largely failed to deepen in the fourth, even though there has been significant appreciative theorizing in this regard.

The problem of formal theory with the process of technological advance has been known for some time. It has, for example, beset the traditional line of research trying to measure the contribution of past $\mathrm{R} \& \mathrm{D}$ investments to total factor productivity growth through an econometric production function (Griliches, 1979). Proxies of technology inputs and/or technology output are related to some measure of the ensuing economic outcome while the analyst is agnostic of the actual process of technological change. The exercise is encapsulated in figure 1.

The diagram suggests: (i) the transformation of $R \& D$ expenditures (R) into economically valuable, but imperfectly observable, technological knowledge stock (K); (ii) the approximation of the change in $\mathrm{K}$ over time $(\mathrm{K}=\partial \mathrm{K} / \partial \mathrm{t})$ with the stock of patents $(\mathrm{P})$ (or any other indicator of technology output; and (iii) the effect of $\mathrm{K}$ and other measurable factors X (e.g., physical capital, labour) on some measure of value $\mathrm{Z}$ (e.g., growth, productivity, profitability, or the stock market value of the firm or industry). Random components are expressed by the error terms $\mathrm{u}$ and $\mathrm{v}$. Thus, an attempt is made to estimate the direct relationship between $P / R$ and $Z$. The intermediate stage of arriving at $\mathrm{K}$ and transforming it into $\mathrm{Z}$ over time, as well as the complex interactions (multidirectional causality) between $\mathrm{X}, \mathrm{K}$, and $\mathrm{Z}$ cannot be appropriately represented due to the lack of knowledge about the behaviour of the factors determining K's intertemporal change - that is, the lack of knowledge of the process of technological advance.

Of course, this is not entirely the result of agnosticism but also of the need to aggregate across innovations and economic agents. To compensate, economists and business analysts have resorted to historical case studies. Detailed case studies of particular innovations are quite informative and show rather high internal rates of return to private $R \& D$ expenditures and even higher social rates of return (on the order of 10 to 50 per cent per annum) (Griliches, 1995). However, they are difficult and costly to pursue and cannot be generalized given the tendency to focus on the prominent and successful. 


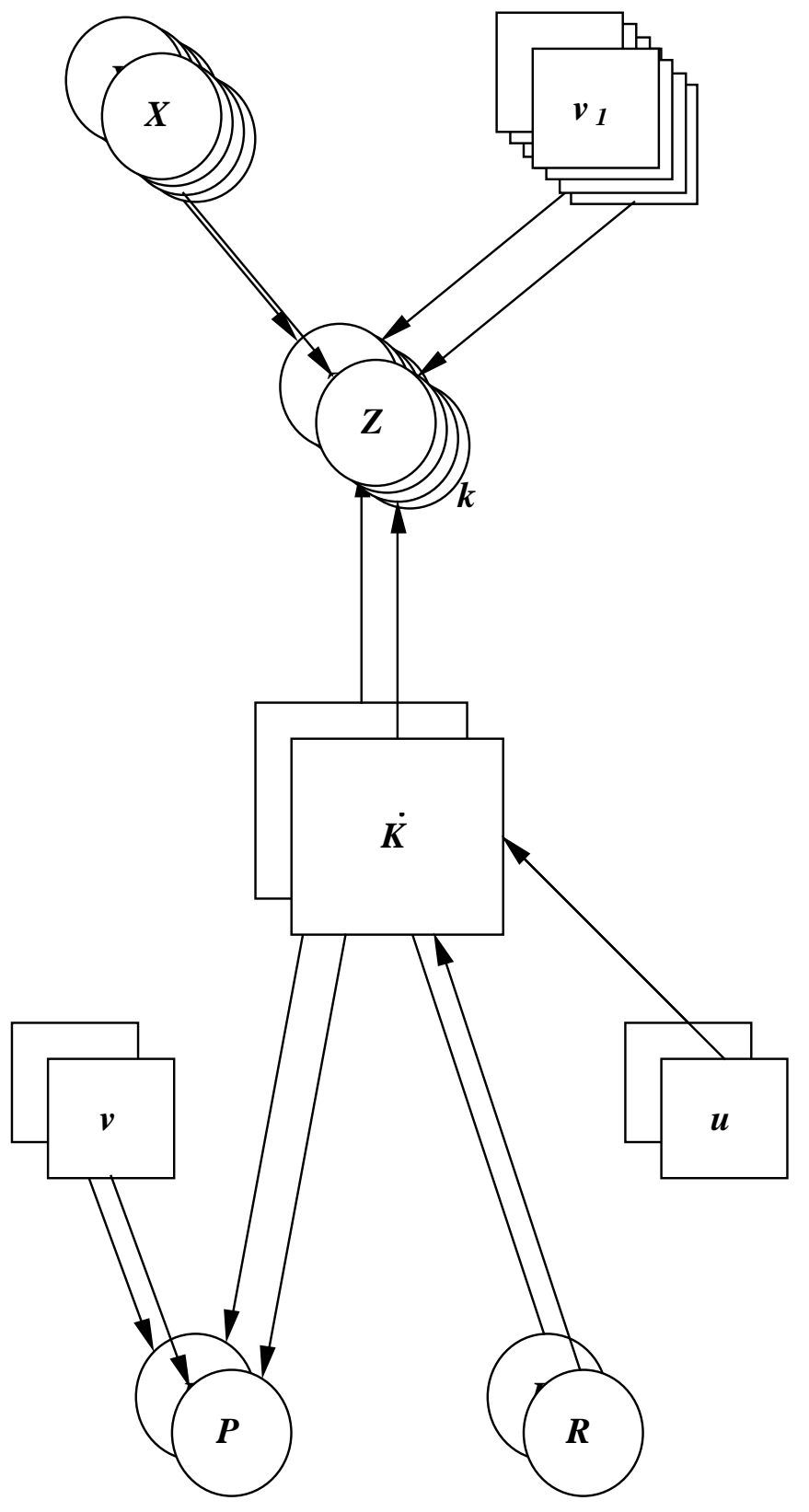

Figure 1 The knowledge production function: A simplified path analysis diagram (Griliches, 1990)

A lesson learned, even though not as quickly as desired, is that no single approach can claim monopoly in explaining the relationship of technological advance and the economy. A complex, multi-dimensional phenomenon like innovation requires multidimensional analytical approaches based on formal theory, aggregate empirical analysis (econometrics), acute observation and appreciative theorizing to establish regularities, and data from diverse sources including large databases, surveys, and case studies. It may even require new ways of conceptualising the process, an 
endeavour undertaken more recently by the rejuvenated evolutionary economic approach.

\section{Returns to R\&D}

A long stream of empirical research has tried to appraise the private and social returns to R\&D. It has been summarized in Griliches (1984) and more recently in Mansfield (1996), Hall (1996), and Nadiri (1993). Most of this work has used variants of the production function approach and has been subject to well known limitations (see previous section). In addition, several limitations must be emphasized when considering these results of this literature, including:

- The private sector has been the main subject of study;

- By and large, these results have been obtained with manufacturing data only;

- The analytical focus has been on the economic effects of technology, much less of science;

- The lack of consistent data has made this an "inexact science", basing the analysis on data that the author(s) often collect for the specific study;

- Methodologies have tended to vary widely, making aggregation across studies a hazardous exercise.

This literature has nonetheless produced important results, some of which are highlighted below.

1. A ubiquitous finding of the empirical studies has been that $R \& D$ expenditures contribute substantially to the growth of output in a variety of industries.

2. A strongly positive relationship between the stock of $R \& D$ and productivity at the firm level has been shown in several studies.

3. The estimated elasticities and the rate of return to $R \& D$ investment vary considerably depending on the type of data used (cross-section or time-series), the method of estimation, and the unit of analysis (firm, industry, country). Elasticities and rates of return are higher with cross-section data than those obtained with time-series data. At the firm level, the elasticities of R\&D tend to fall in the range $10-30 \%$ and the rates of return in the $20-30 \%$ range. At the industry level, the respective levels are $8-30 \%$ and $20-40 \%$. There are significant outliers in both sets of measures at both levels.

4. The majority of available econometric studies find that, for individual companies, the rates of return on R\&D financed internally are significantly higher than those on $R \& D$ financed by the public sector. While the rates of return for private $R \& D$ range between $27 \%$ and $60 \%$, those for publicly financed $R \& D$ are often insignificant and, in some cases, negative ${ }^{1}$. Several strong caveats apply here.

\footnotetext{
${ }^{1}$ Lichtenberg (1988), for example, has argued that public R\&D may crowd out private R\&D in particular industries.
} 
First, such estimations take into account only directly subsidized R\&D and not the broad public investment in scientific and technological infrastructure (human and physical capital, institutions, regulations) that the private sector draws upon all the time to raise the efficiency of and returns from its R\&D. Second, it has been argued that the use of US-based data for such comparisons is inappropriate due to the large share of defence-related R\&D expenditures in that country which do not directly target commercial payoff.

5. The rates of return also vary significantly between product and process innovations. Process innovations seem to receive higher marks in this respect than product innovations - e.g., Griliches and Lichtenberg (1984) calculated returns in the $58-76 \%$ range and $20-30 \%$ range respectively. ${ }^{2}$

6. Results in interrelated factor demand models treating the stock of $R \& D$ as a factor of production indicate that changes in R\&D affect the demand for inputs such as labour, materials, energy, and physical capital. The patterns of substitutions and complementarities between inputs varies across industries (Bernstein and Nadiri, 1989; Nadiri and Prucha; 1990). In general, R\&D investment seems to increase demand for capital but to decrease demand for labour and materials. Also the stock of R\&D is subject to adjustment costs which affect the level of investment and rates of return to $R \& D$. Investments in $R \& D$ are affected by changes in the prices of other factors of production and changes in demand. In short, $R \& D$ investment affects the structure of production; its own demand is affected by changes in the prices of conventional factors of production and changes in demand.

7. Private rates of return to $R \& D$ have generally been found to be lower than social rates of return. This implies that the innovator often has difficulty appropriating the full returns from the innovation due to the existence of one or more of three kinds of spillovers: (a) pecuniary spillovers; (b) knowledge spillovers; and (c) network spillovers. Various studies that Mansfield and colleagues have undertaken during the 1970s and 1980s indicated that detailed information on the nature of new products and processes are in the hands of imitators within a year from market introduction. The extent to which the social benefits from R\&D are appropriable depends on how much competition the potential innovator faces and on the kind of research or development activity in question (including patentability among other factors).

8. Significant effort has gone into capturing the externalities between firms and industries. The pioneering work of Scherer (1982) with technology flow matrices, Jaffe $(1986,1988)$ with estimations of "technological distance", and Los and Verspagen (1996) did indicate the feasibility of using firm-level patent data to look at the direction of the flows of disembodied knowledge spillovers. Inputoutput matrices have been used for some time to capture embodied knowledge spillovers. These roughly correspond to the categories of knowledge spillovers and pecuniary spillovers above respectively. No good effort to empirically appraise network spillovers is known. All available studies show significant flows

\footnotetext{
${ }^{2}$ Undoubtedly a peculiar result if juxtaposed to the clear tendency to spend way more on product R\&D.
} 
of technological knowledge between organizations of different kinds, universities, firms, government laboratories), industries, and nations.

9. There is increasing evidence that academic research has become a major underpinning of industrial innovation in many science-based industries. In a pioneering study, Mansfield (1991) showed that $10 \%$ of the appraised innovations would not have been possible without recent academic research and that the mean time lag between academic research and industrial innovation was seven years. Significant differences between sectors existed. The mean social rate of return of academic research, with the most limiting assumptions, exceeded $20 \%$.

10. Finally, empirical analysis has shown a strong positive relationship between basic research expenditures in the private sector and productivity at the firm level (Griliches, 1986).

11. Estimates of the rate of return to publicly funded research range from $20 \%$ to $60 \%$ (Salter and Martin, 2001). These depend on companies picking up knowledge produced by public research organizations and successfully applying it to their innovative activities. These estimates do not include more general societal returns from basic research which need to be appraised separately.

\section{Value of Public Research ${ }^{3}$}

The contribution of publicly funded and/or performed research to the economy remains a topic of strong interest. During the past couple of decades, a large body of literature has analysed the role of public research in the process of industrial innovation. Since the government has traditionally funded or performed research of more basic and generic nature, whose value is very difficult to calculate in monetary terms, a significant part of this recent literature has tried to appraise its value indirectly by accounting for the knowledge flows from publicly-funded research organizations (PROs) to companies. PROs include universities and various types of research institutes.

Essentially four different methods have been used to evaluate knowledge flows from PROs to industry: production function models using patents or product announcements as the dependent variable; citations of scientific papers; case studies of specific innovations; and surveys of the subjective importance of PROs to firms as a source of knowledge.

Jaffe (1989) used the production function model to estimate spillovers from university research to commercial innovation in the United States. The dependent variable is the number of patented inventions (a proxy for innovative output) and the explanatory variables included private corporate RTD expenditures and university research expenditures. The model estimations provide evidence that expenditures undertaken by universities positively influence corporate patenting activity. Acs et al (1992), use a similar method, replacing the number of patents with the number of product innovation announcements. Their estimations also reported an increased elasticity for

\footnotetext{
${ }^{3}$ This section draws extensively on Arundel and Geuna (2001).
} 
university research expenditures, confirming the importance of public research for industrial innovation.

Patent citations have also been frequently used to trace knowledge flows. A patent citation of a scientific paper is assumed to represent the flow of knowledge from scientific research to the firm that patented the invention. Jaffe et al. (1993) reported that patents granted to U.S. universities received more citations than patents granted to corporations. Narin et al (1997) found that $73 \%$ of the papers cited by U.S. industry patents were produced by PROs. Malo and Geuna (2000) used the same methodology to study science-technology links in combinatorial chemistry and biology using the European Patent Office database. They find that $81 \%$ of patent citations to the literature are to universities and other research institutions. Verspagen (1999) sowed that half the scientific literature citations of patents taken out by Philips Electronic are to papers from PROs.

The case study approach was used by the National Science Foundation in the TRACES project in 1968 to trace the contribution of knowledge from basic research knowledge to four major industrial innovations. It showed that the agriculture and medical research sectors benefited the most from public research investment (Steinmueller, 1996).

Mansfield (1991, 1995) and Mansfield and Lee (1996) used a hybrid method lying between case study and survey methods to gather data from a sample of 76 large R\&D performing firms in seven manufacturing industries for the period 1975-1985. According to the R\&D managers, about $10 \%$ of the new products and processes could not have been developed in the absence of recent academic research (occurring within 15 years of the commercialisation).

The final method involves direct firm surveys. The Yale survey of large R\&D performing firms in the United States in the early 1980s found that university-based research was less important than other sources of scientific output and, surprisingly, that applied knowledge produced by universities was of greater value to the specific line of business of the firm than basic science. (Klevorick et al, 1995). Later surveys, based on the OECD's Oslo Manual asked respondents about the importance of different information sources to the firm's own innovative activities. The results of the first European Community Innovation Survey (CIS) in 1993 show that public research is one of the least important sources of information for firms with less than 500 employees (Arundel and Steinmueller, 1998). The second CIS in 1997 confirmed these results. In contrast, initial results from the 1993 PACE survey of Europe's largest industrial firms found that PROs were one of the most important information sources for large firms (Arundel et al., 1995). 


\subsubsection{Technology Diffusion}

While the importance of R\&D is undeniable, new technology on its own is of limited economic significance. The contribution of R\&D to the economic performance of a nation depends on the ability of firms to utilize and commercialise the results by introducing profitable products and processes. Technological diffusion is thus of the utmost importance (Karshenas and Stoneman, 1995).

Economists have studied technology diffusion extensively through various approaches such as "epidemic" (logistic) models leading to the popular S-curves, technology vintage models, stimulus-response models, and process models. There is general agreement that both supply and demand factors affect the speed and direction of technology diffusion. Diffusion takes time and depends on (Rosegger, 1996):

(i) factors related to the characteristics of the innovation such as its origin, expected effects on other inputs, location of the innovation in the existing production structure, changes in the innovation, complementarities among innovations;

(ii) factors attributable to the structural characteristics of adopters and non-adopters such as technological specificity of the existing system, the firm's financial position, technological capability, market position and alternative strategies, managerial attitudes, age of firms and industries;

(iii) factors having to do with the mechanics of diffusion in a particular setting such as external versus internal information, external interests in diffusion, international diffusion; and,

(iv) factors relating to the institutional environment of the firm and the industry such as the patent system, laws and governmental regulations, specification-writing agencies, insurance companies, labour unions.

\subsubsection{Neo-Schumpeterian Hypotheses}

The work of Schumpeter is mostly associated by later generation with the evolutionary school of thought (see later section). However, for a significant period of time covering the first 3-4 decades after his second major publication (Schumpeter, 1942), mainstream industrial organization economists were preoccupied with empirically verifying two broad hypotheses that have been associated with Schumpeter: ${ }^{4}$

(i) There is a positive relationship between innovation and monopoly power resulting in supernormal profits;

(ii) Large firms are more than proportionately more innovative than small firms.

A third related debate that raged for some time was the technology-push versus demand-pull hypotheses. According to the technology-push hypothesis, the research staff of a firm may be regarded as the initiator of innovations. The important

\footnotetext{
${ }^{4}$ Kenneth Galbraith (1952) seems to have had a lot to do with the formulation of the hypotheses. See Cohen (1995), Cohen and Levin (1989), and Kamien and Schwartz (1982) for reviews of the literature on the Schumpeterian hypotheses.
} 
implications of this view are, first, that firms with large research facilities have an advantage over smaller firms and, second, that the pace of innovative activity will depend on advantages in the scientific base. In the demand-pull hypothesis, initiation of the innovation is seen as coming from the firm's marketing or production staff. The main idea behind this hypothesis is that innovation is a response to profit opportunities. The issue has been settled with an understanding that it is not one or the other, but rather a matter of degree. Radical innovations seem to rely more on technology-push factors; incremental innovations rely more on demand-pull.

The long series of empirical investigations on these hypotheses indicates a strong relationship between resource allocation and technical advance. The search for profits and the allocation of resources do influence the rate and direction of inventive activity, despite the role of serendipity and other motivations for discovery. The relationship appears to be bi-directional, with the state of knowledge shaping and being shaped by profit opportunities and resource availability. Earlier studies (until the late 1970s) seemed to indicate the nature of the innovative process to resemble some features of a neoclassical production process with increasing returns up to a threshold level and decreasing returns beyond. Such thresholds were advocated for both neo-Schumpeterian hypotheses. More detailed data and better controls for industry and company effects have since made such results seem suspect.

More recently, the outcome of the extensive empirical evaluation of the two neoSchumpeterian hypotheses has been interpreted as relatively inconclusive (Cohen and Levin, 1989; Cohen 1995). With regard to the effect of market concentration on the rate of innovation the literature suggests that its direct influence is small and that it likely reflects the influence of other more fundamental determinants of technological advance, specifically technological opportunity and appropriability conditions. With regard to the role of firm size, the literature suggests that it is very important, albeit not in the simple way neo-Schumpeterians imagined. The influence of firm size largely emerges from underlying industry conditions.

Demand (tastes), technological opportunity, and appropriability conditions are now reasonably assumed to determine inter-industry differences in innovative activity over relatively long periods. The uncertainty of this argument indicates the fact that all these conditions are subject to change themselves, particularly in response to radical innovations. Unfortunately, the empirical validation of the importance of all three factors has been limited largely due to the lack of appropriate data. The gap is currently bridged by an emerging body of descriptive evidence on how the nature and effects of demand, technological opportunity and appropriability differ across industries. A small number of surveys have also made their mark in the last couple of decades (Levin et al., 1987; Klevorick et al. 1995; Hansen, 2001).

\subsubsection{Technology and Growth}

Recent years have witnessed a resurgence of interest in growth modelling. To some extent this is a reflection of the changed perspective concerning the sources of growth with the advent of the "new growth" theory. 
In the basic neoclassical growth model developed by Solow (1956) there is no technological change and employment is assumed equal to the supply of labour. Restrictive assumptions of constant returns to scale, perfectly competitive markets, two factors of production only one of which (capital) can be accumulated, and optimising behaviour, result in a stationary path where capital per head does not grow over time. To accommodate the observation that economic growth outpaces the growth of the capital stock, Solow (1957) introduced an exogenous trend of technological change into the production function. While this model was later heavily criticized for its crude treatment of technology, neoclassical growth theory has continued its development course on more or less Solowian principles for sometime. According to this approach, growth of economic output is triggered by changes in the employed factors of production, the capital stock, the labour force, and the available technology. A good compendium of neoclassical growth was presented by Barro and Sala-i-Martin (1999).

In the mid-1980s, a major departure from the neoclassical approach was proposed that has resulted in an impressive collection of publications under the heading of new growth theory. ${ }^{5}$ The clear point of departure is that these studies allow for increasing returns to scale at the level of industries or economies. They stress the existence of Marshallian positive externalities (Lucas, 1988; Romer, 1986) and stress that the sum of individual actions impinges upon the environment of such actions. Most proponents of this new endogenous growth theory focus on the effect of collective learning and knowledge on the efficiency of individual production processes. Externalities can enter in various ways: they can be the equivalent of a growth factor when they consist of endogenising Solow's technological shift factor, or they can affect directly capital or labour. More recent endogenous growth models have placed more emphasis on human capital. Others break capital into a series of different intermediate goods, with R\&D resulting in the discovery of new intermediate inputs. Yet others incorporate innovation as a series of "creative destructions" in an effort to introduce Schumpeterian dynamics (Aghion and Howitt, 1992). Finally, growth in these models can also be realized through public goods and infrastructure that increase the productivity of private factors. New endogenous growth theory models are intuitively appealing because they are able to create a virtuous cycle of intangible investment, learning, physical investment, and market pressures at the macroeconomic level.

Endogenous growth models suffer from a tendency to lead to explosive growth paths. While intuitive appealing, their empirical appraisal has been fairly sketchy, based on reduced forms (e.g., Barro, 1991). The new growth theory has also been criticized for not being that "new" (Nelson 1994). The criticism is that new growth theorists have been three decades late in incorporating the significant insights into growth and the role of technology that appreciative economic theorists like Moses Abramovitz (1952) had been writing for a long time.

The strong attraction to growth theory has traditionally been related to the effort to understand relative movements in international competitiveness and trends in convergence/divergence between countries. An important implication of the neoclassical growth theory is the convergence of economies with different initial

\footnotetext{
${ }^{5}$ See Verspagen (1992) for a review.
} 
endowments. According to the assumption of diminishing marginal returns, the productivity of capital is higher in countries with lower endowments in this factor. Hence, the growth rates in economies with lower capital endowments should exceed growth in the better endowed ("richer") economies and in the long run endowments, and thereby growth rates, should converge. Evidence, however, has been quite mixed, ${ }^{6}$ requiring to move from absolute convergence (initial capital endowments determine growth rates) to conditional convergence taking into account the dynamics of growth.

A large part of the work on conditional convergence has been summarized in Baumol et al. (1994). It essentially amounts to the investigation of a convergence hypothesis according to which:

"When the productivity level of one (or several) country(ies) is substantially superior to that of a number of other economies, largely as a result of differences in their productive techniques, then those laggard countries that are not too far behind the leaders will be in a position to embark upon a catch-up process, and many of these laggard countries will do so. The catch-up process will continue as long as the economies that are approaching the leader's performance have a lot to learn from the leader. However, as the distance among the two groups narrows, the stock of knowledge unabsorbed by the followers will grow smaller and approach exhaustion. The catch-up process will then tend to terminate unless some supplementary and unrelated influence comes into play. Meanwhile, those countries that are so far behind the leaders that it is impractical for them to profit substantially from the leader' knowledge will generally not be able to participate in the convergence process at all, and many such economies will find themselves falling even further behind."

Overall, available long-term growth data seem to support this convergence hypothesis. It is important to mention here that the complexity of the growth process has necessitated the consideration of so many factors that formal economic theory still finds impossible to handle. Hence, most insightful analyses are frequently based on appreciative theorizing. One excellent example is Nelson and Wright's (1992) analysis of the factors responsible for the rise of American technological leadership in the $20^{\text {th }}$ century. Another example is Abramovitz's $(1986,1994)$ account of the postwar convergence boom.

Particularly appealing is Abramovitz's distinction of two sets of conditions that influence the ability of different countries to realize their potential (thus be members of the converging group). The first set of factors amounts to the so-called technological congruence. This is based on the observation that technology does not advance evenly in all directions. It advances in a biased fashion that reflects: (i) the past influence of science and technology on the evolution of practical knowledge; (ii) the complex adaptation of that evolution to the natural resource and factor availabilities and to market scales, consumer demands, and technical capabilities of

\footnotetext{
${ }^{6}$ Barro and Sala-i-Martin (1999) give empirical examples for the convergence hypothesis in which they compare growth rates from the period from 1960 to 1985 to the initial endowment, measured by GDP per capita in 1960 . In the case of 118 countries there is hardly any correlation between the two variables, the evidence even slightly indicates a positive relation, i.e. high endowments cause high growth rates and low endowments result in lower ones. For a selection of the 20 original OECD members the hypothesis holds, the relation is clearly negative and the sample fit is much better.
} 
those relatively advanced countries operating at or near the frontiers of technology. The laggards face varying degrees of difficulties in adapting and adopting the current practice of the leaders according to the extent that resource availabilities, factor supplies, technological capabilities, market scales and consumer demands conform well to those required by the technologies that have emerged in the leading countries. The degree of difficulty is not a constant but changes over time as the laggards' development adapts to the factor supply and to the organizational and institutional challenges presented by more advanced countries.

The second set of factors amounts to the so-called social capability. This covers the country's levels of general education and technical competence, the commercial, industrial and financial institutions that bear on its ability to finance and operate modern, large-scale business, and the political and social characteristics that influence the risks, the incentives and the personal rewards of economic activity including those rewards in social esteem that go beyond money and wealth. Social capabilities are also not constant. They evolve in the directions to which the requirements of a leading technology point, or in the case of a leading country, in the directions defined by those of an emerging technology.

Countries' potentials for rapid productivity growth by catch-up, therefore, are not determined solely by the gaps in the levels of technology, capital intensity and efficient allocation that separate them from leading countries. They are also restricted by the natural resource endowments and more generally because their market scales, relative factor supplies and income-constrained patterns of demand make their technical capabilities and their product structures incongruent with those that characterize countries that operate at or near the technological frontiers. And they are limited by those institutional characteristics that restrict their capabilities to finance, organize, and operate the kind of enterprises that the frontier technologies require.

\subsubsection{Evolutionary Theorizing}

Perhaps the most comprehensive challenge to mainstream economic theory has come from a set of propositions and models collectively referred to as evolutionary theories. $^{7}$ While the development of these theories has not yet matched that of mainstream economics, there is considerable unanimity among the school's adherents about the intellectual framework and future directions. The challenge is comprehensive because the evolutionary approach is rooted in biology, thus explicitly considering dynamics and path dependence, whereas mainstream economic theory is much more mechanistic, more akin to (older) physics.

At the heart of the evolutionary approach is that history matters: firms are constrained by past experience in their effort to optimise. Experience is embodied in routines explicit and tacit rules of behaviour. Firms develop routines that incorporate both public knowledge about markets, technologies, and the business environment and firm-specific knowledge. In relatively stable competitive environments, this implies a selection process that rewards certain kinds of routines (behaviour) and penalizes

\footnotetext{
${ }^{7}$ Nelson and Winter (1982) is generally recognized as the cornerstone of evolutionary theory. For a broad survey of the approach see Nelson (1995).
} 
others. Routines are gradually adapted on the basis of experience through learning. They tend to change more or less frequently depending on the business and technological environment. Evolution principles also underline the emergence and development of all institutions affecting the general business infrastructure such as laws, regulations, technical standards, etc.

Schumpeter's concept of "creative destruction" is embodied in evolutionary theories in the form of "mutations" through drastic innovation. Drastic innovation changes technologies as well as routines and institutions. The extent to which innovation succeeds or fails is dependent on a complicated interplay of initial conditions and path dependence in addition to standard efficiency criteria and technical superiority. This interplay explicitly recognizes historical and accidental events, and thus hardly fits the characteristics of an optimisation process. When they dominate, drastic innovations set a new process of evolution.

Importantly, the concept of path dependence implies that a successful technology with widespread use may persist in dominating its market even after the reasons for its initial dominance have disappeared. In other words, a well-established technology may be very difficult to replace by demonstrably superior innovations. In contrast, selection in conventional economics is more mechanistic, largely dependent on straightforward efficiency criteria of the technology at hand.

The evolutionary approach is, thus, perceived by many economists to provide a new and, some say, much improved framework for the study of firms, technologies, and markets. This framework seems to be much closer to Schumpeter's theorizing in which technical and institutional innovations played a central role in the economic process. The net effect of the evolutionary/structuralist framework on policy decisionmaking and how that differs from mainstream (sometimes called neoclassical) approach is currently a matter of heated debate among economists. One way of arguing has been put forward by Stanley Metcalfe in several publications whereby policies based on the mainstream approach are concerned with resources and incentives taking the technological possibilities and capabilities of firms as given whereas policies based on the evolutionary perspective focus much more on the process of technological advance, i.e., on changing and enhancing the innovation capabilities and possibilities (options) of firms. This line of argumentation may be compatible with considering the two approaches as complements, each with specific strengths and weaknesses that could be combined to draw valuable policy advise. Yet, others strongly disagree, arguing that the chasm between the two analytical approaches is just too big and often leads to strong differences in policies (Lipsey and Carlow, 1998).

\subsubsection{Summary Implications for European Policy Evaluation}

A general observation from the brief review of economic literature in this paper is that the discipline of economics has much more to offer in the analysis of the incentives for and results from technological innovation than is typically assumed by critics. Major advances in both formal and appreciative economic theory have empowered economists with significant tools to appraise the causes and effects of resources devoted to the production and dissemination of new technological knowledge. 
A mix of important developments and results from the reviewed economic theory with rich implications for RTD policy and policy evaluation include the following.

- No single approach can claim monopoly in explaining the relationship of technological advance and the economy. A complex, multi-dimensional phenomenon like innovation requires multi-dimensional analytical approaches based on formal theory, aggregate empirical analysis (econometrics), acute observation and appreciative theorizing to establish regularities, and data from diverse sources including large databases, surveys, and case studies. It may even require new ways of conceptualising the process, an endeavour undertaken more recently by the rejuvenated evolutionary economic approach.

- R\&D expenditures contribute substantially to the growth of output in a variety of industries.

- There is a strong positive relationship between the stock of $R \& D$ and productivity at the firm level.

- Social rates of return from R\&D are much higher than private rates of return indicating high levels of inter-firm and inter-industry spillovers.

- Rates of return vary considerably between industries, between types of innovations, and by type of sponsor.

- R\&D investment affects the structure of production; its own demand is affected by changes in the prices of conventional factors of production and changes in demand.

- Academic research has become a major underpinning of industrial innovation in many science-based industries. There are significant differences between sectors in this respect. Basic research expenditures raise firm productivity.

- Available estimates of the rate of return to publicly funded research range from $20 \%$ to $60 \%$. Such good rates of return are dependent on the successful application of the knowledge produced by public research organizations in the production process. These estimates do not include more general societal returns from basic research which need to be appraised separately.

- There is significant survey evidence that publicly funded research is responsible for quite significant knowledge flows to industry. Evidence varies, however. For example, two large industry surveys in Europe have shown that R\&D undertaken by public organizations is not a very important source of information at least for relatively small companies (Community Innovation Survey 1993, 1997).

- The contribution of R\&D to the economic performance of a nation depends on the ability of firms to utilize and commercialise the results by introducing profitable products and processes. Technological diffusion is thus of the utmost importance. Diffusion depends on factors related to the characteristics of the innovation, the structural characteristics of adopters and non-adopters, the mechanics of diffusion in particular settings, and the institutional environment of the firm and the industry.

- There is a strong correlation between resource allocation and technical advance.

- Demand (tastes), technological opportunity, and appropriability conditions are now widely recognized to determine inter-industry differences in innovative activity over relatively long periods. All these conditions are subject to change themselves, particularly in response to radical innovations. 
- The recent resurgence of interest in growth theory has coincided with the advent of the "new growth" theory that focuses on endogenous technological advance, increasing returns to scale from $R \& D$ at the levels of industry or the economy, positive externalities, the effect of knowledge and learning on production efficiency, human capital, and the importance of public goods and infrastructure.

- Assisted by new analytical tools, formal and appreciative growth theory has contributed to a better understanding of the conditions for economic convergence between countries.

- A major development in the economic analysis of technological advance has been contributed by evolutionary economics, following on the tradition of Veblen and Schumpeter. While the development of these theories has not yet matched that of mainstream economics, there is considerable unanimity among the school's adherents about the intellectual framework and future directions. Important factors in the evolutionary approach to technological advance include:

$>$ History matters;

> Firms develop routines that incorporate both public knowledge about markets, technologies, and the business environment and firm-specific knowledge. Routines are gradually adapted on the basis of experience through learning. They tend to change more or less frequently depending on the business and technological environment.

$>$ A selection process (market, other) rewards certain kinds of routines (behaviour) and penalizes others;

$>$ Evolution principles also underline the emergence and development of all institutions affecting the general business infrastructure such as laws, regulations, technical standards, etc.;

$>$ Schumpeter's concept of "creative destruction" is embodied in evolutionary theories in the form of "mutations" through drastic innovation. Drastic innovation changes technologies as well as routines and institutions;

$>$ Path dependence; e.g., a successful technology with widespread use may persist in dominating its market even after the reasons for its initial dominance have disappeared. That is, a well-established technology may be very difficult to replace.

- The net effect of the evolutionary/structuralist framework on policy decisionmaking and the differences from the mainstream approach is currently a matter of heated debate among economists. An important argument has been that policies based on the mainstream approach are concerned with resources and incentives taking the technological possibilities and capabilities of firms as given whereas policies based on the evolutionary perspective focus much more on the process of technological advance, i.e., on changing and enhancing the innovation capabilities and possibilities (options) of firms. This line of argumentation may be compatible with considering the two approaches as complements, each with specific strengths and weaknesses that could be combined to draw valuable policy advise. Yet, others hardly see any room for complementarity, arguing that the chasm between the two analytical approaches is just too big and often leads to strong differences in policies. 


\section{References to Section 2.1}

Abramovitz, Moses (1986) "Catching up, forging ahead and falling behind", Journal of Economic History, 46: 385-406.

Abramovitz, Moses (1994) "The origins of the postwar catch-up and convergence boom", in J. Fagerberg, B. Verspagen and N. von Tunzelman (eds.) The Dynamics of Technology, Trade, and Growth, Chentelham, UK: Edward Elgar.

Acs, Z. J., D. B. Audretsch and M. P. Feldman (1992) "Real effects of academic research", American Economic Review, 82: 363-67.

Aghion, P. and P. Howitt (1992) "Model of growth through creative destruction", Econometrica, 60: 323-351.

Arundel, A. and A. Geuna (2001) "Does proximity matter for knowledge transfer from public institutes and universities to firms?" Working Paper, prepared in the context of the TSER project "Innovation-Related Knowledge Flows in European Industries: Extent, Mechanisms and Implications", European Commission, DG Research.

Arundel, A. and W. E. Steinmueller (1998) "The use of patent databases by European small and medium-sized enterprises" Technology Analysis and Strategic Management, 10: 157-173.

Arundel, A., J. N. Cobbenhagen N. Schall (2000) "The Acquisition and Protection of Competencies by Enterprises", Final Report for EIMS Project 98/180, DG Research.

Arundel, A., G. van de Paal and L. Soete (1995) "Innovation Strategies of Europe's Largest Firms. Results of the PACE Survey", European Innovation Monitoring System, Report No.23, European Commission.

Barro, R. J. (1991) "Economic growth in a cross section of countries", Quarterly Journal of Economics, May.

Barro, R. J. and X. Sala-I-Martin (1999) Economic Growth, Cambridge: the MIT Press.

Baumol, William J., Sue Ann Batey Blackman, and Edward N. Wolff (1994) Productivity and American Leadership: The Long View, The MIT Press ( $4^{\text {th }}$ printing).

Bernstein Jeffrey I. And M. Ishaq Nadiri (1988) "Rates of return on physical and R\&D capital and structure of the production process: Cross section and time series evidence", in B. Raj (ed.) Advances in Econometrics and Modeling, London: Kluwer Academic Publishers.

Caves, Richard E. (1982) Multinational Enterprise and Economic Analysis, $1^{\text {st }}$ edition, Cambridge: Cambridge University Press.

Caves, Richard E. (1996) Multinational Enterprise and Economic Analysis, $2^{\text {nd }}$ edition, Cambridge: Cambridge University Press.

Chandler, Alfred (1977) The Invisible Hand: The Managerial Revolution in American Business, Cambridge, MA: Belknap Press.

Cohen, Wesley M. (1995) "Empirical studies of innovative activity" in P. Stoneman (ed.) Handbook of the Economics of Innovation and Technological Change, Oxford: Blackwell.

Cohen, Wesley M. and Richard C. Levin (1989) "Empirical studies of innovation and market structure", in R. Schmalensee and R. Willig (eds.) Handbook of Industrial Organization, Amsterdam: North Holland.

Freeman, Chris (1982) The Economics of Industrial Innovation, $2^{\text {nd }}$ edition, London: Pinter. 
Freeman, Chris (1994) "The economics of technical change", Cambridge Journal of Economics, 18: 463-514.

Galbraith, Kenneth J. (1952) American Capitalism, Boston: Houghton Mifflin.

Griliches, Zvi (1979) "Issues in assessing the contributionof research and development to productivity growth", Bell Journal of Economics, 10: 92-116.

Griliches, Zvi (ed.) (1984) R\&D, Patents and Productivity, Chicago: Chicago University Press.

Griliches, Zvi (1986) "Productivity, R\&D and basic research at the firm level in the 1970s", American Economic Review, 76(1): 141-154.

Griliches, Zvi (1990) "Patent statistics as economic indicators: A survey", $\underline{\text { Journal of }}$ Economic Literature, 28(4): 1661-1707.

Griliches, Zvi (1995) "R\&D and productivity: Econometric results and measurement issues", in P. Stoneman (ed.) Handbook of the Economics of Innovation and Technological Change, Oxford: Blackwell.

Griliches, Zvi and Frank Lichtenberg (1984) "Interindustry technology flows and productivity growth: A reexamination", Review of Economics and Statistics, 61: 324-329.

Grossman, Gene M. and Elhanan Helpman (1991) Innovation and Growth in the Global Economy, Cambridge, MA: The MIT Press.

Hall, Bronwyn H. (1996) The private and social returns to research and development”, in B. L. R. Smith and C. E. Barfield (eds.) Technology, R\&D and the Economy, Washington, DC: The Brookings Institution and American Enterprise Institute.

Hansen, John A. (2001) "Technology innovation indicator surveys", in John Jankowski, Albert Link, and Nicholas S. Vonortas (eds.) Strategic Research Partnerships, Arlington, VA: National Science Foundation.

Heertje, A. (1977) Economic and Technical Change, London: Weidenfeld and Nicholson.

Jaffe, Adam B. (1986) "Technological opportunity and spillovers of R\&D: Evidence from firms' patents, profits, and market value”, American Economic Review, 76: 9841001.

Jaffe, Adam B. (1988) "Demand and supply influences in R\&D intensity and productivity growth", Review of Economics and Statistics, 70:431-437.

Jaffe, A. (1989) "Real effects of academic research", American Economic Review, 79: 95770.

Jaffe, A., M. Trajtenberg, and R. Henderson (1993) "Geographic localization of knowledge spillovers as evidenced by patents citations", Quarterly Journal of Economics, 63: $577-98$.

Kamien, Morton I. and Nancy L. Schwartz (1982) Market Structure and Innovation, New York: Cambridge University Press.

Karshenas, Massoud and Paul Stoneman (1995) "Technological diffusion" in P. Stoneman (ed.) Handbook of the Economics of Innovation and Technological Change, Oxford: Blackwell.

Klevorick, Alvin K, Richard C. Levin, Richard R. Nelson, and Sidney G. Winter (1995) "On the sources and significance of interindustry differences in technological opportunities", Research Policy, 24: 185-205.

Levin, Richard C., Alvin K. Klevorick, Richard R. Nelson, and Sidney G. Winter (1987) "Appropriating the returns from industrial research and development", Brookings Papers on Economic Activity: Microeconomics, 3: 783-820. 
Lichtenberg, Frank (1988) "The private R\&D investment response to Federal design and technical competitions", American Economic Review, 78: 550-559.

Lipsey, Richard G. and Kenneth Carlow (1998) "Technology policies in neo-classical and structuralist-evolutionary models", STI Review, 22: 31-73.

Los, B. and B. Verspagen (1996) "R\&D spillovers and productivity: Evidence from U.S. manufacturing microdata," Working Paper \#2/96-007, MERIT, University of Maastricht.

Lucas, Robert (1988) "On the mechanisms of economic development", Journal of Monetary Economics, 22: 3-42.

Lundvall, Bengt-Ake (ed.) (1992) National Systems of Innovation: Towards a Theory of Innovation and Interactive Learning, London: Pinter.

Malo, S. and A. Geuna (2000) "Science-technology linkages in an emerging research platform: The case of combinatorial chemistry and biology", Scientometrics, 47: 30321.

Mansfield, E. (1991) “Academic research and industrial innovation”, Research Policy, 20: 112.

Mansfield, E. (1995) "Academic research underlying industrial innovations: Sources, characteristics, and finance", The Review of Economics and Statistics, 77: 55-65.

Mansfield, Edwin (1996) "Contributions of new technology to the economy", in B. L. R. Smith and C. E. Barfield (eds.) Technology, R\&D and the Economy, Washington, DC: The Brookings Institution and American Enterprise Institute.

Mansfield, Edwin and J.-Y. Lee (1996) "The modern university: Contributor to industrial innovation and recipient of industrial R\&D support”, Research Policy, 25: 1047-58.

Mansfield, E., J. Rapoport, A. Romeo, S. Wagner, and G. Beardsley (1977) The Production and Application of New Industrial Technology, New York: Norton.

Marshall, Alfred (1911) Principles of Economics, London: Macmillan.

Mokyr, Joel (1990) The Lever of Riches, New York: Oxford University Press.

Nadiri, Ishaq M. (1993) "Innovations and technological spillovers, C.V. Starr Center for Applied Economics, Research Report \#93-31, New York University.

Nadiri, Ishaq M. and Ingmar R. Prucha (1990) "Dynamic factor demand models, productivity measurement, and rates of return: Theory and an empirical application to the U.S. Bell system", Structural Change and Economic Dynamics, 1: 263-289.

Narin, F., K. S. Hamilton, and D. Olivastro (1997) "The increasing linkage between U.S. technology and public science", Research Policy, 26: 317-20.

Nelson, Richard R. (1994) "What has been the matter with neoclassical growth theory?", in G. Silverberg and L. Soete (eds) The Economics of Growth and Technical Change, Chentelham, UK: Edward Elgar.

Nelson, Richard R. (1995) "Recent evolutionary theorizing about economic change", Journal of Economic Literature, XXXIII: 48-90.

Nelson, Richard R. and Sidney G. Winter (1982) An Evolutionary Theory of Economic Change, Cambridge, MA: Harvard University Press.

Nelson, Richard R. and Gavin Wright (1992) "The rise and fall of American technological leadership", Journal of Economic Literature, XXX(4): 1931-1964.

Romer, Paul (1986) "Increasing returns and long run growth", Journal of Political Economy, 94: 1002-1037. 
Romer, Paul (1990) "Endogenous technological change", Journal of Political Economy, 98: 71-102.

Rosegger, Gerhard (1996) The Economics of Production \& Innovation, $3^{\text {rd }}$ edition, Oxford: Butterworth-Heinemann.

Rosenberg, Nathan (1976) Perspectives on Technology, Cambridge: Cambridge University Press.

Rosenberg, Nathan (1982) Inside the Black Box, Cambridge: Cambridge University Press.

Salter, A.J. and B.R. Martin (2001) "The economic benefits of publicly funded basic research: A critical review", Research Policy, 30: 509-32.

Scherer, Frederick M. (1982) "Inter-industry technology flows in the US", Research Policy, 11(4): 227-245.

Schumpeter, Joseph A. (1942) Capitalism, Socialism and Democracy, New York: McGrawHill.

Smith, Adam (1976) An Inquiry into the Nature and Causes of the Wealth of Nations.

Solow, Robert (1956) "A contribution to the theory of economic growth", Quarterly Journal of Economics, 70: 65-94.

Solow, Robert (1957) "Technical change and the aggregate production function", Review of Economics and Statistics, 39: 214-231.

Steinmueller, W. E. (1996) "Basic research and industrial innovation", in M. Dodgson and R. Rothwell (eds). The Handbook of Industrial Innovation, Cheltenham: Edward Elgar.

Stoneman, Paul (1983) The Economic Analysis of Technological Change, Oxford: Oxford University Press.

Stoneman, Paul (ed.) (1995) Handbook of the Economics of Innovation and Technological Change, Oxford: Blackwell.

Tirole, Jean (1988) The Theory of Industrial Organization, Cambridge, MA: The MIT Press.

Verspagen, B. (1992) "Endogenous innovations in neo-classical growth models: A survey, Journal of Macro-Economics, 14(4): 631-662.

Verspagen, B. (1999) "Large firms and knowledge flows in the Dutch R\&D system: A case study of Philips Electronics", Technology Analysis \& Strategic Management, 11: 211-33 


\subsection{Innovation and the Firm}

\section{Introduction}

This report is part of work activity 2 of the "ASIF" project, which deals with the economic rationale for technology policy. In particular it focuses on activity 2.1.2 (i.e. Innovation and the firm). As such, the study reviews the extant management literature with a twofold aim: First, it attempts to identify the major factors that research has shown to influence the firm's capacity to innovate. Second, it reviews findings pertaining to the impact of innovation activities on firm performance.

Innovation has always been a key element in economic development and firms' competitive success. During the 1990s, however, innovation has become a managerial imperative, something like a 'recipe' for success in the face of hyper-competition stemming from globalization and technological revolution. As even the most stable environments (eventually) change, firms need to adopt or initiate innovation activities continually over time in order to maintain or improve their competitive positions. At the same time, however, all these activities are influenced by a number of internal or external to the firm factors that promote (or inversely, inhibit) its capacity to innovate.

The material presented here is necessarily selective. The management literature on innovation is vast, and an exhaustive presentation of all relevant theoretical angles and findings is well beyond the scope of the present study. The remaining of this report unfolds as follows: As a preamble to our main objectives, in the next section we briefly introduce the domain of organizational innovation by presenting its generic characteristics as defined in the management literature. The third section reviews the determinants of innovation as advanced by two basic research streams; one that may be called 'traditional' and the emerging resource-based view of the firm. The fourth section examines the impact of innovation on major dimensions of firm performance. The study concludes with a summary of the findings and some policy implications.

\subsubsection{Organizational Innovation: Defining the domain}

In the field of management, innovation is generally defined as an internally generated or externally purchased device, system, policy, process, product or service that is new to the adopting organization (Damanpour, 1991). Under this view, innovation represents a means of transforming an organization, whether as a response to changes in its internal or external environment or as a proactive action taken to influence this environment. Among numerous typologies of innovation advanced in the extant literature, three have gained wide recognition; administrative vs. technical innovations, product vs. process innovations, and radical vs. incremental innovations (Wolfe, 1994). Each centers on a different set of generic characteristics.

Technical innovations pertain to products, services and production process technologies; they are related to basic work activities and can concern either product or process. Administrative innovations refer to organizational structure and 
management processes; they are indirectly related to the basic work activities and directly related to the management core of a firm. Product innovations are new products or services introduced to meet an external user or market need. In contrast, process innovations are new elements into an organization's production or service operations - input materials, task specifications, devices, information and knowledge mechanisms. Radical innovations are those that produce fundamental changes in the activities of an organization and represent clear departures from existing practices. Incremental innovations, on the other hand, refer to relatively minor departure from established rules and norms.

\section{The determinants of innovation}

The study of factors that facilitate, or inhibit the capacity to innovate has long been the subject of theoretical and empirical inquiry in the management literature. It is generally argued that innovation is subject to influences by organizational and environmental characteristics. A body of research that we will term 'traditional' innovation literature, stresses the role of internal context and external environment in influencing innovation activity (e.g. Kimberly \& Evanisko, 1981; Damanpour, 1991; Wolfe, 1994; Duncan, 1976; Daft, 1992). By contrast, more recent research informed by the resource-based view of the firm, without neglecting the above factors, emphasizes the role of internal organizational resources and capabilities (see for example, Rumelt, 1984; Barney, 1991; Wernefelt, 1984; Teece et al., 1997) as those that define the firm's capacity to innovate. Figure 1 depicts the major determinants as posited by these perspectives. In what follows, we review the main theoretical arguments and empirical evidence offered by these two research streams. Appendix I provides a summary of hypotheses and relevant findings. 
Figure 2. "Traditional" and Resource-based perspectives on the determinants of Innovation

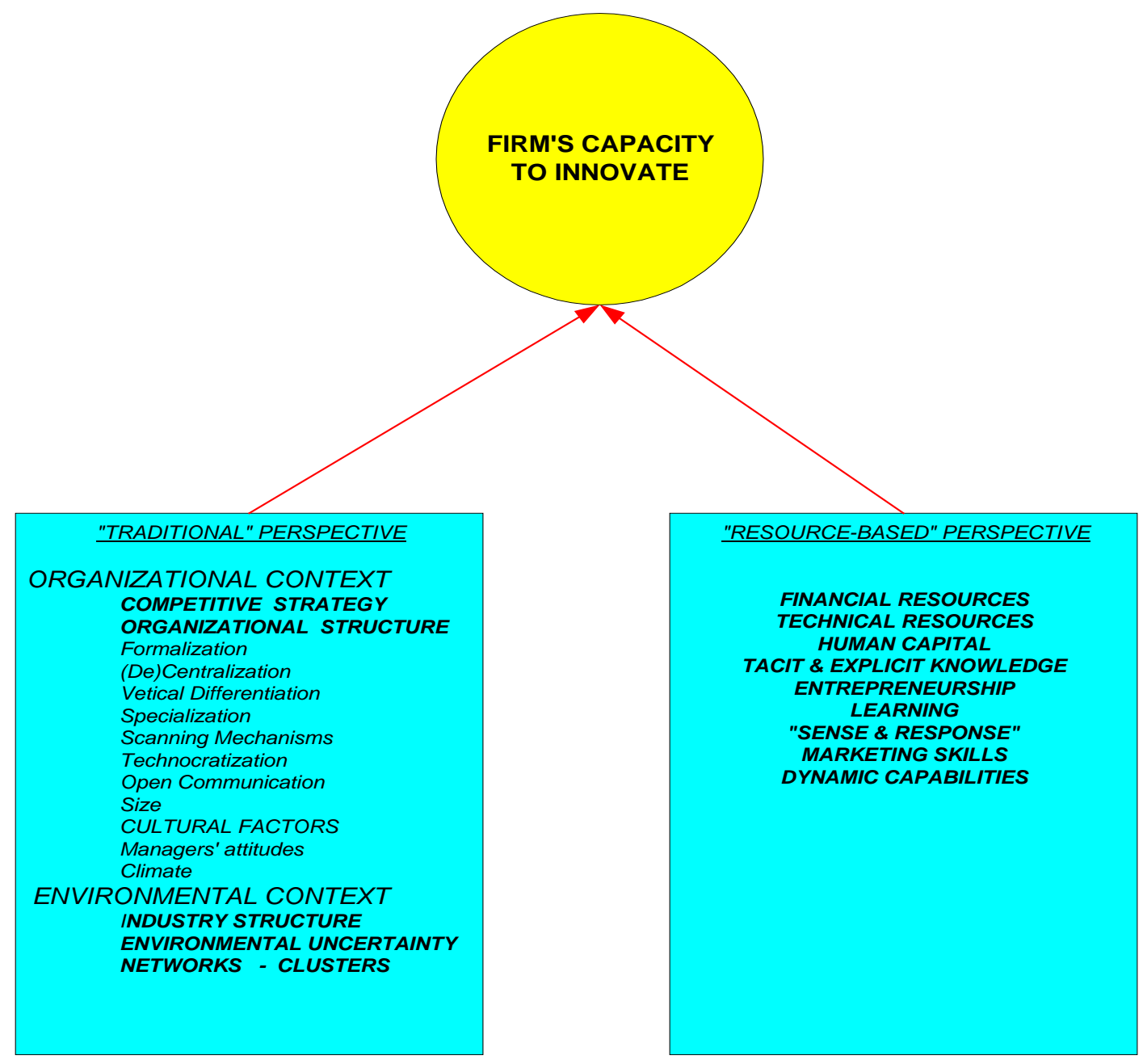

The 'traditional' perspective on organizational innovation: Theoretical linkages and empirical evidence

Traditional innovation research focuses on two major categories of factors that affect the capacity of a firm to innovate; namely, organizational context and external environment.

\section{Organizational context and innovation}

The organizational context refers to all these internal characteristics that facilitate (or inversely inhibit) the creation of an environment conducive to innovation; one that motivates the generation and flow of ideas and importantly, their transformation into innovative products and services. The traditional literature has emphasized the relevance of internal factors such as competitive strategy, organizational structure (e.g. formalization, centralization, etc.) and cultural characteristics (e.g. managers' 
attitude towards change, and organizational climate) as important determinants of the firm's capacity to innovate.

Competitive strategy (or more specifically strategic business orientation) reflects the actual strategies pursued by a firm with respect to its competitors (Venkatraman, 1989). According to Levebvre et al. (1997), a competitive posture characterized by proactiveness, futurity, aggressiveness, and defensiveness are strong predictors of a policy that actively seeks technological opportunities, which, in turn, leads to greater innovation efforts (see also Maidique \& Patch, 1978; Ettlie \& Bridges, 1982).

The role of organizational structure has been widely studied in the literature and many authors have pointed to its primary importance as a determinant of innovation (Damanpour, 1987; Kim, 1980; Kimberly \& Evanisko, 1981). Among several structural characteristics, formalization, centralization, and vertical differentiation are those that are perhaps most widely examined. This is because they collectively define what is termed a mechanistic organizational structure, which is generally assumed to reduce the firm's capacity for innovation and flexibility (Burns \& Stalker, 1961).

Formalization refers to the existence of formal job descriptions, rules, policies, and procedures. Increased reliance on these discourages new ideas and initiatives, inhibits open and cross-functional communication and thus constrains innovative activity (Subramanian \& Nilakanta, 1996; Liker et al., 1999). Other studies (Subramanian \& Nilakanta, 1996; Whittington et al., 1999; Chandrashekaran, 1995) found that the concentration of decision-making authority (i.e. centralization) prevents innovation by reducing organizational members' awareness, commitment and involvement. Similarly, high levels of vertical differentiation (i.e. tall structures with many hierarchical levels) are found negatively related with innovation (Damanpour, 1991, 1996; Pilai, 1998; Bertels et al., 1999). To summarize, research has shown that firms that adopt a mechanistic structure have more difficulty implementing change and innovation because authority is consolidated with top managers who interact less directly with the environment, formalization blocks innovative solutions, and tall vertical hierarchy limits cross-functional communication.

Specialization is another important structural characteristic that refers to the variety of job tasks in an organization. The relevant findings, however, present an ambiguous picture with regard to the specialization-innovation relationship. Some researchers argue that specialization provides a broad knowledge base, increase the crossfertilization of ideas and hence promotes innovation (Subramanian \& Nilakanta, 1996; Germain, 1996). On the other hand, others (e.g. Liker et al., 1999) note that excessive specialization may adversely affect cross-functional collaboration, block the flow of ideas and reduce the capacity to innovate.

Within the same line of research, several authors recognize the positive effects of scanning mechanisms on innovation. Scanning mechanisms refer to efforts directed towards the strategic awareness of rivals actions, technology evolution, and customer preferences/needs. Lefebvre et al. (1997), for instance, have argued that the systematic use of scanning mechanisms that enable the identification of opportunities and threats stemming from competitors or emergent technologies is crucial and should be viewed as a powerful determinant of firm's technology policy which, in turn, positively influences innovation (see also Weiss \& Birnbaum, 1989). 
Another structural factor that was found positively related to innovation is the concentration of technical and scientific knowledge within firm boundaries, a phenomenon also termed technocratization. Past research (e.g. Collins et al., 1988; Ettlie \& Bridges, 1987; Lefebvre et al., 1997) has found that an increased number of scientists, technicians or engineers in an organization is a powerful determinant of innovativeness, and a significant predictor of firm's technology policy.

Cross-functional cooperation, and more generally open communication within the firm are strongly emphasized in the management literature of innovation. Organizational communication refers to both the flow of information, ideas and knowledge among organizational units (internal communication) and between the firm and other organizations (external communication). Evidence on the effects of cross-functional cooperation and organizational communication has consistently produced positive results. Several researchers argue that the creation of intra and inter-organizational cooperative networks (e.g. cross-functional teams, participation in industry associations), facilitate the free flow of ideas and knowledge across departments (or between firms), promote organizational communication and thus fuel the generation of innovation (Sivadas \& Dwyer, 2000; Tsai \& Ghoshal, 1998; Lucchini, 1998; Damanpour, 1991; Ross, 1974; Kusunoki \& Nonaka, 1998).

The final structural characteristic that is often argued to influence innovation is firm size. The relevant findings, however, are rather mixed. Firm size is usually expressed in terms of human, financial or physical resources (e.g. number of employees, total profits, number of plants or manufacturing equipment). Research in different contexts, such as in Europe (Premkumar et al., 1997; Marbella et al., 1997; Thong \& Yap, 1995; Huiban \& Bouhsina, 1998), India (Lal, 1999), and the US (Premkumar \& Roberts, 1999) has provided evidence that large organizations are endowed with slack resources and tolerance to potential losses, a fact that positively affects innovation. In contrast, others (e.g. Acs \& Audretsch, 1988; Phillips, 1965) argue that small firms may be more flexible, less bureaucratic and more adaptive to change and innovation. Research on Dutch (Brouwer \& Kleinknecht, 1996; Vossen \& Nooteboom, 1996) and German manufacturing firms (Felder et al. work, 1996) found that although innovation generally increases with firm size, R\&D intensive SMEs tend to be more innovative than large firms. In a similar vein, Arvanitis \& Hollenstein (1996) examining Swiss manufacturing firms identified an inverted U-shaped relationship between firm size and innovation. Taken overall these results provide an ambiguous picture as regards the firm size-innovation relationship. Thus, further research is needed before definitive conclusions could be drawn.

Apart from structural characteristics, the management literature also stresses the role of cultural factors in the creation of an environment conducive to innovation. For example, managers' positive attitude towards change is taken to positively influence innovation because it enhances entrepreneurship and creativity, and thus provides opportunities for innovation to flourish (Premkumar \& Roberts, 1998; Daellenbach et al., 1999; Verona, 1999; Chiesa et al., 1996). In a similar vein, organizational climate is also argued to affect innovation. Organizational climate refers to the specific set of norms, values, and beliefs that shape (and are shaped by) peoples' attitudes and behaviors. It appears that a climate that supports and motivates new ideas generation 
by providing the right incentives, training and tolerance to failures, enhances firm's innovative capacity (Kanter, 1983; Klein \& Sorra, 1996; Nevis et al., 1995).

\section{Environmental context and innovation}

The market environment within which a firm operates presents certain threats and opportunities for its survival and growth. In this sense, it is generally argued that every organization should be open to communication with customers, suppliers, distributors, institutional groups, and (even) rivals, in order to exploit opportunities to produce innovative forms of competitive advantage and adapt to changing market conditions. The traditional literature has focused on environmental factors such as industry structure, environmental uncertainty, pressures towards interorganizational networks, and regional clustering. These were found to have the greatest impact on firm's capacity to innovate.

The research on the effects of industry structure on innovation has produced mixed results. For example, research on Dutch (Acs \& Audretsch, 1990) and Northern Ireland manufacturing firms (Harris \& Trainor, 1995) has found that highly concentrated markets inhibit innovation. In the same vein, several studies found that low competitive intensity relates negatively to innovation, mainly because competition is regarded as a driving force that induces firms to actively search for new and innovative ways to maintain or improve their competitive positions (Leibenstein, 1966; Thong \& Yap, 1995; Premkumar \& Roberts, 1998; Premkumar et al., 1997). In contrast, other studies (Scherer, 1967; Bozeman \& Link, 1983; Huiban \& Bouhsina, 1998; Dijk et al., 1997) identify a positive relationship between industrial concentration and innovation. Still other researchers (Marbela et al., 1997; Brouwer et al., 1999) argue that no significant relation exists between innovation and industry concentration. Obviously these conflicting results warrant further empirical exploration.

Another dimension of industry and market environment that is often emphasized in the traditional literature is that of uncertainty. Environmental uncertainty basically refers to the frequency and (un) predictability of changes in environmental factors such as competitors' moves, or customers' preferences. Past research shows that environmental uncertainty positively affects all aspects of organizational change and innovation (Huber et al., 1993; Covin \& Slevin, 1989). For example Lawrence and Lorsch (1967) argued that organizations operating in dynamic environments, are in the midst of flows of information, changing consumer needs and potential new opportunities. Such environments are conducive to innovation. Within this line of reasoning, Hambrick (1981) has advocated the stimulating role of uncertainty towards innovativeness. Furthermore, Pierce and Delbecq (1977), Damanpour (1996), and Mishra et al. (1996) explicitly confirmed the positive relationship between uncertainty and innovation.

Market and institutional pressures towards inter-organizational networks (i.e. enduring transactions, flows, and linkages between organizations) positively affect the capacity to innovate by providing opportunities for shared learning, transfer of knowhow, and resource exchange (Nohria \& Eccles, 1992; Goes \& Park, 1997). According to a recent OECD report $(\mathrm{OECD}, 2000)$ the number of strategic alliances and organizational links rose threefold during the last decade, leading to an increase of innovative products and services introduced to the market. Similarly, many studies in 
different contexts (Premkumar and \& Roberts, 1999; Sivadas \& Dwyer, 2000; Stuart et al., 1999; Sawhney \& Prandelli, 2000; Cooke \& Wills, 1999) confirmed the positive relationship between networking and innovation.

Regional clustering also seems to affect clustered firm's capacity to innovate. It appears, however, that the relationship is complex and ambiguous. As some scholars argue (Pouder \& John, 1996; Staber, 1996; Harrison et al., 1996) there exists a temporal variation in the effects of clustering on innovation. Initially, economies of scale result in low transactions costs, resource exchange, and transfer of knowledge. These, together with institutional forces create an environment conducive to innovation. In the course of time, however, those same factors tend to create a homogeneous culture that eventually suppresses innovation. Therefore, in the long run, innovation seems to relate negatively with clustering. Admittedly, however, clustering represents an open research question that warrants further exploration. (Glasmeier \& Fuellhart, 1996)

\subsubsection{The Resource-based perspective on organizational innovation: Theoretical linkages and empirical evidence}

The resource-based literature on the determinants of innovation is based on the fundamental premise that organizational resources and capabilities are those that underlie a firm's capacity for innovation. Resources are generally defined as those tangible (or intangible) assets that are tied semi-permanently to the firm (Maijoor \& Witteloostuijn, 1996), whereas capabilities refer to its ability to exploit and combine resources through organizational routines in order to accomplish targets (Amit \& Schoemaker, 1993). Within this perspective, organizational resources (tangible and intangible) are taken to provide the input that in turn is combined and transformed by capabilities to produce innovative forms of competitive advantage.

The literature has identified a number of resources that are critical for innovation. Studies on Spanish (Del Canto \& Gonzalez, 1999) and Northern Ireland manufacturing firms (Harris \& Trainor, 1995) found that financial resources for R\&D spending are, as one would expect, a prerequisite for innovation. Skillful and committed to innovation employees is also found as an asset positively related to innovation (Kessler \& Chakrabarti, 1999; Song \& Parry, 1997; Huiban \& Bouhsina, 1998). In the same vein, many studies confirmed the positive effects of technical resources (e.g. engineering and production equipment, IT systems) on innovation (Cooper, 1979, 1984, 1994; Kanter, 1988; Song \& Parry, 1997; Gatignon \& Xuereb, 1997; Mitchell \& Zmud, 1999; Liyanege et al., 1999).

More recent research has shifted attention from tangible to intangible resources. In fact, the focus on intangible assets has led to the emergence of the so-called knowledge-based view, where knowledge (tacit or explicit) constitutes a strategic resource that plays a critical role in a firm's competitive success (Decarolis \& Deeds, 1999). In this respect, there exists strong evidence that confirms the positive relationship between organizational knowledge and the capacity to innovate. For example, Joyes and Stivers (1999) established the positive effects of market knowledge in their study of a sample of Canadian and US firms. Hoopes and Postrel (1999) found that shared knowledge is an important resource underlying new product 
success. Tiger and Calantone (1998), in their study of the US software industry found that thorough customer knowledge enhances new product development. Similarly, Helfat (2000) argued that market knowledge could form the foundation for generating multiple new product lines, while Whittington et al. (1999) in their study of large European firms confirmed that systemic change and innovation is high in organizations with increased knowledge intensity.

If resources provide the inputs, organizational capabilities represent the firm's capacity to coordinate, put it in productive use, and shape inputs into innovative outputs (Collis, 1994). Entrepreneurship, organizational learning, 'sense and response' capability, marketing skills, and 'dynamic' capabilities are those most strongly emphasized in the extant literature.

Entrepreneurship refers to the articulation of a long-term vision for the firm that aims at higher growth through the introduction of innovative products and technologies at the expense of short-run profit maximization. Entrepreneurship also entails leadership skills that will motivate organizational members to buy into that vision by providing direction and incentives. Findings concerning entrepreneurial capability identify positive effects on the capacity to innovate, especially within the context of global competition and technological change. Cohen (1995), for example, analyzing the adoption of new technology and commercialization of innovations notes the crucial role of the entrepreneur (see also Schumpeter, 1943;). Many other studies (e.g. Lal, 1999; Iansiti \& West, 1999; Pllai \& Meindl, 1998; Markham, 1998) reached similar conclusions examining US and Japanese industrial settings.

Research evidence on organizational learning has also indicated positive effects on innovation. For example, Lynn et al. (1999) studying high technology US firms found a positive relationship between learning and innovation. Bartezzaghi et al. (1997), Helfat and Raubitschek (2000), and Lane and Lubatkin (1998), reached similar conclusions examining Italian and Swedish companies.

Similar positive effects also seem evident for 'sense and response' capabilities. 'Sense and response' skills refer to the ability to rapidly sense changes in the environment, conceptualize a response to that change, and reconfigure resources to execute the response. Quinn (2000) argued that these skills are critical for continuous innovation, and Souder and Jensen (1999) confirmed the positive relationship in their study of Scandinavian and US telecommunication firms.

Marketing skills also appear important for the implementation and exploitation of innovation. Several authors found a positive association between innovation and marketing competences examining US, European, and Japanese contexts (Song et al., 1997; Song \& Parry, 1996, 1997; Hultink et al., 2000). Moreover, what constitutes perhaps a more important capability for the firm is the integration and interaction between marketing and R\&D functions in order to facilitate information flow within and between departments, accelerate innovation process and achieve successful innovation output (Souder and Jenssen, 1999).

Finally, with this same line of reasoning, Teece et al., (1997) have put forward the so called 'dynamic capabilities' framework. Dynamic capabilities refer to the firm's ability to integrate, build, and reconfigure internal and external competences to 
address rapidly changing environments. In their view, coordination/integration, learning and transformation are the fundamental dynamic capabilities that serve as the mechanisms through which available stocks of resources (e.g. marketing, financial and technological assets) can be combined and transformed to produce new and innovative forms of competitive advantage.

\subsubsection{The impact of innovation on firm performance}

In the field of management, a significant body of research has examined the link between innovation and firm performance. Whereas many of these studies have established that innovation is associated with firm success (e.g. Damanpour \& Evan, 1984; Damanpour et al., 1989; Zahra et al., 1988; Khan \& Manopichetwattana, 1989), others have found no significant differences in performance between innovative and non-innovative firms (e.g. Antonelli, 1993; Yamin et al., 1999). Admittedly, these findings are not always comparable a fact that may attributed to different samples, operationalization of measures (particularly with respect to how innovation is conceptualized and measured) and econometric specification employed.

Another factor contributing to these inconsistencies may be the fact that performance is a multidimensional phenomenon. In this respect, no single measure may fully account for all aspects of organizational performance. Accordingly, the impact of innovation may differ across the different performance dimensions. A number of different performance measures have been used in the extant literature, of which, profitability, growth, productivity, and export intensity are those most commonly studied.

\subsubsection{Innovation and Profitability}

Empirical findings on the innovation-profitability relationship have generally produced positive results. For example, the adoption of technological innovations is associated with profit advantages derived from higher quality products, lower production costs, or increased diversity (Lefebvre et al., 1997). Capon, Farley and Hoenig (1996) examined large US manufacturers and found that those most profitable were also the ones that spend more on new product development. Moreover, these firms tend to consider themselves to be technically innovative and at the cutting edge of technology. Similarly, Geroski and Machin (1992), and Wynarczyk and Twaites (1997) studying large firms identified persistent profit differences between innovators and non-innovators. Han et al. (1998), examining the US banking industry found that innovation has a positive, direct impact on return on assets (ROA). In the same context, Subramanian and Nilakanta (1996) reported a positive association between administrative innovations and ROA or ROE (Return on Equity).

Studies that examine innovation from a resource-based perspective offer similar results. For example, Tiger and Calantone (1998), and Hoopes and Postrel (1999), examining firms in the US software industry, found that market knowledge motivates product innovation, which in turn exerts a positive influence on ROA and before-tax profits. Zahra and Garvis (2000) found that entrepreneurship and innovation activities positively affect profitability (ROA) in a sample of US manufacturing firms. In the same vein, other researchers (e.g. Covin \& Slevin, 1991; Baden-Fuller \& Stopford, 
1994; Dean et al., 1993) argue that firms highly entrepreneurial appear to obtain important financial benefits from their innovation, risk taking, and new business creation activities.

By contrast, other studies that mainly focus on SMEs (e.g. Heunks, 1998; Symeonidis, 1996), found that innovation may be associated, at least in the short-run, with lower profits. These scholars argue that low profits may be the cost of innovation-related investments, and that profits will not increase until some years after the initial investments due to the liquidity problems that most small firms face (Lefebvre et al., 1997).

\subsubsection{Innovation and Growth}

Research on the effects of innovation on firm growth has also produced generally positive results. Through improved or newly developed products a firm is able to capture a greater share of the existing demand and to generate a new market for its innovative offerings. Subramanian and Nilakanta (1996) examined the US banking industry and found a direct positive association between (technical) innovation and sales growth. Similarly, Lawless and Anderson (1996) in their study of the US microcomputer industry found that the adoption of technological innovations positively affects firms' market-share growth. Joyce and Stivers (1999) adopting a resource-based perspective, found that knowledge and technology intensity motivates innovation, which in turn exerts a positive impact on average sales growth of a sample of US and Canadian Fortune 500 firms. Unlike findings concerning profitability, it appears that innovation positively affects SMEs' growth, as indicated by a number of studies (e.g. Roper et al., 1996; Roper, 1997; Moore, 1995; Wynarczyk \& Twaites, 1997).

In contrast, however, to results pertaining to sales (or market-share) growth, findings on the effects of innovation on employment growth are somewhat more ambiguous. Brouwer et al. (1993) found that (product) innovation positively affects employment growth. Freel (2000) studying English manufacturing firms found that innovative firms outperform non-innovators in terms of new jobs creation. Other researchers (e.g. Moore, 1995; Westhead \& Cowling, 1995; Tether \& Massini, 1998) reached similar conclusions examining mainly SMEs. By contrast, other authors found no support for this proposition (see for example, Kalantaridis \& Pheby, 1999; Wynarczyk \& Twaites, 1997; Roper, 1997; Oakey, 1991). One possible explanation for these inconsistencies may relate, at least partly, to methodological differences (i.e. differences in the operationalization of the innovation construct) (Freel, 2000).

\subsubsection{Innovation and Productivity}

The management literature has also provided evidence of a positive relationship between innovation and productivity. Cesaratto and Stirati (1996), studying Italian manufacturing SMEs found a positive association between productivity and innovation. Specifically, they reported productivity increases over the period 19901992 , of $3.86 \%$ and $2.5 \%$ for innovators and non-innovators, respectively. Similarly, Hitt and Brynjolfsson (1997), studying large US firms, found that firms that adopt 
both technological and administrative innovations (i.e. decentralization) are on average 5\% more productive than non-innovators. Lipovatz et al. (2000) in their study of the Greek food and beverage industries confirmed the positive effects of (technological) innovation on labor productivity (output/man-hours).

Many resource-based studies offer similar results. For example, Black and Lynch (1997) examining US manufacturing firms found that certain administrative innovations (i.e. new work practices), which are themselves supported by training programs and IT resources, have a positive impact on plant productivity. Wakelin (1997) found that financial resources enabling R\&D spending have a positive role in productivity growth. Other studies (e.g. Tremblay (1999); Hatch \& Mowery (1998); Kusunoki et al. (1998), and Joyce and Stivers (1999) that focused on the role of knowledge and technical skills reached similar conclusions examining the innovationproductivity relationship in various contexts.

\subsubsection{Innovation and Export intensity}

Export intensity refers to the proportion of sales turnover derived from exporting. Research evidence on the effects of innovation on export performance has generally produced positive results (e.g. Moore, 1995; Wynarczyk and Twaites, 1997). Cesaratto and Stirati (1996), for example, found that innovative Italian manufacturing firms experienced a significantly higher rate of exporting in comparison to noninnovators. Lefebvre et al. (1997) and Sterlacchini (1999) in their studies of Canadian and Italian SMEs, confirmed the positive effects of innovation activities on export performance (share of exports on sales).

\subsubsection{Conclusions and Implications}

As noted in the introduction, the purpose of this study is twofold: (a) identify the major factors that influence a firm's capacity to innovate, and (b) to review the findings pertaining to the impact of innovation on firm performance.

With respect to the former, the literature suggests that the creation of an internal environment conducive to innovation is of paramount importance. In particular, research has shown that firms need to develop decentralized, informal and "flat" structures in order to obtain flexibility, enhance employees' entrepreneurship, and facilitate the implementation of change and innovation. Furthermore, characteristics such as intense internal cooperation and communication, together with the formation of intra and inter-organizational networks should be the basic elements of a firm's innovation policy. These factors are particularly relevant because, within the context of global competition and increased technological change, no individual firm can consistently innovate alone. Cooperation and networking offer significant innovation opportunities stemming from shared learning, transfer of know-how, and resource exchange.

Relevant empirical findings also demonstrate the positive role of organizational resources and capabilities. Intangible assets (particularly knowledge) and human capital constitute a significant source of innovative ideas, while, at the same time, enable firms to exploit Information and Communication technologies and thus achieve sustained competitive advantage. 
As regards the effects of innovation on firm performance, the literature provides evidence of a positive impact on growth, productivity, and export intensity. With respect to the innovation-profitability and innovation-employment relationships the relevant findings are somewhat less clear. It appears that whereas innovation affects positively the profitability of large firms, it may have a negative impact, at least in the short-run, in the case of SMEs. This phenomenon warrants careful attention to the particular idiosyncrasies of SMEs. It could be argued that, as far as policy formulation is concerned, policy programs that aim at stimulating the SMEs capacity for innovation, in addition to financial incentives, need to provide assistance for developing complementary intangible assets such as employees skills, entrepreneurial culture and mechanisms for knowledge creation and exploitation.

Perhaps the most important policy implication of the management literature on innovation lies on the recognition of the fact that a host of firm qualities appear to act as catalysts of innovative activity. Our review has shown that these primary relate to organizational structure, culture, and relevant resources and capabilities. Because, however, the capacity to innovate depends on qualities that are mostly intangible and idiosyncratic (e.g. an "open" communication culture), it seems logical to argue that the relationship between external (i.e. policy) stimuli, in the form of e.g. financial incentives, and firm response (i.e. innovation activity) is not linear and mechanistic. If this is true, then it is perhaps imperative that policy intervention complements its traditional apparatus of direct support measures with schemes that ignite the firms' capacity to innovate and/or sustain innovation activities. Admittedly this is not an easy task. Nor it is possible that these "capacity stimulation" measures can be tailormade to address the particular needs of each specific firm. What seems feasible however, as well as appropriate, are steps to promote the creation of institutional environments addressing the needs of (more or less) homogenous firm populations, to exert conformance pressures towards innovation rather than inertia.

\subsubsection{Summary}

- In contrast to the economics literature, the management literature examines innovation exclusively from the point of view of the firm. It is concerned with identifying the factors that promote (or inhibit) the firm's capacity to innovate as well as with the performance consequences of innovation activities

- A firm's capacity to innovate is subject to influences by factors of the internal (firm-specific) environment (i.e. structural characteristics, resources and capabilities) and factors of the external environment (i.e. industry structure, clustering).

- The management literature suggests that a host of firm qualities act as catalysts of innovative activities. These internal qualities are mostly intangible and idiosyncratic, and include:

$>$ The adoption of decentralized and informal organizational structures

$>$ The formation of intra and inter-organizational networks

$>$ "Open" communication culture

$>$ Human capital as an important innovation input

$>$ The use of Information and Communication Technologies

$>$ The existence or the ability to access to financial resources

$>$ Knowledge accumulation and exploitation 
$>$ Enhancement of employees entrepreneurship

- The management literature has also shown that the impact of innovation on firms competitive advantage is generally positive, particularly with respect to growth, productivity, and export performance. As regards profitability, empirical findings support a positive impact on the profitability of large firms, but are equivocal as far as SMEs are concerned.

- In fact, some studies have shown that innovation activities may have a negative impact on the profitability of SMEs. Certain policy measures (at a European level) should address this phenomenon by focusing on:

- Financial incentives (e.g. easy access to venture capital), and

- Support in the development of complementary assets (employees skills, entrepreneurial culture, mechanisms of knowledge creation and exploitation) that are critical for the capacity of SMEs to innovate

- At a broader level, because innovation is dependent -to an important extent-, to factors that are internal and idiosyncratic, direct policy intervention through support measures may be inadequate.

- The fundamental challenge here is to complement direct support measures with schemes that indirectly promote the creation of a culture conducive to innovation.

- One possible way of achieving this would be steps to promote the development of institutional environments that exert conformance pressure towards innovation rather than inertia. 


\section{References for Section 2.2}

Acs Z.J., Audretsch D.B., (1988), 'Innovation in large and small firms: an empirical analysis', American economic Review, 78, 678-690

Acs Z.J., Audretsch D.B., (1990), 'Innovation and small firms', Cambridge: MIT Press

Amit R., Schoemaker P., (1993), 'Strategic assets and organizational rent', Strategic Management Journal, 14, 33-46

Antonelli, C., (1993), 'Investment and adoption in advanced telecommunications', Journal of Economic Behavior and Organization, 20, 227-245

Arvanitis S., Hollenstein H., (1996), 'Industrial innovation in Switzerland: A model-based analysis with survey data', in Kleinknecht A. (ed), Determinants of innovation-the message from new indicators, 13-62, Macmillan Press

Baden-Fuller C., Stopford M.J., (1994), 'Rejuvenating the mature business', Harvard Business School Press, Boston

Barney, J., (1991), 'Firm resources and sustained competitive advantage', Journal of Management, 17, 99-120.

Bartezzaghi E., Corso M., Verganti R., (1997), 'Continuous improvement and inter-project leaning in the new product development', International Journal of Technology Management, 14, 116-138

Bertels K., Jacques J.M., Neuberg L., Gatot L., (1999), 'Qualitative company performance evaluation: Linear discriminant analysis and neural network models', European Journal of Operational Research, 115, 608-615

Black S.E., Lynch L.M., (1997), 'How to compete: the impact of work place practices and information technology on productivity', NBER Working Paper No.6120

Bozeman B., Link A.N., (1983), 'Investments in technology: Corporate strategy and public policy alternatives', New York: Praeger

Brouwer E., Kleinknecht A., (1996), 'Determinants of innovation: a micro econometric analysis of the three alternative innovation output indicators', in Kleinknecht A. (ed), Determinants of innovation-the message from new indicators, 99-124, Macmillan Press

Brouwer E., Kleinknecht A., Reijnen J.O.N., (1993), 'Employment growth and innovation at the firm level', Journal of Evolutionary Economics, 3, 153-159

Brouwer E., Nadvornikova H.B., Kleinknecht A., (1999), 'Are urban agglomerations a better breeding place for product innovation? An analysis of new product announcements', Regional Studies, 33 (6), 541-549

Capon N., Farley J.U., Hoenig S., (1996), 'Toward an integrative explanation of corporate financial performance', Kluwer Academic Publishers, Massachusetts

Cesaretto S., Stireti A., (1996), 'The economic consequences of innovation in Italian manufacturing firms: theory and results from the Community Innovation Survey', ESRC Center for Business Research, University of Cambridge

Chandrashekaran M., Sinha R.K., (1995), 'Isolating the determinants of innovativeness: A Split- Population Tobit (SPOT) duration model of timing and volume of first and repeat purchase', Journal of Marketing Research, 32, 444-456

Chiesa V., Coughlan P., Voss C.A., (1996), 'Development of a technical innovation audit', Journal of Product Innovation Management, 13, 105-136 
Cohen, W.M., (1995), 'Empirical studies of innovative activity', in Stoneman P. (ed), Handbook of the Economics of Innovation and Technological Change, 182-264, Oxford: Blackwell

Collins P.D., Hage J., Hull F.M., (1988), 'Organizational and technological predictors of change in automaticy', Academy of Management Journal, 31, 512-543

Collis, D., (1994), 'How valuable are organizational capabilities?', Strategic Management Journal, 15, 143-152

Cooke P., Wills D., (1999), 'Small firms, social capital and the enhancement of business performance through innovation programs', Small Business Economics, 13, 219-234

Cooper, R.G., (1979), 'The dimensions of industrial new product success and failure', Journal of Marketing, 43, 93-103

Cooper, R.G., (1984), 'New product strategies: What distinguishes the top performers?', Journal of Product Innovation Management, 2 (2), 151-164

Cooper, R.G., (1994), 'New products: The factors that drive success', International Marketing Review, 11 (1), 60-76

Covin J., Slevin T., (1989), 'Strategic management of small firms in hostile and benign environments', Strategic Management Journal, 10, 75-87

Covin J.G., Slevin D., (1991), 'A conceptual model of entrepreneurship as firm behavior', Entrepreneurship: Theory and Practice, 16, 7-25

Daellenbach U.S., McCarthy A.M., Schoenecker T.S., (1999), 'Commitment to innovation: the impact of top management team characteristics', R\&D Management, 29, 199-208

Daft R. L., (1992), 'Organization Theory and Design', West St. Paul, MN

Damanpour F., Evan W.M., (1984), 'Organizational innovation and performance: the problem of 'Organizational Lag', Administrative Science Quarterly, 29, 392-409

Damanpour F., Evan W.M., Szabat K.A., (1989), 'The relationship between types of innovation and organizational performance', Journal of Management Studies, 26, 587-601

Damanpour, F. (1991), 'Organizational Innovation: a meta-analysis of effects of determinants and moderators', Academy of Management Journal, 34, 555-590

Damanpour, F., (1987), 'The adoption of technological, administrative, and ancillary innovations: Impact of technological factors', Journal of Management, 13,.675-688

Damanpour, F., (1996), 'Organizational Complexity and Innovation: developing and testing multiple contingency models', Management Science, 42, 693-716

Damanpour, F., (1996), 'Organizational complexity and innovation: Developing and testing multiple contingency models', Management Science, 42, 693-717

Dean C.C., Thibodeaux M.S., Beyerlein M.S., Ebrahimi M., Molina D., (1993), 'Corporate entrepreneurship and competitive aggressiveness: a comparison of US firms operating in Eastern Europe and the Commonwealth of the Independent States with US firms in other high-risk environments', Advances in International Comparative Management, $8,31-54$

Decarolis D., Deeds D.L., (1999), 'The impact of stocks and flows of organizational knowledge on firm performance: an empirical investigation of the biotechnology industry', Strategic Management Journal, 20, 953-968

Del Canto J.G., Gonzalez I.S., (1999), 'A resource-based analysis of the factors determining a firm's R\&D activities’, Research Policy, 28, 891-905 
Dijk B.V., Hertog R.D., Menkveld B., Thurik R., (1997), 'Some new evidence on the determinants of large and small firm innovation', Small Business Economics, 9, 335343

Duncan, R.B., (1976), 'The ambidextrous organization: Designing dual structures fir innovation', in R. H. Kilmann, L.R. Pondy, D.P. Slevin (Eds.), The management of organization: Strategy and implementation, 1, 167-188, New York: North-Holland

Ettlie J.E., Bridges W.P., (1982), 'Environmental uncertainty and organizational technology policy', IEEE Transactions on Engineering Management, 29, 2-10

European Commision, (2000), 'The Fifth Framawork Programme: The research programmes of the EU 1998-2002', Research Directorate-GeneralBrussels

Felder J., Licht G., Nerlinger E., Stahl H., 'Factors determining R\&D and innovation expenditure in German manufacturing industries', in Kleinknecht A. (ed), Determinants of innovation-the message from new indicators, 125-154, Macmillan Press

Freel, M.S., (2000), 'Do small innovating firms outperform non-innovators?', Small Business Economics, 14, 195-210

Gatignon H., Xuereb J.M., (1997), 'Strategic orientation of the firm and new product performance', Journal of Marketing Research, 34, 77-90

Gemain, R., (1996), 'The role of context and structure in radical and incremental logistics innovation adoption', Journal of Business Research, 35, 117-127

Geroski P., Machin S., (1992), 'Do innovating firms outperform non-innovators?', Business Strategy Review, summer, 79-90

Glasmeier A., Fuellhart K., (1996), 'What do we know about how firms learn?', unpublished paper presented at the European International Business Academy (EIBA) $22^{\text {nd }}$ annual conference, Stockholm 15-17 December

Goes J., Park S., (1997), 'Interorganizational links and innovation: the case of hospital services', Academy of Management Journal, 40, 673-696

Hambrick, D., (1981), 'Specialization of environmental scanning activities among upper level managers', Journal of Management Studies, 18, 299-320

Han J.K., Kim N., Srivastava R.K., (1998), 'Market orientation and organizational performance: Is innovation a missing link?', Journal of Marketing, 62, 30-45

Harris R., Trainor M., (1995), 'Innovations and R\&D in Northern Ireland manufacturing: a Schumpeterian approach', Regional Studies, 29 (7), 593-604

Harrison B., Kelley M.R., Gant J., (1996), 'Innovative firm behavior and local milieu: exploring the intersection of agglomeration, firm effects, and technological change', Economic Geography, 72, 233-258

Hatch N.W., Mowery D., (1998), 'Process innovation and learning by doing in the semiconductor industry', Management Science, 44, 1461-1477

Helfat C.E., Raubitscek R.S., (2000), 'Product sequencing: co-evolution of knowledge, capabilities and products', Strategic Management Journal, 21, 961-979

Heuks, F., (1998), 'Innovation, creativity and success', Small Business Economics, 10, 263272

Hitt L., Brynjolfsson E., (1997), 'Information technology and internal firm organization: an explanatory analysis', Journal of Management Information Systems, 14(2)

Hoopes D.G., Postrel S., (1999), 'Shared knowledge, "clitches" and product development performance', Strategic Management Journal, 20, 837-865 
Huber G.P., Sutcliffe K.M., Miller C.C., Glick W.H., (1993), 'Understanding and predicting organizational change', in Huber G.P., and Glick W.H. (eds.), Organizational change and redesign, Chapter 5, Oxford University Press, NY

Huiban J.P., Bouhsina Z., (1998), 'Innovation and quality if the labor factor: An empirical investigation in the French food industry', Small Business Economics, 10, 389-400

Hultink E.J., Hart S., Robben H., Griffin A., (2000), 'Launch decisions and new product success: an empirical comparison of consumer and industrial products', Journal of Product Innovation Management, 17, 5-23

Iansiti M., West J., (1999), 'From physics to function: an empirical study of research and development performance in the semiconductor industry', Journal of Product Innovation Management, 16, 385-399

Joyce T., Stivers B.P., (1999), 'Knowledge and innovation: a classification of US and Canadian firms', International Journal of Technology Management, 18, 500-509

Kalantaridis C., Pheby J., (1999), 'Processes of innovation among manufacturing SMEs: the experince of Bedfordshire', Entrepreneurship and Regional Development, 11, 57-78

Kanter R.M., (1988), 'When a thousand flowers bloom: structural, collective, and social conditions for innovation in organization', in Staw B.M., Cummings L.L.(eds), Research in Organization Behavior, 10, 169-211, Greenwich, CT: JAI Press

Kanter, R., (1983), The Change Masters, London: Allen \& Unwin

Kessler E.H., Chakrabarti A.K., (1999), 'Speeding up the pace of new product development', Journal of Product Innovation Management, 16, 231-247

Khan A.M., Manopichetwattana V., (1989), 'Innovative and non-innovative small firms: types and characteristics', Management Science, 35, 597-606

Kim, L., (1980), 'Organizational innovation and structure', Journal of Business Research, 8, 225-245

Kimberly J., Evanisko M., (1981), 'Organizational Innovation: the influence of individual, organizational and confextual factors on hospital adoption of technical and administrative innovations', Academy of Management Journal, 24, 689-713

Klein K.J., Sorra J.S., (1996), 'The challenge of innovation implementation', Academy of Management Review, 21, 1055-1080

Kusunoki K., Nonaka I., Nagata A., (1998), 'Organizational capabilities in product development of Japanese firms: A conceptual framework and empirical findings', Organization Science, 6, 699-718

Lal, K., (1999), 'Determinants of the adoption of information technology: a case study of electrical and electronic goods manufacturing firms in India', Research Policy, 28, $667-680$

Lane P.J., Lubatkin M., (1998), 'Relative absorptive capacity and interorganizational learning', Strategic Management Journal, 19, 461-477

Lawless M.W., Anderson P.C., (1996), 'Generational technological change: effects of innovation and local rivalry on performance', Academy of Management Journal, 39, $1185-1217$

Lawrence P., Lorsch J., (1967), 'Organization and environment', Boston: Harvard Business School, Division of research

Lefebvre L., Mason R., Lefebvre E., (1997), 'The influence prism in SMEs: the power of CEO's perceptions on technology policy and its organizational impacts', Management Science, 43, 856-878 
Leibenstein, H., (1966), 'Allocative efficiency vs. X-Efficiency', American Economic Review, 56, 392-415

Liker J.K., Collins P.D., Hull F.M., (1999), 'Flexibility and standardization: Test of a contingency model of product design-manufacturing integration', Journal of Product Innovation Management, 16, 248-267

Lipovatz D., Mandaraka M., Mourelatos A., (2000), 'Multivariate analysis for the assessment of factors affecting industrial competitiveness: the case of Greek food and beverage industries', Applied Stochastic Models in Business and Industry, 16, 85-98

Liyanage S., Greenfield P.F., Don R., (1999), 'Towards a fourth generation of R\&D management model-research networks in knowledge management', International Journal of Technology Management, 18, 372-393

Lucchini, M., (1998), 'European technology policy and R\&D consortia: the case of semiconductors', International Journal of Technology Management, 15, 542-555

Lynn G.S., Skov R.B., Abel K.D., (1999), 'Practices that support team learning and their impact on speed to market and new product success', Journal of Product Innovation Management, 16, 439-454

Maidique M.A., Patch P., (1978), 'Corporate strategy ant technology policy', The president and fellows of Harvard College

Maijoor S., Van Witteloostuijn A., (1996), 'An empirical test of the resource=based theory: strategic regulation in the Dutch audit industry', Strategic Management Journal, 17, 549-569

Markham, S.K., (1998), 'A longitudinal examination of how champions influence others to support their projects', Journal of Product Innovation Management, 16, 490-504

Marlerba F., Orsenigo L., Peretto P., (1997), 'Persistence of innovative activities, sectoral patterns of innovation and international technological specialization', International Journal of Industrial Organization, 15, 801-826

Mishra S., Kim D., Lee D.H., (1996), 'Factors affecting new product success: a cross-country comparisons', Journal of Product Innovation Management, 13, 530-550

Mitchell V.L., Zmud R.W., (1999), 'The effects of coupling IT and work process strategies in redesign projects', Organization Science, 10, 424-438

Moore, B., (1995), 'What differentiates innovative small firms?', Innovation Initiative Paper No.4, ESRC Center for Business Research, University of Cambridge

Nevis E.C., DiBella A.J., Gould J.M., (1995), 'Understanding organizations as learning systems', Sloan Management Review, 73-85

Nohria N., Eccles R., (1992), 'Networks and organizations’, Boston, Harvard Business School Press.

Oakey, K., (1991), 'High technology small firms: their potential for rapid industrial growth', International Small Business Journal, 9, 30-42

OECD, (2000), 'A new economy? The changing role of innovation and information technology in growth', OECD, Paris

Phillips, A., (1965), 'Structure, innovation and investment', in Alderson W., Terpstra B., Shapiro J. (eds), Patents and progress: The sources and impact of advancing technology, 37-58, Homewood (IL): Irwin

Pierce J., Delbecq A., (1977), 'Organization structure, individual attitudes, and innovation', Academy of Management Review, 2, 27-37 
Pillai R., Meindl J.R., (1998), 'Context and charisma: a 'meso' level examination of the relationship of organic structure, collectivism, and crisis to charismatic leadership', Journal of Management, 24, 643-671

Pouder R., John C., (1996), 'Hot spots and blind spots: geographical clusters of firms and innovation', Academy of Management Review, 21, 1192-1225

Premkumar G., Ramamurphy K., Grum M., (1997), 'Determinants of EDI adoption in the transportation industry', European Journal of Information Systems, 6, 107-121

Premkumar G., Roberts M., (1999), 'Adoption of new information technology in rural small business', Omega, 27, 467-484

Quinn, J.B., (2000), 'Outsourcing innovation: the new engine of growth', Sloan Management Review, 41, 13-28

Roper S., Love J., Dunlop S., Ashcroft B., Hoffman H., Vogler-Ludwing K., (1996), ‘ Product innovation and development in U.K., German and Irish manufacturing, Northern Ireland Economic Research Center, Queens University

Roper, S., (1997), 'Product innovation and small business growth: a comparison of the strategies of German, UK and Irish companies', Small Business Economics, 9, 523537

Ross, P.F., (1974), 'Innovation adoption by organizations', Personnel Psychology, 27, 21-47

Rumelt, R., (1984), 'Toward a strategic theory of the firm', In Lamb, R. (ed), Competitive Strategic Management, Englewwod Cliffs, NJ:Prentice-Hall, 556-570

Sawhney M., Prandelli E., (2000), 'Communities of creation: managing distributed innovation in turbulent markets', California Management Review, 42, 24-54

Scherer, F.M., (1967), 'Market structure and the employment of scientists and engineers', American Economic Review, 55, 524-531

Schumpeter, (1943), 'Capitalism, Socialism and Democracy', London: Allen \& Unwin

Sivadas E., Dwyer F.R., (2000), 'An examination of organizational factors influencing new product success in internal and alliance-based processes', Journal of Marketing, 64, $31-49$

Song X.M., Parry M.E., (1996), 'What separates Japanese new product winners from losers', Journal of Product Innovation Management, 13, 422-439

Song X.M., Parry M.E., (1997), 'The determinants of Japanese new product success', Journal of Marketing Research, 34, 64-76

Song X.M., Souder W.E., Dyer B., (1997), 'A causal model of the impact of skills, synergy, and design sensitivity on new product performance', Journal of Product Innovation Management, 14, 88-101

Souder W.E., Jenssen S.A., (1999), 'Management practices influencing new product success and failure in the United States and Scandivavia: a cross-cultural comparative study', Journal of Product Innovation Management, 16, 183-203

Staber, U., (1996), 'Accounting for variations in the performance of industrial districts: the case of Baden-Wurttemgerg', International Journal of Urban and Regional Research, $20,299-316$

Sterlacchini, A., (1999), 'Do innovative activities matter to small firms in non-R\&D intensive industries? An application to export performance', Research Policy, 28, 819-832

Stuart T.E., Hoang H., Hybels R.C., (1999), 'Interorganizational endorsements and performance of entrepreneurial ventures', Administrative Science Quarterly, 44, 315349 
Subramanian A., Nilakanta S., (1996), 'Organizational Innovativeness: Exploring the relationship between organizational determinants of innovation, types of innovations, and measures of organizational performance', Omega, 24, 631-647

Teece D.J., Pisano G., Shuen A., (1997), 'Dynamic capabilities and strategic management', Strategic Management Journal, 18(7), 509-533

Tether B., Massini S., (1998), 'Employment growth in small technological and design innovators in the UK during the 1980s', Small Business Economics, 11, 353-370

Thong J., Yap C., (1995), 'CEO characteristics, organizational characteristics and information technology adoption in small business', Omega, 23, 429-442

Tiger L., Calantone R.J., (1998), 'The impact of market knowledge competence on the new product advantage: conceptualization and empirical examination', Journal of Marketing, 62, 13-29

Tremblay, P.J., (1999), 'Organize to generate innovation', International Journal of Technology Management, 17, 797-813

Tsai W., Ghoshal S., (1998), 'Social capital and value creation: the role of intrafirm networks', Academy of Management Journal, 41, 464-476

Venkatraman, N., (1989), 'Strategic orientation of business enterprises: The construct, dimensionality, and measurement', Management Science, 35, 942-962

Verona, G., (1999), 'A resource-based view of product development', Academy of Management Review, 24, 132-142

Vossen R.W., Nooteboom B., (1996), 'Firm size and participation in R\&D', in Kleinknecht A. (ed), Determinants of innovation-the message from new indicators, 155-168, Macmillan Press

Wakelin, K., (1997), 'Productivity, growth and R\&D expenditure in UK manufacturing firms', MERIT, 2/97-018

Weiss A.R., Birnbaum P.H., (1989), 'Technological infrastructure and the implementation of technological strategies', Management Science, 35, 1014-1026

Wernefelt, B., (1984), ‘A resource-based view of the firm', Strategic Management Journal, 5, 171-180.

Westhead P., Cowling M., (1995), 'Employment change in independent owner-managed high technology firms in Great Britain', Small Business Economics, 7, 111-140

Whittington R., Pettigrew A., Peck S., Fenton E., Conyon M., (1999), 'Change and complementarities in the new competitive landscape: A. European panel study, 1992 - 1996', Organizational Science, 10, 583-600

Wolfe, R. (1994), 'Organizational Innovation: Review, critique and suggested research directions', Journal of Management Studies, 31, 405-431

Wynarczyk P., Thwaites A., (1997), 'The economic performance, survival and non-survival of innovative small firms', in Oakey R, Muktar (eds.), New Technology Based Firms in the 1990s: Volume III, Paul Chapman, London

Yamin S., Gunasekaran A., Mavondo F.T., (1999), 'Innovation index and its implications on organizational performance: a study of Australian manufacturing companies', International Journal of Technology Management, 17, 495-503

Zahra S.A., Belardino S., Boxx W.R., (1988), 'Organizational innovation: its correlates and its implications for financial performance', International Journal of Management, 5, 133-142 
Zahra S.A., Garvis D.M., (2000), 'International corporate entrepreneurship and firm performance: the moderating effect of international environmental hostility', Journal of Business Venturing, 15, 469-492 


\section{Appendix 1: The Determinants of a firm's capacity to innovate}

\begin{tabular}{|c|c|c|c|}
\hline $\begin{array}{c}\text { Determining } \\
\text { Factor }\end{array}$ & Definition & $\begin{array}{l}\text { Expected } \\
\text { relationship }\end{array}$ & Empirical evidence \\
\hline \multicolumn{4}{|c|}{ Traditional perspective } \\
\hline $\begin{array}{ll}\text { Competitive } & \text { strategy } \\
\text { (or strategic } & \text { business } \\
\text { orientation) } & \end{array}$ & $\begin{array}{lr}\text { Reflects the } & \text { actual } \\
\text { strategies pursued by a } \\
\text { firm with respect to its } \\
\text { competitors, } \\
\text { characterizes a firm along } \\
\text { six and } \\
\text { aggressiveness, analysis, } \\
\text { defensiveness, futurity, } \\
\text { proactiveness, } \\
\text { riskiness }\end{array}$ & + & $\begin{array}{l}\text { Venkatraman, 1989; Levebvre et } \\
\text { al., 1997; Maidique \& Patch, } \\
\text { 1978; Ettlie \& Bridges, } 1982\end{array}$ \\
\hline Formalization & $\begin{array}{l}\text { The existence of formal } \\
\text { job descriptions, policies } \\
\text { and procedures }\end{array}$ & - & $\begin{array}{l}\text { Subramanian \& Nilakanta, 1996; } \\
\text { Liker et al., } 1999\end{array}$ \\
\hline Centralization & $\begin{array}{l}\text { The concentration of } \\
\text { decision-making authority } \\
\text { in top-management }\end{array}$ & - & $\begin{array}{l}\text { Subramanian \& Nilakanta, 1996; } \\
\text { Whittington et al., 1999; } \\
\text { Chandrashekaran, 1995 }\end{array}$ \\
\hline Vertical differentiation & $\begin{array}{l}\text { The way that a firm } \\
\text { allocates resources to } \\
\text { organizational tasks. It } \\
\text { involves choices on the } \\
\text { number of hierarchical } \\
\text { levels, departments and } \\
\text { managerial span of control }\end{array}$ & - & $\begin{array}{l}\text { Damanpour, 1991, 1997; Pillai, } \\
\text { 1998; Bertels et al., } 1999\end{array}$ \\
\hline Specialization & $\begin{array}{l}\text { The variety and range of } \\
\text { job tasks in an organization }\end{array}$ & $?^{8}$ & $\begin{array}{l}\text { Subramanian \& Nilakanta, 1996; } \\
\text { Germain, 1996; Liker et al., } 1999\end{array}$ \\
\hline Scanning mechanisms & $\begin{array}{l}\text { The strategic awareness of } \\
\text { the competitive actions, by } \\
\text { conducting market studies, } \\
\text { following competitors' } \\
\text { strategies, and predicting } \\
\text { sales behavior and } \\
\text { customer needs }\end{array}$ & + & $\begin{array}{l}\text { Weiss \& Birnbaum, 1989; } \\
\text { Levebvre et al., } 1997\end{array}$ \\
\hline Technocratization & $\begin{array}{ll}\text { The concentration of } \\
\text { scientists, technicians } \\
\text { engineers in a firm }\end{array}$ & + & $\begin{array}{l}\text { Levebvre et al., 1997; Ettlie \& } \\
\text { Bridges, 1982; Collins et al., } \\
1988\end{array}$ \\
\hline $\begin{array}{l}\text { Cross-functional } \\
\text { cooperation }\end{array}$ & $\begin{array}{l}\text { The extent that different } \\
\text { units or departments of a } \\
\text { firm interact and exchange } \\
\text { information and ideas }\end{array}$ & + & $\begin{array}{l}\text { Sivadas \& Dwyer, 2000; Tsai \& } \\
\text { Ghoshal, 1998; Lucchini, } 1998\end{array}$ \\
\hline $\begin{array}{l}\text { Organizational } \\
\text { communication }\end{array}$ & $\begin{array}{lrr}\text { The free } & \text { flow of } & \text { of } \\
\text { information, ideas and } \\
\text { knowledge } & \text { among } \\
\text { departments of an } \\
\text { organization } & \text { (internal } \\
\text { communication) } & \text { or } \\
\text { between the organization } \\
\text { and other firms and } \\
\text { institutions (external } \\
\text { communication) }\end{array}$ & + & $\begin{array}{l}\text { Damanpour, 1991; Ross, 1974; } \\
\text { Kusunoki \& Nonaka, } 1998\end{array}$ \\
\hline
\end{tabular}

\footnotetext{
${ }^{8}$ ? Refers to hypothesized relationships that have produced equivocal empirical findings
} 


\begin{tabular}{|c|c|c|c|}
\hline Organizational size & $\begin{array}{l}\text { The operating scale of an } \\
\text { organization, usually } \\
\text { expressed in terms of } \\
\text { financial or human } \\
\text { resources (e.g. total profits, } \\
\text { number of employees). }\end{array}$ & $?$ & $\begin{array}{l}\text { Marbella et al., 1997; } \\
\text { Premkumar et al., 1997; Lal, } \\
\text { 1999(+); Thong \& Yap, 1995; } \\
\text { Huiban \& Bouhsina, 1998; } \\
\text { Premkumar \& Roberts, 1999; } \\
\text { Acs \& Audretsch, 1988; Phillips, } \\
\text { 1965; Brouwer \& Kleinknecht, } \\
\text { 1996; Felder et al., 1996; Vossen } \\
\text { \& Nooteboom, 1996; Arvantris } \\
\text { \& Hollenstein, 1996 }\end{array}$ \\
\hline $\begin{array}{l}\text { Manager's attitude } \\
\text { towards change }\end{array}$ & $\begin{array}{l}\text { Top managers' attitude } \\
\text { (support) towards change } \\
\text { initiatives }\end{array}$ & + & $\begin{array}{l}\text { Premkumar \& Roberts, 1998; } \\
\text { Daellenbach et al., 1999; Verona, } \\
\text { 1999; Chiesa et al., } 1996\end{array}$ \\
\hline Organizational climate & $\begin{array}{l}\text { The specific set of norms, } \\
\text { values, and beliefs that are } \\
\text { shared by people and } \\
\text { groups in an organization }\end{array}$ & + & $\begin{array}{l}\text { Kanter, 1983; Klein \& Sorra, } \\
\text { 1996; Nevis et al., } 1995\end{array}$ \\
\hline Industry structure & $\begin{array}{l}\text { The number and size } \\
\text { distribution of companies } \\
\text { in an industry, mainly } \\
\text { expressed in terms of } \\
\text { market concentration. }\end{array}$ & $?$ & $\begin{array}{l}\text { Scherer, 1967; Bozeman \& Link, } \\
\text { 1983; Huiban \& Bouhsina, 1998; } \\
\text { Dijk et al., 1997; Acs \& } \\
\text { Audretsch, 1990; Harris \& } \\
\text { Trainor, 1995; Marbella et al., } \\
\text { 1997; Brouwer et al., 1999; } \\
\text { Thong \& Yap, 1995; Premkumar } \\
\text { \& Roberts, 1998; Premkumar et } \\
\text { al., 1997; Leibenstein, } 1966\end{array}$ \\
\hline $\begin{array}{l}\text { Environmental } \\
\text { uncertainty }\end{array}$ & $\begin{array}{l}\text { Environmental uncertainty } \\
\text { has two important } \\
\text { dimensions: environmental } \\
\text { complexity - the extent } \\
\text { and variety } \\
\text { environmental } \\
\text { components, and } \\
\text { environmental variability - } \\
\text { the frequency and } \\
\text { predictability of changes in } \\
\text { industry components }\end{array}$ & + & $\begin{array}{l}\text { Huber et al., 1993; Hall, 1987; } \\
\text { Covin \& Slein, 1989; Lawrence } \\
\text { \& Lorsch, 1967; Hambrick, } \\
\text { 1981; Hrebriniak \& Snow, 1980; } \\
\text { Pierce \& Delbecq, 1977; } \\
\text { Damanpour, 1996; Mishra et al., } \\
1996\end{array}$ \\
\hline $\begin{array}{l}\text { Pressures towards } \\
\text { inter-organizational } \\
\text { networks }\end{array}$ & $\begin{array}{l}\text { Market and institutional } \\
\text { pressures towards } \\
\text { organizational networks } \\
\text { (i.e. enduring transactions, } \\
\text { flows, and linkages } \\
\text { between organizations) }\end{array}$ & + & $\begin{array}{l}\text { Nohria \& Eccles, 1992; Goes \& } \\
\text { Park, 1997; Sivadas \& Dwyer, } \\
\text { 2000; Stuart et al., 1999; } \\
\text { Sawhney \& Prandelli, 2000; } \\
\text { Cooke \& Wills, } 1999\end{array}$ \\
\hline Regional clustering & $\begin{array}{l}\text { The concentration of a } \\
\text { number of firms in a } \\
\text { specific } \\
\text { region }\end{array}$ & $?$ & $\begin{array}{l}\text { Pouder \& John, 1996; Staber, } \\
\text { 1996; Harrison et al., 1996; } \\
\text { Glasmeier \& Fuellhart, } 1996\end{array}$ \\
\hline \multicolumn{4}{|c|}{ Resource-based perspective } \\
\hline $\begin{array}{l}\text { Organizational } \\
\text { resources }\end{array}$ & $\begin{array}{l}\text { The assets (tangible or } \\
\text { intangible) that are semi- } \\
\text { permanently owned or } \\
\text { controlled by the firm (e.g. } \\
\text { financial, human, technical } \\
\text { and R\&D resources) }\end{array}$ & + & $\begin{array}{l}\text { Delcanto \& Gonzalez, 1999; } \\
\text { Harris \& Trainor, 1995; Kessler } \\
\text { \& Chakrabarti, 1999; Song \& } \\
\text { Parry, 1997; Huiban \& Bouhsina, } \\
\text { 1998; Gatignon \& Xuereb, 1997; } \\
\text { Mitchell \& Zmud, 1999; } \\
\text { Liyanege et al., 1999; Kanter, } \\
\text { 1988; Cooper, 1979, 1984, } 1994\end{array}$ \\
\hline
\end{tabular}




\begin{tabular}{|c|c|c|c|}
\hline $\begin{array}{l}\text { Organizational } \\
\text { knowledge }\end{array}$ & $\begin{array}{l}\text { Knowledge is an intangible } \\
\text { asset, which is created and } \\
\text { organized by the flow of } \\
\text { information, anchored on } \\
\text { the commitment and } \\
\text { beliefs of its holder }\end{array}$ & + & $\begin{array}{l}\text { Decarolis \& Deeds, 1999; Joyes } \\
\text { \& Stivers, 1999; Hoopes \& } \\
\text { Postrel, 1999; Tiger \& } \\
\text { Calantone, 1998; Helfat, 2000; } \\
\text { Whittingnon et al.,1999 }\end{array}$ \\
\hline Entrepreneurship & $\begin{array}{l}\text { The articulation of a long } \\
\text { term vision for the firm } \\
\text { that aims at higher growth } \\
\text { through the introduction of } \\
\text { new technologies and } \\
\text { innovative products rather } \\
\text { be content with short run } \\
\text { profit maximization }\end{array}$ & + & $\begin{array}{l}\text { Schumpeter, 1943; Cohen. 1995; } \\
\text { Lal, 1999; Iansiti \& West, 1999; } \\
\text { Pillai \& Meindl, 1998; Markham, } \\
1998\end{array}$ \\
\hline $\begin{array}{l}\text { Organizational } \\
\text { learning }\end{array}$ & $\begin{array}{l}\text { The capacity or process } \\
\text { within an organization to } \\
\text { maintain or improve } \\
\text { performance based on } \\
\text { experience and } \\
\text { accumulated knowledge }\end{array}$ & + & $\begin{array}{l}\text { Lynn et al. 1999; Bartezzaghi et } \\
\text { al., 1997; Helfat \& Raubitschek, } \\
\text { 2000; Lane, } 1998\end{array}$ \\
\hline $\begin{array}{l}\text { Sense and response } \\
\text { capability }\end{array}$ & $\begin{array}{l}\text { The ability to rapidly: } \\
\text { sense changes in the } \\
\text { environment, } \\
\text { conceptualize a response to } \\
\text { that change, and } \\
\text { reconfigure resources to } \\
\text { execute the response }\end{array}$ & + & $\begin{array}{l}\text { Quinn, 2000; Souder \& Jenssen, } \\
\text { 1999; Lefebvre et al., } 1997\end{array}$ \\
\hline Marketing capabilities & $\begin{array}{l}\text { Refer to the market } \\
\text { research tools, marketing } \\
\text { mix policies, and the } \\
\text { dissemination of market } \\
\text { information across the } \\
\text { organization }\end{array}$ & + & $\begin{array}{l}\text { Song et al., 1997; Song \& Parry, } \\
1996,1997 ; \\
\text { et al., 2000 }\end{array}$ \\
\hline Dynamic capabilities & $\begin{array}{l}\text { The firms ability to } \\
\text { integrate, build, and } \\
\text { reconfigure competences } \\
\text { to address rapidly changing } \\
\text { environments }\end{array}$ & + & Teece et al., 1997 \\
\hline
\end{tabular}




\subsection{Industry-Science Linkages}

The relationship between scientific research and technology is an important one and has gained increasing attention in the last two decades regarding that scientific research is an important factor in modern industrial development and long-run growth. Universities and science in general contribute substantially to the competitiveness of industries in the long run, but they may also be of great importance in the short run. This is why in most economies national and regional policy has sought to bring the worlds of scientific and commercially oriented research closer together.

Due to the innovation system approach (Lundvall 1992, Nelson 1993, Edquist 1997), knowledge, learning and the resulting capacity to react on changing demand play a crucial and growing role for firms. Useful products and processes result from knowledge inputs from a variety of sources, and meet performance constraints along multiple dimensions. The current focus on knowledge has - combined with the interactive theory of innovation - led to the analysis of specific factors, which determine successful innovations, or influence the absorption of outside created knowledge. In this context it is not only firms that are involved in the process of innovation, but also a set of other actors of various kinds. The interactions between them build the backbone of a system of innovation. The proposition that firms rarely innovate on their own but involve interactions with market and non-market institutions is evidenced by several surveys 9 . Pivotal for all innovation oriented interactions between firms and other actors is the associated flow of knowledge.

In this context universities as producers of new knowledge may play a crucial role. According to the share of $\mathrm{R} \& \mathrm{D}$ by sector of performance in most developed countries, the majority of $R \& D$ is performed by the private enterprise sector, followed by the university sector (OECD 2000). Furthermore, universities represent the largest and most manifold pool of scientists and researchers, within the national innovation system and are the major producers of human capital by professionally transferring scientific knowledge through education. Universities thus contribute to the production of knowledge and knowledge inputs in the business sector in at least three major ways. First, the business sector receives inputs from universities in the form of highly educated human capital. Although these individuals may require further training, university education lays the foundations for the following more specialized industrial training. Nevertheless, this influx of fresh trained graduates will lead to an inflow of new knowledge to the firm. Second, by developing and providing new knowledge through research which is disseminated through publications and presentations. Third, by developing and providing new knowledge through research which is disseminated through co-operative research projects or consultancy for the business sector.

\footnotetext{
${ }^{9}$ For example the so called Community Innovation Surveys (CIS-I and CIS-II) performed by the member states of the EU or the survey carried out by the OECD Focus Group on „Innovative Networks“

(Christensen et al. 1999).
} 
Moreover, the university systems of highly industrialized countries are going through a period of profound change due to a rise in society's expectations for economic returns of basic research. This has led to counteracting pressures on the institutional organization and roles played by universities within many EU countries: (1) the different impacts of private and public financing, (2) conflicts between the free advancement of basic knowledge and the research frontier and applied research driven by the needs of industrial firms. From the early 1980s onwards, policies and priorities of universities have been increasingly influenced both by the quest for relevance of university research to national and/or societal ${ }^{10}$ needs and by the pressure of accountability and cost reduction. ${ }^{11}$ If, within the frame of the scientific system, knowledge is discussed, one normally thinks of basic research in universities as opposed to knowledge gained from the results of applied or commercial research and development. Nevertheless, recent studies (Pavitt 1997, Smith 1994) show that the boundaries between basic and applied research as well as between science and technology are becoming more and more unclear and permeable. This makes international programmes, like the Framework Programme (FP) of the European Union which are based on inter-nationally and inter-sectoral co-operations interesting. Knowledge production within co-operative projects increasingly is transdisciplinary and depends on the ability of researchers to work with others across a broad spectrum of disciplines and sectors.

The structure of the paper is organised as follows: first, we briefly discuss the various conceptual approaches of the role of science including new approaches measuring the impact of science to innovation. Section 3 presents a benchmarking approach of IndustryScience Relations and Section 4 summarises the results of different analysis of the science-industry linkages within the European Framework Programme.

\subsubsection{The role of science - a methodological and conceptual overview}

Basic science is one of the major building blocks of innovation systems and of a good innovation infrastructure. However, the nature of the relationship between basic science and the economy is much more complex than the old linear approach leading from pure science over applied science and development to marketable innovations may suggest. Moreover applied scientific activity becomes increasingly interdisciplinary, and as the boundaries between university and other parts of the knowledge-producing system become increasingly blurred. This influences the theoretical approaches: for years it was quite attractive to measure the direct economic returns to basic research on the basis of econometric evidence. In the meanwhile the focus lies less on the macro level because many of the benefits that flow from basic research are difficult to capture in economic statistics. Hence, recent findings try to explore some micro-level mechanism which aim to explain the sources and mechanism behind macroeconomic benefits identified by econometricians.

\footnotetext{
${ }^{10}$ Sweden: third mission as an distinct example

11 See Geuna (1999) for a discussion of this empirical trend as well as for a critical assessment of the changing rationale for European university research funding.
} 


\section{Conceptual approaches}

From a theoretical point of view the seminal contribution to the analysis of the production and distribution of basic scientific knowledge, notably the analytical work of Nelson (1959) and Arrow (1962), gave an underlying economic justification for the governmental support of basic research even within the strict neoclassical point of view. They analysed the implications of the difficulties of privately appropriating the economic value of basic research findings. According to this paradigm, new research findings are thought of as a public good which is freely available with the main characteristics defined in terms of indivisibility and non-excludability from the use. These characteristics were necessary to the objective of the economic analysis, namely to understand why perfect competition fails to achieve an optimal allocation of resources, i.e. why companies systemically under-invest in basic research and why should the state fund such an investment. With government funding, new economically useful information is created and the distribution of this information enhanced through the tradition of public disclosure in science.

Looking back at the intellectual framework which justified public intervention in research, it is striking that over time, progressively fewer references have been made to the empirical evidence, and more to the standard theorems of welfare economics. In stressing the public-good character of science, the distinction and interaction between science and technology has been more or less ignored.

Much of the public debate about science and technology policy has for decades been implicitly dominated by this specific model ("linear" model) of the innovation process. In that model, basic research produces a flow of theories and findings (i.e. "discoveries") that are refined through applied research, tested in the development process, and finally commercialised as industrial innovations. Hence, this model builds the framework for categorising the processes of knowledge creation according to their commercial aims. But this linearity includes a theory of knowledge production as well. Each level in the linear model produces outputs that are transferred to the next level as inputs. In keeping with the sequential nature of the model, the flow is unidirectional: later stages do not provide inputs for earlier stages (Steinmueller, 1994).

In recent years "dissident" scientists, policy experts and policy advisors have been travelling round the world to spread the message: "the linear model of innovation is dead" (Rosenberg, 1994, p. 145). New theories and approaches about innovation and its social and economic embeddedness are challenging the old paradigm for policy intervention. They argue that the linear model depicts only one of academia's potential contribution to the creation of technological know-how. As many empirical studies have shown, only a few industries, like chemicals and pharmaceuticals have always benefited directly from basic research in organic chemistry, clinical medicine and molecular biology (Pavitt, 1991). Thus, the linear model applies only in rather special circumstances and in a limited range of industries.

In general, the traditional pattern of connecting basic research to industrial innovation is waning. Its assumption about the self-governance of science and the unidirectional transfer of knowledge from science to technology are inconsistent with empirical studies 
of the conduct and institutions of science. Evolutionary theory, systems of innovation approaches and new knowledge about the social shaping of technology show that there are many contributions from academia to industry and most of them are indirect and difficult to measure (Kline and Rosenberg, 1986; Rosenberg, 1982; Dasgupta and David, 1994). The significance of these studies is that, on the one hand, they cast suspicion on the separability of the activities performed by scientists from external social and technological influences. On the other hand, related studies of industrial innovations have revealed a much more complex pattern of knowledge creation, transfer and utilisation than suggested by the linear model. Thus, there are reverse flows of causation that shape the development of R\&D on firm level as well as the development of science. This means that the 'linear' model of knowledge transfer is not the proper one. Science does not 'cause' innovation in such a direct way that increasing the amount of science will automatically increase the amount of innovation: funding more science will result mostly in more science (with some long-run impact on the private funding of RTD). Although science may still be the pursuit of knowledge "without practical ends", the very definite means and constraints that shape scientific activity has to be considered (Rosenberg, 1982). Thus, according to the 'innovation-system approach', the amount of economically productive technology adoption can not be increased without the availability of skills and knowledge. The results of the academic research are important on the one hand, but creating the potential and the human capital to ensure the adoption of new findings are essential for the performance of the enterprise, as well.

\section{New approaches}

Given the difficulties to measure the economic impact of research at the macro level the received rates of return seem not to be very robust. This does not mean that, however, the effects of basic research are not real nor that they are not substantial. But it should indicate, that the traditional methods for measuring the benefits of basic research do not cover all results of the research process. It remains the assurance that regardless of the specific results all studies show positive rates of return. It can at least be said that research matters and does have positive impact on the economic performance. This leads to the necessity to analyse the effects and the utility of research done mainly at universities on a microeconomic level, hence to look at the paths and transfer mechanism on the firm level.

One of the reasons for the lack of attention concerning the broader impact of basic research and the interface between science and technology in particular has been a "common confusion" (Pavitt, 1991, p.112). Although the results of science has some attributes of a public good (i.e. non-rival, codified, published, easily reproduced and therefore deserving of public subsidy), it is certainly not a free good (i.e. costless to apply). Adopting this new approach by focusing on the user-side of the knowledge production, greatly complicates the assignment of causation, but offers several directions of research.

According to new models of innovation, the process of creating new technologies does have a more collective character which implies that the role of basic research is much more embedded in an economically and technological context than being the exogenous 
transmitter of knowledge. Hence, the results of basic research can not costlessly assimilated by any potential user. Only large companies (or firms with the relevant specialised stock of human capital) may have the complementary assets in terms of particular investments, capabilities and personnel needed to put specific scientific results to economic use. Obviously, knowledge flows from universities to firms are determined by a variety of factors. There are firm-specific factors and industry-related factors in which types of knowledge are needed, how much knowledge is needed, how knowledge is conceived, how the acquisition of knowledge is organised, who participates in the acquisition of knowledge, etc. Different sectors of industrial activity face different technological opportunities (Pavitt 1984, Klevorick et al., 1993), which means that they differ in the feasibility and sources of advance in their product- and process relevant technologies. New scientific developments and university research results constitute one source of new contributions to an industrial sector's pool of technological opportunities.

If university research is analysed in some more detail on the level of fields of research, it becomes evident that although firms become increasingly ,multi-technological'(Pavitt, 1997), not all research carried out at universities is equally interesting for all sectors of industrial activity and vice versa. Klevorick et al. (1993) find in their analysis that industrial sectors such as the production of drugs or food products rely more heavily on (specific) university research than all others. Vice versa, scientific fields of research such as computer science or materials science are highly relevant to a large number of sectors of industrial activity, whereas e.g. geology does not bear high relevance to any of sector of industrial activity. It therefore seems justified to analyse the patterns of knowledge interactions between universities and firms and their determinants on the levels of sectors of industrial activity and fields of university research. This new understanding of knowledge production and absorption has led to a variety of studies during the 90s analysing the economic benefits resulting from basic research mainly done at universities. The focus of most of the studies ${ }^{12}$ on university-firm-interactions was laid on detailed analysis of science-industry linkages in narrowly defined fields of research and technology (so-called 'high-tech' industries) (Bania et al., 1993, Acs et al., 1994), on the aggregate effect of university research on knowledge production in firms (Jaffe, 1996; Varga, 2000; Anselin et al., 1997), or on certain types of knowledge interactions such as citations of university research in firms patents (Jaffe et al., 1993; Almeida et al., 1995), personal mobility (Bania et al., 1992; Almeida et al., 1995), joint publications (Hicks et al., 1993) and spin-off formations of new firms by university members (Parker et al., 1993; Kelly et al., 1992).

\section{Patterns of knowledge transfer}

A variety of studies (Brooks, 1994; David et al., 1994; Pavitt, 1991, 1997; Rosenberg and Nelson, 1994; Salter and Martin, 2001; Schartinger et al., 2001b; Schibany et al. 1999) provide an interesting list of economic benefits which result from basic research mainly done at universities. The scientific research process generates economically important outputs other than published findings and theories. Examples are the training of individuals and the development of instrumentation that are complements in the conduct of future scientific and industrial research (Dasgupta and David, 1992).

\footnotetext{
${ }^{12}$ See Varga (2000) and the SPRU study (Salter et al., 2000) for an overview
} 
These different forms of benefits are, however, interconnected and mutually supporting; for example, the training of skilled graduates not only promotes the development of professional networks but also facilitates the transfer of new information and methodologies into industry. Hence, some contributions will be direct, when academic research leads to applicable discoveries, engineering research techniques and instrumentation. Others will be indirect, when academic research training, background knowledge and professional networks contribute to business firms' own problem-solving activities.

In a broad view, science (i.e. higher education and public sector research establishments) contribute to innovation in industry through four major channels:

- Industry receives inputs from science in the form of well-trained individuals. Although these individuals may require further training (which may also be supplied by higher education institutions), university education is the backbone of the production of human capital engaged in research activities at firms. Personnel mobility of researchers between science and industry (and vice versa) contributes not only to the dissemination of codified knowledge but also to the exchange of tacit knowledge.

- Knowledge produced at science institutions is disseminated as codified knowledge through publications, conferences and patents and serves as a stock of knowledge which is available to the public and might be used by industry as a public good input to commercial research. However, the use of the "public good" knowledge requires certain adoption and absorptive capacities. Thus, the increasingly complex and specialised nature of modern science makes it difficult to use potential fruitful knowledge, especially by SMEs.

- Universities and public research institutions are increasingly involved in cooperative R\&D projects with industry. Although these collaborations take on various types, they are all characterised by an exchange of knowledge among participants, with science usually in the role of the most important supplier of basic knowledge.

- In recent years, the creation of technology-based enterprises by researchers from science or by graduates received increasing attention (see OECD 2000b, Bania et al. 1993). So-called academic start-ups or spin-offs are regarded as an important instrument for rapidly transferring new technological developments and innovative business ideas created at the science side into commercial use.

The intensification of the interaction and co-operations between universities and industry presently to be observed (see Schmoch 1999, Hicks 2000, OECD 2000) owes much to the following two, interrelated factors:

- Increasing budgetary stringency forces policy makers to make tough choices in the allocation of resources which affect the science system. Universities and other public research institutions are forced to seek external sources of income and are thereby encouraged to carry out research work financed by industry. Indeed there is a clear trend of a growing share of funding of HERD by the business sector while the total public share is steadily declining. 
- At the same time, growing "knowledge intensification" (see OECD 1996) of industrial production makes scientific knowledge more valuable to industry. So called "science-based technologies" (biotechnology, information technologies, new materials) are defined as fields with frequent references to scientific knowledge. This trend is also indicated by a growing number of citations of scientific literature in patent documents (Schibany et al. 1999).

In practice, the contributions of science to innovation and the relations between research institutions and enterprises are not as straightforward as a linear view of the innovation process would imply: The functioning of the science system is governed by rationales and different institutional settings different to those prevailing at the enterprise sector. Furthermore, there are considerable differences between national science systems resulting in divergent missions and attitudes towards the role of science in innovation and industrial competitiveness. Depending on these national designs of innovation systems, the exchange of knowledge between science and industry takes place through different channels and is affected by various factors - not all of them necessarily functioning smoothly.

Table 1. HERD by Funding Source 1983 - 1997 for 7 EU countries (in \%)

\begin{tabular}{|c|c|c|c|c|c|c|c|}
\hline & $\begin{array}{c}\text { Total } \\
\text { public } \\
\text { share }\end{array}$ & $\begin{array}{c}\text { General } \\
\text { university } \\
\text { funds } \\
\text { (GUF) }\end{array}$ & $\begin{array}{c}\text { Direct } \\
\text { government } \\
\text { funds }\end{array}$ & Foreign & Business & $\begin{array}{c}\text { Other } \\
\text { Income }\end{array}$ & $\begin{array}{c}\text { Private } \\
\text { non-profit } \\
\text { orga- } \\
\text { nisations }\end{array}$ \\
\hline 1983 & 94.0 & 68.3 & 25.7 & 0.6 & 2.9 & 1.1 & 1.5 \\
\hline 1985 & 92.7 & 65.2 & 27.5 & 0.7 & 3.7 & 1.3 & 1.7 \\
\hline 1989 & 89.9 & 60.2 & 29.7 & 1.4 & 5.4 & 1.2 & 2.1 \\
\hline 1991 & 89.4 & 61.7 & 27.7 & 1.6 & 5.5 & 1.2 & 2.3 \\
\hline 1993 & 87.7 & 60.1 & 27.6 & 2.5 & 5.8 & 1.4 & 2.7 \\
\hline 1995 & 85.6 & 59.0 & 26.6 & 3.2 & 5.7 & 1.8 & 3.7 \\
\hline 1997 & 84.6 & 57.9 & 26.8 & 3.5 & 6.4 & 1.7 & 3.8 \\
\hline
\end{tabular}

a Higher education expenditures on research and development

b Denmark, France, Germany, Italy, Ireland, the Netherlands, the UK; figures represent the weighted average.

Source: OECD $(1998,2000)$, calculations by the authors

\section{Universities as source of information and co-operation partners}

Within the scope of the development process, enterprises use a variety of information sources. They use this information in different ways, among other things, to be able to improve the judgement of current market situations, to find solutions for technological problems, to find relevant suppliers, to improve the integration of customer needs, to analyse developments achieved by competition, etc. As may be derived from the Community Innovation Survey (CIS), universities are considered as an important source of information in the course of the innovation process only in a minority of cases. In 
1996, only between 3 and 4 per cent of innovative enterprises use public science, i.e. universities and public research labs, as an important information source in their innovation projects. Compared to internal sources (e.g. in-house R\&D, information from marketing departments, enterprises within the own firm group) and to market stimuli (clients, competitors, suppliers), public science plays no major role for driving innovation activities in the majority of enterprises. This patterns is a robust finding throughout the EU member states.

However, universities as well as public research labs are more important as a cooperation partner in innovation projects, e.g. to carry out certain types of $R \& D$ even if the information source for starting and directing an innovation comes from other sources. Figure 3 reveals that science is of almost the same significance as co-operation partner in innovation as are suppliers or clients. Nevertheless, only 6 to 10 per cent of all innovative enterprises in Europe (in the reference period 1994 to 1996) have carried out innovation activities in co-operation with science, whereby the co-operation may take a variety of forms and need not be restricted to collaborative research.

\section{Figure 3: Information Sources and Co-operation Partners in Innovation: Results from the CIS}
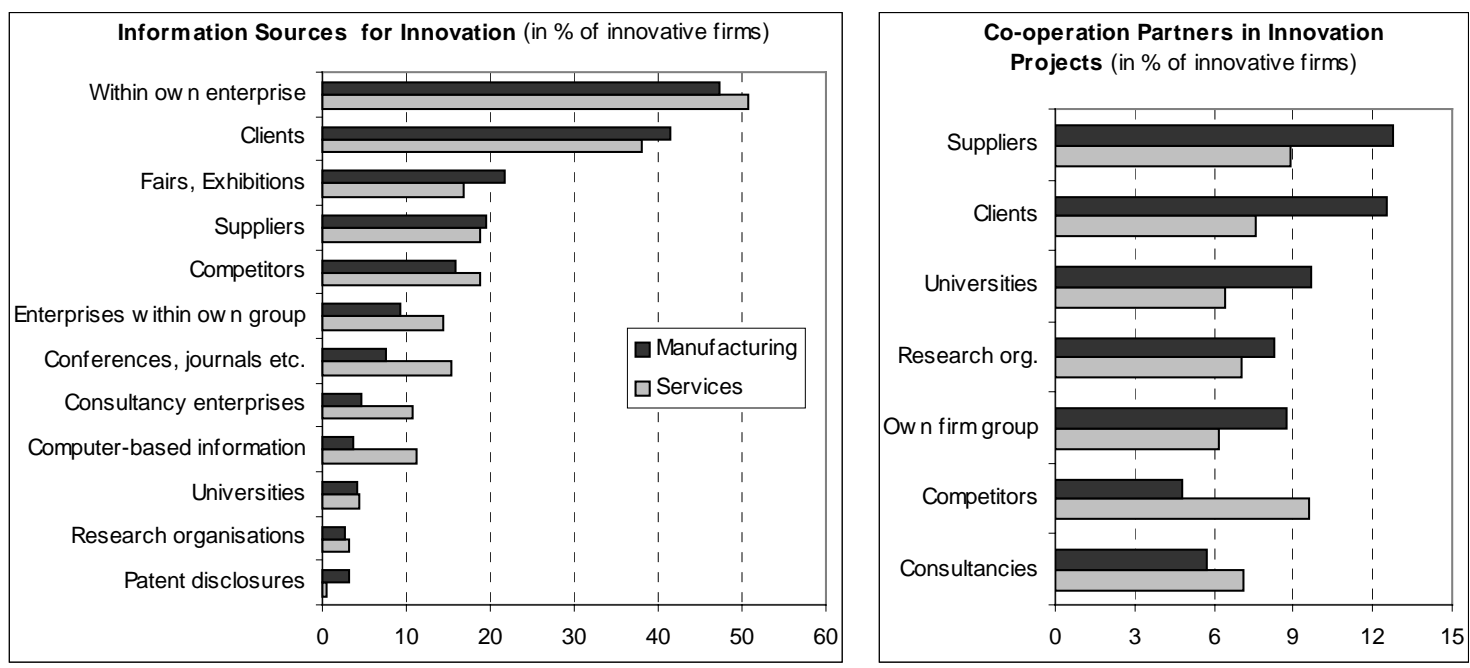

Source: Eurostat New Cronos (CIS2), all EU-countries, calculation by the authors

\subsubsection{The benchmarking approach}

As was mentioned before, the linkages between science and industry, and the effectiveness and efficiency of these linkages for a smooth exchange of knowledge and successful innovation, are many-facetted and notoriously difficult to measure and evaluate. Historical development, cultural and social attitudes, political decisions and objectives, institutional settings and economic specialisation and structures result in a country-specific pattern of industry-science relations (ISR). These country-specific features cannot be captured accurately by a single set of quantitative indicators. Consequently, these different national settings make it extremely difficult to compare the structure and performance of ISR by a single analytical method such as for example, 
econometric modelling. In particular, one has to take into account the very different framework conditions for ISR. In order to capture the variety of these framework conditions and their impact on ISR performance, a benchmarking approach seems appropriate. Benchmarking ISR thus attempts to provide insights in how to improve relations within a national system of innovation in order to increase innovation performance and, in the end, industrial competitiveness. ${ }^{13}$ However, within a benchmarking approach a detailed analysis of both structural characteristics and policyrelated framework conditions in areas with a high performance in ISR allows the identification of good practices which depend upon specific barriers and incentives prevailing in a certain national innovation system (see Figure 4).

Figure 4: A conceptual model for analysing industry-science relation

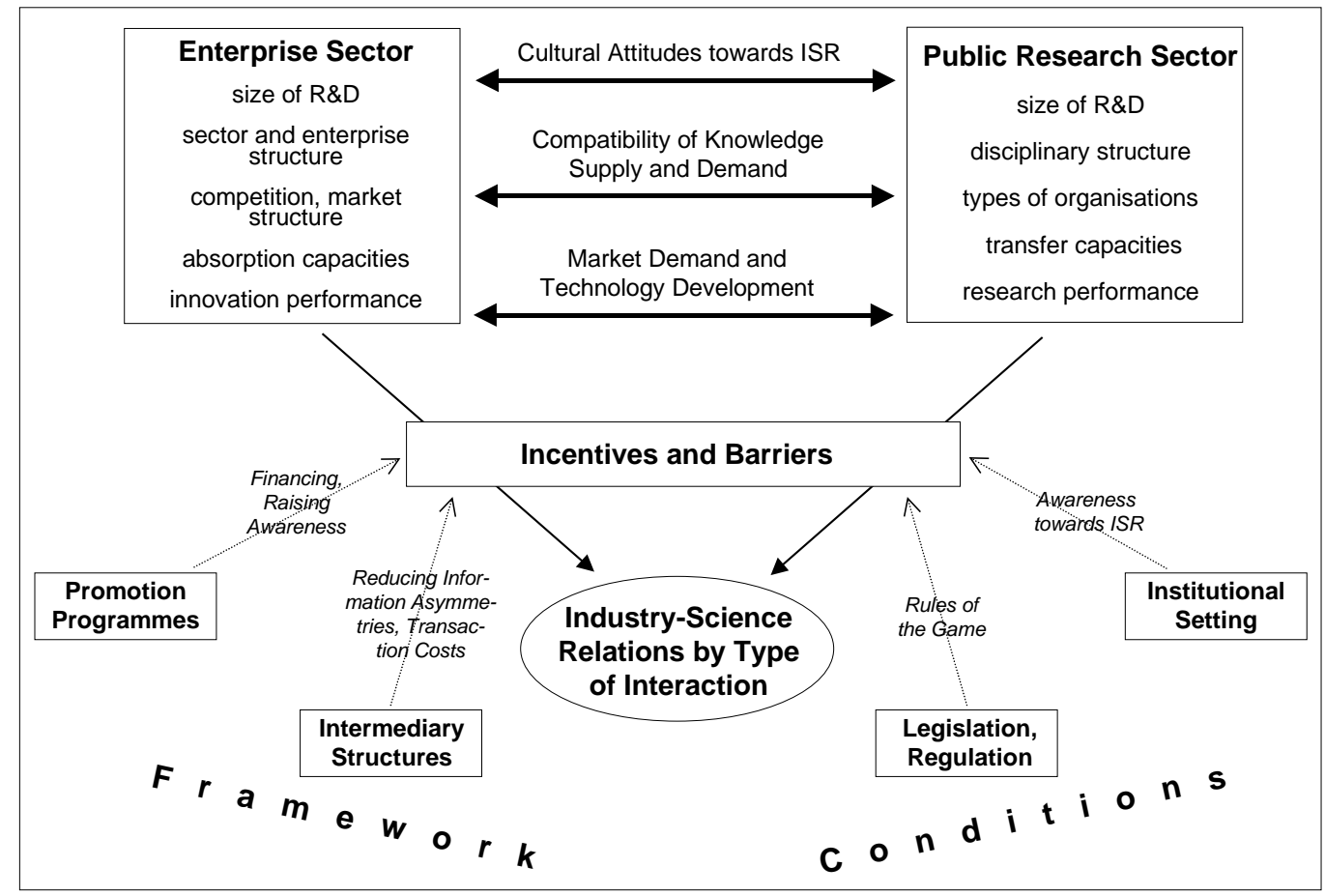

Source: Polt et al., 2001a

The model developed refers to a market conceptualisation of ISR, i.e. ISRs are regarded as the result of market decisions by the various actors on the "knowledge market". The knowledge market is characterised by high information asymmetries and low market transparency; high transaction costs (because of the need for transfer and absorption capacities); high spill-overs and a relatively low level of private returns from knowledge acquired; restrictions on investment in knowledge production and exchange due to riskaverse and short-term oriented financial markets; indivisibilities and the existence of joint products; and sometimes a need for reciprocal interaction and collaborative production of knowledge (see Foray 1994, David and Forray 1995, Foray and Lundvall 1996, Machlup

\footnotetext{
${ }^{13}$ The following is the result of a benchmarking study commissioned by the European Commission, DG Enterprise and the Austrian Federal Ministry of Economy and Labour (see Polt et al., 2001a; Polt et al., 2001b).
} 
1980). These features result in peculiar incentive structures and barriers to market interaction, and emphasise the importance of policy-designed framework conditions which compensate for market failures and stimulate knowledge transfer.

\section{Channels of interactions}

Recent work has shown that there are very different types of knowledge exchanged in innovation processes, and that there are differences in the effectiveness of various kinds of channels for exchanging a certain type of knowledge (see Foray 1997, Gibbons et al. 1994, Lundvall 1988). Therefore, both industry and science typically use a broad set of channels when interacting with each other. The relative importance of the channels varies with the type of innovation activity carried out, the type of knowledge demanded, the absorption and transfer capacities at enterprises and science, the type and extent of market failures prevailing on the knowledge market etc. (see Saviotti 1998, Smith 1995). Due to comparison, types of interactions that involve some degree of formalisation should be used, as well as personal interactions which may affect the transfer of tacit knowledge.,Many studies exhibit the transfer of tacit knowledge as a critical factor for learning and successful innovation (see Schmoch 1999, Abramson et al. 1997, Schartinger et al. 2001a, Brooks 1994). Based on OECD data, data from the Community Innovation Surveys, as well as assessments by national experts the following variables were used to measure the various channels of interactions:

- Collaborative research

- Contract research and technology related consulting

- Personnel mobility between firms and public science institutions

- Co-operation in the education of graduate students

- Vocational training for employees

- Use of Intellectual Property Rights (IPRs) by public scientific organisations

- Start-ups of technology-oriented enterprises by researchers from public scientific organisations

- Informal contacts and personal networks

\section{Characteristics of the main actors}

The structure and performance of the enterprise sector is expected to determine the demand for ISR. In particular, we considered the composition of sectors (i.e. the specialisation on high-tech sectors which may rely heavily on new scientific knowledge generated by academia), enterprise structure (relevance of large corporations versus SMEs, relevance of foreign-owned enterprises), market structures within each field of technology (degree of competition, level and quality of demand), absorptive capacities (i.e. skills, innovation management capabilities of enterprises), and the level of innovation activities with respect to the specialisation on certain stages in the innovation cycle. A low R\&D potential and an unfavourable structural setting for innovation activities will reduce the demand for scientific knowledge and thus the relevance of ISR for the enterprise sector. 
The structure and performance of the public science sector determines knowledge supply and knowledge transfer capacities. Major variables in this respect are the disciplinary structure (i.e. the share of different scientific disciplines in total research activities), the types of organisations (relevance of various types of public research institutions such as universities, polytechnic colleges, public research labs, joint industry-university labs, as well as the relation between civil and military research), the transfer capacities covering the research orientation and research mission (long-term, pure basic research, oriented basic research, short-term applied research) as well as the mode of financing, personnel qualification and staff capacities, and the research performance with respect to scientific excellence.

The level of ISRs is strongly affected by the extent to which demand for knowledge interaction and absorptive capacities at industry side meets knowledge supply and transfer capacities at the science side. Here, the congruence between technology specialisation in the enterprise sector and disciplinary structures at the science side plays a crucial role. Furthermore the specialisation of enterprises within the innovation cycle (i.e. on invention, adaptation, diffusion and product differentiation stages) and the orientation of research performance at science on industry needs affect the level of ISRs. Market demand and technology development trends in the various fields of technology play also a major role as they represent major information sources and competitive pressures for firms to direct and strengthen their innovation activities. Finally, cultural and social attitudes towards the role of science in society and the degree to which science should orient towards technology transfer to industry and adjust its scientific efforts and themes of research on industry needs, which may be regarded as a particular feature of a national innovation system and not directly changeable by policy measures.

A match of knowledge supply and demand provides a necessary condition for establishing ISRs in innovation activities. The extent to which this potential is utilised depends on the working of incentive structures and barriers inside an innovation system and the way they influence the behaviour and decisions of market actors. Figure 5 shows major incentives for and barriers to ISRs in the enterprise sector, in the public research sector, and in the relation between both sectors.

The main incentives are of course the income for public research institutions out of research collaboration with enterprises, and the access to knowledge for enterprises which may act as a competitive advantage. Other incentives refer to the field of education and personnel recruitment, network building, and mutual learning. The barriers to ISRs rest on certain behavioural features of the market actors (such as risk-averse behaviour, idiosyncratic behaviour, innovation management capabilities), on market inefficiencies (such as lack in qualified personnel or in financing sources), on market failures (information asymmetries, lack in transparency, transaction costs, spillovers, uncertainty etc.), and on incentive structures unfavourable for ISRs (such as evaluation solely oriented towards academic criteria, short-term orientation in enterprise strategies due to short-term oriented financial markets). 
Figure 5: Incentives for and Barriers to ISRs

\begin{tabular}{|c|c|c|}
\hline Enterprise Sector & $\begin{array}{l}\text { Relations } \\
\text { Incentives }\end{array}$ & Public Research Sector \\
\hline $\begin{array}{l}\text { - Access to knowledge, absorption of new } \\
\text { knowledge } \\
\text { - Access to complementary R\&D resources } \\
\text { - Reducing costs for in-house R\&D } \\
\text { - Access to innovate networks and clusters } \\
\text { - Use of special R\&D infrastructure } \\
\text { - Opening-up new business fields } \\
\text { - Recruitment of R\&D personnel }\end{array}$ & 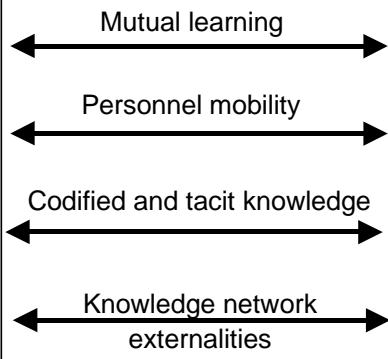 & $\begin{array}{l}\text { - Securing and diversifying the financial and } \\
\text { personnel basis } \\
\text { - Extra earnings for researchers } \\
\text { - New impulses for research and education } \\
\text { - Improvement of research infrastructure } \\
\text { - Better labour market opportunities for } \\
\text { graduates }\end{array}$ \\
\hline & Barriers & \\
\hline $\begin{array}{l}\text { - Lack in knowledge absorption capacities } \\
\text { and innovation management capabilities } \\
\text { - Reluctance to use external knowledge } \\
\text { - Risk -averse behaviour, short-term } \\
\text { orientation in business strategies } \\
\text { - Lack in qualified personnel } \\
\text { - "Not invented here" behaviour } \\
\text { - Fear of loosing confidential knowledge } \\
\text { - Market entry barriers for new enterprises }\end{array}$ & $\begin{array}{l}\text { Information asymmetries } \\
\text { low market transparency } \\
\stackrel{\text { divergent "cultures " }}{\text { Incompatible objectives, }} \rightarrow \\
\underset{\text { Hinh transanction costs, }}{\text { Uncertainty of outcome, }} \rightarrow \\
\text { large spillovers }\end{array}$ & $\begin{array}{l}\text { - Evaluation of research solely oriented } \\
\text { towards academic criteria } \\
\text { - "Freedom of research" regarded as ruling } \\
\text { out industry-oriented research } \\
\text { - High teaching and administration duties } \\
\text { - Bureaucratic regulations, civil servants law } \\
\text { - No rewards for commercialising research } \\
\text { results } \\
\text { - Risk-averse behaviour }\end{array}$ \\
\hline
\end{tabular}

Source: Polt et al. (2001)

\section{Public Framework conditions}

Some incentives and barriers are the direct result of certain publicly designed framework conditions such as institutional settings, evaluation procedures, market regulations, and legislation on ISR-relevant issues. At the same time, policy attempts to reduce market failures, remove barriers to knowledge interaction, and thus stimulate ISR. Thus several policy-related framework condition affect the actors' behaviour (see also Figure 4):

- Legislation and regulation may act as incentives encouraging ISR (e.g. transferoriented regulation of intellectual property) but may also impede ISR (e.g. civil servants law that complicates personnel mobility).

- Public promotion programmes often provide financial resources for ISR and compensate for market failures on the knowledge market. Furthermore, programmes attempt to raise public awareness towards ISR and change individual behaviour and attitudes unfavourable for ISR.

- Intermediary structures should facilitate ISR by raising awareness, reducing transaction costs, and supporting transfer activities. They cover both physical and organisational infrastructure such as transfer (liaison) offices, technology centres, incubators, consulting networks, and data-bases.

- Institutional settings in higher education and public research establishments determine incentives and barriers for public sector researchers to engage in ISR and may include evaluation criteria and procedures, individual remuneration, 
financing sources, institutional missions, organisational cultures, recruitment policies, administrative support etc.

\subsubsection{ISR in the European context}

In Europe there is an increasing perception of a gap between a high scientific performance and a deteriorated industrial competitiveness, labelled as the "European paradox" (see Pavitt 2000). If science matters in economic development, a decline in competitiveness raises questions as to whether science fails to make the kinds of contributions on which advanced industrial economies have become increasingly dependent, whether industry lacks the ability to use effectively the new knowledge produced in the science sector, or whether there are barriers to, or a lack in incentives for ISR.

It is common among policy makers in the field of innovation to make reference to the paradox, through the comparison of science and technology indicators for USA, Japan and the European Union: although in Europe the number of publications relative to public R\&Dspending is comparable to that of the USA and Japan, the return of that investment, measured in terms of patents, is low. This has led to the conclusion that "one of Europe's major weaknesses lies in its inferiority in terms of transforming the scientific and technological potential into viable innovations" (Greenbook of Innovation, 1996). Usually the technological gap between Europe and the USA and Japan is shown in terms of the following indicators (see Table 2).

Table 2: Main R\&D indicators of the Triad

\begin{tabular}{lccc}
\hline & USA & Japan & EU \\
\hline RTD in percent of GDP (1997) & 2,71 & 2,92 & 1,83 \\
$\begin{array}{l}\text { Scientists per 1000 employees (1996), (USA: 1993) } \\
\text { Public R\&D expenditure as a share of business R\&D }\end{array}$ & 14,4 & 9,2 & 5,0 \\
$\begin{array}{l}\text { (1998) } \\
\text { Business R\&D in percent of GDP (1997), (USA: }\end{array}$ & 2,08 & 2,1 & 9,2 \\
$\begin{array}{l}\text { 1998) } \\
\text { Patent applications per 10.000 inhabitants (1997) }\end{array}$ & 4,5 & 7,0 & 2,14 \\
Share of patent applications at the EPA (1997) & 28,1 & 17,6 & 46,1 \\
\hline \multicolumn{1}{c}{ Source: OECD } & & & \\
\hline
\end{tabular}

Source: OECD

While using publications as an indicator which measures the scientific output, the following shows that several European countries are above the US and Japan. Except for UK and Netherlands, this group of countries also scores a growth rate of number of scientific publications above the USA, moreover the US decline in number of publications and its negative growth rate are quite remarkable. 
Figure 6: Scientific output

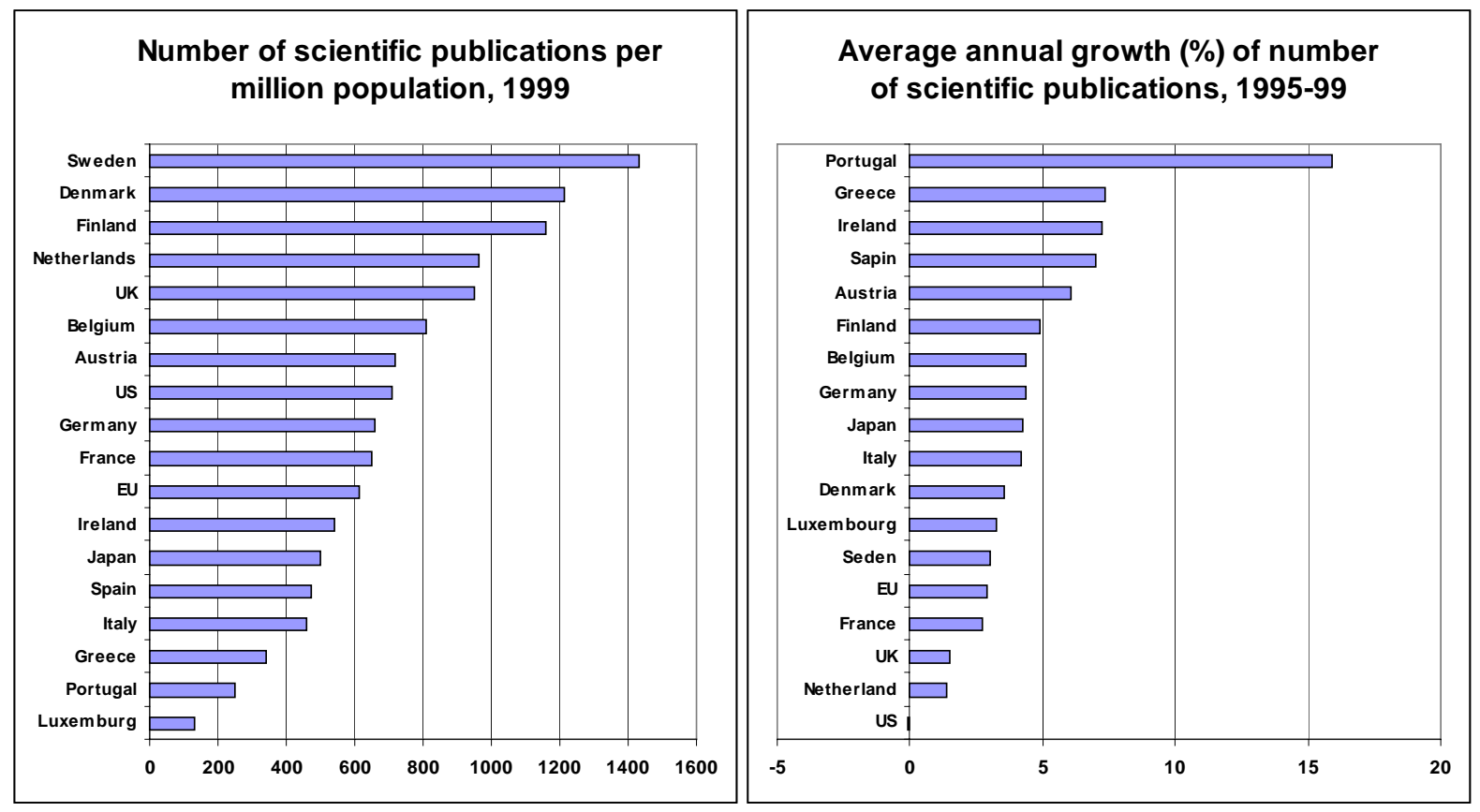

Source: NSIOD

However, one should bear in mind that the European Paradox is a bit more complicated than a simple weakness of transforming scientific results into innovation. As was pointed out by Pavitt (2000) it is more revealing to mention the differences in the various scientific disciplines (OST, 2000). EU-15 has its strongest publication performance compared to the USA in the well-established disciplines of chemistry and physics, whilst the strongest US performance is the recently established disciplines of molecular and cellular biology, biomedical engineering, and informatics. These are the very disciplines that are the basis of the US strengths in biotechnology and ICT, and their development has been strongly supported by scientific research in these fields. Moreover, a simple lack of transformational capability implies a linear correlation between science and technology which is not adequate in this context.

However, the Framework Programmes were launched by the EU as a targeted programme for improving industrial competitiveness through the mechanism of co-funded research. Using the mechanism of collaborative research the objective was to link up the diverse and complementary technical and scientific capabilities of companies, universities and research laboratories in European countries in pursuit of common technological goals. However, the most important effect of the FWPs is that they have gradually become the driving force behind the formation of dynamic networks which go beyond formal collaboration since they bring together researchers from the best laboratories in European firms and give private firms the opportunity to benefit from a larger pool of resources than is available in only one single European nation. They have unquestionably fostered the emergence of closer linkages and the creation of a critical mass through networking. In addition, they provide stable financial support, reduce unnecessary competition among researchers and between researchers and industry, and provide access to complementary skills, means and tools (Vavakova, 1995; Lucchini, 1998). EU policy aimed at promoting 
networking has materialised solely through the funding of these research consortia. The success of this policy instrument (at least at that level) has prompted the EU to adopt additional measures in this direction: the establishment of multiple transnational networks for technology transfer and dissemination (CEC, 1994) has recently become a key policy tool. Moreover, EU funding of R\&D collaboration among organisations throughout Europe remains the major policy instrument for the promotion of networking, with positive effects notably for SMEs (Caloghirou and Vonortas, 2000).

\section{Cross-sector collaboration patterns in the Framework Programme}

Since the early 1990s, several impact studies of the EU Framework Programmes have been carried out in EU member countries. Although different in their methodological approaches most of the studies have shown, among other conclusions, that EU research programmes have been successful in promoting cross-sector collaboration, strengthening the science base and promoting the education and training of young scientists and engineers (Luukkonen, Niskanen 1998; Peterson, Sharp 1998; Luukkonen, Hälikkä 2000; Schibany et al. 2001).

Within the Framework Programme relationships between industry and academia/public research labs are important because they offer an important avenue for the interaction among knowledge-exploiting (companies) and knowledge-producing (universities and research centres) organisations around research agendas of common interest. As part of the trend towards the internationalisation of research, Framework Programmes represent a useful vehicle to carry out transnational and multisectoral RTD-joint ventures. Although it is fair to say that this matter is not really well explored some studies show distinct patterns of project consortia.

The recent Finnish evaluation study (Luukkonen, 2000) shows that in the Fourth FP, as many as $64 \%$ of the projects with Finnish participants involved company and university, or company and research centre, collaboration. When looked from the point of view of companies $70 \%$ of the companies collaborated with an university and $75 \%$ with a research centre in their EU project. Compared with the results of the CIS II which show a much lower cooperation intensity between companies and universities in Finland it can be concluded that EU FP projects effectively promote cross-sector collaboration.

Using an extensive databank ${ }^{14}$, which covers all five FPs Caloghirou et al. (2000) investigates university-industry collaboration in the EU FPs. The databank contains information on European cross-national R\&D co-operation established through the FPs covering those programmes with a focus on industrial research. In order to find significant difference between Research Joint Ventures (RJVs) including universities and those without universities a binary probit regression model was estimated with the following results:

- The data indicate an increasing trend of the involvement of universities in RJV with the focus on industrial research over time.

- Universities tend to participate more in larger and longer-term RJVs due to the more basic nature of the research they undertake.

\footnotetext{
${ }^{14}$ The databank was built within the TSER project STEP TO RJVs. See Caloghirou, Y.D. and N. Vonortas (2000) for further descriptions of the databank.
} 
- Universities have been very active, participating in more than fifty percent of RJVs in all but one technology areas, the highest rate being in the area of biotechnology (92\%). This result is approved by the finding of Luukkonen (2000) indicating that in industrial technologies, nearly one hundred percent of the project had cross-sector collaboration in the fourth FP. In other programmes like the environment programmes the proportion was only $35 \%$.

- The country dummy in the model show that the possibility involving a university as a project co-ordinator from Europe's peripheral countries like Greece or Ireland is higher than from the core countries. This result goes along with the results of Geuna (1998) indicating that universities from Greece and Ireland have an advantage on the level of participation that can be interpreted as a result of the policy objectives of the European Commission in terms of technological and economic convergence among member states.

\section{Determinants of university participation in the FP}

Different capabilities to join in EU collaboration and university-industry collaboration are present at various universities and even departments. However, most of the impact studies (see e.g. Niskanen 2001; Schibany et al. 2001) exhibit that previous experience in international research collaboration is an important factor in explaining the unit's level of activity in EU research programmes. University institutes participating in EU FP programmes are evidently more internationally oriented. Further, it can be assumed that these existing contacts and co-operations with foreign university partners are an important basis for the materialisation of cooperative (and likewise multi-nationallyoriented) EU projects. About $72 \%$ of Austrian university institutes participating in the EU FP said that in the past the cooperated frequently or very frequently with foreign universities while a mere of $5 \%$ of university institutes never had or only rarely had cooperative relationships with foreign universities (Schibany et al. 2001). With regard to collaboration between universities and business existing collaboration experience is more focused on collaboration with domestic companies than on foreign. This goes hand in hand with existing studies of the interactions between the scientific- and business sectors stating that such interactions require long-term mutual trust that is also based on different kinds of interactions (personal contacts, common research projects, expertise, etc.). This is of course easier to build up with domestic firms, as the transaction costs are of course lower.

\section{Impacts of the participation in the FP}

It is the final goal of every national impact study to establish the programme effects at the national economy and society levels as well as the level of national politics. However, estimating the effects on the macro level is particularly demanding from a methodological standpoint. Firstly, there is a multitude of influencing factors at various levels. Secondly, the methods to record and evaluate these influencing factors are inaccessible. Thirdly, in programmes of relatively low volume (in comparison to total economic magnitudes like value added and employment) it must be considered whether or not such effects actually breach the threshold of perceptibility. 
"Macro impact is very likely to be lost in the noise of effects arising from other inputs to RTD and the stages beyond." (Georghiou, Bach, 1998)

Table 3 shows effects to be considered when one want to arrive at real net effects at the total economic level from an observation of gross effects at the participant level:

Table 3: The calculation of economic net effects

\begin{tabular}{|ll|}
\hline Private, gross effects at the participant level \\
\hline$+/-$ & Indirect effects (intended and unintended) \\
- & Entrainment effects \\
$=$ & Private net effects \\
+ & Spill-overs (effects on non-participants) \\
- & Replacement effects \\
\hline
\end{tabular}

Source: Schibany et al. (2001)

Such net effects can be measured using two methods:

- First, the relationship between research spending and output magnitudes can be measured with macro-economic production functions. Regardless of the fact that externalities cannot be recorded in this way, there are many objections with respect to the usability of this concept when it comes to the effect of public research spending, more so with comparatively smaller programmes in relation to remaining public and private research spending. (see e.g. Georghiou and Roessner 2000).

- Secondly the attempt can be made to measure the social and total rates of return from research expenditures and from the investment in certain technologies. In the process, consumer and producer incomes are ascertained and added. This method assumes that demand and supply curves can be constructed and that they vary based on the observed investments in research and technology. Regardless of the fact that it is difficult to completely evaluate externalities, the calculation of supply and demand curves is only possible with much effort for little technological investment - the effects of basic research or from completely new products and processes cannot be recorded in this way (see e.g. Cozzens et al. 1994).

The main question at the centre of every impact study is: to what extent are the measurable effects really the result of the programme, i.e. causally attributable to participation in the program?

This question is anything but trivial especially in contexts with mostly intangible programme goals like increasing competence and the formation international networks. For instance a participant can report that a project was a total failure in regard to the technological targets of the research project. Still, a new partner was met in the process and in subsequent activities with that partner a highly successful product has been developed and marketed. The problem of attribution has different aspects. The following graphic attempts to display this: 


\section{Figure 7: The problem of attribution}

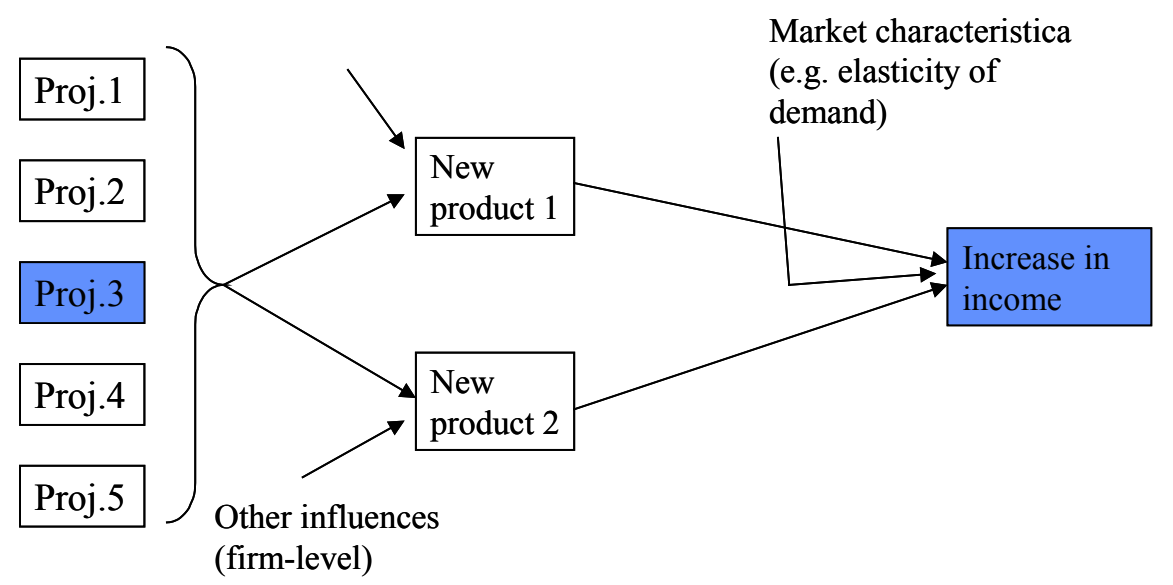

- First, EU research projects frequently turn out to be one of many projects within a company's research portfolio. If these projects are complementary then new products or processes resulting from research activities are hard to attribute to this one project.

- Second, indirect effects can play a major role. While direct effects are directly related to the programme goals, indirect effects come about when the effects go beyond the programme goals - for instance when the research project enhances the reputation of the firm or contributes to improvements in management. These can lead to an improvement in the company's competitive position.

- Third, rising turnover, increased value added or cost savings are generally the result of multiple influences both internal and external to the firm. The research activities themselves are generally only a small part of these. Whether or not an improved process or a successfully introduced new product lead to a mid-range increase in value-added is, for instance, greatly dependent upon how quickly competitors react to the new situation or the level of demand elasticity.

\section{Some general conclusions}

The paper has shown that the theoretical concepts of how to measure the impact of academic research have changed over time. Most of the econometric studies found a positive rate of return, and in most cases the figure has been comparatively high. However, these attempts have been beset with both measurement difficulties and conceptual problems such as the assumption of a simple production function model of the science system.

New approaches have found different forms of economic benefits from basic and academic research and that there are several other forms of benefits. This has changed the traditional justification for the public funding of basic research, which is based on the role of basic research as a source of new useful knowledge, especially in codified form. Industry-Science Relations (ISR) have thus gained increasing attention in the last two decades. Based on the analysis of specific knowledge transfer mechanism scientific knowledge is viewed as a major input for technological advance. Smooth interaction between firms and the science system is regarded as a major element in innovation. However, industry-science relations are to a certain extent determined by a set of policy- 
related framework conditions, which may influence the level, effectiveness and efficiency of knowledge exchange between public science and industry. Within the benchmarking approach key questions are concerned whether there are certain framework conditions that impede a smooth interaction and which type of framework condition facilitate ISR. This approach involves the identification of the key elements shaping ISR, the definition of key performance indicators, and the systematic comparison of national experiences in order to identify good practices and to learn from the way ISR work in other countries. Thus it goes beyond the mere comparison of performance indicators, trying to describe, analyse the systematically compare the processes that lie behind performance differences. The final part of the paper presents some evidence of the role and determinants of the participation of universities in the Framework Programme of the EU. It addresses the importance of EU collaboration and states that the impact of cooperation on the European level becomes more and more important. 


\section{References For Section 2.3}

Abramson, H.N., J. Encarnacao, P.R. Reid, and U. Schmoch /eds. (1997): Technology Transfer Systems in the United States and Germany. Lessons and Perspectives, Washington: National Academy Press.

Acs Z., F. Fitzroy, I. Smith (1994): High Technology Employment and University R\&D Spillovers: Evidence from US Cities. Paper presented at the 41st North American Meetings of the Regional Science Association International, Niagara Falls.

Almeida, P., Kogut, B. (1995): The Geographic Localization of Ideas and the Mobility of Patent Holders; Paper presented at the Conference on Samll and Medium-Sized Enterprises and the Golbal Economy. Organized by CIBER, University of Maryland, October 20, 1995.

Anselin L., A. Varga, Z. Acs, (1997): Local Geographic Spillovers Between University Research and High Technology Innovations. Journal of Urban Economics (forthcoming).

Arrow, K.J. (1962): Economic Welfare and the Allocation of Resources for Inventions; in: Nelson, R. (ed.) (1962).

Bania N., R. Eberts, M. Fogarty, (1993): Universities and the Startup of New Companies: Can We Generalise from Route 128 and Silicon Valley? The Review of Economics and Statistics 75, 761-766.

Bania N., L. Calkins, R. Dalenberg,, (1992): The Effects of Regional Science and Technology Policy on the Geographic Distribution of Industrial R\&D Laboratories, Journal of Regional Science 32, 209-228.

Bernstein, J., Nadiri, I. (1988): Interindustry Spillovers, Rates of Return, and Production in HighTech Industries; in: American Economic Review: Papers and Proceedings (Vol. 78, pp. 429-434.

Bernstein, J., Nadiri, I. (1991): Product Demand, Cost of Production, Spillovers, and the Social Rate to R\&D; in: NBER Working Paper Series, Working Paper No. 3625.

Brooks, H. (1994): The Relationship Between Science and Technology; in: Research Policy 23, $477-486$

Caloghirou, Y., A. Tsakanikas. N.S. Vonortas (2001): University-Industry Co-operation in the Context of the European Framework Programmes; in: Journal of Technology Transfer 26 (1/2), pp. 153-161.

Caloghirou, Y.D. and N. Vonortas (2000): Science and Technology Policies Towards Research Joint Ventures, Final Report to the Commission, DGXII, TSER Programme.

CEC (1994): Good Practice in Managing Transnational Technology Transfer Networks, 10 years of Experience in the Sprint Programme", CEC DG XIII.

Christensen, J.L., Rogaczewska, A.P., Vinding, A.L. (1999): Synthesis Report of the Focus Group on Innovative Firms and Networks; http://www.oecd.org/dsti/sti/s t/inte/index.htm, OECD, Paris.

Cozzens, S., et al. (1994): Methods for Evaluating Fundamental Science, RAND/CTI DRU875/2-CTI, Washington DC.

Dasgupta, P., David, P. (1994): Toward a new economics of science; in: Research Policy 23 (1994), pp. 487-521.

David, P., Mowery, D., Steinmueller, W. (1994): Analysing the Economic Payoffs from Basic Research; in: Mowery, D. (1994). 
David, P.A. and D. Foray (1995): Accessing and expanding the science and technology knowledge base; STI-Review 16, 13-68.

Dodgson, M., Rothwell, R. (1994): The Handbook of Industrial Innovation; Edward Elgar.

Edquist, C. (1997): Systems of Innovation, Pinter Publishers, London and New York.

Foray, D. (1994): Production and Distribution of Knowledge in the New Systems of Innovation: the Role of Intellectual Property Rights, STI-Review 14, 119-152.

Foray, D. (1997): Generation and Distribution of Technological Knowledge: Incentives, Norms and Institutions; in: Edquist, C. (ed.), Systems of Innovation: Technologies, Institutions and Organizations, London: Pinter, 65-85.

Foray, D., and B.-Å Lundvall (1996): The Knowledge-Based Economy: from the Economics of Knowledge to the Learning Economy, in: OECD (ed.) Employment and Growth in the Knowledge-based Economy, Paris.

Georghiou, L., Bach, L. (1998): The Nature and Scope of RTD Impact Measurement; Brussels.

Georghiou, L., Roessner, D. (2000): Evaluation Technology Programmes: tools and methods; Research Policy 29, 657-678.

Geuna, A. (1998): Determinants of university participation in EU-funded R\&D cooperative Projects; Research Policy 26, 677-687.

Geuna, A. (1999): The Changing Rationale for European University Research Funding: Are there Negative Unintended Consequences, SPRU Electronic Working Papers Series, No. 33, Brighton, UK.

Gibbons, M., C. Limoges, H. Nowotny, S. Schwartzman, P. Scott, and M. Trow (1994): The New Production of Knowledge. The Dynamics of Science and Research in Contemporary Societies, London: Sage.

Goto, A., Suzuki, K. (1989): R\&D Capital, Rate of Return on R\&D Investment and Spillover of R\&D in Japanese Manufacturing Industries; in: Review of Economics and Statistics Vol. 71, pp. 555-564.

Griliches, Z. (1992): The Search for R\&D Spillovers; in: Scandinavian Journal of Economics, Vol. 94, supplement, pp. 29-47.

Griliches, Z. (1995): R\&D and Productivity: Econometric Results and Measurement Issues; in: Stoneman, P. (ed.) (1995).

Hicks, D., Isard, P., Martin, B. (1993): University-Industry Alliances as Revealed Joint Publications, Mimeo, SPRU.http://www.sussex.ac.uk/spru/

Hicks, D. (2000): Using Innovation Indicators for Assessing the Efficiency of Industry-Science Relationships. Paper presented at the Joint German-OECD Conference "Benchmarking Industry-Science Relations", Berlin, 16-17 October, 2000.

Jaffe, A., M. Trajtenberg, R. Henderson (1993): Geographical Localization of Knowledge Spillovers as Evidence by Patent Citations, Quarterly Journal of Economics 58, 577-598.

Jaffe, A.B.(1996): Economic Analysis of Research Spillovers: Implications for the Advanced Technology Program. http:/www.atp.nist.gov/www/eao/gcr708.htm.

Kelly K., J. Weber, J. Friend, S. Atchinson, G. DeGeorge, W. Holstein (1992): Hot Spots. America's New Growth Regions are Blossoming Despite the Slump, Business Week October 29, 80-88. 
Klevorick, A.K., R.C. Levin, R.R. Nelson, S.G. Winter (1993): On the Sources and Significance of Interindustry Differences in Technological Opportunities, Research Policy 24, 185205.

Kline, S.J., Rosenberg, N. (1986): An Overview of Innovation; in: Landau, R., Rosenberg, N. (eds.), The Positive Sum Strategy: Harnessing Technology for Economic Growth, Washington: National Academy Press, 275-305.

Levy, D., Terleckyj, N. (1983): Effects of Government R\&D on Private R\&D Investment and Productivity: A Macroeconomic Analysis; in: The Bell Journal of Economics, Vol. (14) 2, pp.551-561.

Lucchini, N. (1998): European Technology Policy and R\&D Consortia: The Case of Semiconductors; International Journal of Technology Management 15 (6/7), pp. 542-553.

Lundvall, B.-A. (Ed.) (1992): National System of Innovation. Towards a Theory of Innovation and Interactive Learning (Pinter Publishers, London and New York).

Lundvall, B.-A., (1988): Innovation as an Interactive Process: from User-Producer Interaction to the National System of Innovation; in: Dosi, G., Freeman, C., Nelson, R., Silverberg, G., Soete, L. (eds.), Technical Change and Economic Theory, London: Pinter.

Luukkonen, T., Niskanen, P. (1998): Learning through collaboration - Finnish participation in EU framework programmes; VTT Group for Technology Studies, Helsinki.

Luukkonen, T. and Hälikkä, S. (2000): Knowledge Creation and Knowledge Diffusion Networks. Impacts in Finland of the EU's Fourth Framework Programme for Research and Development, Helsinki: TEKES.

Machlup, F. (1980): Knowledge: Its Creation, Distribution and Economic Significance. Knowledge and Knowledge production (Vol. 1), Princeton: Princeton University.

Mansfield, E., Rapoport, J., Romeo, A., Wagner, S., Beardsley, G. (1977): Social and Private Rates of Return from Industrial Innovation; in: Quarterly Journal of Economics, (77), pp. 221-240.

Martin, B., Salter, A. (1996): The Relationship between Publicly Funded Basic Research and Economic Performance; Report prepared by Science Policy Research Unit, University of Sussex.

Mowery, D. (1994): Science and Technology Policy in Interdependent Economies; Kluwer Academic Publisher.

Nadiri, I. (1993): Innovations and Technological Spillovers; in: NBER Working Paper Series, Working Paper No. 4423.

Nelson, R. (1959). The Simple Economics of Basic Scientific Research; in: Journal of Political Economy 67 (1959), pp. 297-306.

Nelson, R. (ed.) (1962): The Rate and Direction of Inventive Activity: Economic and Social Factors; Princeton University Press, Princeton.

Nelson, R.R. (1982): The role of knowledge in R\&D efficiency; Quarterly Journal of Economics 97, 453-470.

Nelson, R.R. (1998): The agenda for growth theory: a different point of view; Cambridge Journal of Economics 22 (4), 497-520.

Nelson, R.R. (Ed.) (1993):National Systems of Innovation: A Comparative Study (Oxford University Press, Oxford). 
Niskanen, P. (2001): Finnish universities and the EU Framework Programme - towards a new phase; VTT report, Helsinki.

OECD (1996): Science, Technology and Industry Outlook, Paris.

OECD (2000), Main Science and Technology Indicators, Paris.

OECD (2000b): Analytical Report on High Tech Spin-Offs, Paris.

OST (2000) Science \& Technologie Indicateurs

Parker D., D. Zilberman (1993): University Technology Transfers: Impacts on Local and U.S. Economies, Contemporary Policy Issues 11, 87-99.

Pavitt, K. (1991): What makes basic research economically useful?; in: Research Policy 20 (1991), pp. 109-119.

Pavitt, K. (1997): The Social Shaping of the National Science Base; SPRU Electronic Working Papers Series, Paper No. 5.

Pavitt, K. (2000): Academic research in Europe, SPRU Working Paper No. 43.

Peterson, J., Sharp, M. (1998): Technology Policy in the European Union; Houndsmill and London Macmillan Press.

Polt, W., C. Rammer, H. Gassler, A. Schibany, and D. Schartinger (2001a): Benchmarking Industry Science Relations: the Role of Framework Conditions, Project Report, Vienna: Joanneum Research. .

Polt, W., C. Rammer, H. Gassler, A. Schibany, and D. Schartinger (2001b): Benchmarking Industry Science Relations: the Role of Framework Conditions, in: Science and Public Policy, (in print).

Robson, M. (1993): Federal Funding and the Level of Private Expenditure on Basic Research; in: Southern Economic Journal, Vol. (60) 1, pp. 63-71.

Rosenberg, N. (1982): Inside the Black Box: Technology and Economics; Cambridge University Press.

Rosenberg, N. (1994): Exploring the Black Box; Cambridge.

Rosenberg, N., Nelson, R. (1994): American Universities and Technical Advance in Industry; in: Research Policy 23, pp. 323-348.

Salter, A., D’Este P., Pavitt, K., Scott, A., Martin, B., Geuna, A., Nightingale, P., Patel, P. (2000): Talent, Not Technology: The Impact of Publicly Funded Reserach on Innovation in the UK, SPRU-Publikation, University of Sussex.

Salter, A.J., Martin, B.R. (2001): The economic benefits of publicly funded basic research: a critical review; Research Policy 30, 509-532.

Saviotti, P.P (1998): On the dynamics of appropriability of tacit and codified knowledge, Research Policy 26, 843-856.

Schartinger, D., Rammer, C., Fischer, M.M., Fröhlich J., (2000a), Knowledge Spillovers from Universities Within the Austrian Innovation System. Report ÖFZS-S 0045k, Seibersdorf.

Schartinger, D., Schibany, A., Gassler H. (2001b) Interactive Relations Between Universities and Firms: Empirical Evidence for Austria; in: Journal of Technology Transfer, 26, pp. 255268.

Schibany, A., Jörg, L., Polt, W. (1999) Towards Realistic Expectations. The Science System as a Contributor to industrial innovation; tip-study, Vienna. 
Schibany, A., Jörg, L., Gassler, H., Warta, K., Sturn, D., Polt, W., Streicher, G., Luukkonen, T., Arnold, E. (2001): Evaluation of the effects of Austrian participation in the 4th EU Framework Programme for Research, Technological Development and Demonstration; Vienna.

Scherer, F. (1984): Using Linked Patent and R\&D Data to Measure Interindsutry Technology Flows; in: Griliches (1984).

Schmoch, U. (1999), "Interaction of Universities and Industrial Enterprises in Germany and the United States - a Comparison", Industry and Innovation 6 (1), 51-68.

Smith, K. (1994): New directions in research and technology policy: identifying key issues; STEP report 1/94, Oslo.

Smith, K. (1995), "Interactions in knowledge systems: foundations, policy implications and empirical methods", STI-Review 16, 69-102.

Steinmueller, E.W. (1994): Basic Research and Industrial Innovation in: Dodgson, M., Rothwell, R. (eds.) (1994).

Stoneman, P. (ed.) (1995): Handbook of the Economics of Innovation and Technological Change; Blackwell.

Sveikauskas, L. (1981): Technology Inputs and Multifactor Productivity Growth; in: Review of Economics and Statistics Vol. 63, pp. 275-282.

Terleckyj, N. (1974): Effects of R\&D on the Productivity Growth of Industries: An Exploratory Study; in: National Planning Association, Washington, DC.

Varga, A. (2000): Regional Economic Effects of University Research: A Survey. Working Paper. Department for Economic Geography and Geoinformatics, University of Economics and Business Administration Vienna.

Vavakova, B. (1995): Building Research-industry Partnerships through European R\&D Programmes", International Journal of Technology Management, 10 (4/5/6), pp. 567-585. 


\subsection{Rationale for Science \& Technology Policy}

The objective of this part was to analyze the economic rationale of the science and technology (S\&T) policies. The way to answer this question was to identify the main theoretical frameworks on the basis of which innovation related phenomena are currently analyzed in economic terms, and then, for each framework, to try derive the justifications for State intervention as well as the main forms that this intervention may take. It is important to emphasize that each framework provides rationales for Science policy, Technology policy, or more broadly Innovation policy (and even for others, e.g. competition policy, trade policy, education policy and so on), although the mix between these different policies and the frontiers between them vary from one framework to the other. In other words, in each framework, all policies are based on the same rationale. This is why we have not artificially (from an analytical point of view) separate the Science from Technology policy.

Following (Lundvall \& Borras, 1997) ${ }^{15}$, in order to simplify the presentation and the very subtle, complex and sometimes controversial scholar debates, we have distinguished two main frameworks : neo-classical and evolutionary structuralist, both including different approaches highlighting some specific aspects. For each framework, we have identified:

- the main features, especially regarding innovation

- the "circumstances" under which the innovation processes do not work well and do not adequately fulfill the role they are supposed to play, and the consequences of these so-called "failures"

- the principles of State intervention to remedy these failures, illustrated by the most representative types of S\&T policy action that can be adopted; but it is clear that frameworks are heuristic tools rather than the basis for directly operational policy advices; a detailed description of these would be out of the scope of this work

- the main problems raised by these principles when they are to be translated into real actions; government failures will be mentioned here.

The distinction between macro-based, micro-based and science-based perspectives has not been adopted here (although it will be mentioned here or there) since the frameworks presented are cross-cutting these dimensions.

In Part 1. and 2. respectively, we present the two frameworks and their S\&T policy implications. As most of the elements of this analysis are largely documented in the literature, we focus only on the main aspects, or aspects which are not always emphasized. The Tables 1 and 2 summarize the analysis. Table 1 exhibits the main features of each framework and the type of "failures" that can be connected to each of them. Table 2 shows the basic principles of S\&T policy that are central to each framework for remedying these failures, and how the main types of S\&T policy actions

${ }^{15}$ See also works by Metcalfe $(1995,1998)$, (Metcalfe \& Georghiou, 1998) and (Lipsey \& Fraser, 1998). 
can be seen as specific applications of these principles (the presentation has the advantage of comparing the underlying principles from which real although archetypal policy actions are carried out). Part 3. will be devoted to some comments about the comparison of policy principles and policy actions resulting from both frameworks. In Part 4., we lay out some tracks to consider the crucial problem of additionality in the analytical context provided by each framework. And finally some hints about questions specific to the EU policy context are proposed in Part 5.

\subsubsection{The neo-classical framework and its implications in terms of "failures" and S\&T policy principles}

\section{Allocation of resources, technology as information and market failures}

It is undoubtedly the most coherent of the two frameworks (from an analytical point of view and because of its inherent linear logic which goes from its very foundations to some measurement tools), and probably for this and for historical reasons, it is still the dominant one, although it has been strongly challenged by the other paradigm since the late $80 \mathrm{~s}$. Without entering into too many details, the key point as regards innovation and technological progress is the way they have been endogeneized by the neo-classical approach (roughly since (Arrow, 1962), whereas before they were treated as exogeneous to the economic rationale (more precisely they were considered as "given" whithout questioning their origin, and included as such in the choice parameters of agents or equally influencing all of them). In accordance with the "input/output" neo-classic way of reasoning, the innovative activity is performed by an individual agent (the innovator) using inputs to produce a particular good, the technology, considered as information. The line of argument, put forward on theoretical grounds by Arrow (1962), but also followed on a more empirical and business-oriented perspective by Nelson (1959) is roughly as follows: the peculiar activity of innovation and its peculiar good do not show the "adequate" properties that the theory requires to optimize the decision of the agent. Namely, there are some indivisibilities in the inputs as well as in the outputs, the result is uncertain (and may take a long time to be obtained) and it is a non-rival and nonexcludable good, and then a non appropriable good.

The consequence is the famous "lack of incentives" to innovate from the part of the innovator: the activity is risky (uncertainty about the result and the demand) and costly (indivisibility). Moreover, the economic gains are difficult to appropriate since they may benefit : i) consumers or clients, who have access to better products without necessarily being charged a corresponding price increase; this is the base of the consumer surplus and "market" externalities; ii) competitors and finally all of the economy that could use the technology produced by the innovator without paying anything, giving birth to "knowledge" and "network" externalities (see for instance (Griliches, 1979) on market and knowledge externalities and (Jaffe, 1996) on a clear exposition of the links between the three). In other words, the private rate of return to the potential innovator is too low for him to invest, although the social rate of return for the rest of the economy may be high which means that the innovation should be done from the point of view of the society as whole. In this respect, the resource allocation mechanisms at the very heart of the neo-classical approach do not work in a way to generate the socially optimal 
situation: the investment in innovative activity is inferior to its socially optimal level because of these "market failures".

\section{S\&T policy principles and actions}

Therefore the State can adopt S\&T basic principles to remedy these situations. Roughly again, it can :

1. try to provide a better information in order to reduce the uncertainty of the environment;

2. substitute wholly or partially for the market, on the supply side (carrying out itself innovative activity, or contributing to the firm's investment in R\&D by means of subsidy, tax credits, grant, ...), or on the supply side (order innovative outputs to firms or help agents to buy such outputs), in order to reduce or share the uncertainty and the risk and to reduce the cost for firms. By "substitute", we mean that public action takes over private action that would have been required in order to reach the social optimum ${ }^{16}$. The basic assumption is that the cost reduction for firms will compensate their loss due to externalities, therefore the amount invested by the State should not be larger than the sum of the externalities;

3. promote mechanisms or regulations to remove or diminish the externalities or facilitate their internalization in agent's optimizing calculations :

a. provide a property right to the innovator on his technology for he can be retributed for knowledge externality

b. promote cooperation between users and producers of technology (vertical cooperation) to share the market externalities and diminish the uncertainty;

c. promote cooperation between producers of technology (horizontal cooperation level) to share the knowledge externalities and share the costs and the risk associated with the production of technology.

The table 2 specifies these basic principles and exhibits a list of the main corresponding S\&T policy actions that could be carried out.

According to the neo-classical approach, thanks to these corrections of the market failures, the optimizing rationality of agents will lead them to allocate resources through market mechanisms in such a way that a "second-best" equilibrium could be reached. In other words, the "first-best" equilibrium could not be reached in any way because of these market failures; but the State intervention to correct market failures allows the system to reach a "second-best" equilibrium, which is inferior to the "first-best" one but better than if there had not been any State intervention. Correspondingly, if State intervention leads to such a situation, there is "additionality" (see a brief discussion on this concept below).

\footnotetext{
${ }^{16}$ Another problem is the substitution of public action to actual private action (see the discussion about additionality problem blow).
} 
Some refinements of the pure neo-classical approach and their implications for $S \& T$ policy

Obviously, the picture is oversimplified, and many arguments developed since the Arrow's seminal paper have made it more complex, although, from our perspective, remaining within the same general framework. For instance, the consequences (in terms of strategies, incentives and modes of coordination of agents) of uncertainty, imperfect information and related asymmetries between agents have been deeply investigated (see for instance (Lafond \& Tirole, 1993). We would be tempted to state that they have not profoundly modified the framework, but have mainly complexified the different situations of market failure and allowed to finely tune the applications of State policy actions listed above to specific contexts in terms of information at the disposal of actors.

At the basis of another prolongation of the analysis, particularly important for explaining the role of cooperation is the question of the costs of transaction associated with market relations but not included in prices and their influence on the optimal mode of coordination. But again, most of the theoretic renewal in this field falls within the scope of the same framework, because it does not essentially preclude considering technology as information and favouring optimizing rationality. But perhaps one of the most important developments at the boundary of the neo-classical paradigm has been the socalled "economics of science and technology" developed among others by Dasgupta, Stoneman and David (Foray, 1991). On the one hand, it has helped to understand the implications of the public-good properties of technology considered as information, as well as the inherent and specific properties of the latter (for instance about the value of information, its cumulative and combinatory nature, the often high cost associated with its production in comparison with the always low cost associated with its duplication, the network externalities associated with it, etc). On the other hand, it has proposed to draw a new line between science-related and technology-related activities and their respective outputs. A tentative summary of the proposed distinction would be to say that it does not rely so much on the very nature of the ouptuts (both fundamentally subject to non-rivality and at least partial non-excludability) than on :

- the practices of diffusion associated with incentive schemes (openess or free access to scientific results, with priority to the inventor associated with social rewards; closeness or property rights on technology outputs associated with appropriation of the economic gains from innovation through market mechanisms);

- the indivisibility of its production process (with comparatively higher cost for science than for technology)

- the more generic usefuleness of scientific outputs thus allowing for larger externalities

- the higher uncertainty in the production and use of scientific results.

One fundamental consequences of these new developments is that they allow for a better justification of the analytical distinction between Science and Technology policies in the neo-classical framework. In the field of Science, State intervention is rather direct through fundings, while it is rather indirect in the field of Technology (through co- 
fundings and property right system). In this respect, Science policy is almost always acknowledged as indispensable, even though some argue (probably too simply given the analysis developed above) that the type of results produced by publicly supported basic research is useless for the industry, because if it was not the case, the industry would do it itself (Kealy, 1996).More generally, following the linear model of innovation, Education policy is aiming at providing the system with "good inputs" (researchers), and Diffusion policy is aiming at helping agents to adopt innovation and at circulating the information about existing or pontential needs and resources.

From another standpoint, the endogeneisation of technology in economic analysis has also been the ambition of macroeconomic analysis, in the field of endogeneous growth theory or New Growth Theory (NGT). But there as well, despite the technical refinements, only some types of development, accumulation and diffusion of information have been introduced, guided by rather simple forms of appropriability regimes and incentives, and most frequently associated with other classical hypotheses related to behaviour and search for equilibrium (see for instance (Firth \& Mellor, 2000) ${ }^{17}$. In total, it is questionable whether these approaches have as such provided more than an illustration at macro-level and modelisation of innovation-related phenomena already identified, which is obviously a very useful achievement. To move along this line, one must also acknowledge that learning phenomena are not completely absent from the neoclasssical perspective, especially in new growth theory. Certain forms of learning by doing may for instance be compatible with this perspective.

NGT and economics of S\&T are at the frontier of both frameworks. Especially the second approach, which in many ways avoid this fundamental feature of the neo-classical paradigm, i.e. that, "... the closest we get to something called learning is information acquisition" (Lundvall \& Borras, 1997). Precisely, one of the main (or the most important ?) differences with the second framework resides in this point, as outlined below.

\section{About empirical problems of applications and "government failures"}

Without entering into a large debate about the relevance of the neo-classical view and its compliance with reality, the main problems raised by the application of the principles of State intervention must be recalled.

The first is the identification of the situation in which "market failures" occur, and most of all the identification of "where" to correct them : which firm to support, which project to finance, which information to diffuse, how far to extend the property rights, and so on. The neo-classical framework as such does not provide the tools to directly translate real phenomena into the limited number of variables that are required to operate the optimizing calculation (see also the discussion on additionality below).

The second problem is inherent to the way adopted to correct the market failures. In this perspective, a first aspect is related to the proposed solution to the lack of appropriability, namely the property right system. Briefly, on the one hand, the information should be

${ }^{17}$ This is not to say that specialists of NGT, as Romer, ignore the tacit dimension of knowledge, but they did not fully incorporate this dimension in their models. 
innovator's property in order to urge the innovator to innovate, but on the other hand, it introduces asymmetries of information between actors when this information does not diffuse to all actors. The "pure neo-classical" axioms stipulate that all agents have the same information, and this specific feature leads the system to the social optimum. Any departure from this hypothesis entails at best that the reachable equilibrium is only a "second-best" one. In other words, there is a trade-off between guaranteeing the property right to the innovator and diffusing the technology throughout the society, and the right balance between both ways is not easy to find. Moreover, the patent system may induce duplication of innovative efforts by firms in competition for being the first to be protected; over-investment could then result or conversely under-investment again if the "patent race" is dominated by one firm. Both results would not be socially optimal. Roughly, one may put forward the same argument as for the subsidy principles : subsidy causes asymmetry to the one who benefits, which is fundamentally against the "pure neoclassical" axioms. The fact that, in theory the amount of subsidy should not exceed the amount of externalities generated by the innovation only insures that a "second-best" optimum can be reached. Again the same argument is relevant for the promotion of cooperation which restricts the diffusion of information and economic gains to a limited number of agents.

The general idea behind these trade-offs is that solving a given market failure always makes another market failure emerge. Thus the crucial question is the balance between the positive effects resulting from the correction of the first and the negative effects of the second. There is sometimes the risk that corrective public actions create other market failures worst than the ones that were supposed to be solved, i.e. that the increase in social surplus obtained thanks to the corrective action is inferior to the decrease in social surplus induced by the created market failure ${ }^{18}$. If it is the case, we are in presence of what is called "government failure" or "policy failure". In any case, the balance between positive and negative effects form State intervention is hard to assess, and thus often as much a matter of policy decision as of an economic one ${ }^{19}$.

Another case at stake is the possibility that the benefit effects are less important than the cost of intervention, this latter including the cost of the research of information about the presence of market failure and the evaluation of the actual and "corrected" situation. These are both typical cases of "governement failures" associated with the neo-classical framework.

It is not surprising that these two fundamental difficulties are related to the set of information owned by the State, and its capacity to acquire new information. It is arguable that the State has more information than the markets, and moreover that it is more able to adapt its information structure than the market. To follow this line of

\footnotetext{
${ }^{18}$ On the basis of the same argument, other types of public policies may be required to limit the damage caused by technology progress on health or environment.

${ }^{19}$ Let us just mention here the basic exceptions to competition policy basically accepted by the public authorities : patents, financial support to supply side in case of high cost and natural monopoly caused by indivisibility and related economies of scale phenomenon as exceptions to monopoly regulation, $R \& D$ cooperative agreement as an exception to cartel and agreement regulation (with the idea of "precompetitive" cooperation fully coherent with the distinction between science and technology mentiond above).
} 
argument, it should also be mentioned that other theoretical developments in economic theory favour a more dynamic idea of competition, which would be seen as based on a continuous creation and exploitation of asymmetries, especially regarding information. As long as technology is treated as a set of information and the choice of agents is seen as an optimization taking into account existing or anticipatable alternatives, these approaches still remain within the boundaries of the neo-classical paradigm. Despite the progress of analytical tools and continuous refinements and complexification of contractual schemes in this field, there is still room for more dynamic approaches to take care of these asymmetries of information. But this kind of analysis also explains why "governement failures" are expressed in terms of negative or counter-voluntary effects.

Another occurence of "government failure" emphasized by some researchers in the field of public administration theory is related to the process of decision in public bodies, reflecting private interests, lobbying, etc and raising the unsolvable problem of the aggregation of individual preferences, at least with the neo-classical analytical apparatus.

\subsubsection{The evolutionary structuralist framework and its implications in terms of "failures" and S\&T policy principles}

\section{Creation of resources, knowledge and "learning failures"}

Under this heading there is a constellation of approaches that nevertheless have some strong common features. Often inspired by other disciplines than economics (sociology, history, psychology, management, epistemology, biology, ...), they claim part of the heritage of Schumpeter views, and have a long time been built against the neo-classical framework. But for ten to twenty years, they have been developing and refining very fast, and probably have strongly been gaining in coherence with the emergence of the knowledge-based approaches.

Again, it is out of the scope of the study to specify the main features of this framework. It is needless to underline that most of them can be seen as opposite to the ones of the neoclassical framework. But what is probably more relevant to stress here is that this framework fully acknowledge the learning or more generally the cognitive capacity of all agents or groups of agents : it does not only embrace a capacity to learn something that would exist somewhere, but merely a capacity to create new knowledge, especially by changing the way of thinking, the beliefs, the visions, the routines, etc. As regards innovation, the cognitive capacity concerns (not only) scientific and technical knowledge which can not be reduced to pieces of information, but is a mix of tacit and codified knowledge ${ }^{20}$. This point has some decisive consequences on appropriation and diffusion phenomena : among others, learning is obviously a cumulative and collective rather than purely individual process, which logically leads to admit that it is a context-dependent process : it varies from one agent, group of agent, firm, industry, clusters of industry, region, institutions, etc to the other.

\footnotetext{
${ }^{20}$ The economics of science and knowledge also recognizes this tacit dimension of knowledge but without emphasing the cognitive dimension associated with knowledge.
} 
The three main approaches that, very artificially and for pedagogical purposes, we have distinguished here, more or less explicitly share all these features. But each of them has focused on some specific aspects and therefore has added some decisive concepts and analytical tools to the global framework; it is remarkable to note that these concepts, most often with quite minor adaptations, have been adopted by the other approaches which use them as indispensable bricks for their own conceptual construction.

In order to follow the same logic of presentation as for the neo-classical framework, we would be tempted to argue that the evolutionist, systemic (including national or local systems of innovation as well as clusters) and knowedge-based approaches have respectively provided the "general logic" of the evolution, the "how it works" and the "basic engine" of evolution. But the main problem remains to define what would correspond to the neo-classical optimal situation. Surely there is neither a static nor a dynamic equilibrium-like situation, which has very little meaning, if any, in this learningoriented framework. Correspondingly, there is nothing like optimality, even though it is sometimes possible to assess ex post if one situtation is preferable to another. Referring to Schumpeter's cycle analysis reinterpretated and enriched by paradigmatic, systemic and other approaches, the only apparent consensus on this point could be reached by saying that the system follows some trajectory induced by paradigm, and therefore it must be able to exploit a "good trajectory" as well as ensure a "good transition" from one paradigm to the other. In order to be able to do so, in the whole system and at all levels of the system, there should be enough diversity among which the selection processes should perform satisfactorily, and without to much lack of cohesion that would unbalance he system and/or prevent it from evolve well. And the basic engine that allow for all of this would be the maintenance or increase of the cognitive capacity of all agents or groups of agents at all levels of the system.

With an approach in which all phenomena and processes are so complex and intrinsically related, it is then rather difficult to identify and especially isolate "failures", as we did for the neo-classical paradigm. Indeed, the term failure is adopted for simplicity's sake, but may be misleading. In the "market-oriented" framework, as stated, there is always an implicit or explicit reference to an "optimal situtation" that would be reached if all conditions were fulfilled, that is if markets and behaviour were perfectly equal to theory prediction. It is by reference to this mythical "optimum" that something is seen as going wrong, as "failing". Within the alternative framework, this reference to an optimal situation does not exist so much, then it is not exactly proper to consider "failures". One should better considers rather "traps", "dysfunctions", "gaps", "holes", leading to "dilemma" and "trade-offs" between existing forces driving the system rather than "dilemma" and "trade-offs" between to possible states of the system (as choosing between two "second-best" situations). Different authors have already pointed out some of them (see for instance (Malerba, 1996), (Smith, 1996), (Lundvall \& Borras, 1997), (Metcalfe, 1998) and (Teubal, 1998), but there is no unified and unanimously accepted list of failures in the evolutionary constructivist framework.

We will consider here that what basically matters are generally speaking "learning failures", i.e. problems that limit the cognitive capacity of agents and groups of agents or refrain its use. A series of failures that are expressions of learning and cognitive problems 
in different context and at different levels of analysis fall within this general type of failure. We propose to distinguish :

- $\quad$ exploration/exploitation failures : misallocation of efforts and most of all of cognitive attention to one activity to the detriment of the other;

- $\quad$ selection failures : technology, practice, firms (infant firms for instance) and all "species" at which selection is at work are eliminated too rapidly or according to inappropriate criteria; on the contrary, others are wrongly maintained

- $\quad$ system failures : lack of coordination and complementarity between cognitive activities of agents and groups of agents; rigidity of cooperative structures; lack of appropriate institutions allowing a collective creation and diffusion of knowledge; bad adjustment and desynchronisation between the evolution of institutions and technological evolution

- $\quad$ knowledge processing failures : codification problems (lack of standards and plateforms, rigidity linked to excess of standardization, appropriability of codes...); lack of / limitation of / absence of / control over absorptive and emitting capacity; lack of capability to articulate knowledge coming from different sources (for instance external and internal to a firm); structure of knowledge badly adapted to appropriate sharing and distribution.

As suggested before, the negative consequences of these different types of failures (and thus basically resulting from a deficit of cognitive capacity) are principally the lockin in "bad trajectories", the lack of diversity in the system, the difficulty of making new paradigms emerge and warrant the transition between old and new paradigms, and the existence of "gaps" in terms of knowledge, networks, institutions, economic and social conditions and so on which unbalance the evolution of the system.

\section{S\&T policy principle and actions}

Therefore, the basic principle of State policy would be to help by all possible means to the development and the orientation of the cognitive capacity of actors and the provision of the conditions of use of this capacity. The different approaches developed within the evolutionary framework will put the emphasis on different aspects of this question. For instance, researchers investigating Innovation Systems will defend the role of institutions, infrastructures and collective interactions, or the knowledge-based economics will debate of the necessity to help to the codification process or to support the development of knowledge infrastructure allowing for a better use of the increasing amount of codified knowledge witthin the whole society. Therefore the basic principle mentioned above can be activated by very different actions, such as the promotion of norms, plateforms or other knowledge-related infrastructures, the support to communities and agents of knowledge, the reinforcement and adaptation of the education system, the renewal of property right system to take into account not only the cumulative nature of knowledge creation but also the nature of the knowledge and of its other modes of appropiration, the support of infant firms at their different stages of development, etc. Above all, it must be adapted to contexts defined according to geographical, industrial, sectoral, market-related, institutional dimensions. Table 2 only shows the main S\&T 
policy actions, which can be combined, adapted, refined, etc and thus give birth to a large range of practical initiatives.

To close the loop, the use of the cognitive capacity is then supposed to provide the conditions for appropriate selection processes, sufficient diversity among which the selection mechanisms operate, without too many "gaps" in the system. In turn, this would garantee the evolution of the system along satisfycing trajectories and through relevant paradigms. This rather naive picture could obviously be made more sophisticated, by orienting it towards some specific aspects involved in learning. But fundamentally, it would not escape from this simple and sometimes apparently tautological argument.

In this framework, the frontiers between Science policy, Technology policy and other Innovation-related policy becomes blurred for different reasons : the actors are interacting at different levels of the system, the practices of diffusion, the incentives and the very activities are not strictly differenciated between science and technology, and the nature of the knowledge produced is not fundamentally different. Moreover, knowledge is created everywhere in the system, and thus there is not a clear functional separation between activties and between actors as regards creation of knowledge, transformation of knowledge into innovations and diffusion. Therefore, coordination, coherence and complementarity of policy actions are crucial in order to make the overall system better able to learn. For instance, recent work by Sherer (2001) shows that this is probably a combination of different policy tools that have favour the re-dynamisation of the US economy, especially as regards its innovative activity.

\section{About empirical problems of applications and "government failures"}

Having said that, we still face a situation in which it is as easy to identify, in real world, tracks, examples, partial assessments, and finally pieces of evidence of the fundamental relevance of this approach (see the striking amount of case studies, monographies and other empirical studies provided within the last twenty years) as it is difficult to define metrics and tools to operationalize and measure all the concepts that have been emerging for almost 20 or 30 years. The problem is complex and located at different levels : it concerns the "measurement" of some aspects, even in qualitative terms (for instance diversity, learning capacity), the definition of what would be a good or satisfying level of the corresponding variable, and the desirability to reach some degree of homogeneity in the metrics, scales or analytical tools. With the complexity of the approach due to its systemic and constructivist nature, this is probably the main problem encountered with this framework, notably because it prevents analysts and policy makers from really envisaging the adequate policy options that would favour the adequate balance of all dilemma and other trade-offs. Another problem resides at another level : it is the dominance of the neo-classical framework in the mind of the majority of analysts and decision-makers, although public action has begun to take on new rationale, roles and tasks.

A very important difference between both frameworks lies in the very "place" of the State. As underlined in 2.4.1, in the neo-classical framework the State is basically considered as normally "outside" the system of markets, and is needless if markets and 
behaviours are consistent with what the theory says. This is only when some market failures occur that the State "appears". Then it arise the questions of public/private rate of return, crowding effect, substitution, and the like, and finally those traditionally related to additionality. In the second framework, the perspective is quite different. The systemic, path-dependent and cumulative approach fully recognises the State-related institutions and their influence on institutional, technological, social and economic changes as being part of the game; State-related institutions are learning roughly according to the same basic rules as other actors. And they have not necessarily more knowledge, a better cognitive capacity, a more broader vision, etc than the other parts of the system. Therefore, most of the "learning failures" listed above and affecting society affect public bodies as well, and logically entail "government failures" (see for instance (Malerba, 1996). In this respect, the main source of "governmental failures" probably lies in the desynchronization of the speed of adaptation of public institutions and the speed of technological and scientific change in the system. This default in the speed of adjustment may have some negative counter-cyclical effects. Because of their specific role, public institutions are urged to develop integrative and coherent policy visions, tools and instruments, and to adapt constantly to the new requirements and trends of the economy. In this perspective, the "adaptive policy maker" should also permanently try to implement experimental policies, to use different policy instruments, to change the mix of instruments, and to make use of benchmarking approaches as policy learning mechanisms.

Policy learning should also encompass "diagnostic learning" : it is also the ability to identify the changes in the environment and the changes in the relative position of actors (firms, countries, etc) in this environment that is at stake. The recent debate about the "European innovation paradox" clearly shows the importance of this learning capacity upstream from the innovation policy itself (Muldur, 2001).

\subsubsection{Some elements of comparison between the policy principles and their policy implications}

- $\quad$ One of the main conclusions of the analysis presented here is that the S\&T policy actions derived from both analytical frameworks are neither necessarily different nor antagonistic. In addition, they could be seen as complementary. The crucial point is that a given policy action (for instance : subsidy to firm R\&D activities) apparently common to both frameworks (although a much more detailed analysis would obviously reveal some differences in the practical applications of this given policy principle), is justified on different grounds according to each framework, because it set up for different purposes. But much conceptual and empirical work remains to be done if one wants to really articulate the perspectives provided by both frameworks, and really benefit from a "dual use" of policy actions. Another consequence of this dual dimension of most if not all policy actions is that logically the impact of one given policy action should not be evaluated the same way whether we envisaged it in one framework or the other. In other words, as $S \& T$ policy principles are based on different rationale related to different theoretical frameworks (leading to different objectives), Evaluation techniques and tools are based on different evaluation perspectives 
related to different theoretical frameworks (leading to different "objects" of evaluation). A knowledge of this coherence requirements is certainly useful when one wants to launch any evaluation exercice.

In the past few decades, policy options have also been analyzed as favouring horizontal or conversely vertical dimension. Again, in each framework, the different alternatives could be justified, and one could not pretend that one option is analytically stemming from a particular framework. Neo-classical externalities could be higher between sectors than within sectors or market failures could be more prominent and damaging in certain sectors (see for instance (Martin \& Scott, 2000), and the collective cognitive capacity could potentially be more or less transversal to sectors. Another classification of S\&T policy orientations is to distinguish between mission and diffusion-oriented policies (Ergas, 1987). At first sight, one could claim that mission-oriented policy is more connected to the neo-classical framework, while the diffusion-oriented policy is more rooted in the evolutionary constructivist one. But there may be some circumstances in which the concentration of support on a small number of technologies and on larger firms is the best way to develop cognitive capacities and enlarge the knowledge-base; conversely, diffusion of information and cooperation are not absent from the neo-classical perspective (see for instance (Cantner \& Pyka, 2001). The two distinctions referred to above are rather empirical orientation of policy which always borrow implicitely or explicitely from both frameworks.

It is also interesting to pay attention to the role that the State can play in terms of market creation. Obviously markets play a key role in the neo-classical framework as the main if not the only mode of coordination, but its role is not completely denied by the alternative framework, being acknowledged for instance as a decisive element of the selection process. But whereas in the neo-classical framework, the creation of markets requires the creation of demand or supply, the definition of property right on the good which is exchanged, and general conditions of market operation, in the alternative framework the main focus is put on the creation of infrastructure and knowledge capacity which are required to make the market exists. In other words, this alternative framework tends to adopt a sociologist view of the market being a social construction involving cognitive capacity, and not so much a natural way of organizing the economy. This also has consequences on the forms of State intervention in the S\&T policy field.

In both frameworks, there is a need for combining S\&T policy with other policies (anti-trust, commercial, education etc). In the neo-classical one, the distinction between the different policies is straightforward, since each of them can act on a limited an a priori defined set of variables of the neo-classical model (such as incentives, prices, market structure, etc). In the alternative framework, the differences are less evident and almost all policies can impact of the whomle system because of all the interactions at all stages. Recent works (for instance (Koelliker, 2001) shows for instance the combined impact of S\&T and anti-trust policies on innovation. Policy mix and complementarity is discussed in another part of the ASIF study. 


\subsubsection{The question of additionality}

The question of additionality is obviously at the heart of the justification of State intervention in the field of Science and Technology, and thus intrinsically linked with the rationale for the S\&T policy. But it is also linked with evaluation and assessment problems. In this part, we try to focus on the first point, but inevitably some links with evaluation related question will be addressed.

Following Cameron \& Georghiou (1998), the problem could be expressed in the following term : what difference does State intervention make ? But this question should immediately be linked to a second one : Does this difference justify State intervention?

Additionality is then directly linked to policy action. But since policy action aims at objectives and that these objectives, as explained above, are to be linked to rationale, this raises a double problem :

- $\quad$ difference could be assessed in the light of the targeted objectives, but other differences may occur out of the scope of the targeted objectives and unexpected;

- $\quad$ these unexpected differences can be coherent with the framework that gave birth to the objectives or not; if they are not, it is required to adopt the theoretical view of the other framework to identify them and if possible to evaluate them.

An essential dimension of the additionality problem is related to the situation which is to be considered as alternative to the one in which there is a State intervention. The temporal dimension is here essential. Two possibilities are generally envisaged. The "null hypothesis" stipulates that everything would continues as before State intervention. The "counterfactual scenario" is a fictive construction about what could happen if there were no such State intervention. It is to be noted that this perspective can be adopted if one looks at the situation before the State intervention and after (and possibly during its course). There is another question related to the temporal dimension : the time horizon over which the additonality is examined. "One-shot differences" or short-term differences are one thing, but probably more crucial is the question of the persistence of these differences (possibly decreasing or increasing ) over time.

Ex ante, additionality is between the targeted situation (e.g. the objectives) and the forecasted alternative scenario. Ex post additionality is between actual situation and the "re-built" alternative scenario, but this actual situtation may be better or worst than the one that has been targeted.

Directly linked to this question is the one of the level at which the alternative scenario is under consideration : project level, firm level, programme level, policy level, etc. As this alternative and hypothetical situtation must be compared to some sort of evaluation of the actual or anticipated situation "with" the State policy, both situations must logically be considered at the same level. 
For a long time, the debate was based on a way of analyzing policy action as a mean to provide some inputs to the innovative process resulting (or not) in outputs of the process. It must be stressed here that this view is itself largely influenced by the neo-classical way of analyzing the activity of the agents. Also, it is more adapted when the policy action takes the form of providing input to the innovation process. This view has led to the first two types of additionality that are most often quoted : input additionality and output additionality. The next step has been to concentrate on the process itself, making the ambiguous question of behavioural additionality emerge. The recent development of knowledge-based economics (and its influence on the evolutionary structuralist framework mentionned earlier) suggests that a fourth type of additionality could be envisaged, that is the cognitive capacity additionality. Each of these four types of additionality shed some light on the global problem of additionality. But none of them can alone address this global problem, and the sum up of the four types is not equal to the global additionality. In the following first four Parts, these types of additionality are briefly defined and discussed in the light of the two frameworks proposed earlier. The question of the relevance of this Input-Output-Behaviour-Cognitive Capacity additionality scheme for all types of policy action is then briefly evoked in Part 4.5.

\subsubsection{Output Additionality}

This first type of additionality is at first sight the most intuitive : Would we have obtained the same outputs without the policy action ? Clearly this question is related to the main question addressed by the ASIF project, which is the definition of the impacts of S\&T policy actions and their evaluation. Thus it will not be treated here. We will just make four comments.

The first is that again, the notion of output is very much connected to the neo-classical framework. Products, processes and other physical devices, patents, articles, blue prints and other forms of S\&T products can more or less be compatible with an output perspective (see the list of outputs adapted from the COMEVAL study for instance). At most, knowledge, standards and norms can also be considered as outputs, but with specific properties sometimes far from those of the information-like outputs . But the cognitive capacity and all types of capacities which are rooted in it do not fit in the picture.

Second is that, as it is recalled elsewhere in the report, the account for outputs does not express as such the "differences" the output made possible; it is indispensable to assess the impact generated by the use (production, exchange, etc) of these outputs to derive a global assessment of additionality from the existence of output additionality only.

Thirdly, the counterfactual scenario does not need to be analyzed in details, important is the achievement and not so much the process by which its is obtained. The only problem is to find a common definition and measure to compare the output obtained and the one that could have been obtained "if".

Finally, it may be some cases in which there would be no additionality as regards the outputs corresponding to the objectives of a given policy action, but additionality as regards other types of outputs from the same policy action. This shows the crucial 
importance of the choice of the "array" of outputs taken into consideration when assessing additionality.

\section{Input additionality}

The question here is the following : does public action add to the inputs dedicated by the agents to the innovative process or does it completely or partially displace such inputs ? It is often argued that the additionality problem is envisaged with this second perspective because there is a lack of available materials to elicitate the output additionality problem. We would rather said that it is only when we assume the relevance of the input/output type of analysis that this "proxy" analysis is really relevant. This question is largely discussed by (David \& al., 2000). Other academics provide empirical hints (Jaffe, 1996) and theoretical rules (Usher, 1994) with its "incrementality test") in order to choose the right public action (i.e. for instance the right project to fund). Many arguments could be put forward to explain why there could be displacement. The main is rather direct : if the State financially support actions that would anyway have been conducted by the agents, the agents are tempted to use their resources for other activities. Therefore, there is additionality when the State supports actions that would not have been carried out by the agents (i.e. to which they would not have dedicated inputs), provided that the actions are socially desirable. In terms of the neo-classical framework, it means that these actions result in a social rate of return higher than the private rate of return of the agent (this difference is often called "spillover gap"), whereas this private rate of return is inferior to the minimum required by the agent. The application of this "rule" has extensively been discussed in an ex-ante context, that is when the State and the agents have to make their investment choice.

Innovative activity being a risky one, this ex-ante problem obviously is more complicated by the fact that the investment choice criteria become more like a trade-off between rate of return and risk. Public funds could also motivate an agent to carry out activities with high risk but high rate of return leading to complementarity rather than displacement. Apart from the problem of uncertainty inherent to this type of investments, there is also the possibility that in some instances the State favours privately profitable projects in order to show some kind of success of its policy.

But there could be other ways, more subtle, through which at least partial displacement may occur. The main case at stake is the impact of State support to innovative activities on the supply of inputs to innovative activities; if it is inelastic, the prices could increase and make the cost of these activities so high that the agents reduce their efforts in this field. The support given by the State to one agent could convince the competitors of this agents to reduce their own effort because they fear they might be disadvantaged in the competition. State support may be seen as a revenue instead of an input to produce innovation. Last example the funds provided by the State may convince other providers of funds to reduce their requirements in terms of profitability; this is of course the sharing of risk argument.

It is quite clear that the application of input additionality as a parameter of public choice between actions to be taken is linked with the neo-classical approach described before. In particular, it more or less explicitely requires the following assumptions : 
- $\quad$ there is a clear link between input and output of the innovation activities

- $\quad$ divisibility and constant return to scale of the innovative activity;

- $\quad$ no differences in the nature of the output generated by public funds and private funds.

Naturally, these views are contested by the advocates of the evolutionary structuralist framework. On the one hand, the analysis of public financial support should always take into account the way it is provided and the context in which it is used. On the other hand, they will defend the complementarity of input rather than their substitutability related to crowding effects. Apart from the question of increasing returns or threshold effects in the production of innovative output, other arguments more deeply rooted in the framework will be for instance that public funds could help to develop the knowledge base of the agents and their absorptive capacity, which could even allow them to reduce their own investment while increasing the profitability of their own investment, which in turn could even be reduced. Another line of argument is that thanks to the cumulative nature of knowledge creation, public support could increase the efficiency of future innovative activity, by increasing the cognitive capacity of the firm.

The advantage of input additionality is that the variable to handle (basically the respective public and private resources invested in innovative activities) are more easily defined than the one required to assess the other sort of additionality. It does not mean that it is a relevant concept to assess the additionality as a whole. To summarize the short examination of the links between input additionality and the two frameworks presented before, one can say that this concept is closely linked with neo-classical analysis and related to the concept of output additionality. It is whithin this first framework that it really makes sense. Wherease it has no general application in the alternative framework : we can say that some public money displaces, complements or adds to private money, but it is only when looking at the specific context in which public money is used that we can conclude about the additivity.

\section{Behavioural Additionality}

What is behind this term is sometimes misleading, especially when one thinks about the time period over which the behaviour of the agents is under consideration. A first interpretation would be that, in the absence of public action, the agents would have acted differently during the period corresponding to the course of the policy action (for instance during a State-supported project) : the project could have been less ambituous, with different partners, could have taken more time etc. A second interpretation would be that, thanks to public support, the agent will later (i.e. after the project) behave differently : he will use different routines (project management, research activities...) or will use existing ones differently, he will interact differently with his environment, etc.

The problem of this first interpretation is that investigating the behaviour of agents does not directly inform on whether the behaviour "with" State action is better or worst than the behaviour "without" State action, i.e. if there is additionality or not. To a certain extent also, examining this first type of behaviour additionality seems quite redundant 
with the attempt to build the counterfactual scenario mentioned before, even though it could be a much more comprehensive and detailed scenario than in the case of the output additionality. From an analytical point of view, this approach of behaviour additonality only provides explanation for the existence or the absence of the other types of additionality. For instance, if one assume that the objective of action supported by the State would have been reached (although maybe later) even without this State action but differently, the difference looked for in the additionality analysis lies in the behaviour of the agents. In other words, by this means one could enriched the evaluation with an analysis of the innovation process in itself, which could eventually help the policy maker to refine the way he implements his programme. To this extent, it does not add too much to the solving of the additionality problem neither from a neo-classical perspective, nor from an evolutionist structuralist one. But it may allow us to compare different ways of reaching the same result, in particular different learning processes if we adopt the second framework.

The second interpretation seems more coherent with the additionality question, and orient the debate towards another perspective. We are not anymore preoccupied by the inputs and outputs, but rather by the change affecting the agents themselves, more precisely their ways of doing : Do the agents behave differently after the project than before? This is clearly a crucial type of difference possibly generated by public action. Nevertheless, this position entails some overlaps between behavioural additionality and output additionality on the one hand and with the aboved referred cognitive capacity additionality on the other. Firstly, some behaviour may be rooted in explicit routines: quality management, project management, contractual arrangements, systems of information, etc, which are sometimes part of the very output of the activity supported by the State, and in other instances acquired by the agents in the course of this activity. Secondly, changes in behaviour of firms are intrinsically linked with the modification of their knowledge base and the cognitive capacity generated by this activity.

\section{Cognitive capacity additionality}

Logically following the arguments developed in Part 2, we could add to the picture a fourth type of additionality, that is cognitive additionality. From an evolutionary structuralist perspective, it is probably the most crucial one, and one could claim that it is the equivalent of the output additionality in the neo-classical framework. The basic idea is: Does the policy action change the different dimensions of the cognitive capacity of the agent? This question is complementary with the one asked when we looked at the second acceptance of behaviour additionality. Both question are dealing with the impact the State policy action has on the system which is targeted by this action (which is clearly different than the question of the outputs produced by the system thanks to the policy action). Theoreticians from organisation would probably even argue that a third question could be added in order to tackle this question of the change of the system : Does the policy action affect the structure of the system? ${ }^{21}$ It is also obvious that cognitive capacity additionality is linked with the two previous ones detailed above. It depends on certain

${ }^{21} \mathrm{cf}$ three possible ways to apprehend an organisation : through its behaviour, its cognitive feature and its structure. 
types of physical devices and on the knowledge itself, which are outputs of the activity itself or which have been acquired during its performing (output additionality); it results from the behaviour of the agent during the project (first behaviour addtionality); and it is partially expressed in new behaviour (second behaviour additionality).

It must be acknowledged that the difficulty of putting this concept into practice relates to the difficulty to define all the dimensions of the cogitive capacity, and of the change in the capacity. Only pieces of the puzzle can be apprehended. Some important dimensions could concern the absorptive capacity of the agent, its ability to master the codes used to articulate the existing and emerging knowledge, its capacity to interact with its environment, etc.

Last point, it is easily understandable that the question of the counterfactual scenario is even much more complex for the cognitive additionality than for the output additionality, and probably too complex to cope with. The null hypothesis, although already very difficult to define, would be the only solution, if any.

\subsubsection{Are these four types of additionality relevant for all S\&T policy actions?}

It is not obvious that the four types of additionality described above are directly transferable to the analysis of the other types of policy actions (the basic ones are listed in Table 2). Firstly, input is sometimes difficult to apprehend; obviously all policy actions are costly, so they always involve financial expenses from the part of the State but it is not sure that this would be the best variables to take into account. Perhaps a broader concept to use would be the displacement / additivity of resources in the general meaning of the word. For instance in the case of property rights, comparing the investment from the State in the legal system to the resources devoted by the agent to establishing some type of protection; in the case of cooperation, the investment from the State in the fundings of networks with the resources devoted by firms to the same purposes, etc.

As for the output additionality, the problem is also difficult. Following the logic of the neo-classical framework, additionality of indirect ways to increase the incentives to innovate could be handled in the same way as direct financial support. Other types of output could be in theory the information system at the disposal of the agents. A rich list of outputs is probably even more required when analyzing those types of policy actions, which render the understanding of the link between outputs and "differences" looked for by additionality research even more crucial.

The study of alternative ways of getting the same results (first interpretation of the behavioural additionality) is paradoxically as easy whatever the policy action, at least in theory.

Finally the cognitive additionality (including the second interpretation of behavioural additionality) seems to be relevant for all policy actions, since according to the second framework, all of them may be acting towards the increase of the cognitive capacity of agents. 
The conclusion of this analysis is that the very problem of additionality is relevant in both frameworks, but has some very different meanings in each, leading to different and possibly complementary concepts of additionality. Output additionality is more relevant in the neo-classical framework, whereas cognitive additionality is central according to the evolutionist structuralist one. As we have already mentioned, real policies do not fully stick to one or the other frameworks, and the policy action can be envisaged and interpreted (and possibily evaluated) in both of them. For this reason also, there is probably a strong need to try to reconciliate both frameworks. This may be the same for additionality. Refinements have nevertheless to be made to adapt those concepts to different types of policy actions.

\subsubsection{Some questions specific to the EU policy context}

Most, if not all, EU innovation-related policies could be related to one or the other principles descibed above. It is obviously not the purpose of the present study to further investigate such correspondances. But it is important to note that there are some other principles adopted by the EU from time to time which are very difficult to be directly linked to the ones derived from our analysis

For instance the support to other EU policy is difficult to fit into the picture. One should rather speak about coherence with other policies, which then make sense in both frameworks. The rationale for the specific support to SMEs is not a such to be found in neither framework. But if one looks at the supposed features of SMEs, bridges with both frameworks could more easily be found (for instance problem of economy of scales on the one hand, lack of knowledge-related resources on the other).

The question of cohesion is a little bit different. There is but a few traces of this notion in the neo-classical framework, to the notable exception of the actors' sets of information which should reach a certain degree of coherence in order to achieve the coordination of the system through price and market mechanisms. Conversely, cohesion is crucial in the evolutionist structuralist approcah, as underlined above.

Social objectives and quality-of-life related objectives raised other questions. Actually, theoretically they could be fully integrated in the neo-classical framework, provided that they could be expressed in terms of prices, quantity and incentives for choice. In this perspective, at most there is nothing like "economic", "social" or "environmental" effects or objectives, but effects or objectives than can be expressed in the computable with the neo-classical tools. To put it simply, unemployement is merely a matter of adjustment of demand and supply for labor, pollution relates with the amount of money one want to pay to avoid it, etc. As for the evolutionist structuralist framework, the question is less clear, since there is not such an unified vision and coherent set of analytical tools than in the first framework.

Different models of the innovation process can help us understand why and when science, technology and innovation (ST\&I) policies are needed and how they can play a part in the attainment of select societal goals. This understanding can then determine the choice of particular policy instruments and help frame their implementation. Typically this happens via the specification of goals in line with the overall rationale and, in the 
case of collaborative R\&D programmes, their subsequent translation into selection criteria for individual R\&D projects. Evaluators can then focus on issues such as the efficacy of selection procedures and ways of assessing whether or not individual project and overall programme goals are actually realised.

In reality, however, the goal-sets typically associated with individual ST\&I policy mechanisms are often broader than those for which these mechanisms are best suited. This is simply because ST\&I policies are invariably formulated within the context of more general policy formulation systems, all of which have as their focus the attainment of a vast array of societal goals. It is not surprising, therefore, that ST\&I policy mechanisms are often asked to achieve more than can realistically be expected of them. Unfortunately, one of the less desirable consequences is that evaluators are often expected to focus on goal attainment in these spheres, even though the contribution of individual instruments to many of these broad societal goals is likely to be slim.

Within the European Union, the Framework Programmes have long been the main ST\&I policy instrument. When first launched in the 1980s, the rationale for the early programmes tended to be couched in neo-classical terms, with a particular emphasis on market failure and a plethora of public good arguments for the support of science and technology. Over time, however, an increasing emphasis on the networking benefits associated with participation and the need for increased scientific and technological competence within the context of 'knowledge societies' have added an evolutionary edge to contemporary discussions of the rationale for these programmes.

In terms of overall goals for the Framework Programmes, there has also been a broadening of scope and heightening of ambition levels. The dominant goals over the whole period have remained the same - the strengthening of the scientific and technological basis of European industry and enhanced competitiveness at an international level - but these goals have been increasingly complemented by a set of associated aims which call for the Framework Programmes to support the achievement of many high-level socio-economic and political goals, including increased cohesion, enhanced employment prospects and a healthier environment. Naturally, this has had direct consequences for both project selection procedures and, down the line, for ex post evaluation, with the focus of many evaluation efforts expanding from assessments of project goal attainment to include tentative and exploratory attempts to assess downstream socio-economic impacts.

Within the Framework Programmes, application of the concept of European Added Value (EAV), defined here as: "the value resulting from EU support for RTD activities which is additional to the value that would have resulted from RTD funded at regional and national levels by both public authorities and the private sector",22, can be used to illustrate the evolving relationship between rationales, goals, selection criteria and evaluation. Ever since its earliest days the European Union has been expected to justify its actions in terms of the additional value they might have over the actions of individual

22 Guy, Denis and Galant, 'Identifying the constituent elements of the European Added Value of the EU RTD programmes: conceptual analysis based on practical experience', Report to DG Research by Yellow Windows NV/SA, Technofi SA and Wise Guys Ltd., November 2000. 
Member States. This principle has been formally embodied in successive versions of the EC Treaty and has underpinned programme formulation and the selection of suitable activities. At Maastricht, for example, the general criteria of subsidiarity and proportionality as the principles governing EU activities were introduced and later expanded in an annex accompanying the Treaty.

The principle of subsidiarity has two aspects, both of which have to be fulfilled to justify EU activities. In the first instance, the principle says that proposed actions are only justified if they cannot be sufficiently achieved by the actions of Member States in the framework of their individual national constitutional systems. Secondly, actions are only justified if they can be better achieved by action on the part of the EU. The principle of proportionality then states that any action by the EU shall not go beyond what is necessary to achieve the objectives of the Treaty. The EC Treaty further adds that EU activity is only justified if:

- it has trans-national aspects which cannot be satisfactorily regulated by action by the Member States;

- actions by Member States alone would conflict with the requirements of the Treaty;

- lack of action by the EU would conflict with the requirements of the Treaty;

- action at the level of the EU would produce benefits of a scale or impact which could not be achieved by Member States alone.

As a primary plank in the rationale for the EU, EAV has always constituted a high-level goal for the Framework Programmes. It this sense it is equivalent to any other high-level EU goal, e.g. enhanced competitiveness, but in practice it has been treated differently. Whereas consideration of other high-level goals helped to frame the specific objectives of individual programmes and the content of work programmes, the concept of EAV was used instead to frame modalities at a programme level and to suggest activities likely to lead to EAV. High-level goals aimed at preserving the environment, for example, led to the constitution of a specific programme of RTD in this area, whereas application of the concept of EAV led to a focus on modes of collaboration involving international partners (e.g. collaborative projects and networks) and excluded modes which - although likely to lead to goals such as an enhanced environment - would not result in EAV (e.g. projects involving participants from only one country). The concept of EAV was thus used to filter out certain activities once other goals had determined the general thrust of individual programmes, namely those likely to attain the other goals but unlikely to satisfy the demands of subsidiarity.

Over time, however, the use of EAV as a filter became exceedingly mechanical and trivial, with the involvement of partners from different Member States taken as sufficient in itself to demonstrate EAV and justify inclusion within the Framework Programmes. Not surprisingly, this eventually led to a situation where the attainment of EAV was given insufficient priority relative to the attainment of other goals.

The declining priority accorded to EAV came to a halt with the onset of FP5. The first Five-Year Assessment of the RTD Framework Programmes in 1997 considered that EAV 
had not been given sufficient priority in previous programmes and recommended that it be accorded equal status with the other strategic goals of the EU. Subsequently, the Council Decision covering FP5 set out the goals of EU RTD policy and the way the concept of 'value added' was to be applied. EAV became one of the key criteria for selecting the themes and objectives of Community actions. Critically, EAV also became a key criterion at the project selection stage, with applicants asked to specify the potential EAV associated with their projects and proposal evaluators expected to assess this potential contribution. Further down the line, programme evaluators were also expected to evolve ways of measuring EAV.

Even though these changes rightly emphasized the centrality of EAV in shaping the Framework programmes, it soon became clear that its use as a selection criterion and its measurement were problematic. Participants found it difficult to relate their projects to the concept and proposal evaluators found it equally tasking to assess the potential EAV of individual projects. For programme evaluators, too, the task of measuring and assessing EAV was challenging. The concept of EAV is actually a composite of a number of many other tricky concepts, few of which are widely understood and none of which are easy to measure. These include the 'EU concepts' of subsidiarity and proportionality, the related concept of additionality, in all its various forms, and even the generic - but still difficult to define - concept of value itself.

The difficult task of estimating EAV which confronted programme evaluators was a direct consequence of the shift from a compliance model of the selection process to an attainment model. In a compliance-oriented model, project proposals are judged in terms of their fit with EAV-oriented modalities (e.g. do they involve research on large-scale projects necessitating international collaboration? Do they involve work on the development of international standards?). The primary task of ex post evaluation is then to explore qualitatively whether or not any progress occurred in these spheres. In contrast, an attainment-oriented model involves asking questions of a quantitative nature at both the project selection and the ex post evaluation stages about the amount or extent of EAV which is likely to be generated.

Shifting towards an attainment model asked too much of both proposal evaluators and $e x$ post programme evaluators. A more fitting solution would have been to ensure - via informed debate at the highest levels - that the concept of EAV was not trivialised during the framing of programme activities, objectives and modalities, thus guaranteeing that all proposed actions and modalities were in line with the concept and likely - if successful to lead to outcomes with genuine additionality from a European perspective.

There are lessons here, too, for the assessment of ST\&I policies generally. It is entirely appropriate for programme evaluators to be asked to focus on both qualitative and quantitative assessments of goal attainment when the goals in question are directly in line with the rationales furnished by contemporary developments in innovation theory. It is diversionary, however, to expect them to also provide estimates of attainments relating to goals which are generic high-level societal goals concerned, for example, with health, employment and the general state of the environment. Surely the onus here should be on policymakers themselves to agree that the actions they frame are those most in line with the long-term interests of the constituencies they represent. Evaluators can certainly flag 
whether achievements in these areas are in line with expectations, but their main priority should necessarily be on the assessment of attainments directly associated with the state's primary motivations for supporting science, technology and innovation. 


\section{References for Section 2.4}

Arrow K. J., 1962, "Economic Welfare And The Allocation Of Resources For Invention", The Rate And Direction Of Inventive Activity, Princeton University Press, Princeton, 609625.

Belussi F., 1996, "Local Systems, Industrial Districts, And Institutional Networks : Towards A New Evolutionary Paradigm Of Industrial Economics ?, European Planning Studies, 4.

Callon M. 1994, "Is Science A Public Good?", Science Technology And Human Values, 19(4), Autumn, 395-425

Cantner U. \& Pyka A., 2001, "Classifying Technology Policy From And Evolutionary Perspective”, Research Policy 30, Pp. 759-775.

Cohen W., Levinthal D. 1989, "Innovation And Learning, The Two Faces Of R\&D". Economic Journal, 99, 569-596

Cohen E. \& Lorenzi J.-H., 2000, "Politiques Industrielles En Europe”, Rapport Pour Le Conseil D’analyse Economique, La Documentation Française, Paris.

Cohendet P. \& Steinmueller W.E., "The Codification Of Knowledge : A Conceptual And Empirical Exploration", Industrial And Corporate Change, Vol. 9, N. 2, Pp. 195-209.

Dasgupta P., David P. 1994, "Towards A New Economics Of Science", Research Policy, Vol. 23, 487-521

David P.A., 1999, "Science Reorganized ? Post Modern Visions Of Research And The Curse Of Success", Forum Engelberg Science-Economie-Société / Science Et Economie : Les Grands Défis, 6-7 Mai, Paris.

David P. A., 1999, "Knowledge Spillovers, Technology Transfers And The Economic Rationale For Pubic Support Of Exploratory Research In Science", Forum Engelberg ScienceEconomie-Société / Science Et Economiée : Les Grands Défis, 6-7 Mai, Paris.

David P. A., Foray D., Steinmueller W. E., 1997, "Global Science System Workshop Framing The Issues", Mimeo Iiasa, Laxenburg, Austria.

David P.A., Hall. B.H., Toole A.A., 2000, "Is Public R\&D A Complement Or Substitute For Private R\&D ? A Review Of The Econometric Evidence", Research Policy, 29, Pp. 497529.

Dosi G. 1982, "Technological Paradigms And Technological Trajectories: A Suggested Interpretation Of The Determinants And Directions Of Technical Change", Research Policy, 11 (3), 147-162

Dosi G., Freeman C., Nelson R. R., Silverberg G., Soete L. (Eds), 1988, "The Technological Change And Economic Theory",. Pinter Publishers, London, 349-369

Ergas H., 1987, "The Importance Of Technology Policy"

Firth L. \& Mellor D., 2000, "Learning And The New Growth Theories : Policy Dilemma", Research Policy 29, Pp. 1157-1163.

Foray D., 1991, "Economie Et Politique De La Science : Les Développements Théoriques Récents", Revue Française D’economie, Vol. Vi, 4.

Gibbons M., Metcalfe J.S., 1996, “Technology, Variety And Competition”, Economie Appliquée, Xxxix, N³, 493-520. 
Guellec D., Van Pottelsbergue De La Potterie B., 2001, "The Effectiveness Of Public Policies In R\&D", Revue D'economie Industrielle, Numéro Spécial : What Policies In Support For R\&D ?, N94, 1er Trimestre.

Griliches Z., 1979, "Issues In Assessing The Contribution Of R\&D To Productivity Growth", Bell Journal Of Economics, 10 (Winter), 92-116.

Jaffe A.B., 1996, "Economic Analysis Of Research Spillovers - Implications For The Advanced Technology Program", Http://Www.Atp.Nist.Gov/

Johnson B. 1992, "Institutional Learning", In Lundvall, B.-Å. (Ed.), National Systems Of Innovation. Towards A Theory Of Innovation And Interactive Learning, Pinter: London, $23-44$.

Kealy, 1996, "The Economic Laws Of Scientific Research",

Klette T.J., Møen J., Griliches Z., 2000, "Do Subsidies To Commercial R\&D Reduce Market Failures ? Microeconometric Evaluation Studies", Research Policy 29, Pp. 1157-1163.

Laffont J.J., Tirole J., 1993, "A Theory Of Incentives In Procurement And Regulation", Mit Press, Cambridge.

Koelliker A., 2001, "Public Aid To R\&D In Business Enterprises : The Case Of The Us From An Eu Perspective", Revue D'economie Industrielle, Numéro Spécial : What Policies In Support For R\&D ?, N94, 1er Trimestre.

Lispey R.G., Fraser S., 1998, "Technology Policies In Neo-Classical And StructuralistEvolutionary Models", In Oecd, 1998.

Luukkonen T., 2000, “Additionality Of The Eu Framework Programmes”, Research Policy 29, 711-724.

Lundvall B.A, 1992, "National System Of Innovation, Towards A Theory Of Innovation And Interactive Learning", London, Pinter \& Publisher.

Lundvall B.A. \& Borrás S., 1997, "The Globalising Learning Economy : Implications For Innovation Policy", Eur 18307 En, Tser / Science, Research And Development/ Ec, Luxembourg.

Malerba F., 1996, "Public Policy And Industrial Dynamics : An Evolutionary Perspective", In Research Project Final Report On "Innovation Systems And European Integration (Ise)", Funded By The Tser/4th Fp, Dg Xii/Ec (Contract Soe1-Ct95-1004, Dg Xii Sols).

Martin S. \& Scott J.T., 2000, "The Nature Of Innovation Market Failure And The Design Of Public Support For Private Innovation”, Research Policy 29, Pp. 437-447.

Metcalfe J.S., Georghiou L., 1998, "Equilibrium And Evolutionary Foundations Of Technology Policy", In Oecd, 1998.

Metcalfe J. S., 1998, "Innovation As A Policy Problem : New Perspectives And Old On The Divisions Of Labour In The Innovation Process", Sme And Innovation Policy : Networks, Collaboration And Indstitutional Design, 13th Ovember, Robinson College, Cambridge.

Metcalfe S., 1995, "The Economic Foundations Of Economic Policy : Equilibrium And Evolutionary Perspectives", In Stoneman P. (Ed)., 1995, "Handbook Of The Economics Of Innovation And Technological Change", Blackwell Handbooks In Economics, Oxford Uk And Cambridge Usa. 
Muldur U., 2001, "Is Capital Optimally Allocated In The Overall Process Of European Innovation", Revue D'economie Industrielle, Numéro Spécial : What Policies In Support For R\&D ?, $\mathrm{N}^{\circ} 94$, 1er Trimestre.

Nelson R. R., 1959, "The Simple Economics Of Basic Scientific Research", Journal Of Political Economy, Vol. 67, 323-348

Nelson R. R., Winter S. G., 1982, “An Evolutionary Theory Of Economic Change”, Cambridge, Harvard University Press

Nelson R. R., 1995, "Recent Evolutionary Theorizing About Economic Change", Journal Of Economic Literature, $\mathrm{N}^{\circ} 35$.

Nelson R.R., 1999, "The Sources Of Industrial Leadership", The Economist, N 147, January.

Oecd, 1998, "New Rationale And Approaches In Technology And Innovation Policy", Sti Review $\mathrm{N}^{\circ}$ 22, Paris.

Pavitt K., 1987, "The Objectives Of Technology Policy", Science And Public Policy Vol. 14, $182-188$

Shapira P., 2001, "Emerging Frameworks For U.S. Technology And Innovation Policy", Presentation At Beta-L. Pasteur University, Strasbourg, France.

Sherer F.M., 2001, "Us Government Programs To Advanced Technology", Revue D'economie Industrielle, Numéro Spécial : What Policies In Support For R\&D?, N94, 1er Trimestre.

Soete L. \& Ter Weel B., 2001, "Schumpeter And The Knowledge-Based Economy : On Technology And Competition Policy", Document Merit.

Smith K., 1996, “Systems Approaches To Innovation : Some Policy Issues”, In Research Project Final Report On "Innovation Systems And European Integration (Ise)", Funded By The Tser/4th Fp, Dg Xii/Ec (Contract Soe1-Ct95-1004, Dg Xii Sols).

Teubal M., 1998, "Policies For Promoting Enterprise Restructuring In Nsi : Triggering Cumulative Learning And Generating System Effects", In Oecd, 1998.

Usher D., 1994, "The Collected Papers Of Dan Usher", E.Elgar Publishing, Aldershot, Uk.

Yellow Window Management Consultants Sa/Nv, Technofu Sa, Wise Guys Ltd, 2000, "Identifying The Constituent Elements Of The European Added Value (Eav) Of The Eu Rtd Programmes : Conceptual Analysis Based On Practical Experience", Final Report For The Dg Xii Ec, Contract Eva5ct19990006. 


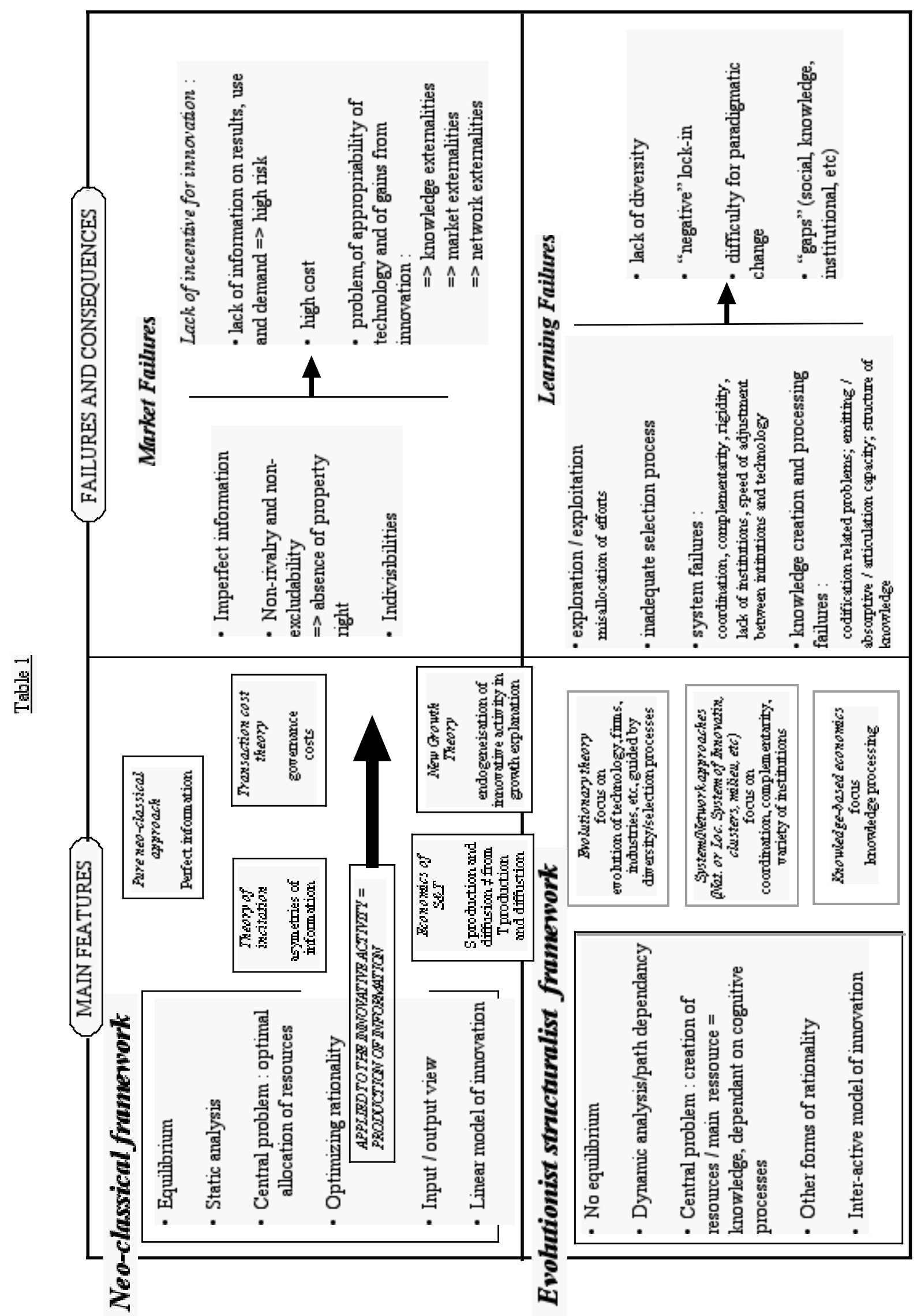




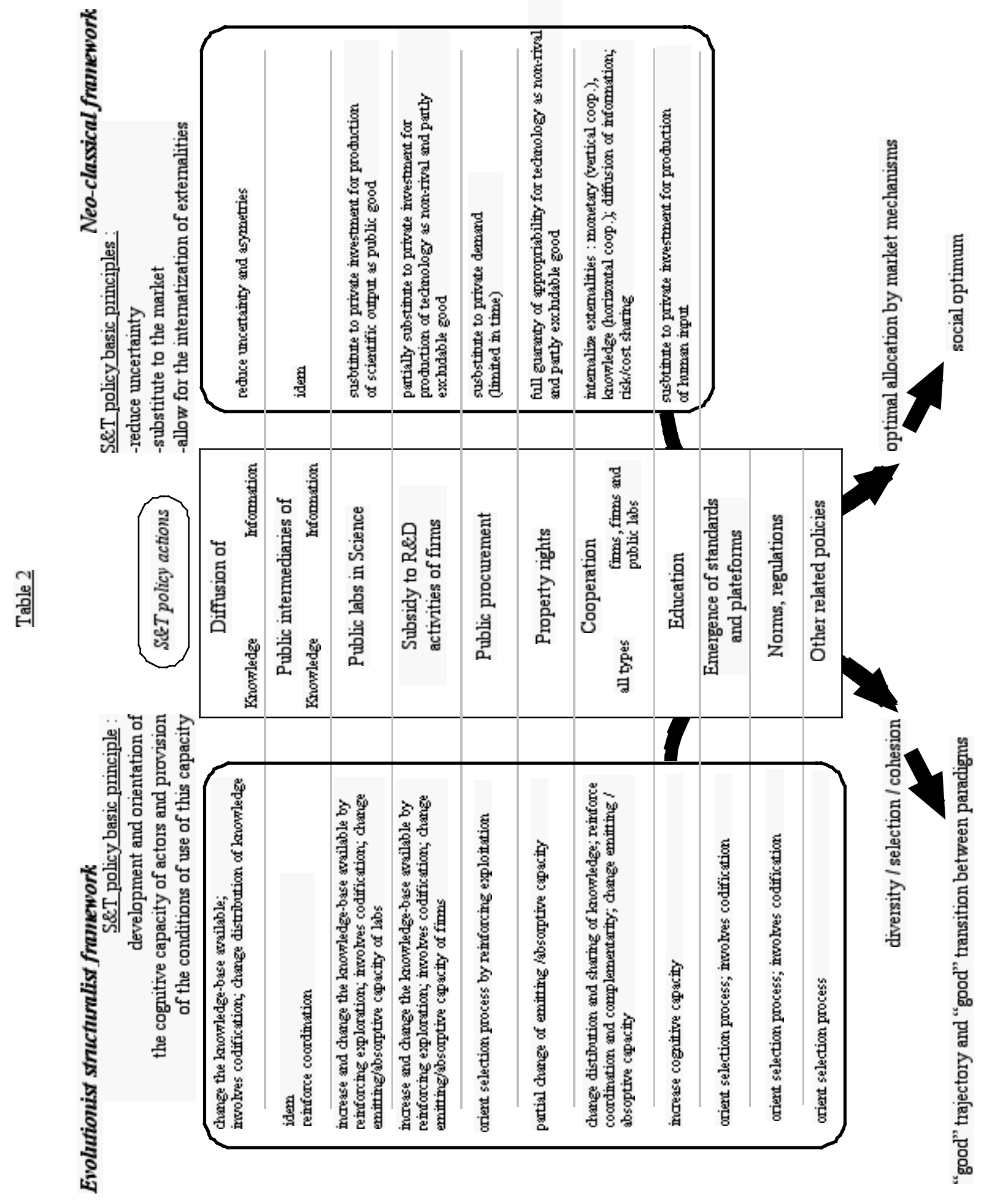




\subsection{Review of the key developments of the knowledge-based economy}

In this part, we propose a review of the current thinking on the combined role of ICTs, innovation and knowledge in economic growth and their impact on organisations. In part 1. we will try to described the main features that are commonly used to characterize a $\mathrm{KBE}$, to explain the overlaps, complementarity and/or differences with other notions such as New Economy, Learning Economy or 5th Schumpeter-type cycle, and to briefly relate the paradoxes and controversies raised by different analysts and which are largely related to the difficulties of measuring the key variables at stake in the analysis. The links between real phenomena connected to the development of KBE and the theoretical framework relevant to better understand these phenomena will be underlined in Part 2., in which we argue that only a Knowledge-Based Economics perspective allow us to really cope (at least partly) with the KBE reality. Finally, Part 3. is devoted to the exposition of some of the main questions and challenges raised by the emergence and development of $\mathrm{KBE}$, at economic and social levels, both levels being obviously intrinsically linked. In Part 4, we briefly summarize some basic policy recommendations stemming from the analysis previously presented.

\subsubsection{KBE : Main features}

Although there is not a unique definition of the $\mathrm{KBE}$, there is a quite general agreement on the statement that the $\mathrm{KBE}$ is an economy directly based on the production, distribution and use of knowledge and information. More or less important differences between definitions concern the relative importance of information and especially the development of Information and Communication Technology (ICTs), the links between the role of knowledge and information on the one hand and growth on the other, and the importance of other phenomena such as globalisation and deregulation.

\section{More precise elements of definition}

Rather than listing the numerous definitions put forward since economists have started to invest massively this field of research (roughly back in the early $90 \mathrm{~s}$ ), we will try to summarize the main features that help to understand the complexity of the phenomena at stake.

The emergence and development of $\mathrm{KBE}$ is characterized by the convergence and mutual reinforcement of two phenomena (Foray, 2000), notably observable in statistics roughly since the 90 s or even mid-90s (probably earlier in the US) : the increasing role played by knowledge in the economy and society as whole (possibly following a long term tendency) and the rapid development and pervasive use of a whole range of new ICTss. The consequence of these two related phenomena would be a significant increase of growth coupled with an increase of labour productivity.

- Different pieces of evidence show the increasing importance of role played by knowledge. The most frequently cited are the following : 
> There would be an increasing amount of resources devoted to the production, the transmission and the use of knowledge. Some statistics confirming this thesis show the large and often increasing investment in intangible capital, especially in knowledge, superior to the investment in physical capital. The investment in intangible capital has for instance been evaluated as the sum of the investments in education and training, health, safety and mobility and in R\&D. According to Kendrick (1994) this investment has been dominant since the mid-70s and its ratio on tangible capital has doubled between 1920 and 1990. Moreover, Abramovitz and David (1996) have shown that since the $20 \mathrm{~s}$, technological progress has tended to raise the productivity of intangible capital, while during the nineteeth century, its influence was more towards an increase of labour productivity thanks to investment in tangible capital; in other words, there has been a change in the bias of technological progress. More recent statistics developed by OECD and more focused on investment in knowledge show similar results : the investment in R\&D, education and software ranges between 8 and $12 \%$ of GNP for the OECD countries, although with structural differences according to countries. However, R\&D funding has fluctuated over the past years with the end of the cold war and the decrease in defence related R\&D. Roughly, public R\&D funding decreased in the early $90 \mathrm{~s}$, but in the second half of the 90s, R\&D intensity has increased again in some countries, thanks to private R\&D funding or to new public funding.

> There would be a growing importance of knowledge-intensive sectors. Whatever the definition of knowledge-intensive sectors, it has been acknowledged that their share in the GNP has strongly increased, especially recently. Statistical bases diverge on the figures (see below), but the most recent attempts of OECD to define the knowledge-based industries ${ }^{23}$ show that since the mid 90s, the share of these sectors in business added value has reached the $50 \%$ level in the EU and in the US, and its rate of growth from 1986 to 1996 has been higher than the average rate of growth of the business sector (OECD, 2000b).

> The high-skilled workers would represent a increasing share of all workers. All studies converge in showing the skill-biased evolution of employment in recent years : for instance the average annual increase of knowledge-workers (scientists, engineers, ICTss specialists, etc) amounted to $3.3 \%$ from 1992 to 1999 in the US and EU countries, while it ranged roughly from 2 to $3 \%$ for the previous ten years (OECD, 1996), (OECD, 2001). For both periods, this rate was significantly higher than the one of any other groups of occupations (especially the low-skill based group). This tendency has also been acompanied by the creation of a large range of new types of jobs and qualifications, of which the ones directly related to Internet and widely publicized are only the emerging part of the iceberg. However, it seems that some cross-sectoral differences exist, to the advantage of the knowledgeintensive sectors in which the upskilling has probably occured faster and to a

\footnotetext{
${ }^{23}$ high-tech sectors and medium high tech sectors (according to their R\&D intensity) + Communication Services + Finance, Insurance and other business services + Community, social and personal services.
} 
large extent. Moreover, the trend is often accompanied by changes in qualification and changes in wages distribution.

$>$ Knowledge and innovation would have an increasing importance in the competition processes. Numerous case studies provide partial evidence of this tendency, which is expressed in the diversification of products, the number of new products put on the markets, the number of new firms based on new products or completely new domains, the apparently endless reduction of time to markets, the reduction of products and technology life cycle, etc. (See WP 2.1.2 on this point). Statistics from the innovation surveys carried out at national and European levels (CIS 1 and 2) confirm this point. Some econometric studies have recently been carried out in order to directly relate innovation to firms performance, showing not only a positive relation between these two variables but also a positive relation between the persistence of innovation activity and the persistence of performance on the markets (Cefis, 2001). A huge amount of other studies at meso or regional or cluster levels also give hints on that point.

The increasing importance of ICTss is attested by numerous statistics. On the one hand, this importance could be evaluated with an "output perspective", i.e. by taking into account the share of GNP produced by the ICTss sectors. But this share is relatively low, and most of all does not express the pervasive influence of ICTss throughout the economy. Therefore an alternative way is to take an "input perspective" according to which the investment in ICTs by the economy is investigated ${ }^{24}$. For instance, the growth in ITC expenditure per capita has been more than twice the growth in GDP per capita between 1995 and 2000 in the EU, the USA and Japan ${ }^{25}$ (source : EITO). According to OECD statistics, investment in ICTs has increased considerably in recent years and in 1997, represented 4\% of OECD GDP (OECD, 2000a) and 10 to $20 \%$ of all investment in the business sector in value, and more than $50 \%$ in volume. In France, the most recent calculation shows that investments in ITC (ICTs equipment and software) have doubled in twenty years and account at present for $20 \%$ of investment, against $36 \%$ for the US (Mairesse et al., 2000). But statistical difficulties make comparisons difficult.

A complementary view on this consists in looking at the sectors which are ICTsintensive, in the sense that they invest more in ICTs than the others : services, banking, and a few industrial sectors. Here again, it seems that the more growth-oriented sectors are those which are the most ICTs-intensive. Another set of statistics, very diverse, attest to the rapid expand of various uses of ICTs throughout all sectors and levels of the economy, however largely varying from one country to the other (in terms of PCs, Internet connections, firms networks, etc).

- The question of the respective impact of knowledge and of ITC on growth and productivity, and moreover that of their combined influence on these variables is

24 Another solution is to evaluate the different impacts of this investment in ICTs (see below and (OECD, 2000a).

25 source : European Information Technology Observatory 
undoubtedly more difficult to evaluate, and has given rise to different, partial and sometimes controversial analyses. For the time being, the main results are the following:

$>$ As for the impact of knowledge, the only figures available at macroeconomic level are related to the impact of R\&D on growth and productivity (see WP 3, Contribution 2.1.1)

$>$ As for the impact of ICTs, different calculations have been proposed (for instance (OECD, 2000), (Mairesse et al., 2000), (Oliner \& Sichel, 2000), Jorgenson \& Stiroh, 2000). First, there is undoubtedly a significant impact of ICTs on growth especially in the second half of the $90 \mathrm{~s}$, whereas it had decreased in the first half. But 1995-99 figures range from 0,29 over 2,2\% of GDP growth per year for France (Mairesse et al., 2000) to 1,1 over 4,8 \% for the US (Oliner \& Sichel, 2000) with differences according to countries and according to studies. More important, this impact has dramatically increased since the 1980-85 period. This impact also seems significantly higher in sectors which are ITC intensive. Second, there are some strong differences in the multifactor productivity ${ }^{26}$ according to countries, but in the first half of the $90 \mathrm{~s}$, it did not seem that the ICTs had a specific impact on it. But recent studies seem to show that, at least in some countries especially in the US, not only the MFP has increased in general, but this increase is not restrICTsed to ICTs sector. In other words, statistics may be interpreted as showing a pervasive influence of ICTs on productivity in the economy as a whole. Studies at firm level are going in the same direction .

\section{Related trends and phenomena}

According to most of the analyses in the field, the emergence and development of KBE is accompanied by some fundamental trends of modern economies, partly reinforced by specific policies. At least three of them are the most often quoted, and are closely interconnected :

- the globalisation of the economies, induced by political (consolidation of EU, changes in former Eastern Europe...) as well as economic factors (globalisation of markets, etc); this globalisation is facilitated by ICTs which favour the flows of information, and in turn calls for more ICTs capacities. But many differences in terms of economic performance and structural characteristics as regards ICTs and knowledge-related phenomena still persist between the different countries, which leaves open the debate about the convergence of economies (see for instance (Fagerberg et al., 1999) for quantitative economic analysis, (Lundvall \& Borras, 1997) for a more global one, and the reference always made to this dimension in the different OECD publications cited in the bibliography)

- the development, the increasing variety and the complexification of financial markets; with the development of markets, more financial resources are made available, and more and more specific financial tools are designed to be adapted to the different steps of innovative initiative;

\footnotetext{
${ }^{26}$ which is supposed to account for the efficiency with which labour and capital factors are used.
} 
- the movement towards deregulation and liberalization of the economies, represented by the openess of markets and all forms of anti-trusts, demonopolization or other public aid surveillance related policies.

\subsubsection{Overlapping concepts}

The concept of KBE and obviously the real phenomena it is supposed to allow to apprehend has undoubtedly some connections with other approaches. Three of these must be mentioned here.

The first is the "learning economy". It is probably the closest concept, provided that the analysis of the KBE emphasizes the learning and cognitive dimension of phenomena that drive the economy, rather than too narrow views focused on the role of information and the role of purely technical innovation. Moreover, as it will be argued below, the term "learning economy" could be more appropriate to describe what some analysts consider as being really at stake in the economy and society as a whole.

Another approach related to KBE is the hypothesis that modern economy would have entered a new long wave growth cycle, namely a fifth one according to the Kondratieff/Schumpeter type of classification (see for instance (Freeman \& Soete, 1997). This new cycle would have started in the $80 \mathrm{~s}$, and :

- would be mainly based on information and communication related technologies, products and industries, with electronic chips as the key input available at low price;

- $\quad$ would contribute to solving techno-economic problems impeding the survival of the precedent cycle (such as trade-offs between scale and scope economies unfavourable to rigid and mass-production oriented production systems, limitations of technical properties of materials or device overcome by ICTs controlling and piloting systems...);

- $\quad$ would be accompanied by some new forms of firm organizations, of cooperation and of competition (network organisation, quality oriented management, etc).

Although this type of approach is trying to encompass very different dimensions of change (social, organizational, technical, ...) accompanying the emergence of this fifth cycle, it favours the technological factor as the basic engine of evolution, in a Schumpeterian tradition, without focusing too much on the knowledge-related aspects.

Finally, we have to mention the common features of KBE and of the so-called "New Economy". New Economy has been the term the most frequently used to qualify the recent evolution of the most advanced modern economies (see the synthesis in (OECD, 2000a), (OECD, 2001). But beyond the "hype" and the "commercial" and superficial arguments frequently used throughout traditional or more professional media, this approach tends to focus on the importance of the ICTs-based sectors and on the role of ICTs in the diffusion of information, neglecting other profound tendencies related to the 
production, use and diffusion of knowledge. This focus is probably due to a particular analytical perspective adopted to understand the evolution of economies (see below).

\section{Controversies and paradoxes}

Apart from the very interpretation of the systemic relations between knowledge, ICTs and growth, to which we will come back later, the study of KBE has to cope with measurement and technical problems disturbing the production and interpretation of data. Problems are at stake at different levels, and correspond either to quite classical debates in economics or to newer ones. It must be stressed however that an increasing number of economists, statisticians and econometricians are developing tools and techniques more adapted to the specificity of these problems, particularly with the help of OECD and other governmental organisations.

A first problem concerns the difficulty to define the relevant types of variables to account for knowledge and information-related investment, as well as the ambiguity between knowledge and information in the different statistics regarding production or investment. As we will discuss, this problem is deeper than a pure technical one. It is largely due to the problem encountered on the side of statistics about knowledge-related investment, which just begin to be available, at least to a certain extent. It is for instance worth noticing that the different analysts sometimes use similar variables to evaluate knowledge-related investment and ICTs (such as software). The OECD has recently set up the first steps of a statistical system to reach a higher level of homogeneity and availability.

A second problem is to measure the related variables, provided that they are properly defined. The work on statistical system adequate for ICTs related investment is much more advanced, but technical problems still exist. To name but a few, there is the problem of homogeneity at international level of the treatment of software (which seems close to be solved), the problem of the rapid obsolescence of ICT equipment and products, and moreover the distinction between volume and price which is even more crucial, especially with the rapid decrease in prices of many products in this area combined with a rapid increase in the level of quality and functionality. Sophisticated methods are presently developed, not for the sake of statistician professional integrity, but because traditional models have led to very different empirical results about ICT investment and impact on other economic variables (Cette et al., 2000).

A third class of problems is related to the assessment of knowledge and ICTs related investments on growth and productivity. Classical debates about the relevance of econometric tools and practices related to the calculation of multifactor productivity or the use of production function are here at stake.

These problems and actual limitations of available data partially explain some of the controversies that arose in the late $90 \mathrm{~s}$. One of these is about the importance of knowledge in growth, which according to different interpretations would be a recent phenomenon or conversely a more long term tendency (Howitt, 1996), (Abramowitz \& David, 1996). But the debate that has drawn most attention was about the so-called "productivity paradox" once mentioned by Solow in the 80 s and later on popularized well 
beyond the expectations of its author. The question put forward was basically that we could see computers everywhere except in the statistics on productivity. Very recently, this apparent discrepancy between reality and statistics has largely disappeared, with the rather clear link established between ICTs investment and productivity. Different questions have then be analyzed. A first one was about the relevance of statistical and econometric tools : having made them more relevant would have helped to better evaluate an existing link between both variables. Another debate took place between the hypothesis of a shock provoked by a new generation of ICTs and the hypothesis of a more long term tendency to ICTs capital accumulation which took time to impact on and express in productivity statistics. The second hypothesis has recently been supported by including in the explanation other parameters related to the organisational dimension of the economy, and in particular the changes in internal organization of firms and modes of interaction between firms and their environment. It is argued that the importance of ICTs expenditure is positively linked with the implementation of new work practices such as teamwork, job rotation schemes, employee involvement, flatter management, etc (see (OECD, 2001) for figures at national level). The solving (or the disappearance) of the productivity paradox would be due to the fact that the organizational changes required to fully benefit from ICTs have been introduced more slowly than the ICTs themselves, and then the latter have impacted on the productivity with some time lag. It is also possible that during a first phase, the organizational problems caused by the introduction of ICTs had had a negative impact on productivity (see (Greenan \& Mairesse, 2000) and (Foray \& Mairesse, 1999) for comprehensive surveys on these points).

Lastly, we could mention the present debate about the problems encountered by many firms representative of the New Economy (in particular firms involved in e-business and mobile telecommunications) and the slowing down of the rate of growth observed in the US as well as in the EU since a couple of months. For the upholders of the knowledgebased economy, this could only be a short term adjustment.

\subsubsection{Knowledge-based economics: a key to understanding the knowledge-based economy}

The attempts to proposed fine interpretation and rigorous explicative schemes of the above tendencies are obviously made more complicated by the systemic nature of the evolution, which is widely acknowledged by all analysts (if not exploited through the empirical tools of measurement). It is also blurred by the combined influence or the congruence of other trends observable almost on the same time horizon.

Following Foray and Lundvall (1996) and Foray (2000), we will assume that there is not only a change in the economic and social conditions of growth corresponding to the emergence of a knowledge-based economy, but also a change in the ways economists (perhaps following researchers from other disciplines) envisage these evolutions. There would be in parallel with the emergence of the knowledge-based economy the emergence of the knowledge-based economics; this latter considers that the locus of economic evolution is to be found in the processes of production, diffusion and use of knowledge and the cognitive capacity of agents and groups of agents inherent to these processes. Moreover, we do think that it is only when one adopts this perspective (at least in complementarity with others) that one can understand the nature of the real phenomena 
related to the knowledge-based economy, apprehend their different dimensions as well as their coherence and articulation, and identify their consequences.

The importance of a knowledge-based economics perspective is precisely to escape two traps. First, to interpret the fact that the recent growth observed in the developed countries (especially in the USA) has been parallel with the development of the ICTs and their growing and pervasive influence on most if not all sectors of activities, by assuming that the increasing production and availability of information is the only explanation of this growth. Second to consider that the combination of developing ICTs and the increasing importance of innovation (and in particular technological innovation) relies only in a new feature of the innovation process, i.e. its ability to create more information which would be easily spread and exploited throughout the economy, with globalisation, financial resources availability and deregulation as speeding up the whole process.

The core of the argument is connected with the nature of knowledge processing. More and more scholars acknowledge the importance of the tacit dimension of knowledge, and moreover the importance of the combination of tacit and explicit knowledge in the "knowledge base" of any agent or part of the economic system and society. More recently the debate has slightly shifted to the question of tacit vs codified knowledge, taking into account the variety of codes under which knowledge can be expressed (Cohendet \& Steinmueller, 2000) and the very process of codification. Another dimension is that not only the processes of knowledge production, but all processes of knowledge transmission and use involve a cognitive dimension. Transmissions are not like exchange of data between computers, and use is not only reading data and running a computer programme : beliefs, representations, visions, habits, education, etc are part of it. Lastly, these processes are by nature collective, although involving different intensity and frequency of interactivity between actors.

These considerations help to understand the specific properties of knowledge, which are only partly common to the ones of information (for instance non-rivality, non a priori determined form of return as for its production, or cumulative and combinatory properties).

As suggested earlier, the consequences of this differences between information and knowledge are decisive. The first, and maybe the most important, is that the transmission and diffusion (and hence the appropriability) of knowledge is far for being as easy as transmission and diffusion of information. In other words, emitting and absoptive capacity of agents are diverse, depending not only on the knowledge to be transmitted, but also on the context and on their cognitive capacity since they often involve a recreation of knowledge. It is often argued that codified knowledge is similar to information. As far as we stick to a "computer-oriented" definition of information (set of 1 and 0 ), it would conversely been argued that information is only one form of codified knowledge among others. What kind of codified information may be transmitted through Internet ? For economists interested in $\mathrm{KBE}$, the question of the nature of the outputs from scientific activities and technological activities is closely linked with this point (see WP3 Part 2.2 of this report). 
A second consequence is related to the respective possibility of storage and retrieval of the knowledge and information, which obviously are not the same. It is just to mention the difficulties encountered by firms to set up efficient interactive and regularly actualized digital knowledge bases (see Hansen et al., 1999).

A third consequence of this knowledge-oriented perspective is the delimitation of activities or sectors which are supposed to produce the key resources for the KBE. Three debates can be briefly reviewed here. Firstly, knowledge is frequently reduced to science or technology-related knowledge, whereas it should encompass all kinds of knowledge, for instance related to capacity to manage, to cooperate, to motivate, etc (see for instance the recent work about the competences to innovate (Munier, 2000) and (Foray \& Mairesse, 1999). Correspondingly, any activity fundamentally involves the creation of some sort of knowledge (as for instance Gaffard \& Amendola (1988) underlined), and even the most repetitive ones may result in learning by doing (see Arrow (1962b) for the most famous contribution, although not the only one). Second, even if we focus on science or technology-related knowledge, we have to consider other sources than R\&D activities and access to knowledge codified in the form of articles, patents and data bases; these other sources are for instance related to all interactive forms of collective learning involving different type of partners and forms of partnerships, and all ways of sharing and diffusing knowledge through knowledge communities or informal social networks (see for instance the various sources of innovation investigated in the Community Innovation Surveys). Thirdly, it may be misleading to concentrate exclusively on the Information Sector following the old definition of Machlup (1962), or even on the so-called Knowledge-based Industries defined by the OECD as combining high-tech sectors and ICTs based sectors (Eliasson, 1990). Again this definition is biased towards R\&D activities on the one hand and ICTs on the other.

The question of the respective value of information and knowledge is another fundamental debate, far much complex to be developed here. It is nevertheless important to emphasize different properties of information as a tradable good : it can be sold without being withdrawn from the seller; it can be used several times; it can be reproduced and transmitted from one physical support to another at a very low cost almost not influenced by the geographical dimension; the seller can not easily evaluate the value of the information without having it; for one agent, its value often depends on the other information he already has or will have in the future, and of the information owned by other agents. Roughly, the value of knowledge and the value of ibformation exhibit the same characteristics, to two important exceptions : the characteristics related to transmission and duplication, and most of all, the value associated to the impact information and knowledge have cognitive capacity of agents.

\subsubsection{Interpretations and challenges}

The elements developed in this contribution tend to show that KBE are economies exhibiting GDP growth and in some cases Multifactor productivity growth ${ }^{27}$ due to a combination of factors, among which the technological development takes a predominant

${ }^{27}$ Although there are some differences according to countries, especially in terms evolution of GDP per capita and Multifactor productivity gains. 
place, especially related to ICTs, the increased level of skills and the development and use of smarter, more collective and efficient ways of working. At sector level, this tendency is particularly sustained in sectors which have massively invested in ICTs and which were previously supposed to be less innovative and less efficient in terms of productivity (such as service sectors). Correspondingly, the relationship between science and technology has evolved towards a more cooperative and probably more marketoriented type, boosting the economic performance of innovative firms and sectors, especially those which rely heavily on science progress (biotechnology, ICTs sector, new materials, pharmaceutics, etc). This evolution has been facilitated by the use of ICTs, allowing networking, flows of information (especially technology-related ones thus facilitating externalities of innovative activities), reduction of transaction costs, shortening of cycle times, etc. Innovation and ICTs are indeed at the heart of the evolution, connected by the learning processes they stimulate and on which they rely. This co-evolution and congruence of multiple factors raise new challenges and new risks, that become more apparent when they are put in the perspective of the knowledge-based economics.

\section{Codification of knowledge}

The question of codification is certainly central in KBE. As stated before, it is far from being a trivial one (i.e. a simple transformation into a series of 0 and 1). One important consequence of this debate is about the impact of codification on the economy and its interaction with ICTs pervasiveness. There would be relatively few "purely" tacit knowledge, but rather the codification would be driven by economic incentives and/or cognitive attention. Two interpretations are proposed (Cohendet \& Steinmueller, 2000). According to the first, there is an increasing amount of codified knowledge because the cost of codification is decreasing thanks to ICTs. Correspondingly, this increasing amount would be more and more easily transmitted and diffused throughout the economy, at a decreasing cost. Moreover, the economic benefits form codification would increase as more and more codified knowledge is available. In other words, ICTs would turn knowledge into like public good (Cowan \& Foray, 1997), and allow for increasing returns as for the codification activity. Therefore, the key point for supporting the economy would be to provide access to ICTs to all agents, favour standardisation in ICTs, and to support any process of codifying knowledge in a form compatible with ICTs. The other view (possibly complementary rather than opposite) is to assume that in order to benefit in economic terms from the codification associated to ICTs, other investments are required : what is important is the capacity of agents to understand, appropriate and use this codified knowledge as well as other forms of codified knowledge, and basing on this to create new knowledge. In other words, the problem is not the information but the capacity to select, classify this codified knowledge, and more than this, the cognitive capacity which depends also on education, social structures, access to informal networks, etc. This point had already been partly raised for instance by Lundvall (1994) : when more formalized and codified knowledge is available to more people thanks to ICTs, the economic value of tacit knowledge increases.

Codification compatible with ICTs technical requirements raise other problems and challenges. For instance : 
- the interface and inter-operability of different ICTs equipments, of which the cost is far from being really evaluated at firm level as well as at the level of the cooperation in supplier-client relations.

- the short life time of ICTs technologies and the problems caused by the replacement of equipments and codes;

- $\quad$ linked to this, the problem raised by digital storage, which introduces one intermediary step between information as a set of 0 and 1 and interpretation (how to use Multiplan data base with Excel 2000 ?), and is from a technical point of view less durable than books for instance;

- the danger of monopolization of the code by a small number of agents and/or firms

- the rigidity and excess of standardization of the form of codification compatible with ICTs, which tend to limit the variety of codes and moreover the capacity to create or develop alternative codes.

A complementary interpretation of the impact of ICTs on productivity and performance

ICTs are frequently assumed to benefit to the economy through the development of new industries, through productivity gains (associated to information flows), but also as incentives to adopt new forms of organization : as mentioned earlier, it has been argued that new forms of organizations have to be set up within and between firms in order to benefit from ICTs. To complete the pICTsure, it must be stressed that a lot of these organizational changes do not realy need ICTs that much, and as such may have some positive impact on performance (Total Quality Management, $5 \mathrm{~S}$, lean production, etc vs SAP). But precisely, they require skill and cognitive capacity from the workers for autocorrection, empowerment, collective behaviour, continuous progress, etc. For instance, when one looks at the programmes set up by firms in the field of enterprise based training, training in ICTs field does not account for the largest share. In R\&D, it has also been suggested that the ICTs could have lesser role than previously evaluated in direct codification, but would rather help to produce various forms of knowledge thanks to the tools available for simulation, modelization and trial-and-error (Steimueller, 2000), (Nightingale, 2000). A detailed examination of the gain form ICTs related to e-commerce is going in the same direction (Margherio et al., 1998), (Rouilleault, 2000) : learning at individual and organizational levels are required and their combination with the use of ICTs is the key point.

\section{New ways of performing $R \& D$}

It is widely acknowledged that new forms of performing R\&D (more collaborative especially between firms and universities and/or public labs, and more market-oriented) have been increasingly used in recent years. But following Gibbons et al. (1994), this trend runs in parallel with a more interdisciplinary research and with a more problemsolving orientation. A learning-based perspective emphasizes that these forms of collaboration requires personal contacts as much as ICTs-type of communications, and results in other forms of codified or non codified knowledge than publications cited in 
patents, co-articles and co-patenting. Moreover, it may also change the traditional distinction between science and technology as regards diffusion and incentives (as suggested by Foray back in the early 90s, (Foray, 1991). Moreover, it is difficult to evaluate the impact of this trend on another aspect of the cognitive capacity of the researcher system, that is its capacity to elaborate new problematic and thus to generate new paradigms.

\section{Outsourcing}

It is often argued that the development of outsourcing has been favoured by ICTs (facilitating information flows and reducing transaction costs). But firms' policy is obviously more determined by trade-offs between cost and competence availability internally or on the market. It is interesting to note that, although the cost-related argument is often the decisive one, more and more firms take into account knowledgerelated arguments to make or revise their decisions, such as : the danger of knowledge dependence vis-à-vis the supplier (for instance in automotive industry), the learning capacity of the supplier (for instance in science-based industries) or the required level of interactions other than through ICTs (Gilley \& Rasheed, 2000).

\section{Social gaps, information and learning divides}

According to the viewpoint developed here, one of the dangers at social level is not so much an increasing "information divide" than an increasing "learning divide" (Lundvall and Borras (1997) talked about IT as Intellectual Tribalism). The difference is not in terms of access to information and ICTs networks but rather in terms of absorptive capacity of information, learning capacity, access to social and economic conditions allowing to learn, and opportunity of collective and interactive learning ${ }^{28}$. It is for instance easier to buy a computer or connect to Internet than to learn how to use it, and in many contexts (especially professional ones) it is probably easier to learn how to use it than to learn what to do with it. More generally also, the human skills required are no longer only "technical knowledge" rather than a human ability to communicate, cooperate, anticipate, negotiate, etc, and obviously learn.

Thus, the skill-biased evolution appearing in statistics (ICTs workers vs others, or researchers engineers vs others, etc) should not be solely observed, but one has to take into account more subtle and deeper divides. In this respect, the pressure on wages in favour of the ICTs workers in general is not only unbalancing the whole labour market, but may be felt as not fully fitting the evolution of marginal productivity of workers.

An important challenge concerns the elderly and the older generation of workers. Here again, focusing only on information could give the impression that the problem is the ability of these populations to manipulate ICTs-related equipments, causing generation gaps. In non-professional contexts, one could also wonder whether their cognitive

\footnotetext{
${ }^{28}$ The same question is raised at international levels : the difference between developed and developing countries is not so much the access to Internet than the interconnection of the latter to the learning processes of advanced countries. Statistics about the intensity of ICTs-equipement (see for instance (UN, 1999) surely misses part of the problems.
} 
structure is adapted to the type of services that can be rendered by ICTs equipments. At the work place, the problem is maybe more crucial (especially in firms older than say, twenty or thirty years). A large part of the non codified knowledge is possessed and shared by the older or medium generation, which has two general consequences : first, they in particular may be reluctant or may meet difficulty with the specific codification required by ICTs; second, it is often the types of knowledge they posess which is required to get benefits from the codified knowldege processed through ICTs.

Another change impulsed by the ICTs is the end of the necessary unity between time, place and team at work. Again, referring purely to the information aspect of the work, the possibility of dissociating these three dimensions with ICTs is enormous. A knowledgebased approach reveals that it is not so simple (as testifies the increasing amount of meetings, workshops, work groups, etc, in most of the organizations). And the social consequences of this, for instance in terms of reduced delimitation between private an professional life, are far to be evaluated yet.

Many other social questions are raised by the emergence of $\mathrm{KBE}$, and can be usefully looked from a knowledge-based perspective. To name but a few :

- $\quad$ the privacy and security problems associated with the use of ICTs; Internet is archetypal on this point;

- the question of industrial and intellectual property rights raised by the diffusion by means of ICTs;

- the discrepancy between classes of population who have time to absorb and enjoy new information-intensive goods but do not necessarily possess the cognitive capacity to do so, and other classes of population who are in the opposite situation;

- $\quad$ the impact of ICTs-based leisure products on young generations;

- the form of education programme to be developed by the eductaive system, allowing to combine the benefits from ICTs and the necessity to develop the learning capacity of students (of all age);

- the consequence of the development of services really specific to Internet;

- the consequence of all the possibility of virtual interactivity;

- the use of ICTs for different forms of direct or decentralized decision systems in national or local public policies;

- etc.

All the questions discussed above clearly show that the key point in KBE is the learning capacity of agents (and thus firms and any other organization), which allows them to create, share diffuse and use new knowledge, whether tacit or codified, and whatever its form of codification. Only this learning capacity make them able to change, to adapt to new economic and social conditions and most of all to create better conditions. In this perspective, it is not surprising that a huge effort is required for supporting any form of education, for children as well as for adults, in order to avoid polarization between learning and non-learning sub-sets of our modern societies, which would also inevitably result in inequalities in economic terms. 


\subsubsection{Policy Recommendations}

Apart from ensuring some general conditions that are essential to any growth policy (such as the preservation of macro-economic stability or the encouragement to openness), public policy should aim at :

- $\quad$ ensuring an environment conducive and receptive to innovation and new technologies, by :

$>$ giving priority to research on which depend future innovations, both by direct support to basic research (in order to increase the stock of fundamental knowledge and to provide highly skilled graduates) and by setting up policies favourable to effective and mutually beneficial collaboration between science and industry;

> improving the effectiveness of public support for innovation;

$>$ developing relevant schemes for IPR questions;

$>$ favouring the entrepreneuship, by setting up financial conditions facilitating the access to financing, especially for start-up firms, and by facilitating the administrative conditions related to entry and exit of firms;

$>$ building up confidence in the use of new technologies for business and consumers, especially ICTs.

- $\quad$ ensuring the investment in and the access to ICTs by setting up regulatory frameworks and market conditions leading to low price, in order to allow all the society to benefit from the cumulative advantages associated to the use of ICTs.

- $\quad$ providing people with the basic tools and skills required to use the new technologies, especially the ICTs, and more generally to adapt to, or better master, the social, economic and cultural evolutions induced by the development of ICTs. This is probably the most important policy challenge, since it is the condition for avoiding too large information and knowledge divides that would have economic (in terms of shortage of human capital) as well as social dramatic consequences. Education and training policies obviously play a key role in this respect, for instance through the investment in high-quality early education, the improvement of school-to-work conditions, the access to training and to education system at all age of life or the strengthening of the links between higher education and the business environment (labour markets, firms, trade unions, etc). 


\section{References for Section 2.5}

Abramowitz M. - David P.A., 1996, "Technological Change, Intangible Investments And Growth In The Knowledge-Based Economy : The Us Historical Perspective", In Foray D. Lundvall B.A. (Eds) Employement \& Growth In The Knowledge-Based Economy, Oecd, Paris.

Amendola M. - Gaffard J.L., 1988, “La Dynamique Économique De L’innovation”, Economica, Paris.

Arrow K. J., 1962a, "Economic Welfare And The Allocation Of Resources For Invention", The Rate And Direction Of Inventive Activity, Princeton University Press, Princeton, 609625

Arrow K. J., 1962b, "The Economic Implication Of Learning By Doing", Review Of Economic Studies, 29, (80), 155-173.

David P. A., Foray D., 1996, "Accessing And Expanding The Science And Technology Knowledge Base. In: Special Issue On Innovation And Standards, Sti (Science Technology Industry)", Review No. 16. Organisation For Economic Co-Operation And Development (Oecd), Paris, 13-68

Bresnahan T., 1999, "Computerization And Wage Dispersion", The Economic Journal, Vol. 109, 456.

Callon M., 1994, "Is Science A Public Good ? Fifth Mullins Lecture", Science, Technology And Human Value, 19(4).

Cefis E., 2001, "Innovative Activities, Profitability And Heterogeneity", Seminar At Beta, L. Pasteur University Strasbourg, June Based On The Presentation Made At The 8th International J.A. Schumpeter Society Conference At Esrc Manchester, 2000.

Cette G. Et A1., 2000, “La Mesure De L'investissement En Technologies De L'information Et De La Communication : Quelques Considérations Méthodologiques", Economie Et Statistiques, 339-340, Pp. 73-91.

Cohendet P., Steinmueller W. E., 2000, "The Codification Of Knowledge: A Conceptual And Empirical Exploration", Industrial And Corporate Change 9(2), 195-209

Colecchia A. - Schreyer P., 2001, "The Impact Of Information And Communication Technologies On Output Growth : Issues And Preliminary Findings", Oecd, Draft Dsti/Eas/Ind/Swp(2001)11, February.

Cowan R. - Foray D., 1997, "The Economics Of Codification And The Diffusion Of Knowledge", Industrial And Corporate Change 6, 595-622

Gilles L. Et Al., 2000, "Les Technologies De L'information Et De La Communication - Des Effets Favorables Sur L’emploi”, Le 4 Pages N 133 , Sessi, Ministère De L'economie, Des Finances Et De L'industrie, Paris.

Gilley K.M. - Rasheed A., 2000, "Making More By Doing Less : An Analysis Of Outsourcing And Its Effects On Firm Performance", Journal Of Management, Vol. 26, N4, Pp. 763790.

Eliasson G., 1990, "The Knowledge-Based Information Economy”, In Eliasson G. Et Al. (Eds) The Knowledge-Based Information Economy, Almqvist \& Wiksell International, Stockholm.

Fagerberg J., Guerrieri P., Verspagen B., 1999, “The Economic Challenge To Europe. Adapting To Innovation Based Growth", Aldershot E. Elgar Publisher. 
Foray D., 2000, , 'L'economie De La Connaissance", La Decouverte, Coll. Reperes, Paris.

Foray D. - Lundvall B.A., 1996, "The Knowledge-Based Economy : From The Economis Of Knowledge To The Learning Economy", In Foray D. - Lundvall B.A. (Eds) Employement \& Growth In The Knowledge-Based Economy, Oecd, Paris.

Foray D. - Mairesse J., 1999, “Innovation Et Performance Des Firmes”, Ed De L'ehess, Paris.

Freeman C. - Soete L., 1997, “The Economics Of Industrial Innovation”, Third Edition, Pinter, London.

Gibbons M. Et Al., 1994, “The New Production Of Knowledge”, Sage Publications, London.

Gordon R., 1999, "U.S. Economy Growth Since 1970 : One Big Wave?", The American Economic Review, 89(2), May.

Gordon R., 2000, "Does The New Economy Measure Up To The Great Inventions Of The Past", The Journal Of Economic Perspectives, 14(4).

Greenan N. - Mairesse J., 2000, “Computers And Productivity In France : Some Evidences", Economics Of Innovation And New Technology, 9(3), Pp. 275-315.

Hansen M. Et Al., 1999, "What's Your Strategy For Managing Knowledge”, Harvard Business Review, March-April.

Howitt P., 1996, “On Some Problems In Measuring Knowledge-Based Growth”, In Howit P. (Ed) The Implications Of Knowledge-Based Growth For Micro-Economic Policies, University Of Calgary Press.

Jorgenson D. - Stiroh K., 2000, “Us Economic Gorwth And The New Millenium”, Brookings Papers On Economic Activity, 1, Pp. 125-211.

Kendrick J.W., 1994, “Total Capital And Economic Growth”, Atlantic Econmic Journal, Vol. 22, $\mathrm{N}^{\circ} 1$, March.

Lundvall B.-A., 1994, "The Learning Economy - Challenges To Economic Theory And Policy", Eaepe-Conference, Copenhagen, 27-29 October.

Lundvall, B. A., Johnson B., 1994, “The Learning Economy”, Journal Of Industrial Studies 2, 23 42

Lundvall B.A. \& Borrás S., 1997, "The Globalising Learning Economy : Implications For Innovation Policy", Eur 18307 En, Tser / Science, Research And Development/ Ec, Luxembourg.

Machlup F., 1962, "The Production And Distribution Of Knowledge In The United-States", Princeton University Press.

Mairesse J. Et Al., 2000, "Les Technologies De L'information Et De La Communication En France : Diffusion Et Contribution À La Croissance”, Economie Et Statistiques, 339-340, Pp. 117-146.

Margherio L. Et Al., 1998, "The Emerging Digital Economy Report", U.S. Department Of Commerce, April, Http://Www.Ecommerce.Gov/Emerging.Htm.

Munier F., 2000, "Compétences Pour Innover : Une Vérification Empirique Des Avantages Comparatifs Des Pme Et Des Grandes Entreprises" Communication Présentée Au Séminaire Annuel De L'utc "Organisation, Innovation Et International", Université Technologique De Compiègne, Compiègne, 24-27 Janvier.

Nightingale P., 2000, "Economies Of Scale In Experimentation: Knowledge And Technology In Pharmaceutical R\&D", Industrial And Corporate Change, Vol 9 (2), June 
Oecd, 2001, "The New Economy : Beyond The Hype", Final Report On The Oecd Growth Project, Meeting Of The Oecd Council At Ministerial Level, Paris.

Oecd, 2000a, "A New Economy ? The Changing Role Of Innovation And Information Technology In Growth", Dsti, Meeting Of The Oecd Council At Ministerial Level, Paris.

Oecd, 2000b, “Science, Technology And Industry Scoreboard 2000”, Oecd/Dsti, Paris.

Oecd, 1999a, "Science, Technology And Industry Scoreboard 1999 - Benchmarking KnowledgeBased Economies", Oecd/Dsti, Paris.

Oecd, 1999b, “Knowledge-Based Economy : Facts And Figures”, Paris.

Oecd, 1996, “The Knowledge-Based Economy”, Oecd/Gd(96)102, Paris.

Oliner S. - Sichel D, 2000, "The Resurgence Of Growth In The Late 1990s : Is Information Technology The Story ?”, Journal Of Economic Perspectives, 14(4), Pp. 3-22.

Rosenberg N., 1982, Inside The Black Box, Cambridge University Press.

Rouilleault H., 2000, “The Workplace And The Workforce In The Knowledge-Based Economy”, Presentation At The Employement Week, Ec, Brussels, 8th November.

Schreyer P., 2000, "The Contribution Of Information And Communication Technology To Output Growth : A Study Of The G7 Countries", Oecd, Sti Working Paper, 2000/2, March.

Steinmueller W. E. (2000), "Does Information And Communication Technology Facilitate 'Codification' Of Knowledge?", Tipik Paper, Targeted Socio-Economic Research (Tser), European Commission Dg Xii.

U.N., 1999, "Rapport Mondial Sur Le Développement Humain", Programme Des Nations Unis Pour Le Développement, U.N., Geneve. 


\subsection{Linkages to Other Policy Areas}

Casting the net wide, one could argue that all laws, regulations, and policies targeted at the economy of a country will affect the country's performance in invention, innovation, and the dissemination of new technology. The effects may be direct or indirect, intentional or inadvertent, and potentially subject to different interpretations. But they will be there.

Governments have become increasingly aware of their role in technological advance through their interest in economic growth. While technological progress is a major contributor to economic growth, however, the only kind of technological advances that contribute are those that result in market applications - i.e., product or process innovations. A government interested in economic growth must, then, be interested in innovation, rather than just technological progress. Technology is just one of the factors involved in innovation. Such a government must be interested in all determinants of private decisions to invent, innovate, and imitate. It must conceive science and technology policy as part of a wider set of economic (and other social) policies affecting the competitiveness and productivity of the private and public sectors.

In fact, since the debate on international competitiveness heated up in the early 1980s an ever broader definition of technology policy is being used (e.g., Stoneman, 1987). In his review article, for example, Mowery (1995) defined technology policy as policies that are intended to influence the decisions of firms to develop, commercialize or adopt new technologies. Such a definition seems increasingly appropriate as the private sector has taken the lead in technology creation and deployment. It includes the whole array of policies that influence firm decisions including macroeconomic, regulatory, and other policy instruments (e.g, national defense policy). Even more, Mowery argues, old-style, supply-side science and technology policies may influence innovative performance relatively less than traditional monetary policies affecting interest rates and inflation, fiscal policies including taxation and public procurement, international trade and investment policies, education and training policies, competition (antitrust) policies, intellectual property rights policies, even regulatory policies related to pension funds. By and large, however, policies in these other areas have not been designed or implemented in the past primarily to affect innovative performance.

This paper suggest that this is less and less the case. Industrial innovation (including manufacturing and service sectors) is coming to the forefront of the policy debate in industrialized country governments conscious of the significant effects of increasing globalization and competition. While we do not expect innovation performance to replace major other economic policy concerns any time soon, we strongly believe that its visibility as a core policy objective will keep increasing in the foreseeable future.

The paper first summarizes the traditional economic argument for policy intervention in the production and dissemination of knowledge ${ }^{29}$ to point out that the factors in question can be influenced by a host of economic and other policies beyond traditional S\&T

\footnotetext{
${ }^{29}$ See Section 2.2 for a more extensive exposition.
} 
policy. Then the paper briefly looks at recent developments in the approach to technology policy on both sides of the Atlantic that have also tended to support casting the policy net wider. Finally, it concludes by referring to new ideas concerning policy in knowledge (or learning) economies that also point the same direction.

\subsubsection{Economic Justification for Government Intervention}

Technological advance involves costs and benefits. This is quite alright for a marketbased system as long as agents take these costs and benefits into account in their transactions. Problems arise when they don't. ${ }^{30}$ Market transactions are then the source of externalities, either negative as in the case of environmental pollution or positive as in the case of knowledge spillovers. Externalities lead to misallocation of resources: negative externalities lead to activity levels in excess of the social optimum whereas positive externalities lead to activity levels below the social optimum.

It is widely agreed that externalities constitute one of three generic sources of market failure. The other two are indivisibilities and uncertainty (Arrow, 1962). Factor indivisibilities cause non-convexities in production functions, making marginal cost pricing impractical. ${ }^{31}$ Severe indivisibilities of factors of production may drive firms to monopolize an industry, thus disassociating marginal cost from output price. Uncertainty causes agents to conflate decisions to produce or invest with decisions to bear risk, often leading them to produce or invest too little (below the social optimum). Separating risk from production or investment activities is difficult because of moral hazard, which arises when action to mitigate risk (e.g., insurance) undermines incentives to produce or invest efficiently.

Knowledge generating activities are subject not only to externalities but to the other two types of market failure as well. Concerning indivisibilities, R\&D programs often involve substantial start-up costs. Moreover, knowledge is inherently discrete which implies economies of scale in any particular use and potentially economies of scope across uses. Concerning uncertainty, R\&D investments add technological uncertainty to the usual market uncertainty present in all strategic investments. The two kinds of uncertainty reinforce each other: for commercially successful products, technological possibilities must be tightly coupled with user needs. In addition, moral hazard is particularly acute in R\&D investments as it is difficult to uncouple two reasons for failure: insufficient effort or real scientific/technological difficulty.

Market failure is generally accepted by economists as a legitimate justification for government intervention. Moreover, the susceptibility of knowledge creating activities to all kinds of market failures has also attracted extensive attention by policy analysts and decision-makers. Governmental involvement in matters affecting technology has

\footnotetext{
${ }^{30}$ There can be many reasons why agents do not consider all costs and benefits including: (a) they may not be aware of side effects to their transaction; (b) they may be aware of them but consider them very improbable; (c) property rights are not well defined; (d) it is impossible to capture the full added value due to market structures and difficulty of property rights enforcement.

${ }^{31}$ The (Pareto) optimum in mainstream economics is based on perfectly competitive markets and marginal cost pricing.
} 
accordingly grown rapidly in all industrialized countries. Since market failures affecting knowledge production and dissemination relate to subjects outside the tool set of traditional S\&T policy, policy analysts have increasingly taken a broader view to capture things such as interest rate policy, taxation, investment regulation (e.g., pension funds, venture capital), competition policy, intellectual property rights protection, and entrepreneurship, to name a few. The competitiveness debate has drawn attention to such a trend (e.g., Burton, 1994; Pregg, 1994).

While technology policy as a corrective to market failure is well established, however, there has been more resistance to accept that government intervention can also fail. Governments may intervene mistakenly for several reasons, including imperfect information, the separation of the sponsors from the beneficiaries, pressure group activity, bureaucratic inertia, and political myopia (Krugman, 1994).

The evolutionary perspective, distinct from the mainstream approach in that it focuses (a) on process and change (rather than equilibrium and state) and (b) on how economic structures develop over time and the consequent patterns of resource allocation in a context of uncertainty and bounded rationality, ${ }^{32}$ employs similar policy tools but may use them in somewhat different ways. Still, basic issues remain. Many of the market failure problems reappear. Given that selection processes are central in the evolutionary argument, it is natural to ask whether the way existing markets select is satisfactory and if it can be improved. Public goods and externalities still raise doubts about the direction of change imposed on the economic system by market selection environments. The effectiveness of selection processes depends on the degree to which market participants are informed about available options. Excessive monopolistic power is still considered suspicious, even though less so for its effects on static efficiency and more for its ability to block challenges to status quo through innovative activity.

The evolutionary approach is still in its infancy and cannot offer general principles of the kind prescribed by mainstream economic theory. The absence of the optimizing policy maker, the uncertainty of outcomes, the learning processes which endogenously change strategies and preferences, and the overall unevenness of the evolutionary progress make the search for simple welfare propositions (like those described by the Pareto criteria) futile (Metcalfe, 1995). Still, several strong messages emerge:

- First, a central policy objective is to stimulate the technological and innovative capabilities of the system, and enhance the learning processes in economic agents to generate variety in behavior.

- Second, the adaptive evolutionary policy maker is far more concerned to influence process than to impose predetermined outcomes.

- Third, the concern of the policy maker is to take responsibility for the design and operation of the national innovation process as reflected in the context of particular technology systems.

- Fourth, the fact that innovation process is very connected and seamless makes the coupling between various types of policy imperative so that they are mutually supportive.

\footnotetext{
${ }^{32}$ See Section 2.1.1 for a more extensive exposition.
} 


\subsubsection{Technology Policy in the United States and the European Union: Shifting Orientation Towards Technology Users}

During the past two decades, the United States (US) and the European Union (EU) have made significant steps towards technology policies to enhance industry competitiveness. Reflecting the changes introduced by increasingly open international markets and a better understanding of the innovation process, government attention has gradually shifted from more supply-oriented technology policies to a greater balance with demand-oriented (technology-user-oriented) innovation policies (Vonortas, 2000).

The transition has progressed differently in the two regions as a result of different institutional environments, policy traditions, and recent political developments. The United States came out of the Cold War era with a very extensive, mission-oriented federal S\&T policy system focusing on national defense, nuclear energy, public health, space, and basic research. The country boasted the most well established antitrust regulation and intellectual property protection systems in the world. Industrial policy has traditionally been left to state governments, with large differences in the degree of policy aggressiveness and sophistication from state to state. Most state governments have lacked sophistication in S\&T policy, besides education and manufacturing extension programs. In addition, total R\&D expenditures in the country have changed dramatically. While the US has kept its prominent international position in terms of overall R\&D expenditures the private sector now provides close to three-fourths of the national R\&D expenditures. Firms also undertake about three fourths of the national R\&D activity.

The European Union entered the 1990s with a 40-year long interest in industrial policy, significant science collaboration among member states (with institutions, however, outside the EU's direct control), and a fledgling technology policy established only a few years earlier. The EU was not a homogeneous region; the industrial and S\&T policy sophistication of member states varied greatly. The biggest and the most industrialized of them have had well established national S\&T policy systems for quite some time (Nelson, 1993). Others in the periphery had used their industrial policies as surrogates until the mid-1980s when their accession to the Community forced them to set up national S\&T policy systems (the four "cohesion" countries: Greece, Ireland, Portugal, Spain). ${ }^{33}$ Importantly, total R\&D expenditure in the EU region continues to be significantly lower than US R\&D expenditure. Moreover, whereas almost all public $R \& D$ expenditure is in the hands of the federal government in the US, only a relatively small percentage of public R\&D expenditure in the EU is controlled by the European Commission; national governments of member states still account for the lion's share.

Despite these differences, a largely similar philosophy towards technology and innovation has developed in the US and the EU during the past couple of decades, focusing on economic growth to a larger extent than ever before. The reasons for policy convergence have largely to do with the lower national security threat and the extraordinary changes in the international economic environment affecting industry all

\footnotetext{
${ }^{33}$ See the country policy position papers prepared for the TSER project "Science and Technology Policy Towards Research Joint Ventures"” (Caloghirou and Vonortas, 2000).
} 
around the world. The importance of the latter cannot be overestimated as the private sector serves nowadays as both the major source and user of new technology. These changes include the rise of new high technology sectors; the accelerating pace of technological change and the shortening product cycle; the increasing knowledgeintensity of industry; the globalization of technology; and the increasingly decentralized nature of the sources of technological knowledge and innovation. Large corporations still accounting for the majority of R\&D expenditures around the world - are shifting strategies, cutting back or eliminating their centralized research laboratories, focusing $\mathrm{R} \& \mathrm{D}$ on core activities, distributing $\mathrm{R} \& \mathrm{D}$ budgets to their operating divisions in order to link it better to production and marketing, and leveraging outside sources of technology. Complex networks of industry-university-government collaborations centered on the creation and distribution of technological knowledge are common. The fast pace of technological change has also created massive opportunities for technological entrepreneurship at small firms that have also been able to exploit the increasing sensitization of universities to the opportunities in the private sector. The decentralization of $\mathrm{R} \& \mathrm{D}$ in larger corporations and the rise of small high-tech firms imply a shorter-term perspective on R\&D and a shift away from fundamental, high-risk, long-term research in the private sector. One may think that the government needs to compensate.

"(T)echnology policy, if it is to contribute to the economy, must be linked to economic policy" proclaimed two highly visible US policy analysts (Branscomb and Florida, 1998, p. 12) This means that technology-cum-innovation policy should be explicitly concerned with productivity and growth of the private sector (i.e., the technology user). Which, in turn, means that the government is not its own customer anymore (as it was in a defenseoriented R\&D system) but it is called to assist private firms to compete in world markets. Needless to say, policy demands are vastly different.

It must be emphasized, however, that there has been more agreement on the usefulness of an active government role in technological innovation than on the best policy approach (Peterson and Sharp, 1998; Vonortas, 2000).

\subsubsection{Policy Linkages in the Knowledge-Based Economy}

The term "knowledge-based economy", as discussed in Section 2.5, reflects an increasing recognition of the role of knowledge in economic growth. "A4 "A knowledge-driven economy is one in which the generation and exploitation of knowledge play the predominant part in the creation of wealth" (DTI, 1998).

What can governments do to encourage the creation, diffusion, and speedy application of knowledge to production? It would appear that widespread spillover benefits to the rest of the economy from increased knowledge underwrite direct government support for R\&D. While there are good arguments for such support - particularly in relation to science and more generic kinds of technology - it can also be overdone. The effectiveness of widespread government direct involvement in stimulating innovation has yet to be proven.

\footnotetext{
${ }^{34}$ See Section 2.3 for a more extensive exposition.
} 
There is much less disagreement over the role of the government in providing an economic environment conducive to innovation. The way to do this is by deregulating markets, by encouraging competition, by removing barriers to the development of new products, and by letting entrepreneurs explore the possibilities. Governments also need to raise the standards of education and skills in order to allow their economies take full advantage of information and communication technologies (ICT) and the expansion of knowledge industries. Obviously, government policies must be much broader than those included in the traditional tool kit of science and technology policy.

A very useful and intuitive distinction between three sets of relevant policy that helps clarify the policy decision making process in the new knowledge-based economy was recently proposed by Lundvall and Borras (1999). These policy sets are:

i. Policies that affect the pressure for change;

ii. Policies that affect the ability to absorb change;

iii. Policies that assist the losers from change.

While different countries will adopt a different policy mix to suit their specific circumstances, at a general level they will all be confronted with the following questions, each corresponding to one of the three policy sets (Vonortas and Tolnay, 2001):

i. How to affect the pressure for change (or how to create the appropriate incentives to economic agents to innovate). Policies here can include:

(a) general economic policy, macroeconomic policy more specifically, and sector level policies that affect relative prices, thus affecting relative expected rewards to investors;

(b) trade policy which affects competition levels;

(c) competition policy which affects domestic competition;

(d) intellectual property rights policy, which affects competition levels, incentives to invent, rates of technology diffusion;

(e) regulatory and institutional infrastructure, which define the basic rules of the game and allow markets to function under the utmost transparency (to decrease certain kinds of uncertainty).

ii. How to affect the ability to absorb change (or how to increase the ability to innovate). Policies here can include:

(a) science and technology policy, which affects the ability to create and disseminate scientific and technological knowledge;

(b) innovation policy, which focuses on the introduction of new technologies and, more than S\&T policy, addresses the demand side of the technology equation (technology user);

(c) human resource policies (including education, training etc.), which create the ability to create and deploy effectively the most important resource in the knowledge-based economy.

iii. How to assist the losers from change (or how to partly redistribute the wealth from the winners to the losers). Policies here can include:

(a) Social policies for income redistribution, unemployment compensation, pension financing for failing industries, etc.; 
(b) Regional policies assisting structural change in regions locked into the "wrong" industries and technologies.

\subsubsection{Implications for European Policy}

In order to be effective in leading a country/region to the new, knowledge-intensive era, S\&T policy must build bridges and blend with broader economic and social policies. That speaks for a more synthetic approach to science, technology, and innovation policy than we've had in earlier decades. This message is clearly supported by both the mainstream and evolutionary economics approaches and is in full agreement with the debate over the knowledge-based economy. The message is also in concert with contemporary technology/innovation policy thinking in Europe as reflected in the discussion over the European Research Area, the Sixth Framework Programme for RTD, and the Action Plan e-Europe 2002. ${ }^{35}$

${ }^{35}$ See:

(i) European Commission (2000) "Communication form the Commission to the Council, the European Parliament, the Economic and Social Committee and the Committee of the Regions: Towards a European Research Area", Brussels, COM (2000) 6, January 18;

(ii) (ii) European Commission (2000) "Proposal for a Decision of the European Parliament and of the Council Concerning the Multiannual Framework Programme 2002-2006 of the European Community for Research, Technological Development and Demonstration Activities Aimed at Contributing Towards the Creation of the European Research Area"; and,

(iii) European Commission (2000) "e-Europe: An Information Society for All", Draft Action Plan, prepared by the European Commission for the European Co8uncil in Feira 19-20 June. 


\section{References for Section 2.6}

Arrow, Kenneth (1962) "Economic welfare and the allocation of resources for invention", in R. R. Nelson (ed.) The Rate and Direction of Inventive Activity: Economic and Social Factors, National Bureau of Economic Research.

Branscomb, L.M. and R. Florida (1998) "Challenges in Technology Policy in a Changing World Economy", in L.M. Branscomb and J.H. Keller (eds.) Investing in Innovation, Cambridge, Mass.: The MIT Press.

Burton, Daniel F. Jr. (1994) "Competitiveness: Here to stay," The Washington Quarterly, 17(4), pp. 99-109.

Caloghirou, Yannis and Nicholas S. Vonortas (2000) "Science and Technology Policy Towards Research Joint Ventures", Final Report of the Project SOE1-CT97-1075, Targeted SocioEconomic Research Programme (TSER), European Commission, DG Research, March.

Department of Trade and Industry (1998) "Our Competitive Future: Building the Knowledge Economy", Secretary of State for Trade and Industry, Vol. Cm 4176, UK: London.

Krugman, Paul (1994) "Competitiveness: A dangerous obsession," Foreign Affairs, 73(2), pp. $28-44$.

Lundvall, Bengt-Ake and Susana Borras (1999) The Globalising Learning Economy: Implications for Innovation Policy, European Commission, Directorate-General XII (Science, Research and Development), Luxembourg: Office of the Official Publications of the European Communities (EUR 18307 EN).

Metcalfe, Stan (1995) "The economic foundations of technology policy: Equilibrium and evolutionary perspectives", in P. Stoneman (ed.) Handbook of the Economics of Innovation and Technological Change, Oxford: Blackwell.

Mowery, David (1995) "The practice of technology policy", in P. Stoneman (ed.) Handbook of the Economics of Innovation and Technological Change, Oxford: Blackwell.

Nelson, Richard R. (ed.) (1993) National Innovation Systems: A Comparative Analysis, New York: Oxford University Press.

Peterson, J. and Margaret Sharp (1998) Technology Policy in the European Union, New York: St Martin's Press.

Pregg, Ernest H. (1994) "Krugmanian competitiveness: A dangerous obfuscation," The Washington Quarterly, 17(4), pp. 111-122.

Stoneman, Paul (1987) The Economic Analysis of Technology Policy, Oxford: Clarendon Press.

Vonortas, Nicholas S. (2000) "Technology policy in the United States and the European Union: Shifting orientation towards technology-users", Science and Public Policy, 27(2): 97-108.

Vonortas, Nicholas S. and Adam Tolnay (2001) "Towards the knowledge-based economy: United States and its APEC partners", in A. N. Link and M. Feldman (eds.) Technology Policy for the Knowledge-Based Economy, Kluwer Academic Publishers. 


\section{Socio-economic Assessment Section}

\subsection{Socio-Economic Assessment of European RTD Policies}

\section{Introduction}

With the implementation of the $5^{\text {th }}$ EU Framework Programme for RTD (FP), impact measurement has gained increasing attention: the Commission's 1995 Green Paper on Innovation had given Europe low marks in the exploitation of scientific and technological knowledge; while indicators suggest the EU's record of scientific performance to be generally well up to world standards, its technological and commercial performance was unsatisfactory and has deteriorated (Guy et al. 1998). Three sets of criteria have been established in order to overcome successfully what the Commission once called the "European Paradox". These criteria ${ }^{36}$ were then used for the selection of themes and objectives and were recommended as guidelines for forthcoming evaluations:

- Criteria related to economic development and scientific and technological prospects, such as expansion and creation of good growth prospects, rendering businesses more competitive and offering dissemination and exploitation possibilities;

- Criteria related to social objectives, such as improving the employment situation, promoting the quality of life and health and preserving the environment;

- Criteria related to the Community "value added" and the subsidiarity principle, such as establishment of human and financial critical mass through the combination of complementary resources available in various member states (Airaghi et al. 1998).

As Fayl et al. (1998: 96) have pointed out, "to be able to cope with these new objectives (...), the European RTD effort needs to be supported by effective and efficient monitoring and evaluation tools, including an appropriate set of indicators (quantitative and qualitative), capable of demonstrating its impact."

The present chapter takes up this task, starting with hindsight: is there anything to learn from past evaluations of European RTD policies? First (section 3.1) some general considerations of the options and limitations of socio-economic impact assessment as well as the meta-evaluation of such assessments are made. Section 3.2 deals with the past evaluation practice of the Framework Programmes. A sketch of historical facts about FPs' impact measurement gives the context into which the research carried out for this paper will be put. Then, the subchapter argues along three lines: first, it deals with the range of effects that have been measured in the past; secondly, it discusses the overall appropriateness of the methodologies used for measurement; and thirdly, some tentative and preliminary recommendations are given with respect to future impact evaluation. At the end of this section, conclusions and recommendations are presented. Section 3.3 deals with other programme initiatives, such as Eureka and the United States' Advanced Technology Policy Program (ATP), so as to make a comprehensive composition of past

36 Criteria as listed in Annex 1 of Article 189(b) of the EC Treaty, 25 November 1998 
impact evaluation practice available. The Eureka and ATP studies are examined to establish the role of evaluation in the identification of impacts and to define a number of key practices upon which successful evaluations converge, notwithstanding the very different evaluation trajectory followed by the programmes operating in different political and social contexts. Both the experiences drawn from the Framework Programmes and other initiatives are then fed into the discussion in section 3.4 of performance indicators, future evaluation design and a series of recommendations on the mapping of research methods to their appropriate targets for the evaluation of the socio-economic benefits of Framework Programme initiatives.

\section{Assessing Assessments of RTD Impacts - Options and Limitations}

There is no substantial controversy, meanwhile, that public intervention and investment in research and technological development (RTD) contribute to innovation and competitiveness, both of individual economic entities and in society as a whole. Politics, economy and society, though, increasingly are demanding evidence of the performance, quality and benefits of publicly-funded research, partly because public funds are scarce and should be employed as "effectively" as possible, and partly because policymakers and the public cherish a certain scepticism regarding the self-centred workings of the science system. Hence, RTD projects, institutions, and programmes increasingly became the subject of evaluation processes (e.g. Bozeman/Melkers 1993; Georghiou 1995a; Papaconstantinou/Polt 1997; Shapira/Kuhlmann 2002).

With the spread of RTD evaluation practices - assessments of projects, programmes, institutions, policies - there was also an increasing concern about the quality and reliability of evaluative information, concepts, methodologies, and procedures: the assessment practice itself became a matter of assessment ${ }^{37}$, in the context of national RTD policies (e.g. Kuhlmann/Holland 1995; Georghiou 1995a; Hong 2000), and even more on the European scale (e.g. Georghiou 1995b; Airaghi et al. 1999; Guy 2002), in order to contribute to both improved evaluation concepts and policy learning. The present section of our report tries to advance the stock of meta-evaluative experience by investigating the European Commission's evaluation procedures.

This systematization purpose given, however, one should keep in mind Michael Power's claim (The Audit Society. Rituals of Verification) concerning the "exploding" use of auditing and accounting practices in modern policymaking which applies well also to RTD evaluation practices: "... the meta-accounting of different auditing practices in technical terms is not simply descriptive but also performative, projecting and enacting ideals of their capability which legitimate the field of knowledge as a whole. But the auditing field of knowledge also operates in an environment which is constantly producing shocks, disturbances, and programmatic demands" (Power 1997, 9). We may - and should - strive for improved procedures and methods for evaluating the impacts of public RTD policies, thus nurturing an evaluation culture, but in the field if science, research and innovation we always have to take into account unexpected scientific

$37 \quad$ Which is, by the way, a general trend in the evaluation of all kinds of policies (see e.g. Chelimsky 1987; Palumbo 1987; Widmer 1996; Mayne/Zapico-Goni 1997; Schwartz 1998). 
findings as well as sudden changes of the political environment that can even revolutionize all previous terms of reference.

\section{Options and limitations of RTD policy assessment}

We have to accept that the relationship between public RTD policies on the one hand and the well-being of society and the performance of the economy on the other is not of a simple nature. Hence, experts widely agree that a linear input/output model is not an appropriate tool for analyzing this relationship (Feller 2000; Guy/Lukkonen 2000; Airaghi et al. 1999; Bach and Georghiou 1998; Papaconstantinou/Polt 1997; OECD 1995).

Any effort to evaluate the "socio-economic" impact of public RTD policies aims at enlightening the relation between a public intervention and the achieved direct or indirect effects in the spheres of science, economy or society. Any analysis of this relationship, though, requires a clarification of the presupposed assumptions of policy-makers as well as of evaluators (Kuhlmann 2002):

- RTD unfold through sensitive and complex social interactions, embedded in long standing national, regional or sectoral systems of innovation.

- Public RTD policy has to be considered as an inherent element of innovation systems. In the course of the last two centuries, in all industrial nations innovation systems emerged co-evolutionarily with political systems.

- The actors involved in public RTD initiatives (policy, industry, science) pursue heterogeneous, partly conflicting interests, assumptions, targets and expectations, i.e. success criteria differ depending on the involved actor group.

- RTD policies relate to a variety of - partly competing - targets, envisaged effects and underlying rationales and functional assumptions mirrored in a variety of policy instruments, partly overlapping or competing.

- Ever more RTD policy interventions aim simultaneously at multiple purposes and heterogeneous actors. For example, the notion of "socio-economic" policy targets presently cutting across the European Union's Framework Programmes (FP) is a reflection of the multi-actor, multi-purpose nature of the FPs, leading inevitably to an increased complexity and interbreeding of input-output-outcome relationships.

- Increasingly, public RTD policies in the EU are simultaneously pursued on regional, national and EU levels. The formally ruling subsidiarity principle is still quite a vague concept, in practice rather generating an overlap and competition among policies, effecting an amalgamation of potential impacts, thus hampering a clear attribution of funding inputs and outputs.

- Last but not least, while science and RTD, as driving forces in modern societies, contribute to many aspects of our public and personal lives, this occurs in complex and unpredictable ways that make it hard to assess their importance: the difficulty of attributing effects such as economic growth, job creation and social integration to particular public interventions seriously constrains our ability to assess the wider effects of RTD support. Another problem arises from the time lag 
between the RTD project itself and any socio-economic outcome (Airaghi et al. 1999).

Thus, any conceptualization of essential scientific guidelines and building blocks for the development of a quantitative model to measure the socio-economic impact of public RTD policies inescapably faces such ambiguities as a priori conditions. The present paper will not make an attempt to resolve ambiguity, but simply to shed some light on some of the structural and intellectual preconditions for conceptual and methodological improvements of RTD policy assessment.

"We can only measure economic and social impacts if we know what we are looking for, and that depends on how we define these impacts" (Airaghi et al. 1999, 10).

\section{Options and limitations assessing assessments of RTD policy}

Our report presents an attempt at assessing the evaluation practice developed and applied in the context of the European FPs. An ideal meta-evaluation of programme impact evaluations would comprise a broad variety of aspects of evaluative information (Widmer 1996, 38f). Besides studying the texts that have been produced, information about the resources impact evaluators had at their disposal would be useful, not least because time and monetary means have been shown to influence quality of evaluations (Kuhlmann/Holland 1995). Similarly, systematic in-depth interviews with impact evaluators could be deemed useful in that they would provide the authors of a study like this with useful context data. However, only the first aspect can be dealt with here in detail due to respective restrictions on resources available to the meta-evaluators of this study. A similar meta-evaluation (in terms of research design) of about twice as many evaluation studies in Germany took two years of intense data mining, interviewing and discussions with different stakeholders to materialise (Kuhlmann/Holland 1995).

Given limited resources, we prudently regard the following effort as a "mini-metaevaluation", focused on the question of how economic, societal, technological and scientific outputs and effects have been measured and evaluated in the $3^{\text {rd }}$ and $4^{\text {th }} \mathrm{FP}$. As any RTD impact assessment, a "mini-meta-evaluation" of such assessments, too, has to start from the fact that there is a huge variety of potential results, outcomes and impacts that might be considered as relevant, depending on the differing interests and expectations of policy-makers, programme managers, participating researchers and the programme's clients the potential. A well-designed evaluation has to take these different perspectives into account and to reconcile related desires for information with constraints on resources and the availability of information. Exhibit 1 shows different classes of impact (short or long-term; direct or indirect) in three different domains: the worlds of science, of the economy and society, and of policy-making respectively.

The "assessability" of each of the cells in the matrix (exhibit 1) differs considerably: the darker the cell the more difficult is a direct attribution of policy input and potential impact, and the more challenging is the task of evaluation: capable and effective evaluation concepts and methodologies are needed. 


\section{Exhibit 1: Impact dimensions of public RTD spending (modified version of Airaghi et al. 1999, 8)}

\begin{tabular}{|c|c|c|c|c|}
\hline \multirow{2}{*}{$\begin{array}{l}\text { Main domains of } \\
\text { impact of public } \\
\text { RTD spending }\end{array}$} & \multicolumn{2}{|c|}{ Direct impacts } & \multicolumn{2}{|c|}{ Indirect impacts } \\
\hline & Short-term & Long-term & Short-term & Long-term \\
\hline $\begin{array}{c}\text { Science } \\
\text { ("Wissenschaft") } \\
\text { Typical impacts }\end{array}$ & $\begin{array}{l}\text { scientific } \\
\text { findings }\end{array}$ & knowledge & $\begin{array}{l}\text { improved } \\
\text { teaching }\end{array}$ & $\begin{array}{l}\text { industrial } \\
\text { spill-overs }\end{array}$ \\
\hline $\begin{array}{c}\text { Economy and } \\
\text { society }\end{array}$ & $\begin{array}{l}\text { improved } \\
\text { technology }\end{array}$ & $\begin{array}{l}\text { improved } \\
\text { technical } \\
\text { know-how }\end{array}$ & $\begin{array}{c}\text { increased } \\
\text { productivity }\end{array}$ & $\begin{array}{c}\text { improved } \\
\text { competitiveness }\end{array}$ \\
\hline $\begin{array}{c}\text { Policy } \\
\text { Typical impacts }\end{array}$ & $\begin{array}{c}\text { improved } \\
\text { understanding }\end{array}$ & problem-solving & $\begin{array}{l}\text { increased } \\
\text { problem } \\
\text { awareness }\end{array}$ & $\begin{array}{l}\text { increased general } \\
\text { satisfaction }\end{array}$ \\
\hline
\end{tabular}

In fact, the European and North American "evaluation culture", meanwhile, has quite a broad range of conceptual and methodological experiences at its disposal. Methods of various types have been developed and utilised to determine attained or attainable effects. The most important are ${ }^{38}$ : peer reviews, before/after comparisons, control or comparison group approaches, a variety of quantitative and qualitative analyses etc. These approaches can be applied individually or in combination with various data and indicators (financial expenditure on research and development, patents, economic, social, technical indicators, publications, citations, etc.), data collection methods (existing statistics, questionnaires, interviews, case studies, panels, etc.), data analysis methods (econometric models, cost/benefit analyses, other statistical methods, technometrics, bibliometrics, peer reviews etc.; see e.g. Grupp/Schmoch/Kuntze 1995). All the procedures have different strengths and weaknesses, which makes using a combination of methods advisable.

At the present stage of evaluation research, and despite all the (necessary) efforts made to objectify the methods and the resulting indicators, one must warn against considering quantitative indicators alone to be adequate for evaluation purposes. The understandable desire for a tool-box of indicators which can be used in a standardised fashion is not realisable vis-à-vis our limited knowledge of the dynamics of innovation processes: a measurable research performance and related output do not automatically produce socioeconomically effective innovations.

38 See e.g. Meyer-Krahmer/Montigny 1989; Bozeman/Melkers 1993; Callon/ Laredo / Mustar 1997; Shapira/Youtie 1998; Georghiou/Roessner 2000. 
As a consequence, our "mini-meta-evaluation" has been conceived rather as a check of the conceptual and methodological "richness" in relation to the functionality of the evaluation exercise under scrutiny - avoiding any ranking of the investigated cases. Having stated this, it is also clear that our "mini-meta-evaluation" must in no way be read as an overall assessment of the actual socio-economic impacts of the European FPs!

\subsection{EU RTD Framework Programmes - a "Mini-Meta-Evaluation"}

The first "Framework Programme" for research and technology, launched by the European Commission in 1984, concentrated on industrial technologies, information technology, telecommunications and biotechnology. Each subsequent FP has been broader than its predecessor in its scope of technologies and research themes, with correspondingly higher expectations of its impact on the economy and society. As a consequence, the rationales underlying the various Specific Programmes under each FP have become increasingly heterogeneous and even contradictory. This complicates attempts to evaluate the overall achievements of each FP (Airaghi et al., 1999).

In addition to the target dimensions applied already in earlier FPs, the present Fifth FP, covering nearly 15 billion Euros, particularly emphasised social objectives that reflect the expectations and concerns of Europe's citizens. It has been claimed that the Fifth FP is a "social contract" which, much more than its predecessors, will aim explicitly to create jobs, promote health and quality of life, and preserve the environment (cf. European Commission 2000a). "Thematic programmes", which are concerned with research and technological development itself (in such areas as "life sciences", "the information society", "sustainable industrial growth", and "energy and the environment"), are intended to be complemented by "horizontal programmes", which will promote cooperation, dissemination, and training and mobility of researchers. It is still difficult to say how radical a change in direction the Fifth FP represents, either in terms of scientific content or in organisation.

\section{Short historical sketch of the Framework Programme's impact evaluation}

Programme evaluation has been used by the European Commission for a long time as a management tool and for performance assessment of the Framework Programmes. Evaluations were expected to assist the implementation of ongoing RTD activities and to provide guidance for future policy-making. Since the Council of Ministers requested the Commission in 1979 to develop a system of evaluation in order to assess:

- the scientific and technical quality of EU RTD,

- the effectiveness of programme management, and

- the contribution of RTD to the socio-economic development of the Community.

The panel approach was applied to do so (Georghiou 1995b). In short, panels consisted of experts from various fields, users of results and management personnel with science policy experience who met regularly over a period of 6-8 months during which they studied evaluative data, carried out interviews with key programme actors and produced a 
comprehensive text. Thus, up to 1994 more than 70 programme evaluations involving some 40 supporting studies were carried out by about 500 experts. Though panels were generally regarded to have done fair and unbiased work, some criticism arose as to whether:

- panels' results were representative in terms of surveys and interviews carried out (methodological aspect),

- panels were able to evaluate the value added by a programme instead of merely studying the scientific quality of EU RTD (additionality aspect),

- panels were truly independent in that experts do not favour channelling resources into their own fields of which they might even take advantage in future (independence aspect) and

- panel's time and material resources (and sometimes skills and knowledge) were substantial enough to meet the self-imposed goals of thoroughly evaluating EU RTD programmes (thoroughness aspect) (Georghiou 1995b).

However, not only the panel approach towards evaluation was criticised, but also the whole evaluation system came under fire due to its manifold shortcomings. Up to 1994, there was neither a coherent evaluation set-up across the 24 different Directorates General nor a minimum set or systematic collection of common indicators to be used in all programmes. Furthermore, evaluation results were not always translated into appropriate input for policy decisions, since either the results were not synchronised with EU decision mechanisms or results were presented in a way that inhibited policy makers from absorbing them efficiently (Guy et al. 1998).

As a result of this process, a new evaluation scheme was introduced in 1995, comprising on the one hand an annual monitoring of both specific programmes and the FP, and on the other a five-year ex post evaluation of the whole FP at a point when the next one is being discussed. So, "in a historical context the present system can be seen as a move away from previous practice of panels" (Georghiou 1999: 71) and aims at ensuring programme:

- efficacy, that is, assessing whether initial objectives are still valid in the light of evolving RTD and societal environmental conditions;

- efficiency, that is, assessing adequate funding, management and contractual behaviour in order for objectives to be achieved in a cost-effective manner and

- effectiveness, that is, assessing social, economic, technological and scientific impacts and effects that accrue from RTD (Fayl et al. 1998).

Evaluation studies had since been co-ordinated by a newly established central evaluation unit, located at the Directorate General XII (DG XII), that - in accordance with an InterService Group of all 11 relevant DGs - puts particular emphasis on the implementation of the evaluation scheme at the Specific Programme level. The situation is summarised in Exhibit 2 (taken from Guy 2002, based on European Commission, 1997b). Major points to note are that (cf. Guy 2002): 
- Continuous monitoring at Specific Programme and FP levels is designed to support the implementation of programmes. Annual Monitoring exercises examine management procedures and overall progress in relation to original objectives, and evaluate whether objectives, priorities and financial resources are still appropriate.

- Programme management carries out the day-to-day monitoring of the Specific Programmes, with external expert panels providing an independent view once a year. The panels give advice on key issues relating to programme development and help to identify and correct weaknesses. At the level of the Framework Programme, a separate expert panel reviews all the Specific Programme monitoring reports and comments on similar issues. The overall aim is to allow programme management to take corrective action if necessary, to check on the continued alignment of the Framework Programme with overall Community objectives, and to generate inputs for subsequent Five-Year Assessments.

- The objective of the Five-Year Assessments is to provide input to policy formulation and decision making, based on feedback from implementation of the programmes. For the Specific Programmes, the aim is to evaluate the activities carried out within each area covered by a programme and the way in which they have been managed. Key issues are relevance of the initial objectives in the light of subsequent developments, the cost-effectiveness of programme implementation, and effectiveness in terms of goal attainment. The exercise also identifies major achievements and lessons learned from programme implementation and makes recommendations for the future.

- The FP Five-Year Assessment Panel receives all the reports produced by the Specific Programme Assessment Panels and combines them at a higher level. It also considers all extant documentation concerning future Framework Programmes and is charged with commenting on future policy in the light of past actions. The first Five-Year Assessment of the Framework Programmes - the 'Davignon' report - was published in February 1997 (European Commission, 1997a). The second - the 'Majo' report - was published in July 2000 (European Commission, 2000).

In addition to the monitoring exercises, the five-year assessments, and evaluations of specific programmes such as ESPRIT or BIOMED, horizontal (cross-programme issues) evaluations have been conducted. Also, since the early 1990s, national "impact studies" with a strong focus on the impact of EU FPs on Member States' science and technology policy and national actors in the science and economic sphere have been carried out. Laredo (1990) examined the role of public and academic research institutions in the FPs, Georghiou et al. (1993), Reger and Kuhlmann (1995), and later a full series of similar studies (e.g. Luukkonen and Hälikkä, 2000) drew conclusions about the impact on national academic institutions as well as national industry and research organizations, thereby shedding light on the interaction between European and national policies. These national impact studies, though certainly milestones in terms of their methodological stance towards impact measurement, were, however, not full evaluations of the FP as they focused largely on the effectiveness of the programme's impacts and paid less attention to the remaining efficacy and efficiency issues mentioned above. Nonetheless, they remain the most detailed cross-Framework examinations ever done since the 
introduction of European RTD policies. As a result of this experience, the Commission made attempts at designing a common core methodology for subsequent impact analyses. Similar attempts, undergone earlier, were not crowned with success due to the various difficulties a harmonised methodology for all member states involves, such as national peculiarities in their respective science and economic systems (Georghiou 1995b).

Against this background, the following analysis should be regarded as a first descriptive step that aims at learning from past experience thereby preparing a starting point from which the general aim - to provide a comprehensive and coherent approach towards impact evaluation - can be achieved successfully. 
Exhibit 2: Overview of EU Commission's RTD Monitoring and Evaluation System (source: Guy 2002)

\begin{tabular}{|c|c|c|c|c|c|c|}
\hline & Coverage & Timing & Objectives & Methodology & Role of Commission & Target Audience \\
\hline Monitoring & $\begin{array}{l}\text { Specific } \\
\text { Programmes } \\
\text { (SP) }\end{array}$ & $\begin{array}{l}\text { Continuous } \\
\text { Annual Reports }\end{array}$ & $\begin{array}{l}\text { Report on implementation } \\
\text { status } \\
\text { Check priorities and adjust } \\
\text { Input for FP Monitoring and } \\
\text { 5-Year Assessment }\end{array}$ & $\begin{array}{l}\text { Expert Panels } \\
\text { Core indicators } \\
\text { Qualitative evidence } \\
\text { Interviews } \\
\text { Report on progress and } \\
\text { intermediate achievements on SP } \\
\text { level }\end{array}$ & $\begin{array}{l}\text { Co-ordination by Evaluation } \\
\text { Unit } \\
\text { Input from Programme } \\
\text { Managers } \\
\text { Respond to recommendations } \\
\text { Distribute reports }\end{array}$ & $\begin{array}{l}\text { Programme Managers } \\
\text { Programme } \\
\text { Committees } \\
\text { CREST }\end{array}$ \\
\hline Monitoring & $\begin{array}{l}\text { Framework } \\
\text { Programmes } \\
\text { (FP) }\end{array}$ & $\begin{array}{l}\text { Continuous } \\
\text { Annual Reports }\end{array}$ & $\begin{array}{l}\text { Report on implementation } \\
\text { status } \\
\text { Check priorities and adjust } \\
\text { Assess progress against } \\
\text { Community objectives } \\
\text { Input for 5-Year } \\
\text { Assessment }\end{array}$ & $\begin{array}{l}\text { Expert Panels } \\
\text { Core indicators } \\
\text { Qualitative evidence } \\
\text { Interviews } \\
\text { Reports from SP Monitoring } \\
\text { Panels } \\
\text { Report on progress and } \\
\text { intermediate achievements on FP } \\
\text { level }\end{array}$ & $\begin{array}{l}\text { Co-ordination by Evaluation } \\
\text { Unit } \\
\text { Input from Programme } \\
\text { Managers } \\
\text { Respond to recommendations } \\
\text { Distribute reports }\end{array}$ & $\begin{array}{l}\text { FP Management } \\
\text { CREST } \\
\text { CERT }\end{array}$ \\
\hline Evaluation & $\begin{array}{l}\text { Specific } \\
\text { Programmes } \\
\text { (SP) }\end{array}$ & $\begin{array}{l}5 \text {-Year } \\
\text { Assessment } \\
\text { before new FP } \\
\text { proposal }\end{array}$ & $\begin{array}{l}\text { Input to FP 5-Year } \\
\text { Assessment and future } \\
\text { programme design }\end{array}$ & $\begin{array}{l}\text { Expert Panels } \\
\text { Core indicators } \\
\text { Qualitative evidence } \\
\text { Interviews } \\
\text { Surveys } \\
\text { Reports from SP Monitoring } \\
\text { Panels and previous evaluations } \\
\text { Report on SP-level achievements }\end{array}$ & $\begin{array}{l}\text { Co-ordination by Evaluation } \\
\text { Unit } \\
\text { Input from Programme } \\
\text { Managers } \\
\text { Respond to recommendations } \\
\text { Distribute reports }\end{array}$ & $\begin{array}{l}\text { Programme Managers } \\
\text { Programme } \\
\text { Committees } \\
\text { CREST } \\
\text { European Parliament } \\
\text { Council } \\
\text { Economic and Social } \\
\text { Committee }\end{array}$ \\
\hline Evaluation & $\begin{array}{l}\text { Framework } \\
\text { Programmes } \\
\text { (FP) }\end{array}$ & $\begin{array}{l}\text { 5-Year } \\
\text { Assessment } \\
\text { before new FP } \\
\text { proposal }\end{array}$ & $\begin{array}{l}\text { Assess progress against } \\
\text { Community objectives } \\
\text { Input to S\&T policy and FP } \\
\text { design }\end{array}$ & $\begin{array}{l}\text { Expert Panels } \\
\text { Core indicators } \\
\text { Qualitative evidence } \\
\text { Interviews } \\
\text { Reports from SP Assessment } \\
\text { Panels and previous evaluations } \\
\text { Report on FP-level achievements }\end{array}$ & $\begin{array}{l}\text { Co-ordination by Evaluation } \\
\text { Unit } \\
\text { Input from Programme } \\
\text { Managers } \\
\text { Respond to recommendations } \\
\text { Distribute reports }\end{array}$ & $\begin{array}{l}\text { FP Management } \\
\text { CREST } \\
\text { European Parliament } \\
\text { Council } \\
\text { Economic and Social } \\
\text { Committee }\end{array}$ \\
\hline
\end{tabular}




\section{What evaluation studies are dealt with in this section?}

Due to the increased relevance of a comprehensive approach towards the measurement of the socio-economic effects and impacts of the Framework Programme in the mid-1990s, the Evaluation Unit at DG XII compiled - on behalf of the Commission - an inventory of all strategic, sectoral and - most importantly output-related programme evaluations that have been carried out within the various Specific Programmes under FP3 and FP4 (Inventory 1999). The document was used primarily as informational input for the Five-Year Assessment Panel. This document has also been quite important to the present study since - to our knowledge - it is the only existing systematic compilation of all European RTDrelated evaluation studies regarding FP3 and FP4. Thus, it was used as a starting point for the collection of the impact studies reviewed here.

\section{Collection process of the reviewed impact studies}

In the Inventory (1999) 26 studies are classified as "programme socio-economic impact including human potential studies", about half the amount of "programme evaluations (mid-term review, technical audits and review boards)". Of these, only 12 could be collected due to several reasons. First and foremost, the physical collection of the studies turned out to be a rather difficult task because of the lack of a central archive at the DG XII headquarter in Brussels from which the authors could have obtained all relevant studies. Thus, two days of intensive search and some great help from many Scientific Officers were needed to assemble the studies analysed here. Secondly, some studies were misclassified as "evaluations" and therefore could not be used as such. However, four studies that were found classified as "sectoral", "strategic" and "success stories" respectively, could eventually be used as "evaluation studies". In addition to the 16 evaluation studies, 6 other ones have been added that the authors came across accidentally during their search at the DG XII headquarters and via some searching on the Internet.

Hence, the sample of 22 studies carried out within specific programmes of FP3 and FP4 is certainly not representative, but covers at least a substantial share of EU's impact evaluation scheme. In addition to these 22 studies, we consider two horizontal and four national "impact studies", and thus cover the impact of the FPs on participation of large companies in European Research Programmes as well as different stakeholders and policies at the member state level. In sum, the analysis is based upon 28 evaluation studies.

\section{Some characterization of the collected impact studies}

A first glance at Exhibit 3 reveals that there are evaluation-intensive areas, such as Biotechnology, Industrial and Materials Technologies or Standards, Measurement and Testing, but also areas of less intensive impact assessment activity, such as Biomedicine and Health, Agriculture, Fisheries and Transport. Hence, our analysis 
does not cover every specific programme within the Framework Programmes but was restricted to those where useful information was available.

Against the background of experience from former RTD policy meta-evaluations (Kuhlmann and Holland 1995) two tables have been drawn up structuring the various studies according to a variety of conceptual aspects. Exhibit 4 provides information about:

- Type of study: identifies the main analytical focus. Two sets of categories are applied here: the EU Commission's Inventory (1999) of evaluation studies distinguishes "socio-economic"; "success story", "strategic", and "sectoral" studies. the authors of the present chapter differentiated between studies "exploring the context" of a RTD policy initiative, actual "impact analyses", and "cost benefit" type of exercises.

- Design of study: examines the time horizon (ex ante, monitoring, ex post) and material aspects (comparison group, scenario, before/after comparison);

- Types of effects studied: classifies studies in terms of effects studied (economic, social and scientific/technological).

Another table (exhibit 5) classifies the studies reviewed according to data and methodology-related issues such as:

- Data collection: whether evaluators use their own data (standardised survey, in-depth interview) or outside sources (patent/publication data, official statistics and company data, documents, application and programme management data);

- Data analysis: what type of analysis has been applied; "variable analysis" covers any analysis that examines quantitative dimensions (growth, size) of units of observation (companies, universities etc.) whereas "case study" indicates a single case in-depth analysis of various aspects that may not easily be counted;

- Methodological stance is somewhat complementary to data analysis in that quantitative and qualitative methodologies are distinguished;

- Level of analysis determines where analyses can best be located at the micro-macro-continuum;

- Stakeholders analysed asks whether the target group and/or other nonparticipants have been examined;

- Methodological reflexivity indicates the awareness of the evaluators in terms of perceived constraints of empirical investigation methods;

- Policy recommendation examines the extent to which impact studies recommend certain action to policy-makers. 

Table 4. List of reviewed impact studies

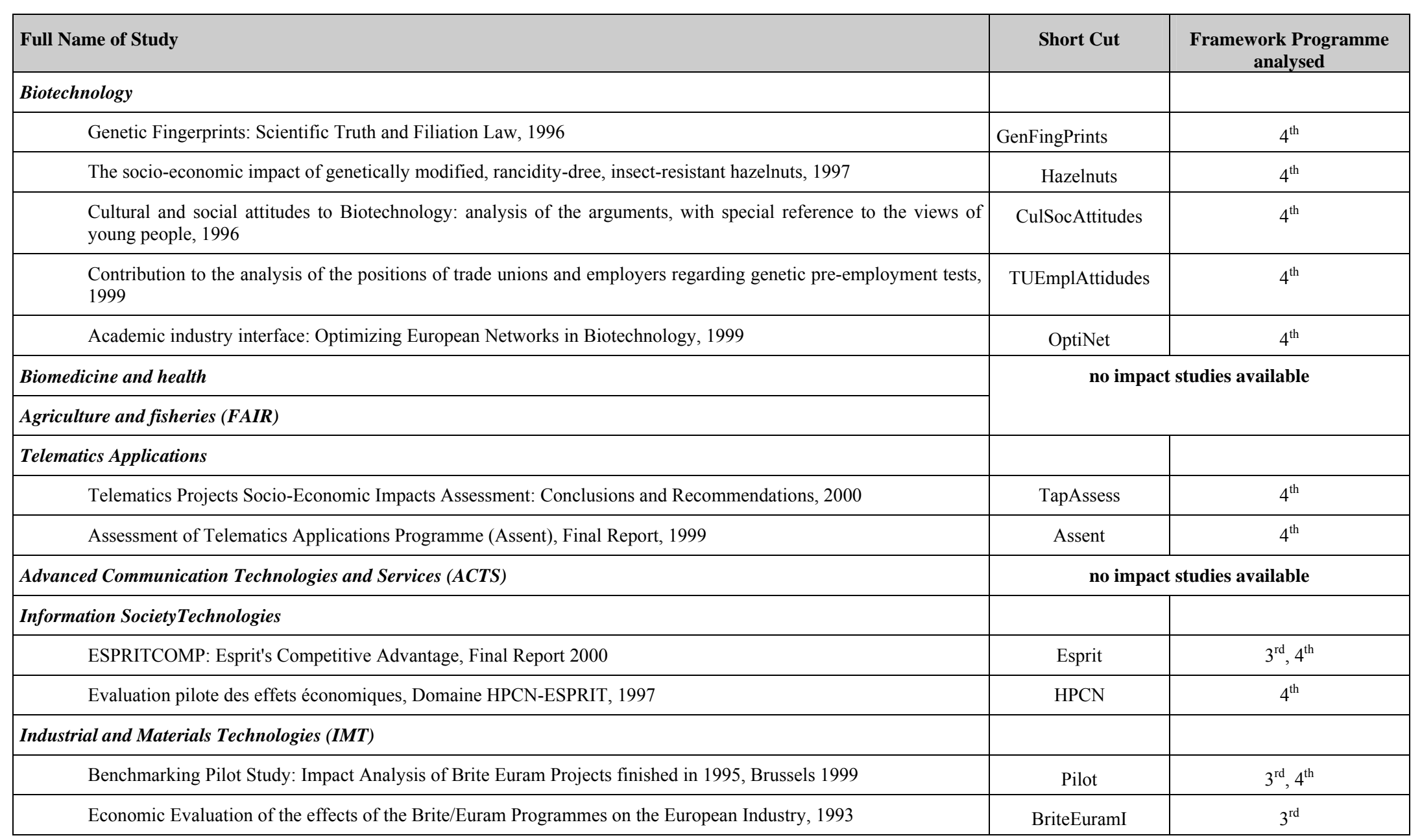




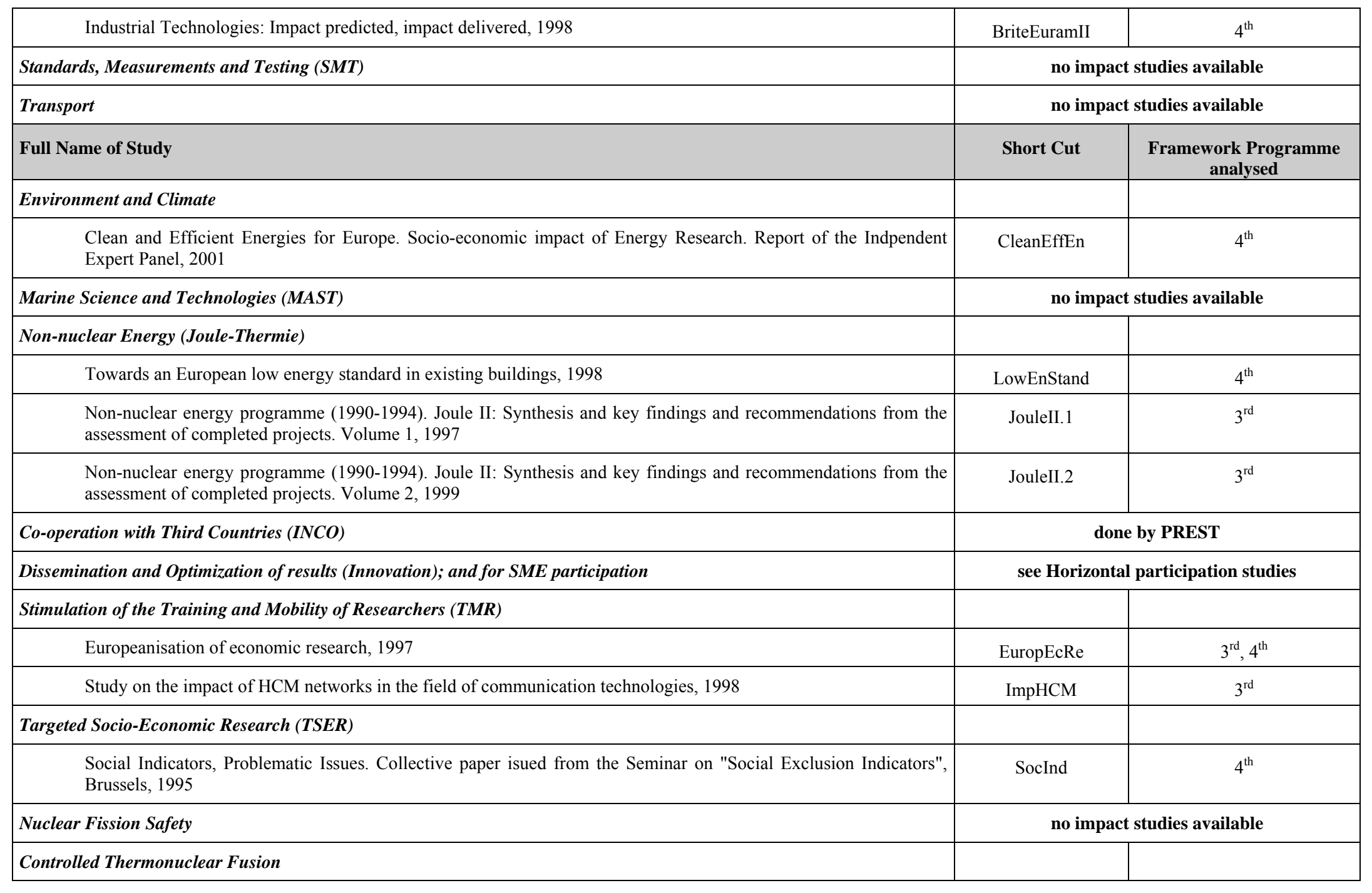




\begin{tabular}{|c|c|c|}
\hline SERF 1997-1998, Final Report 1999 (2 substudies) & SERF & $4^{\text {th }}$ \\
\hline The Joint European Torus Project - Impact on the local economy, 1995 & TORUS & $3^{\text {rd }}$ \\
\hline \multicolumn{3}{|l|}{ Horizontal participation studies } \\
\hline SME Participation in the $4^{\text {th }}$ EU FP for Research and Technological Development, 1998 & ParticipSME & $4^{\text {th }}$ \\
\hline RTD Strategies of the top 500 European Industrial Companies and their participation in the FP and Eureka, 1995 & ParticipLE & $3^{\text {rd }}$ \\
\hline Full Name of Study & Short Cut & $\begin{array}{c}\text { Framework Programme } \\
\text { analysed }\end{array}$ \\
\hline \multicolumn{3}{|l|}{ National Impact studies } \\
\hline $\begin{array}{l}\text { Luukonen T., Hälikkä S. (2000): Knowledge Creation and Knowledge Diffusion Networks. Impacts in Finland of } \\
\text { the EU's Fourth Framework Programme for Research and Development, Helsinki }\end{array}$ & FinImpact & $4^{\text {th }}$ \\
\hline Technopolis Ltd. (2001): The $4^{\text {th }}$ Framework Programme in Ireland, Brussels & IreImpact & $4^{\text {th }}$ \\
\hline $\begin{array}{l}\text { Joanneum Research, Technopolis Ltd., VTT (2001): Austrian } 4^{\text {th }} \text { Framework Programme Impact Evaluation, } \\
\text { forthcoming }\end{array}$ & AusImpact & $4^{\text {th }}$ \\
\hline
\end{tabular}


Exhibit 4: Descriptive overview

\begin{tabular}{|c|c|c|c|c|c|c|c|c|c|c|c|c|c|c|c|c|c|c|}
\hline & \multicolumn{7}{|c|}{ Type of Study } & \multicolumn{7}{|c|}{ Design of Study } & \multicolumn{4}{|c|}{ Types of Effects studied } \\
\hline & \multicolumn{4}{|c|}{ EU inventory List } & \multicolumn{3}{|c|}{ Fraunhofer ISI } & \multicolumn{4}{|c|}{ Time horizon } & \multicolumn{3}{|c|}{ Approach } & \multicolumn{2}{|c|}{ economic } & \multirow[b]{2}{*}{$\begin{array}{l}. \bar{\pi} \\
0 \\
0 \\
0\end{array}$} & \multirow{2}{*}{ 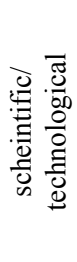 } \\
\hline & 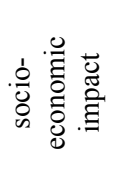 & 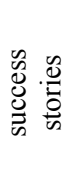 & 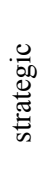 & $\begin{array}{l}\bar{\pi} \\
\overline{0} \\
0 \\
\ddot{n}\end{array}$ & 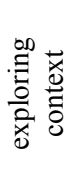 & 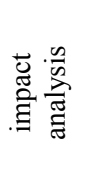 & 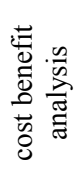 & 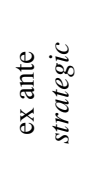 & 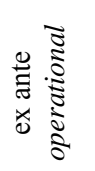 & 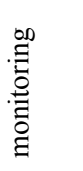 & $\begin{array}{l}\vec{w} \\
0 \\
\vdots \\
x \\
0\end{array}$ & 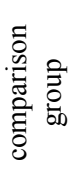 & 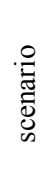 & 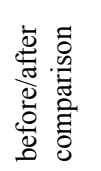 & 苍 & 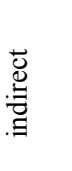 & & \\
\hline \multicolumn{19}{|l|}{ Biotechnology } \\
\hline GenFingPrints & $\phi$ & -- & -- & -- & $\phi$ & -- & -- & $\phi$ & -- & -- & -- & -- & -- & -- & -- & -- & $\phi$ & -- \\
\hline Hazelnuts & $\phi$ & -- & -- & -- & $\phi$ & -- & -- & $\phi$ & -- & -- & -- & -- & $\phi$ & -- & $\phi$ & -- & 道 & 象 \\
\hline BioCult & $*$ & -- & -- & -- & $\phi$ & -- & -- & $\phi$ & -- & -- & -- & -- & -- & -- & -- & -- & $\phi$ & -- \\
\hline TUEmplAttidudes & * & -- & -- & -- & $\phi$ & -- & -- & $\phi$ & -- & -- & -- & -- & -- & -- & -- & -- & $\phi$ & -- \\
\hline Optinet & $*$ & -- & -- & -- & -- & $\phi$ & -- & & -- & -- & $\phi$ & -- & -- & 8 & -- & -- & $\phi$ & -- \\
\hline \multicolumn{19}{|l|}{ Telematics } \\
\hline TapAssess & $\phi$ & -- & -- & -- & -- & $\phi$ & -- & -- & -- & -- & $\phi$ & -- & -- & $\phi$ & $\phi$ & -- & $\phi$ & -- \\
\hline Assent & $\phi$ & -- & -- & -- & -- & $\phi$ & -- & -- & -- & -- & $\phi$ & -- & -- & $\phi$ & $\phi$ & -- & $\phi$ & 8 \\
\hline \multicolumn{19}{|l|}{ IST } \\
\hline Esprit & $\phi$ & -- & -- & -- & -- & $\phi$ & -- & -- & -- & -- & $\phi$ & -- & -- & $\phi$ & $\phi$ & $\phi$ & -- & -- \\
\hline HPCN & $\phi$ & -- & -- & -- & -- & $\phi$ & -- & -- & -- & -- & $\phi$ & -- & -- & 8 & $\phi$ & $\phi$ & -- & $\phi$ \\
\hline
\end{tabular}




\begin{tabular}{|c|c|c|c|c|c|c|c|c|c|c|c|c|c|c|c|c|c|c|}
\hline & \multicolumn{7}{|c|}{ Type of Study } & \multicolumn{7}{|c|}{ Design of Study } & \multicolumn{4}{|c|}{ Types of Effects studied } \\
\hline & \multicolumn{4}{|c|}{ EU inventory List } & \multicolumn{3}{|c|}{ Fraunhofer ISI } & \multicolumn{4}{|c|}{ Time horizon } & \multicolumn{3}{|c|}{ Approach } & \multicolumn{2}{|c|}{ economic } & \multirow[b]{2}{*}{$\begin{array}{l}. \bar{\pi} \\
\dot{0} \\
\dot{0}\end{array}$} & \multirow{2}{*}{ 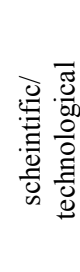 } \\
\hline & 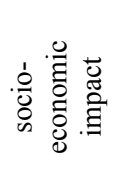 & 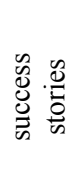 & 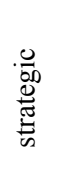 & 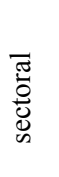 & 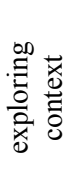 & 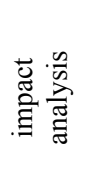 & 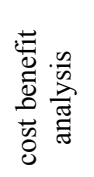 & 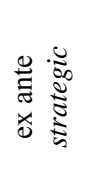 & 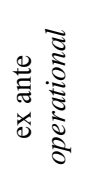 & 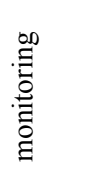 & $\begin{array}{l}\vec{b} \\
0 \\
\stackrel{0}{0} \\
x \\
0\end{array}$ & 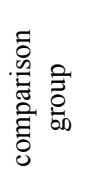 & 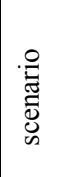 & 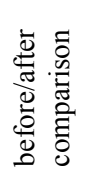 & 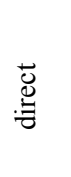 & 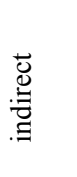 & & \\
\hline \multicolumn{19}{|l|}{ IMT } \\
\hline Pilot & $\phi$ & -- & -- & -- & -- & $\Phi$ & -- & -- & -- & -- & $\phi$ & -- & $\phi$ & $\phi$ & $\phi$ & -- & $\phi$ & -- \\
\hline BriteEuramI & -- & -- & -- & $\phi$ & -- & $\phi$ & -- & -- & -- & -- & $\phi$ & -- & \& & $\phi$ & $\phi$ & $\phi$ & - & $y$ \\
\hline BriteEuramII & $\phi$ & -- & -- & -- & -- & $\phi$ & -- & -- & -- & -- & $\phi$ & -- & 8 & $\phi$ & $\phi$ & $\phi$ & 8 & $y$ \\
\hline \multicolumn{19}{|c|}{ Environment and Climate } \\
\hline CleanEffEn & * & -- & -- & -- & -- & $\phi$ & - & -- & -- & - & $\phi$ & -- & -- & $\phi$ & 8 & $y$ & by & 8 \\
\hline \multicolumn{19}{|c|}{ Non-nuclear Energy } \\
\hline LowEnStand & $\phi$ & -- & -- & -- & $\phi$ & -- & -- & $\phi$ & -- & -- & - & - & $\phi$ & -- & $\phi$ & -- & - & $\phi$ \\
\hline JouleII.1 & -- & $\phi$ & -- & -- & -- & $\phi$ & -- & -- & -- & -- & $\phi$ & -- & -- & $\phi$ & $\phi$ & 8 & $\phi$ & $\phi$ \\
\hline JouleII. 2 & -- & $\phi$ & -- & -- & -- & $\phi$ & -- & -- & -- & -- & $\phi$ & -- & -- & $\phi$ & $\phi$ & $y$ & $\phi$ & $\phi$ \\
\hline \multicolumn{19}{|l|}{ TMR } \\
\hline EuropEcRe & $\phi$ & -- & -- & -- & -- & $y$ & -- & -- & -- & -- & $\phi$ & -- & -- & $\phi$ & -- & $\phi$ & $\phi$ & -- \\
\hline ImpHCM & -- & -- & $\phi$ & -- & -- & $\phi$ & -- & -- & -- & -- & b & -- & -- & 8 & -- & -- & -- & 8 \\
\hline \multicolumn{19}{|l|}{ TSER } \\
\hline SocInd & $\phi$ & -- & -- & -- & $\phi$ & -- & -- & $\phi$ & 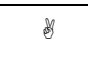 & -- & -- & -- & & - & -- & -- & $\phi$ & -- \\
\hline
\end{tabular}




\begin{tabular}{|c|c|c|c|c|c|c|c|c|c|c|c|c|c|c|c|c|c|c|}
\hline & \multicolumn{7}{|c|}{ Type of Study } & \multicolumn{7}{|c|}{ Design of Study } & \multicolumn{4}{|c|}{ Types of Effects studied } \\
\hline & \multicolumn{4}{|c|}{ EU inventory List } & \multicolumn{3}{|c|}{ Fraunhofer ISI } & \multicolumn{4}{|c|}{ Time horizon } & \multicolumn{3}{|c|}{ Approach } & \multicolumn{2}{|c|}{ economic } & \multirow[b]{2}{*}{$\begin{array}{l}. \bar{\pi} \\
0 \\
0 \\
0\end{array}$} & \multirow{2}{*}{ 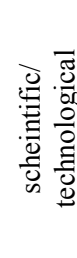 } \\
\hline & 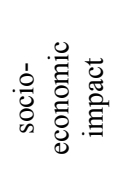 & 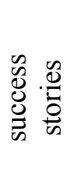 & 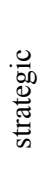 & 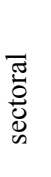 & 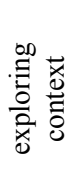 & 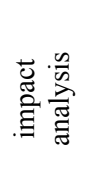 & 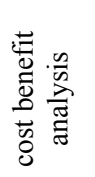 & 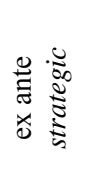 & 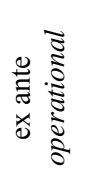 & 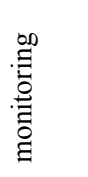 & $\begin{array}{l}\vec{w} \\
\stackrel{0}{0} \\
\underset{0}{0}\end{array}$ & 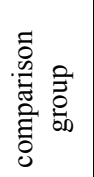 & 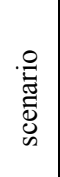 & 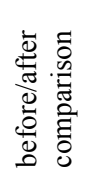 & 荀 & 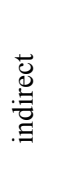 & & \\
\hline \multicolumn{19}{|l|}{ Controlled Fusion } \\
\hline $\begin{array}{l}\text { SERF: external costs and } \\
\text { benefits }\end{array}$ & $\phi$ & -- & -- & -- & -- & -- & $\phi$ & -- & -- & -- & -- & -- & -- & $\phi$ & $\phi$ & $\phi$ & -- & -- \\
\hline $\begin{array}{l}\text { SERF: fusion and public } \\
\text { opinion }\end{array}$ & $\phi$ & -- & -- & -- & $\phi$ & -- & -- & $\phi$ & -- & -- & -- & -- & -- & -- & -- & -- & $\phi$ & -- \\
\hline TORUS & $\phi$ & -- & -- & -- & $\phi$ & $\phi$ & -- & 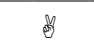 & -- & -- & $\phi$ & -- & -- & $\phi$ & $\phi$ & $\phi$ & $\phi$ & -- \\
\hline \multicolumn{19}{|l|}{$\begin{array}{l}\text { Horizontal participation } \\
\text { study }\end{array}$} \\
\hline ParticipSME & -- & -- & $\phi$ & -- & -- & $\phi$ & -- & -- & -- & -- & $\phi$ & -- & -- & $\phi$ & -- & -- & $\phi$ & -- \\
\hline ParticipLE & * & -- & -- & -- & -- & $\phi$ & -- & -- & -- & -- & $\phi$ & -- & -- & $\phi$ & -- & -- & $\phi$ & -- \\
\hline \multicolumn{19}{|l|}{ National Impact Studies } \\
\hline FinImpact & * & -- & -- & -- & -- & $\phi$ & -- & -- & -- & -- & $\phi$ & -- & -- & 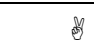 & $\phi$ & 急 & 8 & $\phi$ \\
\hline IreImpact & $*$ & -- & -- & -- & -- & $\phi$ & -- & -- & -- & -- & $\phi$ & -- & -- & -- & $\phi$ & 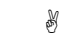 & B & $\phi$ \\
\hline AusImpact & $*$ & -- & -- & -- & -- & $\phi$ & -- & -- & -- & -- & $\phi$ & -- & -- & B & $\phi$ & 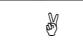 & 8 & $\phi$ \\
\hline GerImpact & $*$ & -- & -- & -- & -- & $\phi$ & -- & -- & -- & -- & $\phi$ & -- & -- & $\theta$ & $\phi$ & $y$ & -- & $\phi$ \\
\hline
\end{tabular}


Exhibit 5: Data and methodology issues

\begin{tabular}{|c|c|c|c|c|c|c|c|c|c|c|c|c|c|c|c|c|c|c|}
\hline & \multicolumn{6}{|c|}{ Data collection } & \multicolumn{3}{|c|}{ Data analysis } & \multicolumn{3}{|c|}{ Methodological Stance } & \multicolumn{2}{|c|}{$\begin{array}{c}\text { Level } \\
\text { of analysis }\end{array}$} & \multicolumn{2}{|c|}{$\begin{array}{c}\text { Stakeholders } \\
\text { analysed }\end{array}$} & \multirow{3}{*}{$\begin{array}{c}\text { Metho- } \\
\text { dological } \\
\text { reflexivity }\end{array}$} & \multirow{3}{*}{$\begin{array}{c}\text { Policy } \\
\text { recommen } \\
\text { dation }\end{array}$} \\
\hline & \multicolumn{2}{|c|}{ by evaluator } & \multicolumn{4}{|c|}{ source other than evaluator } & \multirow[b]{2}{*}{ 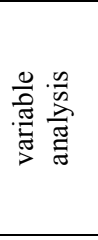 } & \multirow[b]{2}{*}{ 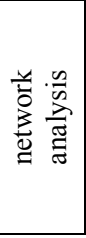 } & \multirow[b]{2}{*}{ 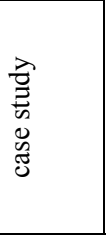 } & \multirow[b]{2}{*}{ 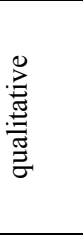 } & \multirow[b]{2}{*}{ 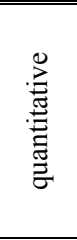 } & \multirow[b]{2}{*}{ 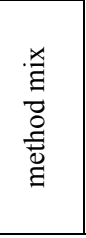 } & \multirow[b]{2}{*}{ 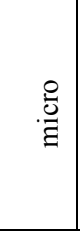 } & \multirow[b]{2}{*}{ 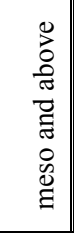 } & \multirow[b]{2}{*}{ 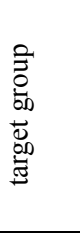 } & \multirow[b]{2}{*}{ 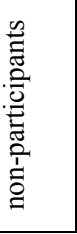 } & & \\
\hline & 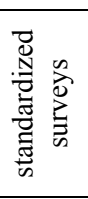 & 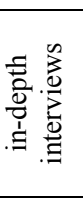 & 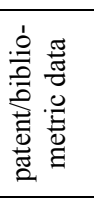 & 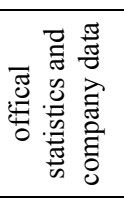 & 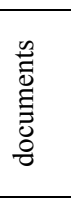 & 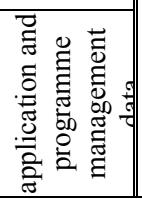 & & & & & & & & & & & & \\
\hline \multicolumn{19}{|l|}{ Biotechnology } \\
\hline GenFingPrints & -- & 8 & -- & -- & $\phi$ & -- & -- & -- & -- & $\phi$ & -- & -- & -- & $\phi$ & -- & -- & -- & 8 \\
\hline Hazelnuts & B & \& & -- & $\phi$ & $\phi$ & -- & $\phi$ & -- & -- & -- & $\phi$ & -- & 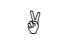 & es & -- & -- & -- & 舟 \\
\hline BioCult & $\phi$ & -- & -- & -- & $\phi$ & -- & 8 & -- & -- & -- & -- & $\phi$ & 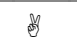 & 8 & -- & -- & -- & -- \\
\hline TUEmplAttidudes & -- & s & -- & -- & H & -- & -- & -- & $\phi$ & $\phi$ & -- & -- & -- & -- & -- & -- & -- & $\phi$ \\
\hline Optinet & $\phi$ & $\phi$ & -- & -- & -- & 8 & $\phi$ & 8 & -- & -- & $\phi$ & -- & $\phi$ & -- & $\phi$ & 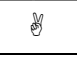 & -- & $\phi$ \\
\hline \multicolumn{19}{|l|}{ Telematics } \\
\hline TapAssess & $\phi$ & $\phi$ & -- & -- & -- & -- & $\phi$ & -- & -- & -- & -- & $\phi$ & $\phi$ & 8 & $\phi$ & -- & $\phi$ & $\phi$ \\
\hline Assent & $\phi$ & $\phi$ & -- & -- & -- & -- & x & -- & -- & -- & -- & $\phi$ & $\phi$ & 8 & $\phi$ & -- & $\phi$ & $\phi$ \\
\hline \multicolumn{19}{|l|}{ IST } \\
\hline Esprit & $\phi$ & $\phi$ & -- & -- & -- & -- & $\phi$ & -- & $\phi$ & -- & -- & $\phi$ & $\phi$ & e & $\phi$ & -- & e & $\phi$ \\
\hline $\mathrm{HPCN}$ & -- & $\phi$ & -- & -- & -- & $\phi$ & $\phi$ & -- & -- & -- & -- & $\phi$ & $\phi$ & -- & $\phi$ & -- & 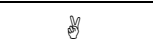 & -- \\
\hline \multicolumn{19}{|l|}{ IMT } \\
\hline Pilot & b & $\phi$ & -- & $\phi$ & -- & -- & $\phi$ & -- & -- & -- & -- & $\phi$ & $\phi$ & -- & $\phi$ & -- & -- & -- \\
\hline BriteEuramI & 8 & $\phi$ & -- & $\phi$ & -- & -- & $\phi$ & -- & -- & -- & -- & $\phi$ & $\phi$ & -- & $\phi$ & -- & 8 & -- \\
\hline \multirow[t]{3}{*}{ BriteEuramII } & -- & $\phi$ & -- & $\phi$ & -- & -- & $\phi$ & -- & -- & -- & -- & $\phi$ & $\phi$ & 8 & $\phi$ & -- & -- & -- \\
\hline & \multicolumn{6}{|c|}{ Data collection } & \multicolumn{3}{|c|}{ Data analysis } & \multicolumn{3}{|c|}{ Methodological Stance } & \multicolumn{2}{|c|}{$\begin{array}{c}\text { Level } \\
\text { of analysis }\end{array}$} & \multicolumn{2}{|c|}{$\begin{array}{c}\begin{array}{c}\text { Stakeholders } \\
\text { analysed }\end{array} \\
\end{array}$} & $\begin{array}{c}\text { Metho- } \\
\text { dological }\end{array}$ & $\begin{array}{c}\text { Policy } \\
\text { recommen }\end{array}$ \\
\hline & bye & uator & & rce other th & evalu & & 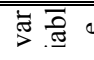 & $\bar{\Xi} \lesssim$. & 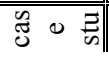 & 票:哥 & 票: & 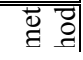 & $\stackrel{\mathscr{g}}{\mathrm{g}}$ & g & 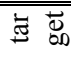 & 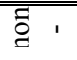 & & dation \\
\hline
\end{tabular}




\begin{tabular}{|c|c|c|c|c|c|c|c|c|c|c|c|c|c|c|c|c|c|c|}
\hline & 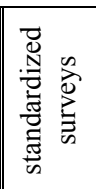 & 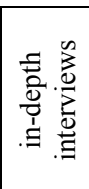 & 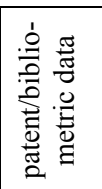 & 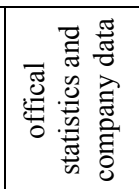 & 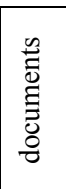 & 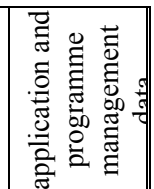 & & & & & & & & & & & & \\
\hline \multicolumn{19}{|l|}{ Environment and Climate } \\
\hline CleanEffEn & $\$$ & -- & -- & $x$ & -- & -- & 8 & -- & -- & -- & -- & $\phi$ & $\phi$ & -- & $\phi$ & -- & 8 & $y$ \\
\hline \multicolumn{19}{|l|}{ Non-nuclear Energy } \\
\hline LowEnStand & -- & -- & -- & $\phi$ & 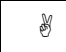 & -- & $\phi$ & -- & -- & -- & $\phi$ & -- & $\phi$ & $\phi$ & -- & -- & -- & $\phi$ \\
\hline JouleII.1 & $\phi$ & $\phi$ & -- & -- & -- & -- & $\$$ & -- & -- & -- & $\$$ & -- & $\phi$ & -- & $\phi$ & -- & $\phi$ & 8 \\
\hline JouleII.2 & $\phi$ & $\$$ & -- & -- & -- & -- & $\phi$ & -- & -- & -- & $\$$ & -- & $\phi$ & -- & $\phi$ & -- & $\phi$ & 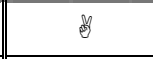 \\
\hline \multicolumn{19}{|l|}{ TMR } \\
\hline EuropEcRe & -- & -- & -- & -- & $\phi$ & $\phi$ & -- & -- & 8 & -- & $\phi$ & -- & -- & $\phi$ & $\phi$ & -- & -- & $\phi$ \\
\hline ImpHCM & -- & 8 & -- & -- & -- & -- & -- & -- & -- & $\$$ & -- & -- & -- & $\phi$ & $\phi$ & -- & $y$ & $\phi$ \\
\hline \multicolumn{19}{|l|}{ TSER } \\
\hline SocInd & -- & -- & -- & -- & -- & -- & -- & -- & -- & -- & -- & $\phi$ & $\phi$ & -- & -- & $\$$ & -- & -- \\
\hline \multicolumn{19}{|l|}{ Controlled Fusion } \\
\hline $\begin{array}{l}\text { SERF: external costs and } \\
\text { benefits }\end{array}$ & $\phi$ & -- & -- & -- & -- & -- & $\phi$ & -- & -- & -- & 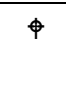 & -- & $\phi$ & $\phi$ & -- & $\phi$ & $\phi$ & -- \\
\hline $\begin{array}{l}\text { SERF: fusion and public } \\
\text { opinion }\end{array}$ & -- & 中* & -- & -- & -- & -- & -- & -- & -- & $\$$ & -- & -- & -- & $\phi$ & $\phi$ & -- & $\phi$ & $y$ \\
\hline \multirow[t]{4}{*}{ TORUS } & $B$ & 8 & -- & $\phi$ & -- & -- & $\phi$ & -- & -- & -- & $\phi$ & & $\phi$ & $x$ & $\phi$ & -- & $x$ & $\phi$ \\
\hline & \multicolumn{6}{|c|}{ Data collection } & \multicolumn{3}{|c|}{ Data analysis } & \multicolumn{3}{|c|}{ Methodological Stance } & \multicolumn{2}{|c|}{$\begin{array}{c}\begin{array}{c}\text { Level } \\
\text { of analysis }\end{array} \\
\end{array}$} & \multicolumn{2}{|c|}{$\begin{array}{c}\text { Stakeholders } \\
\text { analysed }\end{array}$} & \multirow{3}{*}{$\begin{array}{c}\text { Metho- } \\
\text { dological } \\
\text { reflexivity }\end{array}$} & \multirow{3}{*}{$\begin{array}{c}\text { Policy } \\
\text { recommen } \\
\text { dation }\end{array}$} \\
\hline & \multicolumn{2}{|c|}{ by evaluator } & \multicolumn{4}{|c|}{ source other than evaluator } & \multirow[b]{2}{*}{ 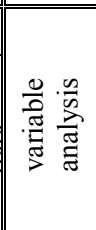 } & \multirow[b]{2}{*}{ 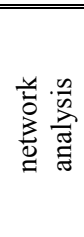 } & \multirow[b]{2}{*}{ 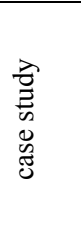 } & \multirow[b]{2}{*}{ 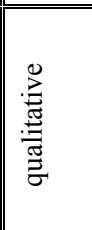 } & \multirow[b]{2}{*}{ 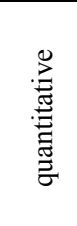 } & \multirow[b]{2}{*}{ 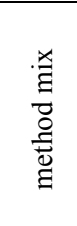 } & \multirow[b]{2}{*}{$\stackrel{\circ}{\stackrel{0}{g}}$} & \multirow[b]{2}{*}{ 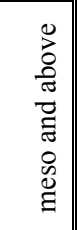 } & \multirow[b]{2}{*}{ 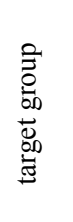 } & \multirow[b]{2}{*}{ 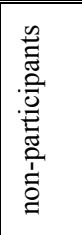 } & & \\
\hline & 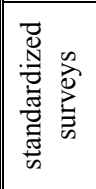 & 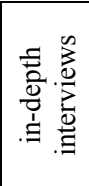 & 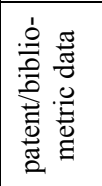 & 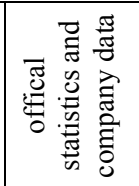 & 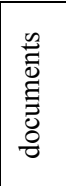 & 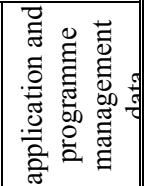 & & & & & & & & & & & & \\
\hline
\end{tabular}


Horizontal participatio

study

ParticipSME

ParticipLE

National Impact Studies

FinImpact

IreImpact

AusImpact

GerImpact

$\Phi=$ yes, substantial

\begin{tabular}{|l|l|l|l|l|l||}
$\oplus$ & -- & -- & -- & -- & -- \\
\hline & $\phi$ & -- & -- & -- & -- \\
\hline
\end{tabular}

\begin{tabular}{||c|c|c||c|c|c||c|c||c|c||c||c|}
$\phi$ & -- & -- & -- & $\phi$ & -- & $\phi$ & - & $\phi$ & -- & - & - \\
\hline$\phi$ & -- & -- & -- & -- & $\phi$ & $\phi$ & - & $\phi$ & -- & -- & -- \\
\hline
\end{tabular}

(1)

= yes, to a limited degree

\begin{tabular}{|c|c|c|}
\hline & $\phi$ & $\phi$ \\
\hline$\theta$ & - & $\phi$ \\
\hline$\theta$ & - & $\phi$ \\
\hline$\theta$ & $\phi$ & $\phi$ \\
\hline
\end{tabular}

\begin{tabular}{|c|c|c||c|c|c||c|c}
$\phi$ & -- & -- & -- & $\phi$ & - & $\phi$ & -- \\
\hline$\phi$ & -- & -- & -- & -- & $\phi$ & $\phi$ & -- \\
\hline$\phi$ & -- & -- & -- & -- & $\phi$ & $\phi$ & -- \\
\hline$\phi$ & -- & $\varnothing$ & -- & -- & $\phi$ & $\phi$ & - \\
\hline
\end{tabular}

\begin{tabular}{||c|c||c||c|}
\hline$\phi$ & - & $\phi$ & -- \\
\hline$\phi$ & -- & $\phi$ & $\phi$ \\
\hline$\phi$ & $\phi$ & $\phi$ & $\phi$ \\
\hline$\phi$ & $\phi$ & $\phi$ & $\phi$ \\
\hline \multicolumn{4}{|c||}{$*$ Group and public discussions }
\end{tabular}




\section{Analysis - Two main types of evaluation studies: "exploratory" and "solid"}

After descriptive information had been gathered, the aforementioned studies were clustered so as to arrive at structurally similar groups of studies. As a result, two main types of "evaluation studies" emerged. There are 8 studies with a focus on "exploratory" impact as opposed to 20 other studies with a focus on "solid" impact. In the following paragraphs each group will be looked at in more detail. This is done by first presenting general results which are then complemented by study-specific information.

What is meant by "exploratory" impact studies? Impact studies are generally designed as ex post analyses that compare a state of the world X1 at timepoint T1 (past) with a state of the world X2 at the respective timepoint T2 (present time). When X1 is an identical group of units in the course of analysis one may speak of a "before/after comparison", in the case of different groups of units in the course of analysis one of them is generally referred to as "comparison group". Exploratory evaluation studies do not have this design, but consider what a future state of the world might look like, given certain framework conditions. Thus, "exploratory" refers to the fact that no distinct effects have manifested themselves whereby one could distinguish different states of the world. Rather, given a state of the world X1 at timepoint T1 (present time) likely impacts that may accrue from the Framework Programme at some future timepoint Ti (where "i" is, say, 3 or 5 years after T1) are taken into consideration, thereby shedding light on formerly unrecognized or even unforeseen aspects of future states of the world.

For instance, when the Commission needs information as to what economic or legal impacts the change of European regulation will bring forth regarding the use of genetic fingerprinting devices in the contexts of industrial relations ("TUEmplAttitudes") or filiation law ("GenFingPrints"), "exploratory" evaluation studies are used as devices with which attitudes, or arguments particular groups of European citizens employ regarding legal, ethical or political questions and forthcoming decisions can be monitored and then possibly fed into political action. As impact analysis is dealt with at the programme level here (discussing Biotechnology as an example), the relevant studies contribute to the general knowledge about and awareness of policy-makers with respect to the future impact of the application of life science results on different societal fields. Unsurprisingly, studies that document these kinds of discussions, legal discourses and attitudinal surveys draw upon various data sources and lack a coherent methodological stance. They are "discursive" in character.

However, there is another group of studies that emerged during analysis and that can equally be named "exploratory" evaluation - subtitle "potential impact" studies. These studies have one aspect in common with the aforementioned ones in that they employ an ex ante time design, but they differ in focussing more on economic rather than social effects, and in using a much more coherent quantitative methodology, including primary use of official statistics and company data. Though they resemble the "solid" evaluation studies (described later on) in these respects, their main analytical focus aims at identifying potential effects which would result from the introduction of certain regulations or political actions. In other words, when the Commission needs information on what effects genetically modified hazelnuts would have in local European markets if they were allowed to be produced ("Hazelnuts"); or how well- 
prepared member states are - regarding the introduction of regulations on thermal insulation of semi-detached houses ("LowEnStand"), then information is needed for evaluating the "potential impact" of political decisions to be taken at the European level.

Exhibit 6: "Exploratory Impact" - Methodology and Relevant Studies

\begin{tabular}{|c|c|c|}
\hline & \multicolumn{2}{|c|}{ Exploratory Evaluation Studies } \\
\hline & "Discursive" Studies & "Potential Impact" Studies \\
\hline Methodology & $\begin{array}{ll}\text { - } & \text { ex ante strategic } \\
\text { - } & \text { societal effects } \\
\text { - } & \text { various data sources } \\
\text { - } & \text { no distinct methodology }\end{array}$ & $\begin{array}{ll}\text { - } & \text { ex ante strategic } \\
\text { - } & \text { economic effects } \\
\text { - } & \text { "hard" economic data } \\
\text { - } & \text { distinct quantitative } \\
& \text { methodology }\end{array}$ \\
\hline Relevant Studies & $\begin{array}{l}\text { - } \text { GenFingPrints } \\
\text { - } \text { BioCult } \\
\text { - TUEmplAttitudes } \\
\text { - SocInd } \\
\text { - SERF: fusion and public } \\
\text { opinion }\end{array}$ & $\begin{array}{ll}\text { - } & \text { Hazelnuts } \\
\text { - } & \text { LowEnStand } \\
\text { - } & \text { TORUS }\end{array}$ \\
\hline
\end{tabular}

To sum up, "exploratory impact" studies comprising "discursive" and "potential impact" analyses (as shown in exhibit 6 ), have a clear prospective focus upon likely economic and societal effects that may accrue from European Research Programmes across various areas. However, they cannot be regarded as "pure" programme evaluation in that they do not ask the typical ex post questions of programme evaluations: "What has been done? What are the effects and how have they been used afterwards?" In this regard these evaluations are not the subject of a more substantive meta-evaluation than is done for the "solid impact" studies later on. Nevertheless, it appears worthwhile to include them here, not just because they are part of the overall programme evaluation scheme of the EU Framework Programme, but because they exemplify the high importance this type of impact evaluation is given within the evaluation practice at the European level. This kind of evaluation study does play an important role, not at least because it provides guidance for decision-making on future RTD policy initiatives.

\section{"Mini-meta-evaluation" of 20 "solid" impact studies}

The second main type of evaluation studies that emerged in our sample of 28 analyses deal with "solid impacts" in that they employ the characteristic evaluation approach that is used for assessing programme effects (Fayl et al. 1998). Hence, the relevant 20 studies need a closer meta-evaluative examination than the "exploratory impact" ones. 
For the sake of analytical convenience, we suggest a functional reference scheme that aims at capturing and linking relevant aspects of these studies, and thus serves as a meta-evaluative device against which background conclusions about the effectiveness of the impact evaluation can be drawn.

\section{Exhibit 7: "Solid Impact" - Methodology and Relevant Studies}

\begin{tabular}{|c|c|}
\hline Methodology & $\begin{array}{l}\text { - } \text { ex post, before/after comparison } \\
\text { - } \quad \text { societal and economic and scientific/technological effects } \\
\text { - } \quad \text { survey data } \\
\text { - } \\
\text { distinct method mix methodology }\end{array}$ \\
\hline Relevant Studies & $\begin{array}{ll}\text { - } & \text { Optinet } \\
\text { - } & \text { TapAssess, Assent } \\
\text { - } & \text { Esprit, HPCN } \\
\text { - } & \text { Pilot, BriteEuramI, BriteEuramII } \\
\text { - } & \text { CleanEffEn } \\
\text { - } & \text { JouleII.1, JouleII.2 } \\
\text { - } & \text { Dissem } \\
\text { - } & \text { EuropEcRe, ImpHCM } \\
\text { - } & \text { SERF: external costs and benefits } \\
\text { - } & \text { ParticipLE } \\
\text { - } & \text { FinImpact, IreImpact, AusImpact, GerImpact }\end{array}$ \\
\hline
\end{tabular}

In the following paragraphs, 14 FP-related, 4 national and 2 horizontal evaluation studies are examined. In accordance with Airaghi et al. (1999, 8; see also exhibit 1) a cross tabulation of important impact dimensions of public RTD spending is suggested here that depicts different classes of effects (outputs and impacts) with regard to time (short-, medium- and long-term) and "worlds" (science, economy and society) (see exhibit 8). On the left side one can see examples of scientific, economic and societal outputs such as new/improved products, technical know-how or regulation. They are drawn from Bach and Georghiou (1998) who have provided a comprehensive taxonomy of possible outputs. These outputs can commonly be assumed to materialize within a short- or medium term perspective - a fact that makes them relatively easy to capture in evaluations. On the right side several examples of impacts both in the short run and the long run are shown. The logic behind this time frame is to differentiate between a local increase in productivity (of, say, two companies) and the substantiality of this effect in a longer perspective and with respect to more than two companies (e.g., a region, a cluster). What should be obvious is that the more to the right one goes in the functional reference scheme as a whole, the more tenuously connected are EU RTD spending and measurable outcomes in a causal sense. The same holds true for proceeding from scientific to societal outcomes: the degree to which a patent or a new product can be observed and attributed to increased RTD spending is usually much higher than is the case for new jobs or consumer safety. Consequently, the uppermost left box will be the easiest one to evaluate, whereas the bottom box on the extreme right will be most difficult to capture by evaluation analysis. 
With this argument in mind, it may be evaluated what efforts are undertaken to produce evaluative information with respect to the different boxes. Implicitly, this raises the question what efforts do evaluators undertake to alleviate the inherent differences (in terms of observability and evaluability) between all boxes. We propose three criteria that seem helpful in analysing these efforts. To sum it up in a question: How do the effects studied and methodologies used in the solid impact studies relate to one another? The criteria are as follows (also depicted in exhibit 8):

- Suitability: whether evaluators arrive at a balance in what they want to evaluate in their studies and how the use of their data and methods fits this purpose (e.g., analysing a network of 50 enterprises without carrying out thorough network analysis is regarded as insufficient).

- Validity and Reliability: whether evaluators make sure data they rely on are valid and reliable, for instance by using more than one source (e.g., interviews and company data).

- Exhaustiveness: whether evaluators make exhaustive use of methods at hand, i.e. whether data collection and data analysis are well-balanced (e.g. mere frequency tables are generally deemed insufficient for the analysis of metrical data).

\section{Exhibit 8: Effect Dimensions of EU's Framework Programmes}

\begin{tabular}{|c|c|c|c|c|c|}
\hline & \multicolumn{2}{|c|}{ Outputs } & \multicolumn{2}{|c|}{ Impacts } & \\
\hline & short-term & medium-term & short-term & long-term & \\
\hline $\begin{array}{l}\text { Scientific and } \\
\text { Technological }\end{array}$ & \multicolumn{2}{|c|}{$\begin{array}{l}\text { e.g., new/improved } \\
\text { technological } \\
\text { know-how }\end{array}$} & $\begin{array}{l}\text { e.g., increased } \\
\text { productivity }\end{array}$ & $\begin{array}{l}\text { e.g., increased } \\
\text { competitiveness }\end{array}$ & \\
\hline Economic & \multicolumn{2}{|c|}{$\begin{array}{l}\text { e.g., new/improved } \\
\text { products, services and processes }\end{array}$} & $\begin{array}{l}\text { e.g., increased } \\
\text { sales and } \\
\text { market share }\end{array}$ & $\begin{array}{l}\text { e.g., new mar- } \\
\text { kets; } \\
\text { development of } \\
\text { SMEs }\end{array}$ & abilty \\
\hline Societal & \multicolumn{2}{|c|}{$\begin{array}{c}\text { e.g., job creation } \\
\text { better infrastructure, healthcare } \\
\text { new regulation }\end{array}$} & $\begin{array}{l}\text { e.g., increased } \\
\text { prosperity } \\
\text { satisfaction } \\
\text { equality }\end{array}$ & $\begin{array}{l}\text { e.g., stable, co- } \\
\text { hesive } \\
\text { society with } \\
\text { highly participa- } \\
\text { tive citizen }\end{array}$ & \\
\hline
\end{tabular}

\section{Effect coverage across 20 "solid impact" studies}

The first step of the "mini-meta-evaluation" presented here is the degree to which different types of effects are covered by the 20 "solid impact" studies. The procedure to arrive at the results presented here was as follows: the authors of this study examined roughly the range of effects every single study comprises. Since the analysis presented here is not primarily content-driven, the variance of effect coverage within single specific programmes are neglected - the authors relied very much on assessing the extent to which certain classes of effects are covered or not. After 
examining every study results were merged into one mark along a five step Likert scale: very substantial (++) to least substantial (--). It was not regarded as useful to break this extimate further down, since the main purpose is to know to what approximate extent a box has been given attention. In addition, exhibit 9, depicting the respective results, inherently provides information about the relative difference between the extent to which impact analysis has focused on the different boxes.

\section{Exhibit 9: Effect coverage in 20 Evaluation Studies}

\begin{tabular}{|c|c|c|c|c|c|}
\hline & \multicolumn{2}{|c|}{ Outputs } & \multicolumn{2}{|c|}{ Impads } & \\
\hline & short-term & mediumterm & short-term & long-term & \\
\hline $\begin{array}{l}\text { Sientificand } \\
\text { Technological }\end{array}$ & & $\oplus$ & :- & m & $\begin{array}{l}-\oplus \text { verysubsantial } \\
-(-)\end{array}$ \\
\hline Exonomic & & $\oplus ;$ & :- & $m$ & m leas substantial \\
\hline Societal & & $\oplus \oplus$ & $\oplus$ & $m$ & \\
\hline
\end{tabular}

Three main results can be derived from exhibit 9 .

- First, outputs are generally better covered in impact analyses than impacts, (nearly) regardless type of effect. This is certainly due to inherent difficulties in establishing true impacts than merely observing different states of the world in terms of products, change in service delivered or employment etc.

- Secondly, short- and medium-term effects, i.e. outputs and impacts, are generally given more attention than what might be regarded as most useful impact information: long-term impacts. This may either be attributed to the ease with which different states of the world can be deemed causally linked to each other. A second explanation lies in current impact evaluation: most studies operate with too small a time lag to really examine impacts rather than outputs.

- Thirdly, socio-economic effects are given slightly more attention than pure scientific and technological issues.

To sum up: impact analyses in the context of EU Framework Programmes did very much analyse what they should analyse, namely economic and societal effects. They did so with different degrees of intensity regarding time and type of effects. One major strength is the substantiality of socio-economic outputs examined. One weakness can be seen in the assessment of long-term impacts that may accrue from outputs. This issue needs to be taken up more thoroughly in future impact analyses. 


\section{Tentative results regarding the functional reference scheme}

In the following section, the functional reference scheme described above is applied to the 20 "solid impact" studies, whereby some tentative conclusions as to whether present EU programme evaluation is effective or not were arrived at. Proceeding similarly as with exhibit 9 (coverage), the authors examined every study according to three criteria: suitability, validity/reliability and exhaustiveness. Again, single results were aggregated so as to arrive at one mark for every box. This was done along a five step Likert scale too: very good $(++)$ to very poor (--). Exhibit 10 provides the respective results.

\section{Exhibit 10: Tentative Results regarding the Effectiveness of Evaluation Studies}

\begin{tabular}{|c|c|c|c|c|c|c|}
\hline & \multicolumn{2}{|c|}{ Outputs } & \multicolumn{2}{|c|}{ Impacts } & & \\
\hline & short-term & medium-term & short-term & long-term & & \\
\hline $\begin{array}{l}\text { Scientific and } \\
\text { Technological }\end{array}$ & & $\odot$ & $:-$ & $M$ & $\begin{array}{l}-\oplus ; \\
:-;\end{array}$ & very good \\
\hline Economic & & 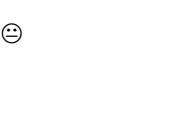 & 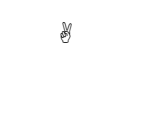 & $M$ & m & very poor \\
\hline Societal & & 8 & 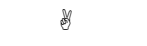 & 幽 & & \\
\hline
\end{tabular}

Exhibit 10 presents following results. First, as has already been seen from the effect coverage discussion, short- and medium-term outputs and impacts are analysed effectively in general, whereas long-term impacts - since covered less substantially are evaluated rather poorly. One reason for this tends to be the rather sophisticated and developed programme evaluation methods for the former, opposed to a less coherent and developed set of empirical tools for the latter. So, this critical result cannot be used to blame evaluators, but pinpoints the challenge to develop better evaluation methods to comprehend and assess socio-economic impacts, particularly long-term ones (Guy et al. 1998: 21).

Secondly, exhibit 10 depicts that effect coverage cannot be used as predictor for the effectiveness with which outputs and effects are finally established. As can be seen from a comparison of exhibit 9 and exhibit 10, economic and societal effects in particular appear well-covered in exhibit 9, but receive mediocre marks in terms of the three effectiveness criteria in exhibit 10, whereas evaluation of scientific and technological effects is done reasonably well. What are the reasons for this? And is this true of all respective criteria?

To start with the latter question: most analyses are well done in terms of suitability. Though with regard to "socio-economic" there is still considerable on-going debate about what this terminus technicus actually refers to (Airaghi et al. 1999), evaluators 
can be said to address the relevant questions when examining different classes of effects in different programmes. They differentiate between different types of effects as well as the way effects relate to different programmes. This is not only the case for FP3 and FP4 (covered here), but also for FP5, where a study has been carried out on behalf of the Commission (European Commission 2000b) that evaluates how well the socio-economic dimension has been implemented in FP5 so far. However, data used for analysis (validity/reliability) are often one-dimensional, i.e. produced "in-house", such as standardized survey or in-depth interview data. There is nothing wrong with that, but efforts to validate information by systematically collecting official statistics and company data would certainly be beneficial to the understanding of socioeconomic impacts of the FP.

To illustrate this argument, consider job creation. Nearly unanimously, programme evaluators ask project managers whether jobs have been created or not, and if yes, to indicate the extent to which this was achieved. At best, programme evaluations state that, for instance, 534 jobs have been created due to FP participation. Not very often, however, such a number is analysed against the background of the general labour market conditions at that time. Neither the issue of whether these jobs would have been created anyway, nor even if their creation has inhibited the emergence of other employment opportunities, is given due attention - not least because non-participants are hardly ever analysed (see for the latter point exhibit 9). So, creation of 534 jobs gives the impression of substantial impact, but little is known whether this can be referred to as real impact of the FP (for this problem, see also Airaghi et al. 1999: 12).

Similarly, half of the studies do not analyse data exhaustively (exhaustiveness). Many programme evaluators collect useful data, most often of ordinal or metric quality, but eventually provide just frequency tables without exploiting all information at hand. So, multivariate analyses, though quite possible, are applied rather seldom. However, our analysis suggests that it is not programme evaluators who can exclusively be made responsible for this. Instead, they regularly report restrictions in terms of time and monetary resources available for analysis, and they mention that the co-ordination of project managers, EU research officials and themselves is not too favorable. Hence the lack of exhaustive utilisation of data collected seems to be somewhat inherent in the overall organisation of EU's impact evaluation.

As regards the three main dimensions of effects, the authors of this study observed that many of the 20 evaluation studies assess the three very similarly. This sometimes includes a "method mix" approach whereby both quantitative (survey data) and qualitative data (in-depth interviews) are collected. Despite this, there is both a tendency to overstate quantitative information and to neglect non-participants' attitudes. With respect to the former, this appears appropriate for scientific and technological as well as for economic effects because they can be deemed easily observable. Hence, studies report quite precisely to what extent new products, knowledge or services have been produced, and estimates about their expected impacts are provided. Bearing in mind the ticklist approach suggested in Bach and Georghiou (1998), which was taken up by many evaluators, it may be argued that this holds also for societal effects - they too can be captured by identifying categories subsumed under, for instance, "cohesion" or "regulation and policy". 
However, as was already pointed out with respect to the measurement of employment effects earlier, establishing real scientific or economic effects implies several problems in terms of causal attribution and observability. This is even truer of the extent to which "participation of citizens", or "co-ordination between regulation on national and community level" can be observed, because these effects rely heavily on individual and collective processes of interpretation and symbolic meaning. This points to the latter problem. The questions, for instance, whether specific programmes, such as Biotechnology or Telematics, have led to reduced social exclusion or better informed European citizens can certainly not be answered solely by people involved in the programmes, but need survey and in-depth interview attitudinal data of a wider user or citizen community - however defined. Therefore, intricate measures, such as societal effects, need a different kind of attention than their scientific and technological counterparts.

As was stated above, many evaluators take this into account by carrying out in-depth interviews with several groups of actors, thus producing helpful evaluative information. This is particularly true of those studies that apply "method mix" approaches. However, even if such data were collected, they are not always used systematically for interpretation. In other words, when evaluators present their arguments (those studies that apply a strong quantitative approach anyway), they tend to give precedence to quantitative information.

Hence, the problem with the evaluation of societal effects is twofold: on the one hand, current efforts to really trace societal effects are underdeveloped and rely too heavily on measurement techniques most appropriate for technological and economic effects; and on the other, when qualitative data are collected, authors of "solid" evaluation studies tend to understate them in interpretation. Whether evaluators thereby attempt to provide mutually comparable data, or want their interpretations to appear as "hard facts" remains unclear. What remains clear, however, is that current evaluation practice leaves societal effects to be less profoundly understood than respective economic, scientific and technological ones.

In conclusion, the results stated above leave the impression that a coherent and comprehensive impact evaluation methodology is lacking, but clearly needed. Evaluators strive for best results, and the 20 "solid" evaluation studies certainly represent great efforts to grapple with the demanding task of shedding light on the way EU RTD policies leave their marks ("impacts") on society.

To complete this analysis, some of the criticism will now be turned into forwardlooking recommendations for future impact evaluation. Thus, selected favourable aspects of the 20 reviewed studies that appear to fit particularly well into the functional reference schemes' criteria will be discussed.

\section{Examples of Good Practice of Impact Evaluation}

Three studies each of which offers valuable approaches with respect to future programme impact analysis will be discussed in short here. The choice does not imply that other studies are of inferior quality though. Rather, CleanEffEn, Tap-Assess, and FinImpact illustrate with outstanding clarity what aspects should be included into analyses to qualify them as "good practice" studies. 


\section{Clean and Efficient Energies for Europe (CleanEffEn)}

This evaluation study released recently (March 2001), aims at examining the scientific and technical results as well as the social and economic impact of a sample of about 90 already finished Non-Nuclear Energy projects, most of them 3 years ago. First of all, the study is a good example in terms of its overall design in that it provides an extensive discussion of the wider political and economic environment of energy research in the EU and a fruitful combination of both quantitative and qualitative evaluative information. Secondly and most importantly, it distinguishes between expected outputs and impacts against the background of two time horizons, one reflecting the direct end of projects, the other 3 years after end of projects. Particularly with respect to the second characteristic the study is a step forward in evaluation analysis due to its discussion of the time lag problem.

On the one hand the study illustrates evidently that the extent of nearly every kind of impact project co-ordinators perceive to take effect 3 years after project end differs from the extent right after the programme's implementation. Thus, regardless of what impacts evaluators might examine they better examine a programme's success (or failure respectively) at more than one point in time to check for impacts. On the other hand, the study makes a point in arguing that impacts - particularly indirect and social impacts - that are brought about by EU RTD programmes need time to establish. This more or less "natural" time lag between the implementation of a programme and its wide range of effects is not sufficiently taken into account in current evaluation practice.

To illustrate the argument, take an example. Regarding the non-nuclear energy programmes it appears reasonable to expect, for instance, energy saving effects on the one hand, and decreasing energy costs on the other one as results from JOULE or THERMIE projects. Both types of effects (or impacts as it were) are aligned with the three major policy objectives of this programme as highlighted by the CleanEffEnReport (p.14):

(a) Improving security of energy supply

(b) Protecting the environment by reducing emission of greenhouse gases

(c) Encouraging the rational use of energy.

With respect to measurable outputs of the programme about two thirds of project managers report that new tools or techniques have been developed. Furthermore, about one third of the managers have been able to improve processes by which energy production is reduced. However, bringing these advances to the market, i.e. to expand share of existing markets or to increase turnover right after project end managers are somewhat sceptical. They are less sceptical, nevertheless, when they think of what might have happened in three years time. Nearly every single economic impact indicator presented by the study shows that after three years impacts might increase by orders of magnitude. Particularly, lower energy costs and energy saving are likely to be materialized only after this period. Similar examples could be found with regard to social impacts of the non-nuclear energy programme.

In sum, the clear message from the CleanEffEn study in terms of future evaluation design is to take deliberately into account different time horizons with which different 


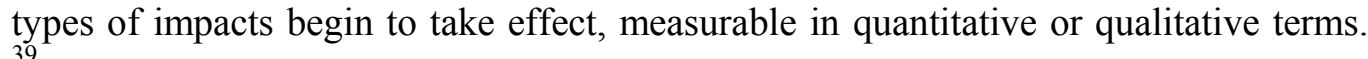

\section{Telematics Projects Socio-Economic Impacts Assessment (Tap-Assess)}

Tap-Assess, a study that has also been released recently (March 2000), can be regarded as another outstanding example of programme impact analysis. Reviewing some 98 Telematics projects completed between 1996 and 1998, this study starts with a fully fledged application of the aforementioned tick-list approach by which different classes of effects are evaluated by a method mix-approach. Again, the overall design is very sophisticated and undoubtedly state of the art of current evaluation practice.

What appears particularly useful here, is that different stakeholders (participants) are analysed systematically. Since different types of actors can be expected to play different roles and may achieve different types of benefits in ICT programmes, the study starts with assuming that merely asking project managers might not be enough for a thorough and well-balanced examination. Rather, ICT-clients and users as well as ICT-suppliers were taken into the sample too, thus controlling for possible differences between three main groups of actors. The authors of the study expected "...to find the first more focused in implementation to scale in their own organisation of the project's results and the second more focused on commercial exploitation" (p.70). However, and perhaps startlingly, results of the study suggest that there were no meaningful and consistent differences of this type between clients and suppliers. The study concludes that "implementation (of ICT) rather than commercial exploitation is the main goal of most participants" (p.1). This, however, is not to say, that the approach of analyzing different actor groups failed in any way. Rather the opposite: because different actor groups were analyzed at all, definite answers as to whether economic and social impacts were spread unevenly among different actor groups could be answered.

In sum, the clear message from the Tap-Assess study in terms of future evaluation design is to control deliberately for different actor group's behaviour, roles and benefits from Framework-Programmes in order to understand in which parts of European society impacts materialize.

\section{Impacts in Finland of the EU's FP4 (FinImpact)}

FinImpact, the second Finnish "impact study" of the effects of EU RTD funding in Finland, commissioned on behalf of the Finnish Secretariat for EU R\&D and published in January 2000, is a good example of how different kind of quantitative data collected during evaluation is analyzed best. Again, the study's overall design is very sophisticated and definitely state of the art of current evaluation practice.

The main achievement of FinImpact is that it combines a tick-list approach with factor analysis. This multivariate method is used to determine interrelations among a set of variables, i.e. underlying "factors" that qualify identifiable outputs and impacts.

39 Quite generally, the same can be said about the other two impact evaluations within the Nonnuclear Energy Programme that are reviewed here. Carried out somewhat earlier, JouleII.1 and JouleII. 2 - in terms of their overall impression to the authors of this study - can take CleanEffEn on any time. 
To clarify the argument, consider an example. When establishing the extent to which FP4 programmes had had an economic impact on Finnish universities, companies and research organisations, the evaluator may examine:

- new business activities

- product diversification

- expansion of markets

- increase of productivity

- improved production processes etc.

Conceptually, these different items belong to different categories of impacts. However, when asking experts to group these items they might come up with quite different suggestions. Factor analysis, similar to correlation analysis, is insofar a solution to this problem as it compares a given list of impacts mathematically and thus produces groups of items that have a common conceptual denominator. In FinImpact, for instance a), b) and c) are thus summarized into "Expanding business activities", whereas d) and e) depict "Productivity". This method then is applied as an general means for identifying several "impact dimensions" thereby reducing the complexity of the substantial tick-list.

The application of this methods allows in a further step to analyse different institutions, i.e. different participants in the FP4. The study states, for instance, "...that large companies and SMEs had very similar goal profiles. (...) As to non-firm organizations, their profiles differed much more from each other" (p.23). These profiles could also be used for explaining intricate issues such as participation motives or inter-firm collaboration - policy objectives that lie at the heart of FP4. Quite generally, embedding the organizational profiles obtained by factor analysis into the overall evaluation design elucidated the understanding of why different types of organizations perceive differently the way impacts of respective projects materialize and what has been specific of Finnish participation and project success in FP4.

In sum, against the background of the aforementioned exhaustiveness problem, i.e. the mismatch between data collection and data analysis, this study clearly gives evidence of a well-balanced evaluation approach that future programme evaluation should take as an example.

\section{"Mini-meta-evaluation: conclusions and recommendations}

The "mini-meta-evaluation" of EU RTD programme evaluations was based upon 28 evaluation studies, partly "exploratory" and mainly "solid" evaluation-like exercises. They were grouped according to type, design, and effects investigated in the study. Then they were classified according to their way of dealing with data collection, data analysis, methodological stance, level of analysis, stakeholders analysed, methodological reflexivity, policy recommendation.

"Exploratory" evaluation studies comprising "discursive" and "potential impact" analyses showed a clear prospective focus upon likely economic and societal effects that may accrue from European Research Programmes across various areas. However, they cannot be regarded as "pure" programme evaluation in that they do not ask the typical ex post questions of programme evaluations: "What has been done? What are 
the effects and how have they been used afterwards?" In this regard these evaluations are not the subject of a more substantive meta-evaluation than is done for the "solid impact" studies later on. Nevertheless, it appears worthwhile to include this kind of evaluation study here since it plays an important role providing guidance for decisionmaking on future RTD policy initiatives.

The 20 "solid" evaluation studies certainly represent great efforts to grapple with the demanding task of shedding light on the way EU RTD policies leave their marks ("impacts") on society. The studies did very much analyse what they should, namely economic and societal effects. They did so with different degrees of intensity regarding time and type of effects, thereby applying a broad range of quantitative and qualitative methodologies. One major strength is the substantiality of socio-economic outputs examined. One weakness can be seen in the assessment of long-term impacts that may accrue from outputs. This issue needs to be taken up more thoroughly in future impact analyses.

Current evaluation practice leaves societal effects to be less profoundly understood than respective economic, scientific and technological ones.

Obviously, a coherent and comprehensive impact evaluation methodology is lacking, and evaluation guideline are needed, classifying the envisaged use of evaluative studies for policymaking (e.g. "exploratory" studies analysing potential future impacts of RTD measures in society and economy vs. "solid" evaluations identifying ex post the actually achieved outputs and impacts)

\section{Basic methodological requirements}

In accordance with Airaghi et al. (1999) we recommend to take care of the following basic methodological requirements:

1) A basic requirement for the monitoring, evaluation and assessment of future Framework Programmes is the systematic collection of data at the level of individual projects, Specific Programmes and Framework Programme itself. This data can only be collected through information at the project or participant level, and this raises several issues:

- The first is one of efficiency. Participants should not be required to deliver the same information to more than one study, whether these originate from inside or outside the Commission.

- Evaluators should have unrestricted access to all relevant documents held by the Commission which relates to projects.

- Surveys carried out under scientific conditions, i.e. they must be piloted, confidential from programme line management etc.

- Expert interviews should be used to compensate for the limitations of surveys conducted by questionnaire.

- Many socio-economic effects take place over an extended period, mostly after the completion of the contract. A tracking system and in-built obligations or incentives should be used to ensure that data can still be collected from participants during this extended period. 
(2) The structure and the quality of the data will determine whether it can be aggregated for the purpose of evaluation at the levels of the Specific Programmes and of the Framework Programme itself.

(3) The reporting frequency for monitoring and assessment could be reconsidered. External monitoring reports should probably be issued every two years, instead of every year as at present. "Evaluation fatigue" can be a problem with project participants who have to respond to many different questionnaires, especially when these ask repeatedly for the same data. It could be avoided by co-ordinating the gathering of data for monitoring and evaluation studies with the information needs of other RTD policymaking bodies. For example, "Impact Studies" on the role played by European RTD programmes in national innovation systems could use existing Commission data. These studies could then feed their own results back into the Framework Programme assessment system.

(4) The panel system used by the Commission to conduct its assessments successfully addresses the need for demonstrated independence. The so far purely panel-based overall "Five-Year Assessments" of the EU FPs were predominantly concerned with recommendations for future high-level policy, and did not include a comparative portfolio analysis, and made only weak reference to the actual results of all the evaluative efforts made by the Specific Panels and others (Guy 2002). Many of the recommendations drew not so much on an evaluation of past Framework activities, but on the collective opinions and assessments of the Panel members concerning the general structure and organisation of science, technology and innovation in the EU. However, since panels do not have a monopoly of wisdom, supporting studies should be conducted and their results made generally available.

(5) Any "intelligent" assessment of RTD impacts by panels needs supporting information which to a great extent can be achieved from independent studies. Information may be needed on:

- future scientific and technological developments, sketched by foresight studies;

- changing socio-economic needs of particular industrial sectors or societal groups, described by in-depth studies in economics and social sciences;

- specific impacts, intended or unintended, of funded RTD activities, analysed by thematic evaluation studies or by technology assessment efforts; and

- the appropriateness of programme designs and methods of implementation, investigated by studies of policy or management.

- Supporting studies may be necessary as an input to the assessment of Specific Programmes as well as of the Framework Programme in general. In each specific case it is crucially important to identify the best evaluation system, not so much by "inventing" new methods as by carefully exploring existing approaches and choosing the most appropriate.

(6) There is still plenty of room for exploring new methodological approaches to the evaluation of socio-economic impacts of RTD funding. For example the identification of the contribution of public RTD to the development of vivid socio-economic clusters and networks of public (centres of excellence in research and education) and 
private (producing companies, knowledge-intensive business services) actors and institutions is methodologically still in an infant stage.

(7) A demanding assessment approach as discussed in this report needs a dedicated budget. Programme managers can only organise monitoring, evaluation and assessment procedures appropriately once certain amounts have been explicitly earmarked for assessment efforts. In other contexts a budget of $0.5 \%$ of the RTD funds allocated has shown itself to be sufficient, so there is clearly still plenty of scope for extending the monitoring, evaluation and assessment budget of the Framework Programme.

\section{RTD evaluation in the "European Research Area"}

Quite likely, an important impetus to future evaluation practices in European RTD will be originated by the attempts at realising a "European Research Area (ERA)". The traditional research policy of the EU FPs supported cross-border cooperation projects and mobility in topics of European interest. Since the Amsterdam treaty these thematic areas are decided by a qualitative majority. EU initiatives are subject to the criteria of subsidiarity and "European Added Value" and thus function in addition to national programmes. However, ERA could drastically break with this multi-layer logic. On the one hand, it would be serious about the coordination and harmonisation of national measures, oriented solely towards the greatest possible European effectiveness. On the other hand, the EU would de facto be in more direct control of national research capacities and the financing of excellence centres and very longterm, comprehensive, large-scale projects.

A possible consequence is that evaluation at a European level will need to extend beyond the evaluation of the FPs (cf. Georghiou, 2002): If the evaluation of ERA initiatives becomes the frame of analysis, the envisaged closer integration of research policies also requires a mutual understanding of what has been achieved and of the balance of benefits. An evaluation of a programme which links national activities needs to comprehend the widely varying institutional settings for the same work (for example an aspect of cancer research could be carried out in a university in one country, a branch of a national research organization in another, a central laboratory in a third and by a non-governmental charitable foundation in a fourth). Comparing inputs to research will require an understanding of the dynamics of all of these settings. It may also be necessary to establish a clearer common understanding of what constitutes quality and excellence in each country. However, progress will require a shift of focus for evaluation towards a broader systems perspective, and common standards. Georghiou (2002) claims that the development of a European Research Area requires a corresponding development of a "European Evaluation Area" in which there is a common methodological and procedural understanding that allows members to accept and validate each other's findings. One among many reasons for a "European Evaluation Area" is, that the integration of researchers and policymakers from the EU Candidate Countries, in particular Eastern Europe. 


\section{References for Section 3.2}

Airaghi A., Busch N.E., Georghiou L., Kuhlmann S, Ledoux M.J., van Raan A.F.J. and Viana Baptista J. (1999): Options and Limits for Assessing the Socio-Economic Impact of European RTD Programmes, ETAN, Commission of the European Communities, January 1999

Bach L. and Georghiou L. (1998): The Nature and Scope of RTD Impact Measurement, A discussion paper for the International Workshop on "Measurement of RTD Results/Impact”, Brussels, 28-29 May 1998

Bozeman, Barry / Melkers, Julia (eds.) (1993): Evaluating R\&D Impacts: Methods and Practice, Boston / Dordrecht / London (Kluwer Academic Publishers)

Callon, Michel / Larédo, Philippe / Mustar, Philippe (1995): La gestion stratégique de la recherche et de la technologie. L'evaluation des programmes, Paris (Economica)

Chelimsky, E. (1987): The politics of Program Evaluation. Social Science and Modern Society, 25, 24-32.

Davignon E. (1997): Five-year assessment of the European Community RTD framework programmes. Report of the independent expert panel chaired by Viscount E. Davignon and the Commissions's comments on the panel's recommendations

European Commission (1997a): Five-Year Assessment of the European Community RTD Framework Programs, 1991-1995: Report of the Independent Panel Chaired by Viscount Davignon, EUR 17644 EN, Brussels: European Commission

European Commission (1997b): The Second European Report on Science and Technology Indicators 1997, EUR 17639 EN, Brussels: European Commission

European Commission (2000a): Five-Year Assessment of the European Union Research and Technological Development Programs, 1995-1999: Report of the Independent Panel Chaired by Joan Majó, EUR 19426 EN, Brussels: European Commission

European Commission (2000b): 1999 Annual Report on the socio-economic dimension in the 5th Framework Programme, Brussels

Fayl G., Dumont Y., Durieux L., Karatzas I. And O’Sullivan L.(1998): Evaluation of research and technological development programmes: a tool for policy design, Research Evaluation Vol.7 No.2, August 1998

Feller, Irwin (2002): The Academic Policy Analyst as Reporter: The Who, What, and How of Evaluating Science and Technology Programs. In: Shapira, Ph., Kuhlmann, S. (eds.): Learning from Science and Technology Policy Evaluation: Experiences from the United States and Europe, Cheltenham (E. Elgar) (forthcoming)

Georghiou L. (1995b): Assessing the Framework Programmes - a meta-evaluation, Evaluation Vol. 1, No.2, October 1995 pp.171-188

Georghiou L. (1999): Socio-economic effects of collaborative R\&D - European experiences, Journal of Technology Transfer 24: 69-79

Georghiou L. et al. (1993): The Impact of European Community Policies for Research and Technological Development upon Science and Technology in the United Kingdom, London: HMSO

Georghiou, L. (2002): Evaluation of research and innovation policy in Europe - new policies, new frameworks? In: Shapira, Ph., Kuhlmann, S. (eds.): Learning from Science and 
Technology Policy Evaluation: Experiences from the United States and Europe, Cheltenham (E. Elgar) (forthcoming)

Georghiou, L. / Roessner, D. (2000): Evaluating technology programs: tools and methods, Research Policy (29) 4-5, 657-678

Georghiou, Luke (1995a): Research Evaluation in European National Science and Technology Systems. In: Research Evaluation, Vol. 5, No. 1, 3-10

Grupp, H. / Kuntze, U. / Schmoch, U. (1995): New Technology Indicators for the Evaluation of Research and Development Programmes. In: Becher, G. / Kuhlmann, S. (eds.): Evaluation of Technology Policy Programmes in Germany, Boston et al. (Kluwer Academic Publishers), 243-284

Guy K. / Luukkonen, T. (2000): Assessing EU RTD Programme Impact. Collecting Quantitative and Qualitative Data at Project Level: Designing Suitable Questionnaires for Measurement of EU RTD Programme Impact, Brussels

Guy K. et al (1998): Strategic Options for the Evaluation of the R\&D Programmes of the European Union, Technopolis, Final Report prepared for STOA, November 1998

Guy, K. (2002): Assessing RTD Programme Portfolios in the European Union. In: Shapira, Ph., Kuhlmann, S. (eds.): Learning from Science and Technology Policy Evaluation: Experiences from the United States and Europe, Cheltenham (E. Elgar) (forthcoming)

Hong, Heung Deug (2000): Meta-Evaluation of National Large-Scale R\&D Programmes. A Comparison of Evaluation Systems of 6 National R\&D Programmes. PhD thesis, University of Manchester.

Inventory (1999): European Commission, Department General XII: Inventory of existing programme output/impact and strategic studies, and projects follow-up procedures. An input to the 1999 five-year assessment, Brussels

Kuhlmann S. / Holland D. (1995): Evaluation von Technologiepolitik in Deutschland. Konzepte, Anwendung, Perspektiven, Heidelberg: Springer

Kuhlmann S., Reger G. (1995): European Technology Policy in Germany. The Impact of European Community Policies upon Science and Technology in Germany, Heidelberg: Springer

Kuhlmann, S. (2002): Rationales and evolution of public RTD policies in the context of their evaluation. In: Polt, W./Rojo, J. (eds.): Handbook on the Evaluation of Research and Technology Policies - Concepts, Tools, and Indicators, Cheltenham (E. Elgar) (forthcoming)

Larédo, P. (1990): L'impact de programmes communitaires sur le tissu scientifique et technique francais, Paris: La Documentation Francaise

Luukkonen, T. / Hälikkä, S. (2000): Knowledge Creation and Knowledge Diffusion Networks. Impacts in Finland of the EU's Fourth Framework Programme for Research and Development. Publication of the Finnish Secretariat for EU R\&D 1/2000. Painotalo Miktor, Helsinki

Mayne, J. / E. Zapico-Goni (1997): Effective Performance Monitoring: A Necessary Condition for Public Sector Reform. In: Mayne, J. / E. Zapico-Goni (eds). Monitoring Performance in the Public Sector: Future Directions from International Experience. Transaction Publishers.

Meyer-Krahmer, Frieder / Montigny, Philippe (1989): Evaluations of innovation programmes in selected European countries. In: Research Policy, 18, vol. 6, 313-331

OECD (1995): Impacts of National Technology Programmes, Paris (OECD)

Palumbo, D. J. (Ed.) (1987): The politics of program evaluation. Newbury Park, CA: Sage. 
Power, Michael (1997): The Audit Society. Rituals of Verification, Oxford (Oxford University Press)

Schwartz, R. (1998): The politics of evaluation reconsidered: A comparative study of Israeli programs. Evaluation, 4, 294-309.

Shapira, Ph., Kuhlmann, S. (eds.) (2002): Learning from Science and Technology Policy Evaluation: Experiences from the United States and Europe, Cheltenham (E. Elgar) (forthcoming)

Shapira, Philip / Kingsley, Gordon / Youtie, Jan (1997): Manufacturing Partnerships: Evaluation in the Context of Government Reform. In: Evaluation and Program Planning, 2, 1, 103-112

Widmer T. (1996): Meta-Evaluation. Kriterien zur Bewertung von Evaluationen, Bern: Haupt 


\subsection{Other Initiatives}

\section{Introduction}

The purpose of this section is to add to the understanding of the evaluation methodologies and effects of pre-competitive programmes achieved by the metaanalysis carried out in the earlier section on Framework Programme evaluation studies through a review of two further significant pre-competitive programmes, the EUREKA Programme and the Advanced Technology Programme (ATP). This section therefore critically reviews the methodologies, indicators and techniques which have been employed throughout the lifetime of both the EUREKA Programme and the ATP to capture a range of socio-economic effects. This part of the report is in three parts: the first two parts review each programme in turn; the third part draws a number of conclusions from the study of the programmes. Each programme review consists of three short sub-sections. The first provides a description of the programme context and the main stated programme aims; the second sub-section examines the methodologies which have been introduced to identify impacts; and the third examines recent evaluation trends and findings.

\subsubsection{Eureka}

\section{Introduction}

This short programme review, which is in three parts, examines the Eureka Programme. The review examines Programme aims, objectives and context, Programme evaluation methodologies, and the reported Programme impacts. The purpose of the review is to make recommendations on evaluation practice by identifying the most suitable strategies for evaluation of socio-economic impacts, and to note where these evaluation strategies have influenced the aims, mode, direction, and balance of the Programme itself.

\section{Programme Aims, Objectives and Context}

The EUREKA Programme is an initiative through which 29 countries and the European Union currently attempt to improve the near-market innovation performance through collaboration between industry, universities and research organisations. Launched in 1985, the Programme has grown steadily to include countries from behind the former Iron-Curtain, the first of which was Hungary which joined in 1991, followed by the Russian Federation in November 1992. In 1997-1998 under Portuguese chairmanship, EUREKA extended the scope of its collaboration activities worldwide and in 1999, under the German Chairmanship, Croatia, Israel and Latvia were admitted as members.

The number of projects started each year has generally increased, in common with the rise in EUREKA membership, reaching a maximum during the French Chair in 1995. During the early 1990s, the number of new projects started was around 95 each year 
while towards the end of the decade, around 175 projects a year were started on average.

The Programme has moved to embrace different themes over its lifespan, and since 1995, it has addressed the challenges presented by globalisation. Currently, the Programme identifies the following five aims and objectives:

- strengthening European competitiveness

- by promoting 'market-driven' collaborative RTD

- involving industry and research institutes across Europe

- using advanced technologies

- resulting in cost-effective products, processes and services.

Projects funded under the aegis of EUREKA have to conform to the following guidelines. These are:

- hi-tech, market-oriented R\&D projects

- involves partners from at least two EUREKA Members

- aim to develop a cutting edge, civilian product, process or service

- funded by the partners themselves, who receive public financing from their national governments

The requirement that industrial partners are included, initially a mandatory requirement has now been dropped. In practice, projects can vary considerably within the guidelines, with projects ranging from the $100+$ partner, 3.8 billion ECU Joint European Submicron Silicon Initiative project (JESSI) to two-partner feasibility projects involving less than 1 million ECU in investment.

By 1996 EUREKA had approved over 1200 projects involving 5,600 participating organisations. Public funding in recent years has been of the order of 3-500 million ECU per year, (around $\$ 340$ million per year) which is generally 20 per cent of project costs. Membership includes several Eastern European countries and Russia. The Programme accounts for only a very small amount of the total European R\&D effort.

\section{Programme Evaluation Methodologies}

Evaluation activities carried out at the international level for EUREKA view impacts as occurring within a complex social and economic context. Impacts are often seen as remote from their causes, both spatially and temporally, and consisting of both small scale and broad network effects and changes to markets. Impacts are difficult to measure economically, although this is done and economic values are given to programme effects. Measurement of net programme impact is considered by evaluations.

The history of EUREKA Programme evaluation carried out at the Programme level may be divided into a number of phases in which evaluation aims and objectives have differed significantly. Some commentators (Hong, 2000) have seen just two main 
periods - the pre and the post continuous systematic evaluation - whereas Georghiou (1999) observed four principal phases in the evaluation of EUREKA. In general, though, internationally coordinated evaluation, as opposed to national evaluations of EUREKA, which are not covered in this review, have moved step by step from the largely procedural and formative kind without a common methodology towards an outcome and impact study based approach, carried out with a clearly prescribed methodology introduced in 1996.

A short historical account of the evaluation trends identifies the main innovations in evaluation practice. The first international evaluation of EUREKA was undertaken with a team led by the Dutch industrialist, Professor Dekker, in 1991 and took the form of a process evaluation rather than impact study. In 1993, whilst France, which had been instrumental in setting up EUREKA, held the Chair of the EUREKA Ministerial Conference, a far broader evaluation strategy was embarked upon. The terms of reference for this second international evaluation followed the principles of the "Hanover Declaration" which required the programme evaluation to examine and make public both the impacts and the difficulties which had been experienced. Such an approach was also intended to feed back suggestions for improvement to both government and industry.

This work was carried out by teams of independent experts from 14 EUREKA countries, with PREST from the University of Manchester taking the role of evaluation secretariat. The evaluation was therefore both formative and impacts based and mainly employed questionnaire surveys of participants and in-depth case studies, selected by the relevant national expert team. The 1995 evaluation of EUREKA was unusual in that it was carried out with the specific objective of examining the substantial number of completed and withdrawn projects under the Swiss Chair in the period 1994-1995.

The next major development in the practice of EUREKA evaluation took place under the Belgian chairmanship and was begun in 1995. This new approach was termed continuous and systematic evaluation (CSE). The CSE procedure required that information be collected systematically every year through a standardised questionnaire to all projects which were completed during that year. This mode of evaluation provided a degree of continuity which had been absent from the previous evaluation activities, and brought greater understanding of the Programme's current performance in relation to past performance. Evaluation activities therefore began to gather impacts about both commercial and employment effects.

The Continuous and Systematic Evaluation (CSE) employs three main instruments:

- Final Report: a four page questionnaire sent to participants at the end of the project R\&D phase;

- Market Impact Reports: a 2-page questionnaire repeating the parts of the Final Report dealing with commercial exploitation of the R\&D results and their employment impacts and sent to participants who have previously recorded commercial effects after one, three and five years from the end of the project;

- Semi-structured interviews: collecting more detailed and qualitative information, normally on projects which were completed three years previously, and also seeking to validate the questionnaires. 
The scale of the evaluation activity is significant: in 1997 the analysis was based upon 434 Final Reports, 265 of which were from firms, the rest from non-industrial partners. This represented response rates of 79 per cent of projects, 77 per cent of main partners and 25 per cent of all participants. In addition, 34 Market Impact reports were received and 30 face-to-face interviews conducted.

The approach is unusual in following up projects some time after completion, an aspect which has proved particularly rewarding. After a pilot year it was decided to convene an Expert Advisory Group to oversee the process, and to recommend an "Annual Impact Report" report to the country holding the chair. This report presents the findings, conclusions and recommendations and is presented formally to the Ministerial Conference which governs EUREKA.

The need for the expert group arose for several reasons, including the need to interpret data, to have suitably qualified people to perform interviews, and to provide an independent validation of the findings and methodology.

Three types of analysis are carried out on the data gathered through the FR and MIR questionnaires. An annual analysis of the questionnaires is the most simple of all and reveals the changes occurring within the year. A cumulative analysis of data aggregates the annual data and provides a means of assessing impacts in the longer term, a key component of successful evaluation. In a addition, at the third level, a historical analysis of the FR and MIR reports provides a way of identifying broader impacts not initially envisaged, such as the development of new markets and changes in policies for science and technology.

According to Hong (2000), the costs of the evaluation of EUREKA have not been clearly identified. However, normally around 1 to $2 \%$ of the total programme budget is available to cover the costs of evaluation, not including the costs of evaluation which take place at national levels. The scale of the financial commitment by the EUREKA Secretariat to evaluation at between 120 and 150 KEURO per year is unlikely to be sufficient to exploit the potential outputs of the methodology.

\section{Recent Evaluation Trends and Findings}

Recent evaluation reports from EUREKA suggest that while 78 per cent of participants were expecting commercialisation at the end of the project (and 45 per cent had achieved it by that time), one year later one third of these had failed to commercialise. The conclusion is that initial expectations based upon technological success may not be realised in the market and hence that findings are sensitive to the timing of evaluation.

There is a skewed distribution of success, defined in terms of impact upon turnover. As Figure 1 shows, just over half of the projects achieved little or no effect ( 3 per cent of total turnover effects) while conversely 2 per cent of projects accounted for 54 per cent of turnover generated. This is not untypical for an R\&D portfolio but it also 
shows the vital importance for large if not comprehensive samples when a handful of star projects can so influence the overall impact of the programme.

Recent impact assessment interviews have generally confirmed the validity of the conceptual frameworks for impact adopted by programme evaluators, suggesting that routes to commercial success are often more complex than those which can be captured in a questionnaire. Typical examples include the following impacts:

- firms which have developed new equipment,

- improved their knowledge base,

- acquired new skills,

- changed concepts or market strategy and entered new networks.

Even where the original project objectives have not been achieved some combination of the above has led to significant economic benefits for the firm, causing it to report a high degree of satisfaction with the Initiative. These participants can be taken more seriously than some in public programmes because not all received public funding.

Figure 8. EUREKA Impact on Turnover

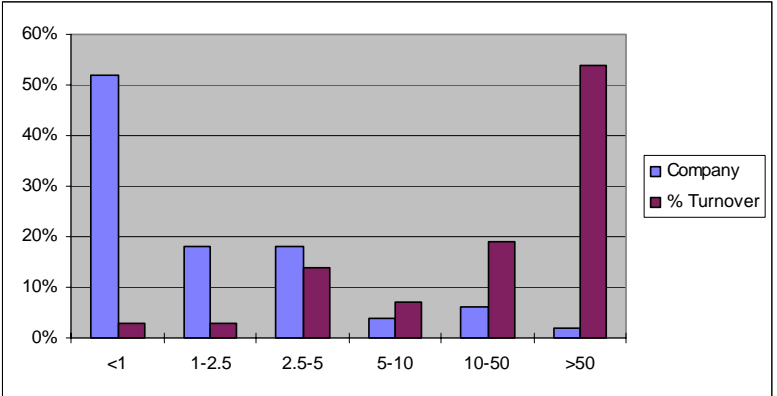

Obtaining information about employment effects has been difficult though. Questions on employment effects were often not answered (a question response rate of c.43 per cent) and interviews showed that participants were uneasy even where they did answer. In terms of real effects at a socio-economic level, the answers received showed that the principal effect had been to safeguard jobs in the organisation concerned. Other recorded effects were usually small but positive. Firms were generally even more uncomfortable with the idea of assessing effects outside their organisation. Such effects included jobs created or destroyed as a result of the application of a product or process. None were able to volunteer information on displacement effects in competing firms.

The reasons for difficulty were generally that employment decisions involved a wider range of considerations. The only unambiguous cases of employment directly associated with a project came when a new firm, factory or line was established to exploit the output of the project. Negative effects often required qualification; they could be replacing dirty or dangerous jobs where there was difficulty in finding labour. Although the evaluation panel is well aware of the difficulties involved in dealing with the employment issue, there is immense political pressure in Europe for 
information on this topic and so the attitude has been that an imperfect measure is better than none if it is treated with due caution.

Recent interest has been shown within the management of EUREKA in the role of private finance in financing innovation and its relationship with the public money allocated to projects, arising from concern with the performance of the venture capital industry in Europe.

\subsubsection{Advanced Technology Programme}

\section{Introduction}

This short programme review examines the United States Advanced Technology Programme (ATP). The review considers Programme aims, objectives and context, Programme evaluation methodologies, and the reported Programme impacts. The purpose of the review is to make recommendations on evaluation practice by identifying the most suitable strategies for evaluation of socio-economic impacts, and to take note of where these evaluation strategies have influenced the aims, mode, direction, and balance of the Programme itself.

\section{Programme Aims, Objectives and Context}

The ATP seeks to promote the movement of innovations from the research laboratory to commercial application and is a federally funded initiative which was begun in 1990 under the National Institute for Standards and Technology. The programme is distinctive because its main aim is to benefit firms and more broadly, the United States economy as whole. In particular, the ATP states that the following distinguish it from other R\&D programmes:

- ATP projects focus on the technology needs of American industry, not those of government. Research priorities for the ATP are set by industry, based on their understanding of the marketplace and research opportunities. For-profit companies conceive, propose, co-fund, and execute ATP projects and programs in partnerships with academia, independent research organizations and federal labs.

- The ATP has strict cost-sharing rules. Joint Ventures (two or more companies working together) must pay at least half of the project costs. Large, Fortune500 companies participating as a single firm must pay at least 60 percent of total project costs. Small and medium-sized companies working on single firm ATP projects must pay a minimum of all indirect costs associated with the project.

- The ATP does not fund product development. Private industry bears the costs of product development, production, marketing, sales and distribution.

- The ATP awards are made strictly on the basis of rigorous peer-reviewed competitions. Selection is based on the innovation, the technical risk, potential economic benefits to the nation and the strength of the commercialization plan of the project.

- The ATP's support does not become a perpetual subsidy or entitlement - each project has goals, specific funding allocations, and completion dates 
established at the outset. Projects are monitored and can be terminated for cause before completion.

The ATP allows partnerships of companies of all sizes, universities and non-profit organisations, encouraging them to take on greater technical challenges with potentially large benefits that extend well beyond the innovators - challenges they could not or would not do alone. Small start-up firms though stand to gain more from the ATP with early support from the Programme making the difference between success and failure. To date, more than half of the ATP awards have gone to individual small businesses or to joint ventures led by a small business. Large firms can work with the ATP, especially in joint ventures, to develop critical, high-risk technologies that would be difficult for any one company to justify because, for example, the benefits spread across the industry as a whole. Participation by smaller firms is high with $59 \%$ of grants awarded going to smaller firms.

Despite its prominence and reputation, ATP's role within the total research and development budget of the US is small. Over the lifetime of the Programme from 1991 until 1999, a total of \$1.6 billion has been allocated from Federal funds, along with $\$ 1.7$ billion from businesses for a combined $\$ 3.3$ billion support of ATP projects. However, during the same period, average Business Funded R\&D in the United States was around $\$ 150$ billion a year, rising to around $\$ 180$ billion a year by 1999 . Gross total R\&D expenditure for the US was around $£ 243$ billion a year by 1999 , of which the ATP amounts, on average, to around one sixteenth of one percent of total yearly R\&D expenditure.

The table below, which gives the US Government commitment to the ATP, indicates a high level of growth in the funding allocated to projects. By 1999, combined funding from Government and Industry reached around \$1 billion a year for projects.

\section{Table 5. ATP Funding 1990-1997}

\begin{tabular}{cc}
\hline Year & Funding Level \\
\hline 1990 & $\$ 10.00 \mathrm{M}$ \\
1991 & $\$ 37.0 \mathrm{M}$ \\
1992 & $\$ 49.4 \mathrm{M}$ \\
1993 & $\$ 67.9 \mathrm{M}$ \\
1994 & $\$ 199.5 \mathrm{M}$ \\
1995 & $\$ 340.5 \mathrm{M}$ \\
1996 & $\$ 221.0 \mathrm{M}$ \\
1997 & $\$ 345.0 \mathrm{M}$ \\
\hline Total & $\$ 1270.3$ \\
\hline
\end{tabular}

The ATP has always been surrounded by controversy. While President Bush considered the programme an exploratory initiative, President Clinton was far more positive, giving the programme strong endorsement, and thereby, perhaps unintentionally, making it a target for political and economic conservatives during his second term of office. The Republican Congress under Gingrich instigated a number of evaluations of the ATP, focusing on its cost-effectiveness and its justifications. 
Sensitivity over the results of the Programme evaluations has led (Vonortas, 2001) to delays in the publication, even when the outcomes of the Programme have been positive.

\section{Programme Evaluation Methodologies}

The ATP was established with an evaluation system at its inception. Evaluation was seen as a management tool which could improve the programme's operation making it better able to deliver its mission and to do so efficiently. Evaluation was also seen as a way of providing information about the Programme and its projects to a variety of interested parties. External demands for information came from individual members of Congress, their staffs, Congressional subcommittees, the General Accounting Office, the Executive Office of the President, the Office of Management and Budget (OMB) and Office of Inspector General, think tanks, and other professional research organisation and, not least, industry itself. At the programme's inception, the American Technology Pre-eminence Act of 1991, required the publication of a report on the outcomes of the ATP to be provided to each House of Congress no later than 1996. The ATP was firmly embedded within an evaluation culture from the first.

The ATP's demands for information from within government about programmes and project performance comes from its parent department, The Department of Commerce. The ATP, like all other federal programmes is bound by the Government Performance and Results Act (GPRA) 1993 which requires a full evaluation and justification for the programme's impacts.

The evaluation of ATP has used a multi-method approach which makes use of the following as a means of identifying impacts (Ruegg, 1999).

1. descriptive (statistical) profiling of applicants, projects, participants, technologies, and target applications;

2. progress measures derived principally from surveys and ATP's "Business Reporting System;"

3. real-time monitoring of project developments by ATP's staff;

4. case studies that focus in depth on project developments and results over defined periods;

5. projections of expected long-term impacts;

6. methodological research to improve the tools of long-term evaluation encompassing spillover effects;

7. special-issues studies to inform program structure, operations, and evaluation; and, ultimately,

8. (8) empirical assessment of long-term project and program outcomes.

The most important of these methods has been the Business Reporting System which was set up in 1994 and is carried out by the Programme managers. Prior to the introduction of the BRS, third party surveys of projects were conducted. The Business Reporting System consists of five types of information: baseline reports, anniversary reports, close-out reports, post-project reports; and quarterly reports.

The ATP Programme evaluation site lists the purposes of these reports within the Business Reporting System as follows: "The initial report describes the planned application areas for the technology and planned strategies for eventual 
commercialization. The quarterly short reports describe the major interim business developments. The annual report describes the progress towards implementing the commercialization strategies and on short-term economic impacts of the projects, including, but not limited to, early sales revenues, shortening of R\&D cycles, collaboration effects, intellectual property creation, and early job creation; a close-out report which completes the reporting of developments during the course of the research project and updates future plans for commercialization; and a post-project report which updates progress and is to be administered three times (every other year) over the period following project completion. A recent ATP report draws from this extensive database to summarize project-, company-, and application-specific progress of over 200 projects added to the reporting system between 1993 and 1995 (Ruegg, 1999).

Evaluation of the ATP has been carried out by a large number of organisations over its ten year life span, in recognition of the political sensitivity of the programme and the diversity of the stakeholders involved. A large number of organisations have contributed evaluations on the operation of the programme, including both internal and external evaluators, universities and industry. There are therefore effectively four different kinds of evaluators involved in the evaluation of the Programme.

The following figure shows the rationale for public support of the ATP. The figure clearly shows that the main aims of the programme are in terms of economic benefits.

Figure 9. Private and Social Returns to Private R\&D Expenditure

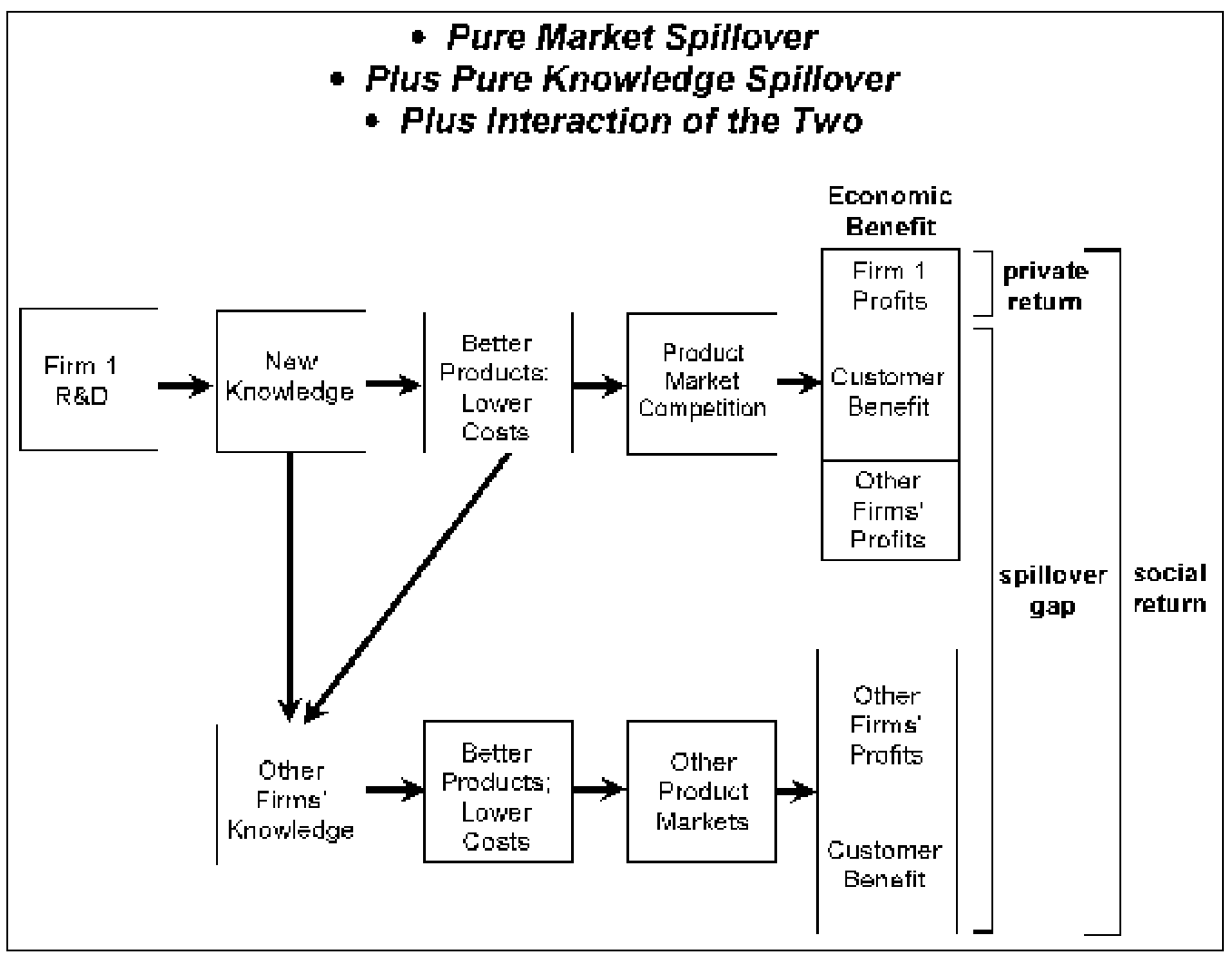

(Source: Jaffe, 1996) 
Methodologies employed to capture and measure the impacts of the ATP are economic and reflect the Programme's neoclassical economic rationale. The main focus of early evaluations of the Programme, were, as discussed above, on the specific benefits for participating organisations. Early studies were directed at individual organisations and often sought to approach difficult counter-factual evaluation questions such as whether the ATP was leveraging private capital or merely replacing it.

Gradually, evaluations have shifted towards an examination of the wider effects of the Programme, although it should be noted that the hoped for effects of the Programme are themselves intended to be broad. The current portfolio of research studies shown below shows the breadth of coverage although the focus of the studies remains economic (Georghiou \& Roessner, 2000).

- Research collaborations

- Inter and intra industry diffusion mechanisms, patterns and rates

- Development and application of new and improved qualitative and quantitative models for measuring economic impacts of publicly funded, privately executed technological advances.

- Impact on firm productivity of government funded research

- Technology financing issues

- Organisational issues affecting project structure, participants and outcomes

Evaluators have occasionally perceived that the evaluations of the ATP habitually ignore the kind of questions which Congress would like to answer, such as measuring the net economic benefit of the programme. In practice, ATP evaluations have explored whether a particular project would have been undertaken without government funding and, if the project had been undertaken, whether the capital invested would have been put to better use in the private sector.

Evaluation of ATP has generally been well-funded with the overall cost assumed to be rather higher than other similar programmes, approaching around 5\% of the total programme budget. This fact is borne out by the comments of The Director of the ATP's Economic Assessment Office who claimed in 1988 that the ATP is probably the most highly scrutinized programme relative to its budget size of any government programme to date" (Ruegg, 1998, page 3) quoted in Georghiou and Roessner (2000, page 669).

\section{Recent Evaluation Trends and Findings}

Broadening of the frame of reference for Programme impacts has seen evaluation efforts not only within the neoclassical framework of spillovers but on changes made within participating institutions to organisational practices and research capabilities. The study of broader effects has seen the use of some macro-economic techniques which have been used to provide projections of Programme impacts on a national scale. Some of these studies report significant benefits at a this level in terms of 
increased GDP and employment effects. Regional level studies using macro-economic techniques are also taking place.

Studies of research joint ventures which involve ATP and those which do not (Vonortas 1997, Draft) suggest that both types of joint ventures target and operate in different ways and are therefore complementary, with ATP joint venture arrangements having a higher participation of universities than non ATP joint ventures. ATP joint ventures also have a lower rate of participation of foreign firms. Collaborations and joint ventures operating with help from the ATP have the highest level of dissimilarity between partners, implying that the projects supported may involve higher risks but with greater chance of producing novel innovation.

The high reputation of the ATP has another indirect impact upon industry and upon research centres. Those organisations which take part in ATP projects enjoy higher credibility, and this is thought to make access to capital more likely.

\subsubsection{Comparison and Conclusions}

\section{Programme Aims, Objectives and Context}

The EUREKA Programme and the United States Advanced Technology Programme are two major collaborative research support programmes with similar commitments in terms of the use of public funds (around $€ 400$ million per year). Both programmes seek to overcome the reluctance of private investors to make investments in areas which have high levels of risk. However, while EUREKA gives support to collaborative market-oriented research, the ATP does not fund product development and supports only work carried out at the pre-competitive stage which leads to significant advances in technology. Both programmes do though lead, in the main, to product and process innovations although in the case of EUREKA, product innovation is slightly more common, while in the case of ATP, process and technological innovation is the main purpose and is more likely. Both Programmes have grown significantly during the period of the 1990s, although EUREKA began in 1985 and ATP in 1990. While EUREKA is Pan European, ATP operates within a country. Both Programmes have flexible rules for project funding in respect of firm size and the number of participants. EUREKA funds a smaller share of project costs (around 20\%) than ATP, which funds around $50 \%$ of project costs.

\section{Programme Evaluation Methodologies}

Both EUREKA and ATP have eventually adopted systematic evaluation strategies, collecting similar information from year to year for a variety of forms of analysis, including time-series, cumulative and historic analyses. In the case of EUREKA, the adoption of a systematic approach took place in 1995-1996, at around the time the number of projects was beginning to increase significantly. In the same way, the early years of the ATP saw the use of third-party surveys to evaluate Programme impacts. This gave way to the use of a systematic evaluation system based on the Business Reporting System (BRS) in 1994.

Programme evaluation expenditure is higher in the case of the ATP than EUREKA as a proportion of overall programme budget. This disparity reflects two major 
differences between the programmes. In the ATP, evaluation is highly institutionalised, although this is not to say that evaluation of EUREKA activities is not extensive. Secondly, the ATP is subject to a high level of outside scrutiny from a large number of important governmental bodies. In neither case though, is the scale of evaluation activity likely to hazard Programme effectiveness.

Programme impacts represent a function of the available financial resources and knowledge of the domain in which the programme will operate. Large scale evaluation activity can cause diminishing marginal returns not only in terms of evaluation information but reduces the budget from which the Programme can make its impacts. Smaller scale evaluation might in the short term provide extra funds for extra project work; but in the longer term, lower levels of evaluation will make programme monitoring and improvement more difficult.

\section{Recent Evaluation Trends and Findings}

Recently, evaluation of both the EUREKA and ATP have focused on broader and longer term impacts of Programmes. In the EUREKA evaluations, cumulative analysis and historical analysis are used to capture broader effects which occur beyond the immediate site of impact of the firm and the product and process innovations. This takes place through a focus on the effects of the programme on participants in the first instance and also more broadly. In the ATP evaluation, increased interest is now being shown on spillover effects. Nevertheless, the ATP evaluation effort is focused upon the task of measurement in relatively narrow economic terms of the costs and benefits of the programme's activities. This emphasis within the evaluations of the ATP is mainly the result of the very strong political demands for the programme to show a positive economic impact upon the United States.

While EUREKA is intended to have socio-economic benefits in terms of employment, the 2000 evaluation of the Programme did not contain any results about employment effects as the there was a very low response rate of both Final Reports and Market Impact Reports. Assessment of socio-economic benefits remains therefore a problematic area for the evaluation of collaborative research and development and technological development programmes. 


\section{References for Section 3.3}

Advanced Technology Programme - Program Web Site

Cunningham, P. \& Nedeva, M. (1999) Towards a system of continuous evaluation and monitoring for European co-operation in scientific and technical research (COST), Research Evaluation, Vol. 8, No. 1 pages 142-154

Dale, A. \& Barker, K. (1994) The Evaluation of EUREKA: a pan-European collaborative evaluation of a pan-European collaborative technology programme, Research Evaluation, Vol. 4, No. 1, pages 66-74

Eureka Evaluation Reports (1995) (1996) (1997) (1998) (1999) (2000)

Georghiou, L. (1999) Socio-economic effects of collaborative R\&D - some European Experiences Journal of Technology Transfer Vol. 24 No.1 April 1999 pp69-79

Hong, H. (2000) Unpublished PhD Thesis, University of Manchester

Ruegg, R. (1999) Advanced Technology Program's Approach to Technology Diffusion, Paper presented at Advanced Research Workshop "Industry as a Stimulator of Technology Transfer" - September 1999 ATP/NIST

Sand, F. \& Nedeva, M. (1998) The EUREKA Continuous and Systematic Evaluation Procedure: As assessment of the socio-economic impact of the international support given by the EUREKA initiative to industrial R\&D co-operation

Sand, F. (2001) Correspondence and Discussion 


\title{
3.4 Inventory of Effects \& Evaluation Methods
}

\author{
Framework Programme Evaluation - Inventory of Effects and Evaluation \\ Methods
}

\section{Introduction}

This final section of the third work package consolidates this work package on the analysis of impact assessment studies. It produces a set of recommendations on the appropriateness of a range of research techniques to assess socio-economic impact. The section consists of three major parts. It begins with a short survey of socioeconomic impacts - effectively an inventory of effects, including programme, mesoand macro-economic level impacts which have been or may be associated with RTD interventions. Then follows a short section which examines the steps in building an approach to the evaluation of socio-economic impacts to identify, understand, scope and measure socio-economic impacts. This section also considers how the economic impact of the Framework Programme could be addressed at an aggregate level, and what role it should take in structuring the European knowledge economy and the Single Market. A third section provides a recommended mapping of methods to particular types of impacts, using the toolbox metaphor which can guide those with responsibility for RTD programme impacts in the design of studies and the interpretation of and valuation of results. A set of conclusions is presented which includes a number of suggestions for improvements to existing methods of socioeconomic evaluation.

The chapter therefore has the following sub-sections:

- Defining Socio-Economic Impacts

- Building the Evaluation Approach and Methods

- Mapping Methods to Impacts - Some recommendations

\section{Socio-economic Impacts - A Survey}

Socio-economic impacts of government and private expenditure have been extensively researched over a long period, see for example studies by Federal Government of Canada (1993), Melkers and Cozzens (1997) and Bach and Georghiou (1998). Within the European Union, the need to define socio-economic impacts has also had a strong imperative, with strong political pressure behind attempts to improve social and economic performance and to protect social welfare. A number of major developments in this area have been occurred. For example, in the ECSC Treaty 1951, Article 68 identifies wage harmonization as an area of policy commitment, while in the EEC Treaty 1957, Article 136 makes a commitment towards the area of Working Conditions. Article 137 of the same treaty argues for close cooperation on social issues, while Articles 146-148 create the Social Fund (European Social Fund - ESF) and The Agricultural Guidance Fund (EAGGF) through which such policy initiatives should be funded. 
After UK Agreement to Join EEC 1973, the European Regional Development Fund (ERDF) emerged as a major vehicle for the promotion of socio-economic development. This development continued, albeit contentiously, in 1992 with the Treaty on European Union (Maastricht) 1992 which established Works Councils, the Single European Act 1986, Adoption of "Economic and Social Cohesion" and Enhancement of Structural Funds and the establishment of the Cohesion Fund on the $25^{\text {th }}$ May, 1994. The Special European Council, November 1997 proposed further action in the area of socio-economic change with proposal to allow further coordination of employment policies. In The Treaty Establishing the European Community (as Amended by the Treaty of Amsterdam) of 1999, Article 125 focused greater resources on the needs for the development of human capital: "developing a co-ordinated strategy for employment and particularly for promoting a skilled, trained and adaptable workforce and labour markets responsive to economic change.."

Table 6. Table of Socio-Economic Impacts

\begin{tabular}{|l|l|}
\hline \multicolumn{1}{|c|}{ Category of Impact } & \multicolumn{1}{c|}{ Type } \\
\hline Economic & $\begin{array}{l}\text { Increased sales revenue } \\
\text { Cost savings }\end{array}$ \\
\hline Social & $\begin{array}{l}\text { Environmental enhancement } \\
\text { Reduced health and safety risks } \\
\text { Improvements in quality of life } \\
\text { Improved quality and accessibility to information }\end{array}$ \\
\hline
\end{tabular}

(Source: Federal Government of Canada, Working Group on S\&T Financial Management and Mechanisms, 1993)

Table 7. Table of Socio-Economic Impacts

\begin{tabular}{|l|l}
\hline Category of Impact & Type \\
\hline Economic & Number of projects the organization funds \\
Matching and leveraged funds \\
Organisations assisted \\
Number of requests for assistance \\
Spin-off / new firms \\
Patent/ license application /receipt \\
Customer satisfaction measures \\
New products \\
Increased sales \\
Cost savings/ cost avoidance \\
Number of collaborations \\
Profits \\
Number of publications \\
(Reduced losses?) \\
Increased capital spending \\
Creation of new jobs \\
Jobs retained \\
Average salary of jobs retained \\
Average salary of jobs created
\end{tabular}

(Source: Melkers and Cozzens, 1997) 
Table 8. Socio-economic Impacts (After Bach and Georghiou, 1998)

\begin{tabular}{|l|l|}
\hline Broad Area & Specific Effects \\
Competitiveness & $\begin{array}{l}\text { Sales, market share, open up markets, create new markets, lower costs, faster } \\
\text { time to market }\end{array}$ \\
\hline $\begin{array}{l}\text { Employment } \\
\text { Organisation }\end{array}$ & $\begin{array}{l}\text { Jobs created, jobs in regions of high unemployment, jobs secured, jobs lost } \\
\text { Formation of new firms, new joint venture to exploit results, new technological } \\
\text { networks/ contacts, new market networks / contacts, improved capacity to absorb } \\
\text { knowledge, core competence improvement, further RTD, change in strategy, } \\
\text { reorganisation of firm to exploit results, increased profile }\end{array}$ \\
\hline Quality of Life & $\begin{array}{l}\text { Healthcare, safety, social development and services, improved border protection } \\
\text { and policing, support for cultural heritage }\end{array}$ \\
\hline $\begin{array}{l}\text { Control and } \\
\text { Care of the } \\
\text { Environment }\end{array}$ & $\begin{array}{l}\text { Reduced pollution, improved information on pollution and hazards, reduced raw } \\
\text { material use. Reduced energy consumption, positive impact upon global climate, } \\
\text { decrease in pollutants, }\end{array}$ \\
\hline Cohesion & $\begin{array}{l}\text { Employment in LFRs, infrastructure of LFRs, participation of LFRs, further } \\
\text { RTD in LFRs, regulation and policy in LFRs }\end{array}$ \\
\hline
\end{tabular}

The European Social Charter of 1989 - The European Fundamental Social Rights of Workers - has also confirmed the importance of this area, particularly in relation to employment with the following definition of twelve fundamental principles.

Table 9. The Social Charter (1989) and the Twelve Fundamental Principles

\begin{tabular}{|l|l|}
\hline 1 & Right to work in EU Country of one's choice \\
\hline 2 & Right to a Fair Wage \\
\hline 3 & Right to improved living and working conditions \\
\hline 4 & Right to social protection under prevailing national systems \\
\hline 5 & Right to freedom of association and collective bargaining \\
\hline 6 & Right to vocational training \\
\hline 7 & Right to sexual equality \\
\hline 8 & Right of workers to information, consultation and participation \\
\hline 9 & Right to health protection and safety at work \\
\hline 10 & Right to protection of children and adolescents \\
\hline 11 & Guarantee of minimum living standards for the elderly \\
\hline 12 & Right of improved social and professional integration for the disabled \\
\hline
\end{tabular}

(Source: The Social Charter, 1989)

Commission Documents have clearly identified socio-economic benefits from FP5 as deriving from both demand and supply side developments. For example, the Communication of the Commission (97) 553 states that socio-economic needs can be delivered from the demand side from research which "promotes health, reconciles economic developments with environmental requirements; improves the response to consumer needs and facilitates consumers' understanding of available products, diets and foods". The same document also outlines the socio-economic impacts which the supply side can deliver: "On the supply side, there is huge potential for economic 
growth and job-creation in this field, both in the traditional industries including primary production (employing some 19 million people in Europe) and in the nascent high technology industries (fast-growing sectors, with a large role for SMEs)." (Comm (97) 553)

\section{Table 10. Actions of the Fifth Framework Programme And Perceived Links To Socio-Economic Benefits}

\begin{tabular}{|l|l|l|l|}
\hline Activity & Actions & Issues & MEURO \\
\hline $\begin{array}{l}\text { First } \\
\text { Activity }\end{array}$ & Indirect & $\begin{array}{l}\text { Theme 1 Quality of Life and Management of Living } \\
\text { Resources } \\
\text { Theme 2 User-Friendly information Society } \\
\text { Theme 3 Competitive and Sustainable Growth }\end{array}$ & $\begin{array}{l}2,413 \\
\text { Theme 4 Energy Environment }\end{array}$ \\
\hline $\begin{array}{l}\text { Third } \\
\text { Activity }\end{array}$ & Indirect & $\begin{array}{l}\text { Promoting of innovation and encouragement of SME } \\
\text { participation }\end{array}$ & 2,705 \\
\hline $\begin{array}{l}\text { Fourth } \\
\text { Activity }\end{array}$ & Direct & $\begin{array}{l}\text { Improving human resource potential and socio- } \\
\text { economic knowledge base }\end{array}$ & 363 \\
\hline & $\begin{array}{l}\text { Serving the Citizen } \\
\text { Enhancing Sustainability } \\
\text { Underpinning European Competitiveness }\end{array}$ & 739 \\
\hline
\end{tabular}

(Source: Nicol \& Salmon, 2001)

Using these outlines from the development of the European Union and from the academic sources, we have drawn two major categories of socio-economic impact with a total of five sub-types in all. The first main type is where socio-economic effects take place within economic institutions and processes. There are three subtypes. These sub-types view socio-economic impacts as taking place within three types of entities: firms, networks of firms and other technology and research organisations; and within the economy itself or its major sectors, for example the biotechnology sector.

Table 11. Categories of Socio-economic Impact for Mapping to Methods

\begin{tabular}{|l|l|}
\hline $\begin{array}{c}\text { Main Category } \\
\text { of Socio- } \\
\text { economic Impact }\end{array}$ & Subsidiary Category of Socio-economic Impact \\
\hline Economic & $\begin{array}{l}\text { Micro - Firm-based capacities and efficiencies (product and } \\
\text { process improvements) }\end{array}$ \\
\hline Meso - Within networks of innovation \\
\hline $\begin{array}{l}\text { Macro - Market and Economy Level increases in capacity and } \\
\text { efficiencies, improvements to stock of knowledge }\end{array}$ \\
\hline $\begin{array}{l}\text { Employment - Human Capital Development, Rate of } \\
\text { Employment } \\
\text { Social }\end{array}$ & $\begin{array}{l}\text { Quality of Life - Service / Product Based Benefits in terms of } \\
\text { Health and Environment (Environmental Protection) and also } \\
\text { Social Cohesion, Inclusion and Security, and Freedom of Action }\end{array}$ \\
\hline
\end{tabular}


Definitions of socio-economic impacts / or socio-economic good are therefore a broad set of descriptions which are to subject to change over historical time. Broadly, they can be observed at the level of individuals, firms, and industry structures and at the level of the whole economy.

\subsubsection{Building the Approach to Evaluation of Socio-economic Impact}

\section{Introduction}

This section examines the major steps in the development of an evaluation of socioeconomic impacts. It is suggested that there are six major steps which should be taken into account when an evaluation is being considered. These are shown in the following table. This section deals with each of these major steps in turn, beginning with evaluation priorities.

\section{Table 12. The Major Stages of the Research Process}

\begin{tabular}{|c|c|c|c|c|c|}
\hline \multicolumn{6}{|c|}{ Major Stages of the Research Process } \\
\hline Step 1 & Step 2 & Step 3 & Step 4 & Step 5 & Step 6 \\
\hline $\begin{array}{l}\text { Evaluation } \\
\text { Priorities }\end{array}$ & $\begin{array}{c}\text { Research } \\
\text { Questions and } \\
\text { Frameworks }\end{array}$ & $\begin{array}{l}\text { Data } \\
\text { Acquisition }\end{array}$ & $\begin{array}{l}\text { Data } \\
\text { Analysis }\end{array}$ & $\begin{array}{l}\text { Reporting and } \\
\text { Dissemination }\end{array}$ & $\begin{array}{c}\text { Feedback and } \\
\text { Use of } \\
\text { Findings }\end{array}$ \\
\hline $\begin{array}{l}\text { What is being } \\
\text { assessed? }\end{array}$ & $\begin{array}{l}\text { How will the } \\
\text { research be done? }\end{array}$ & $\begin{array}{c}\text { How shall the } \\
\text { data be } \\
\text { obtained? }\end{array}$ & $\begin{array}{c}\text { How shall the } \\
\text { data be } \\
\text { analysed? }\end{array}$ & $\begin{array}{l}\text { How shall the } \\
\text { findings be } \\
\text { reported and } \\
\text { disseminated? }\end{array}$ & $\begin{array}{l}\text { What use can be } \\
\text { made of the } \\
\text { evaluation } \\
\text { findings? }\end{array}$ \\
\hline $\begin{array}{l}\text { Assessing causal } \\
\text { relations } \\
\text { - net effects } \\
\text { Measuring } \\
\text { Impacts }\end{array}$ & $\begin{array}{l}\text { Deciding the } \\
\text { Research } \\
\text { Dimensions - } \\
\text { Choosing the } \\
\text { Research Relation, } \\
\text { Timing, Focus, } \\
\text { Methods, } \\
\text { Paradigm and } \\
\text { Scope }\end{array}$ & $\begin{array}{l}\text { Applying the } \\
\text { Frameworks and } \\
\text { Methods to } \\
\text { Generate Data }\end{array}$ & $\begin{array}{l}\text { Use of } \\
\text { Deductive, } \\
\text { Inductive and } \\
\text { Abductive } \\
\text { (Levis-Rozalis, } \\
\text { 2000) Methods } \\
\text { to reach } \\
\text { Conclusions and } \\
\text { Recommendatio } \\
\text { ns Based on the } \\
\text { Data }\end{array}$ & $\begin{array}{l}\text { Use of the } \\
\text { Evaluation } \\
\text { Findings by } \\
\text { Policy-Makers/ } \\
\text { Academics } \\
\text { Stakeholders - } \\
\text { Cox (1977) notes } \\
\text { the problems }\end{array}$ & $\begin{array}{l}\text { Applicability for } \\
\text { Current } \\
\text { Programmes, } \\
\text { Future } \\
\text { Programmes, and } \\
\text { for Impact } \\
\text { Assessment } \\
\text { Methodology }\end{array}$ \\
\hline
\end{tabular}




\section{The Functions and Priorities of the Research}

Before the techniques and detailed issues of any research activity such as an evaluation can be considered, a decision should be taken about its priorities. The two key functions of any research activity are the following: a) - assessment of the link between the cause and the effect of policies (attribution); and b) - the measurement of effects (measurement of scale and effect). Evaluators and those commissioning an evaluation should decide in advance of their research how their particular evaluation should address these functions.

In relation to the issue of attribution, the attempt to find links between the policy input and the output may well be easy. Indeed, the link may well already be explicit, in that the link between outputs/outcomes, and the impacts that follow are an accepted part of theoretical knowledge and are "given". However, while the hypothesis of policy of effect may be popular, it is a poor research and evaluation strategy to assume that the hypothesis will work for all time and in all places. Moreover, most governments are introducing policies into areas of high complexity. In the area of socio-economic development, or in the case of the support of basic research, outcomes and impacts are mediated by complex social processes, and are separated from inputs by time and space. Where there is this separation, and where the environment into which the policy input is introduced is complex, it becomes more important to obtain information about actual working of the programme. The attempt is therefore justified to enquire into whether the "programme hypothesis" and its attendant assumptions properly describe the way in which the programme operates in practice. Therefore, early in the research process for new areas of policy, the issue of attribution should be a priority. Moreover, measurement of the magnititude of effects early in the course of a programme is also unlikely to be fruitful as impacts will not have begun to appear in significant numbers or on a significant scale to be noticeable or significant.

Research to identify the way in which the policy input works can use a range of research principles depending upon the resources available. If the restrictions on resources do not permit a full-scale study of effects, and this is normal given the size of interventions, evaluators will have to adopt a sampling approach either statistically or through the use of case studies. 
Table 13. Evaluation Functions and Priorities

\begin{tabular}{|c|c|c|}
\hline $\begin{array}{l}\text { Evaluation } \\
\text { Priorities }\end{array}$ & Requirement & Specific Issues \\
\hline \multirow[t]{3}{*}{ Attribution } & Cause and Effect & $\begin{array}{l}\text { Unexpected effects and } \\
\text { outcomes }\end{array}$ \\
\hline & $\begin{array}{l}\text { Validity, Reliability, } \\
\text { Transferability/ } \\
\text { Applicability }\end{array}$ & $\begin{array}{l}\text { Selection of cases and Sampling } \\
\text { Methods }\end{array}$ \\
\hline & Effects or Indicators & $\begin{array}{l}\text { Evidence of impacts or proxies } \\
\text { for impacts }\end{array}$ \\
\hline \multirow[t]{6}{*}{$\begin{array}{l}\text { Measurement of } \\
\text { Scale and Extent }\end{array}$} & Net Effects - & $\begin{array}{l}\text { Additionality and Behavioural } \\
\text { Additionality }\end{array}$ \\
\hline & \multirow[t]{4}{*}{ Structuring of Comparisons } & Use of Base Case \\
\hline & & Before and After Comparisons \\
\hline & & $\begin{array}{l}\text { Control Groups and Paired } \\
\text { Comparisons }\end{array}$ \\
\hline & & $\begin{array}{l}\text { Benchmarking/Ranking } \\
\text { Approaches }\end{array}$ \\
\hline & Considering Counterfactuals & $\begin{array}{l}\text { Scope for Counterfactual } \\
\text { Modelling (Link and Scott, } \\
\text { 1998) }\end{array}$ \\
\hline
\end{tabular}

Once the issue of attribution has been addressed, it is possible to enter the area of measurement of the scale of effects. Here, the issue of what net effect the Programme has led to is the key priority and major function. In Table 13, both these two major functions of evaluation are shown.

When evaluators address the second function, they must consider how to make their comparisons and whether it is possible to make use of a control or quasi-control to assess net-effect. Evaluation research that identifies only effects without seeking to address the issue of net-effects could substantially overstate the effectiveness and efficiency of a policy input. However, despite the existence of a wide range of techniques that have been developed, the area of net effect remains one of major difficulty for evaluation practitioners and policy-makers. Analytically, programmes and projects by virtue of "being in the world and changing it" destroy any possibility of the measurement of true net effects. Counterfactual modelling can only use fictional alternative worlds.

In the following section, a number of other essential preparatory steps for socioeconomic evaluation are considered. The consideration of these issues should again precede the selection of specific methods and techniques.

\section{Research Dimensions}

Once the key functions of the evaluation have been understood, the focus often moves to the range of techniques available for impact assessment. This array of methods is truly vast. Many techniques are specialist methods, often derived within social science 
research; others are developed to be uniquely suitable for specific areas of RTD impact assessment; others are flexible and can be used in a variety of contexts. But the choice of methods follows from the issue of the research dimension, the key scoping activity that should precede any enquiry into the social effects of programmes. Any evaluation research activity contains six major stages in which understanding the function of the evaluation is the first step, defining the research dimension is the second and making the choice and development of the methods and techniques themselves the third.

- Functions and Priorities of the Research Evaluation

- Defining the Research Dimensions

- Carrying Out the Research

- Analysing the Data

- Reporting and Dissemination

- Feedback and Use of Findings

This section examines each of these steps in turn, paying particular attention to socioeconomic impact studies, and choice of methods.

\section{The Research Dimensions}

The research dimensions are themselves a complex set of relations between six major elements of an enquiry that determine what some might call the approach to the research. These dimensions include the following: the level of engagement which the evaluation will have with its subject matter, the timing of the research in relation to the events which it wishes to examine; the focus of the research and whether this should be upon data acquisition and analysis, or whether the study should examine existing research (meta-analysis) ${ }^{40}$; whether the research should use single, mixed or multiple methods; the research paradigm - in effect the theory of knowledge embodied in the study; and the scope of the research. The following table shows the different dimensions of the research evaluation.

\footnotetext{
${ }^{40}$ Meta-analysis uses the results of more than one study (evaluation) to broaden and extend a research hypothesis; meta-evaluation is the study of evaluations to assess quality, reliability, scope and applicability - its purpose is to assess methodology. Michael Scriven first proposed the concept of meta-evaluation in 1969 .
} 
Table 14. Major Dimensions of Research Evaluation

\begin{tabular}{|c|c|c|c|c|}
\hline $\begin{array}{l}\text { Dimensions of } \\
\text { Research } \\
\text { Evaluation }\end{array}$ & 1 & 2 & 3 & 4 \\
\hline $\begin{array}{l}\text { The Research } \\
\text { Relation }\end{array}$ & $\begin{array}{l}\text { Action Research - } \\
\text { Applied Research }\end{array}$ & $\begin{array}{c}\text { Disengaged (literally } \\
\text { "academic") Research } \\
\text { - Basic }\end{array}$ & Strategic & \\
\hline $\begin{array}{l}\text { Research Timing } \\
\text { (After Meyer- } \\
\text { Krahmer, 1991) }\end{array}$ & $\begin{array}{c}\text { Ex Ante - } \\
\text { Prospective } \\
\text { Strategic / } \\
\text { Operational }\end{array}$ & $\begin{array}{l}\text { Real Time Research } \\
\text { (Continuously } \\
\text { Engaged) }\end{array}$ & $\begin{array}{c}\text { Monitoring - } \\
\text { Formative (Periodic) }\end{array}$ & $\begin{array}{c}\text { Ex Post - } \\
\text { Retrospective / } \\
\text { Summative }\end{array}$ \\
\hline Research Focus & $\begin{array}{c}\text { Empirical or } \\
\text { Research Based }\end{array}$ & Meta-Analysis & & \\
\hline Research Methods & Single Methods & Mixed Methods & & \\
\hline $\begin{array}{c}\text { Research Paradigm } \\
\text { (After Tashakkori } \\
\text { \& Teddlie, 1998) }\end{array}$ & $\begin{array}{c}\text { Positivist } \\
\text { Quantitative Mode } \\
\text { - Judgements based } \\
\text { on Numerical } \\
\text { Measurement of } \\
\text { Scale, Relationships } \\
\text { or Likelihood }\end{array}$ & $\begin{array}{l}\text { Post-positivist } \\
\text { Mainly Quantitative } \\
\text { Mode }\end{array}$ & $\begin{array}{c}\text { Pragmatism } \\
\text { Qualitative and } \\
\text { Qualitative Modes }\end{array}$ & $\begin{array}{l}\text { Constructivist } \\
\text { Qualitative Mode } \\
\text { - Judgements } \\
\text { based on } \\
\text { Description, } \\
\text { Construction, } \\
\text { Assessment and } \\
\text { Theory Building }\end{array}$ \\
\hline $\begin{array}{l}\text { Research Scope } \\
\text { (Functional, } \\
\text { Impact, Validity) }\end{array}$ & Efficiency & Effectiveness & Appropriateness & $\begin{array}{l}\text { Combination of } \\
\text { any of the three }\end{array}$ \\
\hline
\end{tabular}

Firstly, the research relation describes the extent to which those carrying out the research will engage with those being evaluated or the client. A close relationship between the researcher and the evaluator may allow greater access to staff and to information, deepening understanding of the subject matter. Too close a relationship is counter-productive, as it may suggest a conflict of interest. Working closely in collaboration with the organisation which has commissioned the research has been called "action research", a term made popular by Clark (1972) and Argyris and Schon (1974). Such approaches are iterative and learning, tend to focus on areas where there is a demand for knowledge about new effects - i.e. where there is doubt about the validity of existing categories and concepts and where there may be a demand for new understandings of process and impact. In the area of research of socio-economic impacts, the iterative mode is helpful to consider, because the processes of impact are not often well understood, although the definitions of the socio-economic benefits themselves generally are sound and un-problematic.

The issue of research timing refers to the way in which the research is conceived in relation to the timing of project outcomes and project impacts. Research studies can be not only before or after intended effects, they can also take place during the delivery of programmes. Where for example there are likely to be long-term impacts of policy inputs, evaluations should be scheduled to give these effects sufficient time to emerge before they are investigated. Socio-economic and RTD impacts in many 
sectors will often take years to emerge, see for example case studies 4.1 and 4.3 later in this work.

Research focus is another aspect of the evaluation which has important consequences for the way in the research is to be carried out. Research can review existing reports and studies in a process termed "meta-analysis". This takes the form of a higher-level study of existing evaluations and their data from which a synthesis can be constructed. Syntheses produced from meta-analysis are able to offer greater applicability and more reliable conclusions. Meta-analysis is particularly well known within the field of medical research where the existence of large numbers of comparable studies provides the opportunity to combine research results to obtain findings with higher levels of confidence. A detailed discussion of the problems of carrying out metaanalysis can be found in Rosenthal (1980) and Wachter and Straf (1990).

That meta-analysis should have originated within the field of quantitative research should not preclude its application within the area of qualitative research. However, within the qualitative field, as in the quantitative field, for meta-analysis to offer more reliable conclusions, the studies used should be numerous, and comparable. Where it is not possible to use existing studies to identify likely effects of policy inputs, empirical research is necessary. Many research approaches do though involve an element of both meta-analysis and empirical research with the research exercise beginning with a meta-analysis that supplements the literature review.

The research paradigms which an evaluation adopts appears often to be nothing more than a reflection of the research methods which have been deployed, with the methods themselves embodying to greater or lesser degree, a particular view of what can stand as knowledge in the context of the social and economic world. While there has always been an expectation that the measurement of effect can only take a numerical form, with methods borrowed from the mathematics and statistics (quantitative), and that the understanding of process and intentions can only take the form of a qualitative enquiry, this need not be so in practice. In recent years, evaluators have often employed highly pragmatic research designs based on what may be termed abductive reasoning. These combine a variety of methods (hibridity) in order to take advantage of a range of available information. The creation of indicators for the evaluation of policy - particularly in the context of the national benchmarking of policies - amply demonstrates the central practical difficulty of generating dimensional measures from dimensionless experience.

Research scope refers how the evaluation activity addresses the three central issues of policy function and relevance: a) - how efficient is the policy? b) - how effective is the policy? and c) - how appropriate is the policy. Some evaluations may address one or other of these questions while some may address all. Efficiency evaluation often implies a cost-effectiveness measure, and it should be remembered that even where a cost-effectiveness measure is desired, evaluators will have to address issues such as net-effect as this affects the overall impact of the policy. Effectiveness evaluations show up weaknesses and successes with the delivery of the policy input, while appropriateness takes a higher-level view and considers whether the goal of policy is consistent with other policy initiatives. 


\section{Cost Implications}

The cost requirements for evaluation are determined by the scope of the evaluation required and the degree of precision or reliability of the research. Effectively, cost is a function of requirement for precision $p$ and the scope or difficulty of the exercise under evaluation $s$. mathematically,

$$
\operatorname{Cost}=f(p . s)
$$

Where the demand for accuracy is high, costs of evaluation will increase, while if the object under evaluation is small, the cost of evaluation is low. Increasing the level of resources available to evaluation does not necessarily lead simply to a proportionate increase in the level of knowledge however. The increase in cost depends upon the marginal rates at which precision can be obtained and how the level of difficulty increases. Mathematically, this is shown below:

$$
\Delta \operatorname{Cost}=f(\Delta p . \Delta s)
$$

But the uniformly increasing scope of research in a particular area is not normal in respect of effort and cost implications.

\subsubsection{Mapping of Methods and Impacts}

This section offers a mapping of methods to the socio-economic impacts classification discussed in the previous section. Certain methods can be applied to more than one type of assessment. Some methods are most properly considered as ways of generating data about economic and social phenomena. These are not necessarily theory blind, but their use is generally with a view to collecting data, reporting it, and categorising it. Other methods can then be used to relate the analysis to normative concepts from theory.

- Interview Methods

- Questionnaire Survey

- Expert Judgement Based Methods

- Review Methods

- Case Study Methods

Interview methods are generally divided into three sub-types, un-structured, semistructured and structured. Interviews promise significant depth and understanding of effects which cannot be known in advance. They are particularly useful in the context of identifying new processes of impact. Structured methods are similar to questionnaire surveys, except that the questionnaires are intended for impersonal administration and can therefore be sent to a higher number of potential respondents. Expert judgement methods have been increasingly used in recent years and comprise a wide range of sub-types. Their suitability for socio-economic impact assessment stems from the relative absence of common measures for benefit, or for probability of benefit in areas such as research and development activities. Where benefits are likely to be delayed, expert judgement provides a proxy or estimate of benefit rather than an actual measurement of it. Case study methods provide both the detailed understanding 
of effects of RTD and can also be used to produce sets of comparable cases that may assist evaluators with the assessment of net-effects and efficiency and effectiveness studies.

\section{Table 15. Interview Methods Summary}

\begin{tabular}{|l|l|l|l|}
$\begin{array}{l}\text { General } \\
\text { Methods }\end{array}$ & Specific Sub-Methods & $\begin{array}{c}\text { Framework, Data } \\
\text { Acquisition and } \\
\text { Analysis }\end{array}$ & $\begin{array}{c}\text { Appropriate Applications and } \\
\text { Relevance to Evaluation } \\
\text { Priorities }\end{array}$ \\
\cline { 1 - 2 } & $\begin{array}{l}\text { Un-structured / semi-structured Data Acquisition } \\
\text { / structured }\end{array}$ & $\begin{array}{l}\text { Wide applicability but not suitable for the } \\
\text { collection of statistical samples } \\
\text { Generally ex post }\end{array}$ \\
\hline
\end{tabular}

Table 16. Expert Judgement Based Methods

\begin{tabular}{|c|c|c|c|}
\hline $\begin{array}{l}\text { General } \\
\text { Methods }\end{array}$ & Specific Sub-Methods & $\begin{array}{c}\text { Framework, Data } \\
\text { Acquisition and } \\
\text { Analysis }\end{array}$ & $\begin{array}{c}\text { Appropriate } \\
\text { Applications and } \\
\text { Relevance to } \\
\text { Evaluation Priorities }\end{array}$ \\
\hline $\begin{array}{l}\text { Expert Judgement } \\
\text { Based }\end{array}$ & $\begin{array}{l}\text { Ancillary Peer-Review, Direct Peer Review, } \\
\text { Expert Panels/Peer Review, } \\
\text { Indirect Peer Review, Merit Review (extended } \\
\text { form of Peer Review), Modified Direct Peer } \\
\text { Review, Panel Review, Pre-Emptive Peer } \\
\text { Review, (Georghiou \& Meyer-Krahmer 1992) } \\
\text { Modified Peer Review - use of socio-economic } \\
\text { impact assessment with Traditional Peer } \\
\text { Review (Williams and Rank, 1998), } \\
\text { Professional Evaluators, Traditional Peer- } \\
\text { Review - use of academic experts to make } \\
\text { judgements about the value of projects }\end{array}$ & $\begin{array}{l}\text { Frameworks } \\
\text { Data Acquisition } \\
\text { Analysis }\end{array}$ & $\begin{array}{l}\text { Long term, generally } \\
\text { science based projects } \\
\text { Limit imposed by scope of } \\
\text { expert knowledge } \\
\text { Conservative } \\
\text { Ex ante or ex post }\end{array}$ \\
\hline
\end{tabular}

Table 17. Questionnaire Survey Methods

\begin{tabular}{c|l|c|c|} 
General Methods & \multicolumn{1}{c}{ Specific Sub-Methods } & $\begin{array}{c}\text { Framework, } \\
\text { Data Acquisition } \\
\text { and Analysis }\end{array}$ & $\begin{array}{c}\text { Appropriate } \\
\text { Applications and } \\
\text { Relevance to } \\
\text { Evaluation } \\
\text { Priorities }\end{array}$ \\
\hline $\begin{array}{c}\text { Questionnaire } \\
\text { Survey }\end{array}$ & $\begin{array}{l}\text { Unstructured, Open Questions - Closed Data Acquisition } \\
\text { Questions Based, Employing for example Likert } \\
\text { Scale } \\
\text { (e.g. Alvey Evaluation by Guy, Georghiou, } \\
\text { Cameron, 1997) }\end{array}$ & $\begin{array}{c}\text { Firm-based impacts } \\
\text { Ex ante or ex post }\end{array}$ \\
\hline
\end{tabular}

Review methods again embrace a wide range of sub-types. The rationale for the use of such types is that they supplement the expert judgement based approaches by focusing more explicitly upon future benefits. They are therefore generally seen as an ex ante evaluation method. The following table summarizes the above range of methods which are primarily for the review and identification of benefits. 
Table 18. Review Methods

\begin{tabular}{|c|c|c|c|}
\hline $\begin{array}{l}\text { General } \\
\text { Methods }\end{array}$ & Specific Sub-Methods & $\begin{array}{c}\text { Framework, } \\
\text { Data } \\
\text { Acquisition } \\
\text { and Analysis }\end{array}$ & $\begin{array}{l}\text { Appropriate } \\
\text { Applications } \\
\text { and Relevance } \\
\text { to Evaluation } \\
\text { Priorities }\end{array}$ \\
\hline $\begin{array}{l}\text { Review } \\
\text { Methods }\end{array}$ & $\begin{array}{l}\text { User Review - User Surveys - Clientele Review, Delphi } \\
\text { Methods, Focus Group, Foresight/ Technology Assessment, } \\
\text { Scenario Planning, Historical Tracing, (Technological } \\
\text { Forecasting Models are subdivided by Piric and Reeve } \\
\text { (1997) into Cross-Impact Matrices or Interdependency } \\
\text { Matrices, Scenario Methods, and Morphological Analysis) }\end{array}$ & $\begin{array}{l}\text { Data Acquisition } \\
\text { Analysis }\end{array}$ & $\begin{array}{l}\text { Best prospective - ex } \\
\text { ante - methods }\end{array}$ \\
\hline
\end{tabular}

\section{Table 19. Case Study Based Methods}

\begin{tabular}{|c|c|c|c|}
\hline General Methods & Specific Sub-Methods & $\begin{array}{c}\text { Framework, } \\
\text { Data } \\
\text { Acquisition } \\
\text { and } \\
\text { Analysis }\end{array}$ & $\begin{array}{c}\text { Appropriate } \\
\text { Applications } \\
\text { and Relevance } \\
\text { to Evaluation } \\
\text { Priorities }\end{array}$ \\
\hline Case Study & $\begin{array}{l}\text { Descriptive single / comparative/ within case / } \\
\text { cross-case and generating quantitative data } \\
\text { R\&D Value Mapping - suggests and outlines } \\
\text { methodology but does not apply to specific cases } \\
\text { (Bozeman \& Kingsley, 1997) } \\
\text { Capabilities, Competences, System Level Analysis, } \\
\text { Interactive Group, Observation Ethnography / } \\
\text { Ethnomethodology } \\
\text { Participant Observation }\end{array}$ & $\begin{array}{l}\text { Data Acquisition } \\
\text { Data Acquisition } \\
\text { and Analysis }\end{array}$ & Generally ex post \\
\hline
\end{tabular}

Table 20. Social Science Based Systemic and Network Theory Methods

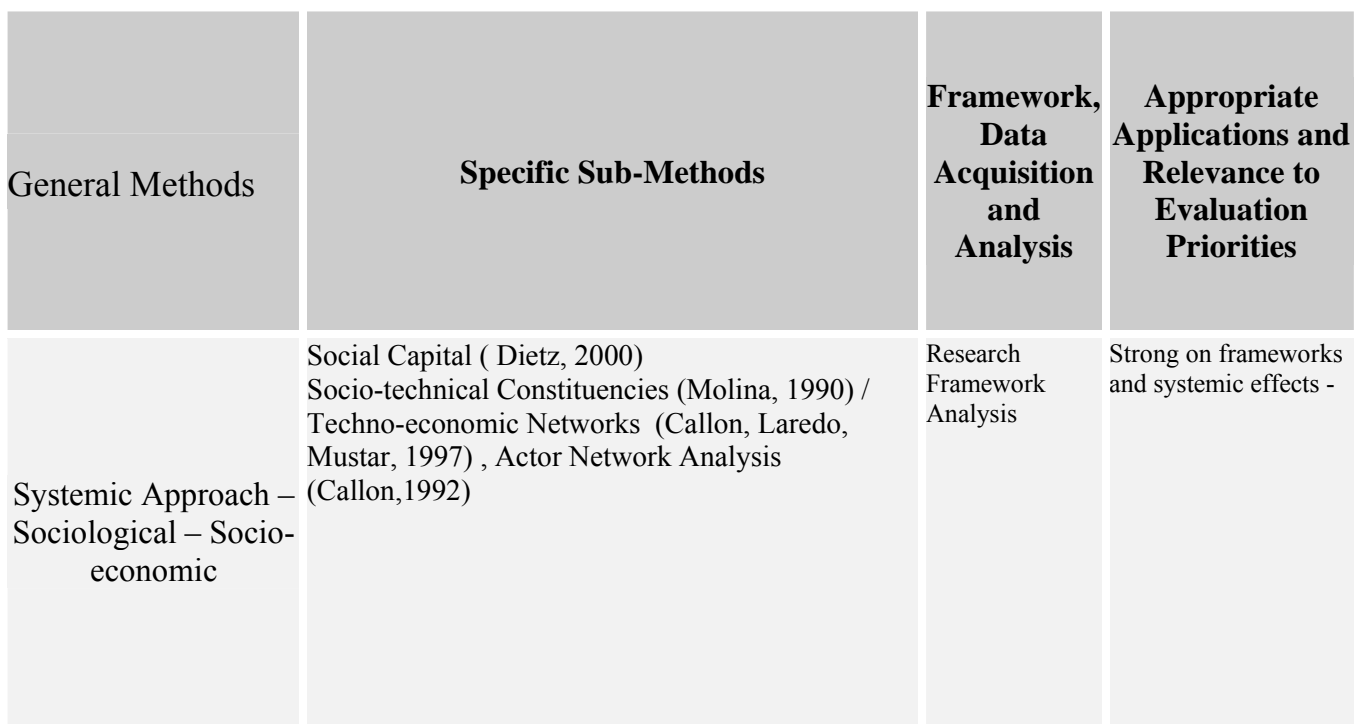


Table 21. Longitudinal / Historical Based Methods

\begin{tabular}{|c|c|c|c|}
\hline $\begin{array}{l}\text { General } \\
\text { Methods }\end{array}$ & Specific Sub-Methods & $\begin{array}{l}\text { Frameworks } \\
\qquad \text { Data } \\
\text { Acquisition } \\
\text { and Analysis }\end{array}$ & $\begin{array}{c}\text { Appropriate } \\
\text { Applications and } \\
\text { Relevance to } \\
\text { Evaluation } \\
\text { Priorities }\end{array}$ \\
\hline $\begin{array}{c}\text { Longitudinal / } \\
\text { Historical } \\
\text { Studies }\end{array}$ & $\begin{array}{l}\text { Tracing Studies - in effect a form of case study, see } \\
\text { TRACES, (IITRI, 1968), also Kostoff, (1994) } \\
\text { Transverse studies - supported in the case of Framework } \\
\text { Programme projects review by Luukkonen (1998) (2000) } \\
\text { problems with concept of "additionality" }\end{array}$ & Data Acquisition & $\begin{array}{l}\text { Examining the } \\
\text { persistence of policy } \\
\text { effectiveness - and } \\
\text { hence additionality } \\
\text { Providing context } \\
\text { relevant information } \\
\text { and comparisons over } \\
\text { time }\end{array}$ \\
\hline
\end{tabular}

Table 22. Sociometric Methods

\begin{tabular}{|c|c|c|c|}
\hline $\begin{array}{l}\text { General } \\
\text { Methods }\end{array}$ & Specific Sub-Methods & $\begin{array}{c}\text { Frameworks, } \\
\text { Data } \\
\text { Acquisition } \\
\text { and Analysis }\end{array}$ & $\begin{array}{c}\text { Appropriate } \\
\text { Applications and } \\
\text { Relevance to } \\
\text { Evaluation } \\
\text { Priorities }\end{array}$ \\
\hline $\begin{array}{c}\text { Sociometric } \\
\text { Studies - } \\
\text { Scientometrics / } \\
\text { Technometrics }\end{array}$ & $\begin{array}{l}\text { Scientometrics } \\
\text { Census Methods } \\
\text { Bibliometric Analysis "Bibliometrics" - Citation } \\
\text { Analysis, Citation Counts, } \\
\text { Co-Citation Analysis (Cluster Analysis) Co-Nomination } \\
\text { Analysis, Content Analysis, Co-Word Analysis, } \\
\text { Multivariate Analysis } \\
\text { Scientific Mapping (Rip, 1988) } \\
\text { Intellectual Property Data Analysis } \\
\text { Patent Data Analysis } \\
\text { Technometrics (Developed by Meyer-Krahmer \& Reiss, } \\
\text { 1992) } \\
\text { Uses product technical specifications to measure } \\
\text { "assess" technological change - suitable ex ante for } \\
\text { assessing potential areas for R\&D support } \\
\text { Benchmarking (specifically see Roessner, 2000) for more } \\
\text { general accounts, see Rush (1985) }\end{array}$ & $\begin{array}{l}\text { Data Acquisition } \\
\text { And Data Analysis }\end{array}$ & $\begin{array}{l}\text { Can identify the impacts } \\
\text { of policy } \\
\text { Methods also proxy for } \\
\text { impacts (indicators) } \\
\text { Provides possibility for } \\
\text { historical comparisons } \\
\text { Modelling and } \\
\text { measurement of impact }\end{array}$ \\
\hline
\end{tabular}


Table 23. Mathematics and Statistics Based Methods

\begin{tabular}{|c|c|c|c|}
\hline $\begin{array}{l}\text { General } \\
\text { Methods }\end{array}$ & Specific Sub-Methods & $\begin{array}{l}\text { Frameworks, } \\
\text { Data Acquisition } \\
\text { and Analysis }\end{array}$ & $\begin{array}{c}\text { Appropriate } \\
\text { Applications and } \\
\text { Relevance to } \\
\text { Evaluation } \\
\text { Priorities }\end{array}$ \\
\hline $\begin{array}{l}\text { Mathematics \& } \\
\text { Statistics Based }\end{array}$ & $\begin{array}{l}\text { Statistics - Sample Statistics, Correlation } \\
\text { Multivariate Analysis - Factor Analysis, } \\
\text { Discriminant Analysis, Cluster Analysis } \\
\text { Neural Network Models } \\
\text { Simulation Models- Macro Micro, Simulation - } \\
\text { Genetic Algorithm Based (Windrum, 1999), } \\
\text { Complexity Theory based methods } \\
\text { Event History Analysis (Rappa 1994) - } \\
\text { Survival Analysis, Hazard Rate Analysis } \\
\text { (Rappa \& Garud, 1992) } \\
\text { Expert System } \\
\text { Q-Sort } \\
\text { Programming - Dynamic Programming, Goal } \\
\text { Programming, Integer Programming, Linear } \\
\text { Programming, }\end{array}$ & Data Analysis & $\begin{array}{l}\text { Broad level of } \\
\text { applicability for } \\
\text { - identifying relationships } \\
\text { between variables } \\
\text { - measuring the strength } \\
\text { of such variables }\end{array}$ \\
\hline
\end{tabular}

Table 24. Scoring Methods

\begin{tabular}{|c|l|l|l|}
\hline $\begin{array}{c}\text { General } \\
\text { Methods }\end{array}$ & \multicolumn{1}{c|}{ Specific Sub-Methods } & $\begin{array}{c}\text { Frameworks, } \\
\text { Data Acquisition } \\
\text { and Analysis }\end{array}$ & $\begin{array}{c}\text { Appropriate } \\
\text { Applications and } \\
\text { Relevance to }\end{array}$ \\
\hline Ecvaluation Priorities \\
\hline Scoring Methods & $\begin{array}{l}\text { Analysis Matrices, } \\
\text { Decision Making matrices, } \\
\text { Multi-criteria Analysis, } \\
\text { Ordinal Ranking, } \\
\text { Relevance Trees }\end{array}$ & Data Acquisition & $\begin{array}{c}\text { Construction of measures of } \\
\text { impacts }\end{array}$ \\
\hline
\end{tabular}


Table 25. Economic and Econometric

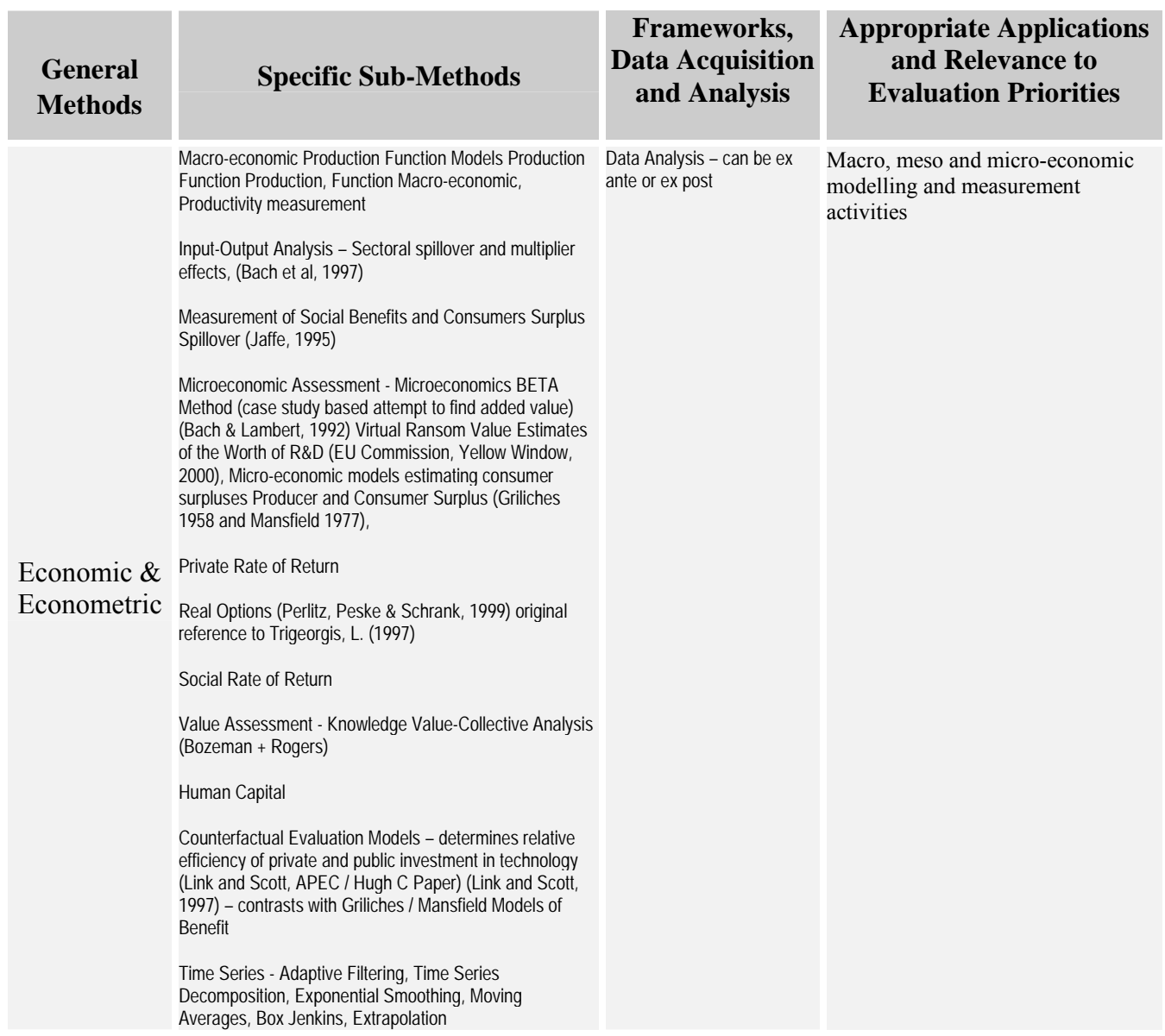

Table 26. Financial \& Accounting

\begin{tabular}{|c|c|c|c|}
\hline $\begin{array}{l}\text { General } \\
\text { Methods }\end{array}$ & Specific Sub-Methods & $\begin{array}{c}\text { Frameworks, Data } \\
\text { Acquisition and } \\
\text { Analysis }\end{array}$ & $\begin{array}{c}\text { Appropriate } \\
\text { Applications and } \\
\text { Relevance to } \\
\text { Evaluation } \\
\text { Priorities }\end{array}$ \\
\hline $\begin{array}{l}\text { Financial \& } \\
\text { Accounting }\end{array}$ & $\begin{array}{l}\text { Benefit Measurement Valuation Models "Cost Benefit } \\
\text { Analysis"- } \\
\text { Cost Effectiveness Analysis - (Rossi and Freeman, } \\
\text { 1993) see also (National Audit Office, 1995) } \\
\text { Cost-Loss Ratio Method (Bach \& Lambert,1992) } \\
\text { Comparative and Portfolio Models - Ex-Ante -Financial } \\
\text { Planning Real Options Valuation, Portfolio Models, } \\
\text { Contingency Analysis, Risk Profiles } \\
\text { Measurement Models - Rate of Return, Internal Rate of } \\
\text { Return, Discounted Net Present Value Return on } \\
\text { Capital Employed (ROCE), Ratio Methods } \\
\text { Programming Models }\end{array}$ & $\begin{array}{l}\text { Framework and Data } \\
\text { Analysis Methods for } \\
\text { calculating values }\end{array}$ & Ex Ante or Ex Post \\
\hline
\end{tabular}




\subsubsection{Mapping Methods to Areas of Research for Socio-economic Evaluation}

This section proposes a mapping of methods to particular types of impact. While the methods described above represent an exhaustive typology, Table 27, shown below provides a shorthand, easy to view method of identifying the most relevant methods for particular forms of socio-economic impact. However, research is an active process in which researchers constantly pioneer new methods, and apply existing methods to new problems or to problems to which methods have not been applied heretofore. Furthermore, new data sets are constantly emerging which make it possible to apply types of methods to areas of socio-economic impact in which those methods have not yet been applied. Finally, the use of existing data sets for national comparisons is often problematic. Comparability of data is often not assured, and continuous or complete data sets may not be available. 
Table 27. Major Methodological Uses for Socio-economic Evaluation by Impact Type

\begin{tabular}{|c|c|c|c|c|c|}
\hline $\begin{array}{c}\text { Methodology } \\
\text { Area }\end{array}$ & $\begin{array}{l}\text { Economic } \\
\text { Micro }\end{array}$ & $\begin{array}{c}\text { Economic } \\
\text { Meso }\end{array}$ & $\begin{array}{l}\text { Economic } \\
\text { Macro }\end{array}$ & $\begin{array}{c}\text { Social } \\
\text { Employment }\end{array}$ & $\begin{array}{c}\text { Social } \\
\text { Quality of } \\
\text { Life }\end{array}$ \\
\hline Interview & $\bullet \bullet$ & $\bullet \bullet$ & & $\bullet$ & $\bullet$ \\
\hline $\begin{array}{c}\text { Questionnaire } \\
\text { Survey }\end{array}$ & $\bullet \bullet$ & $\bullet$ & & $\bullet$ & • \\
\hline $\begin{array}{c}\text { Expert } \\
\text { Judgement } \\
\text { Based }\end{array}$ & & $\bullet \bullet$ & & & \\
\hline $\begin{array}{l}\text { Review } \\
\text { Methods }\end{array}$ & & • & & & • \\
\hline Case Study & $\bullet \bullet$ & $\bullet$ & & $\bullet$ & $\bullet$ \\
\hline $\begin{array}{c}\text { Systemic } \\
\text { Approach - } \\
\text { Sociological - } \\
\text { Socio- } \\
\text { economic }\end{array}$ & & $\bullet \bullet$ & & $\bullet$ & $\bullet$ \\
\hline $\begin{array}{l}\text { Longitudinal / } \\
\text { Historical } \\
\text { Studies }\end{array}$ & $\bullet$ & $\bullet$ & & $\mathrm{O}$ & $\mathrm{O}$ \\
\hline $\begin{array}{c}\text { Sociometric } \\
\text { Studies - } \\
\text { Scientometrics } \\
\text { / } \\
\text { Technometrics }\end{array}$ & $\bullet$ & $\bullet \bullet$ & $\bullet \bullet$ & $\mathrm{o}$ & $\bullet \bullet$ \\
\hline $\begin{array}{l}\text { Mathematics } \\
\text { \& Statistics } \\
\text { Based }\end{array}$ & $\bullet$ & $\bullet$ & & & \\
\hline $\begin{array}{l}\text { Scoring } \\
\text { Methods }\end{array}$ & & - & & $\bullet$ & $\bullet$ \\
\hline $\begin{array}{l}\text { Economics / } \\
\text { Econometrics }\end{array}$ & $\bullet$ & $\bullet$ & $\bullet \bullet$ & $\bullet$ & $\bullet$ \\
\hline $\begin{array}{l}\text { Financial / } \\
\text { Accounting }\end{array}$ & - & $\bullet$ & $\bullet$ & $\bullet$ & $\bullet$ \\
\hline
\end{tabular}

Each of the five following sections indicates the recommended impact assessment techniques which have been or may be used to assess one or other aspect of socioeconomic benefit. Each section contains reference to those factors which are likely to make the assessment of net impacts problematic. The following table consolidates these references and identifies those issues which, for each category of socioeconomic benefit, presents the major difficulties for impact assessment. These issues are principally those of contexts which influence the action of RTD activities. These contexts should be understood before reliable assessments of net socio-economic impact can be made about RTD impacts within those areas. 
Table 28. Influencing Contexts for Types of Socio-Economic Impact

\begin{tabular}{|c|c|c|c|c|c|}
\hline $\begin{array}{l}\text { Contextual } \\
\text { Background }\end{array}$ & $\begin{array}{l}\text { Economic } \\
\text { Micro }\end{array}$ & $\begin{array}{c}\text { Economic } \\
\text { Meso }\end{array}$ & $\begin{array}{c}\text { Economic } \\
\text { Macro }\end{array}$ & $\begin{array}{c}\text { Social } \\
\text { Employment }\end{array}$ & $\begin{array}{c}\text { Social } \\
\text { Quality of } \\
\text { Life }\end{array}$ \\
\hline $\begin{array}{l}\text { Firm Business } \\
\text { Strategy }\end{array}$ & • & & & & \\
\hline $\begin{array}{l}\text { Firm Research } \\
\text { Policy }\end{array}$ & • & & & & \\
\hline $\begin{array}{l}\text { Sectoral and } \\
\text { Industry } \\
\text { Structure } \\
\text { Change }\end{array}$ & $\bullet$ & $\bullet$ & & & \\
\hline $\begin{array}{l}\text { Actors and } \\
\text { Relationships } \\
\text { in the } \\
\text { Innovation } \\
\text { Process }\end{array}$ & • & • & & & \\
\hline $\begin{array}{l}\text { Fiscal / } \\
\text { Monetary Policy }\end{array}$ & $\bullet$ & & & • & \\
\hline $\begin{array}{l}\text { Educational } \\
\text { Policy }\end{array}$ & $\bullet$ & & & • & \\
\hline $\begin{array}{l}\text { Welfare and } \\
\text { Social Policy }\end{array}$ & $\bullet$ & & & $\bullet$ & $\bullet$ \\
\hline $\begin{array}{l}\text { Environmental } \\
\text { Policy }\end{array}$ & • & • & $\bullet$ & & • \\
\hline $\begin{array}{l}\text { National } \\
\text { Government } \\
\text { Research Policy }\end{array}$ & • & & & & \\
\hline $\begin{array}{l}\text { Changing } \\
\text { Personal Values } \\
\text { / Priorities }\end{array}$ & & & & • & • \\
\hline
\end{tabular}

\section{Economic Micro - Firm Level Methods}

A wide range of socio-economic impacts for RTD has been found to exist within the firm itself. These impacts range from the development of new capabilities and processes and result in the development of new commercial opportunities and products. The range of methods available to assess these kinds of impacts is broad. The following are recommended methods:

- Interviews

- Case Studies

- Questionnaires

- Technometric Studies

- Economics and Econometrics

- Financial and Accounting 


\section{Capabilities}

The techniques which are most appropriate here are those which can assess the capabilities which firms develop as a result of their participation in RTD activities directly or from the externalities which result from participation in them by other firms. The techniques which are immediately appropriate for the identification of such benefits - which are often divided into two categories, capacities and absorptive capacities - are interview and case study based. Knowledge of these capabilities are normally derived from interview. Capabilities and competences are often implicit hidden and particular, and need therefore to be identified by questioning. Evidence of them is not normally available in conventional data sources. They are not always disclosed in company information sources and legal disclosures. As capabilities often vary from period to period, comparisons between different periods of time are difficult. Consequently, time series, and other parametric statistical techniques are inappropriate. Numerical quantification of impact is highly problematic in the context of capabilities evaluation.

\section{Products and Services}

When RTD expenditure leads to products or ranges of products, the most appropriate methods to deal with the issues of attribution are interview and case studies. However, when research seeks to identify externalities / spillover from participants in research to those nominally outside, the techniques which should be used are those from costbenefit analysis and econometrics.

\section{Economic Meso / Innovation Process Level Methods}

Socio-economic impact within the innovation process itself has increasingly been seen to be the major benefit of RTD policy and innovation policy. Innovation networks are complex, existing within sectors, regions, and internationally. EU initiatives will increasingly seek to promote such entities through the European Research Area and networks of excellence in particular. These supra-firm level benefits are characterized by heterogeneity and exist as "organisations outside the organisation". The appropriate methods here for data gathering involve the following.

\section{$\underline{\text { Systemic - sociological and socio-economic network modelling }}$}

- Case Studies

- Questionnaires

- Technometric Studies

Interviews and case studies are able to assess the role of individual actors within innovation networks and these accounts can then be assembled to generate a coherent description of the effect of the policy. But in developing the assessment of network and innovation system impacts, the basic unit of analysis need not be at the level of a single firm. Larger entities can be assessed such as statistical aggregates which reflect the performance of firms and their inter-relationships. The relevant tools are the 
family of socio-metric methods which include network theories, network analysis and bibliometrics.

\section{Economic Macro}

The macro-level methods seek to identify benefits at the largest possible level of aggregation. The methods used here are macro-economic production function models, productivity measurement and cost-benefit analysis. Methods suitable for lower levels can be used to aggregate effects at firm and sector level for the macro level.

Economics / Econometrics - Growth Accounting

- Financial / Accounting

Attempts to assess macro-level impacts of Framework Programme activities can stem either from attempts to aggregate the results of studies on lower level effects or from macro-economic (econometric) modelling of the production function through an approach termed growth accounting. As Salter and Martin (2001) note, this approach, in common with many others, involves making inferences from "non-experimental" data. Lower level analyses can use either firm based studies or sectoral studies. Firm based studies have included larger and larger numbers of firms. Mansfield (1991) examined 76 firms in seven US industries. Beise and Stahl (1999) have employed a similar methodology on a larger group consisting of 2300 firms in manufacturing. Later approaches such as that by Narin et al (1997) have used socio-metric methods based on counting patent citations and attributing product and process improvements to publicly funded research. Such approaches are avowedly economic in focus and consequently they identify the benefits of RTD policy largely in terms of products.

\section{Social Employment}

The attention of policy makers in this area is often directed at attempts to reduce the headline rate of unemployment, which is affected by economic reform (for example the Single Market) or by the introduction of new technologies (technological change). The OECD (1998) examination of this area has cast doubt on existing practices of evaluation of employment effects: "The concern about high levels of unemployment in many countries has led to attempts to measure the employment impacts when evaluating technology programmes. Unfortunately, in many cases, the political imperative of being able to point of job gains associated with some innovation and technology policy initiative has come at the expense of analytical rigor in the measurement of employment impacts." The OECD recommendation is that to overcome many of the significant hurdles in the assessment of employment effects, a far more sophisticated approach to the study of policy impacts should be adopted that uses input outputs techniques, macro-economic modelling and general equilibrium approaches. The major concern here is that the measurement of true net effects has previously been neglected and that policy has been misguided as a result. 
Increased wages and raised skill levels which can be traded on the open market for higher wages are often cited as examples of social benefits that accrue directly to employees. While interview based conclusions are useful in determining where these kinds of impacts might have occurred, increases in wages rates in one area of the economy are not likely without some countervailing impact elsewhere. Consequently, net effects (which take into account additionality - behavioural additionality, spillover, etc. (see OECD, 1998) cannot be assumed from a measure of impact.

Interview

Questionnaire Survey

- Review Methods, e.g. Peer Review

- Case Study

- Systemic Approach - Sociological - Socio-economic

- Longitudinal / Historical Studies

- Sociometric Studies - Scientometrics / Technometrics

- Mathematics \& Statistics Based

- Scoring Methods

- Economics / Econometrics

- Financial / Accounting

\section{Social Quality of Life}

This area contains, perhaps not surprisingly, a large number of definitions of socioeconomic benefit / disbenefit. Many are uncontroversial, but a large number are also the subjects of controversy, a result of differences in underlying ideological positions. McDaniel (2001) identifies fundamental disagreements about the function of governments which Nicol and Salmon (2001) confirm in their account of the Treaty of Rome and subsequent developments in social policy, with the formulation of the European Social Model. Those quality of life issues which are relatively uncontroversial include improvements to health, consumer protection and the environment. Even here, though, differences in ideology may cause disagreement over the proper ends of policy.

Measures of quality of life can be derived from cost-benefit analyses, although before and after or counterfactual methods are required in the assessment of net effects. Assessment of the effects of policy may use statistical methods and mathematical modelling. The types of shortcomings exhibited by the assessment of policies directed at quality of life measures such as unemployment could easily apply to the assessment of other quality of life measures. However, wherever possible, research on the effectiveness of new policies should attend firstly to the identification of effects and an understanding of processes before efforts are made to assess the magnitude of policy interventions.

Impacts at the social level are often likely to occur as a result of programme outcomes which also have impacts at the level of the firm, such as increasing sales. The question arises as to whether such social benefits in terms of improved health should be counted in addition to increased sales. 


\section{Conclusions}

This section presents a number of conclusions on the evaluation of socio-economic benefits. Firstly, there is a set of general recommendations on the purpose of socioeconomic evaluation. Secondly, some conclusions are presented on the limits and the legitimate expectations of evaluation of socio-economic impacts. Thirdly, a number of conclusions on the optimal evaluation methods are presented.

\section{Purposes and Functions}

Socio-economic evaluation has the major function of identifying the outcomes and impacts of governmental programmes in all their variety and scale. Such programmes need endorsement by the democratic institutions which provide the resources which allow them to occur. Furthermore, such programmes require management to ensure appropriateness and the validity of the premises upon which such programmes are based. They also need management to ensure efficiency, control and effectiveness in their delivery. Evaluation must serve all these ends. It is a vital task, and the more difficult to achieve because of the complexity of the social and economic processes upon which programmes act. Without evaluation activities, governmental initiatives are blind, lacking the means to justification and to learning, to improvement and to excellence.

\section{Limits and Expectations of Evaluation}

Because intervention in the form of programme initiatives is intended to change the world, programmes which operate on a significant scale necessarily destroy the possibility of comparison, making the assessment of programme impacts difficult and measurements of net programme impact doubly so. Attempts to establish true net impacts therefore must invoke hypothetical and counterfactual constructions - to focus on what might have happened without the programme. Despite the difficulty of carrying through such an aim, it is essential to focus on additionality or net programme impact to obtain any sense and measure of programme action.

\section{Procedures}

Successful evaluation requires a clear focus upon research dimensions (Table 14). While no evaluation can cover each of these dimensions, it is essential to formulate an approach to evaluation in terms of them, so that the aims and the limitations of the evalution can be agreed and acknowledged beforehand. Because socio-economic impacts are diffuse and complex, our recommendation is that a variety of methods are used and that evaluation remains as actively and continuously engaged with its subject matter throughout the lifetime of the project as can be afforded. Where systematic and continuous evaluation mechanisms have been adopted, coverage of impacts is better, cumulative and persistence effects can be noted, and the overall appropriateness and effectiveness of programmes can be revealed.

\section{Choice of Methods}

The methods which can be employed to assess impacts and net impacts are numerous. Methods imply different views of what counts for knowledge in social and economic terms. They should therefore be chosen with the foreknowledge of what they imply. Some methods are incommensurable, being based on understandings which see social and economic phenomena in wholly different terms. Other methods can be combined without risk of generating results which cannot be synthesized. 


\section{Realizing the Value of Evaluations}

Evaluation studies can and should be used for the development of further policy interventions. Central to this process of development and refinement of Framework Programme interventions should be the benchmarking approach which has so far been widely used in the development of national policies. Benchmarking should be fully extended to the arena of the FP where it can contribute to programme delivery, policy learning, and also the process of evaluation itself. 


\section{References for Section 3.4}

Argyris, C, and Schon D.A. (1974) Theory in practice: increasing professional effectiveness, Jossey-Bass

Arnold, E. \& Balazs, K. (1998) Methods in the Evaluation of Publicly Funded Basic Research, Overview for OECD

Averch, H. (1994) "Economic Approaches to the Evaluation of Research", Evaluation Review Vol. 18, No. 1, pages 77-88

Bach, L. \& Georghiou, L. (1998) The Nature and Scope of RTD Impact Measurement, Discussion Paper for International Worksop on Measurement of RTD Results / Impacts, Brussels.

Bach, L. \& Lambert, G. (1992) "Evaluation of the economic effects of large R\&D Programmes: the case of the European space programme" Research Evaluation, Vol. 2, No. 1, pages 17-26.

Bach, L. \& Lambert, G. (1992) "Evaluation of the economic effects of large R\&D Programmes: the case of the European space programme" Research Evaluation, Vol. 2, No. 1, pages 17-26.

Barker, K. (1994) "R\&D Evaluation - Strengthening the impact of R\&D evaluation on policy making: methodological and organisation considerations", Research Evaluation, Vol. 21, No. 6, pages 405-413

Barker, K. (1994) "Strengthening the impact of R\&D evaluation on policy-making: methodological and organisational considerations", Science and Public Policy, Vol. 21, No.6, pages 405-413

Bedford, R. (2001) “A Robust Research/Policy Interface: International Migration and Social Transformation in the Asia-Pacific Region", Social Sciences for Knowledge and Decision Making, OECD: Paris

Bobe, B. \& Viala, H. (1997) "Panels of experts of the European Commission" in Callon, M., Laredo, P. \& Mustar, P. (eds.) The Strategic Management of Research and Technology - Evaluation of Programmes", Economica: Paris

Boddington, A. (1993) “ Research evaluation systems: sources of policy information and "evaluation push"” Research Evaluation, Vol. 3, No. 3 pages 133-208

Bozeman, B. \& Kingsley, G. (1997) "R\&D Value Mapping: A New Approach to Case StudyBased Evaluation" The Journal of Technology Transfer, Vol. 22, No. 1, pages 33-42

Bozeman, B. \& Melkers, J. (eds.) (1993) Evaluating R\&D Impacts: Methods and Practice, Kluwer: Boston

Bozeman, B. \& Melkers, J. (eds.) (1993) Evaluating R\&D Impacts: Methods and Practice, Kluwer: Boston

Clark, P.A. (1972) Action research and organisational change, Harper and Row

Comm (2001) 94 "Decision of the European parliament and of the council Concerning the multiannual framework programme 2002-2006 of The European community for research, technological Development and demonstration activities aimed at Contributing towards the creation of the European research Area

Comm (97) 553 Final "Fifth Framework Programme for Research and Technological Development (1998-2002) Commission Working Paper on the Specific Programmes: Starting Points for Discussion" 
Cunningham, P. \& Nedeva, M. (1999) Towards a system of continuous evaluation and monitoring for European co-operation in scientific and technical research (COST), Research Evaluation, Vol. 8, No. 1 pages 142-154

Dale, A. \& Barker, K. (1994) The Evaluation of EUREKA: a pan-European collaborative evaluation of a pan-European collaborative technology programme, Research Evaluation, Vol. 4, No. 1, pages 66-74

Dietz, J. (2000) "Building a social capital model of research development: the case of he Experimental Program to Stimulate Competitive Research", Science and Public Policy, Vol. 27, No. 2, pages 137-145

European Commission / ETAN Working Paper (1999) "Options and Limits for Assessing the Socio-economic Impact of European RTD Programmes

Georghiou, L. \& Meyer-Krahmer, F. (1992) "Evaluation of socio-economic effects of European Community R\&D Programmes in the SPEAR network", Research Evaluation, Vol. 2, No. 1, pages 5-15

Georghiou, L. \& Roessner, D. (2000) "Evaluating technology programs: tools and methods" Research Policy, Vol. 29, pages 657-678

Georghiou, L. (1998) "Socio-economic Effects of Collaborative R\&D - European Experiences", Journal of Technology Transfer, Vol. 24, pages 69-79

Georghiou, L. (1999) Socio-economic effects of collaborative R\&D - some European Experiences, Journal of Technology Transfer Vol. 24 No.1 pages 69-79

Godlee, F. \& Jefferson, T. (1999) Peer Review in the Health Sciences, BMJ Books: London

Harre, R. (2001) "Causal Mechanism and Social Practices: What can Social Science Contribute to Social Practice? Social Sciences for Knowledge and Decision Making, OECD: Paris

Illinois Institute of Technology (1968) "Technology in Retrospect and Critical Events in Science", IIT Report Series

Irvine, J. \& Martin, B. (1984) Foresight in Science: Picking the Winners, Frances Pinter: London

Kastrinos, N. (2001) "Promoting Dialogue Between Research and Policy-Making: The ETAN Experience" Social Sciences for Knowledge and Decision Making, OECD: Paris

Kostoff, R. (1994) “Assessing research impact: US government retrospective and quantitative approaches", Research Evaluation. Vol. 21, No. 1, pages 13-22

Link A. \& Scott, J. (199?) Hugh ? "Evaluating Public Sector R\&D: A Retrospective Examination of US Approaches" APEC Conference

Link A. \& Scott, J. (1997) "Policy Evaluation in Innovation and Technology Towards Best Practices - Lessons from the National Institute of Standards and Technology" OECD Conference Policy Evaluation in Innovation and Technology Towards Best Practices

Lundvall, B. \& Tomlinson, M. (2001) "Learning by Comparing: Reflections on the Use and Abuse of International Benchmarking" in Sweeny, G. (ed.) Innovation, Economic Progress and the Quality of Life, Edward Elgar: Cheltenham

Luukkonen, T. (1998) "The difficulties in assessing the impact of EU Framework Programmes" Research Policy, No 27, pages 599-610

Luukkonen, T. (2000) "Additionality of EU Framework Programmes", Research Policy, No. 30, Vol. 6, pages 711-724 
Luukkonen-Gronow, T. (1987) "Scientific Research Evaluation: A Review of Methods and Various Contexts for Their Application", R\&D Management, Vol. 17, No. 3, pages 207-221

Martin, F. (1998) “The economic impact of Canadian university R\&D” Research Policy Vol. 27 , pages $677-687$

Massimo, L. (1997) "Lessons from the experience of the European Commission" in Callon, M., Laredo, P. \& Mustar (eds.) The Strategic Management of Research and Technology - Evaluation of Programmes", Economica: Paris

McDaniel B. (2001) "The Crisis In Social And Institutional Integration" Social Science Journal Vol. 38 No. 2, Pages 263-275

Melkers, J. \& Cozzens, S. (1997) "Developing and Transferring Technology in State S\&T Programs: Assessing Performance" Journal of Technology Transfer, Vol. 22, No. 2, pages 27-32.

Narin, F., Hamilton, K. \& Olivastro, D. (1997) "The linkages between US technology and public science" Research Policy, Vol. 27, pages 835-851

National Audit Office (1995) The Department of Trade and Industry's Support for Innovation, Report by the Comptroller and Auditor General, HC 715, 1994-1995

Newby, H. (1994) "The Challenges for social science: a new role in public policy-making" Research Evaluation, Vol. 4, No. 1, pages 6-11

Nicoll, Sir W. \& Salmon, T. (2000) Understanding the European Union, Pearson: Harlow

Papaconstantinou, G. \& Polt, W. (1997) "Policy Evaluation in Innovation and Technology: An Overview", OECD Conference Policy Evaluation in Innovation and Technology Towards Best Practices

Perlitz, M., Peske, T. \& Schrank, R. (1999) "Real options valuation: the new frontier" R\&D Management, Vol. 29, No. 3, pages 255-269

Piric, A. \& Reeve, N. (1997) "Evaluation of Public Investment in R\&D - Towards A Contingency Analysis", OECD Conference Policy Evaluation in Innovation and Technology Towards Best Practices

Porter, A. \& Rossini, F. (1985) Peer Review of Interdisciplinary Proposals" Science, Technology and Human Values, Vol. 10, No. 3, pages 34-42

Rao, I. (1996) "Strategies for Best Practice in Research and Technology Institutes - An Overview of a Benchmarking Exercise", Scientometrics Vol. 25, No. 2, pages 265270

Rip, A. (1988) "Mapping of Science: Possibilities and Limitations" in Van Raan, A. (1988) Handbook of Quantitative Studies of Science and Technology, Elsevier: Amsterdam

Roessner, D. (2000) "Quantitative and qualitative methods and measures in the evaluation of research", Research Evaluation, Vol. 8, No. 2, pages 125-132

Rosenthal, R. (1991) Meta-Analytic Procedures for Social Research, Sage: Newbury Park

Rossi and Freeman (1993) Evaluation - A Systematic Approach, Sage: London

Rush, H. et al (1995) "Strategies for Best Practice in Research and Technology Institutes - An Overview of a Benchmarking Exercise" R\&D Management Vol. 25, No. 1, pages 1731

Salter, A. \& Martin, B. (2001) "The economic benefits of publicly funded research: a critical review" Research Policy, Vol. 30 pages 509-532 
Salter, A. \& Martin, B. (2001) "The Economic benefits of publicly funded basic research - a critical review" Research Policy, Vol. 30, pages 509-531

Sand, F. \& Nedeva, M. (1998) The EUREKA Continuous and Systematic Evaluation Procedure: As assessment of the socio-economic impact of the international support given by the EUREKA initiative to industrial $R \& D$ co-operation

SEC (2000) 1973.

Shadish, William R. Jr., Cooks, Thomas D., Leviton, Laura C. (1991) Foundations of Program Evaluation: Theories of Practice, Sage: London

Shea, M. \& Lewko, J. (1994) “Transferring knowledge to influence 'small p' policy development: examples from the implementation of integrated service delivery systems" Research Evaluation, Vol. 4, No. 1, pages 31-36

Smith, G. (1993) "A comment on the reflexive relationship between social policy and social research" Conference on Evaluation, Social Science and Public Policy, Ottawa, Canada

Spaapen, J. \& Sylvain, C. (1993) "Assessing the value of research for society", Research Evaluation, Vol. 3, No. 2, pages 117-126

Tiler C. \& Boddington, A. (1993) "Outputs, structure and process in the evaluation of social science research centres" Research Evaluation, Vol. 3, No. 2, pages 107-116

Trigeorgis, L. (1996) Real Options: Managerial Flexibility and Strategy in Resource Allocation, Cambridge, MA: The MIT Press

Van Langenhove, L. (2001) "Can the Social Sciences Act as an Agent of Change in Society? - An Introduction to the Workshop on the Contribution of Social Sciences to Knowledge and Decision Making”, Social Sciences for Knowledge and Decision Making, OECD: Paris

Van Raan, A. (1988) Handbook of Quantitative Studies of Science and Technology, Part II, Elsevier: Amsterdam

Van Raan, A. (1988) Handbook of Quantitative Studies of Science and Technology, Elsevier: Amsterdam

Wachter, K. \& Straf, M. (1990) (eds.) The Future of Meta-Analysis, Russell Sage: New York

Walgenbach, P. \& Hegele, C. (2001) "What Can an Apple Learn from an Orange? Or: What Do Companies Use Benchmarking For" Organization, Vol. 8, No. 1, pages 121-144

Wallace H. \& Wallace, W. (2000) Policy -Making in the European Union, fourth Edition, Oxford University Press: Oxford

Williams, D. \& Rank, A.D. (1998) "Measuring the economic benefits of research and development: the current state of the art", Research Evaluation, Vol. 7, No. 1, pages $17-30$

Willinsky, J. (2000) If Only We Knew - Increasing the Public Value of Social Science Research, Routledge: London

Working Group on S\&T Financial Management Mechanisms (Canada) (1993) Methods for Assessing the Socio-economic Impacts of Government S\&T

Yin, R. (1994) Case Study Research: Design and Methods, $2^{\text {nd }}$ Edition, Sage: Newbury Park 


\section{Case Studies}

\subsection{Market-Oriented Case Study}

\section{GENERAL PRESENTATION OF THE CASE STUDY}

\section{Objectives of the Case Study}

The overall objective of the case-studies in the ASIF project is to illustrate and help to understand the relevance and the utility of existing methods and techniques for the evaluation of the socio-economic impacts of the EU RTD Framework Programme. In this context, the role of the Market-Driven Case Study reported in this contribution was to compare different methods that can be used at firm level (or more generally at individual participant level) through applying them to the same case. This approach is intended to be informative on the issues of the applicability of data between different research methodologies, the feasibility of the approaches, their complementarity, their respective scope of relevance, with a particular emphasis on :

- the range of socio-economic effects and impact they take into account;

- their relevance for the evaluation when firms are involved in different RTD projects (some funded by EU and others not);

- the way they are dealing with classical evaluation problems such as additionality and the one related to the determination of the scope of actors affected by EU RTD Framework Programme;

- their relevance for evaluating to which extent the EU RTD Framework Programme help firms to adapt to the permanently changing constraints related to competition, innovation, demand change, etc.

It is important to stress that the final objective is not here to identify a "best method" which, according to the community of evaluators, does not in fact exist. The study is intended to help decision makers to better understand the scope and potential of a limited number of selected methods to cope with a limited number of problems and challenges raised by the evaluation of the socio-economic impacts of RTD programmes. Thus, the main lessons drawn from this study could be answering questions such as : to which extent these methods are usable ? what kind of socioeconomic impacts do they take into account ? are they complementary ? or, would it be possible to mix them?

\section{Workplan}

In order to reach these objectives, the case study was designed as follows.

\section{Step 1}

The first step was to choose a set of existing methods with which some members of the ASIF team were familiar. 


\section{Step 2}

The second step was to set up presentations of the selected methods, shedding some light on the types of results they provide and the way the collection of data required by each method is designed. These information were to be presented in the form of a "protocol" for each method.

\section{Step 3}

Based on the second step, the third step was to compare the different methods according to the requirements mentioned above, and illustrate those comparison with examples and "fictive cases" largely derived from previous uses of the selected methods.

\section{Step 4}

Also based on the second step, the fourth step was to carried out a real case study in order to attempt alternative methodologies and to compare their practicability as well as the resulting effects. It was thought that an ideal case could be a firm with different R\&D projects in process of which some are in the Framework Programme

\section{$\underline{\text { In Detail }}$}

The three remaining methods were selected for the following reasons :

- they are usable at firm's level;

- they provide (at least partly) quantitative results about socio-economic effects/outputs/impacts of RTD projects, even if not in monetary terms;

- classical Cost/Benefit approach being strongly rooted in the standard economics, it can be used as a reference method, whatever problems may arise when one wants to use it empirically;

- the BETA approach is one of the only quantitative methods trying to apprehend the so-called indirect effects (in monetary terms);

- the option approach is often seen as a promising approach which takes into account the uncertainty of RTD project and the potential of future development such project creates for the firms; it is also an ex-ante approach, while the other are mainly ex post approaches

\section{Step 2}

The basic structure of the description of the protocols have been designed by the BETA. The protocols and the results descriptions of the three methods: BETA approach, classical Cost/Benefit approach and Option approach were collected and arranged in an homogeneous presentation by the BETA team

\section{Step 3 and 4}

Comparison according to the requirements was carried out for the methods listed in Step 1 and for which the protocols have been set up as a result of Step 2. Due to problems to find one single firm fulfilling the selection criteria of the case study and agreeing to be interviewed in accordance with the requirements of the case study, a new real case study based on ad hoc interviews has not been carried out. However, in the light of the work achieved in Step 3, the BETA team expressed some doubts 
about the utility of a series of interviews conducted in one single firm. Such an exercise would have probably not brought a large added to the ASIF project, taking the following into account :

- only a limited scope of potential practical problems and difficulties that can occur at firm level would have been revealed or confirmed, since as a matter of fact they are context dependant;

- other potential practical problems and difficulties (described below) can occur at other stages of an evaluation study than the interview of one single firm (sampling, aggregation of data, etc)

- no significant improvements of existing methods would have been tested (for instance concerning BETA method, behavioural additionality or option approach), since such methodological modifications and their practical implementation would be out of the scope of the ASIF project.

Therefore, examples and "fictitious" cases have been set up largely on the basis of past real case studies performed by the Beta team, and illustrate the relevant questions raised by the use of the three selected methods.

\section{Structure Of The Presentation Of The Results Of The Case Study}

Taking into account what has been said in the previous sections, the presentation is organised as follows.

In II., the comparison will be made from the point of view of the feasibility of the selected methods, based on the detailed description of their protocols. In particular, the emphasis will be put on the practical problems that each method may encounter and the identification of the common data they required.

In III. a detailed comparison of the selected methods will be proposed, according to the requirements set out in I.1. The comparison will be made at two levels : i) the scope of effects/impacts and actors taken into account and ii) the way the different methods deal with some general or specific evaluation problems in the context of EU RTD Framework Programme.

In IV. fictitious cases of evaluation carried out at firm level will be provided.

\section{PRACTICAL USE OF SELECTED EVALUATION METHODS: A COMPARISON}

In this part, the selected methods will be analyzed from the point of view of their practicability. It is important to recall that the selected methods have already been used to a certain extent in previous evaluation studies, although at different levels. Therefore, there have already more or less proved to be feasible, and the aim is here rather to compare their feasibility rather than to assess it. Thus there will be no comprehensive description of all aspects of the selected method. The presentation will 
focus on the practical dimension of data collection and storage and on the type of results obtained, for purpose of clarity, comparability and possible homogenisation in the context of a real study. In II.1 we present the protocols, in part II.2 we briefly discuss some points related to the comparison of the feasibility, and in II.3, we try to identify common data and common data collection procedures.

\section{The protocols of the selected methods}

The following tables exhibit the protocols of each of the selected methods, following a common structure of presentation. Three sets of aspects are distinguished:

- the actors covered by the evaluation,

- the collection of data,

- the type of results obtained,

- and the storage and disclosure of data.

Some complementary information to the tables are provided in the Annex, especially about the description of the data required, about the results obtained, and about the way the final quantitative results expressed in monetary terms were obtained in the specific case of the BETA method, this latter being sometimes criticized for a lack of transparency. 


\section{ORGANISATIONS COVERED BY THE EVALUATION}

type of organisation covered

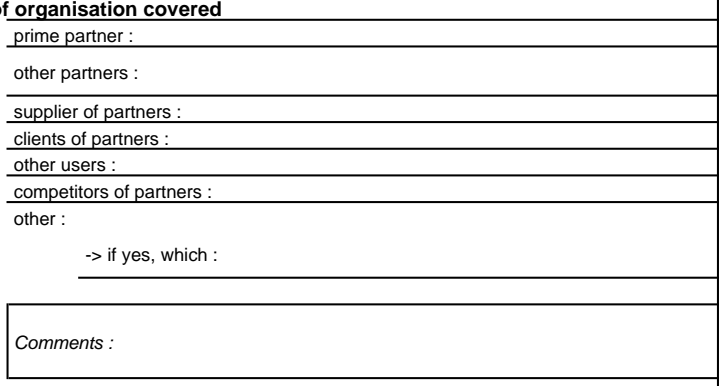

sampling

$\rightarrow$ if yes (detailed by type of organisation covered)

selection criteria :

description the selection process :

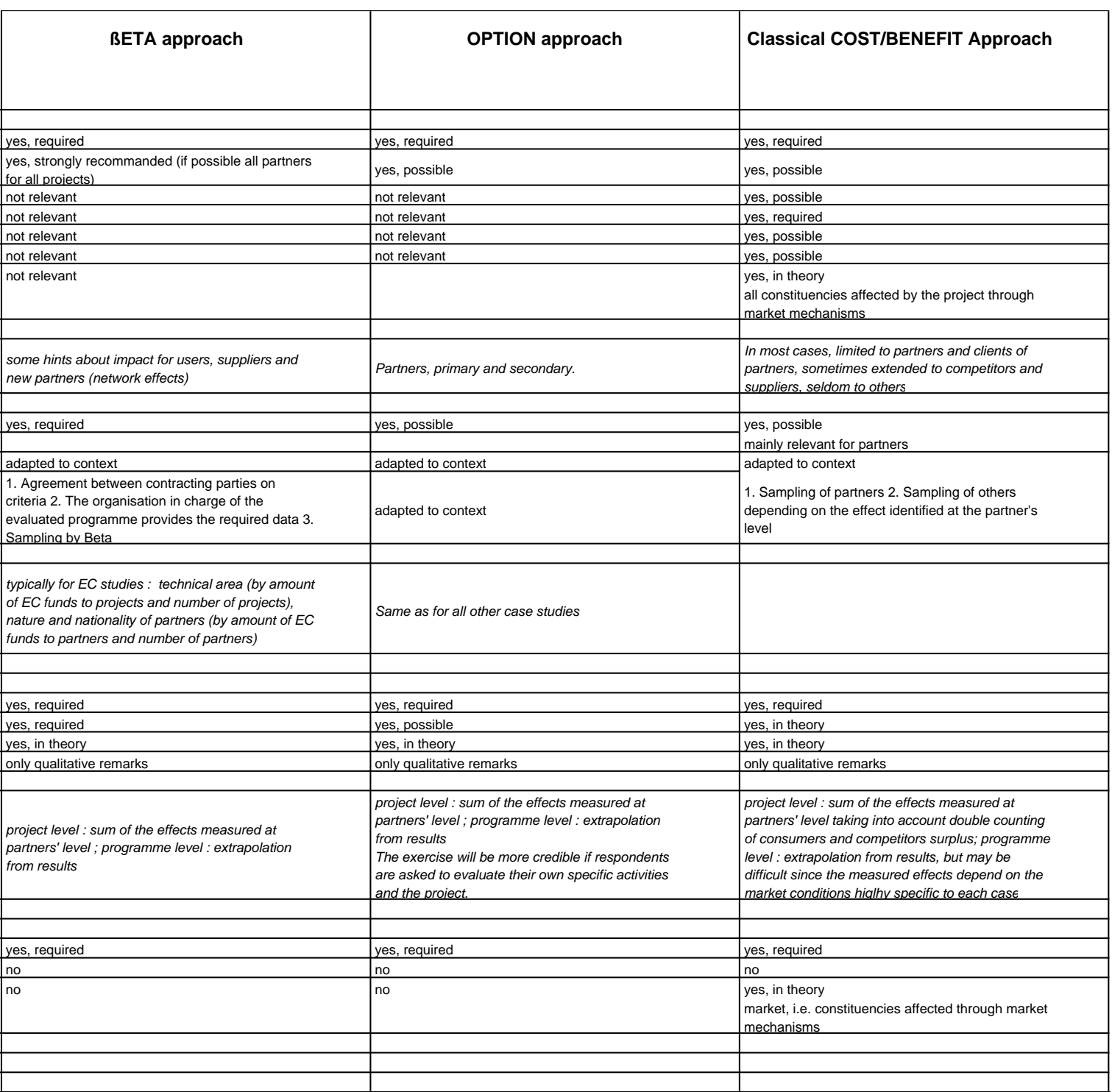




\begin{tabular}{|c|c|c|c|}
\hline & BETA approach & OPTION approach & Classical COST/BENEFIT Approach \\
\hline \multicolumn{4}{|l|}{ II COLLECTION OF DATA } \\
\hline $\begin{array}{c}\text { use of existing statistics } \\
\Rightarrow>\text { if yes, which : }\end{array}$ & no & \begin{tabular}{|l|} 
yes, possible \\
market studies, technological forecast, $\ldots$ \\
\end{tabular} & $\begin{array}{l}\text { yes, possible } \\
\text { related to demand curve, market structure, vertical } \\
\text { integration }\end{array}$ \\
\hline Comments: & & $\begin{array}{l}\text { Some confirmation with existing data on market to } \\
\text { the extent that there is a "twin "investment one } \\
\text { can use. }\end{array}$ & \\
\hline $\begin{array}{l}\text { collection of ad hoc data } \\
\rightarrow \rightarrow \text { if yes : }\end{array}$ & yes, required & yes, required & yes, required \\
\hline self-evaluation: & yes, required & yes, required & yes, required \\
\hline other sources: & seldom & yes, possible & yes, possible \\
\hline Comments: & $\begin{array}{l}\text { completed with interviewers + cross-checking } \\
\text { between partners of same projects }\end{array}$ & $\begin{array}{l}\text { Some confirmation with ad hoc data on market to } \\
\text { the extent that there is a " twin "investment one } \\
\text { can use. }\end{array}$ & $\begin{array}{l}\text { related to demand curve, market structure, } \\
\text { vertical integration }\end{array}$ \\
\hline $\begin{array}{c}\text { postal survey } \\
\rightarrow \rightarrow \text { if yes : }\end{array}$ & no & no & \\
\hline \multicolumn{4}{|l|}{$\frac{\rightarrow \text { if yes : }}{\text { number of questionnaire per organisation surveyed: }}$} \\
\hline \multicolumn{4}{|l|}{ length of questionnaire : } \\
\hline \multicolumn{4}{|l|}{ number } \\
\hline \multicolumn{4}{|l|}{ position } \\
\hline Comments: & $\begin{array}{l}\text { information too detailed, "hidden" and context } \\
\text { dependant to be obtain throuah postal survev }\end{array}$ & $\begin{array}{l}\text { Information too difficult to obtain through a typical } \\
\text { post survev. }\end{array}$ & \\
\hline $\begin{array}{l}\text { interview by phone } \\
\rightarrow>\text { if yes: } \\
\end{array}$ & basically no (see below) & yes, possible but difficult & \\
\hline \multicolumn{4}{|l|}{ number of phone calls per organisation covered } \\
\hline \multicolumn{4}{|l|}{ duration of phone call } \\
\hline \multirow{2}{*}{\multicolumn{4}{|c|}{ person contacted }} \\
\hline \multirow{2}{*}{\multicolumn{4}{|c|}{$\begin{array}{l}\text { number } \\
\text { position }\end{array}$}} \\
\hline & & & \\
\hline Comments: & $\begin{array}{l}\text { information too detailed, "hidden" and context } \\
\text { dependant to be obtain through phone interview }\end{array}$ & see below & \\
\hline $\begin{array}{c}\text { direct interviews } \\
\rightarrow \rightarrow \text { if yes: }\end{array}$ & yes, required & yes, required & \\
\hline$\frac{\rightarrow \text { if yes: }}{\text { number of interviews per organisation covered: }}$ & 1 or 2 & maximum 3 & \\
\hline duration of the interview : & 2 hours to 1 full day ; 3 hours in average & difficult to estimate & \\
\hline number of persons interviewed: & $\begin{array}{l}1 \text { to } 3 \text { or } 4 \text { together; in small organisation very } \\
\text { often } 1 \text {, in big organisation almost always } 2 \text { or more }\end{array}$ & 2 to 3 & \\
\hline position of persons interviewed: & $\begin{array}{l}\text { if } 1 \text { : project manager, research manager, manager } \\
\text { of the organisation; if more : other technical } \\
\text { manager, sales/marketing manaqer }\end{array}$ & $\begin{array}{l}\text { Managers who can estimate cost of investment } \\
\text { funds, technology and market risks. }\end{array}$ & \\
\hline number of interviewers : & $\begin{array}{l}2 \text { except in some few instances (in very small } \\
\text { organisation or ponctual interviews) }\end{array}$ & 1 or 2 & \\
\hline background of interviewers: & $\begin{array}{l}\text { leconomics/management + scientific/technical as } \\
\text { often as possible }\end{array}$ & Some knowledge in risk analysis & \\
\hline Comments: & \begin{tabular}{|l|}
$\begin{array}{l}\text { need experience/practice from interviewers } \\
\text { (around } 10 \text { interviews) }\end{array}$ \\
\end{tabular} & & \\
\hline
\end{tabular}




\begin{tabular}{|c|c|c|c|}
\hline $\begin{array}{l}\text { mix of three methods : } \\
\quad \rightarrow \text { if yes, description : }\end{array}$ & \begin{tabular}{|l} 
yes, required \\
frequent phone calls/fax/e-mail after intrviews \\
only for complementary information
\end{tabular} & $\begin{array}{l}\text { yes, possible } \\
\text { If combination, telephone and onsite interviews. }\end{array}$ & \\
\hline \multicolumn{4}{|l|}{ Comments: } \\
\hline $\begin{array}{l}\text { questionnaire } \\
\rightarrow \text { if yes: }\end{array}$ & no & yes, required & yes, required \\
\hline structured: & & yes, required & yes, required \\
\hline \multicolumn{4}{|l|}{ semi-structured: } \\
\hline \multicolumn{4}{|l|}{ (provide the questionnaire or some elements) } \\
\hline Comments: & $\begin{array}{l}\text { information too detailed, "hidden" and context } \\
\text { dependant to allow for a short and usable } \\
\text { auestionnaire }\end{array}$ & & \\
\hline guidelines & yes, required & yes, required & yes, required \\
\hline $\begin{array}{l}\rightarrow \text { if yes: } \\
\quad \text { (provide the quidelines or some elements) }\end{array}$ & \begin{tabular}{|l|} 
see Complementary Doc. Beta 1 \\
\end{tabular} & & \\
\hline \multicolumn{4}{|l|}{ Comments: } \\
\hline \multicolumn{4}{|l|}{ type of data collected (if not described by the questionnaire or guidelines) } \\
\hline about the nature of partners : & yes, required & yes, possible & yes, possible \\
\hline about the characteristics of projects : & $\begin{array}{l}\text { yes, required } \\
\text { yed }\end{array}$ & $\begin{array}{l}\text { yes, possible } \\
\text { yes }\end{array}$ & $\begin{array}{l}\text { yes, possible } \\
\text { yes }\end{array}$ \\
\hline $\begin{array}{l}\text { about the characteristics of the involvment of the partners in the projects: } \\
\text { about the output impact: }\end{array}$ & $\begin{array}{l}\text { yes, required } \\
\text { yes, required }\end{array}$ & yes, possible & yes, possible \\
\hline qualitative : & yes, possible & yes, possible & yes, possible \\
\hline qualitative ordered (ex. rank from 1 to 10 , or from bad to very & yes, possible & yes, possible & yes, possible \\
\hline $\begin{array}{l}\text { aood, etc): } \\
\text { quantitative but not monetary: }\end{array}$ & yes, required & yes, possible & yes, possible \\
\hline monetary: & yes, required & yes, required & yes, required \\
\hline $\begin{array}{l}\text { (provide the list of data if they are not included in the } \\
\text { questionnaire or quidelines) }\end{array}$ & see Complementary Doc. Beta $1 \& 2$ & see Complementary Doc. Options & see Complementary Doc. CBA \\
\hline
\end{tabular}




\begin{tabular}{|c|c|c|c|}
\hline & BETA approach & OPTION approach & Classical COST/BENEFIT Approach \\
\hline \multicolumn{4}{|l|}{ III TYPE OF RESULTS } \\
\hline type of results (monetary, quantitative, etc) & $\begin{array}{l}\text { sum of the Added Value (+ proxy values) created by } \\
\text { all partners thanks to the evaluated project/ / ratio } \\
\text { (Added Value/Public funds to the evaluated projects) } \\
\text { breakdown of both type of results by type of effects, } \\
\text { types of partners, types of projects etc, coupled } \\
\text { with qualitative information for interpretation }\end{array}$ & $\begin{array}{l}\text { Present value of future gains for partners covered } \\
\text { (Cash-Flows or Income or other indicator), taking } \\
\text { into account options generated by the invetsment in } \\
\text { the project }\end{array}$ & $\begin{array}{l}\text { sum of the variation of social surplus (i.e. consumer } \\
\text { surplus + surplus of all firms covered - partner, } \\
\text { competitors, clients, suppliers -) generated by the } \\
\text { identified effects }\end{array}$ \\
\hline Comments: & & $\begin{array}{l}\text { All of the above (to create the story) with emphasis } \\
\text { on alternative scenaria and probabilities }\end{array}$ & $\begin{array}{l}\text { All type of information may help to enrich the } \\
\text { analysis, but only monetary data are requirec }\end{array}$ \\
\hline \multicolumn{4}{|l|}{ IV STORAGE AND DISCLOSURE OF DATA } \\
\hline \multicolumn{4}{|l|}{ level of confidentiality } \\
\hline disclosure of individual information collected: & no & $\begin{array}{l}\text { no a priori rule; depends on the context of the } \\
\text { evaluated proaramme }\end{array}$ & $\begin{array}{l}\text { no a priori rule; depends on the context of the } \\
\text { evaluated proaramme }\end{array}$ \\
\hline $\begin{array}{l}\text { partial disclosure of individual information collected with explicit } \\
\text { agreement of the interviewed organisation : } \\
\rightarrow \text { if yes: }\end{array}$ & yes, possible & yes, possible & yes, possible \\
\hline with anonymate: & yes, possible & $\begin{array}{l}\text { no a priori rule; depends on the context of the } \\
\text { evaluated proaramme }\end{array}$ & $\begin{array}{l}\text { no a priori rule; depends on the context of the } \\
\text { evaluated proaramme }\end{array}$ \\
\hline without anonymate : & yes, very seldom & $\begin{array}{l}\text { no a priori rule; depends on the context of the } \\
\text { evaluated proaramme }\end{array}$ & $\begin{array}{l}\text { no a priori rule; depends on the context of the } \\
\text { evaluated proaramme }\end{array}$ \\
\hline $\begin{array}{l}\text { disclosure of aggregated data: } \\
\Rightarrow \text { if yes, level of aggregation of results : }\end{array}$ & yes, required & yes, possible & yes, possible \\
\hline by type of effects: & yes, required & not relevant & yes, possible \\
\hline by project: & yes, required & $\begin{array}{l}\text { no a priori rule; depends on the context of the } \\
\text { evaluated proaramme }\end{array}$ & $\begin{array}{l}\text { no a priori rule; depends on the context of the } \\
\text { evaluated proaramme }\end{array}$ \\
\hline by type of partner: & yes, required & $\begin{array}{l}\begin{array}{l}\text { no a priori rule; depends on the context of the } \\
\text { evaluated programme }\end{array} \\
\end{array}$ & $\begin{array}{l}\text { no a priori rule; depends on the context of the } \\
\text { evaluated programme }\end{array}$ \\
\hline by programme : & yes, possible & $\begin{array}{l}\begin{array}{l}\text { no a priori rule; depends on the context of the } \\
\text { evaluated proaramme }\end{array} \\
\end{array}$ & $\begin{array}{l}\text { no a priori rule; depends on the context of the } \\
\text { evaluated proaramme }\end{array}$ \\
\hline Comments: & $\begin{array}{l}\text { aggregation should in no way allows for the } \\
\text { identification of individual results }\end{array}$ & & \\
\hline \multicolumn{4}{|l|}{ data base } \\
\hline only quantitative: & no & no & no \\
\hline only qualitative: & no & no & no \\
\hline mix quantitative/qualitative: & yes, required & yes, required & yes, required \\
\hline Comments: & see Complementary Doc. Beta 3 & $\begin{array}{l}\text { Mixed. A good story combined with quantitative } \\
\text { information and estimation of the value of } \\
\text { sequential investment. }\end{array}$ & mainly quantitative data \\
\hline
\end{tabular}

Cells in grey : the insufficient experience of the ASIF partners makes it impossible to provide the corresponding information. 


\section{Practical difficulties}

The three selected methods reviewed here are based on direct interviews. Sometimes, some complementary sources of data are added, but in general not according to standardized and homogeneous procedures. Two sets of problems arise :

- the sampling, which in principle does not cause any difficulty, provided that there is an agreement on the selection criteria;

- the interviews themselves and the collection of data, which cause specific problems briefly summarized as follows.

In the Beta approach, the difficulties are mainly related to :

- the variety and diversity of effects to be tracked;

- the basic understanding that the interviewers must have of different aspects (technical, organization, economic) of each evaluated project ;

- the necessity to cope with subjectivity and lack of memory of the interviewed managers.

- the necessity in most cases to interview all partners of the projects of the sample.

In the Option approach, the difficulties are mainly related to the necessity to identify future states of the world associated with different variables. More precisely, the main disadvantages of the use of the Decision-Tree Analysis are that building up the tree is very resources-consuming in practice, and that the discount rates should in theory vary from one branche of the tree to the other but are most of the time assumed to be the same in the whole tree. Thus in this second approach of Black\&Scholestype Direct Formula there is no need of building a tree provided that one has an evaluation of reasonnable values for the future income from the commercial investment and for its standard deviation. The main disadvantages are that fiirstly it supposes a certain form of probability function, second it is assumed that the investor are risk-neutral and lastly it does not take into account "options created by options" (cf cumulativness of technical progress).

$>$ In the Classical Cost/Benefit approach, the difficulties are mainly related to the necessity to gather information from different actors which are affected by the evaluated project, but are not directly involved in this project. In particular, the evaluation at the end consumer level may be difficult, since it requires the identification of a demand curve (or from a technical standpoint the measurement of elasticity of demand respective to the price) which does not always exist when new products/services are at stake, or may be modified by price/quantity shifts in the case of improved products/services.

Therefore, for the reasons just mentioned, in all these three approaches the evaluation may be highly resource consuming, and the samples cannot be very large taken into 
account the order of magnitude of the budget generally devoted to evaluation studies (in the biggest BETA study, 50 projects corresponding to 176 partners were covered).

\section{Some overlaps / complementarity between approaches as regards the data and data collection}

- The sampling procedures could be the same for the three approaches.

- Part of the data collected at partner's level could be common, although the CBA and Option approach go a little deeper in the book-keeping data; in particular they require the amount of money invested by the partner and the detailed data allowing for profit calculation, which are not required by the BETA approach. With a slightly longer interview, it would the be possible to use a single interview at partner's level to collect the data required at this level by the BETA approach and in the CBA one.

- Generally speaking, and again at partner level, it would be possible to express some results from the BETA approach in the terms used by the CBA ones, provided that two data are available : the amount of investment made by the partner and a coefficient allowing to infer a profit rate from an added value rate (this type of coefficient could be available from sectoral statistics).

\section{Functions, Priorities and Research dimensions}

As it is analyzed in details in a previous part of the report, any approach in evaluation is the result of a building process following different steps at which theoretical and methodological decisions are to be taken. The objective of this case study being mainly operational, we have focused on the realisation of the evaluation, the analysis and the reporting of the data, and we have left aside part of the last two steps (dissemination, feedback and use of findings). As for the first step (functions and priorities), it could be briefly mentionned that all three selected methods have as priorities the measurement of the scale and extent of the effects, and to a lesser extent the attribution (see below). Finally, the "research dimensions" of the three selected methods (corresponding to the second step) can be described as follows :

\begin{tabular}{|l|l|l|l|}
\hline & \multicolumn{3}{|c|}{ Approaches } \\
\hline Research dimensions & Beta approach & C/B approach & Option approach \\
\hline Relation & $\begin{array}{l}\text { between Action and } \\
\text { Disenqaged research }\end{array}$ & Disengaged research & $\begin{array}{l}\text { between Action and } \\
\text { Disenqaged research }\end{array}$ \\
\hline Timing & ex-post retrospective / summative & $\begin{array}{c}\text { Ex-ante prospective } \\
\text { operational }\end{array}$ \\
\hline Focus & & empirical based \\
\hline Methods & \multicolumn{2}{|c|}{ single method } \\
\hline Paradigm & $\begin{array}{l}\text { between positivist } \\
\text { and post-positivist }\end{array}$ & $\begin{array}{l}\text { efficiency and } \\
\text { effectiveness }\end{array}$ & \multicolumn{2}{|c|}{ effectiveness } \\
\hline Scope & & \multicolumn{2}{|c|}{} \\
\hline
\end{tabular}




\section{Effects covered by the selected evaluation methods : A COMPARISON}

In this part, the selected methods will be compared from two perspectives. First we chose some criteria related to the scope of effects covered by the methods; this analysis enriches and complements the information described in the protocol as regards the type of effects evaluated, the time horizon, the type of actors for which each method has a specific behaviour, etc. Second, we also decided to analyse more general questions relevant in each evaluation analysis such as additionality, aggregation of data etc.

\section{Range of socio-economic effects}

\section{The socio-economic effects, output and impact covered by the selected approaches}

In order to compare the range of socio-economic effects covered by each selected approach and to be coherent with the survey conducted in a previous part of this report, we have used the list proposed in Bach \& Georghiou (1998) and derived from the COMEVAL report : it is one of the most detailed grid of analysis, it has been used (in a simplified form) as a basis for the meta-survey conducted in the present ASIF project, and is rather closed to the list of items investigated in the three studies briefly presented in this meta-analysis as exemplifying "good evaluation practices".

The following tables exhibit the coverage of each approach when compared to this list; they show the outputs and impacts actually evaluated, as well as the ones that could be seen as compatible with each method (different type of compatibility are distinguished).

It clearly appears that the BETA approach is covering the larger range of effects. A lot of effects are directly expressed by this approach, or could very easily be shown if a more detailed breakdown of the different categories of indirect effects was proposed. However, one cannot claim that the BETA approach is exhaustive in this respect. In particular, outputs related to standards, and a whole range of impacts on the society as a whole are not covered, which is obvious since the BETA method is limited to what affects the RTD partners themselves.

It is not surprising to find out that the classical Cost/Benefit approach and the Option approach look at a more narrow scope of effects. The Option also takes into account output and impacts related to the creation of capacity and the possibilities of strategic choice in general, altough in a very specific way. But it must be recall here that with this approach, most of the outputs and impacts are only identified to allow for the description of possible future "states of the world", and not evaluated as such.

The classical Cost/Benefit may also give account of different impacts for the society, provided that there exist some observable of measurable market value for goods or services that are at stake. It can be noted that when these market values are not existing or are not measurable, one can use some more sophisticated and very specific 
methods theoretically coherent with the classical Cost/Benefit approach, even if they are sometimes difficult to apply in real world (for instance contingency valuation). 
OUTPUTS

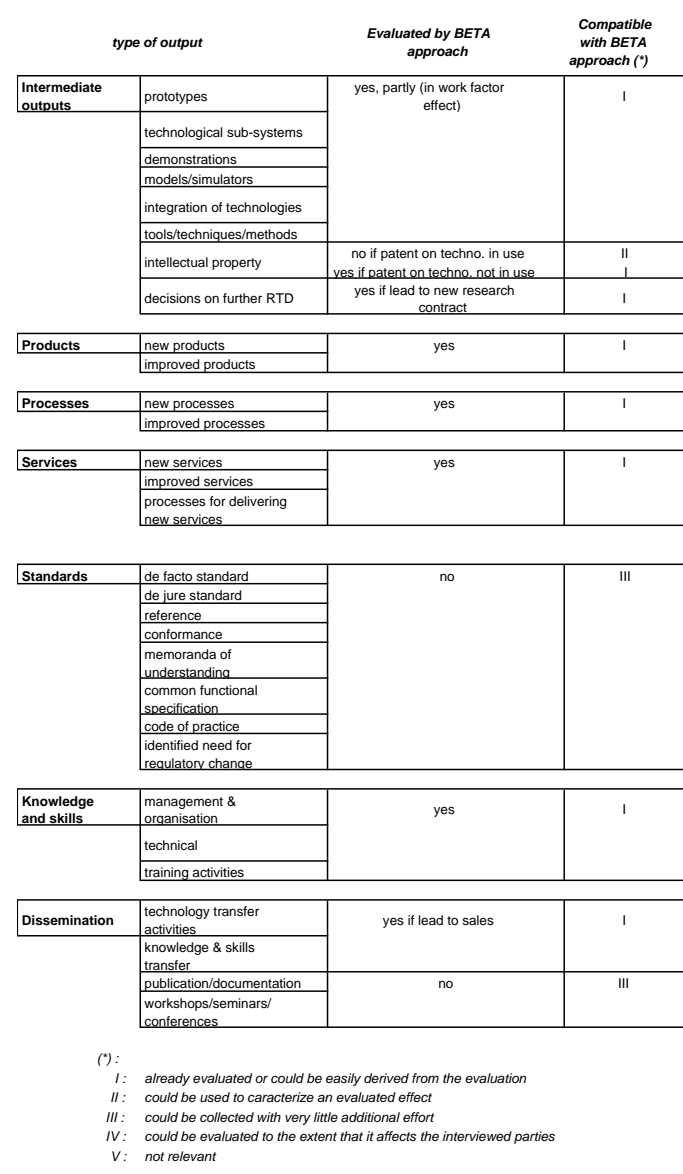

BETA approach and output/impact list
IMPACTS

\begin{tabular}{|c|c|c|c|}
\hline & type of impact & $\begin{array}{c}\text { Evaluated by BETA } \\
\text { approach }\end{array}$ & $\begin{array}{c}\text { Compatible } \\
\text { with BETA } \\
\text { approach (*) }\end{array}$ \\
\hline \multirow[t]{7}{*}{ Competitiveness } & sales & \multirow[t]{7}{*}{ yes } & \multirow[t]{7}{*}{1} \\
\hline & market share & & \\
\hline & open up markets & & \\
\hline & create new markets & & \\
\hline & lower costs & & \\
\hline & \begin{tabular}{|l} 
faster time to market \\
\end{tabular} & & \\
\hline & licence income & & \\
\hline
\end{tabular}

\begin{tabular}{|c|c|c|c|}
\hline \multirow[t]{4}{*}{ Employment } & jobs created & \multirow[t]{4}{*}{ no } & \multirow[t]{3}{*}{ II or III } \\
\hline & jobs in regions of high unemployment & & \\
\hline & jobs secured & & \\
\hline & Jobs lost & & \\
\hline \multirow[t]{9}{*}{ Organisation } & formation of new firm & \multirow{2}{*}{ no } & \multirow[t]{2}{*}{ II or III } \\
\hline & joint venture to exploit results & & \\
\hline & new technological networks/contacts & \multirow[t]{2}{*}{ yes } & \multirow[t]{2}{*}{$\mathrm{T}$} \\
\hline & new market networks/contacts & & \\
\hline & improved capacity to absorb knowledge & \multirow{2}{*}{$\begin{array}{l}\text { yes, partly (in work factor } \\
\text { effect) }\end{array}$} & \multirow[t]{2}{*}{1} \\
\hline & core competence improvement & & \\
\hline & further RTD & \multirow[t]{2}{*}{ yes } & \multirow[t]{2}{*}{1} \\
\hline & reorganisation of firm to exploit results & & \\
\hline & \begin{tabular}{|l|} 
change in strategy \\
increased profile \\
\end{tabular} & no & III \\
\hline \multirow[t]{5}{*}{ Quality of life } & healthcare & \multirow{5}{*}{ no } & \multirow[t]{4}{*}{ IV } \\
\hline & safety & & \\
\hline & social development \& services & & \\
\hline & improved border protection \& policing & & \\
\hline & support for cultural heritage & & $\mathrm{v}$ \\
\hline
\end{tabular}

\begin{tabular}{|c|c|c|c|}
\hline \multirow{4}{*}{\begin{tabular}{|l} 
Control \& care \\
of the \\
environment
\end{tabular}} & reduced pollution & \multirow{2}{*}{ no } & IV \\
\hline & \begin{tabular}{|l} 
improved information on pollution \& hazards \\
positive impact upon global climate \\
\end{tabular} & & $\mathrm{v}$ \\
\hline & reduced raw material use & \multirow[t]{2}{*}{$\begin{array}{c}\text { yes, if concern RTD project } \\
\text { partners }\end{array}$} & 1 \\
\hline & reduced energy consumption & & IV \\
\hline
\end{tabular}

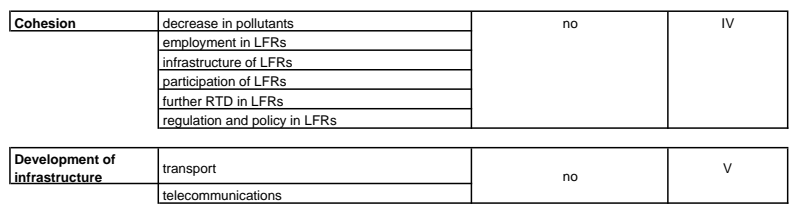

\begin{tabular}{|c|c|c|c|}
\hline \multirow[t]{4}{*}{$\begin{array}{l}\begin{array}{l}\text { Production \& } \\
\text { rational use of } \\
\text { energy }\end{array} \\
\end{array}$} & urban development & \multirow[t]{3}{*}{ no } & \multirow{2}{*}{$\mathrm{v}$} \\
\hline & rural development & & \\
\hline & & & \\
\hline & energy savings & $\begin{array}{c}\text { yes, if concern RTD project } \\
\text { partners }\end{array}$ & IV \\
\hline \multirow{2}{*}{$\begin{array}{l}\begin{array}{l}\text { Industrial } \\
\text { development }\end{array} \\
\end{array}$} & nuclear safety & \multirow{2}{*}{ no } & \multirow[t]{2}{*}{$\mathrm{v}$} \\
\hline & \begin{tabular}{|l|} 
assurance of future supply \\
distribution of energy
\end{tabular} & & \\
\hline \multirow{8}{*}{\begin{tabular}{|l|}
$\begin{array}{l}\text { Regulation \& } \\
\text { policy }\end{array}$ \\
\end{tabular}} & development of SME sector & \multirow{8}{*}{ no } & \\
\hline & development of large organisations & & \\
\hline & support for trade & & \\
\hline & EU regulations or policy & & \\
\hline & national regulations or policy & & \\
\hline & world-wide regulations or policy & & \\
\hline & $\begin{array}{l}\text { co-ordination between national \& Community } \\
\text { RTD programmes }\end{array}$ & & \\
\hline & development of internal market & & \\
\hline
\end{tabular}


OUTPUTS

\begin{tabular}{|c|c|c|c|}
\hline \multicolumn{2}{|c|}{ type of output } & \multirow{2}{*}{$\begin{array}{c}\begin{array}{c}\text { Evaluated by } C B A \\
\text { approach }\end{array} \\
\text { no }\end{array}$} & \multirow{2}{*}{$\begin{array}{c}\begin{array}{c}\text { Compatible } \\
\text { with CBA } \\
\text { approach }\left(^{*}\right)\end{array} \\
\text { III }\end{array}$} \\
\hline \multirow[t]{8}{*}{$\begin{array}{l}\text { Intermediate } \\
\text { outputs }\end{array}$} & prototypes & & \\
\hline & technological sub-systems & & \\
\hline & \begin{tabular}{|l|} 
demonstrations \\
\end{tabular} & & \\
\hline & \begin{tabular}{|l|} 
models/simulators \\
\end{tabular} & & \\
\hline & \begin{tabular}{|l} 
integration of technologies \\
\end{tabular} & & \\
\hline & tools/techniques/methods & & \\
\hline & intellectual property & & \\
\hline & decisions on further RTD & & \\
\hline \multirow[t]{2}{*}{ Products } & new products & yes & 1 \\
\hline & improved products & & \\
\hline \multirow[t]{2}{*}{ Processes } & new processes & yes & 1 \\
\hline & improved processes & & \\
\hline \multirow[t]{3}{*}{ Services } & new services & \multirow[t]{3}{*}{ yes } & \multirow[t]{3}{*}{1} \\
\hline & improved services & & \\
\hline & $\begin{array}{l}\text { processes for delivering } \\
\text { new services }\end{array}$ & & \\
\hline \multirow[t]{8}{*}{ Standards } & de facto standard & \multirow[t]{8}{*}{ no } & \multirow[t]{8}{*}{ III } \\
\hline & de jure standard & & \\
\hline & reference & & \\
\hline & conformance & & \\
\hline & memoranda of understanding & & \\
\hline & $\begin{array}{l}\text { common functional } \\
\text { specification }\end{array}$ & & \\
\hline & code of practice & & \\
\hline & $\begin{array}{l}\text { identified need for } \\
\text { requlatory change }\end{array}$ & & \\
\hline \multirow[t]{3}{*}{$\begin{array}{l}\text { Knowledge and } \\
\text { skills }\end{array}$} & management \& organisation & \multirow[t]{3}{*}{ no } & \multirow[t]{3}{*}{$\mathrm{v}$} \\
\hline & technical & & \\
\hline & training activities & & \\
\hline \multirow[t]{4}{*}{ Dissemination } & $\begin{array}{l}\text { technology transfer } \\
\text { activities }\end{array}$ & \multirow[t]{2}{*}{ yes if lead to sales } & \multirow[t]{2}{*}{1} \\
\hline & knowledge \& skills transfer & & \\
\hline & publication/documentation & \multirow[t]{2}{*}{ no } & \multirow[t]{2}{*}{ III } \\
\hline & $\begin{array}{l}\text { workshops/seminars/ } \\
\text { conferences }\end{array}$ & & \\
\hline \multicolumn{4}{|l|}{ (*): } \\
\hline 1: & \multicolumn{3}{|c|}{ already evaluated or could be easily derived from the eve } \\
\hline II: & \multirow{2}{*}{\multicolumn{3}{|c|}{ could be used to caracterize an evaluated effect }} \\
\hline III : & & & \\
\hline IV: & \multirow{2}{*}{\multicolumn{3}{|c|}{$\begin{array}{l}\text { could be evaluated to the extent that it affects the interviewed parties } \\
\text { not relevant }\end{array}$}} \\
\hline$v:$ & & & \\
\hline
\end{tabular}

IMPACTS

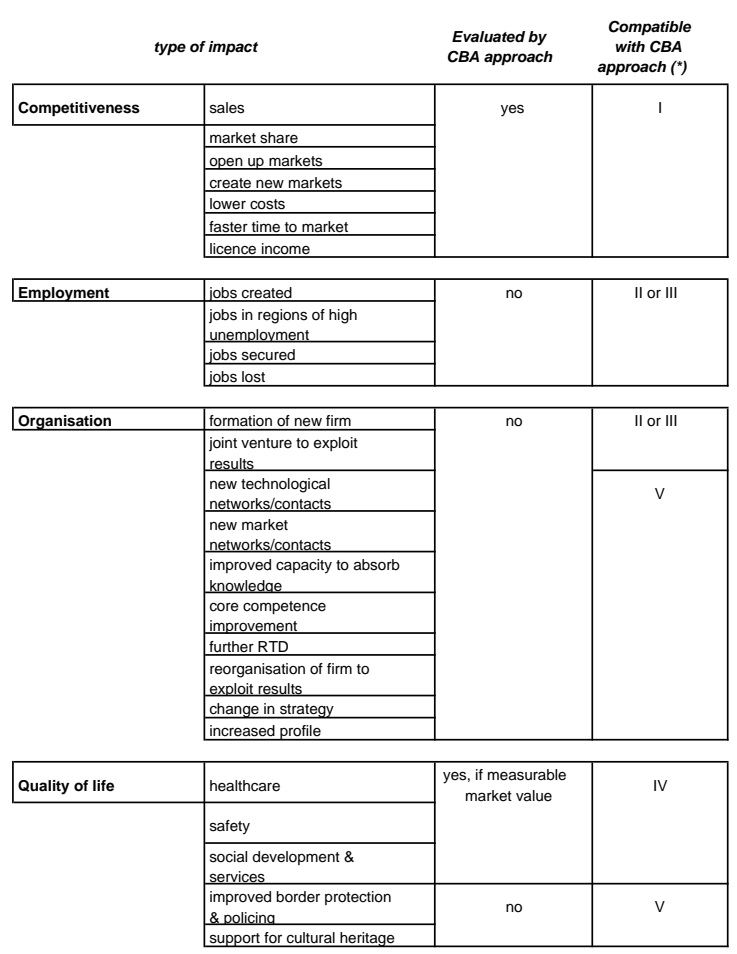

\begin{tabular}{|c|c|c|c|}
\hline \multirow{5}{*}{\begin{tabular}{|l}
$\begin{array}{l}\text { Control \& care of } \\
\text { the } \\
\text { environment }\end{array}$ \\
\end{tabular}} & reduced pollution & \multirow[t]{4}{*}{$\begin{array}{l}\text { yes, if measurable } \\
\text { market value }\end{array}$} & \multirow[t]{4}{*}{ IV } \\
\hline & $\begin{array}{l}\text { improved information on } \\
\text { pollution \& hazards }\end{array}$ & & \\
\hline & reduced raw material use & & \\
\hline & reduced energy consumption & & \\
\hline & $\begin{array}{l}\begin{array}{l}\text { positive impact upon global } \\
\text { climate }\end{array} \\
\end{array}$ & no & v \\
\hline \multirow[t]{3}{*}{ Cohesion } & decrease in pollutants & \multirow{2}{*}{$\begin{array}{l}\text { yes, if measurable } \\
\text { market value }\end{array}$} & \multirow[t]{2}{*}{ IV } \\
\hline & \begin{tabular}{|l|l|} 
employment in LFRs \\
infrastructure of LFRs \\
\end{tabular} & & \\
\hline & \begin{tabular}{|l|} 
participation of LFRs \\
further RTD in LFRs \\
requlation and policy in LFRs \\
\end{tabular} & no & $\mathrm{v}$ \\
\hline \multirow[t]{2}{*}{\begin{tabular}{|l}
$\begin{array}{l}\text { Development of } \\
\text { infrastructure }\end{array}$ \\
\end{tabular}} & transport & \multirow[t]{2}{*}{$\begin{array}{l}\text { yes, if measurable } \\
\text { market value }\end{array}$} & \multirow[t]{2}{*}{ IV } \\
\hline & telecommunications & & \\
\hline
\end{tabular}

\begin{tabular}{|c|c|c|c|}
\hline \multirow[t]{2}{*}{$\begin{array}{l}\text { Production \& } \\
\text { rational use of } \\
\text { energy }\end{array}$} & \begin{tabular}{|l|} 
urban development \\
rural development \\
renewable sources \\
\end{tabular} & no & $\mathrm{v}$ \\
\hline & energy savings & $\begin{array}{c}\text { yes, if measurable } \\
\text { market value }\end{array}$ & IV \\
\hline \multirow[t]{3}{*}{\begin{tabular}{|l} 
Industrial \\
development
\end{tabular}} & nuclear safety & \multirow[t]{3}{*}{ no } & \multirow[t]{3}{*}{$\mathrm{v}$} \\
\hline & assurance of future supply & & \\
\hline & distribution of energy & & \\
\hline \multirow[t]{8}{*}{ Regulation \& policy } & development of SME sector & \multirow[t]{7}{*}{ no } & \multirow[t]{7}{*}{$\mathrm{v}$} \\
\hline & \begin{tabular}{|l|} 
development of large \\
organisations
\end{tabular} & & \\
\hline & support for trade & & \\
\hline & EU regulations or policy & & \\
\hline & national regulations or policy & & \\
\hline & $\begin{array}{l}\text { world-wide regulations or } \\
\text { policy }\end{array}$ & & \\
\hline & $\begin{array}{l}\text { co-ordination between } \\
\text { national \& Community RTD } \\
\text { programmes }\end{array}$ & & \\
\hline & $\begin{array}{l}\text { development of internal } \\
\text { market }\end{array}$ & $\begin{array}{l}\text { yes, if measurable } \\
\text { market value }\end{array}$ & IV \\
\hline
\end{tabular}

CBA approach and output/impact list 


\section{OUTPUTS}

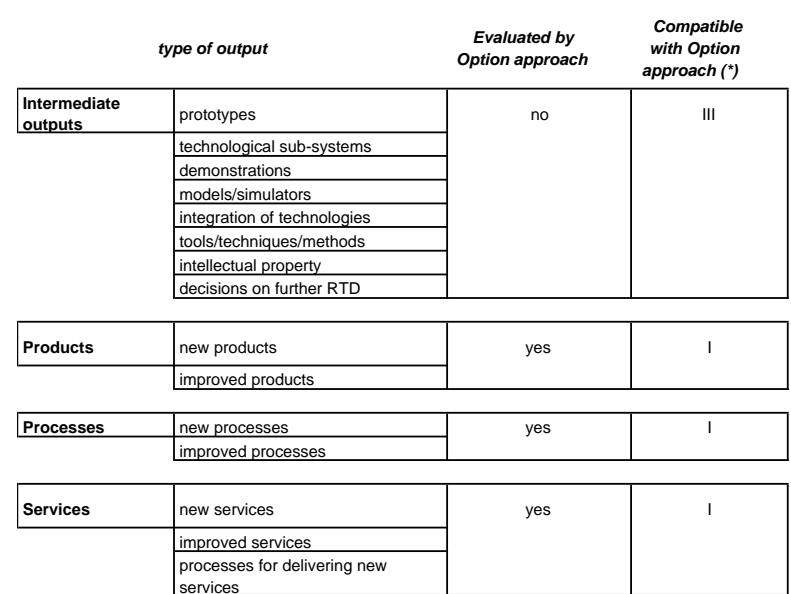

\begin{tabular}{|c|c|c|c|}
\hline Standards & de facto standard & \multirow[t]{8}{*}{ no } & \multirow[t]{8}{*}{$\mathrm{v}$} \\
\hline & de jure standard & & \\
\hline & reference & & \\
\hline & conformance & & \\
\hline & memoranda of understanding & & \\
\hline & common functional specification & & \\
\hline & code of practice & & \\
\hline & $\begin{array}{l}\text { identified need for regulatory } \\
\text { change }\end{array}$ & & \\
\hline \multirow[t]{3}{*}{$\begin{array}{l}\text { Knowledge and } \\
\text { skills }\end{array}$} & management \& organisation & \multirow[t]{3}{*}{$\begin{array}{l}\text { yes, if lead to option } \\
\text { creation }\end{array}$} & \multirow[t]{3}{*}{ I } \\
\hline & technical & & \\
\hline & training activities & & \\
\hline
\end{tabular}

\begin{tabular}{|l|l|c|c|}
\hline Dissemination & technology transfer activities & $\begin{array}{c}\text { yes if lead to } \\
\text { forecasted sales }\end{array}$ & I \\
\hline & $\begin{array}{c}\text { knowledge \& skills transfer } \\
\text { publication/documentation }\end{array}$ & no & $\mathrm{V}$ \\
\cline { 2 - 2 } & $\begin{array}{l}\text { workshops/seminars/ } \\
\text { conferences }\end{array}$ & & \\
\hline
\end{tabular}

(*):

II: could be used to caracterize an evaluated effect

II: could be used to caracterize an evaluated effect

III : could be collected with very little additional effort

$V$ : not relevan

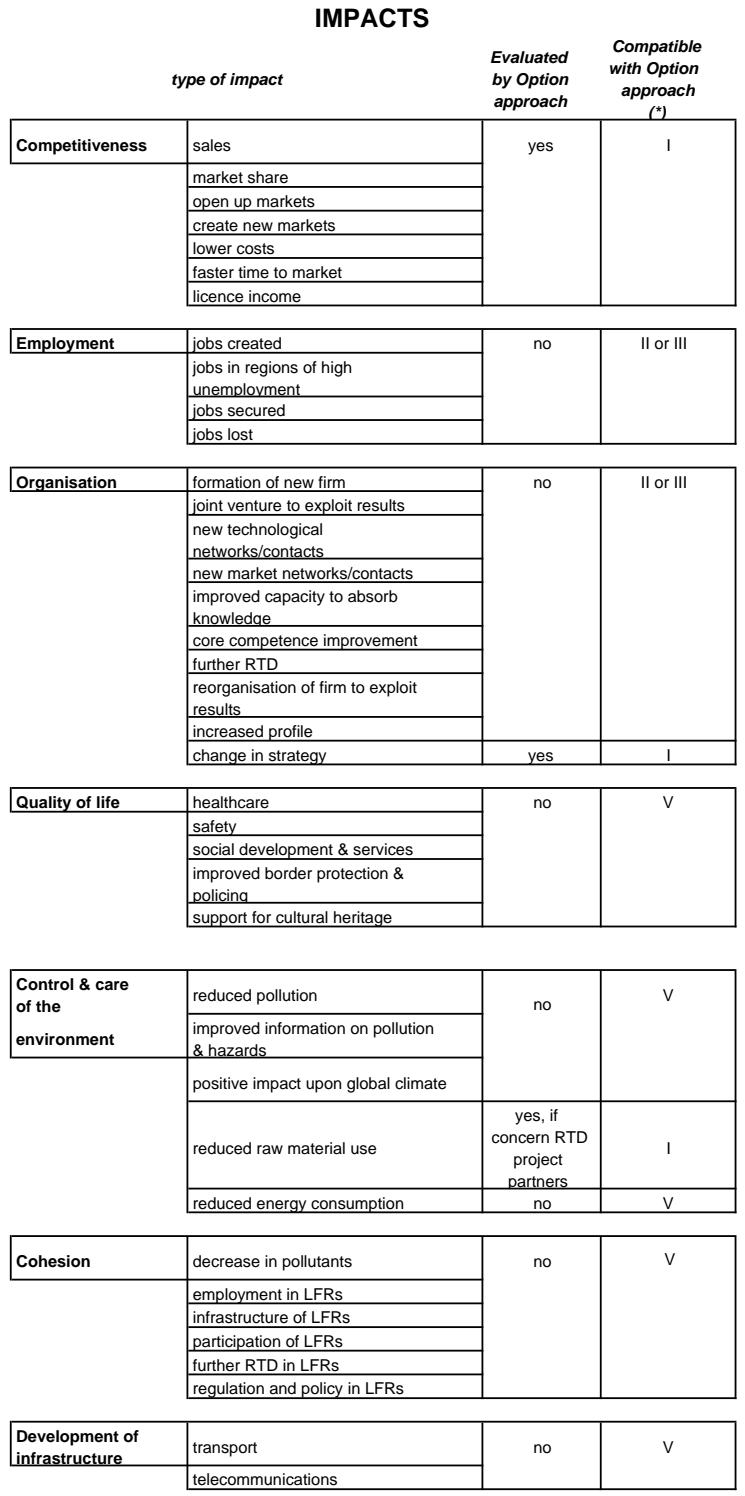

\begin{tabular}{|c|c|c|c|}
\hline \multirow{4}{*}{$\begin{array}{l}\text { Production \& } \\
\text { rational use of } \\
\text { energy }\end{array}$} & urban development & \multirow[t]{3}{*}{ no } & \multirow[t]{3}{*}{$\mathrm{v}$} \\
\hline & rural development & & \\
\hline & renewable sources & & \\
\hline & energy savings & $\begin{array}{c}\text { yes, if } \\
\text { concern RTD } \\
\text { project } \\
\text { partners }\end{array}$ & I \\
\hline \multirow[t]{3}{*}{$\begin{array}{l}\text { Industrial } \\
\text { development }\end{array}$} & nuclear safety & \multirow[t]{3}{*}{ no } & \multirow[t]{3}{*}{$\mathrm{v}$} \\
\hline & assurance of future supply & & \\
\hline & distribution of energy & & \\
\hline \multirow[t]{8}{*}{$\begin{array}{l}\text { Regulation \& } \\
\text { policy }\end{array}$} & development of SME sector & \multirow[t]{8}{*}{ no } & \multirow[t]{8}{*}{$\mathrm{v}$} \\
\hline & development of large organisations & & \\
\hline & support for trade & & \\
\hline & EU regulations or policy & & \\
\hline & national regulations or policy & & \\
\hline & world-wide regulations or policy & & \\
\hline & $\begin{array}{l}\text { co-ordination between national \& } \\
\text { Community RTD programmes }\end{array}$ & & \\
\hline & development of internal market & & \\
\hline
\end{tabular}

Option approach and output/impact list 
Using another distinction proposed in a previous part of the present ASIF report, the three methods covers the following classes of the Effect Dimension of a typical EU's Framework Programme :

Lastly, also referring to an analytical framework put forward earlier in the present

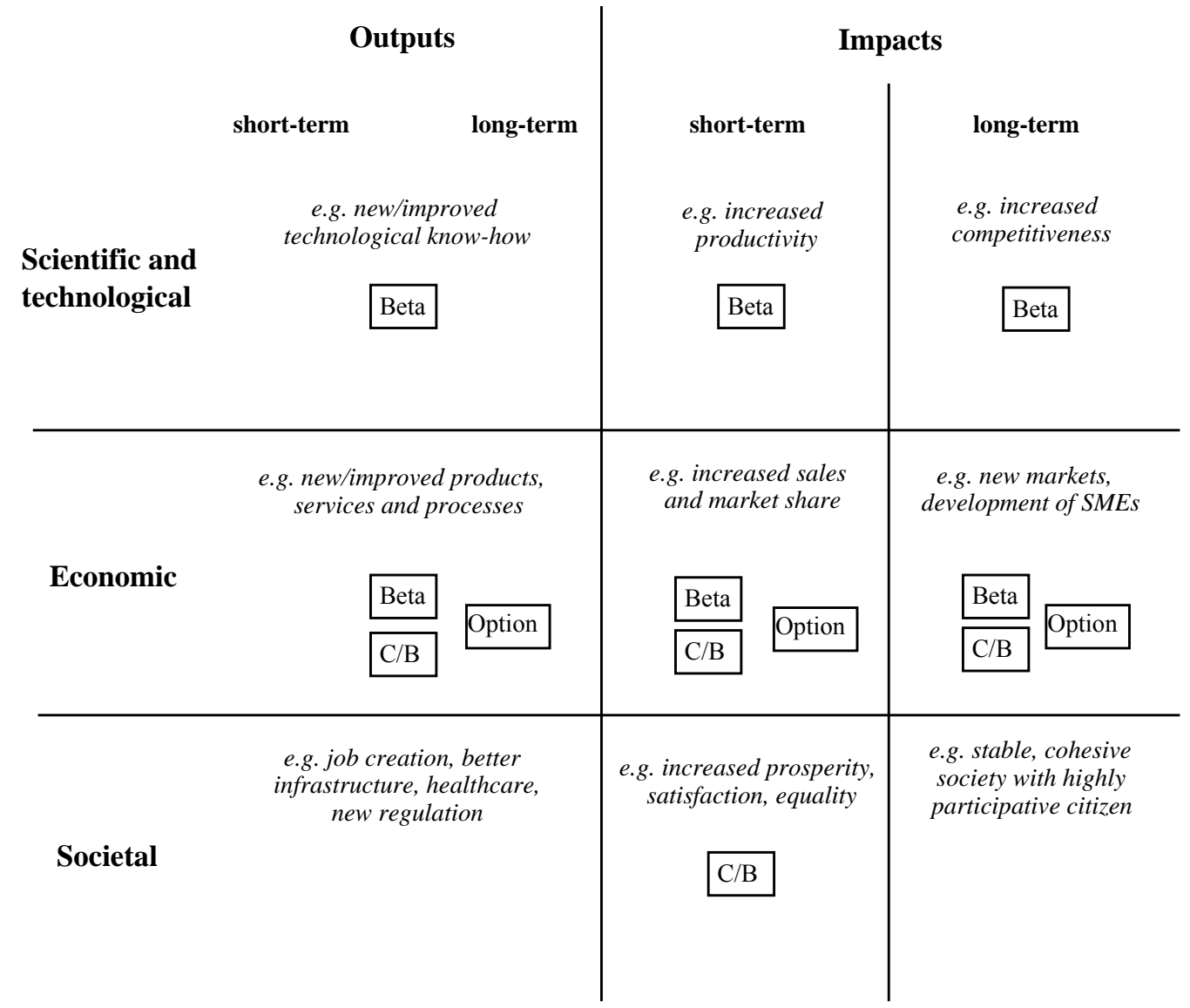

ASIF report, the Cost/Benefit and the Beta approaches can be included in "Solid Impact" family of methodology, while the Option approach would be included in the "Soft Impact" (sub-class "Potential Impact" - ex ante strategic evaluation).

\section{The presence of indirect effects}

In this part, we call "indirect effects" such effects that do not consist in the completion of the RTD projects objectives (as they were expected at the beginning of the project and described in the proposal accepted by the public funding organisation).

\section{BETA}

Let us briefly remind that the originality of the BETA method is to collect information mainly concerning the different learning processes, i.e. the indirect effects which occur in a company due to its participation to a publicly funded project. We suppose that the company may acquire new knowledge and use it to develop new technologies, new networks of external partners and new ways of organising activities. Moreover, we suppose that the knowledge acquired constitutes an "inexhaustible stock" for the company, which we assimilate to the critical mass effect. This knowledge is by 
definition non-rival and it takes time to construct it: it can be used in different activities at different time period; and at last may become obsolete (its value for the company diminishes with respect to time but not with respect to its use). In other words, the quantified technological, networking and organisation effects correspond to the use of the acquired knowledge and the critical mass effect correspond to all the possible uses, effects, options. We will come back to this point when discussing the notion of option.

\section{Option-pricing approach}

The real option-pricing method tries to account ex ante for the value of uncertain investment projects, in our case of R\&D or innovation projects. Valuing such projects means that all the different kind of benefits should be taken into account and especially "intangible strategic benefits that may lead to competitive advantage. The options approach is an attempt to capture these benefits in the valuation analysis. It is imperative that one accounts for all options in order to attain the best estimation value." (Vonortas, Lackey p.5)

One of the problem thus concerns the definition of the different results generated by the options taken into account in the analysis. In other words, does the valuation analysis consider both the direct results or effects of the project (those which meet the objectives) and the indirect results (i.e. the learning side-effects) ? According to Vonortas and Lackey, all the different kind of benefits should be integrated in the valuation exercise : tangible, intangible, direct, indirect, long term, short term, etc.

Theoretically if we agree with this position, to evaluate each option we should take into account the following results and thus the following variables (we suppose that the first sequence of the decision tree takes into account the alternatives "doing the project with public funds" and "doing the project with own resources" $\mathrm{cf}$. the notion of option) :

(i) For the publicly funded project option :

$\mathrm{P}_{\mathrm{PF}}=$ probability of occurrence of the different effects

$\mathrm{D}_{\mathrm{PF}}=$ Direct effects of the publicly funded project

$\mathrm{I}_{\mathrm{PF}}^{\mathrm{E}}=$ Expected indirect effects generated by the publicly funded project

$\mathrm{I}_{\mathrm{PF}}^{\mathrm{NE}}=$ Non-Expected indirect effects generated by the publicly funded project

(ii) For the internal funded project option :

$\mathrm{P}_{\mathrm{IF}}=$ probability of occurrence of the different effects

$\mathrm{D}_{\mathrm{IF}}=$ Direct effects of the internal funded project

$\mathrm{I}_{\mathrm{IF}}^{\mathrm{E}}=$ Expected indirect effects generated by the internal funded project

$\mathrm{I}_{\mathrm{IF}}^{\mathrm{NE}}=$ Non-Expected indirect effects generated by the internal funded project

We suppose that the interviewed managers will be able to distinguish between two different kind of indirect effects, the expected ones and the non expected ones. This means that by experience managers know that in their company some categories of projects generate, besides direct effects, a certain amount of indirect learning effects which can be forseen at the beginning of the research and a certain amount which cannot be foreseen. For instance, if the project deals with the development of a new material, the manager will expect to reach the goal, to use the new acquired 
knowledge in other activities of the company and to expect other technological transfers not foreseeable at the period of evaluation. Practically, to complete such an exercise managers should refer to 'twin' projects.

But it has to be stressed that up to now there has not been any study that had attempted to extend in such way the option approach to the indirect effects.

\section{CBA}

This ex post analysis does in theory not consider the indirect effects. It only evaluates the impacts of the result which was expected in the objective of the project, i.e. the direct effects. This is more due to the focus of the approach then to the technical impossibility to evaluate indirect effects. In other words, if an evaluator first collect information about the existence of indirect effects inside a company, it becomes possible to apply the CBA. The latter will thus evaluate the impact of that indirect result on all the agents (consumers, competitors, suppliers, etc.) affected by this effect via market relations.

\section{Option-pricing approach}

Applying the option approach to a publicly financed $R \& D$ project in a company means conducting an evaluation ex ante and accounting for all the different possible options. This approach refers to a two-step sequences of investment choice : R\&D decision followed by commercial investment. This exercise should help the company and/or the policy maker to value the different options before taking a decision. The main problems of this approach is to define the different options, to specify and to account for the different results generated these options (cf. indirect effects 1.1.2), to assess different parameters necessary to compute the value of the options (cf. protocol).

Concerning the first sequence of the decision tree or the binomial approach, it seems to be important to take into account three alternatives :

- the company will conduct the $\mathrm{R} \& \mathrm{D}$ project by participating to a public programme and by benefiting from public funds ;

- the company will decide to do the project on its own resources ;

- the company will abandon the idea of the project.

The three alternatives will allow the company to take a more accurate decision than just "do the publicly funded project or not". This has also an implication in terms of additionality which will be discussed later.

\section{$\underline{\text { BETA }}$}

The BETA method may be considered as a complement to the option-pricing approach in terms of evaluation of options. The former consists in an ex post evaluation exercise and tries to capture all the effects (direct, indirect, tangible, intangible etc) generated by a publicly funded project.

The BETA method is generally applied after the company has completed the R\&D step and may be after the commercial investment step. This means that the information collected ex post may help to verify and to modify the different branches 
of the tree established ex post (in a DTA) or the forecated value of the gain (in BlackScholes). Compared to a DTA, it means more precisely that the BETA method would allow :

- to specify the different terminal nodes and to compare them with the expectations, i.e. the direct effects and the expected indirect ones expressed in terms of sales and cost savings ; it allows also to specify new probabilities if some of the expectations are not realised when the evaluation exercise takes place.

- to add new terminal nodes which mainly correspond to non-expected indirect effects also expressed in terms of sales and cost savings

- to complement the initial tree with new trees representing new options created by the project and which could not be forecasted ex ante. The BETA method captures these new options in some of the indirect effects which are not measured in terms of sales and cost savings. These indirect effects (quantified or not) are the following : (i) the signature of a new research contract ( open up of new research avenues and options) may be seen as the payment by the interested third party of this new options ; (ii) the price of keeping non-exploited patents may be seen as the purchase of a new option; (iii) the creation of a new network (not quantified but identified during interviews) may be seen as the possibilities to generate new commercial or research options ; (iv) the same may be true when the company establishes a new organisation; (v) finally, the critical mass effect which is measured by a proxy (salary concerning the time spent on the publicly project to acquire the new knowledge) may be seen as the reduction of price to acquire the realised and/or future options. In other words, the price paid $\left(\mathrm{P}_{1}\right)$ to acquire a new option generated by the new knowledge base is lower than the price the company would have had to pay $\left(\mathrm{P}_{2}\right)$ if this knowledge base would not have been constructed. Subsequently, the value attributed to the critical mass corresponds to the sum of the differences between the price which should have been paid without the critical mass and the effective price of the options that can be open up with this new non-rival knowledge : $\sum\left(\mathrm{P}_{2}-\mathrm{P}_{1}\right)$. Some of these options have been realised via measured indirect effects and the others remain potentialities at the time of the evaluation exercise.

\section{Cost-Benefit Analysis}

The Cost-Benefit Analysis is also an ex post study, which means that as the BETA methodology, it allows to verify the realisation of some options and in particular the realisation of the objectives of the project (i.e. mainly the direct effects and not the indirect ones cf. 1.1.2). The CBA is be able to quantify the economic impact on all the actors present in the value chain of the product sold on a market or the process used in a production company. But CBA does not analyse the creation of new options due to the results of the public funded project.

\section{Two levels of evaluation}

We may consider that the evaluation of impact can be conducted according to two dimensions : 
- one dimension concerns in some way a vertical "aggregation" of a policy. For instance the European R\&D policy is formalised by the Framework Programme which implements different kind of programmes and each of these programmes is organised around collaborative projects done by organisations (firms, public research centers, universities). The key question is then : are the socio-economic effects of policy (respectively programme, project) the simple sum of the effects of programme (respectively project, single participant's activity)?

- a second dimension concerns the impact of these above-mentionned elements of the policy respectively on the participants, on a sub-set of the society corresponding to a meso-economic level (for instance consumers, competitors, suppliers of the participants, or networks including the participants) and on a macroeconomic level, which means the society as a whole. As for this second dimension, the key question is : are the impact at the society or macro-level the result of something that was firstly generated at single participants levels and which had affected the higher levels through spreading, diffusion, copy, interactions and s.o. phenomenon?

These two dimensions may be represented in the following way. The different approaches are also located on this sketch, given that :

- one can reasonably assume an aggregation property form participant up to programme level

- CBA is th only one of the three which proposed a framework that enables to consider a diffusion from participant to society level.

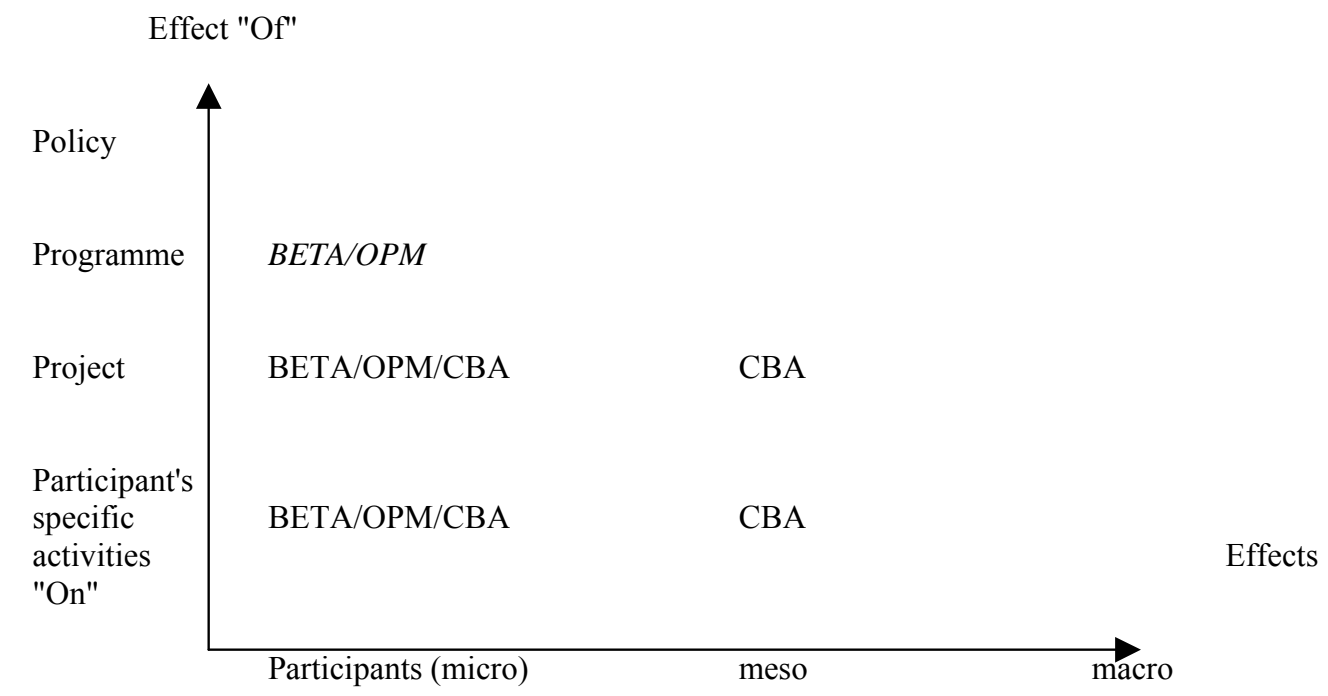

Option-pricing method vs BETA

These evaluation studies cover only the partners of a programme. This means that they take into account the impact of the public funded R\&D activity on the participants. The effects of the project level correspond to the sum of the effects measured at the partners' level. The effects of a programme on the partners can be derived by statistical (representative sample) extrapolation of the projects level. But these kind of analysis have to be done with a lot of caution. The policy level is much more difficult to assess and these studies may only provide qualitative remarks. In 
summary, these methods reveal information about the effects on the participants of the R\&D activity at the firm level, of the project and of the programme. They provide no analysis concerning the diffusion of these results in the rest of the economy (meso and macro levels) but only about the way participating companies have evolved. Their analysis is in some sense focused and partial.

\section{$\underline{\mathrm{CBA}}$}

This approach covers the participants, their clients but can also be extended to their suppliers and competitors and other actors affected by the R\&D result through (but only through) market mechanisms.

It takes into account the economic impacts of the R\&D activity at firm level and of the project (sum of the effects measured at partners' level) on all the agents which are in the value chain of the new technology (customers, competitors, suppliers). CBA thus encompasses the diffusion of the innovation in the economy, but the analysis remains a "partial equilibrium" one. It takes into account only one market (or a few markets in the case of the project) and does not consider the effects on the other sectors of the economy.

\section{Time horizon}

\section{Option-pricing method}

This evaluation takes place ex ante, which means that a large part of the collected data are forecasted by the interviewed managers. The comparison with 'twin' projects is important in this kind of exercise. The time horizon will depend on the ability of the manager to forecast.

\section{BETA/CBA}

These two methods are mainly ex post evaluations. They also take into account an ex ante part, in the sense that they may ask the respondants to forecast what will happen during the next two years after the evaluation exercise has taken place. At what period is it then suitable to conduct the evaluation? The answer to that question could differ between the two methods.

As the Beta approach analyses both direct and indirect effects (i.e. learning processes inside the participant), it faces a tradeoff between the time length necessary to the result to appear and the memory of the interviewed person being able to remember the different results and their impacts. Generally, the BETA conducts evaluation from the end of the projects up to 2 to 3 years after the end of the project.

The CBA evaluates mostly direct effects and their diffusion at a meso-economic level. The time length criteria seems to be more important in this approach as diffusion takes time. In other words, CBA could be conducted later then the BETA one.

\section{General evaluation questions}

\section{Additionality}

\section{Option-pricing method}

The kind of additionality (at the firm and project level cf. above) which can be considered by the approach depends very much on the type of options which are taken into account in the first step of the tree. 
If the first sequence of the tree specifies three alternatives then both input additionality (investing or not in R\&D) and behavioural additionality may be analysed. The latter implies that public funds often allow to realise more ambitious $\mathrm{R} \& \mathrm{D}$ projects, with different kind of partners, to reach valuable results in a quicker time, etc. Considering only two options (realising or not the project) would only take into account input additionality.

\section{$\underline{\text { BETA }}$}

Among the different dimension of additionality (input, ouput and behavioural), the BETA method is able to evaluate ouput and behavioural additionality and is not much concerned with the input dimension. Moreover, the method could also analyse a new possible dimension of additionality related to the cognitive capacity of the firms. The idea is to analyse if the State intervention has increased the learning ability of firms in a significant way.

The BETA approach takes as an alternative scenario the "absence of evaluated project" (or "null hypothesis") into account. Some methodological improvements either on the definition of an alternative reference scenario or by including some control organisations (to be defined) could be made to better answer this additionality problem.

\section{$\underline{\mathrm{CBA}}$}

CBA considers both the input and ouput additionality through the computation of the private rate of return and its comparison on the one hand with the private rate usually required by invetsors and on the other with the public rate of return.

\section{Multiple Projects}

The idea is to analyse how the presence of a portfolio of publicly funded projects can be considered by each methodology.

\section{Option-pricing method}

The method usually computes the different components of the investment associated with the decision to enter the evaluated research project. The components are funded by different sources among which are publicly dunded projects. Consequently, it becomes possible to compare these different investment components in relation with a given research project, as well as to compare different research projects form this standpoint. and managements costs between different types of projects.

The OPM would probably assess the portfolio of publicly funded projects as a whole and analyse the value of the company as an entity. The idea would be to compare the value of the company with the publicly funded projects with the value of the company without these projects (which leads us back to the question of the additionality). But the key point is that the relative importance of the different porjects is only reflected by their corresponding monetary value. 


\section{BETA}

It does not take into account the different costs of investment. But as far as management and organisational aspects of a project are concerned, the method quantifies the cost reduction due to learning effects on these dimensions (cf. organisation and method effects).

This method would evaluate each project separately and provide qualitative analysis able to compare the different projects and their influence on the evolution of the company. With the coefficient of influence, the BETA would be able to separate the impact of each project on the added value of the company.

\section{$\underline{\mathrm{CBA}}$}

This method also computes the different costs generated by an investment decision. The possibility to compare the different access and managements costs between different types of projects is the same as with the OPM.

This method would evaluate each project separately but consider only the direct effects. The problem would probably be to consider in an appropriate way the separability question : is the evaluated effect the result of a specific project or of a group of interdependent ones? It is not clear if the analysis concerns the results (sales on a market) or the portfolio of the projects which gave rise to the different effects.

\section{Adaptation to constraints}

The point discussed here relates to the ability of an approach to analyse the impact of the RTD programme on the evolution of the company and on its adaptative capacity to external constraints and changes (competition, demand, technology, regulation, etc).

\section{Option-pricing Method}

The answer is twofold. On the one hand, this approach considers in general only the direct effects of the programme and does consequently not take into account the learning ability of the company. If the decision tree incorporates both the direct and indirect effects, then the OPM would integrate an adaptation ability via the learning effects. On the other hand, the OPM takes explicitely into account the strategic decision that firm can make as regards further investment after the RTD project. To this respect, the analysis could be enriched by encompassing some sources of information (others than the RTD project itself) that firm could gather because of its participation to the public programme funding the RTD project. This point is closely related to the question of behavioural additionality : in the decision-tree, the branch "RTD project with public support" could then be very different from the "RTD project alone" one.

\section{BETA}

It is by definition an evolutionary approach which considers as very important the knowledge base of the firm and its ability to use it for adaptation purposes. The network effects, the organisation and methods effects are at stake here, and most of all the critical mass effect which is certainly one of the most important element concerning that adaptation question. As we mentioned it before, the critical mass corresponds to all the possible uses of the new acquired knowledge. 


\section{CBA}

CBA does not take into account any adaptation ability ; it just measures the result of a project and not the new potentialities emerging from new created knowledge. However, to the extent that the firm's income is increased thanks to the RTD project, it can be assumed that this supplementary income can be used for future adaptation of the firm to its environment.

\section{$\underline{\text { Fictitous case study }}$}

Examples assembled here in the form of the case study of firm XX are fictitious, but are largely based on real cases analyzed by the Beta team in previous studies, and which have been modified and combined for the purpose of the present study. Real cases were not directly used in order to keep the confidentiality of the information gathered at firm level, and because, according to Beta experience, there is almost no single firm's case that can show the whole range of effects potentially generated by a $R \& D$ project (referring to the Beta typology of effects, over 350 participants to BriteEuram and Esprit programmes covered by the Beta team between 1993 and 1997, only a few participants had experienced direct effect and at least one of each of the four types of indirect effects, and only some of them exhibit a so large variety of effects). The three methods will be used for the identification and the assessment of the same cases, and some references will be made as far as possible to the typology of output/impact.

\section{Description}

$\mathrm{XX}$ is a firm designing and building precision machine-tools and scientific instrumentation, and offering a range of service in this domain (scientific expertise and evaluation, maintenance, calibration, etc). It was involved as prime contractor in a three years Brite-Euram project called ACPP, aiming at studying the possibility of an automatization of the polishing processes, and potentially resulting in the design of the specifications of a robot for automatic polishing. The ACPP project was conducted together with one research center specialized in automatic control and mechanics, one research center specialized in electronics and artificial intelligence, one university lab specialized in optics, and one firm producing lenses for scientific applications. XX has never cooperated with any of these partners before ACPP. XX received $\propto 300000$ from the EU for this project, and the total cost of the project (full cost) was a 1 million.

The project was almost a hundred percent successful : the possibility of a full automatization of the polishing process appeared to be limited as compared to the very first objectives of the ACPP project, and eventually it only concerned a reduced class of lenses with typical bends. One year after the end of the project, a prototype of a robot ("POL Robot") was built and satisfactorily tested. Two years after the project, four POL Robot were sold and ten others were ordered by industrial companies. As prime, XX was marketing and selling the POL Robot, with royalties to be paid to the different ACPP project partners, some of these offering some complementary services to the customers. 
During the ACPP project, the partners decided to launch another research project dedicated to the automatization of the polishing correction alone, but for a larger class of lenses and optics. Some national support as well as an Esprit funding were successfully asked by the same partners.

The research made about the polishing techniques greatly improved the knowledge base of XX in this field, in particular concerning the shapes of polishing tools given the properties of the materials (density, chemical composition, etc) to be polished and the conditions in which the polishing is to be made (temperature, humidity, etc). From this XX was able to define an optimal shape of tools for certain classes of polishing operations and for different materials (not only optics) resulting in an increase in the life time of the tool, a better quality of polishing and with less correction work required. These newly designed polishing tools later equipped some of the machines that $\mathrm{XX}$ sold on specific markets, giving $\mathrm{XX}$ a clear competitive advantage over its competitors.

One technical problem to be solved was to evacuate the microscopic dust created by the polishing operation which could cause very small defaults. XX developped a specific technology for this purpose, with a small device electronically coupled with the constant repositionning of the polishing tool, in order to adapt to the changing speed and direction of dust generation. Later on, the knowledge on which this device was based was transferred to another department of XX specialized in DIY handtools, and it was adapted to help the development of a simplified device added to some of the products of a new line of high price environmental-friendly specialized hand-tools.

XX also had the opportunity to sell some scientific instruments to a consortium of university labs which was currently collaborating with the university lab that was partner of the ACPP project.

Three XX staff members were really involved in the ACPP project : Mr A. (the project manager), one specialist in the field of optics, and one specialist in the field of electro-mechanics who subsequently left the company. The project manager was halftime involved and the specialists were full-time. It was the first experience of $\mathrm{Mr} \mathrm{A}$. as project manager, and it was the first time that $\mathrm{XX}$ was prime on an European project of such scope. Therefore, project management capability has really increased at individual as well as at firm level, consisting in a mix of formal procedures (workplan, resources allocation, monitoring and control, reporting etc) and more informal knowledge (organisation and monitoring of meetings, IPR negociation, problem solving, etc in a multi-cultural context). Two years after the beginning of the ACPP project, XX successfully apply for another Brite-Euram project in the field of materials cheracterization for different cutting and milling tools (N2MT project for New Materials for Manufacturing Tools). One year later, XX also start a Eureka project related to A.I. applied to the control of speed of polishing operations for complex shape of industrial parts. 


\section{Identification and quantification of effects}

\section{BETA approach}

The Beta approach typically consists of a half-day interview of the ACPP project manager, of the technical manager of XX and of a manager from the marketing side. It is made three years after the ACPP project completion.

Quantification is performed on the basis of the quantification models detailed in the annex; according to the cases of effect, some simplifications can usually be made (especially as regards the estimation of the Q1 and Q2 coefficients) ${ }^{41}$.

\section{Direct effect : sales of POL Robot}

the output is a new product, the impact is related to competitiveness and is expressed in added value generated by $X X$

data required :

number of unit : 14

unit price : $: 300000$

rate of added value : $25 \%$ (including the 10\% royalties payed to ACPP partners)

Direct effect : $14 \times$ a $300000 \times 0,25=\propto 1050000$

\section{Indirect effect 1 : new design of polishing tool (Technological effect/product)}

the output is related to knowledge \& skills-technical (knowledge about the shape of polishing tools), the impact is related to competitiveness and expressed in added value generated by $X X$

data required :

number of unit : number of machine-tools sold and that were equipped with new polishing tool : 45

unit price : 0160000 in average

rate of added value : $35 \%$

Q1 coefficient : XX machine-tools are mainly sold because of their technological superiority over the competitors; it is assumed by the interviewees that this factor accounts for at least three-quarter of the sales. The other main factor of success is the ability of XX to provide rapid and efficient after-sales services, based on a very flexible and reactive internal organization.

Q2 : the only influence from ACPP project is on the technological side. But the newly designed tool is only one small part of the machines sold. It accounts for $5 \%$ of its value, and its development cost (including the adaptation of the ACPP derived knowledge) roughly accounts for $10 \%$ of the total development cost of the machine-tools. Another important input was the knowledge on material used for the tools, which partly came from the N2MT Brite-Euram project. Although this new tool, and especially its original shape, is significantly superior to what the competitors may offer and can be considered as providing a real competitive leverage for XX. Therefore it is acknowledged that the ACPP related knowledge has a significant

\footnotetext{
${ }^{41}$ Let us remind that the Q1 coefficients account for the influence of different assets (technological, networking/commercial and procedural competencies etc) on sales or cost reductions, while the Q2 coefficients account for the specific influence of the evaluated project on each of these assets
} 
impact on the technological level of this specific line of XX machine tools, which can be reasonably accounted as ranking from 20 to $30 \%$.

Indirect effect $1: 45 \times 0160000 \times 0,35 \times 0,75 \times 0,2=0378000$.

\section{Indirect effect 2 : DIY hand-tools (Technological effect / product)}

the output is related to knowledge \& skills-technical (knowledge about dust control and storage), the impact is related to competitiveness and expressed in added value generated by $X X$

\section{data required :}

number of unit : 8000

unit price : 0380

rate of added value : $40 \%$

Q1 coefficient : XX hand-tools are sold because of their technological superiority over the competitors, but also because of the very good distribution networks and marketing/promotion strategy set up by XX in very specialized DIY hand-tools, both factor being estimated as having a balanced influence on sales.

Q2 : the only influence from ACPP project is on a technological side. It is difficult to estimate the influence of the very original specific device firstly designed for the ACPP project, but it has some since it is part of the technological solutions adopted by XX to reduce the residual materials which are by-products of DIY activities and that can at large scale cause some damage on health and environment (fiber glass, ceramics, concrete, metals, etc). XX was previously involved in a national programme aiming at developing solutions for filtration, clean storage and treatment of those residuals. XX developed knowledge about the properties of such materials and it was coupled with the ACPP derived knowledge. All in all, 10\% could be an indicator of the specific influence of the ACPP project on the technical feature of the hand-tools.

Indirect effect $2: 8000 \times 0380 \times 0,4 \times 0,5 \times 0,1=060800$

Indirect effect 3 : new sales of scientific instrumentation (Commercial effect/network)

the output is a knowledge about the competitive environment (commercial connection), the impact is related to competitiveness and expressed in added value generated by $X X$

data required :

number of unit : 4

unit price : 085000

rate of added value : $40 \%$

Q1 and Q2 : this sale could not have been made without the ACPP project, since these potenital clients were unknown before this project. Therefore, $100 \%$ of the sales are attributed to the ACPP project. 
Indirect effect $3: 4 \times$ x $85000 \times 0,4 \times 1=\not 136000$

\section{Indirect effect 4 and 5 : New National/Esprit projects (Technological effect/product combined with a commercial effect/network)}

the output is related to knowledge \& skills (both a technical knowledge and a "know-who" type of knowledge), the impact is related to competitiveness and expressed in added value generated by $X X$

data required : together.

one national project + one Esprit project, for which XX received 0200000

rate of added value : $100 \%$ (research money)

Q1 : two factors explained the fact that XX got those two new research contracts : its technological knowledge $(50 \%)$ and its belonging to a good group of partners $(50 \%)$

Q2 : it is assumed that in the specific field investigated by these two new research project, at least half of the previous technological knowledge of XX had been developed under the ACPP project; without the ACPP project, XX would not have been in position to candidate with these partners

Indirect effect 4 (commercial/network) : $: 200000 \times 1 \times 0,5 \times 1=0100000$

Indirect effect 5 (technological/product) : $\propto 200000 \times 1 \times 0,5 \times 0,5=\propto 50000$

Indirect effect 6 : enhancement of project management capability (Organisation and Method effect/project management)

the output is related to knowledge \& skills-management and organisation, the impact is related to competitiveness and expressed in added value generated by $X X$

data required :

The project management capability was first embedded in $\mathrm{Mr}$ A. personnal capability, then diffused to the rest of the $R \& D$ team involved in subsequent large national and international research projects in other technical fields. It is assumed that at least for the first two of these (namely the N2MA project and the Eureka one), the time saved by $\mathrm{XX}$ in preparing and managing the projects thanks to its previous experience in the ACPP project amounts to 2 to 4 months per project. Although it was the whole project (i.e. the activities of XX and its partners) which benefits from the corresponding time saved, it was assumed that a minimal estimation of the gain was equivalent to 2 man-months of project manager. In this case, the gain generated is directely estimated without requiring the estimation of the Q1 and Q2 coefficients.

salarial cost (including overhead) of project manager/engineer : $\propto 10000$ /month

Indirect effect $6: 2 \times 2 \times 010000=\propto 40000$

\section{Indirect effect 7 : work factor}

the output is related to knowledge \& skills-mainly technical (expansion of the knowledge base), the impact is related to competitiveness and expressed in a proxy of added value generated by $X X$ 
data required :

The ACPP project really allowed XX to expand its knowledge base in the fields of polishing techniques, optics, system integration and interfacing of mechanics, electronics and A.I.. Nevertheless, only a part of the time spent in the project has been dedicated to front-edge $R \& D$ activity, the remaining part being devoted to routinized work (experimental preparation, data analysis, technological adaptation of existing knowledge etc). Only $10 \%$ of $\mathrm{Mr}$ A activity was considered as innovative in this respect, with a corresponding figure ranking from $25 \%$ to $50 \%$ as for the work of the specialist in optics (the other specialist has left XX). /month salarial cost (including overhead) of project manager/engineer : $\propto$. 10000 salarial cost (including overhead) of technician : : 7200 /month

Indirect effect $7: 36$ months $\mathrm{x}: 10000 \times 0,5 \times 0,1+36$ months $\mathrm{x}: 7200 \times 0,25$ $=082800$.

\section{Summarizing,}

EC funds received by XX : a 300000 .

Ratio Direct effect / EC funds = o $1050000 /$ o $300000=3.5$

Ratio Indirect effect / EC funds :

000

$\propto(378000+60800+136000+100000+50000+40000+82800) /$ o 300

$=2.83$

\section{Cost/Benefit Approach}

In the context of a standard Cost/Benefit analysis, outputs of R\&D activity must be tangible and take the form of either product or process (or possibly marketed services) if effects are to be identified and quantified. The focus is on these product or processes rather than on the involvment of a firm as a whole in a research project : typical result will be "the rate of return for the product A developed under project B is $\mathrm{x} \%$ " rather than "the rate of return of the involvment of firm $\mathrm{X}$ in the project $\mathrm{B}$ is $\mathrm{y} \%$ ". To put it differently, a given research project is the most frequently assumed to lead to one single product/process on the basis of which effects are evaluated. And as it is explained elsewhere, a real cost/benefit analysis is a very complex one, requiring data from all the actors that can be affected through market mechanisms by the production, the sales and the consumption of this product/process.

Therefore, in the case of our firm XX we will first examplify the type of quantification that can be apply to what was called the Direct effect in the Beta approach (C/B Effect 1). However, in some instances, cost/benefit analysis have been used to assess some limited type of indirect effect, that are the ones based on a technology transfer from a given activity. The indirect effect 1 is probably the only one that corresponds to the type of transferred technology taken into consideration by traditional cost/benefit approaches (C/B Effect 2).

Such typical Cost/Benefit approach would imply:

-the interview of managers from XX (in a quite similar format than for the Beta approach), 
-the identification of actors that are the most affected (usually clients, suppliers and competitors)

-the coverage (by direct or phone interviews) of the most representative organisations among these actors.

\section{C/B Effect 1 :}

the output is a product, the impact is related to competitveness and expressed in profitability generated by sales, loss of market share or lower costs according to the actors affected

\section{data required :}

$\mathrm{XX}$ is affected as "innovator"; but other actors are also affected such as clients of $\mathrm{XX}$, suppliers of XX, competitors of XX, etc.

\section{a) XX :}

in addition to the data required by the Beta approach, roughly the $\mathrm{C} / \mathrm{B}$ approach required all book-keeping data necessary to calculate the net Income or the Cash-Flows related to the sales of POL Robot, as well as those necessary to calculate the Investment made in the development and production of the POL Robot. In order to simplify, let us assume that :

-XX has spent 0,5 million to further develop and launch the POL Robot, in addition to the $\triangle 300000$ normally spent by XX in the ACPP project

-XX has spent 00,25 million to set up all the industrial facilities required to produce the POL Robot

-for each POL Robot unit sold, the Net Income amounts to 050000 and the Cash-Flow amounts to 85000 ;

-no discounting calculation is used

Then a simple calculation of rate of return is the following :

\section{$13 \%$}

$(14 \times \circ 85000) /(\propto 300000+\propto 500000+\propto 250000)=1.13$ equivalent to

b) Other actors.

Let us assume that :

-industrial clients of XX are able to gain 0400000 each thanks to the use of their new machine during the 5 next years

-XX competitors' loss (expressed in Cash-Flow) is equal to 0200000 because $\mathrm{XX}$ has taken over a larger market share

-XX suppliers are gaining o 5000 for each POL Robot by supplying to XX

$75 \%$ ( 1 minus 0,25 equal to the XX's added value rate) of its value

-no discounting calculation is used

Then the net gain is :

o (400000-300 000) x $14-\infty 200000+\infty 5000 \times 14=\infty 1270000$

c) Overall evaluation of C/B Effect 1 :

The social rate of return of POL Robot is then : 


$$
\begin{aligned}
\text { Investment : } & \propto(300000+500000+250000) \text { spent by XX } \\
& \propto(1 \text { million }-300000) \text { spent by the society (EU funds/ACPP }
\end{aligned}
$$

partners)

Gains : $\quad 14 \times 085000$ for $\quad 1 X$

a 1060000 for other actors

$14 \times$ \& $300000 \times 0,1$ for ACPP partners as royalties

This results in :

a $2880000 /$ o $1750=1.65$ equivalent to a $65 \%$ social rate of return

\section{C/B Effect 2 :}

the output is a product, the impact is related to competitveness and expressed in profitability associated with sales or loss of market share, or in terms of benefit for the consumer (quality of life ? reduced raw material or energy consumption ?...) according to the actors affected

a) XX

The same type of calculation can be made than for the C/B Effect 1, but one important problem arises, namely the evaluation on the investment side : should it take into account only the adaptation cost of the dust control knowledge, or part of the cost of the ACPP project ? Let us assume that the first option is choosed and that a $15 \%$ rate of return for $\mathrm{XX}$ is found for this effect

b) Other actors

Basically, what differs from the type of evaluation carried out in the preceeding case is the user, in other words it is the fact that the outpout is a product sold to an end user instead of an industrial user. Therefore, the gain for the user is not savings made on the use of a new process, but rather an increase in the consumer surplus. As it is explained elsewhere, the evaluation of the change in consumer surplus is a difficult task, mainly due to the necessity of the estimation of the relevant demand curve. Linked to that are two problems :

-the unknown demand, in the case of completely new product

-the relative evolution of the price and of the quality of the product sold, in the case of a product improvement achieved thanks to a R\&D project. In some instances, the consumer surplus is increasing because the price is decreasing at constant quality : then normally more consumers are buying the product and the "usual" buyers are paying less than before. In the present case, we could assume that the quality is increasing while the price remains constant, which in economic terms also results in an increasing surplus with a shift of the demand curve. In the present case, the average price of the products of the new line of hand-tools sold by XX is 0380 , but the quality has increased and the demand correspondingly increased from 5000 units to 8000 units. 
Let us assume here that the increase in the consumer surplus is equal to :

$$
(\propto(850-380) \times 8000-\square(700-380) \times 5000) \times 0,5=\square 1080000
$$

Let us also assume that the gain for all of the other actors affected by the commercialization of the new line of hand-tools amounts to 01 million.

\section{c) Overall evaluation of $\mathrm{C} / \mathrm{B}$ Effect 2 :}

The problem of the evaluation of the investment is raised again. Let us assume that it is limited to the investment made by $\mathrm{XX}$, and that the overall rate of return is $75 \%$.

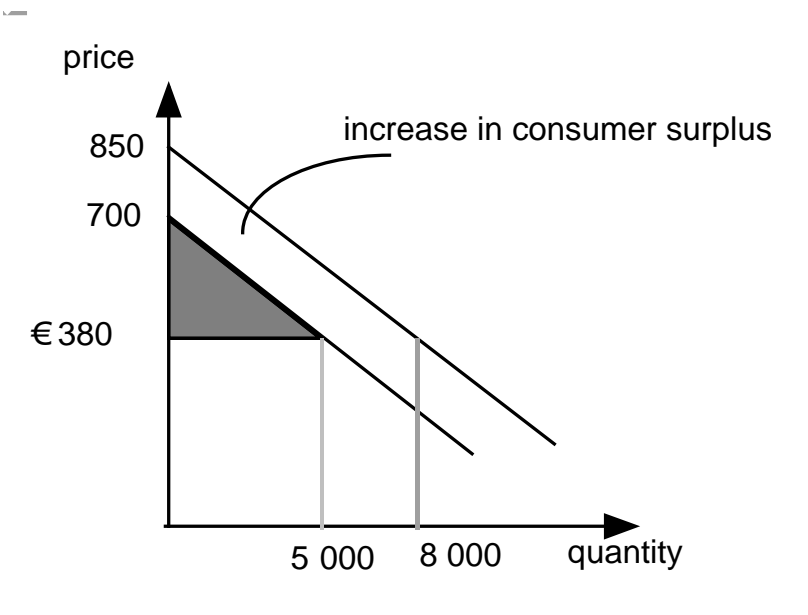

\section{Option approach}

The option approach being an ex-ante tool, the logic of the option approach adopted for the evaluation of $R \& D$ project would lead the evaluator to focus on the direct effect, corresponding to the objective of the ACPP project. For sake of clarity, we will use a simplified version of a Decision-tree approach and we will not discount the Cash-Flow and thus neglect the problem of the discount rate choice. 
In order to compile the different data required by this approach (even a simplified form of it), deeper interview would have been required about the chance of technological success of the ACPP project and about the commercial potential of the results from the ACPP project, and marketing and high level strategic managers would have been enquired in addition to technical managers.

\section{Option Effect 1}

the output is a product, the impact is related to competitveness and expressed in expected profitability for XX associated with sales.

Let us keep the same figures than above as regards the investment and assume that the following scenari and associated probabilities are assessed, taking into account a reasonable chance of success of the project :

probability of fully successfull ACPP project (a) : 0,5

probability of half-successfull ACPP project (b) : 0,3

probability of failure of ACPP project (c) : 0,2

probablity of commercial success in case of (a) : 0,9 , with a cumulated Cash-

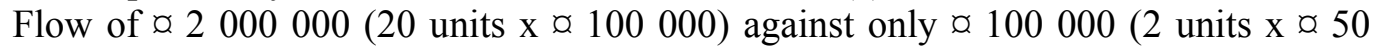
$000)$ in case of commercial failure. With ACPP objectives fully achieved, a standard and well performed industrialization and a relevant commercial campaign, $\mathrm{XX}$ would be well in front of its competitors, with a hudge market widely open. But the novelty of the technical solution makes that a commercial failure is not completely unavoidable.

probability of commercial success in case of (b) : 0,6 with a cumulative CashFlow of a 800000 (10 units $x$ \& 80000 ) against only o 50000 (2 units $x \times 25000)$ in case of commercial failure. Different occurence of semi-success are investigated (semi-automatization only, specific lenses only, etc), and the figures are averaged.

probablity of commercial success in case of (c) : 0 , with no sales

Then the value of the strategic option is :

- . $300000+0.5 \times(-.0750000+0.9 \times 0.2000000+0.1 \times 0.00000)=0$ 230000

or the rate of return of the ACPP project for XX is :

$(0.5 \times(-\propto 750000+0.9 \times \propto 2000000+0.1 \times \propto 00000)) / \propto 300000=1.87$ equivalent to $86 \%$

the option value is equal to :

$-(0.3 \times(-\propto .750000+0.6 \times 0.800000+0.4 \times$ a 50000$)$

$+0.2 \times(-\propto 750000+0)=\propto 225000$

It can be deduced that the ex-ante standard value of the ACPP project is equal to 5000 , which if taken into consideration alone, would probably refrain XX to start the ACPP project. 


\section{Comparison between the three methods}

Some elements of comparison between the three methods can be emphasized, as illustrative of statements already put forward in the previous part of the case study.

- Cost/Benefit analysis does not say a lot about the effects for the firm XX as a whole, but focus on one (or two effects) : complex calculations mixing accounting data should be carried out in order to aggregate the rate of return of $\mathrm{C} / \mathrm{B}$ Effect 1 and 2. But for each of both effects, $\mathrm{C} / \mathrm{B}$ approach takes into account a sub-set of the overall impact on the society, the borderline of this impact being defined by the markets interactions. Conversely, the Beta approach shows a range of effects including indirect ones, allowing to provide a evaluation of the overall effects of the ACPP project for XX. But the Beta approach is limited to the effects for XX, whereas the Cost/Benefit extend its scope to other actors.

- However, if a "unlimited" amount of resrources was dedicated to an evaluation study, some supplementary Cost/Benefit analysis could be made taking as "starting" point some of the indirect effects identified with the Beta approach. But it would required a tremendous amount of work ( $\mathrm{cf}$ for instance the possible impact on environment and health of the new line of DIY hand-tools).

- The Beta Direct Effect 1 (respectively Indirect Effect 2) corresponds to the effect for XX included in the C/B Effect 1 (respectively 2) : but it is clear that the results from the two evaluations cannot be strictly compared (ratio "Effect in added value / EC funds" vs rate of return corresponding to a classical investment appraisal including accounting data such as investment and cash-flows)

- The different effects occur along a 6 years time horizon (with some further sales corresponding to Direct effect and Indirect effect 1 and 2). Therefore the point in time at which the evaluation is performed obviously matters.

- The separability/attribution question is treated differently in the different approaches : while in the Beta approach the "Q coefficients" are assumed to account for the double attribution problem (inter $R \& D$ project and inter innovation assets), the problem is frequently neglected in the $\mathrm{C} / \mathrm{B}$ analysis with a $100 \%$ attribution of all effects to the evaluated $R \& D$ project as a consequence. For instance, it is likely that all sales of polishing machines equipped with the new shaped tools ( $\mathrm{CB}$ effect 2) would be wholly attributed to the ACPP project.

But the problem of "project fallacy" cannot be completely avoided. For instance, part of the Indirect effect 1 is related to the N2MT project, although it had been lanched after the ACPP project. Then if the effects of the N2MT project would have also been evaluated separately, it would have been required to distinguished between the specific influence of each project. Conversely, a higher amount of effects could be evaluated if the effects of Brite-Euram projects on XX in the field of machine-tools are at stake. Another question arises when looking at the Indirect effect 6 (project management related effect) and its attribution to the ACPP project. It is likely that the Esprit project and the N2MT one had little effects on the project management capability of XX since they were carried out after ACPP. But looking at this differently, if the impact of all EU programme on project management capability of 
ACPP should be evaluated, it would probably be smaller than the impact of the ACPP porject alone, since the experience gained in ACPP, N2MT and Esprit projects has been used mainly on the Eureka and only to a small extent on smaller-scale national projects.

- Some of the data required for the three approaches are the same.

- Ex-ante rate of return provided by the option approach can be compared to the ex-post private rate of return provided by the Cost/Benefit approach (C/B Effect 1). Ex-post evaluation shows that the actual situation was not exactly in line with XX expectations used in the option approach : more precisely, the technical success was not total but was "higher" than in the scenario (b), and the limitations of the polishing machine to some specific lenses allows XX to design a well argumented marketing campaign focused on specific clients. Both factors explains that the cumulative cashflow was higher than expected ( $12 \mathrm{x}$ : $90000 \mathrm{vs} 10 \mathrm{x} \times 80000)$.

- Including potential indirect effects in a option approach could increase the expected (ex ante) profitability of a R\&D project as it is expressed by its option value. Conversely, the ex-post evaluation of the effects of a R\&D project on XX (using the Beta approach) could be enhanced by adding the option value of the knowledge acquired during the project and revealed by the existence of the indirect effects.

- Cost/Benefit approach could be related to the investigation of input additionality (investment made by XX vs EC funds) and of part of output additionality, while the Beta approach is more related to different potential forms of output additionality as well as behaviour and cognitive additionality. But in all instances, counterfactual situation should be investigated more precisely with null hypothesis or alternative scenario as reference and for instance before/after or control group as tools).

- The evaluation of the impact of the ACPP project on the capability of XX to adapt to a changing environment (with continuously evolving technology, demand requirements, regulatory aspect or competitor behaviour) can not easily be directly deducted neither from the Cost/Benefit approach nor from the Beta one. But, whereas the only further development open by the former would be to study the evolution of $\mathrm{XX}$ market share, the latter could bring out some hints for finer investigations for instance related to the importance of project management in competition, the comparison between the technological domains in which XX expanded its knowledge base with the ones aimed at by its competitors, the position of its partners in the ranking of university labs in the related domains, etc.

\section{Concluding Remarks}

The advantages, limits and conditions of practical use of the three selected methods have largely been exposed in this section. They all aim at evaluating socioeconomic effects at participant's (and especially firm's level), and thus they all rely on the assumption according to which : 
- all effects (or the bulk of the effects) from a RTD programme derive from the participants' activity in the context of the RTD programme;

- this activity generates different type of outputs and possibly cause some changes in the participants capacity and behaviour;

- these outputs and these changes affect other actors than the participants, by different means depending on the type of relations the participants have with their environment,; thus it generates impacts on different sub-sets of the society and eventually on the society as a whole.

From this perspective (which can be contested), the main limitations are related to the scope of actors covered (in the case of the Beta approach) and to the type of effects and the type of links between outputs and impacts taken into consideration (in the case of Cost/Benefit and Option approach). But all three methods are based on a quite clear theoretical background (roughly neo-classical economics as for Cost/Benefit and Option approaches, and knowledge-based / heterodox economics as for the Beta one), that help to clarify their scope and relevance.

More generally, it appears that some further theoretical and methodological development work is still required in the field of the evaluation of socio-economic at participant level, especially as regards the following questions :

- a better understanding of the different dimensions of additionality, with implications on the design of counterfactual hypothesis and of the relevant evaluation tools and procedures. Apart from the difficulties of these exercises largely documented elsewhere, one key point is probably the fact that, as evaluated RTD actions can be envisaged at individual participant, project, programme and policy levels, additionality could be envisaged at the same levels. Then, evaluation of additionality at firm's level, as it is discussed in this section, only looks at one piece of the puzzle.

- better tools to assess the effects of RTD programmes on the capacity / capability of participants (in all dimensions including scientific, technological, relational, strategic, organisational, managerial, etc) . A whole range of knowledgetype of outputs are produced by participants, and a whole range of structural, behavioural or cognitive changes are affecting them as consequences of their involvment in RTD programmes. Among the approaches explored in this section, the Beta one is obviously the most advanced towards this direction, although some enhancements and modifications are still required before one could claim that this approach really grasp the effects of RTD programme on participants capability.

- clearer attempts to escape from the problem of "project fallacy", either by a better explanations of the means used by each evaluation approach in order to solve the attibution problem, or by reaching a coherent balanced between the evaluation of the effects of one given programme on a set of participants (programme oriented evaluation) and the evaluation of a set of programmes on one given participant (participants oriented evaluation).

- a better complementarity between evaluation works gathering detailed quantitative/qualitative data through direct in-depth interviews of a limited number of participants (as examplified by the three methods) with evaluation works collecting 
more "broader" qualitative data on a larger scale (cf the three examples of "good practices" referred to in a previous part of the ASIF report). This would enable for instance cross-checking of the validity and reliability of results, extrapolation based on accurately defined participants profiles, deeper investigations of specific topics revealed by large scale surveys, etc.

- and obviously a better articulation (as regards the underlying theoretical background as well as the empirical evaluation strategies) between the effects evaluated at participants level with those evaluated at more broader levels.

It must be stressed that some of the perspective in terms of evaluation requirements open by the new RTD Framework Programme are directly related to these points : for instance the multi-project dimension associated with coordination of European and national policies and with Network of Excellence, the additionality associated again with the policy coordination, or the increase in the size of projects (Integrated Projects) demanding more attention to be paid on additionality and complementarity between micro, meso and macro evaluation levels. Beside, the need of evaluation tools will probably be more important as regards the selection of proposals (for which some interesting inputs could be provided by the option approach) and the monitoring / programme implementation and management evaluation (which is out of the scope of this section). 


\section{Selected References for Section 4.1}

References for the Beta method are study reports and publications of the Beta group and of other research groups using the same approache (see BACH et al.)

References for Cost-Benefit Analysis are countless, only four important are provided here (see also some governmental sites - for instance NIH - providing recommendations about the practical use of simplified versions of these approaches)

References for Real Option approach are also ore and more numerous, only two important ones are provided here, as well as an introductive paper from one ASIF participant.

BACH L. et al., forthcoming early 2002, Evaluation of the BRITE/EURAM Programme, in Learning from Science and Technology Policy Evaluation: Experiences from the United States and Europe, Philip Shapira and Stefan Kuhlmann (eds), Edward Elgar, Cheltenham, UK and Nothampton, Mass, USA

BACH L. and GEORGHIOU L., 1998, The Nature and Scope of RTD Impact Measurement, A discussion paper for the International Workshop on "Measurement of RTD Results/Impact”, Brussels, 28-29 May 1998

BOARDMAN A.E. (ed) et al., 2001, "Cost Benefit Analysis : Concepts and Practice", 2nd ed., Prentice Hall.

COPELAND T. - ANTIKAROV V., 2001, "Real Options : a Practitioner's Guide", New York: Texere, LLC.

JAFFE A.B., 1996, "Economic analysis of research spillovers - Implications for the advanced technology program", http://www.atp.nist.gov/

MANSFIELD E. et al., 1977, "Social and Private Rates of Return from Industrial Innovations", Quarterly Journal of Economics, May.

MISHAN E.J., 1976, “Cost-Benefit Analysis”, New-York: Praeger Publishing.

TRIGEORGIS L., 1996, “Real Options”, Cambridge, Mass.: MIT Press.

VONORTAS N., LACKEY M., forthcoming early 2002, Real Options Approach for Evaluating Public Sector R\&D Investments, in Learning from Science and Technology Policy Evaluation: Experiences from the United States and Europe, Philip Shapira and Stefan Kuhlmann (eds), Edward Elgar, Cheltenham, UK and Nothampton, Mass, USA 


\section{Market-Driven Research Case Study - Annex}

\section{Complements to the protocol "BETA Approach":}

- The steps are the followings :

step 1: sampling

step 2: structuration and feeding of data base with information on projects

(collected from the organisation in charge of the evaluated programme)

step 3: direct interviews :

- first telephone/e-mail contact with the person mentionned by the organisation in charge of the evaluated programme in order to arrange a meeting with the relevant persons

- mail/e-mail/fax of confirmation, with short explanation of the study, guidelines of the interview and demand for general information about the organisation

- interview

- following phone calls for complementary information

data base is feeded in real time.

step 4 : final cross checking of data base, treatement and interpretation

- The Beta approach does not rely on the use of a questionnaire, but rather on a discussion allowing to identify the cases of effects that occured in the interviewed organisation. The reason is that the situations and the processes by which effects occur are so diverse from one organisation to the other that it would be counterproductive to review one by one all of them with the interviewed managers.

- Some basic data are asked before the interview (see below), because previous Beta experience revealed that they are almost always required.

- The discussion follow a very general guideline proposed to the interviewed managers before the meeting (see below), but it often happens that the discussion does not follow a strict linear course.

- The Beta researchers know the exact list of possible case of effects grouped in general categories (see BETA Tab1). Sometimes there are new situations, new forms of effects that were not previously revealed by interviews; but it is almost always possible to relate them to some items of the existing list of effects.

- The Beta researchers also know the different ways to quantify the effects (see BETA Tab2 for a general presentation), and use them case by case during the interview. Of course sometimes it is impossible to reach a quantification.

- A data base showing the following structure (see BETA Tab3) includes all collected data.

- The standard way of presenting the quantitative results of BETA evaluation is exhibited in BETA Tab4. 


\section{PREPARATION FOR THE INTERVIEW}

In order to build our data base on the firms visited, we would appreciate if you could provide us with the last available "annual report" of your organisation, as well as with the following figures:

Turnover of the firm :

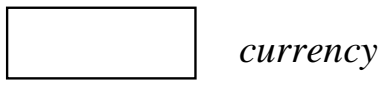

Number of employees of the firm :

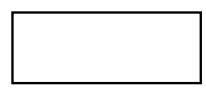

Budget of the R\&D Department :

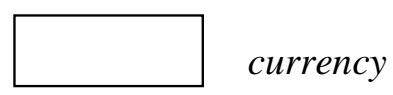

Number of employees of the R\&D Department :

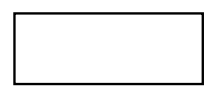

Average rate of added value (sales minus intermediate consumptions)

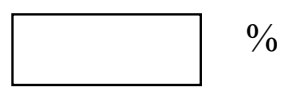

Salary plus overheads (on average) :

of an engineer :

currency of a technician :

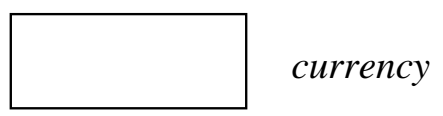




\section{GUIDELINES FOR THE INTERVIEW}

The interviews carried out by the members of the BETA group include the following steps :

\section{1/ Presentation of the study / presentation of the evaluation approach}

Short descRiption of the framework of the evaluation, short description of the type of effects (direct/indirect, classes of indirect effects), short explanation about the quantification principle, exemples (existing + examples that could be found in the organisation).

\section{2/ Description of the firm's activities}

- Main activities of the firm;

- Importance of the Research and Development sector (expenditures, employees,...) relative to the other activities of the firm;

- Description of R\&D activities performed during the evaluated project.

This first part should enable us to list the economic effects generated by the contract in your firm, according to the typology of effects described above.

3/ Detailed description and quantitative evaluation of economic effects listed in step 2/. This will be achieved during the interview and with the help of the members of the BETA research group.

4/ Review of all cases quantified and non quantified

5/ The interview generally ends with a discussion about qualitative aspects relating to the impact of the project (innovation process, diffusion of results,...), and to its working (relations with ..., bureaucracy,...).

Of course, some modifications could be introduced to this general outline if representatives of a firm find that these modifications will lead us to a better identification of the economic effects 


\section{Complements to the protocol "Options Approach" :}

Basically, the option approach relies on the distinction between two types of investment : the investment in the RTD project and the investment in the commercial exploitation of the results of the RTD project. Investing in the RTD project does not necessarily lead to the investment in the exploitation : the latter will be decided in light of the results from the former. Therefore, the initial decision (investment in RTD project or not) is made in a context of sequential decision with increasing information.

Following the document provided by N. Vonortas, two broad families of options approach can be distinguished : one based on the analysis of a decision tree (DTADecision Tree Analysis), and one based on formula derived from the ones used in Financial Analysis, such as the one popularized by Black \& Scholes (B\&S-type Direct Formula). Although both approaches rely on the same principle and both approaches can lead to the same results (under certain hypothesis), they require different sets of data.

\section{$\underline{D T A}$}

- The following data are required :

- the cost of the R\&D investment

- the cost of the commercial investment

- the description of all branches of the tree

- the list of all possible final steps of the tree, with associated gains

- a system of probability for all decision point for fate coupled with a discounted rate including risk premium OR another system of probablity derived from a comparision with certainty equivalent coupled with the risk-free rate of interest.

They are used as follows (in a simplified case with two periods and a limited number of events, as shown in the following figure) :

- IRTD : amount of investment in the RTD project;

- IC : amount of investment in the commercialisation of the result from the RTD project;

- Px: probability of event x (x : (c), (d), (i), (j) (k), (l) )

- Gy : gain in monetary term for the firm when event y occurs (y : (i), (j), (f), (k), (l), (h), (b) )

- rz : period discount rate when event z occurs $(\mathrm{z}$ : (e), (g), (i), (j), (k), (l) )

- in $\mathrm{t}=0$, the firm has to decide between investing IRTD in the RTD project (a) or not (b);

- in $\mathrm{t}=1$, the result of the RTD project will be observed, but looking form $\mathrm{t}=0$ it is uncertain : it can be either (c) with a probability of Pc or (d) with a probability of $\mathrm{Pd}$.

- in $\mathrm{t}=1$ also the firm will have to decide to invest IC in the commercial exploitation;

- in $\mathrm{t}=2$, the results of the commercial exploitation will be observed, but looking from $\mathrm{t}=0$, there are uncertain : they can be either (i) or $(\mathrm{j})$ if the result of the RTD 
project is (c), or either $(\mathrm{k})$ or (l) if the the result of the RTD project is (d) (with respective probabilities of $\mathrm{Pi}, \mathrm{Pj}, \mathrm{Pk}, \mathrm{Pl})$.

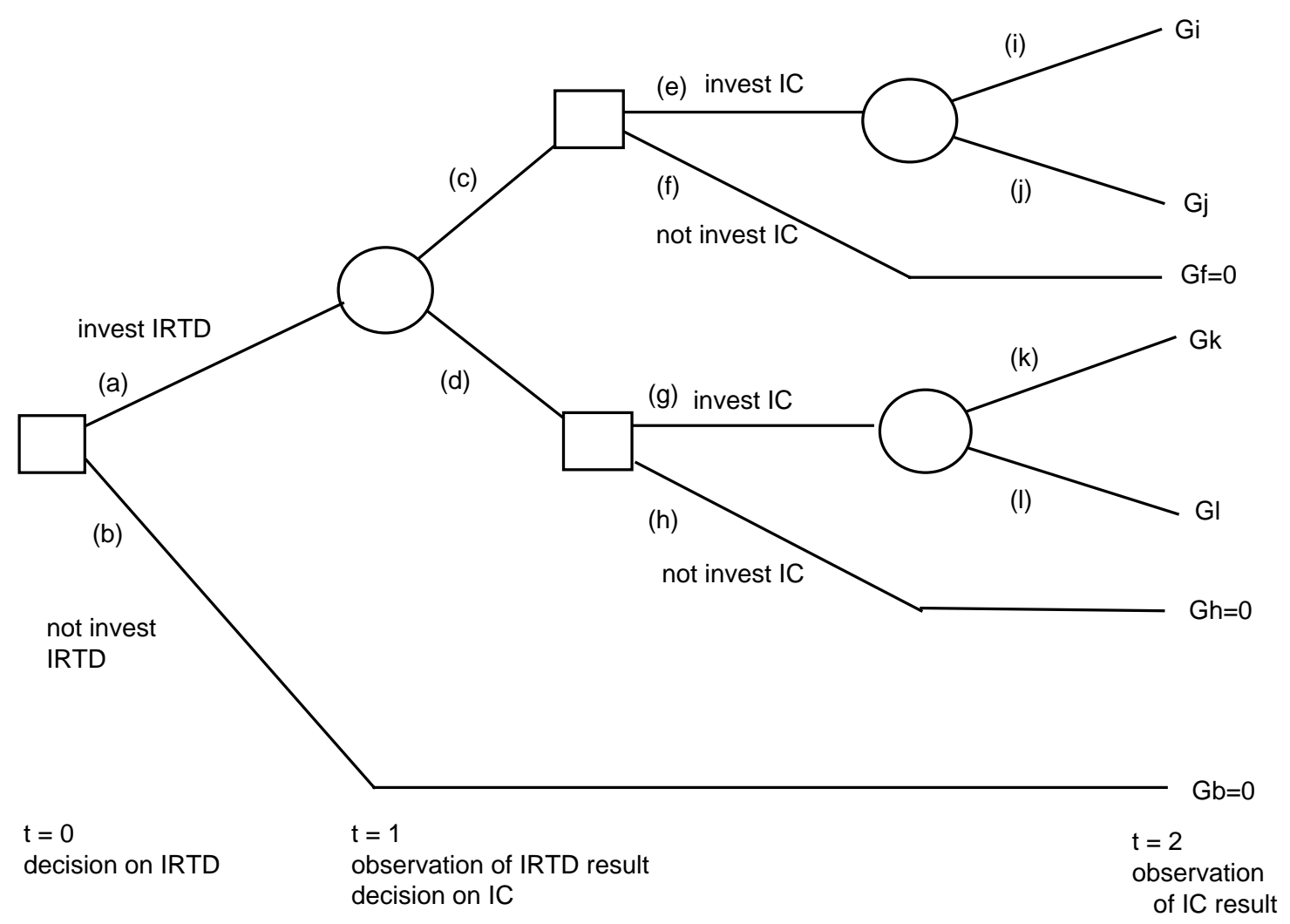

- Then, the results of the evaluation can be expressed as follows :

OPTION-STRATEGY VALUE OF THE INVESTMENT IN THE RTD PROJECT (OSV) :

$$
\begin{aligned}
& -I R T D \\
& +P c \times \max \left[0 ; \frac{1}{1+r e}\left(-I C+\frac{P i \times G i}{1+r i}+\frac{P j \times G j}{1+r j}\right)\right] \\
& +P d \times \max \left[0 ; \frac{1}{1+r g}\left(-I C+\frac{P k \times G k}{1+r k}+\frac{P l \times G l}{1+r l}\right)\right]
\end{aligned}
$$

OPTION VALUE $=$ OSV - CLASSIC Net Present Value (NPV), with :

\section{CLASSIC NPV $=$}




$$
\begin{aligned}
& -I R T D-\frac{I C}{1+r} \\
& +\frac{[P c \times(P i \times G i+P j \times G j)}{(1+r)^{2}}+\frac{P d \times(P k \times G k+P l \times G l)}{(1+r)^{2}}
\end{aligned}
$$

Note : in NPV, it is assumes that the decision in $t=0$ is to make the two investments or to make nothing (no possibility of keeping the option), and the discount rate is always the same.

Decision rule : if the OSV is positive, the firm should invest in the RTD project, even if the NPV is negative. Correspondingly, if the Option Value is greater than the investment in the RTD project (OV > IRTD), the firm should invest in the RTD project. Put it differently, the option value is the maximum amount that the firm would be ready to invest in the RTD project.

To avoid the determination of different discount rates specific to each uncertain event, it is often proposed to :

- use only one single discount rate, but this approach leads to different results which are not right from a theoretical point of view;

- use another system of probability associated to a risk-free discount rate; but this approach requires the comparison of the project with a "twin project" which may be difficult to define and/or measure.

\section{$\underline{B \& S \text {-type Direct Formula }}$}

To avoid the same problem and also to avoid the construction of the decision tree (which can become very complex when the time horizon is remote and when a lot of factors can determine the possible events), another option approach can be used, directly derived from what is used in Finance. The idea is to assume that the gain G are following a given probability law. Formula such as the well known Black \& Scholes are then directly applicable.

- The following data are required :

- the cost of the R\&D investment

- the cost of the commercial investment

- the time horizon

- the risk-free rate of interest

- the standard deviation of the expected gain from the commercial investment (a)

- the forecast value of the gain from the commercial investment (or its expected value) (b)

- the cumulative probability function of the gain (log-normal in the original Black \& Scholes formula that generalize the binomial approach) 
- The result is also expressed in terms of Option Value, Option-Strategy Value or comparison between the Option Value and the amount of investment in the RTD project. 


\section{Complements to the protocol "Classical Cost/Benefit Approach" :}

In classical Cost/Benefit Analysis, the evaluation relies on economic variables directly linked to market transactions between different actors, these transactions being the only relations taken into account. All the evaluated effects are supposed to be embedded in such variables, of which the key one is the price of the goods or services. In theory, an output from a RTD project generates an impact through all the market transactions related to this output, and thus all actors affected by this impact must be covered by the evaluation.

Basically, two types of output are taken into account, leading to three basic cases

- goods (product, service, information... : they are sold by the RTD partner(s) to other actors (end user $=$ case 1 , or to another firm= case 2 ), displace/compete with goods from other firms, require inputs form other firms to be produced : all those actors are thus affected, and the economic impact is spreading to other actors through subsequent market transactions;

- processes, which are used by the RTD partner(s) to produce goods giving birth to the same effects than before (case 3 ).

In most of the studies using this approach, the evaluation is limited to the first "round" of market transactions, that is between the RTD partner(s) and its clients ("partial equilibrium approach"). Sometimes, the suppliers and the competitors of the RTD partner(s) are also included.

The time horizon taken into consideration is the duration of the effect, or very often the time during which it is assumed that the RTD project has provided the RTD partner a competitive advantage compared to its competitors ("lead time advantage").

- The required data are listed in the Table CBA Tab1 below, for the three basic cases.

In addition, the amount of investment made by the public funding to the RTD project (Ipub) is to be measured.

The general formula used for the quantification of the effects are the following.

For a firm :

The effect affecting one given firm is measured in terms of variation of profit, i.e. firm's surplus (this is a general formulation, the precised expression of profit - Cash Flow, Income, etc - depending on the accounting and financial variables taken into consideration), which can be then expressed in terms of Income, Net Income or in terms of Private Rate of Return.

variables :

$P$ : price of good

$C:$ unit cost of producing this good

$Q:$ quantity of good sold 
IPR : investment made by the firm (in the RTD project and in all activities leading to product or process resulting from the RTD project)

1 : refers to the situation "with" the RTD project which can affect any variables depending on the observed case

2 : refers to the situation "without" the RTD project

Variation of Profit $t_{t}=\left(P_{1}-C_{1}\right) \times Q_{1}-\left(P_{0}-C_{0}\right) \times Q_{0}$

(I)

Income $=\sum_{t} \Delta \operatorname{Pr}$ ofit period $t$

Net Income $=-I_{P R}+\sum_{t} \Delta \operatorname{Pr}$ ofit period $t$

Private Rate of Return $=\left(\left(\frac{\left(\sum_{t} \Delta \text { Profit period } t\right)-I_{P R}}{I_{P R}}\right)-1\right) \times 100$

$\underline{\text { For an end user : }}$

The effect affecting the end user is measured in terms of variation of consumer surplus (according to the theory, the expression of the consumer surplus should normally be a little bit more sophisticated), which is then expressed in terms of a sum of consumer surplus over the duration of the effect.

variables (others than the ones already introduced) :

$P \max$ : origin of the Demand Curve (see the following figure)

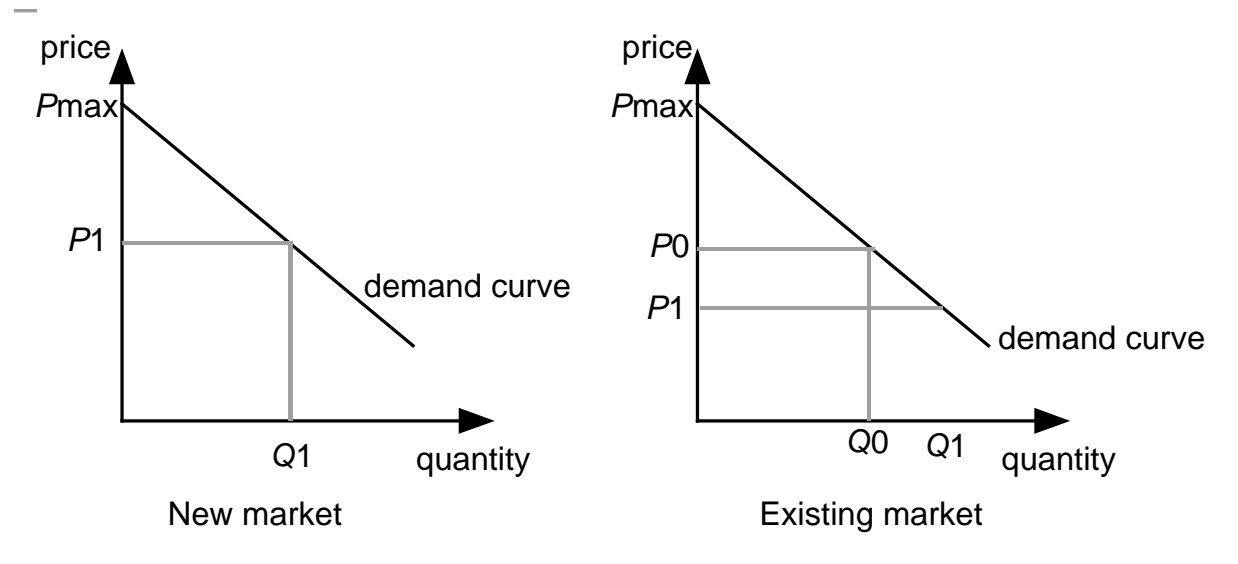

Variation of Consumer Surplus

$$
=\frac{1}{2} \times\left(P_{\max }-P_{1}\right) \times Q_{1}
$$


(II) if there is a completely new market

$=\left(P_{0}-P_{1}\right) \times Q_{0}+\frac{1}{2} \times\left(P_{0}-P_{1}\right) \times\left(Q_{1}-Q_{0}\right)$

(III) if the good is sold on an existing market

The following Table CBA Tab2 details the use of these formula in the three basic cases listed above.

- The overall results of the evaluation exercise is then expressed in terms of Total Income, or in terms of Social Rate of Return, with :

Total Income $=$ Net Income of all firms + Sum of Consumer Surplus - IPUB

Social Rate of Return $=$

$$
\left(\left(\frac{\text { Income of all firms }+ \text { Sum of Consumer Surplus }-\left(I_{P R}+I_{P U B}\right)}{I_{P R}+I_{P U B}}\right)-1\right) \times 100
$$

These results are often compared to the results obtained at partner's level. An example of a typical presentation of the final results is provided below in CBA Tab3. 
This page is intentionally blank. 


\begin{tabular}{|c|c|c|}
\hline \multicolumn{2}{|c|}{ DIRECT EFFECTS } & \multirow[t]{2}{*}{ DIRECT ADDED VALUE } \\
\hline Definition & $\begin{array}{l}\text { The direct effects are the effects which are directly related to the objectives of the projects, as they were defined at the beginning of each } \\
\text { of these. For instance, if the objective is to develop a new product (or a new process), the sales of such products (or the economic effects of } \\
\text { the use of this new process) are considered as direct effects. This rule is similar in the case of more fundamental research-oriented } \\
\text { projects: direct effects are related to the application of the new scientific knowledge or the new technologies in the field foreseen at the } \\
\text { beginning of the projects. }\end{array}$ & \\
\hline \multicolumn{2}{|r|}{ INDIRECT EFFECTS } & \\
\hline Definition & $\begin{array}{l}\text { Indirect effects are those which go beyond the scope of the objectives of the projects. Generally speaking, indirect effects express the } \\
\text { economic valuation of the learning processes experienced during the evaluated project : they derived from the use of what has been learned } \\
\text { during the execution of the project, in participants activities which are not directly related to the objective of the project. All types of } \\
\text { learning leading to the creation of all types of knowledge are taken into account: technological, organizational, networking, management, } \\
\text { industrial, individual/collective, through experience/transfer, from other partners and so on. }\end{array}$ & \\
\hline \multicolumn{2}{|c|}{ TECHNOLOGICAL EFFECTS } & \\
\hline Definition & $\begin{array}{l}\text { transfer of scientific and technical knowledge acquired or developed during the evaluated project to other activities of the participant. } \\
\text { Knowledge may be embodied in artefacts (products, systems, materials, processes...), in human or in any codified forms; it may be more or } \\
\text { less tacit, individual or collective. What is transferred can therefore be of a very diverse nature, from scientific expertise to workers know- } \\
\text { how, including technology laid down as a blue-print, new theories or 'tricks of the trade'. The transfers lead to the design of new or improved } \\
\text { products, processes or services which allow the participant to achieve new sales, to protect existing market shares, to obtain new research } \\
\text { contracts, or lead to the granting of new patents. }\end{array}$ & \\
\hline \multirow[t]{4}{*}{ Sub-classes } & transfer of product technology & DIRECT ADDED VALUE \\
\hline & transfer of preocess technoogy & DIRECT ADDED VALUE \\
\hline & transfer of service technology & DIRECT ADDED VALUE \\
\hline & patents & PROXY PATENTS \\
\hline \multicolumn{2}{|c|}{ COMMERCIAL EFFECTS } & \\
\hline Definition & $\begin{array}{l}\text { include two categories, not directly or necessarily linked to a technological learning process. Network effects refer to the impact of projects } \\
\text { on the creation and/or the reinforcement of cooperation with project partner or other entities, which results in other cooperations than the } \\
\text { evaluated project itself. Second, by working on behalf of a given public programme, participants sometimes acquire a quality label or a good } \\
\text { image. which is afterwards used as a marketing tool. }\end{array}$ & \\
\hline Sub-classes & $\begin{array}{l}\text { network effect } \\
\text { reputation effect }\end{array}$ & $\begin{array}{l}\text { DIRECT ADDED VALUE } \\
\text { DIRECT ADDED VALUE }\end{array}$ \\
\hline \multicolumn{2}{|c|}{ ORGANISATION \& METHODS EFFECTS } & \\
\hline Definition & $\begin{array}{l}\text { transfer of organisational or procedural knowledge acquired or developed during the evaluated project to other activities of the participant: } \\
\text { they occur when experience gained through the project allows the participant to modify its internal organization and/or to apply new methods } \\
\text { in proiect management, quality management, industrial accounting and so on. }\end{array}$ & \\
\hline \multirow[t]{3}{*}{ Sub-classes } & project management & DIRECT ADDED VALUE \\
\hline & other methods & DIRECT ADDED VALUE \\
\hline & organisation & DIRECT ADDED VALUE \\
\hline \multicolumn{2}{|c|}{ WORK FACTOR EFFECTS } & PROXY WORK FACTOR \\
\hline Definition & $\begin{array}{l}\text { describe the impact of the project on the 'critical mass' relative to the human capital of the partner ie the range of competences related to } \\
\text { more or less diversified scientific and technological fields. which are considered to be critical for the future development of the organisation. }\end{array}$ & \\
\hline
\end{tabular}

BETA Tab1 
BETA Tab2

\begin{tabular}{|c|c|c|c|c|c|c|c|c|c|c|c|}
\hline $\begin{array}{l}\text { TYPE OF } \\
\text { QUANTITICATION }\end{array}$ & $\begin{array}{c}\text { identification } \\
\text { of effects }\end{array}$ & $\begin{array}{l}\text { unit } \\
\text { (1) }\end{array}$ & & measure & & \begin{tabular}{|c|}
1 \\
$\begin{array}{c}\text { influence of "asset" on the } \\
\text { variation of sales / cost } \\
\text { (5) }\end{array}$
\end{tabular} & $\begin{array}{c}2 \\
\text { influence of evaluated } \\
\text { programme on the "asset" } \\
(6)\end{array}$ & $\begin{array}{c}\text { Time scale } \\
\text { actual } \\
(7)\end{array}$ & $\begin{array}{c}\begin{array}{c}\text { Time scale } \\
\text { forecast } \\
(8)\end{array}\end{array}$ & $\begin{array}{l}\text { probability if } \\
\text { forecast } \\
\text { (9) }\end{array}$ & AMOUNT OF EFFECT \\
\hline $\begin{array}{l}\text { DIRECT ADDED } \\
\text { VALUE }\end{array}$ & qualitative & \begin{tabular}{|l} 
any new product or service, \\
existing products or service, new \\
research contracts or royalties \\
from IPR that were affected by \\
knowledge acquired or developed \\
during the project \\
AND \\
any sources of cost reduction \\
(including new process or existing \\
processs that were effected by \\
knowledge acquired or developed \\
during the proiect
\end{tabular} & $\begin{array}{l}\text { (2) } \\
\text { monetary : } \\
\text { variation of } \\
\text { sales of (1) }\end{array}$ & \begin{tabular}{|c|}
$(3)$ \\
monetary : \\
variation of \\
costs of (1)
\end{tabular} & \begin{tabular}{|c}
$(4)$ \\
monetary : \\
variation of \\
added value \\
resulting from \\
(2) and (3)
\end{tabular} & $\begin{array}{l}3 \text { types of assets : Technological } \\
\text { competences, Networking } \\
\text { competences, Procedural } \\
\text { competences } \\
\text { expressed in \% of the variation } \\
\text { of sales or cost, range asked } \\
\text { ("at least 10\%", "bettween one } \\
\text { third and one half", etc) from } \\
\text { which minimal end is taken into } \\
\text { account for the evaluation }\end{array}$ & $\begin{array}{l}\text { Influence of project on } \\
\text { Technological competencies, } \\
\text { Networking competenceses, } \\
\text { Procedural competences } \\
\text { expressed in \%; range asked } \\
\text { ("at least 10\%", "between one } \\
\text { third and one hall", etct from } \\
\text { which minimal end is taken into } \\
\text { account for the evaluation }\end{array}$ & $\begin{array}{l}\text { from the origin of } \\
\text { the effect to min } \\
\text { [end of effect, } \\
\text { now] }\end{array}$ & $\begin{array}{c}\text { from now to min } \\
\text { [end of effect, end } \\
\text { of evaluation } \\
\text { horizon] }\end{array}$ & $\begin{array}{c}\% \\
\text { minimal estimate }\end{array}$ & \begin{tabular}{|c|}
$(4) \times(5) \times(6))$ \\
$x$ \\
$((7)+(8) \times(9))$
\end{tabular} \\
\hline
\end{tabular}

\begin{tabular}{|c|c|c|c|c|c|}
\hline $\begin{array}{c}\text { TYPE OF } \\
\text { QUANTITICATION }\end{array}$ & $\begin{array}{c}\text { identification } \\
\text { of effect }\end{array}$ & $\begin{array}{c}\text { unit } \\
\mathbf{( 1 )}\end{array}$ & $\begin{array}{c}\text { measure } \\
\mathbf{( 2 )}\end{array}$ & $\begin{array}{c}\text { Time scale } \\
\text { (3) }\end{array}$ & $\begin{array}{c}\text { AMOUNT OF } \\
\text { EFFECTS }\end{array}$ \\
\hline PROXY PATENT & qualitative & $\begin{array}{c}\text { number of patent } \\
\text { not in use, ie not } \\
\text { protecting a } \\
\text { technology } \\
\text { currently used }\end{array}$ & $\begin{array}{c}\text { monetary: } \\
\text { cost of applying / } \\
\text { defending the } \\
\text { patent }\end{array}$ & $\begin{array}{c}\text { from the origin of } \\
\text { the effect to min } \\
\text { [end offect, end } \\
\text { of evaluation } \\
\text { horizon] }\end{array}$ & (1) x (2) x (3) \\
\hline
\end{tabular}

\begin{tabular}{|c|c|c|c|c|c|}
\hline $\begin{array}{c}\text { TYPE OF } \\
\text { QUANTITICATION }\end{array}$ & $\begin{array}{c}\text { identification } \\
\text { of effect }\end{array}$ & $\begin{array}{c}\text { unit } \\
\mathbf{( 1 )}\end{array}$ & $\begin{array}{c}\text { measure } \\
\mathbf{( 2 )}\end{array}$ & $\begin{array}{c}\text { Time scale } \\
\text { (3) }\end{array}$ & $\begin{array}{c}\text { AMOUNT OF } \\
\text { EFFECTS }\end{array}$ \\
\hline PROXY WORK FACTOP & qualitative & $\begin{array}{c}\text { strategic knowledge } \\
\text { (SK) } \\
\text { salarial cost of } \\
\text { people identified } \\
\text { in (1) } \\
\text { by specific personal } \\
\text { (SP) during the } \\
\text { evaluated project }\end{array}$ & $\begin{array}{c}\text { equivalent to the } \\
\text { time spent by (SP) } \\
\text { to develop (SK) }\end{array}$ & $\begin{array}{c}\text { (2) } \mathbf{x}(\mathbf{3}) \\
\end{array}$ & \\
\hline
\end{tabular}




\section{DATA BASE}

\section{remarks}

one line $=$ one effect $=>$ more than one line per orga.

all monetary data in ECU or € reference year

\begin{tabular}{|ll}
\hline DATA ON PARTNERS & \\
Nationality & provided by EC, crossed-checked with interviewed org \\
turnover & last data available \\
number of employees & last data available \\
R\&D expenditures & last data available \\
R\&D staff & last data available \\
Type & firm (big/different types of sme)/univ/research centre \\
Type of production & tangible/intangible \\
\hline
\end{tabular}

\section{DATA ON THE INVOLVMENT OF PARTNER IN PROJECT}

Amount of EC funds provided by EC, crossed-checked with interviewed org.

Type of activity $1 \quad$ on research scale from basic research to production

Type of activity $2 \quad$ producer/user/tester of technology

\section{DATA ON PROJECT}

EC project code

number of partners

provided by EC, crossed-checked with interviewed org. provided by $E C$, crossed-checked with interviewed org.

total EC funds provided by EC, crossed-checked with interviewed org.

duration provided by EC, crossed-checked with interviewed org.

age of project from beginning to now

tech/scientific success

yes/no

\section{DATA ON EVALUATED EFFECT}

direct/indirect

type if indirect

coef influence 1 asset->measure of effect

coefinfluence $2 \quad$ project->asset

actual value

forecast value

added value rate

BETA Tab3 
BETA Tab4

\begin{tabular}{|l|r|}
\hline Number of projects surveyed & 50 \\
Number of participants & 176 \\
Number of measured economic effects & 632 \\
\hline Ratio of direct effects/EEC fundings & 13.3 \\
Total direct effects in MECU 91 & 522.5 \\
\hline Ratio of indirect effects/EEC fundings & 4.1 \\
Total indirect effects in MECU 91 & 160.8 \\
Technological & $76.5(47.6 \%)$ \\
Commercial & $16.5(10.3 \%)$ \\
Organisation \& Methods & $18.6(11.6 \%)$ \\
Competence and training & $49.2(30.6 \%)$ \\
\hline
\end{tabular}


CBA Tab1

\begin{tabular}{|c|c|c|c|}
\hline & effect=product sold to end consumer & effect=product sold to firm A & effect=process used by partner \\
\hline partner & $\begin{array}{l}\text { data on price, quantity and financial data } \\
\text { allowing the measurement of : } \\
\text {-the increase in profit thanks to the product } \\
\text {-the decrease in profit due to some possible } \\
\text { displaced products } \\
\text { (data on rate of success of equivalent project } \\
\text { to account for sunk costs) }\end{array}$ & $\begin{array}{l}\text { data on price, quantity and financial data } \\
\text { allowing the measurement of : } \\
\text {-the increase in profit thanks to the product } \\
\text {-the decrease in profit due to some possible } \\
\text { displaced products } \\
\text { (data on rate of success of equivalent project } \\
\text { to account for sunk costs) }\end{array}$ & $\begin{array}{l}\text { data on price, quantity and financial data } \\
\text { allowing the measurement of the increase in } \\
\text { profit thanks to the producess } \\
\text { (data on rate of success of equivalent project } \\
\text { to account for sunk costs) }\end{array}$ \\
\hline client=end consumer & $\begin{array}{l}\text { data on demand curve or elasticity allowing the } \\
\text { measurement of consumer surplus }\end{array}$ & D & $\begin{array}{l}\text { data on demand curve or elasticity allowing the } \\
\text { measurement of consumer surplus }\end{array}$ \\
\hline client=firm $A$ & 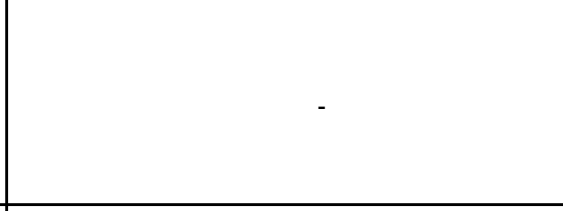 & $\begin{array}{l}\text { data on price, quantity and financial data } \\
\text { allowing the measurement of : } \\
\text {-the increase in profit thanks to the product } \\
\text { bought to the partner } \\
\text {-the decrease in profit due to some possible } \\
\text { displaced products }\end{array}$ & 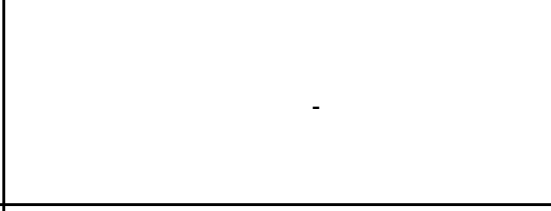 \\
\hline supplier of partner & $\begin{array}{l}\text { data on price, quantity and financial data } \\
\text { allowing the measurement of the variation of } \\
\text { profit realized when supplying to the partner }\end{array}$ & $\begin{array}{l}\text { data on price, quantity and financial data } \\
\text { allowing the measurement of the variation of } \\
\text { profit realized when supplying to the partner }\end{array}$ & $\begin{array}{l}\text { data on price, quantity and financial data } \\
\text { allowing the measurement of the variation of } \\
\text { profit realized when supplying to the partner }\end{array}$ \\
\hline \multirow[t]{2}{*}{ competitor of partner } & $\begin{array}{l}\text { data on price, quantity and financial data } \\
\text { allowing the measurement of } \\
\text { decrease in profit due to displaced products }\end{array}$ & $\begin{array}{l}\text { data on price, quantity and financial data } \\
\text { allowing the measurement of } \\
\text { decrease in profit due to displaced products }\end{array}$ & $\begin{array}{l}\text { data on price, quantity and financial data } \\
\text { allowing the measurement of } \\
\text { decrease in profit due to displaced products }\end{array}$ \\
\hline & $\begin{array}{l}\text { comments: } \\
\text { in theory, other actors can be affected, such } \\
\text { as the competitors of the suppliers etc }\end{array}$ & $\begin{array}{l}\text { comments: } \\
\text { in theory, other actors can be affected, such } \\
\text { as the end user }\end{array}$ & $\begin{array}{l}\text { comments: } \\
\text { in theory, other actors can be affected, such } \\
\text { as the competitors of the suppliers etc }\end{array}$ \\
\hline
\end{tabular}


CBA Tab2

\begin{tabular}{|c|c|c|c|c|c|c|}
\hline & \multicolumn{2}{|c|}{ effect=product sold to end consumer } & \multicolumn{2}{|c|}{ effect=product sold to firm A } & \multicolumn{2}{|c|}{ effect=process used by partner } \\
\hline & New product & Improved product & New product & Improved product & New process & Improved process \\
\hline partner & $\begin{array}{l}\text { (I) with } \mathrm{P} 0=\mathrm{C} 0=\mathrm{Q} 0=0 \\
\Rightarrow>(\mathrm{P} 1-\mathrm{C} 1) \times \mathrm{Q} 1\end{array}$ & 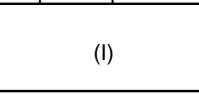 & $\begin{array}{l}\text { (I) with } \mathrm{P} 0=\mathrm{C} 0=\mathrm{Q} 0=0 \\
\Rightarrow>(\mathrm{P} 1-\mathrm{C} 1) \times \mathrm{Q} 1\end{array}$ & (1) & $\begin{array}{c}\text { (I) with in general } \mathrm{P} 1=\mathrm{P} 0 \\
\text { and } \mathrm{Q} 1=\mathrm{Q} 0=\mathrm{Q} \\
\Rightarrow>(\mathrm{C} 0-\mathrm{C} 1) \mathrm{XQ}\end{array}$ & $\begin{array}{c}\text { (I) with in general } \mathrm{P} 1=\mathrm{P} 0 \\
\text { and } \mathrm{Q} 1=\mathrm{Q} 0=\mathrm{Q} \\
\Rightarrow>(\mathrm{C} 0-\mathrm{C} 1) \times \mathrm{Q}\end{array}$ \\
\hline client=end consumer & (II) & (III) & $\begin{array}{c}\text { (II) or (III) but referring to firm } \\
\text { A product }\end{array}$ & $\begin{array}{c}\text { (II) or (III) but referring to firm } \\
\text { A product }\end{array}$ & $\begin{array}{c}\text { (III) referring to a product } \\
\text { using the process, but in } \\
\text { general }=0\end{array}$ & $\begin{array}{c}\text { (III) referring to a product } \\
\text { using the process, but in } \\
\text { general }=0\end{array}$ \\
\hline client=firm A & Not relevant & Not relevant & $\begin{array}{l}\text { (I) or (II) but referring to firm } \\
\mathrm{A} \text { product; in general } \mathrm{P} 1=\mathrm{P} 0 \text {, } \\
\mathrm{C} 1^{\circ} \mathrm{C} 0 \text { since product from the } \\
\text { partner is used as an input for } \\
\text { firm } \mathrm{A} \text { product } \\
\Rightarrow>(\mathrm{C} 0-\mathrm{C} 1) \mathrm{XQ}\end{array}$ & $\begin{array}{l}\text { (I) or (II) but referring to firm } \\
\mathrm{A} \text { product; in general } \mathrm{P} 1=\mathrm{P} 0 \text {, } \\
\mathrm{C} 1^{\circ} \mathrm{C} 0 \text { since product from the } \\
\text { partner is used as an input for } \\
\text { firm A product } \\
\Rightarrow>(\mathrm{C} 0-\mathrm{C} 1) \times \mathrm{Q}\end{array}$ & Not relevant & Not relevant \\
\hline supplier of partner & \multicolumn{6}{|c|}{ (I) or (II) but referring to the product supplied to the partner } \\
\hline competitor of partner & & & t referring to the product comp & displaced by the one of the partner & & \\
\hline
\end{tabular}

cells in grey : the effects are often neglected 
CBA Tab3

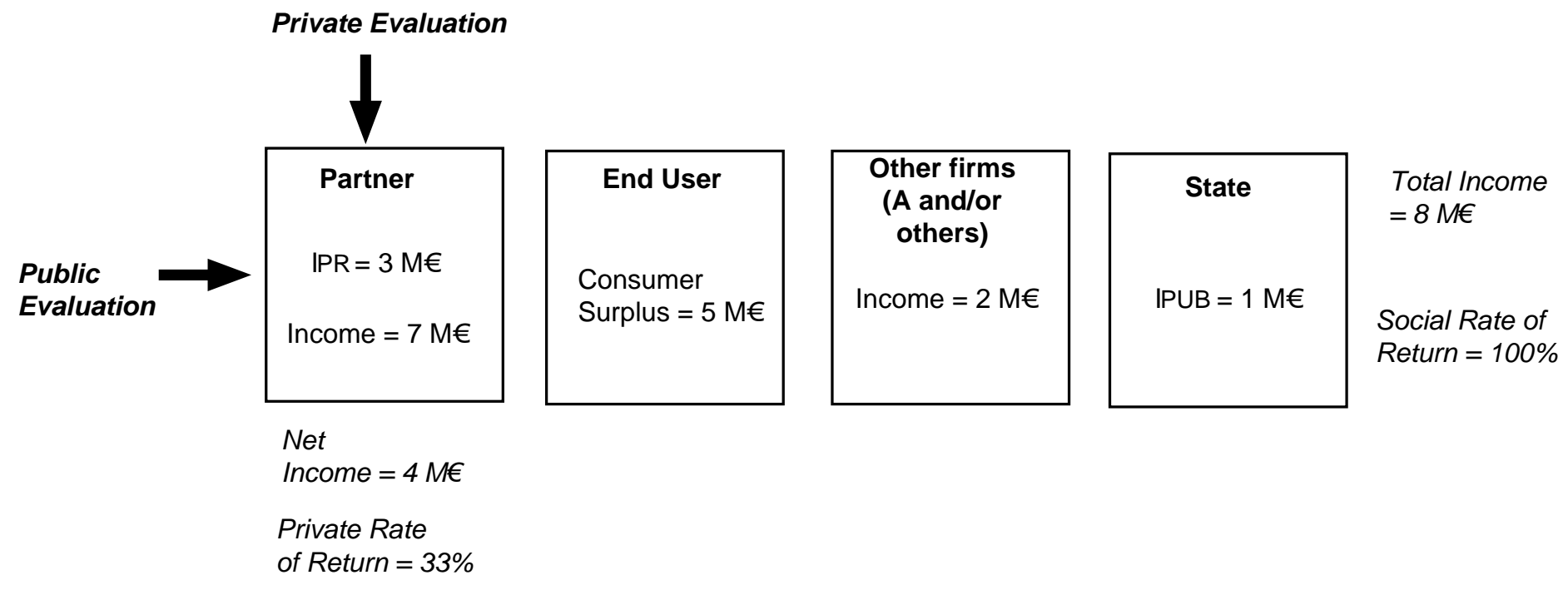




\subsection{Service Sector Case Study}

\section{Introduction}

This case study forms one part of section in which case studies are used to examine the range of impacts of Framework Programme funded research with the twin aims of characterising the research impacts and developing the most suitable evaluation tools and methods to capture those impacts. (The selection of case studies is taken from a broad range of FP supported RTD programmes which comprise those areas of support of special current significance as well as being a cross-section of the normally funded RTD portfolio of activities.) This particular case study examines and characterizes the range of effects of the research and technological development activities supported by the Framework Programme in the area of services, an area of increasing importance in modern economies. It therefore offers a taxonomy of effects based on a single but representative case typical of service sector RTD interventions, and then offers some pointers concerning the evaluation of such impacts.

This case study begins with an introduction to a general survey of the innovation process within services, deriving a broad model of impacts suitable for the context of RTD support to a services project. Thereafter, the case itself is described in terms of the types of its planned outcomes and those which arose in practice. The case study concludes with a discussion of the range of impacts observed and the balance between impacts upon the process of innovation itself and those evident upon direct beneficiaries of the technology whose development was facilitated by the project.

\section{Innovation in Services Contexts and the Prospects for Impact by RTD}

Innovation within the area of services is, as has been noted by a number of commentators, a process involving iterative, complex and dense relations between actors with the repeated exchange of information including much tacit knowledge. The essential innovation processes within the service sector case are often in contrast with the traditional innovation theories. Barras (1986) for example has introduced the concept of "reverse product cycle" in which new technology is used initially to deliver existing services but is eventually used to generate new service innovations. This perception of the innovation process places a far greater emphasis upon recombining technologies to generate new services than is present in existing theoretical approaches to innovation in manufacturing.

Miles (2001) underlines the differences between innovation in services and manufacturing by conceiving the process as one involving the "three 'i's", interactivity, information intensity and intangibility. The involvement of users is often paramount during the innovation process, yielding insights into the viability of particular technologies and their applications which feed back to the product design. Once designs are agreed, and products configured, the process of dissemination begins with the spread of products into the defined markets and often into other areas which had not been anticipated. Further iterations of the design process often follow, leading to new configurations of the technology and the discovery of new users.

Areas of services innovation where interaction reaches a greater intensity have been termed knowledge intensive business services (KIBS) by Miles et al (1995). 
Characteristic of such service activities are the following: - a) the use of professional knowledge; - b) production or use of primary sources of knowledge which are integrated from a variety of sources for clients businesses; - c) which are normally provided to business to acquire or defend a competitive advantage. Any methodology for the study of potential impacts from RTD support to services must seek to identify impacts not only upon the iterative innovation processes but also the impacts upon the professional knowledges involved.

Gadrey, Gallouj \& Weinstein, (1995) again underline the incrementalist form of services sector innovation, proposing a "recombination model" in which innovation leads to new combinations of product characteristics which lie beyond either the simple addition of new characteristics or radical changes in function. The recombination model appears to describe well the results of innovations which are the result of relatively small $R \& D$ expenditures by networks of small firms which are linked together in often transient relationships. Nevertheless, small incremental changes have the potential to make significant changes to the design and attributes of technology, leading to coherence and closure (which sometimes can be short-term) around particular designs. Intangibility, transience and the small scale of firms tend to prevent access to innovation management capabilities and intellectual property right protection facilities.

In this environment of limited recombination of characteristics, strong drivers in the form of innovation champions, see for example Rush (2000), can exercise a powerful influence upon the innovation process. Their activities in integrating different groups and interests (heterogeneous networks) allow technological artefacts or services which embody diverse characteristics to come to fruition. Their activities are particularly important in the context of the small and medium enterprise sector where individual actors are often under-resourced. Innovation champions, according to Rush (2000, page 157), often provide a range of help to SMEs which is vital because of SME's "lack of awareness, their pre-occupation with fire-fighting, their lack of time and resources for strategy and their distrust of government and other official agencies."

At the level of use of services, the network model suggests that the benefits of technological changes can occur not only as a result of the main product development and its downstream use, but also in other areas of the innovation network, often in ways which are difficult to predict. Furthermore, such changes can lead to new paradigms, i.e. developments at a systemic level rather than at the level of a product. The benefits of such changes though can be almost impossible to appropriate, as the examples of Xerox PARC given by Brown and Duguid (2000) demonstrate. The paradox of much service innovation therefore in the information age is this: "What knowledge the firm can hold onto it can't use; What knowledge the firm can use, it can't hold onto." (Brown and Duguid, 2000, page 150.)

\section{Identifying Impacts}

Any RTD supporting activity which seeks to address a service based context will therefore have lead to a range of socio-economic impacts within the process of innovation in the first instance and thereafter upon the users of such technologies and 
those affected by them in the longer term. The range of socio-economic benefits which occur within the innovation process itself will be mainly network and capability effects, while those occurring from the use of technology itself will take the form of more direct health, economic, employment and social, cultural and quality of life effects. The following diagram introduces a schema of potential benefits within the innovation process, which is applicable to services context.

Figure 10. Socio-economic Benefits: the Innovation Process and the Application of Technology

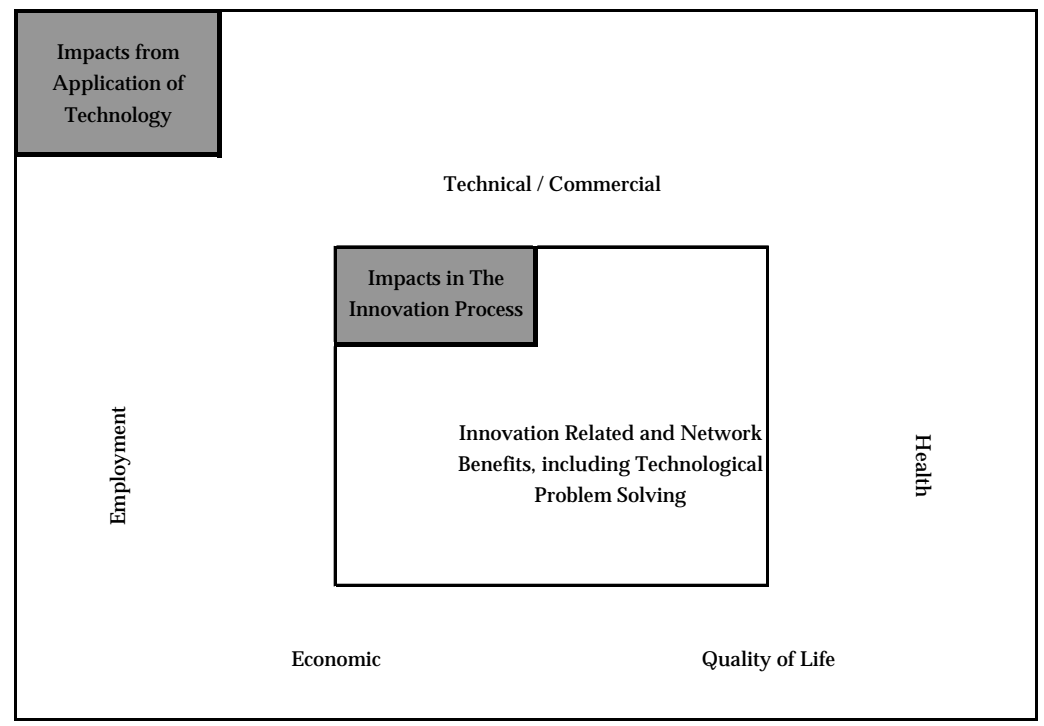

In relation to the former category of effects, it is worth noting, as a report by ZEW/ISI (Preissel, 1996) has shown, that a number of significant barriers to innovation in services are present which innovation policy measures should aim to overcome and where impacts of policy might be found therefore. Such barriers are thought to be as follows:

Box 1. Barriers to Innovation In Services (Preissl, 1998)

- Market Risk - high costs, appropriability problems

- Financial Restrictions - lack of funds for development

- Legal and Bureaucratic barriers - legal and regulatory systems

- Restrictions within the firm- qualified personnel, equipment 
The scope of possible socio-economic benefits within the services innovation context will include therefore those specified in Figure 10. Such benefits though are often dependent upon solutions to the barriers problems outlined above.

\section{Frameworks for Evaluation of Socio-economic Benefits}

In addition to the innovation process related benefits are the direct socio-economic impacts which government hopes to engender. A framework for the discovery of such benefits at project level has been presented by Miles and Barker in their interview methodology for Telematics Applications Programmes evaluation in June 1999. This framework focused on the following issues, all of which are social benefits of some kind and which are directly capable of assessment. All can be reduced to indicators, but not all of them easily.

Improved levels of service/ and higher consumer satisfaction

Improved access to service - higher numbers of people using the service

Improved safety

Better informed consumers - number of people with access to information is increased and there is a reduction in the number of errors caused by misinformation More active citizen participation occurs

Greater trust in the security and reliability of electronic interactions occurs

Reduced social exclusion - more groups defined as socially excluded are able to make use of services

Greater equality between European regions in terms of access

\section{Specifying Socio-economic Outcomes - Evaluation Issues}

\section{Introduction - The Programme Example}

The HECTOR Programme was established under the Telematics Applications Programme (TAP) of the FP4. The TAP projects were organized in the following five areas: AREA A: Telematics for Services of Public Interest; AREA B: Telematics for Knowledge; AREA C: Telematics for Improving Employment and Quality of Life; AREA D: Horizontal RTD Activities; and AREA E: Programme Support Actions. The HECTOR Programme was part of the activities under Area A, Telematics for Health Care. $^{42}$

The overall aim of the HECTOR initiative was to bring forward the development of telematics applications in healthcare which was seen as an area where there was an absence of successful integration activities then taking place but where distinct and cost-effective innovation could take place relatively easily based on existing but unexploited technologies:

\footnotetext{
42 The mnemonic HECTOR has been used by at least three FP initiatives, Health Emergency management and Coordination through Telematics Operational Resources, and HECTOR Harmonized European Concepts and Tools for Organizational information systems, part of ESPRIT 2 and HECTOR 300 High Epsilon materials Cluster Tool for Optimised Rapid deposition of stacked capacitors on 300 mm wafers, part of ESPRIT 4.
} 
"The purpose of HECTOR is to offset the general lack of a multidisciplinary approach geared to global solutions in health care emergency activities. The project will mobilise existing technology and the new capabilities of multimedia and telecommunications to pilot an integrated interoperable solution, with an optimum cost-benefit trade off. Features of the system will include prompt efficient reaction in emergencies, two-way clinical data transmission, medical telesupport at the point of care, and minimal intervention. The system will also provide training to professionals and information to citizens."

The aim of the programme therefore encompassed a range of specific goals which depended upon the successful integration of often existing technologies to create innovations in healthcare service delivery. The Programme aims were therefore based upon an understanding of the recombinative processes that shape the innovation process in the services context. The Programme ran for three years from the start of 1996 with a budget of 7.5 million Euro, and involved 60 partners overall across ten countries.

In addition to the specific project aims listed above, a number of higher level aims were listed for the Telematics Applications Programmes in the final draft of the work plan for the Telematics Applications Programme, generally confirming a new emphasis upon multimedia and cost-effectiveness. ${ }^{43}$ These were described as:

- To further promote the competitiveness of European industry and the efficiency of services of public interest and to stimulate job creation through the development of new telematics systems and services in such areas as telework and teleservices.

- The other, which is a new feature contained in the Treaty on European Union, is to promote research activities necessary for other common policies. The RTD will be based on the experience gained under the Third Framework Programme but will be directed in three new ways. Firstly, the emphasis will shift from data telematics to the new "multimedia telematics". Secondly, more importance will be attached to user requirements. Finally, particular attention will be placed on finding affordable solutions."

\section{UK Participation in HECTOR}

The UK participation in HECTOR took the form of a specific project to demonstrate the practicability of video links between the scene of an accident and the hospital. Lancashire Ambulance Service was awarded $£ 375,000$ funds for participation in the project to develop the mobile camera and data transfer systems. These were not yet at that time operational using existing communications technology and the ambulance service was told that to develop new technologies would be too expensive.

The Operations Manager of the Ambulance Service approached a number of leading manufacturers, including Cellnet, Vodafone and Siemens Nixdorf. The last of these

\footnotetext{
${ }^{43}$ European Commission - DG XIII Telecommunications, Information Market and Exploitation of Research Telematics Applications Programme (1994-1998) WORK-PROGRAMME final draft.
} 
was the only one to take an interest in the aim of the project. The Operations Manager then found another firm which was able to develop the compression software which would allow video pictures to be transmitted using existing mobile phone technologies. This technology could in fact transmit four colour pictures at once using existing $\mathrm{GSM}^{44}$ technologies.

Delivery of the technology came by the middle of 1997, when an ambulance was first equipped with cameras. The system was exhibited in 1997 and subsequently used during the Commonwealth Games in 1998. The technology was then applied in a number of high profile cases for publicity purposes although not operationally in the UK. International press interest was then attracted and a small number of television programmes were made by media companies from Germany and from the US. However, diffusion within the medical and healthcare industries around the world has been relatively slow.

\section{Innovation Process Benefits}

Resources which were made available under the HECTOR project were spent by some participants in funding existing support staff in development work for which there was either no support currently or where there had not been any in the past. These resources were used in the instance of the UK participation to appoint a series of highly qualified temporary managers to carry out the normal work functions of the UK programme member.

These resources allowed the Operations Manager to work on the development of the specific Programme brief, exploring how existing technologies might be used to create a new working telematics product which could demonstrate that the video pictures could be sent over wireless links to allow trained medical professionals based in hospitals to supervise paramedics working at the scene of an accident. This engagement was significant, requiring considerable time and commitment, with many visits to trade shows. These visits eventually provided access to an SME involved in security devices which had the capabilities to write software to compress video pictures. This firm generated software which was then embedded in a module which could be attached to the mobile phone. Existing second generation mobile phone services were then used to make a coherent video link which could send good quality pictures over GSM to hospital based workers.

Participation in the project to demonstrate the practicability of a telematics application based mostly on existing technologies also required the involvement of medical professionals, particularly doctors based at hospitals in the area in which the programme participant was located. One local hospital accident and emergency consultant took an interest, out of a possible three in the area served by the Ambulance Service.

Contact with the local hospital consultant led to the use of the service within the hospital, the demonstration of the concept as practicable to the local medical staff, the start of an small scale clinical trial and a number of publications within the medical literature on the operation and effectiveness of telemedicine applications. Trainee

\footnotetext{
${ }^{44} \mathrm{GSM}$ is the world-wide non proprietary system for mobile phone communications and stands for global system for mobile communications.
} 
doctors (House Officers, SHOs) and above were also introduced to telemedicine, although it is not clear whether interest stimulated by the project in the Blackpool Victoria Hospital has led to the introduction of the technology elsewhere in the United Kingdom. An unexpected outcome of the project was greater awareness of the importance of facial expressions of the patient in diagnosis.

Stemming from the project itself, and taking the form of extended network and innovation process benefits was an interest in other telematics applications and the use of emergency equipment within the ambulance. The Operations Manager's experience of defibrillators led him to work closely with a the major US manufacturer of technology in an attempt to make the technology smaller and more effective. He did this without financial reward for either him or for the hospital or the ambulance service. The exchange of ideas led to the development of a far smaller defibrillator device, and the adoption of the equipment for use in the Lancashire Health Service area.

Impacts extended into health and community medicine through a scheme which the Operations Manager initiated to train first aiders in outlying villagers in Lancashire in the use of the new portable defibrillators. This scheme is now known as the "First Responder Scheme". The Lancashire Ambulance Service has also begun to train paramedics from other areas of the UK in the use of telemedicine technologies, particularly in the use of the 12-lead ECG. There are around 60 Ambulances in the Lancashire area with the new defibrillator.

The HECTOR network was operated by the Spanish electronics firm Sadiel. This firm provided Mr Curry with much help, giving him access to experts in a variety of fields and personal support. After the success of HECTOR, Mr Curry found himself receiving a large number of requests for help and advice on related telematics projects, mainly through contacts made during HECTOR. Following his involvement in HECTOR, Mr Curry began an involvement with the British Association of Communications Officers.

\section{Technical and Commercial Impacts}

Before the project, i.e. before 1996, telemedicine involving the transmission of pictures for emergency use was not practiced in the UK. After the project was completed, a product was delivered which was capable of use within an ambulance. In the local area where the Project operated, around 8 ambulances were fitted with the technology, and it is planned that the technology will be provided to the whole fleet. It is conceivable that other activities might have led to the introduction of the technology, but it is unlikely, largely as a result of the unique social and economic context of the UK Health Service. In terms of immediate commercial benefits, at the end of the project in 1999, a new product had become available in the specific area in which this area of HECTOR was operating, and the price of a unit of the new product which emerged was to fall from $£ 15,000$ at the end of the project to around $£ 2,500$ per equipped ambulance two years later. 
In addition to the single phone line which transmits the pictures to the hospital, a second telephone can also be used to allow the paramedic to talk to the doctor in the Accident and Emergency Department. Cameras are positioned within the ambulance and also outside as this can be used to give additional information to the doctor. Broader technical impacts, which have occurred in other fields have been the use of low wattage cameras to send pictures over longer distances using GSM for surveillance purposes. The UK military is thought to have begun to use the technology. Other military applications of the technology proved by HECTOR elsewhere in the world employ higher wattage transmitters are thought to have occurred, although these are may well have adverse health effects in terms of substantially increased risk of tumours in the head and upper body for those operating the equipment.

\section{Health}

The health benefits which stem from the use of medical and medical related technologies are often delayed by a number of years as the technologies normally require approval from a number of regulatory bodies. In the case of the UK, the relevant authorities include the Department of Health, the Medicines Control Agency, The Medical Devices Agency, the General Medical Council and Royal Colleges of Medicine, which have a licensing role for individual medical practitioners, the National Institute for Clinical Excellence, and other statutory bodies and committees reporting to the Secretary of State for Health. The wider dissemination of information about particular technologies may take place relatively easily through professional journals, but the use of the technologies often requires testing and trialling to build up an evidence base which would justify wider use. Health benefits may also be delayed as management seeks to alter working practices required by the adoption of the new technologies.

In the case of telematics, where pictures are transferred and stored, the issue of privacy must also be addressed as the Data Protection Act stipulates those who are photographed must give their permission for pictures of them to be stored. This permission is however normally forthcoming, and the footage has proved useful in the training of health service staff.

The dissemination of technologies within the UK health service environment is also affected by resource questions, as well as the regulatory framework. In the UK, health service provision has been managed and controlled at a variety of levels. Historically, significant financial management responsibility for provision of the health service lay at regional and sub-region levels, but during the 1980s and 1990s, this was largely devolved to the level of individual hospital trusts. These trusts have been in effective competition with each other to provide a wide range of patient services. Collaboration between different groups on a variety of matters, including the development of new technologies, was ceased abruptly when the trusts were created. It is difficult to assess whether the rate of technological development in the health service was altered by creation of the trusts, or whether the trust system led to a level of competition that would increase the effectiveness of such initiatives such as HECTOR.

Evidence from the academic literature of a wide-spread interest in telematics for emergency medicine is clear. Since the mid 1980s, the medical literature has carried 
reports of the use of the importance of early pre-hospital care, and also the respective efficiencies of paramedics and ambulance technicians in the long term patient outcomes. During the 1990s, articles on the use of telematics, to deliver emergency care began to increase. A simple assessment of the number of articles on telematics shown below in Table 29 indicates a strong growth in professional interest the following

Table 29. Publications on Emergency Telemedicine Per Year, Telematics Information Service

\begin{tabular}{|l|l|l|l|l|l|l|l|l|}
\hline Year & Pre 1995 & 1995 & 1996 & 1997 & 1998 & 1999 & 2000 & 2001 \\
\hline Citations & 3 & 2 & 0 & 3 & 8 & 6 & 5 & 6 \\
\hline
\end{tabular}

The HECTOR study has generated two articles (at 2001) in the medical literature, which appeared in 1998 and 1999. The second article, published by the hospital consultant who worked with the UK participant in HECTOR, has received three citations. The citation of the initial paper suggests the long term importance of the work carried out through the work supported by HECTOR upon three critical areas for emergency care. Firstly, the paper by Istepanian et al (1999) deals with the reliability of the technology of transmission of medical data across GSM networks (for Europe) and IS-54 networks (for the United States). The second paper (Anantharaman \& Han, 2001) is concerned with the transmission of further data, especially that from the 12-lead electro-cardiograph equipment, from the ambulance to hospital with the objective of reducing the amount of time required for diagnosis and therefore the time to treatment in Singapore. The third paper takes the form of a description of the technology to medical practitioners and computing and telematics engineers in Spain.

While there is an international literature on medicine and telemedicine - evidenced by the discussion in the academic literature of the use of telematics in Sweden, Italy, Japan, Greece and Russia - and also an international market for telemedicine equipment, it should not be assumed that telemedicine innovations would have freely diffused into the UK from outside and been adopted at the prevailing rate. In fact, in a sector with a range of complex and interlocking governance and management systems, the diffusion of this new telematics application appears to have occurred by means of a "bottom-up" progression, in which the "invisibility" of the innovation from governance structures has partly secured its future.

\section{Economic and Commercial Impacts}

The economic benefits of the HECTOR initiative examined here arise in two areas. Firstly there are those cost savings from the improved treatment for patients which follow from the improved advice given by doctors to ambulance staff through the medium of HECTOR based technologies. Such benefits also may be visible in the hospital system, whereby as a result of more rapid treatment, lower expenditures on health costs are expended. Thirdly, commercial benefits have followed in the form of extra revenues from the manufacture, sale and operation of the HECTOR based 
technologies. The reduction in the health costs associated with the introduction of the HECTOR technologies could be assessed with economic modelling and auditing.

In relation to first type of economic effects, the evidence on the general level of effectiveness of such treatment from a large scale clinical trial is, as stated above, not yet available. However, some anecdotal evidence does suggest that life-savings treatments have been administered through the use of the telematics applications developed in the UK as a result of HECTOR. Improved clinical outcomes in terms of the saving of life and reduced future life saving and reduced suggests that when the technology is further diffused, other benefits will be delivered. Economic effects in terms of training benefits for those with telemedicine skills have also occurred.

\section{Employment}

The employment effects of the HECTOR technologies have mainly impacted paramedic and ambulance technician crews and doctors operating in accident and emergency facilities in the Lancashire area. These individuals have been in the forefront of the development of new technologies, and some have taken training opportunities as a result. In the longer term, the power to supervise treatment from a distance could be used to broaden the range of activities and treatments which paramedics might carry out or conversely, it could be used to narrow the range of responsibilities. These issues are difficult to decide, and outcomes are only likely to be observed in the longer term.

Telematics applications under HECTOR have given the potential for a greater level of supervision of paramedics at work. Thus far, medical practitioners have used the technology with the aim of improving patient care through assisting paramedics and for training purposes of both paramedics and doctors. However, medical managers and clinicians to some extent could easily begin to use the technology for supervision and surveillance of ambulance crews. In the event of a medical negligence claim though, video pictures could be used against the health service.

HECTOR technologies have been part of an increasing use of information technologies in the health service context. This process has led to significant reductions in the numbers of staff involved in the control and despatch of ambulances. Before the widespread use of computerized despatch of ambulances and computerized information services in ambulances, around 20 people were required at any one time in the ambulance control service for the Lancashire area. As a result of the introduction of information technologies, only 2 people are now required to operate this function. Those operating it are also thought be under less stress as they send information to the ambulances by computer rather than by voice.

\section{Quality of Life}

Quality of life benefits follow from the immediate health benefits which faster and more effective treatment brings. In modern treatment of "heart attack" caused by coronary thrombosis (blood clot), treatment within the hour with thrombolytic drugs has the chance of substantially reducing the risk of death. HECTOR technologies promise to reduce the amount of time taken to administer such drugs, the so -called "time to needle". In acting to promote the development of such technologies and supporting their dissemination, the HECTOR programme has made a contribution to 
patient care to a small group of individuals within a small geographical area in the short term. In the longer term, however, through the demonstration of the technology, these benefits are likely to occur in a far broader geographical area.

\section{Conclusions}

The benefits which have arisen from the HECTOR project involve developments within the innovation process itself and also socio-economic benefits stemming from improved health care service and economic and commercial benefits from the development of technologies. This is a broad range of impacts, some of which have occurred within the relatively short term, particularly those within the innovation process itself. The user focused impacts have taken longer to emerge, and given the nature of general area - health service provision - they are only likely to follow when there is a clear evidence base which demonstrates both cost-effectiveness and safety.

Initially, HECTOR sought to generate impacts by exploring a technological design space and developing solutions to known and perceived problems, some which might then proceed to commercial availability in the area of health telematics. Given that some of the technological developments are directly connected with patient care, the process of technological innovation which stems from HECTOR was likely to involve lengthy verification and review before impacts at the level of technological standards, infrastructures and healthcare treatment protocols could begin to occur. Once such impacts did begin to happen, societal impacts in terms of improved medical care, employment effects were then possible, following which other less tangible but equally significant impacts might arise. The framework of intended impacts therefore would take the form a cascade of impacts beginning with the technological development phase, moving towards the development of a range of technologies and standards from which derive a range of direct benefits from the use of those technologies.

The question has been raised about the relevance or otherwise of the reverse-product cycle model of services innovation (see conceptual discussion), and whether such a model is helpful to attempts to assess impacts of RTD support. In the example given here of the HECTOR programme, existing technologies have been combined to meet a pre-defined, pre-existing service need, with the innovation process occurring within a relatively short time period. In the longer term, an innovation which creates a new commodity or service from technologies implemented by TAP could well occur. While our study does not suggest evidence of a reverse product cycle occurring, we believe that the model should remain a source of insight for policy on services innovation in the medium and longer term. 


\section{References for Section 3.2}

Anantharaman V. \&Han L.S. "Hospital and emergency ambulance link: using IT to enhance emergency pre-hospital care" INT J MED INFORM 61 (2-3): 147-161 MAY 2001

Barras, R. (1996) Towards a theory of innovation in services" Research Policy, Vol. 15, No. 3, pages 161-173.

Barro S., Presedo J., Castro D., et al. "Intelligent telemonitoring of criticalcare patients" IEEE ENG MED BIOL 18 (4): 80-88 JUL-AUG 1999

Boden, M. \& Miles, I. (2000) Services and the Knowledge Based Economy, Continuum: London

Curry GR, Harrop N "The Lancashire telemedicine ambulance" JOURNAL OF TELEMEDICINE AND TELECARE 4 (4): 231-238 1998

Gadrey, J., Gallouj, F. \& Weinstein, O. (1995) "New Modes of innovation", International Journal of Service Industry Management, Vol. 6, No. 3, pages 4-16

Istepanian RH, Woodward B, Balos PA, et al. "The comparative performance of mobile telemedical systems based on the IS-54 and GSM cellular telephone standards" J TELEMED TELECARE 5 (2): 97-104 1999

Miles, I. (1996) "Innovation in services - Services in innovation" Manchester Statistical Society

Preissel, B. (1998) "Barriers to innovation in services: summary of the results of the SI4S project"

Rainer TH, Houlihan KPG, Robertson CE, Beard D, Henry JM, Gordon MWG "An evaluation of paramedic activities in prehospital trauma care" INJURYINTERNATIONAL JOURNAL OF THE CARE OF THE INJURED 28 (9-10): 623627 NOV-DEC 1997

Telemedicine Information Exchange, Portland: Oregon 


\subsection{Programme-Level Case Study}

The impacts associated with projects conducted within the context of RTD programmes can be explored and assessed in many ways. Some approaches specifically attempt to provide quantitative estimates of particular outputs, outcomes and impacts. These include publication, patent and product counts on the one hand and attempts to measure the commercial returns associated with participation in individual projects on the other. Attempts to quantify the downstream externalities associated with individual projects and participations, however, are very rare.

Some of these more quantitative attempts to assess impacts are explored later in another section, particularly those methodologies aimed at assessing the financial benefits which accrue to firms as a result of their participation in RTD programmes. In the first instance, however, we turn our attention to methodologies which prioritise an enhanced understanding of the nature and dynamics of projects - and, crucially, their relationship with different types of impacts - over and above the explicit quantification of benefits in financial terms. In particular, we comment upon:

- the use of ex post questionnaires to assess the range and relative importance of impacts associated with participation in RTD programmes;

- the use of external project evaluators conducting telephone interviews and desktop analyses to perform comprehensive ex post reviews of all projects within a programme;

- the combined use of questionnaires and mini-case studies to identify and analyse projects with high commercial returns.

Questionnaires: The Five Year Assessment of the Framework Programmes, 19951999

As part of the process of assessing performance within the Framework Programmes over the period 1995-99, a questionnaire was designed by the main Framework Panel and distributed by Atlantis Research Organisation to a sample of participants in the Third and Fourth Framework Programmes. Over 2,000 responses were received and the results of the exercise summarised in the resultant report of the Panel $^{45}$ (see Exhibit 1).

The questionnaire analysis demonstrated that the range of impacts associated with participation in the Framework Programmes is very broad, ranging from immediate 'first circle' effects, e.g. project outputs (publications, new or improved methods and tests, demonstrators, prototypes or pilots) and impacts affecting the researchers themselves (improved knowledge bases, enhanced scientific and technological capability); through downstream 'second circle' impacts affecting whole participating organisations (e.g. new or improved products and services, improved competitiveness, commercial returns etc.); to longer-term or 'third circle' socio-economic impacts in a

$45 \quad$ European Commission (2001), 'Five-year Assessment of the European Union research and technological development programmes, 1995-99', Report of the Independent Expert Panel (Chair: J. Majó; Rapporteur: K. Guy), Luxembourg: Office for Official Publications of the European Communities, EUR 19426 
variety of external spheres (e.g. improved economic development, improved policy formulation etc.). 


\section{Exhibit 1 Highlights from the Five-Year Assessment Questionnaire}

Questionnaire responses were received from 2275 participants in the Third and Fourth Framework Programmes. Fifty-seven percent of the responses came from universities and research organisations; $38 \%$ from industry; and 5\% from other organisations.

\section{Benefits}

$70 \% \quad$ said that the benefits of participation outweighed the costs ( $72 \%$ of academic and $62 \%$ of industrial partners)

Relevance

$72 \% \quad$ said that the work conducted was of high strategic importance to their organisations

$70 \% \quad$ said that their projects were highly relevant to the RTD goals of the EU

$62 \%$ felt that their projects were highly relevant to world scientific and technological developments generally

Additionality

$71 \% \quad$ would not have undertaken the work in the absence of the Framework Programmes

$29 \%$ would have done the work but with reduced funds, lower objectives, fewer partners and over longer time-scales

Motives and Goals

$82 \% \quad$ said enhancement of their existing knowledge base was a very important goal

$68 \%$ said the development or improvement of new tools was a very important goal

$67 \%$ said access to complementary expertise was a very important goal

$60 \%$ said the formation of new European research partnerships and networks was a very important goal

$51 \%$ said access to additional funds was a very important goal

Industrial Expectations

$69 \%$ of industry participants said the development or improvement of new tools was a very important goal

$57 \%$ of industry participants said that the production of demonstrators, prototypes etc. was a very important goal

$53 \%$ of industry participants said that the development of new products was an important goal

$48 \%$ of industry participants said that the development of new or improved processes was a very important goal

$35 \%$ of industry participants said that the development of new or improved services was a very important goal

\section{Nature of Work}

$68 \%$ of participants classified their work as applied research (72\% of academic and $62 \%$ of industrial partners)

$37 \% \quad$ classified it as basic research (47\% of academic and $17 \%$ of industrial partners)

$59 \%$ described it as long-term (62\% of academic and 55\% of industrial partners)

\section{Goal Attainment}

95\% felt that participation had improved their scientific and technological standing (high impact for 55\%)

$79 \%$ were very satisfied with the quality of their project outputs, $69 \%$ with their utility and $60 \%$ with their timeliness

94\% attained goals or exceeded expectations in terms of enhancing existing knowledge bases

$89 \%$ attained goals or exceeded expectations in terms of the development or improvement of new tools

90\% attained goals or exceeded expectations in terms of accessing complementary expertise

88\% attained goals or exceeded expectations in terms of forming new European partnerships and networks

Industrial Achievements

$42 \%$ of industry participants continued to develop project outputs in their $R \& D$ units

$34 \%$ of industry participants continued further development in their business units

$75 \%$ of industry participants said that participation had improved their competitive position (high impact for 30\%)

$11 \%$ of industry participants had already received significant commercial returns

$50 \%$ of industry participants had already received some commercial returns

$69 \%$ of industry participants said they had plans for future commercialisation

Programme Management and Administration

$65 \% \quad$ thought the whole application process was too slow and/or costly

$45 \%$ of respondents thought that application procedures were difficult to follow

$35 \%$ felt the accompanying documentation was inadequate or too complex to understand

$24 \%$ were dissatisfied with payment procedures (31\% of SMEs)

$10 \%$ felt that the competence of Commission officials had been an important barrier to the success of their projects $63 \%$ were positive about the help they had received from Commission officials over the lifetime of their projects 
Not unexpectedly - given that respondents were researchers involved in the projects expected 'first circle' impacts were most frequently cited as the most important project goals. Goal attainment, too, was highest in 'first circle' domains. Exhibit 2 shows the relative importance and degree of achievement associated with four types of project goal, namely:

- Knowledge-oriented goals. These are goals of a technical nature concerned with the expansion and consolidation of know-how and knowledge bases. Examples include 'Deepen Understanding', Upgrade Skills' and 'Develop New Tools and Techniques';

- Exploitation-oriented goals. Some goals have a strategic or commercial orientation and are more concerned than others with the eventual exploitation of knowledge and skill bases. Examples include 'Develop New Products', 'Production of Patents and Licences' and 'Improve Competitiveness';

- Network-oriented goals. These relate to network formation and the establishment of new links and partnerships. They have a structural or systemic nature in that they invariably refer to the relationship between an organisation and its environment. Examples include 'Access Academic Know-how' and 'Establish New Academic-Industry Links';

- Strategic Management-oriented goals. Goals such as 'Access Additional Funds', 'Reduce Costs' and 'Spread Risks' reflect a combination of opportunistic, economical and parsimonious practices characteristic of sound R\&D management and stewardship.

It is clear that researchers themselves prioritised knowledge-oriented goals over exploitation-goals, and that they regarded achievements in the former to exceed achievements in the latter sphere. Almost all participants (95\%) felt that participation had improved their scientific and technological standing, whereas only $11 \%$ of industrial participants claimed to have received significant commercial returns by the time the questionnaire was circulated (at the start of the Fifth Framework Programme).

These results are characteristic of many collaborative RTD programmes, with knowledge-oriented goals such as the development of new tools and techniques and the enhancement of existing knowledge bases cited much more frequently as important goals than those more overtly concerned with eventual exploitation, e.g. the development of new products or improved competitiveness in the market place. This does not mean that the latter are unimportant drivers, however. In terms of expected and realised outputs and impacts they were very important. The results simply reflect the fact that the primary goals of RTD projects are couched in terms of knowledgerelated ambitions, whereas the longer-term expectations of the organisations involved in these projects are that improvements to the knowledge base will ultimately be translated - either directly or indirectly - into improvements in overall performance in the market place. 
Exhibit 2 Importance of Goals and Degree of Achievement in the Third and Fourth Framework Programmes
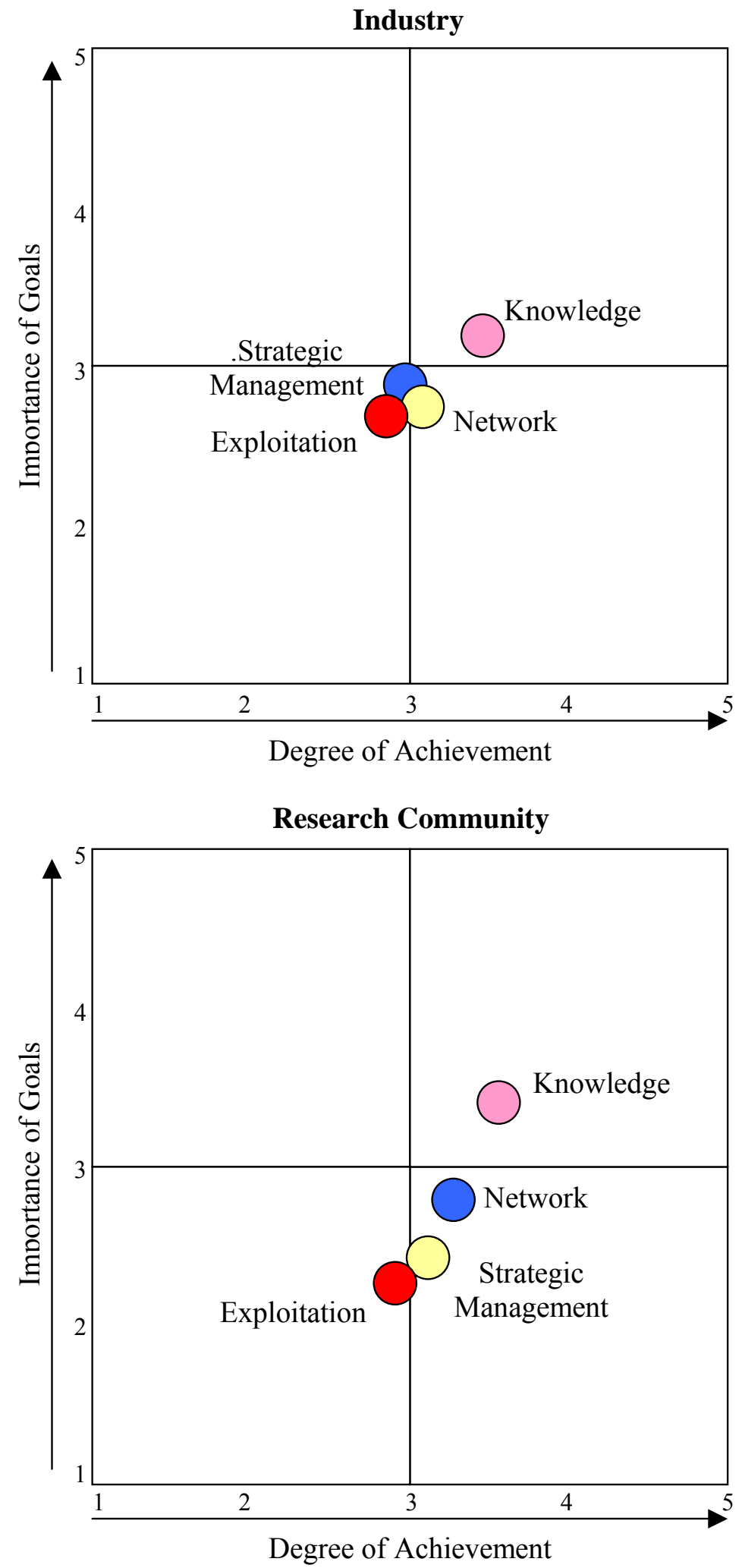
The importance of ultimate exploitation as a driver for the industrial partners in Framework projects was demonstrated in a further analysis of the Five-Year Assessment questionnaire data which looked more closely at the performance of SMEs and Large Enterprises (LEs). ${ }^{46}$ In the first instance, the overall results for both populations were compared and contrasted. Secondly, in order to explore the existence of relationships and associations between a number of variables in the questionnaire, a series of simple cross tabulations were made for the two populations. The variables concerned were as follows:

- Cost/ Benefit Ratios;

- Impact on Own Organisation;

- Strategic Importance;

- Commercial Returns;

- Future Commercialisation Plans;

- Cost of Projects;

- Risks Associated with Projects;

- Projects in Core/Peripheral Technology Areas;

- Projects with Short/Long-term Orientations;

- Projects with Product/Process Orientations;

- Projects with Pure/Process Additionality;

- First Participation of Organisations;

- First Participation of Teams.

The results confirmed a number of a priori expectations, primarily those linking variables such as high impact, high benefit to cost ratios, high perceived strategic importance of projects, location of projects in core technology areas, early commercial returns and plans for future commercialisation. By and large, these associations existed for both large and small firms. They demonstrate clearly that even researchers within firms make a strong conceptual link between strategic importance, high impacts and benefits and ultimate commercial outcomes for their firms. This was particularly the case for SMEs.

There were also a number of interesting - though again not unexpected - associations between the perceived cost and risk levels of projects and other variables. In particular, high cost projects tended to be associated with higher risks, higher strategic importance and higher eventual impacts on organisations. This was true for both SMEs and LEs

The results of this extended analysis for SMEs and LEs involved in Framework Programmes are summarised in Exhibits 3 and 4.

\footnotetext{
46 Conducted at the request of DG Research by Atlantis Research Organisation and Wise Guys Ltd.
} 


\section{Exhibit 3 Similarities between Large Firms and SMEs involved in the Third and Fourth Framework Programmes}

\begin{tabular}{|c|c|}
\hline 1 & The vast majority of SME and LE projects were Shared Cost projects. \\
\hline 2 & $\begin{array}{l}\text { The vast majority of SMEs and LEs regarded their projects as strategically important to } \\
\text { their organisations. }\end{array}$ \\
\hline 3 & $\begin{array}{l}\text { Approximately half of the projects conducted by both SMEs and LEs were linked to } \\
\text { other in-house projects. }\end{array}$ \\
\hline 4 & SMEs and LEs both tended to work with equal numbers of new and familiar partners; \\
\hline 5 & $\begin{array}{l}\text { In terms of goal attainment, outcomes exceeded expectations for the goals considered } \\
\text { most important by both SMEs and LEs, e.g. knowledge-oriented goals related to the } \\
\text { enhancement of existing knowledge bases and the production of new knowledge. }\end{array}$ \\
\hline 6 & $\begin{array}{l}\text { Both SMEs and LEs emphasised that new products, prototypes, processes, services and } \\
\text { new or improved methods or tests were important project outputs. }\end{array}$ \\
\hline 7 & $\begin{array}{l}\text { Presentations in seminars and publications were the dominant modes of dissemination for } \\
\text { both SMEs and LEs. }\end{array}$ \\
\hline 8 & $\begin{array}{l}\text { For both SMEs and LEs, outputs were being demonstrated, evaluated and developed } \\
\text { further within in-house RTD settings. Many outputs had also migrated to business units } \\
\text { and were frequently in regular use in both RTD and business unit settings. } \\
\text { Demonstration and dissemination to other organisations outside the partners involved in } \\
\text { the projects had also commenced. }\end{array}$ \\
\hline 9 & $\begin{array}{l}\text { The manufacturing and service sectors were the dominant end users of SME and LE } \\
\text { project results, with the scientific community as an important intermediate user. }\end{array}$ \\
\hline 10 & $\begin{array}{l}\text { The majority of SMEs and LEs had plans for future commercialisation, though few had } \\
\text { received significant commercial returns by the time of asking. Substantial minorities of } \\
\text { the SME and LE populations ( } 17 \text { and } 24 \% \text { respectively), however, had had no } \\
\text { commercial returns and had no plans for future commercialisation. }\end{array}$ \\
\hline 11 & $\begin{array}{l}\text { EU markets were the most popular targets for SMEs and LEs, with most of the first } \\
\text { commercial returns expected over a year after the completion of projects. }\end{array}$ \\
\hline 12 & $\begin{array}{l}\text { The most important impacts on SMEs and LEs were to enhance their scientific and } \\
\text { technological standing and to improve competitive positions. Downstream impacts on } \\
\text { productivity and employment levels were much less marked. }\end{array}$ \\
\hline 13 & $\begin{array}{l}\text { Considering external impacts at regional, national and EU levels, improved scientific and } \\
\text { technological capability and enhanced competitiveness were again the most frequently } \\
\text { predicted impacts by both LEs and SMEs. }\end{array}$ \\
\hline 14 & $\begin{array}{l}\text { There were few discernible difference between the responses of the LE and SME } \\
\text { populations when asked to comment on a whole series of issues related to the relevance, } \\
\text { calibre and impact of the work they had conducted. }\end{array}$ \\
\hline 15 & $\begin{array}{l}\text { Intrinsic technological difficulties, over-ambitious project goals and insufficient funding } \\
\text { were the dominant obstacles to project progress for SMEs and LEs alike. In terms of } \\
\text { differences. }\end{array}$ \\
\hline 16 & $\begin{array}{l}\text { Relative size made little difference to participants' assessments of EU procedures for } \\
\text { making an application for research funding. The majority of SME and LE populations } \\
\text { found procedures to be slow and costly. }\end{array}$ \\
\hline 18 & $\begin{array}{l}\text { In terms of participants' levels of satisfaction with administrative procedures during the } \\
\text { course of projects, the proportion very dissatisfied with payment procedures was greater } \\
\text { for SMEs than for LEs, but otherwise there were few significant differences between the } \\
\text { SME and LE populations. }\end{array}$ \\
\hline 19 & $\begin{array}{l}\text { Both SMEs and LEs linked success with high strategic importance, high benefit-to-cost } \\
\text { ratios, work in core areas, high commercial returns, and plans for future } \\
\text { commercialisation. }\end{array}$ \\
\hline 20 & $\begin{array}{l}\text { For LEs and SMEs, high cost projects tended to be associated with higher risks, higher } \\
\text { strategic importance and higher eventual impacts on organisations. }\end{array}$ \\
\hline
\end{tabular}




\section{Exhibit 4 Differences between Large Firms and SMEs involved in the Third and Fourth Framework Programmes}

\begin{tabular}{|c|c|}
\hline 1 & $\begin{array}{l}\text { absolute terms, the average size of projects in which LEs were involved was twice that } \\
\text { projects in which SMEs were involved. }\end{array}$ \\
\hline 2 & $\begin{array}{l}\text { The average project for an SME involved more SME partners than LE partners. } \\
\text { Conversely, the average project for an LE involved more LE partners than SMEs; }\end{array}$ \\
\hline 3 & $\begin{array}{l}\text { Half the organisations involved acted as both technology providers and users. Fewer } \\
\text { SMEs than LEs acted as users alone. }\end{array}$ \\
\hline 4 & $\begin{array}{l}\text { LEs generally had more experience in Framework Programmes, with around half of the } \\
\text { SME organisations and teams participating for the first time. }\end{array}$ \\
\hline 5 & $\begin{array}{l}\text { LEs mentioned applied research more frequently as a main project focus. LEs also } \\
\text { conducted basic research more frequently than SMEs, whereas SMEs were involved } \\
\text { more frequently in demonstration and awareness activities. }\end{array}$ \\
\hline 6 & $\begin{array}{l}\text { The work conducted by SMEs was more likely to be in core technology areas and to } \\
\text { have a more pronounced diffusion orientation. }\end{array}$ \\
\hline 7 & $\begin{array}{l}\text { As expected, the LEs involved in Framework Programmes generally had higher R\&D } \\
\text { apabilities than their SME counterparts. }\end{array}$ \\
\hline 8 & $\begin{array}{l}\text { In terms of motives and goals, the most noticeable differences between the two } \\
\text { populations were the high ranking given to enhanced status and reputation by SMEs and } \\
\text { the slightly greater emphasis they placed on the pragmatic development of new tools and } \\
\text { techniques. }\end{array}$ \\
\hline 9 & $\begin{array}{l}\text { Further development was the key factor likely to enhance commercial exploitation for } \\
\text { LEs and SMEs, though SMEs also valued access to further funding and greater } \\
\text { marketing effort whereas LEs laid more frequent stress on the need for more research. }\end{array}$ \\
\hline 10 & $\begin{array}{l}\text { LEs generally involved larger numbers of staff in projects, a hig } \\
\text { were classified as research staff ( } 46 \% \text { for LEs; } 35 \% \text { for SMEs). }\end{array}$ \\
\hline 11 & $\begin{array}{l}\text { ontinuing RTD in further EU programmes was a popular option with all organisations. } \\
\text { Es were more likely than SMEs, however, to continue work in established research } \\
\text { ajectories using their own resources. }\end{array}$ \\
\hline 12 & $\begin{array}{l}\text { was critical for most organisations - SMEs in particular - in that few would } \\
\text { ken the projects in the absence of funding (only } 27 \% \text { of SMEs and } 38 \% \text { of }\end{array}$ \\
\hline 13 & $\begin{array}{l}\text { participation outweighed the costs for the majo } \\
\text { lore appreciative than SMEs. }\end{array}$ \\
\hline 14 & $\begin{array}{l}\text { Es were more frequently hampered by the divergent objecti } \\
\text { quently obstructed by internal restructuring. These are dir }\end{array}$ \\
\hline 15 & $\begin{array}{l}\text { LEs were slightly more positive about the help they received from Commission officials } \\
\text { at all stages of the project life-cycle. Very few LEs or SMEs found Commission } \\
\text { officials unhelpful or obstructive. }\end{array}$ \\
\hline 16 & $\begin{array}{l}\text { ational officials provided little assistance to SMEs and LEs, though when it was } \\
\text { ovided SMEs found national officials to be slightly more helpful than did their LE } \\
\text { unterparts }\end{array}$ \\
\hline 17 & which hadn't had any comm \\
\hline 18 & $\begin{array}{l}\text { Large firms involved in high cost, risky projects were more likely to have plans for } \\
\text { commercialisation than their SME counterparts. }\end{array}$ \\
\hline 19 & $\begin{array}{l}\text { Large firms in product-oriented projects were more likely to have plans for } \\
\text { commercialisation than their SME counterparts. }\end{array}$ \\
\hline 20 & ere more likely to equate long-term work with high risk than SMEs. \\
\hline 21 & $\begin{array}{l}\text { use EU funding to accelerate or enhance work streams } \\
\text { eas than their SME counterparts. }\end{array}$ \\
\hline 22 & $\begin{array}{l}\text { SME teams and organisations with previous experience of participation in Framework } \\
\text { Programmes were involved in more lower cost projects than their less experienced SME } \\
\text { counterparts. This was not the case for LEs. }\end{array}$ \\
\hline
\end{tabular}




\section{Independent Project Assessments: The Evaluation of Projects in the Areas covered by the Growth Programme}

The analysis of the Five Year Assessment data was sufficient to reveal the range of impacts associated with participation in Framework Programmes and the nature of the impacts specifically associated with firms involved, typically, in more marketoriented projects. It also demonstrated, via simple cross-tabulations, some of the associations between certain input variables (e.g. cost and risk), 'first circle' impact variables (perceived cost/benefit ratios) and 'second circle' impacts (impact on own organisation, commercial returns etc.).

More sophisticated analytical techniques were used to explore the relationship between different types of market-oriented projects and goal attainment in another exercise involving a similar data set. During 2001, an ex post evaluation of all projects terminating in 1999 in the programme areas currently covered by the Fifth Framework GROWTH Programme was conducted by the GOPA Consortium. ${ }^{47}$ Rather than sending questionnaires to a sample of participants, teams of independent evaluators reviewed project reports and conducted telephone interviews prior to the completion of a set of assessment project forms covering a range of project characteristics and impacts.

The basic design elements for this evaluation were similar to those used in the Five Year Assessment questionnaire. Indeed, many of the questions and responses were directly comparable, since they had the same format and used similar scoring systems. The main proviso concerning comparability stems from the fact that that the responses to the Five Year Assessment questionnaire were completed by participants themselves rather than by independent project evaluators. It should also be noted that the questionnaire responses were analysed for participants, whereas the GROWTH assessment forms were completed for individual projects.

The results of the exercise indicated that typical projects in the GROWTH programme were medium cost projects of considerable technical complexity but presenting only moderate technical risks and quite modest commercial risks. Projects were applied rather than fundamental, located in core technology areas for the organisations concerned, and were only feasible in the context of collaborative research, i.e. access to complementary expertise was a necessity for most projects rather than a luxury or an unwelcome constraint. Projects were also considered to be strategically important by the partners concerned.

\footnotetext{
$47 \quad$ GOPA Consortium (2001), 'Evaluation of Finished Projects of the EU Research Programmes in the Fields Covered by the Present GROWTH Programme', Report to DG RESEARCH, Brussels: GOPA
} 
In terms of goals, the results were similar to those obtained by the Five Year Assessment questionnaire, with knowledge-oriented goals cited much more frequently as important goals than those more directly concerned with eventual exploitation. As stated earlier, however, this should not be take to mean that exploitation was considered unimportant - more that it was expected to occur as a consequence of primary, knowledge-related goal attainment. Indeed, the importance of exploitation is demonstrated by the fact that $8 \%$ of projects had led increased turnover within three years of project end ( $3 \%$ turnover increase of more than $€ 5 \mathrm{M}$. In contrast, however, it should be emphasised that over $90 \%$ of projects had benefited in 'non-financial' terms, typically in terms of improving their scientific and technological competence and, occasionally, via more downstream improvements to production processes and product and service ranges.

Primary goal attainment within the EVAL 99 batch was high. Projects led to improvements of the following nature:

- Enhanced scientific and technological capability $(61 \%$ of 'participant clusters $^{48}$ felt improvements in this sphere to be either important, very important or critical);

- Improved progress along new (65\%) and existing (63\%) technology tracks;

- New tools, methods and techniques (77\%);

- Enhanced skills of RTD staff $(66 \%)$;

- Improved access to sources of expertise (66\%);

- Improved overview of S\&T developments (68\%);

- Enhanced image and reputation (65\%);

- Improved research networks and partnerships (66\%);

- New or improved innovation options (63\%);

- New or improved business alliances $(43 \%)$;

- Improved production processes (36\%);

- Improved product and service ranges (51\%);

- Productivity improvements $(27 \%)$;

- Increased turnover (31\%);

- Improved competitiveness (43\%);

- Increased market share (30\%);

- Improved ability to manage risk (43\%);

- Improved ability to manage S\&T resources (39\%);

- Improved ability to innovate (53\%);

- Improved ability to collaborate and network (56\%).

From the perspective of the participants involved in the projects, and in the considered opinion of the independent evaluators, a number of factors played a major role in determining the success or failure of projects. Not surprisingly, the technical capabilities of partners figured as a major success factor, as did levels of interest amongst all the involved parties. The results also demonstrated the importance of specifying project goals clearly and utilising relevant human resources within organisations.

48 'Participant clusters' are groups of similar organisations within individual projects, e.g. one cluster within a project could be composed of SMEs, while another could be composed of larger firms. 
Further exploration of the data using Principal Component Analysis (PCA) revealed the existence of eight project groups or clusters, each composed of projects with similar characteristics but differentiated from the other clusters along particular dimensions. One of these stood out immediately in terms of low average success rates (with success defined in terms of the attainment of important project goals). This cluster was generally composed of projects with low ambition levels, low budgets per partner and low levels of commitment amongst the partners. They also scored low in terms of managerial performance and clarity of objectives and experienced many difficulties due to the perceived technical complexity of the projects in which they were involved.

In contrast, two clusters stood out as noticeably more successful, with both clusters experiencing few obstacles to project progress. One of these was composed of projects which can be broadly characterised as moderately ambitious with above average risk levels, close to market and product-oriented. Technical and managerial performance was excellent, project objectives were clearly defined, adequate resources were deployed, and all partners demonstrated a high level of commitment to the projects.

The other cluster considered to be successful shared many of the same attributes: even higher ambition levels; technical complexity, risk and commitment levels which were higher than average; clear objectives; and exemplary technical and managerial performance. The main difference between the two successful clusters was that this latter cluster had a longer-term research orientation and contained a higher proportion of large projects involving large firms.

Taken together with one of the results from the Five Year Assessment exercise namely that higher risk projects are often associated with higher impacts - it is apparent that risk itself is not necessarily something which has to be avoided either by firms themselves or by programmes when selecting projects. All the evidence suggests that key success factors are related to technical and managerial competence, commitment and clarity of objectives, and that these are the qualities which should be uppermost in the minds of evaluators when adjudging project proposals at the project selection stage.

\section{Combined Questionnaires and Case Studies: The Evaluation of the Finnish Energy Technology Programmes}

The evaluations of the GROWTH programme and the Five Year Assessment questionnaire have both demonstrated that simple data collection techniques and analytical procedures can be used to explore the range of impacts associated with $\mathrm{R} \& \mathrm{D}$ programmes and the relationship between particular project attributes and project success and failure, expressed in terms of the achievement or not of particular types of outcomes and impacts. In turn, we have also illustrated how this type of information can feed back positively into programme design and selection procedures.

In another exercise, questionnaire and more labour-intensive mini-case study approaches were combined to provide an even more intriguing and detailed insight into the types of project associated with high commercial returns. During 1998, TEKES, the Finnish agency responsible for the conduct of many national market- 
oriented RTD programmes, asked Technopolis Ltd. of the UK to lead an evaluation of a portfolio of eleven energy technology RTD programmes. ${ }^{49}$ This comprised a number of modules, including a questionnaire to participants and a number of minicase studies ${ }^{50}$ aimed at an improved understanding of the impacts of TEKES-funded energy research, particularly economic impacts. ${ }^{51}$ Correspondingly, the companies chosen for interview were primarily those which indicated in questionnaire responses that there had already been some commercial return from their involvement in the TEKES programmes. Twenty-one companies which had been involved in one or more projects were interviewed. ${ }^{52}$

Determining the economic impact of research and technological development (RTD) projects, however, is an area full of methodological minefields. Classical cost-benefit analysis is one obvious tool to use, but it has its limitations. The main reason why it has not been widely used in RTD evaluation is that it involves large uncertainties and methodological problems while at the same time producing authoritative-seeming numbers. Many people in the European RTD evaluation community have refrained from using cost-benefit techniques because the numbers they produce can be extremely misleading.

A central problem is that the state invests in RTD programmes on behalf of society in order to reap the externalities: namely, the benefits which are not captured by the direct beneficiaries of the programme but which leak away to society more generally. Unfortunately, while cost-benefit techniques are sometimes capable of counting the internal benefits of projects - for example the benefits to a firm of participating in a technology transfer programme - they are systematically bad at capturing these external benefits. This is a pity, because it is just these external benefits that matter to the state in its role as investor.

During the case studies, however, it became increasingly apparent that even for internal benefits, cost-benefit techniques were only applicable to a small sub-set of the range of project types in evidence, namely those where projects were:

- relatively distinct from other projects and activities, so that their unique contribution was easy to identify;

- relatively close to exploitation (whether through product or process changes), so that there were few other intervening factors;

- focused, therefore, on making short-term changes to the performance of the company involved, rather than altering their wider technological capabilities such as their ability to do research or their ability to absorb and exploit future technologies;

\footnotetext{
49 Guy, K. et al (1998), 'Review of TEKES Energy Technology Programmes 1993-1998, Helsinki: TEKES

50 Each mini-case study was based on background material on each project, a questionnaire response and a single short interview with the project leader.

51 A comparison of the methodology used to evaluate this portfolio of programmes with the procedures used by the Commission to evaluate the Framework Programmes can be found in Guy, K. (forthcoming), 'Assessing RTD Programme Portfolios in the European Union', Chapter in book on comparative evaluation practice in the US and EU, edited by Kuhlmann, S. and Shapiro, P.

52 Other companies were seen during the course of the evaluation and review exercise. The 21 companies mentioned here were quizzed specifically about project impacts by Arnold, E. and Guy, K.
} 
- located within a focused strategic business unit, so that benefits and costs related to a single business rather than involving synergies across multiple business units.

Where these conditions were satisfied, it was possible to have a discussion with companies about company-internal financial costs and benefits. (The more important aspect of externalities could not, of course, be handled, since by definition these accrue to others than the participating firm.) However, not a single one of the 21 companies interviewed had any existing data on the benefits of the projects, nor did they have cost data other than those used to compile the project application. They certainly did not consider the opportunity costs of doing TEKES projects, and paid little attention to other cost issues such as R\&D project cost overruns. Taken in combination with other surveys of project impacts in state-funded R\&D programmes, it was inferred that:

- companies generally join such programmes based on the logic of the situation;

- they therefore use heuristic rules rather than 'rational' calculation in many resource-allocation situations, since these heuristics seem to work adequately in their context;

- calculations become more explicit as the absolute amounts of resources to be allocated become larger, and as it becomes possible to compare these with other opportunities. Thus, decisions about research are typically made on the basis of situational logic and an understanding of how the technology frontier is moving, while decisions about development relate (in well-managed companies) to explicit business plans where costs and benefits are calculated;

- inability to calculate the future benefits of research is one of the reasons why shorter-term projects may receive higher priority, even though it is clearly understood within companies that research is important for the long-term future of the firm. ${ }^{53}$

In short, since calculation itself is a resource-consuming activity, companies do sums when they think it makes sense to do so and use heuristics where it does not. They are not always happy at the balance in their choice of method: in particular, R\&D directors are often concerned that they cannot calculate the value of research to their companies so that they can perform the 'right' amount. However, they are defeated by the same practical difficulties of obtaining usable estimates of benefits as prevent scientific policy makers from doing equivalent calculations.

Although it proved impossible to establish any sensible protocols for determining quantitative relationships between TEKES funding and financial returns to the firms involved, it was possible to explore the different ways in which the firms exploited TEKES financing and benefited from involvement. Most of the projects examined fell into distinct categories, though these were not always mutually exclusive. These can be described as:

- Research linkage projects, connecting the research function of large companies into the national research infrastructure;

- Research Association-style work, addressing the common needs of industries which perform little internal R\&D;

53 There are, of course, other good reasons for this, too, including pressure to generate cash flows in the short and medium term, the need to respond to market pressures for incremental changes or quality improvements, and so on. 
- Injecting R\&D into project-based industries, where the style of competition means it is hard to fund $\mathrm{R} \& \mathrm{D}$, even where companies and projects are technologyintensive;

- Invention venturing, where TEKES provides funds (in a mixture of grants and loans) to enable companies to bring interesting but risky inventions to the market;

- Exploring and demonstrating feasibility of energy technologies.

Companies involved in research linkage projects were generally global players. Finnish in origin and ownership, their markets were global and their operations multinational. They had significant research as well as development capabilities. Typically, they thought about $\mathrm{R} \& \mathrm{D}$ as having at least three components. One expressed this using Exhibit 4.

Exhibit 4 Global Player R\&D Portfolio

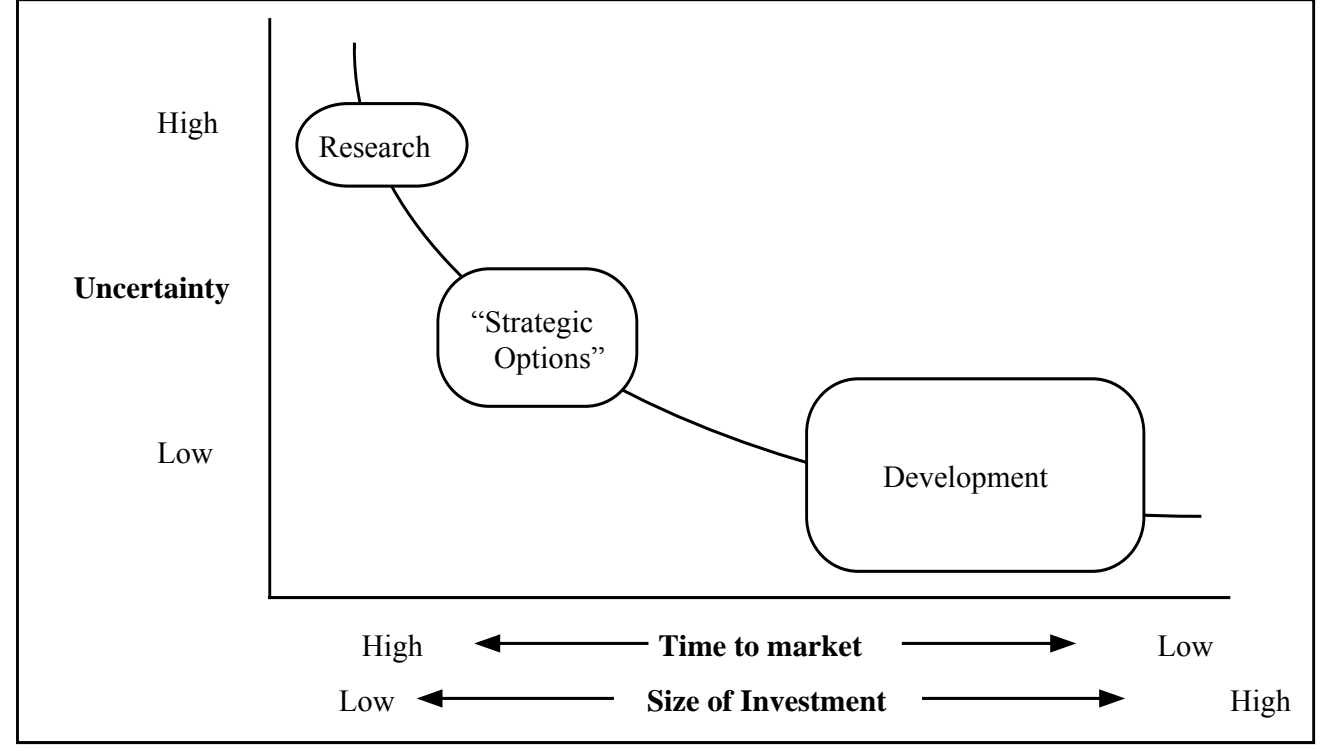

Note - Not to Scale

The proportions of Research, Strategic Options and Development work appropriate to an individual company varies by sector (some are more 'science-based' than others), the stage of the relevant product life cycle and other company-specific factors. For the companies in the Finnish study, most R\&D expenditure (perhaps 70-80\%) was Development, aimed at improving products and processes, carefully planned and costed against specific business plans. Individual projects were large, and a lot of effort went into making sure the right projects were done and that they reached their goals within budget. In large companies, the state plays little or no role here.

Perhaps $15 \%$ of the budget went into 'Strategic Options' work, which clarifies the viability of individual technologies and 'de-bugs' them prior to a decision whether to 
use them in development. (This type of work is called 'experimental development' in the OECD Frascati manual and is generally known as 'advanced engineering' in the automotive industry.)

Research made up a very small part of the total - perhaps 5\%. This is where the company's inventive activities take place, but there is also a great deal of monitoring of scientific and technological changes in the outside world in order to internalise those which seem useful, plus active investment in simulations and feasibility studies. This activity has very uncertain outcomes and is hard to justify financially, even though companies 'know' they need to do it. It is where TEKES money is ostensibly used: to increase the amount of research activity that is undertaken and to establish research linkages. Typically, the TEKES funds flow through the company to universities and research institutes such as VTT, the state-owned research laboratories.

In order to understand and exploit this external effort, companies need to carry on an internal research activity. ${ }^{54}$ It is not therefore possible for TEKES funding completely to displace internal research: if money were reallocated from internal research to other activities and TEKES-funded external research were substituted, the company would lose the ability to make use of research results. A limited amount of substitution is possible, though company R\&D directors naturally claim there is none in practice. TEKES funds therefore increase research directors' and companies' options rather than leading directly to quantifiable results.

Research Association-style projects in the sample involved a collective effort to upgrade capabilities among the companies which provide software for power distribution. Outside the immediate contents of the applications they write and the techniques of software writing, these types of firms tend to have surprisingly limited technological capabilities. Thus, linking them more closely to customer needs and helping them acquire the new techniques needed by customers - such as demand management - helps these companies stay abreast of technological development relevant to them.

The collective approach of one of the Finnish energy technology programmes amounted, more or less, to the creation of a 'virtual' Research Association' ${ }^{55}$ in that RAs tend to address just this type of collective need in medium-technology industries. One of the companies concerned had been involved with about 10 TEKES projects in recent years. About half had produced little benefit. Some had very distinct benefits, not the least of which was the ability to provide key software features required by customers. However, despite the relatively pedestrian nature of the technology, this was also seen as highly risky. The argument for TEKES funding in this case was not the IRR. If such high rates could securely be predicted, there is little doubt that market forces would generate the needed investment. The issue is the perceived risk,

$54 \quad$ Michel Callon, 'Is Science a Public Good?' Science, Technology and Human Values, 19, pp $395-424$.

$55 \quad$ NUTEK in Sweden has a tradition of funding such 'virtual Research Associations' over many years in the form of 'programstyrelser'. Like the NUTEK-funded Research Institutes, they have an industrially-dominated Board. Unlike the Institutes, they have no research facilities of their own, but buy projects where they need them. Programstyrelser have been funded over many years, and are said to have built up and maintained important networks as a result. 
and the comparative inability of certain of the companies to see 'the big picture' and therefore to understand the usefulness of certain types of R\&D investment.

TEKES projects in another of the energy technology programmes fell into the Research Association category because they addressed the needs of a sector performing little R\&D. CHP/District Heating is a business with strong plant engineering capabilities but limited $R \& D$ competence. As the largest player in the business, one company had a small $R \& D$ capability, though this was not organisationally separate from its other engineering functions since the core business of the company was plant operations. Other players in the area lacked R\&D capability entirely.

TEKES projects at the only company with any R\&D capability therefore served a double purpose. First, they were intended to be viable in themselves - which some of them undoubtedly were. For example, a project to define standards and practices in transforming fly ash into construction materials was likely to generate an IRR of over $100 \%$ over a ten-year period by reducing the volume of ash that goes to landfill, thus cutting the cost of tipping ash by $80 \%$. Second, they tended to have a demonstration character, with significant externalities available through imitation by other companies in the Finnish district heating business.

Injecting $\mathbf{R} \& \mathbf{D}$ into project-based industries is a way to deal with the difficulty these branches have in technological development. Contracting and consulting organisations typically compete over individual projects. They hire in large amounts of labour and sub-contract effort on a project basis, so that they effectively reconfigure themselves to meet the needs of each individual contract. Price competition makes it hard to build in a notional cost of $R \& D$, while uncertainty makes it difficult for companies to make own-account $R \& D$ investments in the expectation of recouping these from future projects. Traditionally, these branches learn 'on the job' and by recruiting personnel from more stable environments rather than by doing R\&D.

Two projects involved TEKES in reducing the risk of R\&D through cost sharing and therefore in changing this R\&D-averse behaviour. Improving one company's proprietary waste fermentation process made a contribution towards reaching the efficiency improvements that the company needed in order to maintain a competitive position. Involving another company as the designer in a pilot CHP plant using fluegas recovery enabled the company to acquire this technology and to establish a reference sale, allowing it the chance to capture a major slice of the future market. For the company, an investment of 150 KFIM effectively provided access to a market likely to be worth at least 15 MFIM over the coming 10-20 years. Of course, the effect of the project has been to allow the company the chance to 'play' in this new business. How well it does will also involve a range of other factors, and the monetary value of the 'entry ticket' to the new 'game' is therefore quite uncertain.

Invention venturing, where TEKES provides funds (in a mixture of grants and loans) to enable companies to bring interesting but risky inventions to the market, is a more traditional role for an innovation agency. One company developing a new type of high-capacity battery intended initially for an emerging electric car market constituted an example of this situation. It was a spin-out from Helsinki University of 
Technology which continued to rely heavily on TEKES-funded research at the University. TEKES provided both project grants and 'soft' loans to the firm. While it appeared to have a strong technology, the company had to meet important production and distribution challenges both alone and in partnership with others.

Some Innovation Venturing projects demonstrated a need for follow-up support and measures designed to help small high-tech firms access and communicate with sources of venture capital. One common problem in this area is that the firms concerned have little 'business acumen' and venture capitalists have little understanding of 'technological potential'. This was certainly the case for two companies. While technologically competent, both firms would have benefited from the advice of a 'go between' capable of explaining the potential of their technological developments to venture capitalists, and similarly capable of providing the kind of advice to the firms which would help them formulate business plans capable of allaying the fears of venture capitalists.

Exploring and demonstrating the feasibility of energy technologies is an important role appropriate to the energy technology efforts of the state. One biofuel development company jointly owned by the forest industries was primarily concerned with developing the production and use of wood chippings as biofuels. TEKES cofunded the purchase and operation of three successive prototypes of a mobile chipping machine, which collects and chips brush wood, thinnings and other wooden materials from the forest floor. Several MFIM had been invested at the time of the interviews, and the Finnish-Swedish machine was said to be as good as a long-established rival Swedish product. Significant weaknesses remained, however, in that neither technology seemed sufficiently robust to work well in the field without constant maintenance. If the project were to be successful, however, it would create a market of some tens of millions of FIM in Finland as well as significant exports. It would also increase the production of bioenergy through more total exploitation of the forests (though the effects on the total energy cycle and on the forest ecology need to be explored more fully).

The review of project impacts conducted during the evaluation of the Finnish energy technology programme portfolio demonstrated how difficult it is to measure these even in the limited case of internal benefits. Much more important, however, was the insight the case studies gave into the roles played by TEKES projects in the context of firms' strategies. One salient message for policymakers generally is that there is little point in devoting too much time or resources to attempts to 'measure' the impacts of RTD programmes, but much to be gained from the insights provided by more qualitative reviews of the ways in which state funding of RTD supports and benefits the innovation process.

One particularly important insight was that programmes have to satisfy a very broad range of needs at the firm level. It is not enough, therefore, for policy makers to think in terms of very narrow options such as support only for very long term research projects, or only for near-market work. Much richer and more diverse policy solutions and project mixes within programmes need to be employed if the innovation dynamics of firms with very different needs are to be satisfied. 
An obvious corollary was that these needs should ideally be understood fully before new programmes are formulated - preferably via comprehensive ex ante appraisals of needs and competence. A further implication is that the project selection criteria for individual programmes should be chosen very carefully and applied with great rigour if project mixes are correctly to address the needs identified in these ex ante appraisals.

\section{Comparative Analyses}

Questionnaires, telephone interviews and mini-case studies based on short face-toface interviews constitute simple, cost-effective ways of increasing our understanding about the nature and dynamics of projects and their relationship with different types of impacts. Applied consistently over time and in different contexts, they can even provide the basis for benchmarking studies and time-series analyses. In one exercise, for example, the results from questionnaires informed by the same design ethos and used in five separate programme evaluations across Europe were analysed to explore the characteristics of participation in European Advanced Technology Programmes (ATPs). ${ }^{56}$ More specifically, the results of the surveys were used to:

- highlight similarities and differences between programmes;

- compare the characteristics of specific programmes with 'popular' or 'conventional' descriptions of ATPs;

- identify the existence of a 'deep structure' capable of providing an improved description of ATPs;

- develop suggestions for good programme design and project selection.

The results of the exercise suggested a number of points which might usefully be borne in mind when the objectives and selection criteria for ATPs are framed. In particular, the results suggested that:

- although many ATPs are justified in terms of cost- and risk-sharing, in practice it is misleading to think that ATPs primarily support high risk $\mathrm{R} \& \mathrm{D}$, or that cost-sharing constitutes a strong motivation for participation. Few programmes in real life fit this 'conventional' model of an ATP;

- a fairly small set of variables can be used to characterise the 'essential' elements or dimensions (see below) of a broad set of programmes;

- classification of programmes in terms of some of these underlying dimensions better helps to differentiate between programme types;

- an appreciation of these dimensions should help policy makers frame programmes better suited to the realisation of policy goals.

Three dimensions characterised the underlying nature of ATPs, namely:

- A stimulation dimension reflecting the complexity and excitement involved in participation. Academic bodies and research institutions, in particular, tend to get involved in complex, exciting projects;

- A centrality dimension concerned with the extent to which work is perceived as necessary in a technology area central to the main research interests of the organisation;

$56 \quad$ Guy. K, Clark, J. and Stroyan, J. (1998), Characterising Participation in European Advanced Technology Programmes, STI Review No. (to be added later), Paris: OECD 
- A venture dimension denoting the degree to which projects are considered both risky and costly.

With regard to the dimensions characterising underlying aims, i.e. the motives and goals of participants in ATPs, inspection revealed four dimensions:

- Knowledge goals concerned with the expansion and consolidation of knowledge bases;

- Exploitation goals focusing on the eventual exploitation of knowledge;

- Network goals oriented towards establishing and exploiting new links and partnerships;

- Strategic Management or Stewardship goals reflecting opportunistic, economical and parsimonious R\&D management practices.

More systematic exploration of the data suggested six related dimensions which reflect:

- Expansion of Opportunity through new collaboration and new areas of research;

- Leveraging of Complementary Assets via the parsimonious pursuit of external know-how;

- Enhancing Knowledge Bases via deepening, broadening and acceleration, thus strengthening internal R\&D capabilities;

- Defensive Exploration of potentially interesting new areas;

- Industrial Networking and the exploitation of these links;

- Industrial Exploitation in terms of the pursuit of commercially-oriented outputs and outcomes.

Regarding the utility of these dimensions in formulating plans for future ATPs, it should be noted that the dimension covering the costs and benefits of participation appears to be associated with the centrality and stimulation dimensions, and with the goals related to expansion of opportunity, enhancing knowledge bases and defensive exploration. Phrased more simply, the benefits to participants are greatest when the projects chosen stimulate the researchers involved, help expand internal know-how and lead to further research opportunities. Benefits are also forthcoming either when the work is central to the core interests of organisations or, almost paradoxically, when the potential of new, alternative areas is explored.

In designing new 'best practice' programmes and selecting projects, it therefore makes sense to aim for project portfolios which match these characteristics. In particular, selection processes and criteria should be geared towards understanding:

- the potential of projects to stimulate the researchers involved;

- the centrality of projects to the technology strategies of participating organisations;

- the opportunity provided by projects to enhance the knowledge and skill bases of organisations;

- the likelihood of collaboration leading to new opportunities;

- the extent to which projects allow organisations to access and explore new areas of potential interest.

Few evaluation exercises to date of the EU's Framework Programmes have employed questionnaires similar enough to be used either to compare individual Specific 
Programmes or, perhaps more interestingly, to compare changes over time. One way of doing this would be to request all participants in Framework Programme projects to complete a short questionnaire at project start, at project end and at a specific time (e.g. three years) after project end - with the first questionnaire exploring aims and expectations and the two latter questionnaires exploring attainments in these spheres. An attempt to design such a series of questionnaires has been made ${ }^{57}$, but their use has not yet been sanctioned - perhaps because they are still too long to be an acceptable part of the administrative burden which participants have to shoulder. There is little doubt, however, that the distribution and analysis of shorter versions could prove an extremely cost-effective way of increasing our understanding of the dynamics of these programmes and the impacts associated with them.

57 Guy, K. and Luukkonen, T. (2000), ‘Assessing EU RTD Programme Impact: Collecting Quantitative and Qualitative Data at Project Level and Designing Suitable Questionnaires for Measurement of EU RTD Programme Impact', Report to DG RESEARCH, Brussels: DG RESEARCH 


\subsection{Social Science Research Case Study}

\section{Introduction}

The assessment of the socio-economic impacts of the Framework Programmes requires increasingly an awareness of the form, scope and value of the impacts of socio-economic and social research itself as the Framework Programme funding to this area is increased, both through the requirement for further dissemination activities but also through the involvement of social science research within sectoral research programmes. The case study developed here examines onefunded programme, the TSER THEMATIC NETWORK Contract number SOE2 -CT-97-3059 "Comparative Social Inclusion Policies \& Citizenship in Europe: Towards a New European Social Model" (CSIP). The TSER network was funded by the Fourth Framework Programme and was based initially on an existing social science research network.

This case study forms one part of a section in which case studies are used to examine the range of impacts of Framework Programme funded research with the twin aims of characterising the research impacts and developing the most suitable evaluation tools and methods to capture those impacts. The case study selected for inclusion here is taken from a broad range of FP supported RTD programmes which support basic research in the social sciences. It is intended to be typical of this area of work but also of special significance as social science research takes a larger role within the portfolio of funded RTD of activities. This particular case study examines and characterizes the range of effects of the research and technological development activities supported by the Framework Programme in the area of basic social sciences research, an area of increasing importance to the European Union. Initially, a conceptual discussion takes place in which the potential socio-economic benefits of social research are considered as are the range of methods which may be appropriate in the assessment of funded programmes of research in this area. In the first main section, a conceptual discussion takes place which introduces the research which has been carried out on the use of social science / social research and the assessment of its value and effectiveness. In the second section, the case studies are used to examine the outcomes of FP funded basic research from social science with the aim of categorizing research and suggesting appropriate evaluation approaches.

\section{Conceptual Discussion}

Attempts to derive typologies for research activity whether for the social sciences or natural sciences have generally arrived at a dichotomy between research which is conceptual or basic and that which is in some sense instrumental or applied. A review of classification schemes developed over the last 30 years for the social sciences confirms the persistence of this dichotomy between research on the one hand for the sake of explication of concepts and discovery on the one hand and research for a purpose on the other, see for example Rich, (1977) Shadish et al (1991), and Leviton and Hughes(1981), although these latter authors include a third motive for research, persuasion. However, detailed attempts to characterize the impacts and especially the value, including the socio-economic value of social science research and knowledge, have not met with much success and are rightly regarded as highly problematic. Much 
of the important work has focused on the forms of transfer of academic knowledge derived from academic or academic / industry interactions, see for example Martin and Salter (2001, page 520) which identified six main routes through which knowledge might pass:

Figure 11. Six Types of Benefit from the Funding of Basic Research, (Martin and Salter, 2001)
Basic research as a source of new information
Training of skilled graduates
Creating new scientific instrumentation and methodologies
Forming networks and stimulating social interaction
Increasing the capacity for scientific and technological problem solving
Creating new firms

Attempts to conceptualize "value" for social science research have generally focused on finding indicators of what processes of engagement between social science knowledge and those who might apply it should look like and assessing how the level of interaction which takes place could be measured (Spaapen \& Sylvain, 1993). This indicators based approach, which examines structures for interaction, is paralleled by work which suggests that "learning organisations" (Van Langenhove, 2000) are the means by which social science might realize the goals of society itself. Shove et al (1998) have considered that these processes of learning and exchange take place through longer term associations between individual academics and users. Rather than through specific projects therefore, the value of social research comes from longer term career commitments of individuals and their networks to address specific and related questions. These various attempts though stand in stark contrast to any attempts which might be made to measure the actual benefits themselves.

The attempt to give a specific value to the outcomes of social research is perhaps possible in the narrowest context of social research - consultancy - where the aims of the enquiry are specific and restricted and researchers work to a very limited brief. Where research goes beyond the instrumental though, the measurement of benefit is fraught with difficulty. These difficulties derive from three principle sources.

Firstly, social research acts upon a complex, non-linear system or indeed set of systems (Wright and Shevchuk, 1994) in which the sensitivity of the initial conditions may ultimately undermine policy impacts in the form in which they are originally envisaged. Secondly, the level of interactivity between science and research (itself a complex system) makes tendentious and futile any attempt to label the inputs to research and the outputs from it. Spaapen \& Sylvain (1993) give the following as examples of increasing interactivity between the research and society: - a) Changing orientation of basic research toward practical applications; - b) A growing market orientation for research; - c) New perspectives on the relations between university and industry; - d) A growing interest of policy makers in strategic research; - e) The growing role of the popular press (Felt and Nowotny, 1992)

Thirdly, as social research may act upon the world including the value systems within it, there are grounds for caution as research may take a political role by challenging personal priorities, perceptions, value systems and indeed human rights. Even attempts to verify or validate research goals by reference to reviewers (Van Der 
Meulen, 2000) must eventually accept that value systems may not be commonly agreed.

Notwithstanding the difficulties outlined above, attempts have taken place to promote the transfer of knowledge to society through the use of new enabling information technologies, (principally the Internet) through the work of the Public Knowledge project (PKp) of the Faculty of Education at the University of British Columbia. This approach is modelled on various Enlightenment projects of knowledge transfer, for example Liebniz's "demonstrative encyclopaedia" or Diderot and d'Alembert's "Encyclopedie" and also on more recent conjectures of an universal information source such as H.G. Wells" "world brain". Those following this approach to the public use of research have taken the view that a great amount of social knowledge can quite readily applied by society if only it were to be made available. However, PKp faces strong criticism (Gil, 2001) from those who claim it fails to take full account of what is known about the process of scientific enquiry. Furthermore, doubts exist over whether there are social actors capable of sustaining the interactions required by the model. Van Langenhove's (2000) answer to these kinds of difficulties is a model for a transfer process involving "knowledge brokerage" which provides for the translation of needs and understandings between users and producers of research and the resources to carry it out. Van Der Meulen and Rip (2000) also conceive of a stock of knowledge which may be subsequently used by a wide range of actors, although they see it as having a hybrid nature.

Those who have developed the view that indicators provide the only realistic means of assessment of value such as Spaapen \& Sylvain (1993) cite the increasing levels of mutual involvement between research and society as central to the difficulty of assessing the impact of social science research. Such challenges to linearity are evident across both the human sciences and the physical sciences see for example the view proposed by Nowotny and Felt (1997) of a large techno-science interacting and partly defining the nature of the basic research carried out. The rising level of reciprocal interest and involvement, which takes the form of subtle, interactive relationships, calls for a substantial change to the traditional linear model of our understanding of the links between knowledge (science) and the context of its application (society) which had measured success in terms of the number of "quanta" of information transferred from research to society.

Developing new models for production and use of research - for measuring interactivity - provide a significant challenge. Existing assessment systems reflect the dichotomy of producers and users, with traditional, well-organized peer review methods employed to assess the academic, theoretical aspects of research generally more influential than the methods based on varieties of opinion polling which have been widely used in the attempt to give a measure of "societal value". There is a widespread belief that such a dichotomy should be dissolved and that a new forms of assessment developed to integrate more fully the needs and potentials of both science and society. Attempts to assess the health and quality of the relation of science and society will need to focus upon the viability of structures for interaction and the satisfaction of those served by research: - a) interactivity and communication between science and society; - b) assessment of the relevance of research to a wide range of what Spaapen calls "societal environments" through both agreed metrics and which are resolved to a single indicator which is part of a Societal Quality Research Profile 
(SQRP). The creation of such purposive social structures already takes place through such activities as foresight activities and futures studies, see for example Van der Meulen and Rip (2000). The search for metrics to measure the extent to which research meets a requirement remains highly challenging.

\section{Examples of Good Practice and Their Limitations}

Research carried out through the use of social science which has the aim of ultimately delivering societal benefits can take many forms, as the examples discussed in this section will indicate. From the examples studied during this project, the following general summary indicates both the key steps which underpin successful research that delivers clear benefits to society and the restrictions which currently influence the way in which that research process can develop.

\section{Towards Integration}

Integration of the roles of researchers and users of research appears the key step towards establishing successful research activities. Such integration takes the form not only of professional networks of researchers and policy-makers, as in the case of the Asia-Pacific Migration Research Network, a project supported by UNESCO - MOST (Bedford, 2001) but also requires appropriate forms of public consultation which must take into account existing political structures (Kazemir, 2001) and the tendency for solutions to problems to be sought increasingly within private rather than public alliances and networks (Liberatore 2001).

Such integration imposes a requirement for structural support, including the creation of institutions, the provision of resources for teaching, and the creation of evidence bases (Kasemir 2001), (Bruce 2001) Bedford, 2001). Creating new institutions and systems, as the EU and the UK have done, the latter through the establishment of the Economic and Social Research Council Resource Centre for Evidence based policy intended to be an analogue for Oxford's Cochrane Centre for evidence-based medicine - will assist in the attempt to provide the resources and institutional arrangements to make policy reflect research and vice versa. Larger bases of knowledge may help to broaden the basis upon which policy conclusions are made. Steps taken the UK and also in Canada (Stipich, N., 1994 "Improving Social Knowledge Transfer" Research Evaluation, Vol. 4, No. 1) to produce graduates who are skilled in the areas needed to take part in the new forms of research are also needed.

The involvement of social scientists in research which is useful for society is also likely to depend upon increasing the level of interdisciplinarity, according to Van Langenhove (1999) whose believes, following the perspective on interdisciplinarity presented by Gibbons et al (1994) that the academic enterprise should be refashioned: "A paradigm shift from publication-driven research towards change-driven research and a paradigm shift from disciplinary-driven research agendas towards research driven by problems and their driving forces." Scott et al (1999) give a broad definition of interactivity and show how interactive research requires a variety of academic disciplines, concluding also that 'users' lie not only outside academe but can include both other academics and students. 


\section{Limitations}

This process of integration between users and researchers is subject to a number of constraints, however, some of which are significant. At the level of developing policy-making mechanisms at levels larger than national systems where there are attempts to create international "added value" (in terms of an evidence base or training), there should be concern that specific country differences are not overlooked. Limits on the scope of research to effect change are faced as ever from such nonnegotiable areas as ethics and politics, which are often hidden by or hidden from social science policy researchers. Radical changes such as those envisaged by Beck (1998) that the nation-state axiomatic be discarded in a complete re-evaluation of the terminology and "metaphors of the social realm" (Beck, 1998) quoted in Slocum (2001), may be difficult to achieve, despite the apparent attractiveness to some.

While there are clearly advantages in developing and using evidence bases, Rip (2001) has noted some concerns about the limitations in terms of the validity and applicability of conclusions derived from them. Firstly, as policy has a direct link upon the area of its application, what is termed recursiveness, actions which may be appropriate at one time may loose their efficacy because social actors anticipate them. In economic science, the phenomenon has been noted by many: the Lucas critique states it and "Goodhart's Law" is also an expression of it. Secondly, because social institutions and events are by their nature temporally located, conclusions valid for one period may not necessarily be so for another. Thirdly, the packaging evidence into "wholes or chunks" may remove them from their context in which they have validity. Beyond the context in which they emerge therefore, policies may simply fail to obtain the results they promise. Finally, in relation to the use of evidence upon which policy is made, a number of commentators have argued that policy research may drive a relatively short term research agenda. Researchers and users may therefore fail to collect evidence from longer periods, thereby removing the opportunity to carry out long term, transverse studies which rely upon time-series data.

The process of integration also depends upon a number of pragmatic arrangements which can ease the tensions which may exist between researchers and governments. Ground rules to cover the publication and disclosure of research need to exist for there to be trust. As Batzokas et al report (2001): "The use of social scientists by governments is never innocent".

It has also been noted by a number of commentators that both the dissemination of social research findings and the evidence that such research has delivered benefits should be more widespread. Only when the benefits of social science research become more clearly visible to policy-makers will there be a commitment in terms of resources. Here, the policing and quality control regimes within the research process itself are likely to need modification. Increasingly, evaluation systems need to take account of the broader areas of contribution made by researchers, and this is only likely where Peer Review is replaced with Merit Review (Renaud, 2001).

While integration at the level of research and users is the backbone of the new approaches to delivering value from the social sciences, it is important also to ensure 
that researchers themselves are integrated to produce multidisciplinary groups which are capable of understanding the needs of users.

\section{Theoretical Issues}

To conclude this section it should be noted that for social science research to further increase its effectiveness, researchers and users should be closely integrated, before, during and after research activities, with the purpose of agreeing scope, focus, and methods, although the forms taken by such integration can be diverse. To move research into this interactive and dialogical mode where the major contributions to policy follow, there should be interaction both across the conventional user-producer divide, and also between users themselves and between researchers (Bedford, 2001). Success also depends upon the presence of trust between users and rules for disclosure, and the creation of effective support structures for research, teaching and, of increasing importance, dissemination of results.

The following figure indicates the wide scope of socio-economic impacts of social science research.

\section{Figure 12. Forms of Outputs from the Research Process and Measurement Mechanisms}

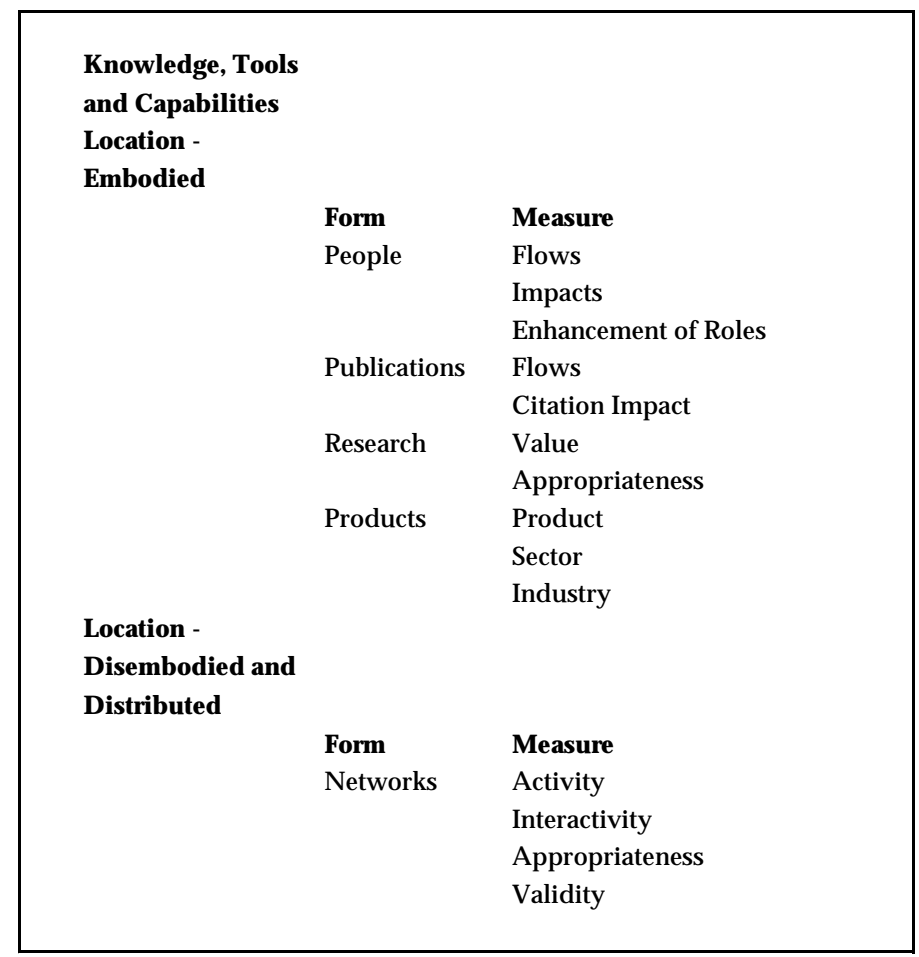

The capture and description of the broader range of impacts from social science research, some of which may be unexpected, should be assisted by an approach which "interrogates" all participants in programmes in which social sciences play a role. By taking into account the views of all participants, a deeper more complete picture 
emerges of the value of the social science contribution to the fulfilment of programme aims. Such an evaluative mechansism, which we term "collaborator review", could be expected to generate new perspectives on intended and unintended results both within the context of programme shaping and delivery and also beyond it in terms of socioeconomic impact. While the views of users are important, those involved in the delivery of programmes are well placed to make an initial assessment of the contribution of social science research also.

\section{The Case Study -Programme Definition}

The EU has always been aware of the need for social and employment policies to deal with the effects of the single market. Freedom of movement of firms within the Union has always carried the risk of what was called "social dumping" 58 , whereby different levels of social provision might give firms located where costs were lower a competitive advantage, a similar phenomenon to that of "fiscal shopping", where firms take into account tax rates in their decision to site their facilities in one place rather than another. Steps to ensure coherence between different economies within the Union have been taken over a number of years, beginning with Article 68 of the ECSC Treaty. In recent years with higher unemployment and further integration of the economies of the Union prior to the introduction of the Euro, the importance of employment policies has grown. In 1989, Jacques Delors, President of the European Commission argued: "Without some gesture at the European level in the direction of improved social provision, there is a real danger that organised labour may Charter react against the 1992 project, particularly when the economic and industrial casualties it will inevitably entail become obvious" (quoted in Nicol and Salmon, 2000, page 270). This has led to growing commitments in the area of social policy, with the introduction of the of the Fundamental Social Rights of Workers signed in Strasbourg in 1989, and the adoption of a new Title to the Treaty on European Union termed "Employment" (Title VIII) making employment matters ones of general concern for the member states.

In 1997, an existing network of academics, the SEDEC Network, obtained funding from the EU's Fourth Framework Programme for Targeted Socio-Economic Research (TSER) to develop and run a Thematic Network on 'Comparative Social Inclusion Policies and Citizenship in Europe: Towards a New European Social Model' (CSIP) and a related research project on 'Inclusion Through Participation' (INPART). The SEDEC Network was established in 1994. This multidisciplinary social science research network contained a wide range of social science researchers - sociologists, labour market analysts, political scientists, economists, lawyers and geographers. The network had developed through a variety of interactions with academics and policymakers to include 13 partners with links beyond the EU to members in the USA, Canada, Brazil and Australia.

The aim of the CSIP programme was to carry out a systematic comparison of social inclusion policies across the EU member states with a view to developing new models for welfare and social inclusion policy. These findings were to be disseminated

\footnotetext{
${ }^{58}$ See for example an analysis of "social dumping" and the related area of "cherry picking" by Graham and Marvin (1994) on social provision.
} 
through a number of workshops for academics and commission officials. The status of the project may well have increased as a result of the Lisbon Council's decision in March 2000 which extended the requirement for member states to produce National Action Plans (NAPs) to the area of social inclusion, in addition to their existing NAPs on employment.

\section{Specifying Socio-economic Outcomes - Evaluation Issues}

The range of outcomes for a project such as the CSIP is broad, encompassing the creation of new subject specific academic knowledge which is transferred through academic publications, the development of new conceptual tools and the identification of further problems through new academic knowledge, and the creation and support of existing networks of policy makers.

CSIP project has led to a number of academic publications and articles. These have however, time lagged the project as a result of the usual delays involved in the process of peer review and book publication. The CSIP immediate academic outputs have been mainly conceptual in the area of developing models of social exclusion and articulating and amplifying the importance of the issue of social inclusion within the context of the development of the single market.

The immediate expectation of the participating academics of improved policy knowledge from the process of benchmarking of social inclusion policies across Europe was not in fact met as research revealed that comparable which could be used for benchmarking was unavailable. This is in itself though a significant finding. The realisation of the importance of comparability between the different national data systems has added weight to a general commitment within the European Union to focus resources on the creation of a new range of social indicators with which to understand better the process of social inclusion and citizenship.

The development of such tools has been influenced to some degree by the CSIP, which while disseminating its research findings to Commission officials from DGs Employment and Research, also communicated its research findings to EUROSTAT, which has taken an increasing interest in the problem. The major work to develop new metrics been undertaken by Sir Anthony Atkinson of Nuffield College, Oxford, whose report, "The Atkinson Report" attempts to bring the codification and measurement of social inclusion data onto a new level across the member states of the European Union. The report was presented at a high level conference of senior civil servants, academics and NGOs at the Antwerp Conference on Social Exclusion, which took place in September 2001. The creation of a set of comparable indicators which can be used across the whole Union is a non-trivial problem. It requires a concerted and long term research activity and is an essential precursor for work aiming to promote common and improved social inclusion policies. Such a benefit of social science research is classifiable as both types 3 and 5 of the Salter and Martin typology, with eventual likely impacts upon the quality of life for EU citizens and for the economic performance of the economies of the area affected by the policies. These though are long term and distant benefits which cannot be easily attributed to any specific actors because they are mediated by a complex process involving a range of actors, networks which are themselves the subject of political developments, 
which, in the area of social policy often play the role of the determining or sufficient conditions.

The dissemination of research findings to NGOs is also felt to have been a useful exercise which has informed a wide range of actors clustering around the area of social inclusion, and unemployment. European NGOs are active and influential. The European Social Platform, which provides a coordinating role for 37 NGOS representing various minorities, operates in the area of "homelessness, exclusion, poverty, unemployment, lifelong learning, health and racism" (European Social Platform Web Service) and has strong links with academic organisations, and with the European Commission.

Dissemination in this project has not involved the interchange of staff from organisation to organisation, except in the case of academic staff moving between academic institutions. It is likely however, that the exchange of staff between academic and policy making organisations would improve this process further.

\section{Conclusions}

This case study of basic research has shown how the demonstration of explicit socioeconomic benefits from social science basic research requires evaluators to follow long complex chains of events, but also to be aware of unexpected consequences. The major unexpected impacts, for which the project is responsible is the realisation of the importance of a set of metrics for social inclusion which can be used across the European Union for comparative studies to support the development of new policies and subject, of course, to the political agreement of member states, a range of common policies.

A further issue of importance for impact and evaluation is that of the involvement of society as a whole in accessing the findings of researchers. Existing dissemination processes have involved government officials, but the transfer of information more widely to the broad range of NGOs and more broadly has been an ad hoc process. The structuring and management of this process is an area which would generate desirable benefits, and at the same time provide frameworks for evaluation. Moreover, the involvement of different groups, including NGOs, which have different epistemologies and methodologies, provides one of the most significant barriers to the development of impacts. 


\section{References for Section 4.4}

Atkinson, A. (2001) Speech at the International Conference on Social Inclusion - Making Common European Objectives Work, Belgium

Batzokas, A. et al (2001) "The Contribution of the Social Sciences to Knowledge and Decision Making: Reports of Four Working Groups" Social Sciences for Knowledge and Decision Making, OECD: Paris

Beck, U. (1998) The Risk Society

Bedford, R. (2001) "A Robust Research/Policy Interface: International Migration and Social Transformation in the Asia-Pacific Region" Social Sciences for Knowledge and Decision Making, OECD: Paris

Bruce, R. (2001) "Scientific Rationality, Public Vale and Democracy: The Failure of Genetically Modified Food and Patenting Debates in the United Kingdom" Social Sciences for Knowledge and Decision Making, OECD: Paris

European Council Lisbon (2000) Presidency Conclusions - Point 32, page 12

Felt, U. \& Nowotny, H. (1992) "Striking Gold In The 1990s - The Discovery Of HighTemperature Superconductivity And Its Impact On The Science System" Science Technol Hum Val 17 (4): 506-531

Gibbons, M. et al (1994) The New Production of Knowledge

Gibbons, M., \& Johnston, R. (1974) "The Role of Science in Technological Innovation" Research Policy, No. 3 pages 22-42

Gil (2001) Book Review

Golub, S., "International Labor Standards and International Trade", IMF Working Paper 97/37 Washington, April 1997

Graham S., \& Marvin, S. (1994) "CHERRY PICKING AND SOCIAL DUMPING: Utilities in the 1990s" Utilities Policy, 4 (2), 113-119.

Harre, R. (2001) "Causal Mechanism and Social Practices: What can Social Science Contribute to Social Practice" Social Sciences for Knowledge and Decision Making, OECD: Paris

Kasimir, B. (2001) "Improving Procedures for Citizen Participation and Stakeholder Involvement" Social Sciences for Knowledge and Decision Making, OECD: Paris

Liberatore, A. (2001) "From Science/Policy Interface to Science/Policy/Society Dialogue" Social Sciences for Knowledge and Decision Making, OECD: Paris

Martin, B. \& Salter A. (1996) The economic benefits of publicly funded basic research: a critical review", Research Policy 30 (3): 509-532 Mar 2001

Nicol, Sir W., \& Salmon, T. (2000) Understanding the European Union, Longman: London

Nowotny, H. \& Felt. U. (1997) After the Breakthrough: The Emergence of HighTemperature Superconductivity as a Research Field. Cambridge: Cambridge University Press

Renaud, M. (2001) "Serendipity and Policy Relevance" Social Sciences for Knowledge and Decision Making, OECD: Paris

Scott, A., Skea, J., Robinson, J., \& Shove, E. (1999) "Designing 'Interactive' Environmental Research for Wider Social Relevance" ESRC Global Environmental Change Programme, Special Briefing No 4, May 1999 
Shadish et al (1991)

Shove, E. \& Rip, A. (2000) "Users and Unicorns: a discussion of mythical beats in interactive science" Science and Public Policy, Vol. 27, No. 3

Shove, E. et al (1998) Exchanging Experience of Exploitation - A study commissioned by the Economic and Social Research Council

Slocum, N. (2001) "Realising the Future - On Collaboration Between the Policy Makers and Social Scientists to Facilitate Social Change" Social Sciences for Knowledge and Decision Making, OECD: Paris

Smith, G. (1993) "Science to Policy and Vice Versa - A comment on the reflexive relationships between social policy and social research" A Paper for the Conference on Evaluation, Social Science and Public Policy, June 1999

Stern, E. (1993) "Ongoing and participative evaluation: purpose, design and the role in the evaluation of a large-scale R\&D program" Research Evaluation Vol. 3, No. 2

Stipich, N., 1994 “Improving Social Knowledge Transfer" Research Evaluation, Vol. 4, No. 1

Tiler, C. \& Boddington, A. (1993) "Outputs, Structure and process in the evaluation of social science research centres", Research Evaluation Vol. 3, No. 2

TSER Thematic Network Contract Number Soe2 -Ct-97-3059 Sedec Network Final Report May 2000 "Comparative Social Inclusion Policies And Citizenship In Europe: Towards A New European Social Model"

Van der Meulen, B. \& Rip. A. (2000) "Evaluation of societal quality of public sector research", Research Evaluation Vol. 8, No. 1, pages 11-25

Van Langenhove, L. (1999) "Re-thinking the social sciences? A point of view" The social Sciences at a Turning Point? OECD Workshop on the social sciences

Van Langenhove, L. (2001) "Can the Social Sciences Act as an Agent of Change in Society? An Introduction to the Workshop on the Contribution of Social Sciences to Knowledge and Decision Marking", Social Sciences for Knowledge and Decision Making, OECD: Paris

Van Spaapen, J. \& Sylvain, C. (1993) "Assessing the Value of Research For Society" Research Evaluation Vol. 3, No. 2

Wallerstein, I. (2000) "From sociology to historical social science: prospects and obstacles", British Journal of Sociology, Vol. 51, No. 1

Wallerstein, I., et al (1996) Open the Social Sciences, Stanford University Press: Stanford, California

Woolgar, S. (2000) "Social basis of interactive social science" Science and Public Policy, Vol. 27, No. 3

Wright, C. \& Shevchuk. L. (1994) "Knowledge, chaos and public policy" Research Evaluation, Vol. 4, No. 1, pages 12-30 


\subsection{Accession Countries Case Study}

\section{Introduction}

The recent wide-ranging and deep social and economic changes in Central and Eastern Europe (CEE) have created new opportunities for the European research community. The various Europe-wide schemes reacted positively to these challenges in the very early days of the long transition process. First EUREKA and COST opened their gates for new members from CEE, and later other organisations (CERN, EMBO, etc.) followed. The European Union opted for a gradual, step by step policy in inviting these nations to participate in its $R \& D$ actions. The EU created a number of funding schemes ${ }^{59}$ to facilitate the CEE R\&D communities' integration into its research activities and to promote the development of research infrastructure. The presently running Fifth Research, Technological Development and Demonstration Framework Programme (FP5) is the first, in which it is possible for all the associated countries to participate at the programme level. It took a decade to achieve this close co-operation from the first individual project participation, through opening some of the specific programmes for project participation, then a broad participation on a project-by-project base, to the full programme level participation.

During the same period, however, these countries have gone through a major socioeconomic transformation, affecting all aspects of their national systems of innovation (NIS).

This section illustrates the socio-economic impacts stemming from FP project participation in a country in transition, and assesses the indicators developed to measure these impacts, using case studies. The unit of analysis has been the particular organisation participating in different FP projects, that is, not individual projects.

Our hypothesis has been that some of the most significant impacts of CEE participation in FP5 can only be understood in the context of the changing NIS. In other words, when assessing impacts, besides the 'usual' questions on product and process development, job creation, etc., a broader set of questions should be asked, concerning managerial, project development, network and collaboration-building capabilities, i.e. the process, and elements, of organisational learning, broadly defined. It also has to be taken into account that this adjustment - or strategic re-positioning takes places when both the domestic and international environments are being reshaped.

Against the background of these considerations first the transition process itself is summarised, and the changing Hungarian NIS is characterised. Then some basic statistics on the Hungarian participation in FP5 are presented. This is followed by a brief section on the methodologies applied, before the case studies are discussed in detail. Finally, the concluding section sums up the lessons learnt, and suggests questions for further research.

\footnotetext{
${ }^{59}$ PHARE, COPERNICUS, etc.
} 


\section{Transition in Hungary and its Impact on the NIS}

\section{Systemic changes and economic performance}

The first phase of the transition process in Hungary is over by now. The most important political and economic institutions have been re-established: e.g. a parliamentary democracy based on a multi-party system, private ownership of assets, free factor and commodity markets and the stock exchange. ${ }^{60}$ Some crucial economic institutions - e.g. a two-tier banking system, a 'Western-type' taxation system (VAT, personal income tax) - were introduced as early as 1987, that is, even before the political changes. Most firms and banks have been privatised by the mid-1990s, mainly by foreign investors, that is, by genuine owners.

After a sharp decline in the early 1990s the Hungarian economy is 'bouncing back': decreasing inflation and unemployment rates together with accelerating GDP growth characterised the last 4-5 years. (Tables 1-2) GDP has reached the 'pre-transition' level, that is, 1989, by 1999. Economic growth is almost twice as much fast than the EU average (2.5\% and 3.4\% for the EU-15 in 1999 and 2000, respectively). Foreign direct investment is the highest per capita compared to other Central and Eastern European countries (over 2000 USD).

Table 30: Main economic indicators, 1990-96 (previous year $=100)$

\begin{tabular}{|c|c|c|c|c|c|c|c|}
\hline & 1990 & 1991 & 1992 & 1993 & 1994 & 1995 & 1996 \\
\hline GDP & 96.7 & 88.1 & 96.9 & 99.4 & 102.9 & 101.5 & 101.3 \\
\hline Exports & 95.9 & 95.1 & 102.1 & 89.9 & 113.7 & 113.4 & 107.4 \\
\hline Imports & 94.8 & 105.5 & 100.2 & 120.2 & 108.8 & 99.3 & 105.7 \\
\hline Consumer price index & 128.9 & 135.0 & 123.0 & 122.5 & 118.8 & 128.2 & 123.6 \\
\hline Trade balance $(\$$ bn $)$ & 0.9 & -1.2 & -0.4 & -3.6 & -3.9 & -2.6 & -2.4 \\
\hline Current account balance (euro bn) & 0.1 & 0.2 & 0.2 & -3.0 & -3.3 & -1.9 & -1.3 \\
\hline Foreign direct investment ${ }^{\mathrm{a}}$ (euro bn) & .. & 1.2 & 1.1 & 2.0 & 1.0 & 3.5 & 1.4 \\
\hline $\begin{array}{l}\text { International reserves (year end, euro } \\
\text { bn) }\end{array}$ & .. & 3.0 & 3.6 & 6.0 & 5.5 & 9.4 & 7.8 \\
\hline $\begin{array}{l}\text { Registered unemployed (year end, } \\
\text { thousands) }\end{array}$ & 80 & 406 & 660 & 632 & 520 & 496 & 478 \\
\hline $\begin{array}{l}\text { Budget balance/GDP }(\%) \\
\text { (without privatisation proceeds) }\end{array}$ & 0.3 & -2.9 & -7.0 & -5.6 & -8.4 & -6.8 & -3.1 \\
\hline $\begin{array}{l}\text { Net foreign debt (including loans } \\
\text { provided by parent firms for } \\
\text { subsidiaries, euro bn) }\end{array}$ & 11.8 & 10.9 & 10.8 & 13.4 & 15.4 & 12.7 & 11.7 \\
\hline
\end{tabular}

Sources: Central Statistical Office, Ministry of Finance and National Bank of Hungary

${ }^{a}$ Equity capital

* Without extraordinary, consolidation-type expenditures

\footnotetext{
${ }^{60}$ The stock exchange was re-opened in 1989, i.e. before the political transition.
} 
Table 31: Macro economic indicators, 1997-2000 $($ previous year $=100)$

\begin{tabular}{lrrrr}
\hline \hline & $\mathbf{1 9 9 7}$ & $\mathbf{1 9 9 8}$ & $\mathbf{1 9 9 9}$ & $\mathbf{2 0 0 0}$ \\
\hline GDP & 104.6 & 104.9 & 104.4 & $105.2^{\mathrm{b}}$ \\
Exports & 129.9 & 122.5 & 115.9 & 121.7 \\
Imports & 126.4 & 124.9 & 114.3 & 120.8 \\
Consumer price index & 118.3 & 114.3 & 110.0 & 109.8 \\
Trade balance (\$ bn) & -2.1 & -2.7 & -3.0 & -4.0 \\
Current account balance (euro bn) & -0.8 & -2.0 & -1.9 & -1.9 \\
Foreign direct investment (euro bn) & 1.6 & 1.3 & 1.5 & 1.5 \\
International reserves (year end, euro bn) & 7.6 & 8.0 & 10.9 & 12.1 \\
$\begin{array}{l}\text { Registered unemployed (year end, thousands) } \\
\text { Budget }\end{array}$ & 464 & 404 & 405 & 372 \\
(without privatisation proceeds) & -4.6 & -6.3 & -3.7 & -3.4 \\
$\begin{array}{l}\text { Net foreign debt (including loans provided by } \\
\text { parent firms for subsidiaries, euro bn) }\end{array}$ & 10.7 & 11.0 & 11.2 & 12.2 \\
\hline \hline
\end{tabular}

Source: Central Statistical Office, Ministry of Finance, National Bank of Hungary

${ }^{\text {a }}$ Equity capital

b Preliminary data

${ }^{c}$ Without extraordinary, consolidation-type expenditures

A strict macroeconomic management regime (since 1995-96) has undeniably contributed to the successful macroeconomic performance. Behind these figures, however, another crucial factor can also be identified, namely the costly and painful microeconomic adjustment. Most companies have been privatised, and fundamentally restructured in terms of their products, markets, production processes, organisational forms and managerial techniques applied. In short, gales of creative destruction have been strong and effective. Yet, still there is a considerable gap between two groups of manufacturing firms. On the one hand, large, mostly export-driven, efficient and profitable foreign-owned firms, operating high-tech equipment, account for the impressive microeconomic statistics. Most of their local suppliers - either foreignowned or domestic - are also successful, and have promising prospects. On the other hand, however, a large number of indigenous, mostly small or medium-sized enterprises can be found, usually lacking capital for development, applying obsolete technologies, and thus facing the threat of bankruptcy, or stagnation with constant, hard struggle for survival - at best a rather risky future with low growth potential.

\section{Fragmented National System of Innovation}

In spite of a relatively strong and successful research system, reflected by publication and citation indices, exploitation of scientific results for economic and social purposes was rarely a success in Hungary, just as in all other planned economies in Central and Eastern Europe. Academia-industry links were weak and ad hoc, as was communication and co-operation among other players. Moreover, a number of crucial institutions required for a strong national innovation system either did not exist, or existed only in a distorted form (e.g. the so-called bridging institutions and financial, trade and legal services specialising in meeting the needs of innovative enterprises). In brief, the very process of innovation was regarded as unimportant, and hence did not receive the adequate attention, resources and institutional backing. 
In the early years of transition this fragile system was further weakened: most former links were cut off as firms were privatised, $R \& D$ institutes reorganised, $R \& D$ expenditures - both public and private - drastically reduced. Hence a large number of business R\&D units have been dissolved when the large domestic companies have been restructured and/or privatised. Lack of capital prevents most new start-up firms from running $R \& D$ activities either in-house or on a contract base. Total $R \& D$ expenditures (GERD), as a percentage of GDP, declined significantly, while the GDP itself was below its 1989 level until 1999. By 1999, total GERD at real prices decreased to 84.6 per cent of the 1991 level. R\&D expenditures by enterprises (BERD) decreased until 1993, then they were continuously increasing. By the end of the decade this trend led to an increase of BERD at real prices. R\&D expenditures from the so-called "other sources" - roughly half of which came from foreign sources, first of all from the European Union - were continuously increasing.

Since the mid-1990s a number of favourable developments have occurred, however. Some missing bridging institutions have been set up, and international R\&D cooperation has intensified. Foreign firms have brought new technologies in, and diffused them among their suppliers. The number of business R\&D units has increased - some of them have been set up by foreign firms ${ }^{61}-$, and firms have initiated again joint projects with universities and research institutes. Yet, attempts to devise and implement a coherent set of policy tools to strengthen the innovation system have failed for a number of reasons.

Until 1996-97 the most frequently mentioned argument was the dire state of the government budget. However, money is always a scarce resource, and when a country is in a particularly difficult situation then there are even more pressing reasons to devise and implement a sound strategy (be it innovation or any other strategy). From a broader perspective one might identify further - and somewhat more 'soft', yet more convincing - reasons. Heritage of the former socio-economic system (e.g. not particularly impressive performance in spite of the plethora of the so-called central development programmes), and partly ideological, partly socio-psychological stands against the apparently increased role of government all constitute obstacles on the road. Moreover, there are vested interests against concerted efforts, just as in many other countries where various government bodies prefer no to share their resources with other agencies even if it might lead to more efficient public spending.

Further, certain illusions and misconceptions have been rather strong in Hungary concerning $R \& D$ and innovation activities. One of the illusions has been that scientific knowledge automatically becomes technological capability, therefore there is no need for specifically designed tools and schemes to facilitate this process. According to another perception, which was especially strong in the first half of the 1990s, innovation is not a prerequisite for economic development, and research efforts can only be increased when a strong economy permits that. ("We will spend more on R\&D, when we will have the necessary surplus in the budget..."). These views obviously cut innovation from science, considering the latter one to be a luxury, a privilege of a narrow elite. ${ }^{62}$

\footnotetext{
${ }^{61}$ Major international companies set up new R\&D units (Nokia, Ericsson, Knorr Bremse, Audi etc.) or expanded the existing, 'inherited' ones (General Electric, Chinoin, etc.) in the second half of the 1990s. ${ }^{62}$ For data and more detailed analysis on these issues see OECD (1993), Havas (1999), (2001), Inzelt (1995), Pungor, Nyiri (1993) and TEP (2001).
} 
In sum, the Hungarian innovation system changed to a significant extent in the past decade. However the process to transform the previously ineffective system into a well functioning, highly efficient one proves to be a much longer one that many policy-makers expected at the beginning. The academia-business relationship is improving, but these links are not strong enough yet. A number of components of a new, more productive NIS have also been created since the early 1990s. The most important current task is to improve the communication and collaboration between the different actors.

\section{Hungarian Participation in FP5}

The total number of FP5 projects (contracted or in retained status) with at least one Hungarian participant is 373 , according to data collected by the Hungarian EU FP5 Programme Committee members and the National Contact Point persons, published by the Ministry of Education in early September 2001. (Table 3) With this figure Hungary is among the top three associated states.

The large number of project proposals demonstrates the relatively high level of FP5 awareness in the country. The IST programme has proved to be the most popular, while it has produced the lowest success (approval) rate. The weight of the Hungarian participation may be reflected by the indicator of retained EU project funding to the Hungarian participants as a percent of the total specific programme budgets. This indicator is usually between 0,24 (IST) and 0,29 (QoL). It is exceptionally high in the case of INCO $(1,09)$ and very low in the case of EURATOM $(0,11)$.

Table 32: Hungarian participation in FP5 (from 1999 to mid 2001)

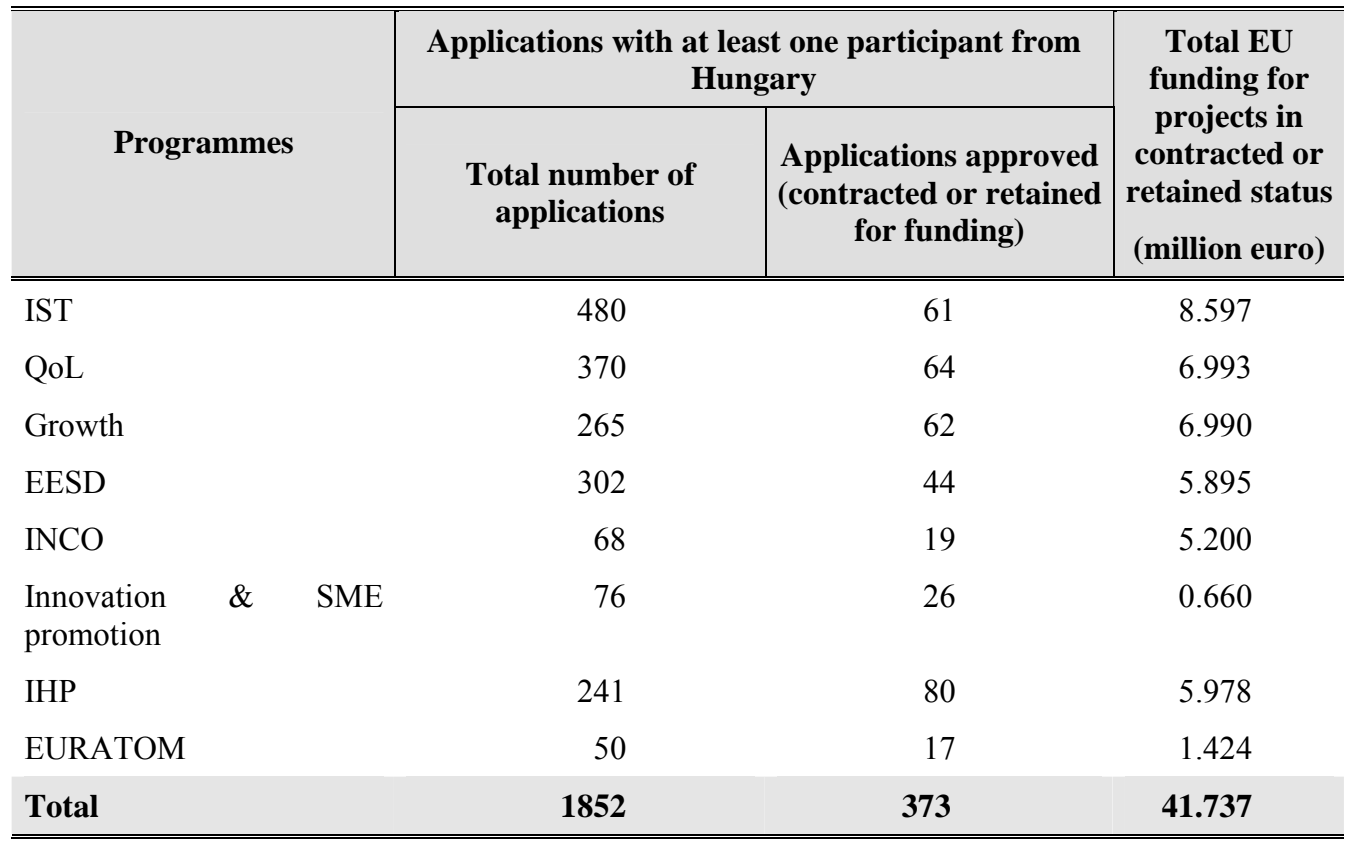

Source: Ministry of Education, Hungary, September 2001 
According to available Commission's statistical analyses and programme monitoring reports, the FP5 has generated a strong interest in associated CEE countries, especially in the traditional academic community. The poor funding of research has significantly increased the 'relative' value of EU funding opportunities. The participation of business entities is much lower than the EU average, which may be understood as a sign of weak national systems of innovation in the region and modest innovation capacities of enterprises. Hungary follows this general pattern in CEE. The major beneficiaries of FP5 funding have been the research institutes of the Hungarian Academy of Sciences (close to 50\% of the total EU support to Hungarian participants has contracted to these organisations so far). The business community has about a $20 \%$ share. SMEs have generally achieved more modest results in the different actions than the EU average, however in the Co-operative Research funding scheme the success rate is higher than the EU average. ${ }^{63}$

\section{Methodology}

As agreed at the first project meeting, two sets of case studies have been completed in Hungary. The main objective of the case studies has been to illustrate the socioeconomic impacts stemming from FP project participation in a country in transition, and validate the indicators developed to measure these impacts. The unit of analysis has been the organisation itself participating in different FP projects, that is, not individual projects. The following criteria have been set to select the candidate organisations:

One public research institute or university $R \& D$ unit and one firm should be interviewed.

Longer traditions in co-operating under different EU framework programmes and broader interest in different specific programmes are preferred.

\section{Interviews}

The main source of information for the case studies has been interviews, conducted on September 10-26, 2001. The Hungarian research team prepared a Questionnaire as guidelines for interviews (Appendix 1), following the recommendations of the ASIF project team. The questionnaires were sent to the interviewees days before the interviews, but they were filled in by the interviewer. The list of persons interviewed is attached (Appendix 2).

\section{Selection of cases}

The Hungarian research team has contacted the National Contact Point (NCP) persons asking them to suggest potential candidates who meet the above criteria best. The final selection has been made by the Hungarian research team: one institute of the Hungarian Academy of Sciences (HAS) and three SMEs have been chosen as subjects of the case studies. We have strongly believed that at least three companies should be interviewed to form some sensible hypotheses on businesses' participation in FPs. To draw well-substantiated conclusions a much larger sample would be needed, of course. During the interview phase we realised that some additional interviews might contribute to the success of the project, and thus two more experts - one person from an EU FP5 consultancy service and a policy-maker - have also been interviewed.

\footnotetext{
${ }^{63}$ For a more detailed description and policy analysis see Nyiri (2002).
} 


\section{Types of impacts considered}

Following the ISI contribution at the first project meeting, we have considered three different aspects when studying the impacts of FP participation: scientific and technological aspects, economic aspects and broader societal outputs and impacts. Thus outputs are understood here as direct impacts of FP participation (short- or medium-term ones), while impacts are defined as indirect results/ consequences (short- or long-term ones). (Table 4)

Table 33: Examples of FP impacts

\begin{tabular}{|c|c|c|c|c|}
\hline & \multicolumn{2}{|c|}{ Outputs } & \multicolumn{2}{|c|}{ Impacts } \\
\hline & short-term & $\begin{array}{l}\text { medium- } \\
\text { term }\end{array}$ & short-tem & long-term \\
\hline $\begin{array}{l}\text { Scientific } \\
\text { and } \\
\text { technologica } \\
\text { l }\end{array}$ & \multicolumn{2}{|c|}{$\begin{array}{l}\text { e.g. new/improved } \\
\text { technological know-how }\end{array}$} & $\begin{array}{c}\text { increased } \\
\text { productivity }\end{array}$ & $\begin{array}{c}\text { increased } \\
\text { competitiveness }\end{array}$ \\
\hline Economic & \multicolumn{2}{|c|}{$\begin{array}{l}\text { new/improved products, } \\
\text { services and processes }\end{array}$} & $\begin{array}{l}\text { increased sales } \\
\text { and market } \\
\text { share }\end{array}$ & $\begin{array}{c}\text { new markets; } \\
\text { development of } \\
\text { SMEs }\end{array}$ \\
\hline Societal & \multicolumn{2}{|c|}{$\begin{array}{c}\text { job creation, } \\
\text { better infrastructure, } \\
\text { healthcare, new regulation }\end{array}$} & $\begin{array}{l}\text { increased } \\
\text { prosperity, } \\
\text { satisfaction, } \\
\text { equality }\end{array}$ & $\begin{array}{l}\text { stable, cohesive } \\
\text { society with } \\
\text { highly } \\
\text { participative } \\
\text { citizens }\end{array}$ \\
\hline
\end{tabular}

Source: Kuhlmann, S., Heinze, T. (2001)

In line with our underlying hypothesis - that some of the most significant impacts of CEE participation in FP5 can only be understood in the context of the changing NIS we have tried to test whether there is yet another type of impact. In other words, a third category, what we may call 'effects', has been introduced. To operationalise this approach we have added a number questions to our interview guide, addressing the effects of FP projects on the participants in the form of managerial and organisational learning and cultural change, that is, new managerial techniques, decision-making methods introduced, new organisational forms and new way of thinking applied. These effects are all the more important as they might diffuse into a broader circle of institutes and firms, and thus can be beneficial when applying for domestic or international (EU) funding (project development and project management skills), building networks, commercialising S\&T results (relevant management techniques), etc.

Our results have confirmed that this set of questions on 'effects' is certainly relevant if one is to identify the socio-economic impacts of FP participation in the case of partners form transition countries. (Sections 5 and 6) 


\section{The Institute (CASE STUDY \#1)}

\section{Introduction}

SZTAKI, the Computer and Automation Research Institute was established in 1973 by merging two research institutes in the field of computer sciences and automation. ${ }^{64}$ The institute soon became one of the major Hungarian basic research organisations in its fields, and became known not only in the CMEA area, but in Western Europe and the US as well.

The main tasks of SZTAKI are to perform basic and applied IST-related (Information Society Technologies) research. It has three important missions:

- creating new knowledge and understanding the general development of knowledge in its fields

- transmitting this knowledge through the traditional education system

- transferring this knowledge to businesses through applications.

Their main fields of scientific interest are as follows: artificial intelligence, expertand knowledge-based systems, robust control, integrated vehicle control system, CIM, distributed information management and new technologies for wide area networks, www-based and multimedia tools.

The institute has gained a strong international reputation, and established close cooperation with partners all over the world. It is member of ERCIM, ${ }^{65}$ the W3 Consortium (led by MIT), the CIRP ${ }^{66}$ and the European Software Institute. Many of their projects are financed by the EU and US grant agencies (both civilian and military). A number of their research fellows are editorial board members of major international scientific journals, and serve as high-level officials of international scientific organisations. ${ }^{67}$

SZTAKI has 320 employees in total, 225 with university degrees. Most of them are engineers and mathematicians. Six researchers are members of the Hungarian Academy of Sciences, and another 77 ones are scientific degree-holders. Around 70 researchers are under the age of 35 . There are $45 \mathrm{PhD}$ students employed, and a further 30 graduate students work there part-time. More than 40 senior researchers teach on a regular basis at universities, the institute runs departments and postgraduate programmes jointly with universities in Hungary.

SZTAKI does not operate as a typical academic institute. A major restructuring in 1991 created 'cost centres' working independently from each other. The basic research labs are more directly financed by the Academy's budget, while the application-oriented research activities are contract-based. To facilitate the latter, SZTAKI has acquired an ISO 9002 certificate.

\footnotetext{
${ }^{64}$ The two institutes were MTA SzK (Computer Centre of the Hungarian Academy of Sciences) and AK (Automation Research Institute of the Hungarian Academy of Sciences).

${ }^{65}$ European Research Consortium of Informatics and Mathematics; membership from 1994.

${ }^{66}$ International Institute for Production Engineering

${ }^{67}$ For example the former director of SZTAKI, Prof. Tibor Vámos was the chairman of IFAC (International Federation of Automation Control).
} 
The annual budget of the institute was 2 billion HUF (about 8 million euros) in 2000, of which $45 \%$ comes directly from the state budget; the remaining should be earned through different sources. The staff is very active and experienced in applying for both national and international funds, as well tendering in the market.

Because of its traditionally strong relations with Western research partners since the 1970s, the changes in world politics in the late 1980s found SZTAKI in a good position. For example already in the mid-1980s the institute became an integral part of the MAP (Manufacturing Automation Protocol) worldwide standardisation process.

\section{EU-related activities of SZTAKI}

In the early 1990s the EU created new funding schemes targeting to facilitate and support the integration of the research community in the countries in transition. The programme called COPERNICUS opened the gates for direct EU funding to projects with the participation from these nations' research organisations. SZTAKI received, for example, 18 different Western European requests for collaboration for only one COPERNICUS call, which demonstrates its good "launching" position.

Table 34: SZTAKI's project participation in different EU RTD Framework Programmes

\begin{tabular}{|cclr|}
\hline FP4 statistics & Number of applications submitted & as co-ordinator & 0 \\
& approved & as partner & 57 \\
& & & 19 \\
FP5 statistics & Number of applications submitted & on-going & 18 \\
& & as co-ordinator & 9 \\
& under evaluation & as partner & 33 \\
& approved & & 8 \\
& & & 12 \\
& & completed & 0 \\
& & on-going & 12 \\
\hline
\end{tabular}

Source: interviews

The first project participation of SZTAKI in EU funded R\&D programmes dates back to 1994. Since that time the institute has participated in 99 consortia, which applied for EU grants and received support in 31 cases. Not taking into consideration the 8 applications under evaluation, the success rate is 34\% (31 contracts out of 91 applications). The total cost of all these projects was 47 million euros. SZTAKI received 2,65 million euros and its own contribution was 1 million euros.

About $45 \%$ of the projects have had a networking character, another $45 \%$ of them is research project, while the remaining $10 \%$ may be considered as accompanying measure action. The institute is one of the 6 Hungarian winners of the Centre of Excellence, INCO 2000 action, receiving 600 thousand euros for 3 years. SZTAKI hosts the IST programme national liaison office, which also runs the IDEAL-EAST 
activity. Under FP4 their most targeted specific programme was the ESPRIT, while under FP5 the highest number of their applications and contracts belong to the IST programme, but several applications have also been sent to the GROWTH and the QoL programmes.

So far SZTAKI has established contacts with 58 business and 86 academic partners from the EU through the different EU projects. (The same figures related to CEE are: 12 business and 66 academic partners.)

The institute is active in other international $R \& D$ programmes as well. It participated 1 COST, 1 EUREKA, 1 CERN, 1 SOCRATES and 3 LEONARDO projects.

Some of the researchers are frequent evaluators of the FP5 project proposals; others are invited by the Commission on a regular basis to participate in programme preparation workshops and expert groups.

SZTAKI applies a distributed FP5 management system. Despite the fact that it hosts the Hungarian IST liaison office (called ISTOK), there is no central service available for the potential project proposal writers working for the institute. However, SZTAKI frequently organises open information days and FP5 promotion actions to assist the potential in-house applicants as well as its academic and business partners by explaining the details of the IST, GROWTH and SME programmes. The research labs and departments, relying on their traditions, have developed their own FP5-related skills, and an informal networking may facilitate the exchange of relevant information and experience among the interested groups and persons. It is planned, as part of the networks of excellence activities, that in the near future proposals before submission to the Commission should be 'pre-checked' locally.

\section{Experiences of EU-related research activities}

SZTAKI is included in quite a few international networks. A large number of its projects are co-financed by external sources (with a moderate share of EU funds), and usually conducted by international teams. The motivations of its collaborating partners have changed in the past decade. At the very beginning of the 1990s CEE, and Hungary as a part of it, was considered by many potential EU partners as a 'mysterious' area, where major political and social changes occurred. The specific funding schemes, set up by both governments and international organisations, however, created good conditions for strengthening the links between the two parts of Europe in the field of science and technology. That times the close personal relationships between the leading scientists played a decisive role in starting project level collaborations. This personal network functioned as the driving force for international co-operation capacity building.

The relatively low labour costs of researchers in Hungary have played a part, at least in the initial phases of co-operation. It has been an important motivation of EU project co-ordinators looking for CEE partners that the highly labour intensive research activities ("hack-work") can be executed reliably and precisely by them. Other factors have also positively contributed to a higher level CEE participation: the extra funding provided for the project co-ordinator as well as other formal or informal incentives, e.g. 'extra points' if CEE participants are involved a given consortium. However, special knowledge and available unique skills form the strongest basis for long-term collaborations. For example in the field of CNN (Cellular Neural Networks) technologies SZTAKI has a research topic with this character. 
Economic considerations, however, play hardly any role for the potential Western partners. So far SZTAKI has not come across a Western European partner purely or mainly motivated by business interests in CEE or Hungary.

\section{Outputs and impacts}

Scientific and technological outputs are much higher valued in an academic research institute than any other aspects. The major outputs of SZTAKI's EU project collaborations can be measured in the form of new knowledge generated, new skills and know-how developed. Good examples of scientific and technological fields in which SZTAKI developed brand new knowledge and skills through EU project participation are as follows: agent-based production control (in FP4) and grid computing technologies (in FP5). The EU projects alone are not sufficient to complete this learning process. Yet, they are good starting points to produce scientific knowledge, what is essential to grasp the problem, necessary to understand the topic, and to navigate the research team moving into the depth of the search process.

EU projects are also supposed to have some marked impacts on technical standards. SZTAKI's experience leads to a somewhat different conclusion. The process of standardisation in the field of automation and computerisation, however, is far longer than the timeframe of the FPs. For example the AMICE consortium (SZTAKI participated in it) has developed the CIM-OSA (Computer Integrated Manufacturing Open System Architecture), which became an accepted and applied standard 11 years after the consortium started to develop it. Thus the requirement in FP5 to demonstrate in every single project how its outputs will contribute to standardisation seems to be mistaken, or at least a 'rushed' criterion.

Economic output cannot be measured in SZTAKI's cases directly, and in their view it seems to be a general phenomenon. The underlying principle of public R\&D is that taxpayers should fund even market-oriented research activities if those are financed fully by the private sector because of their size and/or the level of risk. The main question in relation with the impacts of FP5 would be how risk-taking is managed. Compared to the US where even very high-risk projects may find funding relatively easily, the EU funding policy and methodology is not competitive enough. The reason probably is that the funds granted to EU projects are too low to produce scientific or technological outputs immediately applicable in the industry. Most of the EU-funded projects are not planned to produce $R \& D$ results applicable immediately in the industry. The number of directly business-oriented projects is very limited.

New know-how, however, is generally produced as a result of FP projects, and when it is diffused to firms, it certainly contributes to the introduction of new/improved products, services and processes, and thus leads to increased sales and market share (or sales and market share at least can be maintained in spite of an intense competition). As the diffusion of new knowledge - including know-how - is part of SZTAKI's mission, economic outputs and impacts are likely to occur, but to measure them more organisations have to be interviewed, and time-lag has to be allowed.

In one of the SZTAKI's research fields, global market forecasts suggest that the current efforts on CNN (Cellular Neural Networks) technologies may produce a real breakthrough in a few years, creating a good atmosphere for establishing spin-off companies. That is, one form of medium- to long-term economic impact might be observed. Yet, the project is funded by many international sources, including the FP5. Therefore it would be difficult, if not impossible, to account for the exact economic impacts of the FP5 in this case. We can assume successfully completed EU-funded 
projects, followed by new business entities to manufacture the products based on the newly developed technologies. Yet, it would be very hard to measure, to what extent the various funding sources have contributed to this hypothetical economic success. ${ }^{68}$

A more direct economic effect of FP participation has been the establishment spin-off firms: SZTAKI has founded SMEs to perform business activities necessary for the implementation of given FP projects, but 'alien' in a typical academic institute (like preparation of demonstration, conference/fair servicing etc.). The EU FP projects also contribute to employing young scientists - PhD students and post-docs - and developing the institute's infrastructure by purchasing special hardware and software tools.

As far as societal outputs are concerned, it should be underlined that the creation of new knowledge and development of new skills - as a result of FP projects - has a special importance in an organisation like SZTAKI due to its nation-wide dissemination function. The close links to local applications and the strong interrelationships with the national education system are likely to result in a fast and effective diffusion new knowledge. It also contributes to keeping the national knowledge base continuously at the socially and economically desirable - high level.

In sum, SZTAKI has improved its international competitive position in the 'research market' by participating in EU R\&D projects. It has been able to keep its previous leading position in the local 'market', too, while boosting its image and credibility not only in Europe, but both in the USA and in Asia. The Europe-wide vision, as well as the demonstrated broad links with the major actors played a significant role in this process. However, the institute has not set up any important business relations in the European market as a result of EU-funded R\&D project.

The interviews with firms have also demonstrated that SZTAKI plays a certain liaison-like role in bringing Hungarian SMEs close and into FP5. (Section 6) Two firms have first heard of the EU R\&D programmes by having daily relations with the institute. The well-experienced actor has demonstrated the benefits and difficulties of participation, and helped these firms take the first steps in preparing applications and finding project partners.

\section{Benefits of FP participation}

We have also asked the interviewees to identify and rank the benefits of FP participation for their organisation (Section C of the Questionnaire). At SZTAKI, improving the international and domestic partnerships has been considered the most important result of EU-funded collaborations. The prestige provided by the EU labelled projects may also improve to a large extent the market position of the organisation. It is hard to measure how this kind of benefit can influence the future business relations, but it is assumed that these two factors are correlated.

The closer it gets to business aspects, it meets lower priority in SZTAKI's own list of FP benefits. Access to new markets does not play any role in the institute's decisions joining an FP5 project. It is the least expected benefit of such collaborations. The second lowest is to gain new knowledge on existing or future, emerging markets.

\footnotetext{
${ }^{68}$ A rather crude estimation could simply take the ratio of different funding sources so as to establish their 'weight' in terms of contributing to economic success.
} 
Funding obtained through the EU FP projects does not form a crucial part of SZTAKI's budget. It represents only about $5 \%$ of the total annual budget. In spite of this fact, the managers of the institute consider this source as a very important one. They are convinced that raising funds is a motivation to prepare FP project proposals so frequently. Researchers feel that the EU sources can be spent for activities poorly financed from state funds. The resource allocation system applied in the institute gives the necessary freedom to the project managers (local co-ordinator) to use effectively the available sources, including the EU ones.

The participation in EU actions has largely contributed to the cultural changes, which has taken place at the institute during the past decade. The old-fashioned academic approach has disappeared; most of the research staff learnt the importance of 'selling' their results. The marketing capacity of SZTAKI has developed significantly. An experienced core group has been built, with strong capabilities in international project proposal development and tendering. These skills have also benefited the institute while competing for national funds. The young generation can learn easily how the international research market works by participating in FP projects. Capabilities to manage international research projects have developed significantly during the past decade. At the beginning the lack of necessary management skills put a major burden on FP participation, but learning by doing (taken some years, though) has eliminated this formerly severe disadvantage.

\section{Main obstacles of FP participation}

One of the major obstacles to increase SZTAKI's participation in FP projects seems to be the lack of human resources to manage these projects. The highly qualified researchers, who are experienced in international project management, are overburdened. The dilemma they face is as follows: should they opt for a larger number of small projects or fewer big ones? The Centre of Excellence project pushes the institute to prefer the latter one, but it challenges the existing in-house FP5 management structure, which leaves the labs and departments acting individually. This situation makes more visible the lack of a professional tendering and/or marketing group in the institute.

SZTAKI in its FP project preparation and application capacity building activities does not rely on the national support system (network of NCPs, programme specific liaison offices etc.). The level of existing consultancy and other services does not meet the demand of this institute.

The academia-business links in general are poor in Hungary, but some promising changes are occurring more recently. It is expected that closer relations between local firms and the institute will improve SZTAKI's chances when applying for EU FP funding.

The institute has always financed the contribution required by the EU contracts as the management considers this requirement as a high priority.

\section{Main obstacles to capitalise on FP project results}

The institute considers the low level of commercialising skills as the main obstacle of exploiting the project results. It is a general problem, not only related to FP5 projects. This capacity is usually less developed at academic institutes, but SZTAKI plans to improve these skills. 
The local market is not developed enough, especially in those areas where SZTAKI is active. The size of the market is also too small for introducing leading-edge technologies.

As already emphasised above, FP projects usual end some phases before commercialisation starts. SZTAKI has not participated in any FP project so far, which has produced results directly applicable in the market. According to their experience, in this sense there is no major difference between the CEE and the EU partners' usual approach. In reality the motivation of the FP consortia members is rarely to meet direct business targets, rather to develop new knowledge, to be used later as a sound basis for process or product development.

\section{FIRMS (CASE STUDY \#2)}

\section{Introduction}

Three firms have been interviewed, each specialising in IST. Two of them closely cooperate under the same FP5 projects, while the third one represents a rare case where a Hungarian organisation co-ordinates an FP5 project.

The interviewed companies are as follows:

Firm \#1: Applied Logic Laboratories (ALL)

Firm \#2: MT System

Firm \#3: IQSOFT

Firm \#1 (ALL) was established in 1986 as a spin-off company. Previously its core group worked on applied logic as a research department of SZÁMALK, then one of the biggest Hungarian IT companies. In 1986 SZÁMALK won a CMEA tender to coordinate a fifth generation computing development project with Russian and Ukrainian partners. ALL was specifically founded to implement this project. However, the forewarning signs of the forthcoming major political changes 'swept away' this project, hence the company had to modify its business strategy at the very beginning of the transition process. Thus in 1989 it intensified its activities in the field of medical diagnostics and therapy.

The company is owned by Hungarian private investors, most of them are $A L L$ 's employees.

ALL's main mission is to conduct scientific investigations based on a new, unifiedlogic-oriented approach in the area of advanced information technology. Its main activities are connected to the development of various methods of plausible reasoning. The reasoning methods developed and applied by $A L L$ includes several methods for data mining and knowledge extraction, like statistical methods (used in geological and medical expert systems), plausible logical methods (used in pharmacological design and diagnostic systems) and neuron network (used in medical decision support systems).

$A L L$ also has experience in modelling different processes of living systems. Special methods and tools have been developed for this purpose, such as the neural network, consisting active neurons. These methods provide, among others, tools in non-linear dynamics to analyse the self-organisation processes of the network of active neurons. 
The main research (and business) areas of ALL are as follows: knowledge processing and knowledge transfer, knowledge acquisition and data mining, knowledge base integration, machine learning, medical informatics, guideline-based decision support systems, intelligent partner systems, intelligent geo-information systems.

In the meantime $A L L$ has become an organisation of international reputation with a wide network of scientific co-operation, including R\&D groups in Moscow and Kiev. The key researchers have been members of various global networks since the 1980s. In the fifth generation computing project they co-operated with Japanese firms, too. Its international reputation is illustrated by the fact that in 1992-1994 two of their major projects were financed by the Aerospace Institute (CERT ONRIA) of the Ministry of Defence, France: ALL developed an intelligent real-time logic programming tool for a multiprocessor board computer, as well as theoretical and methodological background of an intelligent partner system for technical diagnosing. They worked on a PROLOG development project in the early 1990s, co-operating with Digital Equipment Corporation (DEC). The company has accumulated highly appreciated expertise in several fields, and thus they are invited to participate in hightech research projects by US and Japanese partners.

ALL is an SME, having altogether 14 employees. Half of them have scientific degree (3 PhD, 1 DSc, and 1 member of the Russian Academy of Natural Sciences), mostly in mathematics and computer science related engineering. Most of them are active in higher education, too. The annual turnover in 2000 was 60 million HUF (around 240 thousand euros).

Firm \#2 (MT System) was established in 1995 by a large Hungarian firm, Müszertechnika (MT) Holding. It is $100 \%$ owned by this firm.

It provides consultancy in the field of system integration, develops services in distance learning, and runs training programmes in IST related areas. The company only operates in the Hungarian market. It is a typical outsourcing-intensive, not research-related firm. Its major buyers are big public services (including the national health insurance and medical system, public administrations etc.). The holding's manufacturing companies, on the other hand, form a solid base at the input side of MT System's business activities: they sell their products through high value added integration, provided by MT System.

This company is also an SME with 12 employees, but 'virtually' expanded by a large number of permanent subcontractors. All the employees hold university degree (10 engineers and 2 economists). They have traditionally good relationship with the related Hungarian research institutes (exclusively good contact with SZTAKI - see the previous chapter) and university departments. The annual turnover in 2000 was about 100 million HUF (roughly 400 thousand euros).

Firm \#3 (IQSOFT) was established in 1990 as a spin-of company, when the Theoretical Laboratory of SZKI (Computer Research and Innovation Centre) ${ }^{69}$ was reorganised. Since the early 1980s this laboratory had worked on the development of MPROLOG with partners from Germany and Canada. The very promising business opportunities of MPROLOG made the Bank of Austria interested to join SZKI setting up an independent firm based on the knowledge and skills of this research group, and

\footnotetext{
${ }^{69}$ The Centre was originally founded to co-ordinate the Hungarian involvement in IT development projects under the umbrella of CMEA (Council for Mutual Economic Assistance), but in the late 1990s in reality it operated as a software house.
} 
they established an independent business entity, just for this high-tech development project. Since then, the ownership structure has changed: now the KFKI Group ${ }^{70}$ has the majority (55\%), while the management and employees hold a $37 \%$ stake.

IQSOFT is a software house specialising in intelligent systems, object oriented and database technologies, as well as office automation solutions. Major business areas of IQSOFT are as follows: product distribution and localisation; product development (IQPMS Portfolio Management system, add-ons to Rational Rose modelling tools); professional services in system integration, training and consulting; custom-designed application development (the fastest growing business activity).

IQSOFT is an SME, too, having 94 employees. All of them have university degree, 86 staff members are scientists (mostly mathematicians) or engineers. Many of the researchers teach regular courses at universities. The annual turnover in 2000 was 1,57 billion HUF (about 6.3 million euros).

Research has always been an important part of the operation of IQSOFT. Their key research staff has a long tradition in international collaboration. The logic programming group (the core group of the newly funded enterprise in 1990) has about twenty years experience in the development and application of logic programming languages. This group developed the MPROLOG modular logic programming system, one of the earliest commercial PROLOG systems, as well as several PROLOG applications. In 1990 IQSOFT joined the international Gigalips collaboration, partnering with the Argonne National Laboratory (USA), the University of Bristol (UK) and the Swedish Institute of Computer Science. The main goal of this project was to develop a prototype parallel implementation of the full PROLOG language exploiting or-parallelism. This implementation, called Aurora, reached a fairly mature stage by the mid-1990s. This research project was followed by a number of EU supported R\&D projects in the area of logic and constraint programming, knowledge-based systems and object oriented technologies. The results of these projects are used in commercial projects both in Hungary and abroad. IQSOFT is one of the Hungarian software companies developing software for Western markets (its customers include NOKIA, Astra Zeneca, SICS, DEC).

\section{EU-related activities of the firms}

All the three firms are involved in FP5 projects, but they have been active in EU R\&D programmes from the very beginning of the 1990s (ALL and IQSOFT) or since their establishment (MT System).

\footnotetext{
${ }^{70}$ The former business activities of KFKI (Central Physics Institute of the Hungarian Academy of Sciences) in the field of computer and other IT related areas were taken out of the academic network in the early 1990s. The KFKI Group is a holding consisting of 5 firms (all together 560 employees and about 60 million euro revenues in 2000).
} 
Table 35: Participation in different EU RTD Framework Programmes

\begin{tabular}{|c|c|c|c|c|}
\hline & & $\begin{array}{l}\text { Firm \#1: } \\
\text { ALL }\end{array}$ & $\begin{array}{l}\text { Firm \#2: } \\
\text { MT System }\end{array}$ & $\begin{array}{l}\text { Firm \#3: } \\
\text { IQSOFT }\end{array}$ \\
\hline \multirow{4}{*}{$\begin{array}{l}\text { FP4 } \\
\text { statistics }\end{array}$} & \multirow{2}{*}{$\begin{array}{c}\text { Number of applications submitted } \\
\text { approved }\end{array}$} & 10 & 3 & 17 \\
\hline & & 0 & 3 & 7 \\
\hline & completed & 0 & 3 & $6^{*}$ \\
\hline & on-going & 0 & 0 & 0 \\
\hline \multirow{5}{*}{$\begin{array}{l}\text { FP5 } \\
\text { statistics }\end{array}$} & \multirow{2}{*}{$\begin{array}{c}\text { Number of applications submitted } \\
\text { approved }\end{array}$} & 5 & 9 & 6 \\
\hline & & 3 & 4 & 1 \\
\hline & under evaluation & 2 & 0 & 0 \\
\hline & completed & 0 & 0 & 0 \\
\hline & on-going & 3 & 4 & 1 \\
\hline
\end{tabular}

Source: interviews

Note: * One project has been stopped before its completion due to the co-ordinator's financial difficulties.

The three selected firms participated in 50 project preparation processes under FP4 and FP5. EU support has been granted in 18 cases, which means a very good success rate, that is, $36 \%{ }^{71}$ Most of the projects have been co-ordinated by non-Hungarian participants. IQSOFT is the only one having the project co-ordinator status.

The interviewed firms have participated in 7 research projects, 2 take-up measures, 1 accompanying measure and 4 demonstration, technology and knowledge transfer actions.

The total size of the 18 projects is over 30 million euros, the interviewed Hungarian firms have been granted more than 1,8 million euros, an average of 100 thousand euros per project. Assuming that the firms' own contribution is about the same amount, ${ }^{72}$ the Hungarian partners have a $12 \%$ share in the projects' funds.

IQSOFT has pursued different strategies than the other two companies: its participation both financially and professionally was much more significant (it financed close to $40 \%$ of all the project costs, more than half granted by the EU). The other two companies have usually much lower share in funding the EU projects.

As it is expected most of the project partners came from business (64\%): 47 companies from the EU and 5 ones from CEE. The partnership with academic institutes seems to be more typical in demonstration and networking projects. (The academic participants are more balanced between the EU and CEE - 17 from the EU and 12 from CEE).

None of the interviewed firms has ever participated in research projects under the umbrella of other European schemes (COST, EUREKA, CERN etc.).

\footnotetext{
${ }^{71}$ In fact it is even higher if we take into consideration that 2 proposals were still being evaluated at the time of writing.

${ }^{72}$ It is not true in some accompanying measures, but these projects are far smaller than the research ones, which makes this assumption more or less plausible.
} 
IQSOFT's leading scientists have participated in FP project evaluation several times (not only in the IST, but also in GROWTH programmes). Its chairman is frequently invited by the Commission to participate in IST-related programme planning meetings and have already participated in EU funded project auditing activities. He is also active in advising the national government in IST strategic issues.

The firms have no separate in-house unit for facilitating and preparing EU project proposals. $A L L$ earlier had one person dedicated exclusively to this job, but at the end of FP4 the management evaluated this activity (10 proposals submitted, all failed), and sent back this person to conduct research activities. Both at MT System and IQSOFT there is one co-ordinator for the EU activities.

\section{Experiences of EU-related research activities}

The interviewed firms have operated under the same external and internal macro conditions as it has been described in Section 5. Their experience concerning the motivations of the EU partners in EU-funded R\&D collaboration is very similar to that of SZTAKI. Especially at the very beginning the good personal relations played a decisive role in building contacts as a basis for co-operation. For example the current chief scientist of IQSOFT spent years in the UK in late 1980s working on a research project partially funded by the EU. When new support schemes started to facilitate the preparation of research projects with CEE countries, this good personal relation immediately created new proposals. In another case a Hungarian origin (American) expert has introduced the EU FP opportunities, then assisted to form a consortium with the participation of MT System.

In the period discussed all the firms have also enjoyed the benefits of the sympathy toward Hungary and the appreciation of the successful economic and social transition. Several accompanying measures and other formal and informal means (like political "messages" from the Commission, declared programme targets, applied set of evaluation criteria, etc.) promoting the participation of CEE participation in FP projects have probably contributed in many cases to build new partnerships, then forming FP consortia. There are two other professional factors, the firms interviewed feel as strong motivation for EU partners: special knowledge available in CEE; and the relatively cheap and reliable scientific services what CEE partners can offer.

\section{Outputs and impacts}

As expected, the general picture composed after the interviews conducted is more colourful and balanced than in the case of SZTAKI ("The Institute"). Economic impacts appear to have more or less an equal weight compared to the scientific and technological ones. It is important to note that the managers do not consider these two factors in a hierarchical way (in which the economic factors are at the top).

The firms interviewed consider the knowledge acquired and/or skills developed through FP participation as the major scientific and technological outputs. Some of them stated that in the past decade the EU actions they participated in provided their companies the major source of new skills and knowledge. IQSOFT introduced both the object-oriented technologies and the constraint programming in its business activities having participated in relevant FP projects. MT System has learned webbased application integration, supply chain management and ERP (Enterprise Resource Process) technologies and tools through participating in FP4 and FP5 projects. All these now form the knowledge base of the company's services provided at local markets. 
Neither standardisation, nor new know-how is considered as a very important output by the persons interviewed. IQSOFT underlined that the participation in different EU R\&D actions has contributed to a large extent to keep the company at the frontier of PROLOG technology. In the case of a highly research-oriented firm, like $A L L$, the scientific publications as outputs of EU projects are also important, because they may improve globally the 'visibility' of its accumulated special skills and knowledge. That, in turn, may contribute to gain a better international market position.

Economic outputs of FP participation can hardly be detected at the firms interviewed. Even in the case of those projects, in which the original targets have been to develop well-defined products or services, ${ }^{73}$ the consortia have not taken the final steps to transform the project results into profit. Some managers have acknowledged that mostly during the FP4 they were not experienced enough in intellectual property management, and thus they signed inappropriate contracts. Now they see it as a learning process, not considering it as a loss, but as skills needed to learn. Obviously, under FP5 they do not want repeat the same mistake.

In the majority of the FP projects the original aim has been to stop R\&D activities at the pre-product phase. This fact underlines the importance of indirect results, that is, economic impacts. The competitive position of firms has improved due to FP project participation. IQSOFT has become the local market leader in the application of object-oriented technologies. MT System is also convinced to have a direct correlation between the strength of its local market position and the skills acquired through FP projects. ALL managers, however, feel that in the area they focus on the Hungarian market is small and not strong enough, and thus the impacts on their competition position cannot be measured at home markets, rather at the European and global level. They think that the EU grants have only had a slight positive impact in this sense so far. The other two firms do not directly target the European markets. However, the FP project participation have improved their knowledge on European markets, and developed their international business contacts. IQSOFT, as part of KFKI Group is even expected to contribute to the European expansion of the group as a whole in the near future by exploiting this knowledge and skill.

There are three major societal impacts noted by the firms interviewed. First, because many of their employees teach on a regular basis at universities the new knowledge is transmitted almost immediately through the education system. Second, the involvement in the European R\&D "circus" " may result in a growing number of experts, who can navigate carefully in both global and European affairs, and this skill may be rather useful in national policy formulation and strategic thinking. The chairman of IQSOFT can be considered as such a person. Third, some of the FP projects have impacts not only on the participating firms, but also on a much broader community. For example the ESATT project, aiming at disseminating the communication networking technologies and routines in the CEE region has contributed to a large extent to the development of this culture in Hungary (and probably not only in this country, but in other participating nations in the region as well).

\footnotetext{
${ }^{73}$ As we discussed above, these projects have represented the minority of all the projects the firms participated in.

${ }^{74}$ Including not only the large number of projects under the FPs and other continental organisations and initiatives, but also the "think tank"-like activities, strategy formulation processes, high level preparatory bodies, the work of the Commission itself.
} 


\section{Benefits of FP participation}

Based on the experiences of FP participation, the firms interviewed have a very colourful set of benefits. New knowledge on existing and future (technologically emerging) markets, improving business networks, learning how to manage international R\&D projects and applying for EU grants are at the top of this list. Increasing the company's prestige either internationally or locally is highly scored only by IQSOFT. The importance of learning project management techniques and the EU funding mechanisms and rules is well reflected by the fact that MT System has opened a new business unit offering EU FP consultancy (partner search, consortium building, proposal writing, project management, etc.). Acquiring new technological knowledge and skills are also considered as an important benefit, but at a slightly lower scale than the above mentioned ones. This seems to be somewhat surprising, because all the companies agree that one of the most important requirements to improve their competitive position in the market is to bring in and/or create new knowledge. Two firms have shared the opinion that one of the major impacts of the FP project they participated in has been new skills development.

Access to new financial sources does not play a significant role in their decisions whether to join EU projects. Usually they do not think of this factor as a major benefit. However, IQSOFT has stated that the EU projects have significantly contributed to keep alive their in-house research activities. In a business environment all the company units are expected to produce income. By the EU grants the internationally respected research group could satisfy this expectation. It is very important for the company to motivate the research and business staff to work together, and the FP projects may facilitate bridging this gap. While the FP project grants from the EU do not have a big share in the company's annual turnover, the above factors have increased the significance of the EU-sources.

\section{Main obstacles of FP participation}

The financial aspects are considered as important factors, which may influence the management's decision on FP participation, especially in SMEs, like the firms interviewed. The firms' own contribution required by the Commission does not constitute major difficulties. In a small company, however, even at the present size of the EU grants, the management should analyse carefully the actual cost/benefit of these projects. Not only the financial in-flow, but also its price must be taken into consideration. The lower financial risk-taking capacity of SMEs makes them very sensitive to this matter.

The partner search capacity is poor at SMEs. Their international connections are usually not well developed, so to form a European consortium is a real challenge to them. CORDIS has been used for partner search by two of the firms, while the third one has a negative experience in finding partners through the Internet. The only project co-ordinated by a Hungarian team has been born as a result of CORDIS services.

The FP5 is the first programme in which the CEE participants enjoy the same status as their EU member partners. The lack of experience of CEE actors in managing FP projects has practically prevented them from playing this role. The Commission has also signalled in various forms (at information days and official meetings with government representatives) not to favour having CEE co-ordinators at the very beginning of the full participation in FP5. 
IQSOFT is the only firm in our sample with experience in FP project co-ordinating. Some of their experiences may be valuable for others. Project management itself requires significant extra energy (and various forms of investments) by the coordinator. IQSOFT underestimated the management costs in the preparatory phase. Their experience also underlines the special importance of the careful selection of consortium members.

The national supporting services (liaison network, NCPs, etc.) have not been used frequently by the firms interviewed. The FP5 information days have low value for them. The most important sources of information are the CORDIS database and their business and project partners.

FP financing practices have also led to some negative experiences. Some 'guidance' is issued to the project co-ordinators advising them on CEE financial practices. Some of these advice are not correct; others are irrelevant in certain countries. For example in the cost allocation process not only the human costs are calculated at a lower rate for CEE partners, but other costs as well, while there is no difference in travel or accommodation costs by citizenship. In Hungary the fees of internationally respected local experts, especially for those from the business sector, are about the same as in the EU countries, but nobody takes this fact into account in the cost planning process. The lack of information on the banking system in a given CEE country may also create major difficulties. ${ }^{75}$

The high level of bureaucracy seems to be a frightening factor for SMEs. Their usual pragmatic approach is far away from the practice of FP management processes. For example the extremely long closing phase (more than 9 months) may result in financial losses for the participating firms by keeping at least $10 \%$ of the project costs until the Commission officially approves the report. According to a very critical opinion the paper work is sometime more important, than the work itself.

\section{Main obstacles to capitalise on FP project results}

The lack or low level of innovation management skills is considered by all the firms interviewed as the strongest factor hampering the commercialisation of their R\&D results (not only those of the EU-funded projects).

As far as the local market conditions are concerned two contradictory opinions have been expressed. $A L L$ feels that in its business area the Hungarian market is too small and weak, while IQSOFT does not see any difference between the European and the local market in relation to prices, quality requirements and expectations. The difference in perceptions may be explained by the major differences between the two firms' business activities.

\section{Conclusions}

The case studies summarised above only represent a minor share of the Hungarian participation in FP projects. Their role has been in testing the methodology developed to identify the various types of impacts of FP participation and validating the related indicators, rather than attempting to provide a representative, general overview. Therefore we cannot draw firm policy conclusions. However, it is our strong view

\footnotetext{
${ }^{75}$ An extreme case: the project co-ordinator only transferred the grant to the local bank account of the participants if they provided official bank guarantee, which, of course, significantly increased the cost of participation.
} 
that it would well worth the effort to apply this methodology - based on the techniques applied in current EU-members, and tailored to the systemic characteristics of a country in transition - to a larger, statistically representative sample. Thus a reliable description could be obtained, on which basis sound policy conclusions could also be drawn.

Our main hypothesis has emphasised the importance of the overall institutional context, namely two underlying characteristics of the Hungarian national system of innovation. First, it had been fragmented during the planned economy period, most importantly the academy-industry relations had been rather weak. Second, due to the overall socio-economic transition it is also in flux, some of the former - already weak - links have been further damaged, while new players have appeared on the scene (some of the old ones re-appeared with significantly reshaped), and new, stronger incentives have been put in place to form new partnerships, and strengthen collaboration among the various actors. Against this background, 'soft', that is, behavioural and organisational 'effects' of FP participation are likely to be crucial besides the 'usual' outputs and impacts. Impact studies, therefore, should ask a broad set of questions in order to identify a wide range of corollaries. Our methodology has been developed accordingly - introducing the above new category, namely 'effects' (Section 4.3) -, and the interviews have validated the relevance of this approach.

Not surprisingly, there are some differences between research institutes and businesses concerning the impacts of FP participation. Scientific and technological outputs are higher valued by academic research institutes than any other aspects. Closely related to that, intensified international and domestic partnerships and improved prestige have been considered the most important results of FP projects. EU projects are also supposed to have some marked impacts on technical standards. The process of standardisation in certain fields, however, is far longer than the timeframe of the FPs. Thus the requirement in FP5 to demonstrate in every single project how its outputs will contribute to standardisation seems to be mistaken, or at least a 'rushed' criterion.

Economic output cannot be measured directly, and it seems to be a general phenomenon for the following reason: EU projects do not have the sufficient funds to produce scientific or technological outputs immediately applicable in the industry. New know-how, however, is generally produced as a result of FP projects, and when it is diffused to firms, it certainly contributes to the introduction of new/improved products, services and processes, and thus leads to increased sales and market share (or sales and market share at least can be maintained in spite of an intense competition). New knowledge is also diffused through teaching activities, and thus important indirect economic impacts are expected, albeit with considerable time gap.

The lack of human resources to develop project proposals and manage FP projects or indeed any other major international ones - was a major obstacle in the early 1990s. Therefore experience accumulated and skills developed through participation in FP projects are crucial assets. These skills can also benefit the academic institutes while competing for other funds. As for commercialisation, the low level of the required managerial skills is one of the main obstacles to exploit S\&T results.

As for firms, economic impacts appear to have more or less an equal weight compared to the scientific and technological ones. The new knowledge acquired 
and/or skills developed through FP participation are the major scientific and technological outputs. Economic impacts, that is, indirect results, have seemed to be more important than economic outputs: the competitive position of firms interviewed has improved due to FP project participation through improved their knowledge on European markets as well via intensified international business contacts. In general, it seems a rather difficult - if not an impossible - task to attribute e.g. the extent of productivity change, or changes in sales or market shares to an individual FP project.

Various types of societal impacts have also been detected, e.g. diffusion of new knowledge through teaching activities of researchers employed by firms. Insights gained on EU R\&D affairs are also important inputs for national policy formulation and strategic thinking. Finally, some of the FP projects have impacts not only on the participating firms, but also on a much broader community.

Improved proposal writing and project management skills have been important for firms, too.

The above results are not really striking; somewhat similar impacts can be expected in the current EU member states, too, although with important differences occurring between countries at different level of socio-economic development. There are some socio-economic impacts, however, which seem to be more significant in CEE countries than in the EU15 countries:

FP project participation may be used as a benchmarking tool. CEE participants may realise their true real scientific and/or business values, which no doubt will improve their self-confidence.

Various fields of regulation in CEE are often directly influenced by EU regulation. The local R\&D communities are usually not involved in these actions, and hence FP participation can have rather limited impacts on regulation.

Especially the academic sector has realised as an outcome of FP participation that the commercialisation of its $R \& D$ results is not a 'strange', but a normal activity. Learning the tools, management methods and good practices how to run this business in an effective way should be considered as one of the most important benefits of FPs for countries in transition.

The FP participation has also contributed to make the lack of necessary in-house co-ordination visible. This may induce the management to take the necessary steps.

Some managers have acknowledged that during the FP4 they were not experienced enough in intellectual property management, and thus they signed inappropriate contracts. By now they have realised the importance of learning and using these specific skills.

The relatively large share of FP-related topics in the national R\&D systems may result in major changes in public funding allocation as well as in the application culture. Research institutes have already understood that they cannot perform all the tasks themselves, and thus outsourcing of several activities should be a daily practice. The reaction of the market is clear: a new business and non-profit service sector has already emerged (consultancy on EU-schemes).

The lack of appropriate communication between policy-makers (including their advisors preparing decisions) and the 'shop floor' level actors (both at the 
academia and businesses) has become visible in several CEE countries due to the FP-oriented national actions. The S\&T community is usually lacking important pieces of information on both EU and national policy schemes, while governments and other major national institutions (like the academies) do not pay attention to, and do not understand the challenges at micro level. The actual size of this gap may characterise the effectiveness of policy decisions and their implementation country by country. The FPs may contribute to narrowing this gap.

The above analysis, focussing on methodological issues, and relying on limited empirical findings confined only to Hungary, could be broadened in a number of directions. Three of them are hinted at very briefly below.

One can ask whether there are significant differences between Hungary and the other accession countries, i.e. to what extent one can generalise the above findings. Lacking the results of thorough, well-designed research projects, at best some well-grounded, but still speculative hypotheses can be formulated at this stage. One has to bear in mind that 'history does matter' not only in terms of defining certain technological trajectories and individual innovations, but even more so the development of innovation systems. The evolution of institutions, norms and behaviour of the actors and their interactions is a cumulative, 'sticky' process; the main characteristics cannot be changed overnight -even in the case of abrupt political and economic changes. Therefore the national innovation systems are far from identical in the CEE countries, and hence the impacts of FP participation can also differ. However, some 'stylised facts' are not that different: lack/ low level of a number of crucial skills (e.g. project development and international project management, innovation management, commercialisation). Therefore largely similar 'soft effects' can be expected (besides the 'conventional' outputs and impacts) as in we have seen in Hungary. The former ones are likely to be more important in other CEE countries, too - of course with a different 'weight' country by country - but not necessarily more 'visible' than the 'traditional' outputs and impacts, at least not without a careful 'look'.

Another legitimate - and potentially fruitful - question for further research could be to compare the current Hungarian (CEE) case with Western European countries who joined earlier. Some preliminary considerations show that some aspects of the learning process, that is, the 'soft, organisational' effects were important for those large French or German companies, too, which had not been experienced in international RTDI co-operation. It would be also relevant to revisit the experience of the smaller countries, who recently joined, e.g. Austria and Finland (again, with rather different NIS!), while Ireland might provide information to study the (changing) impacts for a longer run. Spain can also be an interesting case, having come back form a rather lengthy international isolation. In short, more effort on comparative research seem to be absolutely crucial, as it is likely to lead to highly relevant, useful insights. This future research can rely on well-designed secondary analysis of existing impact studies, completed with a relatively small number of interviews in order to tap into the 'institutional memory' of the EC, relevant national government agencies and policy research organisations who have been involved in decisions or previous analyses.

Having highlighted some of the current characteristics, one might also be interested in an outlook: what can be expected in 5-10 years' time? Are the above special features likely to prevail, or Hungary - and other CEE countries - would move closer to the 
current EU15 countries? Of course one cannot predict the future impacts of FP participation, because all the elements of this 'interactive system' might change significantly. To start with, FPs themselves tend to be different when any of them is compared to the preceding one. Especially FP6 is likely to pursue a markedly different approach compared to FP5, but to the very least radically new tools are going to be applied. Transition countries are still in the flux, especially their NIS, due to a few years lag between the starting date of the overall transition and of the reshaping of the innovation system. With all these caveats in mind, one can develop scenarios as visions of possible futures. Given space limits, only the best case scenario is summarised here, but the interested readers can construct their own versions. Assuming a successful, relatively fast learning process on the side of Hungarian (CEE) participants one would expect overall a lessening relevance of the 'soft (organisational, behavioural and managerial) effects', and more 'traditional' outputs and impacts. Specifically, academic institutes would have a larger number and closer contacts with businesses, in projects with a stronger emphasis on socioeconomic exploitation of S\&T results. Firms, on the other hand, would enjoy more significant economic impacts than now. It is not a 'pre-programmed' trajectory, however, i.e. it can, and should, indeed, be assisted by relevant policies. Moreover, this scenario requires 'patient' policy-makers, focussing not only on 'hard' - easy to measure and understood - results (new products, processes, job creation, exports, etc.), let alone immediate 'financial returns' in terms of EU FP grants. In other words - and it can be regarded as an extremely worst case scenario - some policy-makers, especially those in the Finance Ministries, might want to pull out from FPs altogether if ( $i$ ) the accession process is further delayed, i.e. the current, specific FP membership fee has to be maintained, and (ii) the funds 'won' are constantly lower than the membership fee. It is of crucial importance that RTDI policy-makers understand the systemic nature of NIS in any case, but when this kind of threats arise, it is even more important. 


\section{References to Section 4.5}

Freeman, C. (1995): „The 'National System of Innovation' in historical perspective”, Cambridge Journal of Economics, Vol. 19, pp. 5-24

Havas, A. (1999): „A Long Way to Go: The Hungarian science and technology policy in transition", in Laki M., Lorentzen A, Wiedmaier B (eds): Institutional change and industrial development in Central and Eastern Europe, Aldershot: Ashgate Publishing

Havas, A. (2001): „National Innovation Policy Profile: Hungary”, country study for Reid A, Nauwelaers C, Radosevic S (eds): Innovation Policy in Six Applicant Countries: The challenges, http://www.cordis.lu/innovation-smes/src/studies.htm

Hanson, P., Pavitt, K. (1987): The Comparative Economics of Research, Development and Innovation in East and West: A survey, Chur: Harwood Academic Publishers

Inzelt, A. (1995): For a Better Understanding of the Innovation Process in Hungary. STEEP Discussion Paper No. 22, SPRU, University of Sussex

Kuhlmann, S., Heinze, T. (2001): „A Review of Impact Studies: Preliminary results”, preentation at the first ASIF project meeting, Brussels, 18 June, 2001

Nyiri, L. (2002): „Az EU K+F keretprogramjában való magyar részvétel tapasztalatai és tanulságai" (Lessons of the Hungarian participation in EU RTD FPs), Magyar Tudomány, forthcoming

OECD (1993): Science, Technology and Innovation Policies: Hungary, Paris, OECD

Pungor E., Nyiri L. (1993) "The Recognition of Science \& Technology in Hungary", Technology in Society, Vol. 15, pp. 25-39

TEP (2001): Az Irányító Testület jelentése (Steering Group Report), Hungarian Technology Foresight Programme, Budapest, Oktatási Minisztérium 
Appendix \#1: Questionnaire

ASIF Questionnaire Guidelines

Hungarian Case Studies

\begin{tabular}{|ll|}
\hline Name of Person & Position: \\
Interviewed: & \\
Phone: & E-mail: \\
Date of Interview: & \\
\hline
\end{tabular}

(A) Administrative data related to EU FP participation

1. Name of the Organisation interviewed:

2. Type of the Organisation (business, academy, higher education, government, other):

3. If business, the major products and markets:

4. Size of the organisation

4.1. number of employees:

4.2. sales in 2000, Ft (if relevant):

4.3. annual budget in 2000 , Ft (if non-business organisation):

5. Number of employees with higher education degree in 2000 :

5.1. of which scientists, engineers:

5.2. other:

6. Basic data on EU FP projects

6.1. Number of projects

\begin{tabular}{l}
\multicolumn{1}{c}{ Project status } \\
\hline \hline Submitted under FP4 \\
Submitted under FP5 \\
\hline Currently being evaluated \\
\hline Rejected \\
Of which under FP4 \\
Of which under FP5 \\
Granted under FP4 \\
of which Completed \\
On-going \\
\hline Granted under FP5 \\
of which Completed \\
On-going \\
\hline \hline
\end{tabular}

6.2. Financial data

\begin{tabular}{l||c|c|c|c|c} 
Projects & $\begin{array}{c}\text { Framework/ } \\
\text { Specific } \\
\text { Programme/ } \\
\text { Action }\end{array}$ & $\begin{array}{c}\text { Duration } \\
\text { of project } \\
\text { (start - } \\
\text { end) }\end{array}$ & $\begin{array}{c}\text { Total budget } \\
\text { of the project } \\
\text { (thousand } \\
\text { euro) }\end{array}$ & $\begin{array}{c}\text { Budget for the } \\
\text { Hungarian part } \\
\text { (thousand euro) }\end{array}$ & $\begin{array}{c}\text { EU financial } \\
\text { support for the } \\
\text { Hungarian part } \\
\text { of the project } \\
\text { (thousand euro) }\end{array}$ \\
\hline \hline Project A & & & & & \\
\hline Project B & & & & & \\
\hline Project C & & & & & \\
\hline
\end{tabular}

6.3. Participants (please use the same letter identifying the projects as under point 6.2) 


\begin{tabular}{|c|c|c|c|c|c|c|}
\hline \multirow[t]{2}{*}{ Projects } & \multicolumn{2}{|c|}{$\begin{array}{l}\text { Number of business } \\
\text { partners }\end{array}$} & \multicolumn{2}{|c|}{$\begin{array}{c}\text { Number of academic } \\
\text { partners }\end{array}$} & \multicolumn{2}{|c|}{$\begin{array}{c}\text { Number of other } \\
\text { partners }\end{array}$} \\
\hline & EU & $\operatorname{CEE}\left(H^{*}\right)$ & EU & $\operatorname{CEE}\left(H^{*}\right)$ & EU & $\operatorname{CEE}\left(H^{*}\right)$ \\
\hline \multicolumn{7}{|l|}{ Project A } \\
\hline Project B & & & & & & \\
\hline Project $\mathrm{C}$ & & & & & & \\
\hline
\end{tabular}

Note: of which Hungarian, excluding the organisation interviewed

7. Number of projects (finished or running) under other European R\&D collaboration schemes:

7.1. Under COST:

7.2. Under EUREKA:

7.3. Under CERN:

7.4. Under ESA:

7.5. Under other scheme (specify):

(B) Effects and outputs of FP participation

1. Scientific and technological effects and outputs

1.1. New know how

1.2. Standardisation

1.3. New skills developed

1.4. Other (specify)

2. Economic impacts and outputs

2.1. New and/or improved products, process or services (describe briefly)

2.2. Productivity change $(\%)$

2.3. Competitive position (improved significantly, slightly improved, no impact, etc.)

2.3.1. in local markets

2.3.2. in regional markets

2.3.3. in EU markets

2.3.4. in global markets

2.4. Change of market shares (\% point)

2.5. Change of sales (by major markets) $(\%)$

2.6. Impact on SME development (e.g. spin-off, new products, production processes or markets suitable for existing or new SMEs)

3. Societal impacts and outputs

3.1. Output

3.1.1. Job creation (at the organisation; elsewhere)

3.1.2. Infrastructure development

3.1.3. New regulation (policy effects)

Health or health care (actual or potential impacts)

3.1.4. Education (actual or potential impacts)

3.1.5. Other (specify)

3.2. Increased societal prosperity, satisfaction, equality (potential short-term impacts)

3.3. Stable, cohesive society with highly participative citizens (potential longterm impacts)

(C) Major benefits of FP participation

Take the total benefit 100 and please give your estimation on the weight of the following potential benefits: 
1. New knowledge on existing and future (emerging) markets

2. Access to new markets (specify)

3. New partnerships (domestic and/or international)

4. Access to new financial sources

5. Acquiring comprehensive technological skills and knowledge

6. Learning about EU funding opportunities, preparing project proposals

7. Learning how to manage international $R \& D$ projects

8. Increased prestige (domestic and/or international)

9. Other (specify)

(D) Main obstacles to FP participation

1. Low level of management skills required for international $R \& D$ projects

2. Lack/ low level of supporting services (e.g. project development)

3. Lack/ low level of adequate policy support (schemes, flow of information)

4. Poor relations between business and academy in Hungary

5. Poor relations with the potential EU partners

6. Hard to finance the contribution required by the EU

7. Other (specify)

(E) Main obstacles or difficulties to capitalise on FP projects' results

1. Poor relations between business and academy in Hungary

2. Poor relations with the potential EU partners

3. Hard to get access to Hungarian financial sources

4. Low level of innovation management skills (lack of experience in commercialising R\&D results)

5. Poorly developed local markets

6. Hard to get access to export markets

7. Lack of supporting services (e.g. legal, financial, marketing)

8. Other (specify) 


\begin{tabular}{lll}
\begin{tabular}{l} 
Appendix \#2: List of Interviewed Persons \\
\multicolumn{1}{c}{ Organisation }
\end{tabular} & \multicolumn{1}{c}{ Name of persons } & Title \\
\hline SZTAKI & INZELT, Péter & Director of the Institute \\
SZTAKI & MONOSTORI, László & Deputy Director for Research \\
SZTAKI & KOVÁCS, György & Head of CIM Research Laboratory \\
SZTAKI & HAIDEGGER, Géza & EU Project Co-ordinator \\
\hline Applied Logic Lab & GERGELY, Tamás & CEO \\
\hline MT System & BORI, Zsuzsanna & Director for Consultancy \\
IQSOFT & DÖMÖLKI, Bálint & Chairman of the Board \\
IQSOFT & SZEREDI, Péter & Chief Scientist \\
\hline $\begin{array}{l}\text { Ministry } \\
\text { Education }\end{array}$ & of SIEGLER, András & Advisor to the Minister on EU affairs \\
\hline $\begin{array}{l}\text { Science } \\
\text { Technology }\end{array}$ & \& & GROÓ, Dóra \\
Foundation & SZENDRÁK, Erika & CEO \\
\hline
\end{tabular}




\section{Evaluation of Socio-Economic Effects in the European Research Area}

\section{Introduction}

Following a document published by the Commissioner for Research at the beginning of 2000, Towards a European Research Area (European Commission, 2000), the European Commission has been shifting its research policies from the trajectory they have followed for the past fifteen years; that is to say confined to the two major instruments of support of collaborative research and work in the Commission's own laboratories. A central aim of this shift is to mobilize the entire research resource of Europe rather than the small fraction (around 5\% of public funding) accounted for by the EU's programmes. New policy instruments have been developed for application within and beyond the sixth Framework Programme. The implications of these developments for the evaluation of economic and social effects of RTD are considered in this section.

\section{Networks of Excellence}

Networks of excellence are designed to strengthen scientific and technological excellence on a particular research topic by networking together at European level the critical mass of resources and expertise needed to provide European leadership and to be a world force on that topic. This expertise will be networked around a joint programme of activities aimed principally at creating a progressive and durable integration of the research capacities of the network partners, while, of course, at the same time advancing knowledge on the topic.

Co-operation is fostered between excellent capacities existing in universities, research centres, enterprises and technology organisations. New members may be added as the network progresses.

The joint programme of activities undertaken by members of a network of excellence encompasses integrating activities, joint executed research, spreading of excellence, one of the main components of which is training outside the network, and management activities. Integrating activities may include exchanges of personnel, development and use of joint research infrastructures or sharing of existing equipment and joint management of the knowledge produced.

The duration is expected to be, as an average, five years and more in exceptional cases where a longer period would be necessary to allow for lasting integration.

The Community contribution would be a "fixed grant for integration", to be calculated on the basis of the number of researchers constituting the research capacities of the partners on the topic of the network, through the application of a per capita grant for those researchers and according to the duration of the network. Nevertheless, the grant for integration would never exceed the quarter of the total value of the resources and capacities proposed for integration by the participants.

From an evaluation perspective, several issues are raised. NoE research activities are intended to lie within the priority theme areas of the Framework Programme, or in 
areas that meet needs arising from Community policies or emerging areas of knowledge. Nonetheless, the long term nature of the work makes it incompatible with the precise specification of outputs and effects of the nature of products, processes and services.

It is likely that the principal focus of evaluation will be in terms of the added value arising from the existence of the networking activities. The funding mode implies that the scope of evaluation will extend beyond activity directly funded by the Commission and into the core activities of the participating institutes. The true measure will not be the productivity of a shared activity as in a project but in the structuring of the research capacities on the topic and positioning at European and world level.

Economic aspects of the evaluation will need to be sensitive to the multiple pathways by which basic research affects the economy, with a particular focus on the production of people trained in the context both of scientific excellence and European added value. The knowledge management activity will be of particular interest to economic evaluators. Additionality will lie both in the immediate EAV generated and in the persistence of the integration beyond the funding period. Evaluation will need to take a long term perspective.

\section{Integrated Projects}

Integrated projects (IPs) aim to reinforce European competitiveness or to contribute to the solution of important societal problems through the mobilisation of a critical mass of research and technological development resources and skills existing in Europe. In this case clearly defined objectives are expected in terms of scientific and technological knowledge and the project will be directed at obtaining specific results applicable in terms of projects. IPs may include research, technological development and demonstration activities. They are expected to cover innovation, dissemination, transfer and exploitation of knowledge.

Participants will enjoy greater autonomy in terms of distributing the Community contribution among themselves and among activities, being able to modify the joint programme and launching new activities in response to changing circumstances. New partners may be added. The increased ambition of targets is accompanied by a longer duration, up to five years. The scale of resources could reach tens of millions of euros. A unified management structure may integrate several inter-related sub-projects.

In terms of evaluation, the socio-economic dimension clearly has priority for this instrument. However, the approach is somewhat different to that for evaluation of smaller isolated projects. In the case of the IPs the project should achieve a critical scale whereby the strategic direction of a sub-sector of the economy is affected. This implies that the evaluation needs to engage with the socio-economic status of that sub-sector to understand the potential and actual impact of the IP. Effects could include such broader aspects as market structure. This can be described as a mesolevel evaluation. In terms of relevant past experience, the evaluation of projects such as JESSI provide some relevant experience. 


\section{Benchmarking}

One dimension of the European Research Area which has been moving forward is the idea of benchmarking policies for science and innovation. Such studies have migrated from the industrial domain to public policy ${ }^{76}$. The intention is to identify and spread best practice. While benchmarking is a fashionable term, most of the data currently being employed is the common currency of evaluation and S\&T indicators: bibliometrics, peer assessments and the like. The language of benchmarking, "relevant performance indicators", "qualitative understanding of best practice", "monitoring mechanisms", is close to, if not the same as the language of evaluation. The principal concern for evaluators would be the use of such data without clearly linking it to the systems which generate it. In the specific domain of economic evaluation the focus will be on production of indicators such as patents and income from intellectual property. Both of these are highly context-dependent and need to be used with due caution.

\section{Mobility and Cooperation with Third Countries}

Considering this aspect of the ERA aims, with the objective of increasing mobility of researchers within and beyond the European Union, some broader issues are raised for socio-economic evaluation. Provision of a high quality scientific workforce is one element of the broader capabilities which a geographical research area needs to offer if it is to attract and retain high technology industry and top quality scientific institutions. Realisation of this element of the knowledge economy has been reflected in a shift in the rationale for science towards a ability to sustain and attract economic activity. For evaluation, the effect is to shift the focus away from outputs and impacts and towards assessment of capability and potential.

\section{Integration of Research Policies}

A natural consequence of these developments is that evaluation at a European level will need to extend beyond the evaluation of the Framework Programme. Closer integration of research policies requires mutual understanding of what has been achieved and of the balance of benefits. An evaluation of a programme which links national activities needs to comprehend the widely varying institutional settings for the same work (for example an aspect of cancer research could be carried out in a university in one country, a branch of a national research organization in another, a central laboratory in a third and by a non-governmental charitable foundation in a fourth). Comparing inputs to research will require an understanding of the dynamics of all of these settings. As collective activities the specific benefits of critical mass, shared resources and new synergies need to be assessed. Opening of national programmes creates new evaluation issues related to the degree to which the processes allow for efficient and effective cooperation.

\footnotetext{
${ }^{76}$ See for example the document on CORDIS from the Commission entitled Comparing performance: a proposal to launch a benchmarking exercise on national R\&D policies in Europe.
} 


\section{Towards a European Research Area}

It may also be necessary to establish a clearer common understanding of what constitutes quality and excellence in each country. However, progress will require a shift of focus for evaluation towards a broader systems perspective. The problem is one of standards. One could posit that the development of a European Research Area requires a corresponding development of a "European Evaluation Area" in which there is a common methodological and procedural understanding that allows members to accept and validate each other's findings.

Without this, member states are likely to greet with suspicion proposals that a particular institution or centre meets a particular level of excellence in some dimension of its performance. Nonetheless, evaluation needs to be applied flexibly such that it does not impose homogeneity and stifle diversity where this continues to be a source of strength for Europe.

One ERA goal, the integration of researchers from Eastern Europe with the West, requires the development of evaluation cultures which would enable replacement of the original political and bureaucratic systems for allocation of resources with one which rewards and encourages growth of the best performers. To avoid the impression that evaluation is a panacea, it is important to note that that competition is not enough; without sufficient investment from government these systems will exhaust the human and capital potential they have retained from better times and may reach the point of decline from where it would take decades for them to catch up.

\section{Concluding Remarks}

This study has explored a wide body of knowledge in the literatures and practices which surround the issues of socio-economic evaluation of RTD. The full implications for research policy in general and for the practice of evaluation in particular are too numerous to be encapsulated in a conclusion - rather they are distributed throughout the report. It is also important to stress that this report has been closely specified as a study of socio-economic aspects of evaluation. It does not address many important issues relating to criteria of scientific quality and policy appropriateness. It also does not cover in general issues concerning the organisation and implementation of evaluation systems, though these are addressed where they occur within the context of specific studies. All of these areas are worthy of further attention. However, on the basis of the material which was surveyed, the following general principles may be stated:

- There is a body of evidence in the economic literature which provides a justification for public investment in RTD. While traditional economic approaches support this general conclusion, more recently developed frameworks provide more specific policy guidance and stress in particular the critical importance of building the capacities of actors and the networking capabilities of research and innovation systems. The rationale for the Sixth Framework Programme is most easily constructed within these terms.

- Additionality provides a key bridge between ex ante rationale for a programme or policy and the ability to test through evaluation whether the intervention has made a difference. Understanding of this concept has grown 
in sophistication in parallel with the development of policy rationales. The implication for practice is hence that performance should be assessed as much in terms of capacity and system building as in terms of the direct outputs and effects of projects.

- Past evaluation practice in the context of the Framework Programme has made an important contribution to the development of evaluation capability across Europe and to methodology more generally. The principal challenge for the future is to ensure that good practice is consistently applied and extended. There is also considerable scope for reinforcing evaluations with supporting socio-economic studies and evidence. The wide menu of techniques identified in this report can be configured within appropriate methodologies to a variety of types of innovation activity, sectors and socio-economic contexts so as to provide valuable policy learning information. The precondition for this is an adequate investment in evaluation and the application of quality criteria to its processes and outputs.

- The European Research Area represents a step-change in the demands made upon evaluation. At a basic level there a range of new instruments for which evaluation procedures will have to be evolved as they are implemented. The initial thoughts presented in this study will undoubtedly need revision as these instruments are fully realised. The whole scope of evaluation is redefined by ERA. Moving from a purely programmatic mode to integration also implies a move from evaluation strictly along the lines of accountability to evaluation in the context of shared accountability and responsibility. In this context good quality evaluation itself becomes an instrument of integration. 


\section{Appendix 1}

Workshop on - "Towards an Evaluation System for FP-6/ERA: First ideas on concrete methods and practical steps" - March 4

\section{Introduction}

The purpose of the Workshop was to take forward the ideas on socio-economic evaluation set out in the report and develop these in a form that would help current work by the Commission on how to evaluate FP6 and the European Research Area. One of the key principles for such future Commission evaluation work and the intellectual setting for discussions at the Workshop was the need to strengthen the Commissions assessment of longer-term impacts.

The programme for the Workshop was structured into a series of presentations followed in the afternoon by interactive discussion groups. A short overview of the presentations and the work of the discussion groups is described below. Participation at the conference was by invitation to three separate groups - members of the European Evaluation Network, members of the 2001 Framework programme monitoring panels, members of the ASIF consortium, and members of the European Commission.

\section{Presentations}

The first presentation was from Professor Luke Georghiou from the Policy Research in Engineering Science and Technology (PREST) group at Manchester University, which was the lead team in the ASIF Consortium. He introduced the report and gave a step-by-step guide through its contents and major conclusions.

In his introduction Professor Georghiou drew attention to the breadth of the study but also noted that the remit was to produce a rigorous appraisal of the different elements of socio-economic impact, and not necessarily all forms of research impact. The work had been separated into three tasks: present the economic rationale for RTD Programmes through an analysis of both academic and policy literature; an analysis of the main elements of socio-economic impact and relevant methodologies for its assessment in the context of the Framework Programmes; and produce illustrative case studies to highlight different approaches to evaluation. The context for the study, which in effect represented a fourth aim, was to make observations and reveal lessons about evaluation that would benefit future evaluation work in the light of recent changes to the European research system.

In terms of the rationale for RTD, Professor Georghiou described the three approaches as belonging to neo-classical or mainstream economics, new growth theory, and evolutionary theory. The features of each approach and the implications for evaluation were outlined. Other conceptual issues discussed were additionality and European Added Value. Turning to the second issue, the minimeta evaluation, it was described how the study drew attention: to problems with the 
lack of validation of uni-dimensional data; insufficient statistical analysis; overemphasis on quantitative information; insufficient attention to societal effects; and lack of coherent methodologies for assessing impact. Five case studies were then presented; a market-oriented case study; a service-sector case study; a programme level case study; a social science case study and an accession country case study. Finally the possible impact of changes resulting from introduction of the European Research Area ideas and new instruments were explored. Networks of excellence were seen to have a focus more on basic research and their assessment would depend principally on the added value arising from the existence of networking activities. For evaluation, this would mean that the scope would extend beyond activity funded by the Commission and into core activities of participating institutes. Critically important will be the need to take account of the way in which basic research affects the economy and society through multiple pathways, a particular example of which will be the production of trained people. For integrated projects, Professor Georghiou suggested that perhaps the crucial issue will be their scale such that the strategic direction of a sub-sector could be affected. Evaluation will need to take account of this through examining meso-level effect for the sector as well as direct effect on participants. Similarly, the ex-ante aspect of evaluation for strategic project will require an element of strategic vision or intelligence.

The next presentation was by Thomas Heinze from the Institut für Sytemtechnik und Innovationsforschung (ISI) at Karlsruhe who outlined the work of the mini-meta evaluation, which had been a part of the project. The aim of this part had been to check the conceptual and methodological richness of past FP3 and 4 evaluation studies; identify examples of good practice; and put forward tentative recommendations. It was described how 28 impact studies had been collected and assessments made using a rough categorisation and a functional reference scheme which examine the issues of suitability, validity and exhaustiveness.

The final presentation, which was given by Dr John Rigby, outlined a mapping of impacts and appropriate evaluation techniques for the assessment of socioeconomic benefits. The presentation began with a discussion concerning the difficulties of designating impacts of research and the importance of attending to the changing nature of the concept of societal benefit over time. The presentation then reviewed the range of evaluation and research methods available and suggested a mapping between methods and particular types of societal benefit. Each family of research and evaluation methods was defined and the important sub-types noted. The review of methods also considered the primary purpose of each method in terms of whether it was used for measurement, data collection or analysis, and in relation to particular types of societal benefit. The presentation then referred to a mapping within the report itself, which consolidates the material from the reviews of the individual methods.

Each of the presentations was concluded with a question and answer session at which both details of the presentation and more general issues were raised. Some of the matters covered included the challenge of defining what is meant by basic research; how one of the benefits of research is the ability to make rapid changes in the commercial and technological direction of a company; the potential for better use by evaluators of the Commission's Technology Implementation Plans; the importance of systems for continuous monitoring in identifying those projects with major effects; 
and the difficulty of finding workable definitions and applications in research of the counterfactual principle.

Interactive Sessions

Three groups were convened:

\section{Basic Research Priorities}

\section{Applied Research Priorities;}

\section{ERA Objectives and Instruments.}

Membership of the groups was on the basis of self-selection by the Workshop participants. In order to give some structure to the discussion within the groups four common questions were set by the Commission officials for the group members, led by respective group Chairmen, to consider. However groups were also allowed the flexibility to set their own questions or adapt if they so wished, the ones that were set by the Commission. These were as follows:

- What are the major strengths and weaknesses of the Community $R \& D$ programme evaluation system currently in place?

- How can data be aggregated from the micro-level at which it is collected (single organisation) to the macro-level ( $R \& D$ programme level) at which the evaluation must be undertaken?

- What are the main indicators (relating to instruments, projects, impacts) needed in the evaluation of applied research programmes?

- How can impact assessment in member states be better aligned with impact assessment at the Commission level?

The responses of the groups to each of the questions and to the theme in general for each separate group are summarised below.

\section{Session on Basic Research Priorities}

Question 1 - What are the major strengths and weaknesses of the Community $R \& D$ programme evaluation system currently in place?

- a lack of suitable information on research outputs remains the single most important barrier to the evaluation of impacts in this area of basic research - this is the most difficult area of the three areas considered in terms of information problems;

- evaluation difficulties in this area also stem from the problems of blurred borders between subject areas, a phenomenon that is referred to as Mode 2 research, which defines the research product and the benefits in the context of use, thereby going beyond disciplinary linkages and making attribution very difficult. 
Question 2 - How can data be aggregated from the micro-level at which it is collected (single organisation) to the macro-level ( $R \& D$ programme level) at which the evaluation must be undertaken?

- the problems of data aggregation were considered by the group to be more significant in this area than in any other;

- techniques which might be used within one area were generally specific and the results of applying one could not be easily collated with others;

- cost benefit analysis were the most widely known and still the most appropriate for this area, but the difficulties came with supplying reliable estimates of the costs and the benefits for the purposes of comparison.

\begin{tabular}{|l||c||c|c||}
\hline \hline \multicolumn{4}{|l|}{ Table 36 Schematic of Effects and Techniques } \\
\hline \hline & Micro & Meso & Macro \\
\hline \hline Policy & $\mathrm{x}_{1}$ & $\mathrm{x}_{5}$ & $\mathrm{x}_{9}$ \\
\hline \hline Programme & $\mathrm{x}_{2}$ & $\mathrm{x}_{6}$ & $\mathrm{x}_{10}$ \\
\hline \hline Project & $\mathrm{x}_{3}$ & $\mathrm{x}_{7}$ & $\mathrm{x}_{11}$ \\
\hline \hline Partner & $\mathrm{x}_{4}$ & $\mathrm{x}_{8}$ & $\mathrm{x}_{12}$ \\
\hline \hline
\end{tabular}

The table shown above was used by the group, each type of benefit and each level requires a different form of measurement technique, noted here as $X_{n}$. Each technique yields a different result, which may or may not be comparable with the results from other areas. As results are not comparable, an additive process to impacts is not workable.

Question 3 - What are the main indicators (relating to instruments, projects, impacts) needed in the evaluation of basic research programmes?

- the question of finding useful indicators was linked with other issues, notably the difficulties of defining exactly what is basic research and identifying where basic research was likely to be carried out; the existence of some actors who carry out basic and other types of research often in linked ways; the difficulties of assessing impacts because of time lags; and the lack of systematic collection of data in many areas;

- more effort should be directed at collecting IP data in areas such as patents, publications, even Ph.D. student production;

- looking into the future, the 'wish list' for possible new indicators should cover more than just the measurement of impact. Indicators need to address areas which are currently not well understood such as change within organisations; changes in networks and changes in the impacts themselves. 


\section{Applied Research Priorities}

Discussion within this group tended to focus on questions 1 and 3. For question 2 group members felt unable to comment fully and suggested that it was impossible to propose an overall approach and that the issue was best dealt with during individual evaluation exercises. With question 4 the group did not put forward any opinion and suggested that the parallel session on the ERA would be better placed to tackle the issue. The detailed outcomes of the discussion were as follows.

Question 1 - What are the major strengths and weaknesses of the Community $R \& D$ programme evaluation system currently in place?

- there is currently a wide diversity in the evaluation practice of different programmes - there does not seem to be a systematic approach to programmatic evaluation across Directorates.

- current R\&D project selection procedures do not seem to relate systematically to the ex-post evaluation of programmes.

- specifically with R\&D project selection, the suggestion was that review panels have tended to be heavily skewed towards science and technology skills, thus biasing project selection accordingly. Technical reviewers may not be the most appropriate to judge added value. Moreover, the process was said to rob programme directors of the ability to bring in a strategic direction to their programmes. It was proposed therefore that review panels for project selection needed to more balanced and include a larger number of representatives from the user community and business experts.

- data collection in general and the lack of a central data storage facility were identified as major problems. These are compounded by different approaches to data collection and storage among the different Directorates and the perception of different levels of 'eagerness' to do this work. A key example of the current difficulties is with the Technology Implementation Plan (TIP) which potentially is a rich source of information although cannot currently be used in evaluation work partly because of the way the data is collected and for reasons of confidentiality. Note was taken of the Commission proposals for a three step process to address some of these issues.

- The assessment of long-term impact has been hindered because of the practice of undertaking evaluations immediately after the completion of a programme. Existing evaluation practice has tended to ignore the fact of the completion of research and the full assessment of its results.

Recommendations that were put forward included:

- creating an improved evaluation "culture" across programmes and Directorates and encouraging Programme Directors to prioritise evaluation work;

- better linkage between ex ante and ex post evaluation;

- more harmonisation of evaluation procedures between programmes; 
- more attention be given to the appraisal of long-term impacts. This will require new evaluation procedures and indicators based more on the appraisal of processes and capability building; ${ }^{77}$

- the full evaluation of applied R\&D programmes requires a wide variety of approaches. While quantitative approaches, including statistical and econometric analysis, are more feasible in this area than basic research, all approaches listed in the report are applicable and can provide complementary perspectives, especially when looking at longer-term impacts.

Question 2 - How can data be aggregated from the micro-level at which it is collected single organisation) to the macro-level (R\&D programme level) at which the evaluation must be undertaken?

- different member states vary considerably in terms of their competency and sophistication in R\&D programme evaluation. The Finnish organisation TEKES was mentioned as an example of a national agency that has made significant progress in aggregating from project appraisal to programme evaluation. R\&D investment portfolio analysis is one of the utilized approaches. The Commission could benefit from it as well.

Question 3 - What are the main indicators (relating to instruments, projects, impacts) needed in the evaluation of applied research programmes?

- evaluation needs to take account of the new conceptualisations of the process of technological advance in the light of the new realities of FWP 6 and ERA. This will require developing new indicators to better capture the qualitative aspect (process, capability building) of $\mathrm{R} \& \mathrm{D}$ programmes; indicators to capture the medium- and long-term effects of $R \& D$ programmes;

- the new generation of innovation network indicators currently under development with DG Research support ${ }^{78}$ could offer useful insights. Such indicators promise to reveal linkages between strategic partnerships, patents (and citations), and scientific publications (and citations) and between independent organizations and researchers. Using such indicators the Community's differential contribution to the creation and maintenance of inter-organizational linkages in programmes could be examined.

- new indicators to capture capabilities building, learning processes, knowledge communication mechanisms, etc. are also needed.

- TIP indicators must become one of the core tools in evaluating the impact of R\&D projects and programmes. This will require TIP data to be made available at the level of the organisation (firm, university, public research organization) and to brought together with publicly available information such as longitudinal financial performance and sector classification of companies. Furthermore, qualitative information will need to be transformed into a more quantitative format, perhaps along the lines of the ETIP directive. For all this

\footnotetext{
77 The highlights the distinction between existing evaluation approaches which tend to reflect mainstream economic analysis that is concerned more with the value of direct outputs and evolutionary analysis which tends to give more emphasis to process and capabilities. Both approaches are complementary and necessary in evaluation.

78 This work is also independently funded by the US National Science Foundation
} 
to happen would open up new evaluation possibilities for Community R\&D programmes.

\section{ERA Objectives and Instruments}

Those in this session felt that the common set of questions was less easily applied to the discussion of ERA and instead therefore proposed two modified questions.

Question 1 - What should be the Community $R \& D$ programme evaluation system for the ERA's Objectives and Instruments?

- it was recommended that the development of an effective evaluation approach to ERA will require an explicit definition of its rationale;

- the evaluation of individual programme and projects, as components of ERA, will also require clear understanding on the individual rationales, these in turn being linked to the high-level rationale for ERA itself.

Question 2 - What are the main indicators (relating to instruments, projects, impacts) needed in the evaluation of ERA activities?

- a key issue being highlighted was the need for the creation of early warning indicators and on the implementation of programmes by the departments responsible. Early warning indicators show whether policy initiatives are on target and whether changes to the way in which the initiatives are being delivered need to be made.

\section{Summary and Next Steps}

The workshop highlighted above all that the complex forms in which social impact and benefit are revealed requires a variety of assessment approaches at different levels. Assessment must fit both the context in which the research takes place and also the particular information needs of policy-makers. There is no one-size that fits all. Amongst other things this points to a major problem in the way that multiple indicators are combined and presented for decision making.

It follows that the development of evaluation methods must work closely with developments in the research process and its setting. In the context of current Commission policy, new approaches and techniques are required in the light of policy for the ERA and in particular integrated projects and networks of excellence.

Any proposals for new approaches must however be rooted in what is practical and achievable. It is well known and has been often highlighted in evaluation studies that the Commission faces acute difficulties in the management of research-related information. Future evaluation approaches will require more comprehensive, 
continuous and at the same time less burdensome means for collecting information and using such data for multiple applications.

Finally, evaluation of the quality, use and appropriateness of social science research within social policy and more widely within the context of interdisciplinary research requires not only good ex post studies but structures and resources to ensure that such research is fully engaged ex ante with society and its constituents. This includes the societal processes and their representatives or stakeholders, and not forgetting those on the margins of society (e.g. what are termed the socially excluded). 


\section{Appendix 2}

\section{Attendees at the Interactive Sessions}

\section{Basic Research Priorities}

\author{
L. BACH \\ T. HEINZE \\ A. SILVANI \\ R. BAREIKIENE \\ E. KOBAL \\ A. BERGE \\ D. WAGNEROVA \\ K. VERLAECKT \\ V. RUSIN
}

\author{
ASIF Consortium \\ ASIF Consortium \\ Commission \\ European Evaluation Network \\ European Evaluation Network \\ European Evaluation Network \\ European Evaluation Network \\ European Evaluation Network
}

\section{Applied Research Priorities}

N. VONORTAS

J. RIGBY

B. MAFFEI

L. O' SULLIVAN

F. SAND

B. WILKINSON

A. AHOLA

B. HOGAN

K. ZINÖCKER
ASIF Consortium ASIF Consortium ASIF Commission ASIF Commission ASIF Commission 2001 FP Monitoring Panel European Evaluation Network European Evaluation Network European Evaluation Network

\section{ERA (objectives \& instruments)}

K. GUY

L. GEORGHIOU

W. POLT

K. H. ROBROCK

Ch-H. METZGER

S. ROGERS

A. O'BRIEN

M. FLAGEOLLET

K. KARACHALIOU

P. BRENNIER

M. HORVAT 2001

$\mathrm{N}$.

CONSTANTOPOULOS

H. MARTINSON

L. ROVIRA
ASIF Consortium

ASIF Consortium

ASIF Consortium

ASIF Commission

ASIF Commission

ASIF Commission

ASIF Commission

ASIF Commission

ASIF Commission

Commission

FP Monitoring Panel Chairman

European Evaluation Network

European Evaluation Network

European Evaluation Network 